\title{
EXPERIMENTAL POLLINATION
}

\author{
AN OUTLINE OF THE \\ ECOLOGY OF FLOWERS AND INSECTS
}

BY

Frederic E. Clements and Frances L. Long

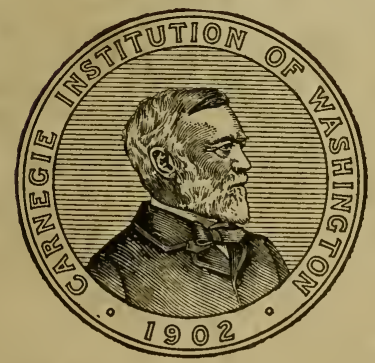

QK926 C6

Published by the Carnegie Institution of Washington

WASHINGTON, 1923 


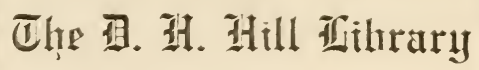

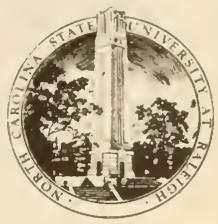

Nurtḥ Caraliua tate Zluiuersity

olina State Library

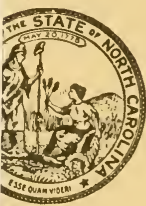

GIFT OF 
THIS BOOK IS DUE ON THE DATE INDICATED BELOW AND IS SUBJECT TO AN OVERDUE FINE AS POSTED AT THE CIRCULATION DESK.

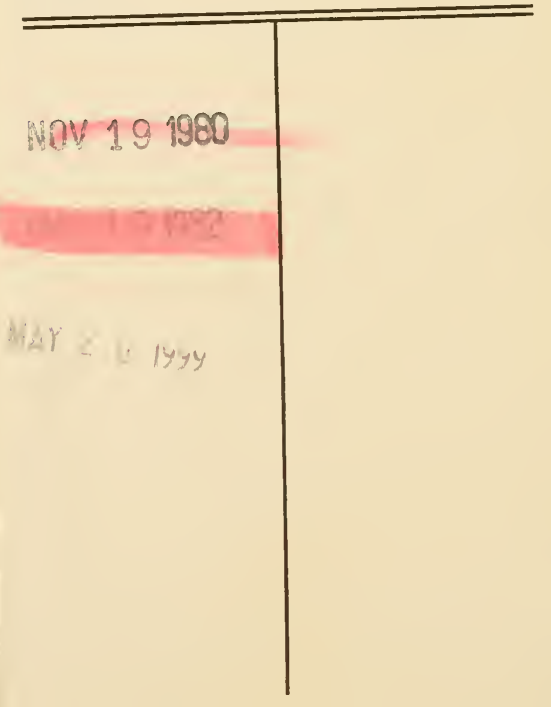



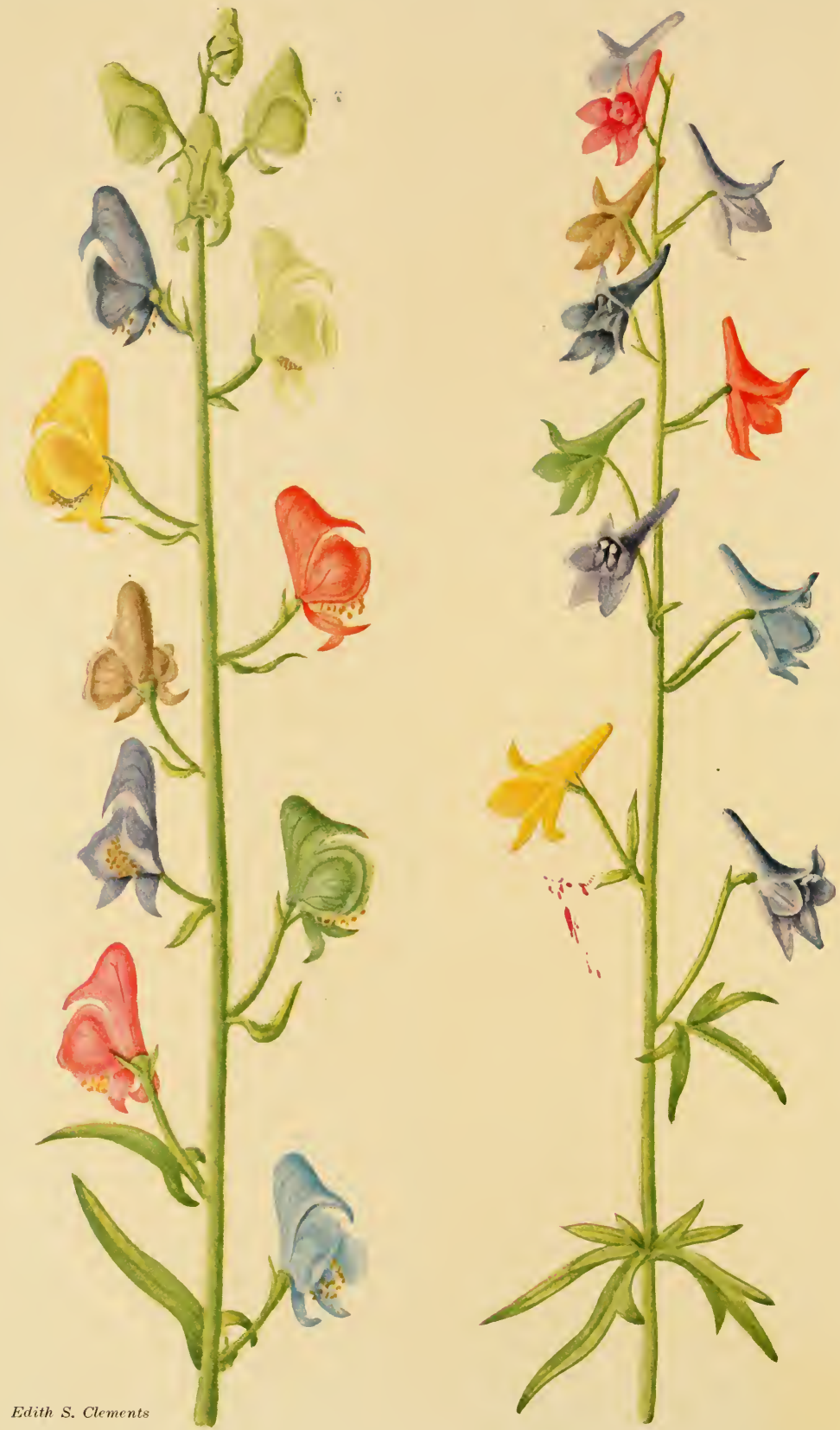

Painted flowers of Aconitum and Delphinium, showing the method of experiment. 


\section{EXPERINENTAL POLLINATION}

\section{AN OUTLINE OF THE \\ ECOLOGY OF FLOWERS AND INSECTS}

BY

Frederic E. Clements and Frances L. Long

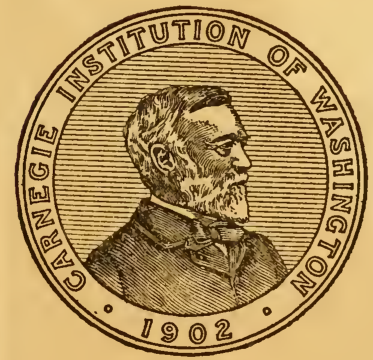

North Qarólina State Librarv

p-1 - is

Published by the Carnegie Institution of Washington WASHINGTON, 1923 


\section{CARNEGIE INSTITUTION OF WASHINGTON}

Publication No. 336

$$
\begin{aligned}
& \text { Copies of this book } \\
& \text { fn-? isand } \\
& \text { NOV } 6-1923
\end{aligned}
$$

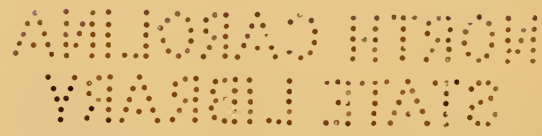




\section{CONTENTS.}

1. Introduction and Methods.......

Introduction. . . . . . . . . . .

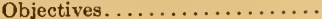

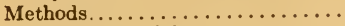

General principles............

Normal pollination...........

Experimental pollination.......

Organization of experiments.....

Change of position or place.....

Concealing or disguising flowers..

Mutilation...............

Artificial and painted flowers....

Addition of parts or substances..

Competition. ...............

Manipulation of insects.........

Life-history methods and records.

Life-history record of a representative species.............

2. Normal and Experimental Pol-

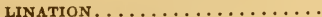

Aconitum columbianum..........

Normal pollination............

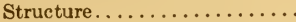

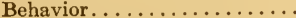

Experiments. . . . . . . . . . .

Change of position...........

Horizontal racemes. ........

Racemes inverted..........

Mutilations................

Cotton plugs.............

Stamens removed.........

Hood split. .............

Hood removed............

Hood and nectaries removed

Lower sepals removed......

Side petals removed........

Competitive relations......

Artificial and painted flowers.

Normal colors...........

Artificial flowers..........

Painted flowers...........

Addition of honey and odor. .

Honey.................

Perfumes. .............

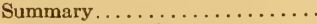

Delphinium scopulorum.........

Normal pollination...........

Habit and structure.........

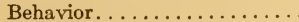

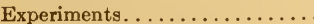

Change of position..........

Inverted racemes..........

Horizontal racemes. . . . . . .

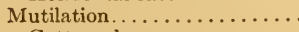

Cotton plugs............

Petals removed...........

Spur removed ...........

Landing-platform removed.

Artificial and painted flowers. .

Crepe-paper corollas.......

Crepe-paper corollas with spurs................

Painted flowers...........
Page

3

2. Normal and Experimental PoL LINATION (Continued).

Delphinium scopulorum (Continued). Addition of odor........... 25

Perfume.............. 25

Summary............... 26

Rubus deliciosus............. 26

Normal pollination........... 26

Habit and structure....... 26

Behavior............... 26

Variation in visits........ 27

Experiments. . . . . . . . . . . 29

Mutilation............. 29 Petals split or shortened.... 29 Stamens covered......... 29

Artificial and painted flowers. . 30 Crepe-paper corollas...... 30 Painted corollas. ......... 30

Addition of honey or odor.... 31 Honey. . . . . . . . . . . . 31

Summary............... 31

Rubus strigosus.............. 32

Normal pollination......... 32

Habit and structure......... 32

Behavior............... 32

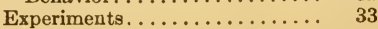

Mutilation............. 33

Floral envelopes or stamens removed............. 33

Rosa acicularis.................. 33

Normal pollination.......... 33

Habit and structure........ 33

Behavior.............. 33

Experiments................ 34

Mutilation .............. 34

Corolla shortened.......... 34

Stamens masked......... 35

Artificial and painted flowers.. 35

Crepe-paper corollas...... 35

Addition of honey and odor... $\quad 36$

Honey.............. 36

Honey and talcum powder. $\quad 37$

Camphor............. 38

Summary............... 38

Geranium caespitosum.......... 39

Normal pollination.......... 39

Habit and structure........ 39

Behavior............... 39

Calendars................ 40

Experiments............ 41

Change of position......... 41

Flowers vertical or inverted. 41

Mutilation............ 41

Cotton over nectaries..... 41

Excision............ 42

Artificial and painted flowers.. 43

Crepe-paper corollas....... 43

Addition of honey and odor... 43

Honey............ 43

Summary............... 45

Chamaenerium angustifolium...... 45

Normal pollination.......... 45

Habit and structure......... 45 
2. Normal and Experimental PolLINATION (Continued).

Chamaenerium angustifolium (Cont.).

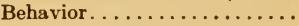

Experiments...............

Change of position.......... Racemes inverted.........

Mutilation.............. Floral envelopes removed... Upper petals and the included sepal removed....

Stamens and style removed.

Artificial and painted flowers.. Crepe-paper corollas. . . . . . . Painted corollas........... Addition of honey and odor... Honey. . . . . . . . . . . . . Odor...................

Perfumes................

Flavoring extracts........

Summary................ Pachylophus caespitosus.........

Normal pollination...........

Habit and structure.........

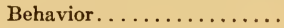

Experiments.............

Artificial flowers. .........

Crepe-paper flowers. . . . . . .

Petals obscured..........

Mentzelia multiflora............

Normal pollination............

Habit and structure.........

Experiments...............

Crepe-paper flowers and competition..............

Crepe-paper corollas. ........

Summary................

Frasera speciosa. . . . . . . . . . . .

Normal pollination...........

Habit and structure .........

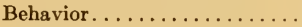

Experiments.............

Mutilation.............. Types.

Artificial and painted flowers. Crepe-paper corollas....... Painted corollas.......... False corollas............

Addition of nectar and odor... Nectar. . . . . . . . . . . . . .

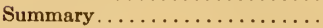
Mertensia pratensis............

Normal pollination...........

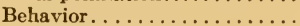

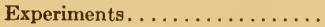

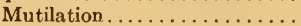
Changes of corolla........ Castilleia miniata . . . . . . . . . . . . .

Normal pollination............ Habit and structure.........

Behavior. ..............

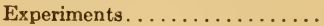
Mutilation.............. Upper lip removed, spike inverted................

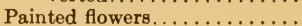
Painted bracts. ...........
PAGE

2. Normal and Experimental Pol Lination (Continued).

Pentstemon glaber.............. 65

Normal pollination.......... 65

Habit and structure........ 65

Behavior.............. 65

Calendars.............. 66

Experiments.............. 68

Change of position ........ 68

Racemes inverted........ 68

Racemes horizontal....... 70

Mutilation........... 70

Cotton at the corolla mouth. 70

Styles, stamens, and staminode removed.........

Corolla split. . . . . . . . .

Corolla lips separated and staminode raised.........

Upper lip removed at the throat.....................

Lower lip shortened half....

Lower lip removed.........

Lower lip and part of the tube removed..........

Lips removed except lower lobe...................

Corolla tube shortened half.

Petals separated...........

Lower lip split into three petals ....................

Tube end of a corolla slipped over the staminode......

Comparative relations.......

Artificial and painted flowers...

Crepe-paper corollas. ......

Corolla painted with watercolors...............

Honey and odor ..............

Sirup added................

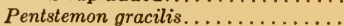

Normal pollination............

Habit and structure.........

Behavior. . . . . . . . . . . . .

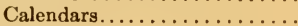

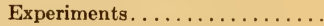

Change of position.........

Racemes inverted.........

Racemes horizontal. . . . . . . .

Mutilation....................
Landing-platform removed.

Brush of staminode removed

Anthers and recurved portion of upper lip removed Upper lip partly removed. .

Lobes of upper lip separated

Petals split to the base......

Pentstemon glaucus.............

Normal pollination...........

Normal behavior. ..........

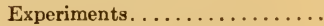

Mutilation...............

Upper lobes split to base...

Lower lip removed.........

Outer lobes of lower lip removed.............

Staminode removed........ 
2. Normal and Experimental Polhination (Continued).

Pentstemon glaucus (Cont.).

Middle lobe of the lower lip removed.............. Upper lip removed. ........

Pentstemon secundiflorus.......... Normal pollination............

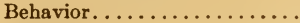

Calendar. . . . . . . . . . . . .

Experiments...............

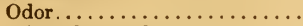

Powders and extracts ......

Cotton wads sprinkled with peppermint............

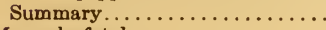

Monarda fistulosa.............

Normal pollination...........

Habit and structure.......

Behavior. . . . . . . . . . . .

Experiments. ...............

Mutilation and competition. .

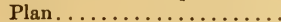

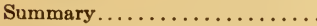

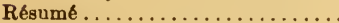

Variation in number of visits...

Changes of position...........

Masking with cotton..........

Mutilation................

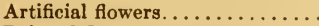

Painted flowers..............

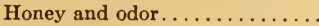

3. Competition and Constanct .....

Significance................

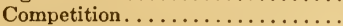

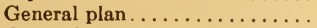

Rubus strigosus. . . . . . . . . . . .

General relations. ............

Rubus strigosus and Rubus deliciosus Comparison...............

Experiments. . . . . . . . . . .

Summary....................

Rubus strigosus and Rubus deliciosus

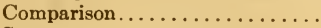

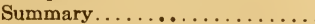

Competition of Rubus with Frasera,

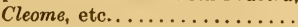

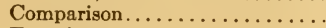

Experiments. . . . . . . . . . .

Summary................

Rubus strigosus and two or more

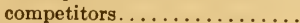

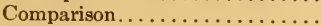

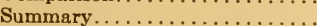

Rubus deliciosus. . . . . . . . . . .

Experiments. . . . . . . . . . . . .

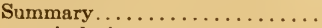

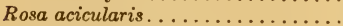

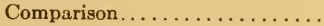

Experiments. . . . . . . . . . . .

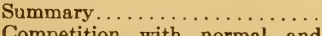
Competition with normal and
mutilated Aquilegia.........

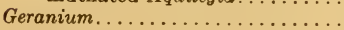

Comparison....

Experiments. . . . . . . . .

Summary............... 109
3. Competition and Constanct (Continued).

Chamaenerium angustifolium. . . . . 110

Comparison................ 110

Experiments............... 110

Summary................. 110

Pentstemon................ 110

Comparison............... 110

Experiments.............. 113

Summary................ 113

Monarda fistulosa. . . . . . . . . 115

Comparison.............. 115

Experiments.............. 115

Summary............... 115

Weight and composition of pollen loads............... 119

Value and methods......... 119

Discussion............. 127

Constancy................ 128

Definitions.............. 128

Early observations of constancy 129

Bennett's studies of constancy 130

Christy's studies of methodic habits............... 130

Mueller's results............ 130

Bulman's studies........... 131

Ord's conclusions........... 131

Plateau and Pérez........... 131

Constancy in Bombus........ 132

Lovell's conclusions............ 132

Kranichfeld's observations. ........ 133

Origin of oligotropism....... 133

Résumé................... 134

Experimental results in competition............... 134

Effects of competition......... 134

Constancy as shown by pollen loads................ 135

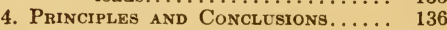

Introductory.............. 136

Early experiments of Plateau and others............... 136

Artificial flowers............. 136

Nectaries................ 137

Color sense of bees........... 138

Response to detached petals. . . 139

Color preferences of nocturnal moths..................

Response to color without antennæ.................. 140

Perception of form............. 140

Response of wasps to color...... 143

Response of wasps to odor...... 145

Main researches of Plateau...... 145

Masked flowers............ 145

Removal of corolla........... 147

Response to different colors..... 148

Addition of honey to vivid nectarless flowers............... 149

Anemophilous flowers.......... 150

Entomophilous flowers of dull color................. 150

Artificial flowers, second series... 150

Artificial flowers of green leaves. . 151

Conclusions as to artificial flowers 152

General summary............ 152

Rôle of vexillary organs........ 153 
4. Principles and Conclusiona (Continued),

Main researches of Plateau (Continued).

Choice of colors by insects......

Errors made by Anthidium.....

Admiration of syrphids for bright

flowers. . . . . . . . . . . . .

Attraction of colored cloths and brilliant objects. ...........

Constancy among bees.........

Mistakes made by bees........

Removal of the antennæ of bumble-bees. ..................

Evidence of the attractive rôle of

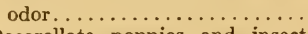

Decorollate poppies and insect

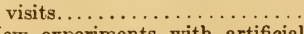

New experiments with artificial flowers............... Conclusions as to artificial flowers Macroglossa and false flowers.... Entomophilous flowers little visited by insects ............

Related studies and critiques......

Comparative importance of odor and color...............

Pérez's critique of Plateau's work

Effect of colors at the hive......

Critiques of Kienitz-Gerloff......

Knuth's critique.............

Reeker's experiments with artificial flowers..............

Decorollate poppies............

Response to color and odor by a hawk-moth..............

Vexillary nature of the plume in

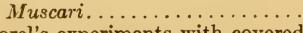

Forel's experiments with covered dahlias and with artefacts....

Response of Syritta..........

Andreae's experiments with artificial flowers. .............

Andreae's conclusions.........

Andreae's criticisms of Plateau's work. ...................

Plateau's criticisms of Andreae's work . . . . . . . . . . . . . . .

Wery's experiments with decorollate and artificial flowers.......

Plateau's criticisms of Wery's experiments.................

Experiments of Weismann and Errera....................

Orientation of the honey-bee at flowers of the same species....

Discrimination between similar

species of flowers..............
Orientation of the bee within the

flower......................... imitations...................

Knoll's critique of Plateau's
study of Macroglossa....... study of Macroglossa.......

Recent investigations.............
The color sense of the honey-bee

The color sense of the honey-bee
PAGE

4. Principles and Conclusions (Continued).

Recent investigations (Continued).

The pollination of green flowers.. 195

Conspicuous flowers rarely visited by insects...............

Response of honey-bees to colored artefacts................

Pattern vision in the honey-bee. .

Experiments with cotton blossoms....................

Color sense and memory in the honey-bee..............

Frisch's researches-sense of color and form in the honey-bee....

The supposed color sense of the honey-bee. ...............

Seasonal changes in response to honey...................

The sense of smell in the honeybee. ....................

Bombylius and the colors of flowers.................

Vision and flower behavior of Macroglossa stellatarum.......

Response of bees to spectral bands

Evaluation of Plateau's researches

Forel's estimate.............

Contradictory nature of Plateau's later conclusions............

Conclusions as to Plateau's views

Senses of insects. . . . . . . . . . .

Sight..................

The mosaic theory.......... Criticisms of Plateau's views as to vision.............. Sensibility to color..........

Perception of form and movement by insects...........

Discrimination of form .......

Vision in honey-bees. . . . . . . .

Vision in ants.............

The rôle of ultra-violet in attraction................

The homing faculty in bees and wasps ................

Fabre's experiment with bees and wasps ..............

Lubbock's and Forel's critique of Fabre's conclusions ......

Homing faculty of bees......

Sense of direction in groundwasps................

Disturbance of memory in wasps................

Observations on the homing of Bembex and Pampilus......

Memory of place in Osmia....

The field and nest flights of the bumble-bee............

The homing of the mud-dauber wasp.................

Experiments on the orientation of bees in homing.........

Homing ability in Polistes.... 
4. Principles and Conclugions (Continued).

Smell (Continued).

Sense of smell in insects deprived of antennæ.........

Forel's criticisms of Graber's results..............

Hauser's experiments. . . . . . . .

Olfactory pores............

Experiments with antennæ removed, mutilated, or costed .................

Experiments with wings, legs, and stings mutilated.....

McIndoo's experiments with deantennate insects.......

Present status as to the seat of the olfactory sense........

Intelligence. . . . . . . . . . .

Relation between the senses and mental faculties of insects................ Memory and general intelligence of wasps..........

Memory of place in bees.....

Memory of time and association of impressions......

Memory of time and memory association in honey-bees...

Intelligence of honey-bees.... The psychic powers of insects
PAGE
4. Principles and Conclusions (Continued).

General résumé............... 238

Treatment............... 238

Attraction............... 238

Color.................. 238

Mutilation .............. 238

Artificial flowers............ 239

Painted flowers............ 240

Inclosing flowers in glass ..... 241

Green flowers and showy nec-

tarless flowers........... 241

Color preference........... 241

Odor.................. 244

Masking or covering flowers to conceal color.......... 244

Odor of honey............ 244

Effect of added odors....... 245

Relative value of color and

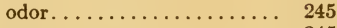

Form.................. 245

Distinction and rôle....... 245

Attraction at a distance and near at hand ............... 246

Learning and habit......... 247

Memory and intelligence...... 247

5. Pollinators and Flowers Visited...... 249

6. Flowers and their Visitors ......... 256

Bibliography. ................ 268

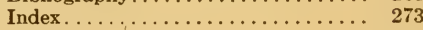

Description of Plates........... 276 


\section{EXPERINENTAL POLLINATION \\ AN OUTLINE OF THE ECOLOGY OF FLOWERS AND INSECTS}

BY

Frederic E. Clements and Frances L. Long 


\section{LIST OF PLATES.}

Plate

1. Painted flowers of Aconitum and Delphinium................ Frontispiece

2. Life-history of the flowers of Aconitum columbianum and Delphinium scopulorum. 272

3. Life-history of Rubus strigosus and Potentilla gracilis................ 272

4. Life-history of Heracleum lanatum and Sedum stenopelatum . . . . . . . . . . . 272

5. Life-history of Galium boreale and Saxifraga bronchialis............... 272

6. Life-history of Campanula rotundifolia and Erysimum asperum . . . . . . . . . 272

7. Life-history of Geranium caespitosum and Dodecatheon meadia . . . . . . . . . . . 272

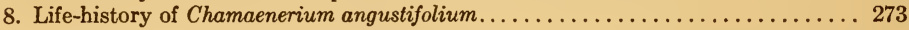

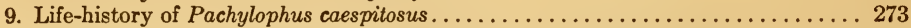

10. Life-history of Pirola elliptica, Frasera speciosa, and Gentiana amarella . . . . . . . 273

11. Life-history of Gilia aggregata and pinnatifida, Mertensia sibirica, and Lithosper-

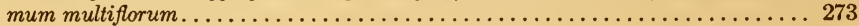

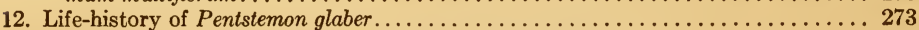

13. Life-history of Castilleia miniata and Monarda fistulosa . . . . . . . . . . 273

14. Life-history of Allium cernuum and Zygadenus elegans............... 274

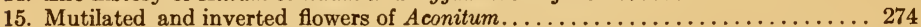

16. Mutilated flowers of Aconitum, Delphinium, and Monarda . . . . . . . . . . 274

17. Mutilated flowers of Geranium, Chamaenerium, and Pentstemon glaber....... 274 


\section{INTRODUCTION AND METHODS.}

\section{INTRODUCTION.}

The original plan for the development of quantitative ecology contemplated two series of monographs, one dealing with the plant in its vegetative relations, the other in its reproductive aspects. The first has received attention in a number of monographs, some of which deal with the individual and some with the community, but the factors and processes involved in the behavior of the flower were necessarily somewhat neglected for a time. Studies of the life-histories of flowers were first begun in 1910 and these were followed by observations and experiments upon the relations of flowers and insects. These served to disclose the nature of the problem and to indicate the methods needed for a comprehensive experimental attack upon it. The main investigation was begun in 1918 and has been carried on actively during the succeeding summers. As a consequence the limits of the field have expanded greatly and the present treatment is to be regarded as a preliminary endeavor to organize it upon an adequate experimental and quantitative basis in nature.

The study of the relations between flowers and insects, begun effectively by Kölreuter (1761) and Sprengel (1793), underwent an enormous expansion at the hands of Delpino (1867), Hildebrand (1867), Mueller (1873), Darwin (1876), Kerner (1876), and Knuth (1894) without becoming experimental in even a small degree. The first investigator to recognize that the great mass of observational results needed to be refined by means of experimental methods was Plateau $(1877,1895)$, and practically all other experimental studies have been a direct or indirect consequence of his work. ${ }^{1}$ The present investigation constitutes the exception, as it was begun with a different objective and with contacts sufficiently slight to permit an independent development of methods. This was of especial importance in view of the comprehensive nature of the plan, as well as in affording a detached view of the methods already employed. This appears to have been justified by the outcome, not only in the matter of methods but also with respect to results and conclusions. Moreover, the difference in objectives has made it possible to plan experiments and interpret results without a bias in favor of Plateau's views or those of his critics. While the relative values of color and odor in attraction constitute one of the most interesting phases of the general problem, they have too long held the center of the stage as a consequence of Plateau's dramatic challenge. However, even in the present case, the adequate analysis and evaluation of the work that has been done make it necessary to treat attraction as the paramount theme.

This investigation has been carried out at the Alpine Laboratory, which is situated at an altitude of 8,500 feet in the montane forest climax on Pike's Peak. It is perhaps unique in dealing with an insect fauna in exclusive contact with a native flora, though some of the experiments have

1 Since this was written, the admirable monographs of Frisch and of Knoll have become available. These deal almost exclusively with intensive control researches into the response of one or two species to color, odor, or form, and are indispensable to students of experimental pollination. While it is now impossible to abstract them as fully as they deserve, a general account of the methods and results will be found in Chapter 4 . 
concerned species that are probably outside the normal experience of the visitors. Some studies have also been made in the plains grassland at the base of the range, and in the alpine meadows on the summit of Pike's Peak, as well as a few preliminary ones in Arizona and California, but these are reserved for the most part for a later treatment.

For the flowers the nomenclature is that employed in Clements and Clements" "Rocky Mountain Flowers," while the names of the Lepidoptera are those found in Holland's "Butterfly Book" and "Moth Book." In the other groups the determinations have been made by the following specialists, to whom grateful acknowledgment is made: Dr. J. M. Aldrich, Bureau of Entomology, Washington, D. C.; Professor T. D. A. Cockerell, University of Colorado, Boulder, Colorado; Professor C. Howard Curran, University of Kansas, Lawrence, Kansas; Dr. F. E. Lutz, American Museum of Natural History, New York; Professor S. A. Rohwer, U. S. National Museum, Washington, D. C.; Professor O. W. Oestlund, University of Minnesota, Minneapolis, Minnesota; Professor M. W. Swenk, University of Nebraska, Lincoln, Nebraska; Professor C. T. Vorhies, University of Arizona, Tucson, Arizona; Professor H. L. Viereck, Biological Survey, Washington, D. C.

Objectives.-As already indicated, the primary object of the present investigation is to place the study of the flower in relation to its environment on the basis of experiment and measurement. At the same time it is intended to give the fullest value to the synthetic nature of the problem by placing the chief emphasis upon the mutual relations of flowers and insects. The life-history of the flower has been given greater attention than heretofore and it is felt that the life-history of the insect in the broader ecological sense must receive similar study. The central theme is attraction and the behavior of the insect at the flower, and in spite of the work already done, this offers an enormous opportunity for quantitative research. The efficiency of both flower and insect is susceptible of much greater accuracy of measurement and it appears probable that this will disclose a new field of correlations. In this connection the experimental study of competition is especially significant and promises to throw a flood of light upon reciprocal adaptation, as is likewise true of mutilation experiments. This leads to the consideration of the evolution and phylogeny of flowering plants under the influence of insect and wind pollination, as well as a re-examination of the effectiveness of cross and self pollination. With respect to the insects the major queries concern the respective rôles of the senses, the acquisition and fixity of habits, and the relation between instinct and intelligence.

\section{METHODS.}

General principles. - An endeavor has been made to develop a comprehensive system of research, based primarily upon experiment and measurement. This has been made as complete as possible, though it is fully recognized that the further development of this great field will reveal new objectives and new methods of attack. The great majority of the methods have been tested in the present study, others are now being used in the work under way, and a few are still to be applied. Most of the latter have been employed by other investigators and hence are considered for the sake of 
completeness. The observational method has necessarily been continued in connection with normal pollination and the life-history of the flower, but it has been made as quantitative as possible and has frequently been supplemented by experiment. The experimental methods have been made as simple and direct as possible and have been applied chiefly to attraction, behavior at the flower, and competition between flowers in this first series. Most of them have been subjected to repeated check and the results are thought to be fairly conclusive for the region and the time concerned. The conditions have differed materially from those obtaining in practically all other studies in this field, in that both flowers and insects were in the natural relations that have existed for a long period. While gardens yield behavior results of as much interest as those of natural habitats, it is obvious that their essentially exotic nature renders them of little value in questions of adaptation and evolution. This difference is also to be taken into account in other respects; for example, artificial flowers appear to be much more readily visited in gardens than in nature, as would be expected from the difference in the habits of the insects.

Moreover, it is thought that the experimental investigation of a native insect fauna in the midst of its natural floral environment, and the converse, furnishes a norm to which can be referred other studies that are artificial in some degree. Some such standard appears indispensable, since it is evident that many of the contradictions and discrepancies in the results of various investigators are to be explained by differences in conditions and setting rather than by faults of method or observation. This is certainly true of many of the points at issue between Plateau and his critics. The effects of time, place, weather, grouping, etc., are often decisive, as shown in the next chapter, and they need always to be checked by actual trial, or, much better, eliminated by simultaneous observations in contiguous areas in so far as possible. The time of day, week, or season not only has an effect due to lapsed time, but also one especially of difference in sun, cloud, temperature, wind, condition of flowers, habit of insects, etc. Even the weather of the previous day may have a profound effect, if it has been rainy, unusually cold or warm, or windy. Differences of location and particularly region usually produce decided effects, owing to changes of conditions as well as of flower and insect populations. In fact, marked differences of behavior have been noted in spots a yard apart where no differences of sunlight, temperature, or wind were demonstrable at the time, but where the behavior of the insects had been determined by earlier shade, exposure, by nearness to their nests, etc. The kinds, number, and grouping of the species and individual flowers naturally have a pronounced effect, as do also the time of blooming, the position in the flowering period, the nectar flow, and the rate of nectar production. It is equally evident that the composition of the insect fauna as to orders and species, the number of individuals, the sexes, social habits, age, etc., will greatly affect the results. Finally, it has been found that the position and nearness of the observer, as well as his clothing (cf. Lovell, 1914:407), produce effects to be taken into account, while an increase in the number of observers in the same spot may completely change the response. Still other factors enter into the problem, thus completing the certainty that researches 
widely removed in time and space will differ much in detail and often in principle as well.

Normal pollination.-This is primarily a matter of observation and is important in experimental studies chiefly because it furnishes a background of normal behavior against which departures may be measured. The methods are simple and have long been exemplified in the works of Delpino, Hildebrand, Axell, Mueller, Darwin, Kerner, Knuth, Loew, MacLeod, Robertson, and others. For the more exact results needed in connection with experiments, it has proved necessary to enter into finer details as to behavior, to deal with a larger number of individuals, and especially to record the number of visitors of each species, as well as the number of flowers visited by each individual. The failure to note the number of visitors of each species deprives practically all of the observational studies of any quantitative value, in spite of the contention of Knuth (1906:195) that the "statistical" method of Mueller has greater possibilities than one would be inclined to believe and that the reproach of affording an inaccurate idea of the number of pollinators because it counts the visits of species and not of individuals is of no importance. This is contradicted by the earlier statement that 'a disadvantage is involved, though one that can hardly be avoided, as it is almost impossible to count all the individual visits to a conspicuous flower.'

In a critique of Knuth's "Blütenbiologie," Roberston (1922:148) states that anthecological data "are lists of insect visitors made to show the species, their frequency, their efficiency as pollinators, and the possibility of their having some influence in determining the characters of the flowers. Mueller's lists show these details. In the case of the bees he indicated the sexes, and whether they were sucking nectar or collecting pollen. To note the sexes is important, because female bees fly longer than males and are more likely to make repeated visits. To note the fact of pollencollecting is also important. A female bee will carry pollen all day from flowers on which the male rarely occurs. From observations at Carlinville the females of nest-making bees average 20.6 visits to the males 10.3 . The inquiline bees show females 8.8 to males 8.0. In anthecology Mueller's lists are valuable as regards species and visits, but they fail to indicate the frequency. In 1908 I rejected Mueller's method and adopted the practice of capturing the individuals as they came, noting species and counting individuals It is impossible to indicate the importance of insects to flowers by lists of species, because efforts to increase the lists involve an exaggeration of the importance of rare and exceptional cases."

Experimental pollination.-This includes practically all the experimental methods that deal with the relations of flowers and insects, though competitive methods are considered separately for the sake of convenience. No sharp line can be drawn between these and the methods that make use of colored objects or odorous substances, but it seems better to consider the latter in a separate section. Experiments may be devised to show the rôle of different parts in attraction, landing, or guidance, the behavior of insects in securing nectar or pollen, or their efficiency in the transfer of pollen. However, in many cases two or more of these processes are affected 
by the same change, and for this reason the various experimental methods are organized with respect to the change concerned. There is almost no limit to the number of changes and combinations that ingenuity can devise, but the following discussion is restricted essentially to changes that have been used or are now in process of being used.

Organization of experiments.-All experiments have been made in the field under natural conditions. Controls have been regularly employed and the results checked by repetition. Comparative values have been secured by using a definite number of flowers, an equal area, or an equal number of them. The latter method alone seems to be entirely without error and has completely replaced the others, since it yields exact and directly comparable expressions of choice. For the same reasons experiments should be observed at similar times and for periods of the same length in so far as possible. For the best results it is often necessary to have two or three observers, so that the time difference can be eliminated and the same group of competing insects followed under the same conditions. The grouping of the plants and the relative position of the flowers are matters of much importance and must be considered with reference to the habits of the insects and the type of behavior to be tested. All experiments carried on with a plant or group that insects have been in the habit of visiting must reckon with the effect of the habit itself. While such results are dependable as to behavior, they do not permit an exact analysis of the factors entering into it. On the other hand, advantage may be taken of habit to insure certainty in regard to a response, as when artificial or mutilated flowers are alternated in the cluster with normal ones. It must also be recognized that the reactions of mature insects contain a large element of habit and that the real response to certain stimuli can be obtained only by using young ones that have just emerged. Moreover, it has become more and more desirable to deal adequately with individual behavior, and this can be done only by working with marked bees.

Plateau has more than once pointed out that experiments with flowers and insects demand the greatest patience and almost unlimited time, and that one must expect to have many of them rendered incomplete by changes of weather and other hazards. The problem is the same as in all experimentation in nature and must be met in so far as possible in the choice of the region, the detailed organization of plans, and the introduction of the maximum degree of control.

The modifications brought about for experimental purposes may be grouped as follows: (1) changes of place, grouping, or time; (2) concealing or disguising flowers or clusters; (3) removal or mutilation of flowers, parts, markings, etc.; (4) artificial or painted flowers or parts; (5) addition of flowers, parts, substances, etc.; (6) combinations of two or more changes. The distinctions between the different types of modification are far from absolute and certain changes might well be placed in another group.

Change of position or place.-These may concern the plants or flowers of one species, or of two or more species. In the latter case they have to do primarily with competition and are considered later under that heading. Changes that have to do with the time of blooming or the grouping may be 
utilized to hasten or retard flowering or to increase the total attraction of a group of individuals. Changes of position are especially valuable in connection with the study of normal behavior and in determining the correlation between habit and intelligence in different species and individuals. They may deal with the cluster, the flower, or the flower part, but in the last case the change is essentially a mutilation and is considered as such. The simplest method is to change the entire cluster in position by 90 or 180 degrees, either by bending and fastening it in the position desired, or by cutting it off, placing the end in a vial or in wet cotton, and attaching it alongside a normal inflorescence. The use of single flowers permits a wider range of changes, as these can be turned through two circles with the assumption of very different positions. Such changes not only affect the appearance of the flower with respect to attraction, but they necessitate a different behavior in one or more of the successive processes of landing, guidance, obtaining nectar, collecting pollen, and departure. A completed visit thus becomes a new problem in the solution of which species and individuals exhibit striking differences.

Concealing or disguising flowers.-This may operate upon the plant or cluster, a single flower, or a part of it, such as the petals or stamen-mass. When the nectary is obstructed by a cotton plug, the effect is essentially one of mutilation, while the use of green leaves to mask the corolla or the disguising of the rays of one species with those of another produces an artificial flower in effect. Masking is primarily a device to conceal the color and thus permit the determination of the rôle of odor, but it must always be done with the effect of habit in mind. Clusters or single flowers may be covered with pots, boxes, wire cages, or other objects, or they may be variously disguised by means of paper, cloth, leaves, etc. The perianth may be similarly covered on either one or both faces, one or more of the petals covered, the anthers or nectaries masked with paper, cotton, or foreign petals; in short, any part or parts may be concealed in any manner that seems desirable. This is similarly true of the rays and disks of composites, and of all vexillary organs, such as spathes, colored bracts, etc. Painting the petals or other parts is also a type of masking. Finally, odor may also be masked by means of glass globes, tubes, etc., permitting color and form to act alone as attractive factors.

Mutilation.-By this is understood the removal of flowers or parts, the splitting or cutting of parts, and such changes of position as result in a different form. The removal of flowers is chiefly significant in such definite inflorescences as the umbel and head with show-flowers or rayflowers, in which all or part of either kind of flower may be cut out to disclose the rôle of the other. With respect to other changes a radiate head resembles a single flower to a considerable degree. In regular flowers the most important mutilations arise from the removal of corolla or perianth in whole or in part, the shortening of the petals, or splitting them into parts of various forms. The mutilation of irregular flowers may also be made to throw light upon attraction, but it is particularly valuable in revealing the rôle of the specialized parts, as in the larkspur, peas, and mints. Hoods, spurs, standards, keels, and lips may be removed wholly or partly, or they 
may be variously split to increase the attractive surface. In the interior of the flower any or all of the stamens, staminodes, or pistils may be removed or modified, one or more of the nectaries excised or otherwise changed, and the protective hairs of various sorts trimmed or cut as desired. All vexillary organs external to the flower may be treated in the same manner as petals. Decisive changes in form may be effected by bringing petals together or turning them back, or by treating them to produce an artificial zygomorphy, while the internal arrangement of the flower may be modified by changing the position of stamens, staminode, style, scales, etc. It is obvious that the nectar may be completely removed and the odor also modified in various ways. Two or more mutilations may be combined in the same flower or progressive mutilation may be carried out in a series, ranging from normal flowers through those with more and more parts removed until the pedicel alone is left. Finally, mutilation may be applied to the guide lines, stripes, grooves, etc., but these are usually best modified by masking them with water-colors.

Artificial and painted flowers.-Between the purely artificial flower at one end of the series and the painted natural flower at the other lie many forms, which differ chiefly in the degree to which artificial or foreign materials are used. Artificial flowers proper may be made of paper, cloth, wax, or other materials, and may be either crude or accurate copies of natural flowers, according to the purpose intended. Plateau has raised many objections to those used by his critics (p. 163), but these seem to have little weight (p. 239). Flowers with one or more artificial parts are termed composites and usually consist of the natural center of a flower or head supplied with artificial petals or rays. In some cases the entire flower or head is used and accessory colored parts added. Artificial stamens, staminodes, or pistils may be added in special cases to replace the natural ones, but such uses are limited. Imitations may be made of green leaves, with or without natural centers, and they are also fashioned by using the centers or disks of one species with the petals or rays of another. One modification of particular value consists in replacing the nectaries or anthers of one species with those of another. The best results have been obtained with natural flowers painted with water-colors, since these are artificial only in color. Such paints may also be employed to mask stripes and spots or to supply new markings to test the directive value of the guide lines. In certain cases natural flowers may be killed by the vapors of osmic acid or otherwise, or they may be used in the dried form when the petals or rays are papery in texture. Bits of colored paper or cloth, or detached petals, have something of the value of artificial flowers, but belong properly in the category of colored objects that can be employed to test color vision.

Addition of parts or substances.-Additional parts, such as petals, rays, stamens, etc., may be supplied from flowers of the same species or from those of different species. Perhaps the most interesting change of this kind is where the number of nectaries is doubled, and especially when those of another species are alternated. In flowers where the nectar accumulates in considerable amounts in tube or spur, it may be withdrawn and exchanged with that of a different species. Pollen may similarly be 
transposed or the same result obtained by the exchange of stamens. In the great majority of cases, however, addition deals with honey or sugar solutions on the one hand or odorous substances on the other in order to determine the rôle in attraction. The results with odors depend largely upon whether these are natural ones to which the insects are accustomed to respond and the best method is to employ fragrant flowers or parts regularly visited.

Competition.-Competition is regarded as natural when plants of two or more species grow so close or intermingled that their flowers compete for the same group of visitors. It is brought about artificially when plants, clusters, or flowers are transferred in such manner as to result in competition. The distinction practically disappears when individuals are transplanted or seeds sown in such a way as to form a competition group. Natural competition groups are also constituted when the flowering period of one species is retarded by pruning or cutting back, or accelerated in various ways to cause it to overlap in some degree the period of an associated species. However, when one or more species are transplanted to a different climax or region, the resulting group is more or less artificial in its relations. As a rule, the simplest method is by the transfer of inflorescences or single flowers, which are kept fresh in bottles of water or by means of wet cotton. Clusters have the advantage in saving time and effort and in exerting a stronger attraction for visitors. The best results are obtained when two species are employed reciprocally as bouquet and plant at the same time, but this demands two observers. Mixed bouquets of two or more species or separate bouquets of the same often give good results with a single observer. When visitors are not too abundant, as many as a half-dozen species may be followed at one time if the flowers are close together and not too numerous. Most mutilation experiments are essentially studies of competition between normal and mutilated flowers and it is often profitable to combine these with competition tests between normal flowers of several species. It is especially desirable to have the number of flowers or heads the same for each competitor, and this is secured by basing the number in bouquet or cluster upon that in the group to be used, or by removing flowers to the number desired. Since the standard or species in the natural position is regularly favored in consequence of the habit of the visitors, it is desirable to scatter the competitors through the group, as they may otherwise remain unnoticed.

Manipulation of insects.-As has been indicated, it is felt that the greatest advance in the study of insect behavior can now be made by dealing with individuals. This not only permits greater accuracy in organizing the results for orders, genera, and species, but it also opens up a new and fertile field scarcely touched as yet. A prerequisite for such work is a simple and rapid method of eatching and marking individuals, such as the one devised by Giltay (1906:468). While this will demand still more time and patience, the gain in detail and accuracy over present methods will be as great as that secured by replacing lists of species by a record of visitors and visits. In fact, the actual number of visitors, especially in terms of flight from the nest or hive, can be determined in no other 
way. Many new facts are revealed as to flight, speed of working, constancy, seasonal adjustment in relation to changing maxima of flowering, and so forth.

The analysis of behavior rests upon three factors-instinct, habit, and individual adjustment. Instinct is here regarded as fixed habit, and can be largely evaluated by investigating the comparative behavior of related species and genera. It is probable that habit is constantly passing over into instinct, as seems well illustrated by the perennial adjustment made by groups of species and individuals in the particular floral environment to which their round of activities is restricted. As both observation and experiment have shown, visits to flowers are largely determined by habit, and it is impossible to secure conclusive evidence as to the senses and mental powers of insects without eliminating this actor. The best, though hardly the simplest, way of doing this is to base all studies of attraction, for example, upon the use of individuals that have just hatched and hence have had no opportunity to form habits. This demands the location and control of nests and the marking of individuals as they emerge. It can be done in a less exact manner by transferring nests or hives to a different climax, as from the plains at the foot of Pike's Peak to the montane or alpine zone, but even here marking or cages must be employed for accurate results, except where a species peculiar to the plains is used. Pollination cages afford the best means of complete control, but those so far employed have separated nest and flower group, with the result that the caged bees finally became panic-stricken. Cages several meters long and high enough to accommodate an observer when seated, into which nests are introduced before the young emerge, furnish an almost ideal installation for the study of initial responses to color, form, and odor and the gradual fixation of habits. These can then be removed with their occupants to a totally different group of species, or the flowers to which they are accustomed can be mutilated to call forth new responses and the consequent adjustment of habits to new conditions. Here, as in all experimental ecology, the basic problem is to secure laboratory control under field conditions, and the pollination cage appears much the best solution. However, there will always remain certain experiments that can be carried on best or solely in the laboratory, where maximum control, uniformity, and accuracy can be secured. The requisite technique has been so carefully developed by Frisch $(1914,1919)$ and Knoll $(1921,1922)$ that their methods will serve as the point of departure for all such work in this field (cf. also Porsch, 1922:485).

The most conclusive evidence as to the rôle of color in attraction has been furnished by insects with the antennæ coated or amputated, even Plateau admitting its cogency. The relatively small number of experiments made with anthophilous insects indicate the desirability of extending such work, and the questions raised by McIndoo's researches render this imperative. Owing to the injury usually caused by the amputation or excision of the antennæ or other organs, the chief task is to discover a substance that will coat them with litt'e or no injury and that can not be readily removed. All substances that contain alcohol, turpentine, essential oils, etc., must be avoided and the preference given to mixtures of paraffin 
and vaselin with the lowest possible melting-point and corresponding penetration. The individuals must be marked and observed from day to day, and only those utilized which are essentially normal. The tests should be made under natural conditions with materials to which the insect has been accustomed, and should meet the requirement laid down by Forel, namely, that the insect recognize a certain substance and distinguish it from others in a constant and indubitable manner when normal and not when mutilated. The application of such tests to normal insects, those with the antennæ coated and those with the olfactory pores covered, should be decisive. The results can be rendered even more decisive by covering the insects' eyes and contrasting the response of insects with either the antennæ or the olfactory pores coated to fragrant flowers that are habitually visited. Many other modifications of insects are possible and can be developed as need arises, such as removing the scopa, attaching artificial ones, filling the corbiculæ with wax, etc. In connection with determinations of efficiency, constancy, etc., it is helpful to stain the pollen of various species with particular dyes and thus simplify reading the pollen record of its behavior. One of the most interesting series of experiments contemplated deals with the reversal of the characteristic habits of diurnal and nocturnal pollinators.

Life-history methods and records. - In the endeavor to determine the exact relation of the flower and its behavior to the habitat, simple methods have been devised for following and recording all changes in minute detail. Quite apart from yielding a complete account of the development of the flower, such records have proved indispensable in correlating floral changes with physical factors and insect behavior, as well as in connection with competition and autogamy. The methods are essentially observational, though the subject affords an increasing opportunity for the use of experiments in the correlation of flowers or parts. The essential features are: (1) labeling flowers in the order of development; (2) visiting the plants sufficiently often to obtain a detailed record; (3) recording changes on a tabular form that permits ready checking against the preceding observation. The usual plan has been to mark two or three adjacent plants and to follow the development of 10 flowers on each simultaneously. This furnishes an adequate check on individual behavior, and it is practically impossible to follow a larger group when a number of species is concerned. When the buds are sufficiently large, a label is attached to each and the flowers are numbered in the order of their appearance. Ordinary price-tags are employed and the size determined with respect to the flower. In the case of minute flowers, especially those of umbellifers and grasses, the smallest tags are too large for individual flowers, and other devices must be employed. Tags may be placed at every third or fifth flower in large umbels or at corresponding spikelets in panicled grasses, but in the smaller inflorescences this often produces great distortion. Diagrams with the flowers numbered sometimes afford the best solution, while with the smaller radiate heads of composites the rays may be numbered in ink and thus furnish divisions that enable one to follow the disk-flowers accurately. In large heads and umbels and such spikes as those of Phleum, the inflorescence is labeled and 
threads are used to mark divisions sufficiently small to permit following the florets with accuracy.

Visits are regularly made once each day, except during the rapid development of the warmest days, when morning and afternoon visits are often necessary. Once or twice during each series, records are taken in the early morning, at noon, and in the evening in order to obtain the finest details in the changes. Similarly, one or two visits at sunrise and sunset are necessary to determine the times of opening and closing of many species. The regular visit is made in the morning, preferably at the same hour, though this must often be modified as a result of weather or by other duties. The use of two persons, one to observe and the other to record, effects a great saving of time, but when this is impossible, the entire record should be made by the same individual. The record sheet for each species is ruled to hold the entries for 20 flowers, extra sheets being employed when all the flowers of a head or umbel are to be taken into account. The same form is used for both the field and the final typewritten record and an endeavor is made to enter the observations so that the field sheet can be copied directly. This necessitates a fixed set of abbreviations in order to save both time and space. The entries for each visit are made beneath the preceding one, the space being left blank when no change has occurred, as this permits ready comparison with the last condition. The date and the hour are entered in the first column for each species, the round of visits always being made in the same order to allow the same interval, especially when two or three visits are made in one day. A record is kept of periods of cloudiness and rain, in addition to the usual records of temperature and humidity. The striking differences in the rate of floral development in sun and shade ecads of the same species have been the subject of a special study, in which temperature and humidity were also determined under the forest canopy.

Life-history record of a representative species. - The detailed lifehistories have been recorded for about 100 species of the Pike's Peak region. For the majority of these this was first done in the summer of 1912 and has been repeated in 1921 and 1922, two simultaneous sets of readings being taken in 1921 by different observers. Because of the limitations of space, the detailed table (table 1) is given for a single species only, and this is restricted to 10 flowers on two different plants, taken from the 1921 observations. The main features of the life-history of 26 species are illustrated in plates 2 to 14 , and the stages described in the corresponding legends. 
TABLE 1.-Aconitum columbianum.

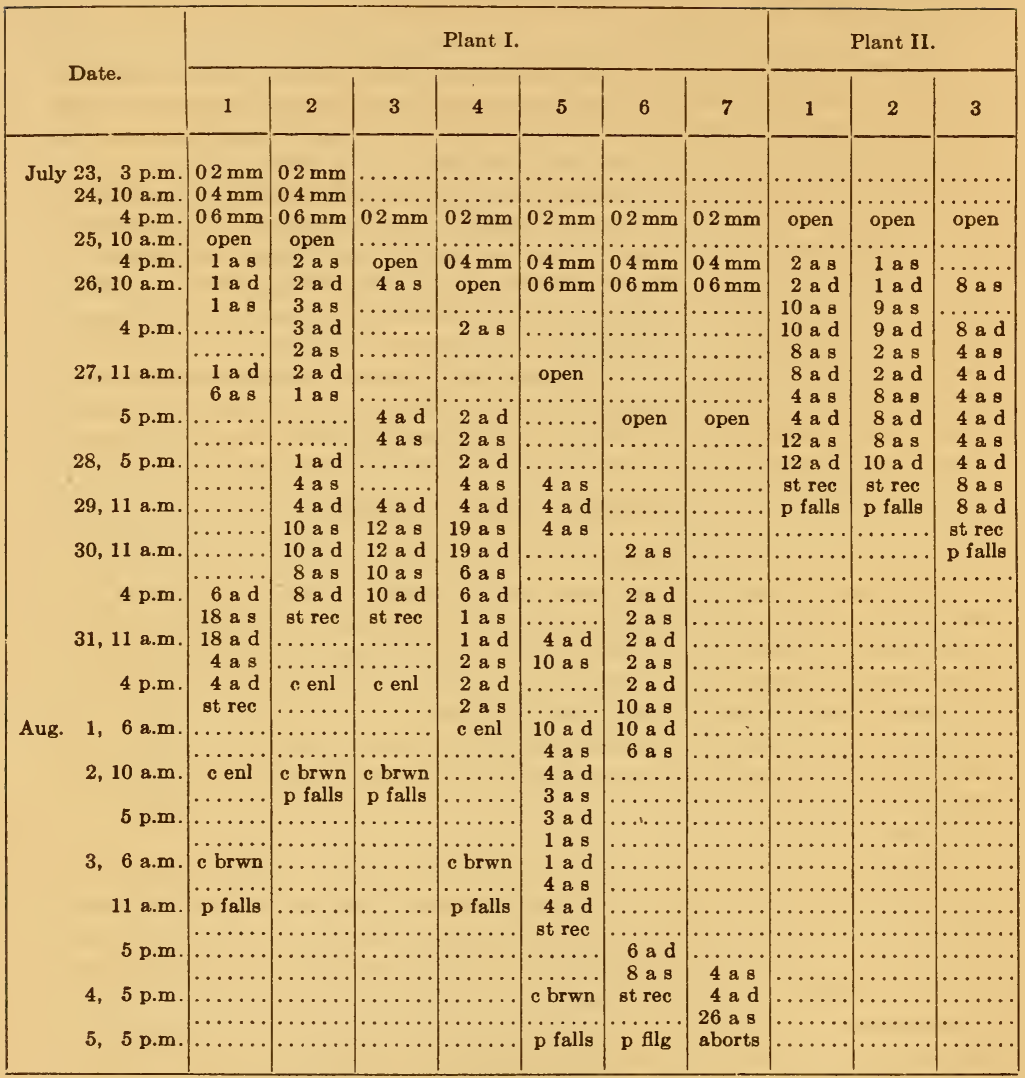

\section{Contractions.}

$\begin{array}{lclll}\text { o open. } & \text { st stigma. } & \text { s shedding. } & \text { rec receptive. } & \text { brwn turning brownish. } \\ \text { a anther. } & \text { c carpels. } & \text { d shed. } & \text { enl enlarging. } & \text { flg falling. }\end{array}$




\section{NORMAL AND EXPERIMENTAL POLLINATION.}

Treatment.-In the following treatment the species have been arranged in general accordance with their phylogenetic sequence, beginning with the buttercups and terminating with the mints. The discussion of each is divided into two sections, the first dealing with normal pollination, the second with experimental pollination. The experiments are considered under four headings: (1) change of position; (2) mutilation; (3) artificial and painted flowers; (4) addition of honey and odor. Those that deal with competition and constancy are reserved for the following chapter. References are given to the European and American observations on the pollination of the same or related species, accompanied by a brief abstract where it seems warranted. Each table or group of tables is summarized in detail and a résumé of the general results is given at the end of the chapter. These are further discussed in connection with the conclusions of other investigators in the final résumé at the end of the fourth chapter.

\section{ACONITUM COLUMBIANUM.}

\section{NORMAL POLLINATION.}

Structure.-The hood in Aconitum is formed of two colored sepals united, the other two sepals making a landing-platform for insect visitors. Two petals are modified into nectaries, while two form the sides of the hood. The sepals and petals are colored alike, increasing the amount of color in the flowers and making them more easily seen and attractive. The sepals that constitute the landing-platform are smaller than the other sepals and petals, but large enough to support the weight of the visitors. The side petals arch above the stamens and protect them to some extent from the rain, but do not interfere with the access of pollinators. However, they hide the stamens from view when the flowers are seen from certain positions. The nectaries are long and stalked, with a crested hood at the top. To secure nectar, the visitors must have a proboscis $10 \mathrm{~mm}$. long in order to reach through the stalk to the hooded portion containing the nectar (plate 2).

Behavior.-The most frequent visitors to Aconitum are Bombus juxtus and bifarius, of which the former is far more frequent, evidently because this species is more numerous in the region. It is larger than bifarius and covers more of the flower. It lands on the two lower sepals, with its head toward the base of the nectaries, and the hind legs curve around the small sepals, while the front pair grasp the side ones. The under part of the thorax rubs back and forth against the anthers and stigmas as the bee sucks nectar. It pushes the proboscis into both nectaries and often stops to brush the pollen from its sides on to its legs, as it leaves the flower. $B$. juxtus visits the flower for nectar, but in getting this, pollen is brushed from its hairy thorax on the stigmas, and at the same time pollen is dusted on the bee. When sucking nectar, the tip of the abdomen reaches to the three styles. The bee scrapes pollen from its head parts as it leaves the flower. It usually goes from the lower flowers on the raceme to the upper ones and then down again. 
Bombus bifarius lands on the sepal platform with its head above the group of stamens and pointing toward the base of the nectaries. It then moves up to such a position that its thorax is above the stamens and its head is at the base of the nectaries, the hind legs resting upon the two front sepals. As it sucks nectar, its body moves back and forth, thus rubbing the lower side of the thorax and abdomen against the anthers and stigmatic surfaces.

None of the North American species of Aconitum has previously been studied with respect to its pollination. In Europe, A. napellus and lycoctonum have received the most attention, and Kronfeld has pointed out that the species of this genus are almost exclusively bumble-bee flowers, the areal limits of Aconitum and Bombus coinciding in a remarkable way. In addition to Bombus, Knuth cites only visits by Macroglossa and Lycaena (1908:50); in the Pike's Peak region the sole visitors are bumble-bees.

\section{EXPERIMENTS.}

\section{CHANGE OF POSITION.}

Horizontal racemes. - Racemes were placed in a horizontal position and attached to the normal ones by thread. Since the flowers of Aconitum are fastened at various points around the stem, the tip of the hood on some pointed sidewise and in others it pointed up or down. Both Bombus juxtus and bifarius easily went into flowers with the hood pointing downward, using the side petals instead of the lower sepals as a landing platform. They then secured nectar without taking an uncomfortable position. $B$. juxtus hovered over the hood in flowers where it pointed sidewise. Finally, it went to the open end where the stamens were exposed, pushed its proboscis about as if exploring, and then found the nectary. The next flower had the tip of the hood pointing up, and $B$. juxtus landed at once on the side petals and took nectar without any inconvenience. In another case where the hood pointed sidewise, the bee hovered over the spur first, apparently trying to find a place to land. It then went to the side of the flower and attempted to land, but slipped off the edge of the side petal, succeeding only on the second attempt. The next flower was horizontal with the hood directed upward. The bee hovered at the spur, went to the other end, and landed easily. It did not learn by one experience that it could find the nectar at this end when the flower was in the horizontal position. In each case it hovered where it would normally expect to alight, before going to the place where landing was possible.

Racemes inverted.-Racemes were cut off and tied to the plant in an inverted position and a piece of moist absorbent cotton was placed around the cut end to prevent wilting. Some individuals of both Bombus juxtus and bifarius found the nectar readily, while in other cases they were frightened away or gave up too soon. The former passed over some flowers without attempting to land, and merely hovered near others. A few individuals started to alight and then flew away as if bothered by the change. Some bees landed at the lower sepals, which now pointed up and occupied the position usually taken by the hood, turned around, and quickly walked into the flower upside down. The next flower was normal and $B$. juxtus went to this as usual. The third was inverted and the bee 
proceeded exactly as in the first inverted flower, apparently noticing the change of position before landing. One $B$. bifarius mastered the situation readily and went to five inverted flowers in succession, turning upside down just after alighting at each one. Another $B$. juxtus landed three times at a group of inverted flowers, tried to push its proboscis into the hood without turning upside down, and in each case failed to find the nectary.

\section{MUTILATION.}

Cotton plugs.-When absorbent cotton was placed in the nectary, Bombus juxtus landed, pushed out its proboscis to find the opening, and tried repeatedly to make a way through the cotton into the nectary. At the next flower it hovered but did not land. When the styles and stamens were hidden by a cotton wad, $B$. bifarius made the same unsuccessful effort to find the nectary opening. Another individual jerked back as it was about to land, and then quickly flew away to the next flower. A third hovered above the flower and departed without landing, as did several others of both species.

Stamens removed. - Bombus juxtus noticed the change as readily as when the flowers were covered with cotton wads, while $B$. bifarius either hovered above the flower before alighting, or landed directly and flew away at once without projecting the ligule or trying to find the nectar.

Hood split.-The hood was split longitudinally in some flowers, thus making them more conspicuous, as it then exhibited a pair of wings ascending behind the nectaries. In some cases this change had no effect upon landing, as it appeared neither to frighten the bees nor to attract them in increased numbers, but in others it greatly increased the attraction. They landed in the usual manner, but had a very hard time hanging on to the stamens. Because they were unable to find a suitable position, they often went away without getting nectar.

Hood removed.- The hood was removed, leaving the two nectaries to project above the remaining flower-parts. This made the nectaries conspicuous and changed the general aspect of the flower very much. The effect on the visiting bees was not uniform. Bombus juxtus sometimes hovered above the flowers, but did not land, or stopped without pushing out its ligule. Some exposed the ligule, then noticed the change, and flew away. Others were more persistent, for they landed, at once found the slit down which the nectar runs, and emptied each of the nectaries, repeating this performance at the next flower.

Hood and nectaries removed.-An individual of Bombus juxtus alighted as usual, and explored in all directions with its tongue, in the unsuccessful endeavor to find the opening. One adventurous individual crawled between the side petals as if expecting to find the nectary. When it got through, it turned around, crawled over the stamens, and flew away.

Lower sepals removed.- Since this is the part of the flower on which Bombus usually rests its hind legs, it found difficulty in balancing properly while seeking the nectary, but finally succeeded in reaching the nectar. 
Side petals removed.- Some bees evidently noticed the changed appearance brought about when these were removed, and hovered above the flowers without landing. However, most of them seemed to observe no change, for they landed and sucked nectar as if the flowers were normal, and even came back a second time. The second pair of legs in these cases was crowded closer to the base of the stamens and rested there. Flowers with side petals removed were also placed in the horizontal position with the hood pointing upward. One bifarius treated these flowers as it did Rosa and tumbled about on the stamens, collecting pollen and making no effort to get nectar. Another followed and did the same thing. This was in marked contrast to all other olservations on normal Aconitum, in which Bombus had never made any effort to collect pollen. Ordinarily, the pollen was collected accidentally as the body moved back and forth across the stamens in the act of gathering nectar.

Competitive relations.- The five types of mutilation were represented by 5 flowers each, and these were arranged with 25 normal ones (plates 15 and 16). Table 2 gives the results; mere inspections are indicated by an $i$.

TABLE 2.-Tisits to normal and mutilated fowers.

\begin{tabular}{|c|c|c|c|c|c|c|c|c|}
\hline Date. & Time. & Species. & Normal. & $\begin{array}{l}\text { Side } \\
\text { petals } \\
\text { off. }\end{array}$ & $\begin{array}{c}\text { Nectary } \\
\text { and hood } \\
\text { off. }\end{array}$ & $\begin{array}{c}\text { Hood } \\
\text { off. }\end{array}$ & $\begin{array}{l}\text { Hood } \\
\text { split. }\end{array}$ & $\begin{array}{c}\text { Cotton } \\
\text { over } \\
\text { stamens. }\end{array}$ \\
\hline \multirow[t]{2}{*}{$\begin{array}{l}\text { July } 27 \\
\text { July } 28\end{array}$} & \multirow[t]{2}{*}{$\begin{array}{l}3 \text { to } 5 \\
9 \text { to } 11\end{array}$} & $\begin{array}{l}\text { Bombus juxtus... } \\
\text { Bombus bifarius. } \\
\text { Bombus juxtus. . }\end{array}$ & $\begin{array}{r}27 \\
5 \\
35\end{array}$ & $\begin{array}{l}2 \\
0 \\
7\end{array}$ & $\begin{array}{l}2: 16 \mathrm{i} \\
2: 3 \mathrm{i} \\
5: 11 \mathrm{i}\end{array}$ & $\begin{array}{r}3 \\
6 \\
14\end{array}$ & $\begin{array}{r}14 \\
8 \\
32\end{array}$ & $\begin{array}{l}0 \\
1 \mathrm{i} \\
1 \mathrm{i}\end{array}$ \\
\hline & & Total. & 67 & 9 & $9: 30 \mathrm{i}$ & 23 & 54 & $2 \mathrm{i}: 95$ \\
\hline
\end{tabular}

The number of visits to the mutilated flowers was nearly a half greater than those to the normal, due chiefly to the response to the flowers with the hood split. This greatly increased the extent of the color surface and the attraction even to a greater degree, as each flower received 4 times as many visits as a normal one. Since those with the hood off averaged nearly twice as many visits as the latter, the exposure of the nectaries evidently played a part in the attraction. The other mutilations were visited about the same as the normal flowers, except where cotton was present, this change being noted even in rapid flight. Individual differences in behavior were especially noted in the case of the flowers with the hood and nectaries removed. Three bees inspected these flowers to one that landed, and of the latter some flew away at once, while others extended the ligule several times in the endeavor to find the opening to the nectary.

\section{ARTIFICIAL AND PAINTED FLOWERS.}

Normal colors.-The flowers of Aconitum columbianum are either blue-purple, or white. The plants studied grew along brook-banks and were lighted by sunflecks, which made the purple flowers more conspicuous than the white ones, though the two were equally numerous. The response 
of Bombus to the two colors is shown by table 3, which records the number and order of visits, each time given representing a different bee.

TABLE 3.-Visits to white and purple flowers.

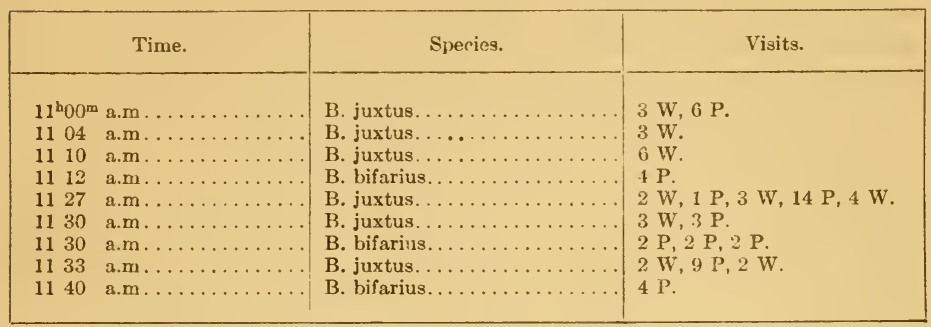

During the 40 minutes, 9 bees visited 75 flowers, of which 26 were white and 49 purple. On another day, 63 flowers each of purple and white were observed for half an hour. During this period Bombus juxtus visited 64 purple and 68 white flowers, and $B$. edwardsi 1 purple and 3 white ones. The total number of visits was 65 to the purple and 71 to the white.

Artificial flowers.-To obtain further evidence as to color preference, other colors were tried. This was done in two ways: (1) by replacing the corollas and calyxes with crepe-paper floral envelopes, leaving stamens, pistils, and nectaries intact, or surrounding the natural corollas by crepepaper disks, and (2) by painting the perianth with water-colors. Artificial corollas and calyxes of crepe-paper were made to resemble those of the natural flowers as nearly as possible, the effect being essentially lifelike. Yellow, green, white, red, pale blue, and purple were the colors used. The artificial corollas were not attached until after the bees had visited all the flowers under observation, in order to make sure that nectar was present and that nothing about the flowers was objectionable. In placing the artificial flowers the following combinations were used:

(1) A colored erepe flower was paired with a normal one at various points on the stem.

(2) A raceme was leit with as many normal as crepe flowers of the various colors, and these wore scattered in no definite order.

(3) Flowers of a single color of crepe-paper, but as numerous as the normal flowers, were seattered at various points on the stem.

(4) One half the raceme was left normal and artificial corollas of one color of crepepaper were used on the other half.

These experiments were tried on several days during the season for four different years, with essentially the same results. Bombus would fly within $2 \mathrm{~cm}$. of the crepe flowers, but would then pass without landing. The only two exceptions to the above were the flowers with the pale-blue and white perianths. Bombus stopped at the white ones and worked as if noting no difference, while pale-blue flowers were visited at 7 different times by as many individuals of juxtus. In two cases after visiting the flower and taking nectar, this species returned for another visit. 
To render the natural flowers more conspicuous, strips of crepe-paper were cut a half-inch wide lengthwise of the roll. Fine wire was run through this strip along one edge, making a ruffled disk which was placed around the stamens and nectaries. An equal number of normal flowers and of those with red, green, white, yellow, or blue crepe ruffles were used. The flowers appeared very showy and the nectaries and stamens were conspicuous. Bombus juxtus visited only normal flowers to a total of 29 , while bifarius stopped at but 5 normal ones. It hovered low over green, white, and blue modifications, but did not land on them.

Painted flowers.- In further experiments, flowers were treated with water-colors. The white flowers were usually painted, as they took the colors better than the purple. The perianths were washed on the outside alone. Ten natural flowers and 5 of each color were used, making a total of 30 colored ones, or 3 times as many painted as normal (plate 1).

TABLE 4.-Visits of Bombus juxtus to painted flowers.

\begin{tabular}{|c|c|c|c|c|c|c|c|c|}
\hline Date. & Time. & Normal & Red. & Vermilion. & Green. & Yellow & Blue. & Indigo. \\
\hline \multirow{6}{*}{$\begin{array}{c}\text { July } 27 \\
\text { July } 28 \\
\text { Do. } \\
\text { Do. } \\
\text { July } 30\end{array}$} & $10^{\mathrm{h}} 50^{\mathrm{m}}$ to $11^{\mathrm{h}} 45^{\mathrm{m}}$ & 29 & 4 & 11 & 6 & 4 & 8 & 10 \\
\hline & 1115 & 11 & 0 & 4 & 2 & 3 & 7 & 2 \\
\hline & 100 & 4 & 0 & 4 & 3 & 2 & 3 & 3 \\
\hline & 255 & 13 & 2 & 7 & 9 & 6 & 4 & 8 \\
\hline & 1000 & 9 & 0 & 0 & 0 & 0 & 5 & 0 \\
\hline & Total. ...... & 66 & 6 & 26 & 20 & 15 & 27 & $23: 117$ \\
\hline
\end{tabular}

While this species visited nearly twice as many painted as normal corollas, the actual ratio was $39: 66$, indicating a distinct preference for the natural flowers. Among the painted ones, blue, vermilion, and indigo were sought most, green, and yellow less, and red by far the least.

The response to the colored flowers varied at different times, but the general behavior of visitors is shown by the following field calendar, derived from another experiment:

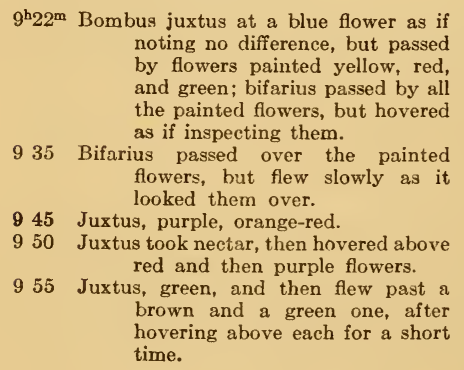
$11^{\mathrm{h}} 15^{\mathrm{m}}$ Juxtus, green.
1117 Juxtus, orange-red for 45 seconds.
1120 Bifarius, red, red.
11.21 Juxtus, blue, purple.
1123 Juxtus, yellow.
1124 Juxtus, blue.
1126 Juxtus, blue.
1127 Juxtus, blue, purple.
1135 Bifarius, purple, orange, red, purple, blue, purple; passed over brown and yellow.
1137 Juxtus, yellow.
1139 Juxtus, purple, blue; passed by yellow, red, and green.
1140 Bifarius, purple, blue, green, purple,
red, white.

During the time of the above observations, Bombus visited normal flowers as well as the colored ones listed. A summary shows that the bees visited flowers of all colors used except brown. Of the 32 visits recorded, 
10 each were made to blue and purple, 4 to red, 3 each to green and orangered, and 2 to yellow.

Both the inside and outside of 10 perianths were painted with each of the following colors: red, blue, yellow, green, purple, and 10 normal flowers were used for comparison. The following short record shows the resulting behavior, each line indicating a different visitor:

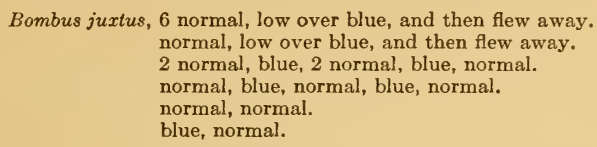

\section{ADDITION OF HONEY AND ODOR.}

Honey.-In order to throw light on the rôle of nectar in attraction, four kinds of sweets were used, viz., honey, diluted honey, diluted white Karo sirup, and beet-sugar solution. These were put on the side petals of some flowers, on the stamens and styles of others, and in the nectary opening of still others. In some cases, Bombus juxtus went directly to the nectary of flowers with honey at the sides of the petals, sipped as usual, and flew away without discovering the honey. In other cases, it flew down to these flowers, almost landed, and then flew away as if frightened, perhaps by the unusual appearance. When the various sugar solutions were put into the nectary openings, Bombus took nectar as usual, but stayed longer at each flower, owing to the increased supply. When Karo sirup or sugar solution was put on the stamens, $B$. juxtus and bifarius did not notice it in some cases, for they went past to the nectary and then flew away. Other individuals of $B$. juxtus landed in such a way that the mouth-parts accidentally touched the sirup. After taking sirup from such a flower a bee flew to a normal one, pushed its ligule around the stamens as if looking for more sirup, then advanced to the nectary opening, and obtained nectar as usual. In the next flower, where the stamens were covered with honey, it proceeded to take this supply and fly away without trying for nectar.

The procedure of Bombus juxtus was various in the flowers where the honey drop was placed on the stamen group. One bee landed without noticing the honey on the anthers, but pushed its head into the hood and took nectar. Another alighted in such a way that its head touched the honey. It obtained honey in 3 flowers of this type, without paying any attention to the nectary. A third did not notice the honey drop, but secured nectar in the usual manner. As it started to fly away its thorax stuck to the anthers, and it scraped the honey from its front legs, without even discovering that it was sweet or edible. B. bifarius went in succession to 6 flowers with drops of honey on the anthers; it did not notice the honey, but took nectar as usual. $B$. juxtus landed on the lower sepal of a flower in such a way that its head touched the honey on the anthers, and it sipped until the drop was all gone. Instead of pushing its ligule into the nectary, it flew to the next flower, where a drop of honey was in the same position, and proceeded to suck all of it. When it started to fly away, its tongue stuck in the honey and it had a difficult time to free itself. 
Perfumes.-Sachet powders and perfumes of various sorts were also tried, but without positive results. Bombus juxtus and B. bifarius hovered above the flowers without landing in many cases, and in others flew about as if not noticing them at all. In one case juxtus alighted at a flower with arbutus sachet and took nectar as if noting no change. In general, if Bombus noticed the odor at all, it seemed repelled rather than attracted by it.

\section{SUMMARY.}

In general, the bumble-bees had less trouble with horizontal than with inverted racemes, though there were marked individual differences. Some bees passed readily from normal to inverted fiowers, adjusting their behavior to each without apparent difficulty. The use of cotton usually prevented landing, and this was frequently the case also when the stamens were remored. In spite of individual departures the other mutilated flowers were usually visited about as much as normal ones. In the competition study, however, those with the hood split or removed received many more visits, while those with the hood and nectaries gone received 3 inspections to one visit, and those with cotton over the stamens obtained but rare inspections.

No distinction was made between white and purple in the normal flowers, but blue and purple were given a decided preference over the other colors in the case of artificial and painted ones. Since white-crepe corollas with natural centers were visited normally, the choice appears to have been determined largely by the colors regularly present in the species. With the exception of white and blue, none of the artificial flowers yielded visits, though some of these were inspected. Painted flowers, on the other hand, received a third to a half as many visits as normal ones. The addition of honey did not render the flowers more attractive, and no positive results were obtained with perfumes.

\section{DELPHINIUM SCOPULORUM.}

\section{NORMAL POLLINATION.}

Habit and structure.- The anthers are very conspicuous in young Delphinium flowers. They become erect when mature, taking a position very near the opening into the nectary and after dehiscence they bend down again. The two petals, which have the tips deflexed, then close together over the shrunken anthers. As the stigmatic surfaces mature, the styles bend up, bringing the stigmas near the opening of the nectary (plate 2).

Behavior.-Bombus edwardsi and juxtus are the most frequent visitors to Delphinium. When both species are present, edwardsi visits many more flowers than juxtus. The latter uses the two lower sepals for a landingplatform, the forelegs resting on the front spur of the petals or on the sides of the sepals. After landing, it moves the head forward above the stamens, pushes the ligule down the spur, and takes nectar. While it comes for nectar alone, at the same time pollen collects on the legs and thorax. The flow of nectar in these flowers must be rapid, as one individual went twice to 15 flowers on the same plant and to 9 flowers three times in succession while on one trip, and another individual visited 22 flowers twice on the 
same trip. B. juxtus sometimes visits withered flowers, stopping to seek nectar at those in which the lower side petals have dropped off. B. edwardsi and morrisoni land and take nectar in the same manner as juxtus. As Thanaos martialis lands on the lower sepals, the delicate ligule is pushed into the nectary and the hairs on the under side of the head come in contact with the anthers.

Robertson (1889:120) states that the white upper petals are a sure guide to the nectar in Delphinium tricorne, in which the lateral petals serve to protect the pollen. It agrees with $D$. elatum and $D$. consolida in being protogynous and especially adapted to bumble-bees. In Europe these species are exclusive bumble-bee flowers (Knuth, 1908:44), but Robertson notes several other genera of bees and a number of butterflies and moths.

\section{EXPERIMENTS.}

CHANGE OF POSITION.

Inverted racemes. - Bombus juxtus hovered above 6 flowers which were inverted, but apparently noticed that something was wrong and did not land. At the seventh flower it made an attempt at landing, but found the pointed front part of the spur too narrow. After slipping off twice when it tried to put its hindlegs in this spur, it flew away. Other individuals flew above these flowers, but did not alight.

Horizontal racemes. - In these flowers the hood pointed down and Bombus juxtus was not bothered by the change. It landed and found the nectar easily, using a side sepal and one of the lower ones for a landing platform.

\section{MUTILATION.}

Cotton plugs.-Absorbent cotton was placed in the opening to the spur, which serves for the nectary. Bombus juxtus stopped, but when it found no opening did not attempt to probe around the cotton, but went to the next flower. A slender cotton roll was placed in the nectary in such a way that it projected $1 \mathrm{~cm}$. in front of the flower and changed the whole aspect of the latter. This bee landed on the cotton projection and tried to find the opening to the nectary, but failed. It repeated the performance on the next flower with the same results.

Petals removed.-The petals, which recurve and protect the stamens, were removed, thus making the black group of anthers very conspicuous. The curved white filaments showed above the anthers, and the nectary openings were visible above the filaments, thus changing the aspect of the flower materially. On the first day of this experiment, Bombus juxtus took no notice of the change and found the nectary without difficulty. On another day the results were quite the reverse and 5 individuals passed by these flowers during a period of 15 minutes. B. edwardsi went to 7 of the mutilated flowers, apparently without noticing the difference (plate 16).

Spur removed.-Bombus juxtus pushed its tongue back and forth 9 times in one of these flowers, the tongue projecting 6 to $7 \mathrm{~mm}$. beyond the cut end. In another instance, the tongue was rapidly pushed back and forth 4 times through the opening. A third individual noticed the change in the flowers and did not land. 
Landing-platform removed.-The landing-platform in this flower consists of the lower two sepals. When these were removed, juxtus hovered above two flowers without landing. At the third flower it landed successfully by placing the hind pair of legs on the sepals of an adjoining flower.

A comparison was made between 25 normal and 25 mutilated flowers, consisting of 5 of each type. In the fifth type of mutilation, pieces of grass culms $2 \mathrm{~cm}$. long were used to close the nectary openings and to change the appearance of the flowers (table 5).

TABLE 5.-Visitors to normal and mutilated flowers.

\begin{tabular}{|r|c|c|c|c|c|c|c|}
\hline Species. & Normal. & $\begin{array}{c}\text { Lower } \\
\text { sepals } \\
\text { off. }\end{array}$ & $\begin{array}{c}\text { Side } \\
\text { sepals } \\
\text { off. }\end{array}$ & $\begin{array}{c}\text { Upper } \\
\text { petal and } \\
\text { spur off. }\end{array}$ & $\begin{array}{c}\text { Spur } \\
\text { off. }\end{array}$ & $\begin{array}{c}\text { Grass culm } \\
\text { in nectary } \\
\text { opening. }\end{array}$ & Total. \\
\hline Bombus edwardsi...... & 14 & 7 & 7 & 6 & 9 & 2 & 31 \\
juxtus....... & 15 & 1 & 2 & 2 & 1 & 2 & 8 \\
\cline { 2 - 7 } Total........... & 29 & 8 & 9 & 8 & 10 & 4 & 39 \\
\hline
\end{tabular}

The mutilated flowers were visited somewhat more frequently than the normal ones, the kind of mutilation making little difference, except when the grass section was present. However, the two species exhibited a marked difference in behavior, Bombus edwardsi visiting twice as many mutilated flowers as normal ones and juxtus but half as many. In the case of the grass section, two individuals of each species of Bombus tried hard to push the ligule into the nectary, but did not succeed, their persistent efforts at the proper spot indicating that they knew where the nectary was.

\section{ARTIFICIAL AND PAINTED FLOWERS.}

Crepe-paper corollas.-In order to give Delphinium the same general form as Rubus deliciosus, disk-like corollas of red, white, green, yellow, or blue paper were placed around the pedicels after the floral envelopes had been removed. This did not change the odor or the essential parts of the flower, but increased the size in addition to changing the color. There were 147 open flowers under observation, 10 of each of the 5 colors, and 97 normal ones, approximately twice as many normal as changed flowers. During the hour and a half of observation, Bombus juxtus was the only visitor, going to 93 normal flowers and to one with a green paper corolla. During this time it visited 4 normal flowers on one branch where the majority were blue, and 5 normal ones on a branch where most of them were white, but in neither case did it venture to try the artificial flowers.

Crepe-paper corollas with spurs.-In order to study the response to color without change of form, life-like crepe corollas with spurs were used to replace the floral envelopes. In addition to 27 normal flowers, 4 of each of the five colors, red, blue, green, yellow, and white, were used for comparison, with the following results. Three individuals of Bombus juxtus visited 3,2 , and 3 normal flowers respectively, not even stopping to investigate those with crepe corollas. Two $B$. proximus visited 2 normal flowers each and no crepe ones. This group of flowers was covered over night with 
a paper sack to protect the crepe-paper from the rain, this also preventing bees from securing the nectar until the time of observation. B. juxtus was the only visitor and the several individuals went to $9,3,2,3,5$ normal flowers respectively, some flying low over the colored ones as if inspecting them, but not alighting.

Painted flowers.-A further study of the reaction of pollinators to color was made by means of water-colors (plate 1). Three colors, green, red, and yellow, were represented by 11 flowers each, and these were arranged so that each one adjoined a normal flower. The first visitor was Bombus juxtus, which went to all the green flowers once and to some twice, but visited no others. B. proximus visited 3 normal flowers in one group, 4 flowers in a nearby cluster, and then 2 green flowers. The last visitor was a very persistent individual of juxtus, which came to the flowers in the following succession: 10 normal, 3 yellow, 2 green, 1 green, 3 green, 25 normal, 21 normal, 3 normal, 3 normal, 2 green, 4 normal, 4 green, 4 yellow. In the next experiment, 12 normal flowers and 6 each of red, yellow, green, and brown, were used, but without being arranged in any definite order. Three visitors came during the hour of observation with the following results: 2 individuals of juxtus visited 17 and 19 normal flowers respectively and edwardsi 3 normal ones, none paying attention to the colored flowers. Five days later, when the same number of colored and normal flowers were used in the same type of arrangement, the results were quite different. The first visitor stopped at a normal flower only, but the next one visited the flowers as follows: normal, green, blue, and normal, while edwardsi visited 2 normal flowers alone. The last juxtus went to normal, blue, yellow, normal, normal, red, blue, red, and blue flowers in order. In the next experiment 5 flowers each were painted red, green, blue, yellow, or purple, on both sides of the corolla, and 25 normal flowers were left on the same stalk for comparison. B. edwardsi visited 127 normal and 3 blue flowers, but no red, yellow, purple, or green ones, flying low enough over all those painted to distinguish the colors. B. juxtus visited 116 normal, 4 blue, 2 green, and 1 yellow, but no red flowers.

The total number of visits to painted flowers was 51, in contrast to 323 to normal ones, the ratio being 1:7. The individual range in behavior was of the greatest, one juxtus visiting green flowers alone and another none but normal ones, while a third did not discriminate between them and a fourth went to twice as many painted as natural flowers. When the colors employed were red, yellow, and green, the latter was given a marked preference, but when blue was added, this was visited more than all others combined.

\section{ADDITION OF ODOR.}

Perfume.-Rose perfume on absorbent cotton was wrapped around the pedicels under the flowers on one-half of the stalk. The flowers perfumed were on the side away from the wind, in order to make the odor more noticeable on the one half. Bombus juxtus visited 9 normal and 2 perfumed flowers, these being the only visits during 2 hours of observation. On another day, carnation perfume was placed on cotton wads wrapped around the pedicels of one-half of the stalk. Nearby, powder made from camphor balls was sprinkled at the center of the stamens on flowers in a similar 
arrangement. The two odors were on stalks near enough together for observation, but not so close that the odors were likely to mingle. $B$. juxtus visited 30 normal flowers and 29 with the carnation odor on one plant and 15 normal and 20 with camphor odor on the other. B. proximus went to 27 normal and 14 with carnation odor, but none with camphor odor. Thanaos martiales visited 1 normal on the carnation stalk, but none with the carnation odor, and 1 normal and 3 with the camphor odor on the other stalk.

B. juxtus and proximus both went from normal to flowers with carnation odor and from those to normal flowers. All told, 83 visits were made to normal and 68 to perfumed flowers, the number to carnation being twice that to camphor.

\section{SUMMARY.}

The experiments with flowers in changed positions indicate that the bumble-bee not only perceives such changes readily, but also distinguishes between the two positions with respect to the ease of landing. In general, mutilated flowers were visited as readily as normal ones, even the removal of the landing-platform causing but temporary difficulty. Individuality of behavior was more or less marked as usual, the removal of the petals having no effect on one day and leading to such flowers being completely ignored on another. As a rule, the bees were quick to learn the significance of the different changes, solving the problem of landing after a few attempts. The response to paper flowers with natural centers was in sharp contrast to that to painted flowers; the former received but one visit to 125 for normal flowers, while the latter yielded one to each 7 for the normal. This suggests that the eyes of the bumble-bee are even more accurate than our own in perceiving small differences of color and form. The figures in the case of visits to perfumed flowers are not decisive, though they indicate that the bees found the added odor somewhat disturbing.

The experimental results with Aconitum and Delphinium are essentially in harmony, as might be expected from the ecological similarity of the flower's. Changes in position and form produced much the same response, as did paper flowers and added perfume. In the case of painted flowers of Aconitum, however, there were more than half as many visits as to the normal ones, the ratio being $1: 1.7$ in contrast to $1: 7$ for Delphinium.

\section{RUBUS DELICIOSUS.}

\section{NORMAL POLLINATION.}

Habit and structure.-The bushes of this species are tall and spreading, the branches profusely laden with flowers which are the showiest in bloom during its period. With respect to attraction the flower consists essentially of a mass of yellow stamens surrounded by very large white petals, and possesses a pleasant odor. The corolla is widely expanded and the stamens fully exposed. The nectar is formed at the base of the stamens, where it appears as a circle of tiny drops.

Behavior.-Bombus juxtus collects pollen chiefly with the hind legs as it tramples about, packing it in large masses on them, the hairs of the body becoming well dusted in the process. As it moves about, pollen is 
transferred to the stigmas from the under parts, or autogamy results as the stamens are spread and brought in contact with the stigmas. This bee drives Halictus out of the flowers and occasionally enters a flower with dried anthers. Apis mellifica walks around the margin of the flower, apparently because the anthers mature there first, and then across the center, ignoring those with brown stamens. While it is trampling about and collecting pollen, the ligule is sipping the nectar found around the edge of the petals at the base of the stamens. Monumetha albifrons works around the margin in similar fashion, collecting pollen in smaller amounts on the under side of the abdomen, legs, and head. Andrena crataegi pushes its head under the anthers, bites them open, and shakes the pollen out in order to pack it on the hind legs. Vespa germanica sucks.nectar in various positions, often entering flowers in which the anthers are quite dry.

Variation in visits.- In order to determine the effect of time and place on visits, detailed calendars were made on several different days and in several places. Since these are too long to be given, the results are summarized in tables 6 to 9 . In the first series the time alone was varied by making use of three different days close together, while in the second the two days were taken at different parts of the flowering period.

An hour and a half of observation at the Alpine Laboratory on June 10, 11 , and 13 yielded the list of visitors to 100 flowers (table 6), the second figure, as usual, indicating the number of flowers visited.

TABLE 6.-Visitors on different days in early season.

\begin{tabular}{|c|c|c|c|c|c|c|c|}
\hline Species. & $\begin{array}{c}\text { June } \\
10\end{array}$ & $\begin{array}{c}\text { June } \\
11\end{array}$ & $\begin{array}{c}\text { June } \\
13\end{array}$ & Species & $\underset{10}{\text { June }}$ & $\begin{array}{c}\text { June } \\
11\end{array}$ & $\begin{array}{c}\text { June } \\
13\end{array}$ \\
\hline Apis mellifica. & $22: 127$ & $5: 5$ & $0: 0$ & Musca sp.. & $1: 1$ & $0: 0$ & $8: 8$ \\
\hline Andrena crataegi........ & $0: 0$ & $2: 2$ & $1: 1$ & Osmia melanotricha. . & $0: 0$ & $0: 0$ & $1: 1$ \\
\hline sp............... & $0: 0$ & $0: 0$ & $2: 2$ & densa.............. & $2: 2$ & $0: 0$ & $0: 0$ \\
\hline Bombus morrisoni...... & $1: 1$ & $1: 1$ & $0: 0$ & bruneri....... & $1: 1$ & $0: 0$ & $0: 0$ \\
\hline juxtus.......... & $0: 0$ & $6: 6$ & $4: 4$ & Papilio turnus. . . . . . . & $0: 0$ & $0: 0$ & $2: 2$ \\
\hline Bombyliad............ & $0: 0$ & $3: 3$ & $0: 0$ & Prosopis elliptica......... & $0: 0$ & $0: 0$ & $1: 1$ \\
\hline Halictus pulzenus. . . . . . & $0: 0$ & $0: 0$ & $10: 10$ & Syrphus americanus..... & $1: 1$ & $6: 6$ & $0: 0$ \\
\hline Monumetha albifrons.... & $1: 1$ & $0: 0$ & $0: 0$ & Total. & $29: 134$ & $23: 23$ & $29: 29$ \\
\hline
\end{tabular}

TABLE 7.-Visitors in mid and late season.

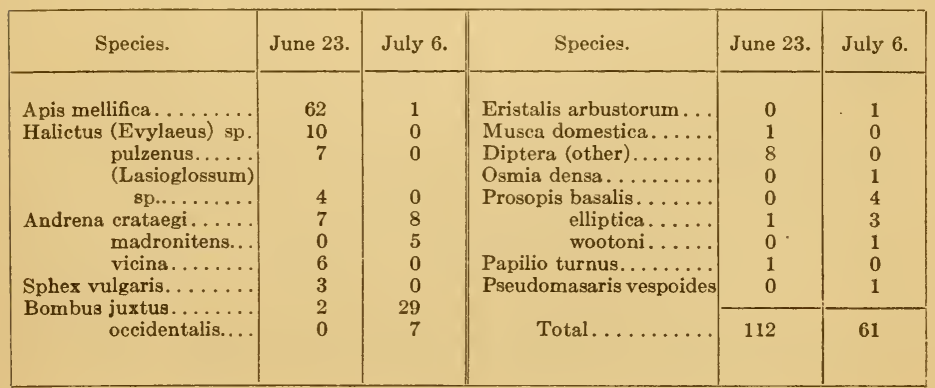


The most significant variation was that of Apis, indicating the possible fluctuations from day to day, but similar differences of less degree are to be noted for practically every species.

The visitors noted at the same time of day, $8^{\mathrm{h}} 30^{\mathrm{m}}$ to $9^{\mathrm{h}} 30^{\mathrm{m}}$ a.m., at the same location, with 65 open flowers in bloom and under observation in each case, are shown in table 7 . The first list represents the visitors at about the middle of the flowering season and the second those at the end. There were no plants of Rubus deliciosus in bloom lower down in the canyon at the time the second list of visitors was made.

Apis and Halictus, the two most important pollinators of the middle of the flowering period, were almost completely absent at the end, but the situation was exactly reversed for Bombus and Prosopis. On the contrary, Andrena maintained its number throughout, though the three species showed as many types of distribution.

TABLE 8.-Visitors to adjacent areas on different days.

\begin{tabular}{|c|c|c|c|c|c|}
\hline Species. & June 5. & June 7. & Species. & June 5. & June 7. \\
\hline $\begin{array}{r}\text { Apis mellifica........... } \\
\text { Bombus occidentalis.... } \\
\text { juxtus (worker) } \\
\text { juxtus (queen). } \\
\text { bifarius........ } \\
\text { edwardsi...... } \\
\text { hunti........ } \\
\text { morrisoni ...... } \\
\text { Andrena canadensis.... } \\
\text { madronitens.. } \\
\text { crataegi...... } \\
\text { prunorum..... } \\
\text { vicina........ }\end{array}$ & $\begin{array}{r}12 \\
35 \\
37 \\
4 \\
10 \\
1 \\
1 \\
0 \\
14 \\
4 \\
4 \\
4 \\
2\end{array}$ & $\begin{array}{r}77 \\
2 \\
0 \\
0 \\
1 \\
0 \\
0 \\
2 \\
0 \\
0 \\
3 \\
1 \\
0\end{array}$ & 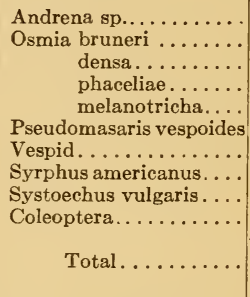 & $\begin{array}{r}1 \\
5 \\
5 \\
1 \\
1 \\
2 \\
1 \\
2 \\
0 \\
0 \\
146\end{array}$ & $\begin{array}{r}0 \\
1 \\
2 \\
0 \\
1 \\
0 \\
0 \\
0 \\
1 \\
3 \\
94\end{array}$ \\
\hline
\end{tabular}

TABLE 9.-Summary by genera.

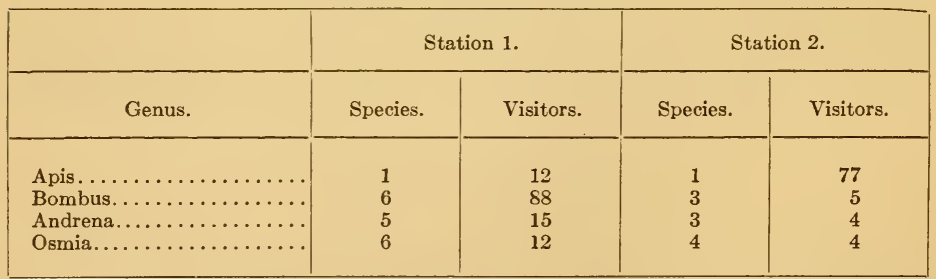

Reciprocal checks at the two stations showed that the differences recorded were due to location and not to time. Since they were situated in the same canyon and but 150 meters apart, it is probable that the contrast between the numbers for Apis and those for Bombus, Andrena, and Osmia is to be ascribed to the difference in the associates of Rubus in the two places. In station 1 it was grouped with Prunus demissa and P. pennsylvanica, while at station 2 it was associated with Geranium especially. However, it is quite possible that the difference was due to habit rather than to any difference in conditions. 


\section{EXPERIMENTS.}

\section{MUTILATION.}

Petals split or shortened.-When each petal was cut lengthwise into four ribbons, giving a daisy-like appearance to the flowers, Bombus juxtus, B. morrisoni, and Andrena vicina visited them just as they did normal flowers. In order to reduce the attractive surface, the petals were clipped to half their length, giving the corolla a rotate form, with no spaces between the petals. The flowers used were at the same stage of development, the number of normal and mutilated ones being the same on each day. Table 10 shows the effect of this reduction in attractive surface.

TABLE 10.-Visits to normal and mutilated flowers.

\begin{tabular}{|c|c|c|c|c|c|c|}
\hline \multirow{3}{*}{ Species. } & \multicolumn{3}{|c|}{ June 26.} & \multicolumn{3}{|c|}{ June 27.} \\
\hline & \multirow{2}{*}{ Normal. } & \multicolumn{2}{|c|}{ Corolla reduced. } & \multirow{2}{*}{ Normal. } & \multicolumn{2}{|c|}{ Corolla reduced. } \\
\hline & & Visited. & Inspected. & & Visited. & Inspected. \\
\hline Apis mellifica . . . . . . . . & 60 & 15 & 5 & 25 & 3 & 2 \\
\hline Bombus juxtus............. & 22 & 5 & 5 & 8 & 1 & 1 \\
\hline occidentalis......... & 0 & 0 & 0 & 7 & 2 & 1 \\
\hline hunti............. & 2 & 1 & 0 & 0 & 0 & 0 \\
\hline Andrena crataegi............ & 11 & 1 & 0 & 0 & 0 & 0 \\
\hline edwiniae........... & 1 & 1 & 0 & 0 & 0 & 0 \\
\hline vicina............ & 3 & 0 & 0 & 0 & 0 & 0 \\
\hline imitatrix.......... & 1 & 1 & 0 & 0 & 0 & 0 \\
\hline Halictus pulzenus. . . . . . . . & 2 & 2 & 0 & 0 & 0 & 0 \\
\hline (Lasioglossum) sp . .. & 2 & 0 & 0 & 0 & 0 & 0 \\
\hline Megachile wootoni.......... & 1 & 0 & 0 & 4 & 0 & 0 \\
\hline Prosopis basalis. ........... & 0 & 0 & 0 & 3 & 0 & 0 \\
\hline episcopalis.......... & 0 & 3 & 0 & 0 & 0 & 0 \\
\hline Systoechus vulgaris. ........... & 1 & 2 & 0 & 1 & 0 & 0 \\
\hline Pseudomasaris vespoides..... & 1 & 0 & 0 & 0 & 0 & 0 \\
\hline Eristalis arbustorum......... & 13 & 4 & 0 & 3 & 2 & 0 \\
\hline 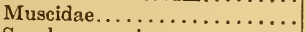 & 9 & 4 & 0 & 7 & 4 & 0 \\
\hline Syrphus americanus........ & 3 & 1 & 0 & 0 & 0 & 0 \\
\hline 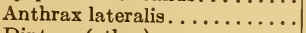 & 2 & 1 & 0 & 0 & 1 & 0 \\
\hline Diptera (other) ........... & 13 & 3 & 0 & 0 & 0 & 0 \\
\hline Total......... & 147 & 44 & 10 & 58 & 13 & 4 \\
\hline
\end{tabular}

The number of visits to the normal flowers was nearly four times as great as to those with the petals shortened. Since conditions were otherwise identical, this not only proves the importance of the corolla in attraction, but also shows that its effectiveness is related to its expanse. The 14 inspections were made by Apis and Bombus and indicate that about onefourth of the visits failed because of the disturbance of the usual perception. This was especially true of $B$. juxtus, which flew away in 7 different cases when only a centimeter from the flower. Moreover, Apis was forced to change its method of working, since it could no longer walk around the stamen mass on the petals.

Stamens covered.- The stamens were covered with absorbent cotton in 30 flowers and an equal number of normal ones taken for comparison. Apis visited 25 of the latter, but found the stamens in only one of those 
covered, though it hovered low over 3 others. Bombus occidentalis went to 7 normal flowers and hovered over 2 of the changed ones, while for $B$. juxtus the numbers were 8 and 1 respectively.

\section{ARTIFICIAL AND PAINTED FLOWERS.}

Crepe-paper corollas.-In all the flowers employed the anthers were just beginning to dehisce, as flowers at this stage had been found to be most attractive to insects. Other open flowers nearby were removed, so that they would not attract visitors from the group under observation. After the petals and sepals were removed, artificial corollas of red, blue, yellow, or white crepe-paper were wired below the anthers. A normal flower was left for comparison near each artificial one, 3 flowers of each color being used in the experiment, making a total of 15 for each of the two kinds. Table 11 shows the response to them, as well as the color preferences.

TABLE 11.-Visits to natural and paper flowers.

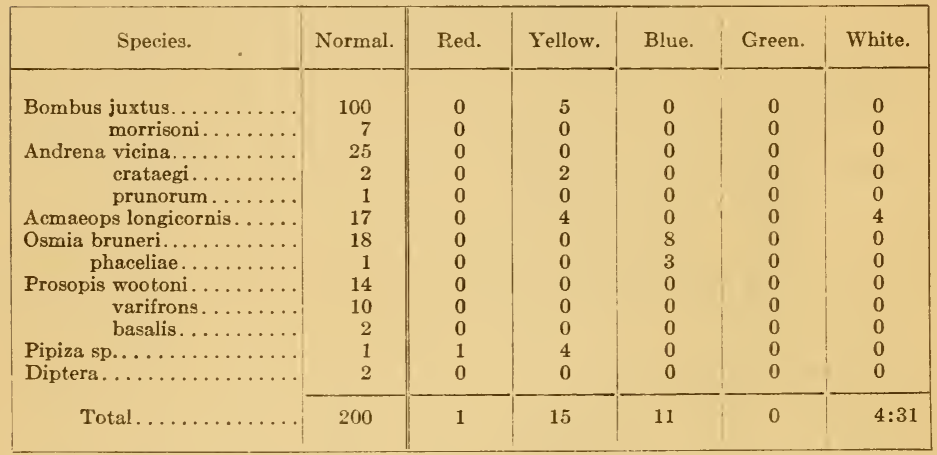

The visits to normal flowers were six times as many as to the artificial ones. While the bees clearly avoided the imitations as a whole, there was a great difference in response to the various colors. The visits to green, white, and red were negligible.

Artificial corollas similar to those used in the previous experiment were made of crepe-paper, but with the petals fringed by cutting them lengthwise. Four artificial flowers of each color and 16 normal flowers were used. Observations from 8 to $10 \mathrm{a} . \mathrm{m}$. on the first morning and from 8 to 9 a.m. on the second gave the results shown in table 12 .

Of 222 visits, only 18 were made to the artificial flowers, chiefly by Bombus and Osmia, a fly being the only other visitor to them. It is significant that $A$ pis did not go to a single imitation. While the numbers are too small to be of much value, it is interesting to note that blue and yellow were again the preferred colors.

Painted corollas.-When the petals were painted blue, green, or yellow with water-colors, Bombus juxtus visited as many painted as normal flowers, in contrast to the ratio of $11: 1$ for natural and paper flowers. Andrena crataegi went only to the blue flowers, in addition to the normal ones. 
TABLE 12.-Visits to natural flowers and flowers with fringed paper corollas.

\begin{tabular}{|c|c|c|c|c|c|}
\hline Species. & Normal. & Red. & Yellow. & Green. & Blue. \\
\hline Apis mellifica. & 106 & 0 & 0 & 0 & 0 \\
\hline Bombus bifarius. . & 39 & 0 & 0 & 1 & 3 \\
\hline juxtus... & 12 & 1 & 0 & 0 & 0 \\
\hline proximus.. & 4 & 1 & 0 & 0 & 0 \\
\hline Andrena crataegi.... & 8 & 0 & 0 & 0 & 1 \\
\hline 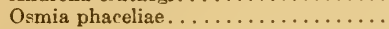 & 8 & 0 & 2 & 1 & 1 \\
\hline Musca sp......... & 1 & 0 & 0 & 0 & 1 \\
\hline Total... & 178 & 2 & 2 & 2 & $6: 12$ \\
\hline Bombus proximus... & 10 & 0 & 0 & 0 & 0 \\
\hline bifarius..... & 7 & 0 & 1 & 0 & 0 \\
\hline Andrena crataegi............... & 2 & 0 & 0 & 0 & 0 \\
\hline madronitens............. & 2 & 0 & 0 & 0 & 0 \\
\hline Syrphus americanus... & 2 & 0 & 0 & 0 & 0 \\
\hline Halictus pulzenus.... & 1 & 0 & 0 & 0 & 0 \\
\hline Prosopis elliptica........... & 0 & 0 & 2 & 0 & 0 \\
\hline 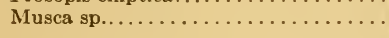 & 2 & 0 & 2 & 1 & 0 \\
\hline Total. . & 26 & 0 & 5 & 1 & $0: 6$ \\
\hline
\end{tabular}

\section{ADDITION OF HONEY AND ODOR.}

Honey.-In this installation one-third of the flowers were supplied with a drop of honey at the base of the filaments, another third with a drop at the center of the stamen mass, and the remainder were left normal. Halictus pulzenus visited 4 normal flowers and 10 with honey at the filament base. Andrena crataegi visited but one flower of this sort; it actually landed at others but flew away at once, as did Bombus proximus. The total number of visits to normal flowers was 46 , in contrast to 11 for those with honey added, giving a ratio of $4: 1$.

\section{SUMMARY.}

A comparison of the tables obtained from the various calendars not only reveals the differences arising out of time and place, but also throws light upon discrepancies between the results of different observers and investigators, making it clear that comparison is often misleading if not impossible when different years and regions are concerned. There was much difference in the number of visits on successive days in the same spot, and a marked one when different portions of the flowering period were concerned, arising chiefly out of the period of flight for the various genera. Neighboring areas likewise showed a distinct divergence, which was strikingly evident in the ratios of visits for the bees, namely, Apis 1:6, Bombus 17:1, Andrena $7: 1$, and Osmia $3: 1$.

The decisive effect of cutting the petals back to half their length is especially significant in connection with the question sometimes raised as to the value of the corolla in attraction. Covering the stamens excluded visits entirely and suggests that insects distinguish clearly between the corolla and the stamen mass, or at least readily recognize that the latter is changed. Although 49 visits were made to paper flowers of various colors, 
this was less than one-eighth of the number paid to natural ones at the same time. All the colors received visits, as follows: red 3, yellow 22, green 3 , blue 17 , white 4 . In accordance with the general rule, painted flowers were visited much more than paper ones, doubtless owing to the fact that they differed but little from the normal ones, as shown especially by the behavior of Bombus. The attractive power of honey was again found to be slight, flowers with honey receiving but one visit to 4 for the normal ones.

\section{RUBUS STRIGOSUS.}

\section{NORMAL POLLINATION.}

Habit and structure.- These flowers open later than those of Rubus deliciosus, but the two are in bloom together for a considerable period. They are quite inconspicuous because of their small size and recurved petals and the scattered position among the leaves. However, the large amount of easily available nectar makes this species very attractive to several kinds of insects. The nectar is formed within the stamen circle at the base of the ovaries. It oozes out in drops and if not kept lapped up by the bees, the depressed ring becomes filled with it. In order to find out how rapid this flow of nectar is, 4 plants profuse with flowers were covered with paper bags in the evening, so that no visitors could get nectar until the flowers were examined. At 9 the next morning, when the visits of the bees were becoming numerous, the bags were removed. Flowers outside the bag, which had been receiving the morning visitors, showed only the glistening droplets of nectar, while a full nectar ring was very conspicuous in all the bagged flowers mature enough to produce it (plate 3 ).

Behavior.-Apis mellifica hangs suspended from the flowers while sucking nectar. It scrapes pollen from its head and thorax with the second pair of legs on to the corbiculæ of the third pair. One individual flew half an inch above flowers with dry anthers and discovered without landing that there was no nectar. Prosopis episcopalis goes to open flowers for nectar and lands on the petals. If the petals are closed, it goes around the edge of the bud and inserts its ligule between the petals. The normal visitors on 3 successive days during periods of 2 hours to 100 open flowers are listed in table 13.

TABLE 13.-Visitors on three successive days.

\begin{tabular}{|c|c|c|c|c|c|c|c|}
\hline Species. & $\begin{array}{c}\text { June } \\
29 .\end{array}$ & $\begin{array}{l}\text { June } \\
30 .\end{array}$ & $\begin{array}{c}\text { July } \\
1 .\end{array}$ & Species. & $\begin{array}{l}\text { June } \\
29 .\end{array}$ & $\begin{array}{l}\text { June } \\
30 .\end{array}$ & $\begin{array}{c}\text { July } \\
1 .\end{array}$ \\
\hline Apis mellifica & 34 & 118 & 47 & Andrena crataegi & 0 & 0 & 1 \\
\hline Bombus bifarius. & 0 & 6 & 15 & Osmia bruneri. . & 0 & 2 & 0 \\
\hline juxtus. & 0 & 8 & 15 & Prosopis episcopalis. & 1 & 4 & 2 \\
\hline \multirow{3}{*}{$\begin{array}{r}\text { proximus..... } \\
\text { Andrena vicina....... } \\
\text { madronitens.. }\end{array}$} & 2 & 8 & 7 & Monumetha albifrons. & 2 & 0 & 0 \\
\hline & 0 & 3 & 3 & \multirow{2}{*}{ Total......... } & 40 & & \\
\hline & 1 & 0 & 0 & & 40 & 149 & 90 \\
\hline
\end{tabular}

Rubus strigosus is primarily a honey-bee flower, as is shown by the fact that 199 of the 279 visits were made by Apis; of the remaining 80 visits, 61 were made by Bombus. 
No previous floral study of Rubus has been made in America, but several European species have received much attention (Knuth, 1908:352).

\section{EXPERIMENTS.}

\section{MUTILATION.}

Floral envelopes or stamens removed.-Apis mellifica started to land at a flower with the stamens removed, but flew away. The nectar was clearly visible, but the excision of the stamens changed the appearance of the flowers so much that it seemed to frighten this bee. Andrena madronitens worked at flowers with the calyx and corolla or stamens gone as at normal flowers. Prosopis episcopalis stopped at one with the stamens and corolla removed and worked as usual, while Osmia bruneri visited a flower with the perianth gone. These results are opposed to those obtained with Rubus deliciosus, but this is readily explained by the difference in the size and visibility of the petals. In strigosus these are not only several times smaller than in deliciosus, but their position further decreases their attractiveness.

\section{ROSA ACICULARIS.}

\section{NORMAL POLliNATION.}

Habit and structure.- The corolla of Rosa is pink in color and widely expanded, forming a broad landing-platform and a bright disk of color, evidently visible to insects from some distance. The stamens are numerous and the pollen abundant. A mild sweet odor adds to the apparent attractiveness of the flower.

Behavior.-Bombus edwardsi tumbles about the stamens very rapidly, collecting pollen in the corbiculae, on the mouth-parts, and the hairs of the abdomen. Pollen was gathered at Rubus deliciosus in much the same manner, and this bee goes from Rosa to Rubus or the reverse without showing a preference for either. It did not stop at flowers in which the stamens and pistils were covered by the unfolding petals, but went on to the next open flower. The anthers in Rosa are not mature when the petals are unfolding and the bee has perhaps learned by experience that the pollen is not available until the petals are broadly expanded. One individual of Bombus flavifrons endeavored to open a half-expanded flower, landing on the lower petal and trying to push its head in, but after making several unsuccessful attempts it flew away. B. bifarius tramples back and forth among the stamens collecting pollen, the tip of its abdomen at the same time rubbing the stigmatic surfaces and depositing pollen previously collected. $B$. proximus collects pollen on the rose; it flies low above flowers which are opening but lands only on those with dehiscing anthers.

Andrena crataegi collects pollen most industriously, even visiting flowers with petals gone and stamens brown, trying to get pollen from the withered anthers. Andrena vicina tramples rapidly over the stamen mass, going round and round with its head buried among the anthers. The first two pairs of legs gather pollen and pack it on the third pair. A. madronitens arches the tip of its abdomen downwards toward its head, inclosing a group of stamens. While in this position, it collects pollen rapidly with 
the front legs and stores it on the hind ones. Prosopis elliptica works very rapidly with its mouth-parts and with the front pair of legs. It opens the anther with the front legs, scrapes out pollen, and also picks it up from the corolla. Anthophora simillima poises 7 to $15 \mathrm{~cm}$. above the flower, meanwhile buzzing loudly, and then makes a dive for it. While diving, head and abdomen tip are together, and as it lands it grasps the stamens with its front legs and slides down the bunch of filaments. When the anthers are reached, a struggling movement takes place, during which pollen is put on the third pair of legs, when it buzzes into the air again and dives for another flower. It often darts repeatedly into the same flower, apparently getting some nectar during this process. Monumetha albifrons tramples around on the stamens with its head buried in the mass. It moves very rapidly, working all three pairs of legs and storing the accumulated pollen on its ventral scopa. The latter also rubs rapidly against the anthers and collects pollen. Osmia bruneri tramples over the stamens in the same manner as Bombus. Megachile wootoni moves around very rapidly while on the stamens, the first two pairs of legs scraping out the pollen and passing it to the third pair, which place it on the scopa. This is raised in the air and usually does not come in contact with the anthers.

Table 14 shows the visitors observed during 30 minutes on 42 flowers of Rosa, 14 of which were just opening and the anthers beginning to dehisce. The lists were made on successive days, and exhibit the difference often to be expected.

TABLE 14.-Visitors to normal flowers.

\begin{tabular}{|r|r|r|r|r|c|}
\hline \multicolumn{1}{|c|}{ Species. } & Visitors. & $\begin{array}{c}\text { Visitors } \\
\text { and visits. }\end{array}$ & Species. & Visitors. & $\begin{array}{c}\text { Visitors } \\
\text { and visits. }\end{array}$ \\
\cline { 2 - 3 } Bombus bifarius.... & 18 & $0: 0$ & Halictus pulzenus... & 3 & $0: 0$ \\
proximus... & 7 & $0: 0$ & Prosopis elliptica... & 2 & $1: 2$ \\
juxtus.... & 0 & $3: 5$ & Megachile wootoni. & 0 & $3: 3$ \\
occidentalis. & 0 & $1: 2$ & Syrphus sp....... & 2 & $0: 0$ \\
Andrena crataegi... & 14 & $4: 4$ & Total........ & 47 & $12: 16$ \\
vicina.... & 1 & $0: 0$ & & & \\
\hline
\end{tabular}

The pollination of the rose appears to have received no attention in this country, but several species have been studied in Europe (Knuth, 1906:348). These are chiefly visited by beetles, though several genera of bees have been taken on $R$. canina, and two species of Bombus on rubiginosa.

\section{EXPERIMENTS.}

\section{MUTILATION.}

Corolla shortened.-The petals of Rosa were cut to half their length, giving the corolla a rotate form. This made them paler in color, as the petals are almost white toward the base. Since the flower is smaller, the stamens also become more conspicuous. At such flowers, Bombus juxtus landed, collected some pollen and then passed on to the next, never securing all of the available pollen at any flower. Monumetha albifrons remained at each flower a long time and collected much pollen. In order to determine 
the comparative effect of reducing the attractive surface of the corolla, 10 such flowers were grouped with 10 normal ones. Table 15 shows the visitors during an hour of observation.

TABLE 15.-Visitors to normal and reduced flowers.

\begin{tabular}{|c|c|c|}
\hline Species. & Normal. & Reduced. \\
\hline 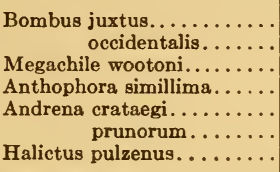 & $\begin{array}{r}21 \\
8 \\
8 \\
3 \\
1 \\
1 \\
0\end{array}$ & $\begin{array}{l}9 \\
1 \\
2 \\
0 \\
0 \\
0 \\
1\end{array}$ \\
\hline Total............. & 42 & 13 \\
\hline
\end{tabular}

In accordance with the rule, the reduction of the corolla surface greatly decreased the attractiveness of the rose, since there were three times as many visitors to the normal flowers.

Stamens masked.-The stamens of 10 flowers were masked with a veil of cotton and 10 normal blossoms left for comparison. Two hours of observation gave the results shown in table 16.

TABLE 16.-Visits to normal and masked flowers.

\begin{tabular}{|c|c|c|}
\hline Species. & Normal. & Masked. \\
\hline Andrena madronitens...... & 2 & 1 \\
\hline vicina............... & 2 & 0 \\
\hline crataegi.......... & 1 & 0 \\
\hline Bombus bifarius.......... & 3 & 0 \\
\hline proximus.......... & 1 & 0 \\
\hline Megachile texana......... & 1 & 0 \\
\hline Anthophora simillima..... & 1 & 0 \\
\hline Syrphus americanus...... & 1 & 0 \\
\hline Total. . & 12 & 1 \\
\hline
\end{tabular}

Andrena madronitens landed on the veil of cotton, walked over it, and finally slipped under the edge to the stamens. A second bee tried the same method, but failed to find them. Bombus proximus and 3 individuals of $B$. bifarius inspected the masked flowers, but did not stop at them. Where the cotton had slipped a little at the edge exposing the stamens, proximus landed in the flower, but its legs became tangled in the cotton and it flew away as though frightened.

\section{ARTIFICIAL AND PAINTED FLOWERS.}

Crepe-paper corollas. - The corollas were replaced by artificial ones of red, green, and yellow crepe-paper, resembling the normal in size and form. The crepe flowers were paired with normal ones in the various positions on the bush. Bouquets of flowers in bottles of water were sus- 
pended from the branches to increase the number of normal flowers under observation. One Halictus pulzenus went to all flowers, making no distinction between the normal and those with artificial corollas. Another individual visited one yellow, two green, and many normal flowers. Bombus proximus went to 118 normal flowers and only 18 with crepe corollas, Syrphus americanus to 3 yellow, 2 green, and 11 normal, and Clisodon terminalis to 18 normal and 1 white crepe flower.

The results of observations made on another day are given in table 17, which shows the visits to normal and crepe flowers during an hour. Eight natural flowers were used, together with 4 of each color, making 20 artificial flowers in all.

TABLE 17.-Visits to natural and artificial flowers.

\begin{tabular}{|c|c|c|c|c|c|c|}
\hline Species. & Normal. & Violet. & Red. & Blue. & White. & Green. \\
\hline Bombus juxtus. & 20 & 0 & 0 & 0 & 0 & 0 \\
\hline proximus. & 19 & 0 & 0 & 0 & 1 & 0 \\
\hline Halictus pulzenus. & 19 & 0 & 1 & 0 & 0 & 0 \\
\hline Andrena crataegi. & 2 & 1 & 0 & 0 & 0 & 0 \\
\hline Total. & 60 & 1 & 1 & 0 & 1 & $0: 3$ \\
\hline
\end{tabular}

Later, Bombus proximus and juxtus visited these bushes several times, but stopped only at the natural flowers, passing by the artificial corollas. The first stopped twice at a petal lying on some leaves and examined it, but did not land at any of the artificial flowers in passing from one natural flower to others more distant.

\section{ADDITION OF HONEY AND ODOR.}

Honey.-Diluted honey was placed in the center of the stamen group, so that visitors coming for either pollen or nectar would be sure to come in contact with it. This glistened in the sunlight and was distinctly visible 3 meters away from the flowers. In general, Bombus proximus avoided flowers treated in this way, and when it did land usually paid no attention to the honey. When this was noticed, the bee flew away suddenly, or avoided it and trampled among the anthers on the other side of the flower. One individual landed at a flower with diluted honey, commenced at once to sip nectar, and stayed for a long time. It flew away for a second, came back again, and took more nectar. This bee went to the next flower which was normal and trampled among the stamens in the usual fashion. No pollen was collected in the next two flowers with honey-drops, but the bee secured nectar. Three normal flowers were then visited in succession and at each it trampled among the stamens and collected pollen. Monumetha albifrons sipped honey for 60 seconds on a flower that had pure honey-drops on the stamens. It also went to those in which the honey-drops were diluted, but showed no preference for either kind.

Twenty flowers of each kind were used in the following experiment to find out whether honey would prove an added attraction to visitors; the period of observation was an hour. 
TABLE 18.-Visits to normal flowers and those with honey on the stamens.

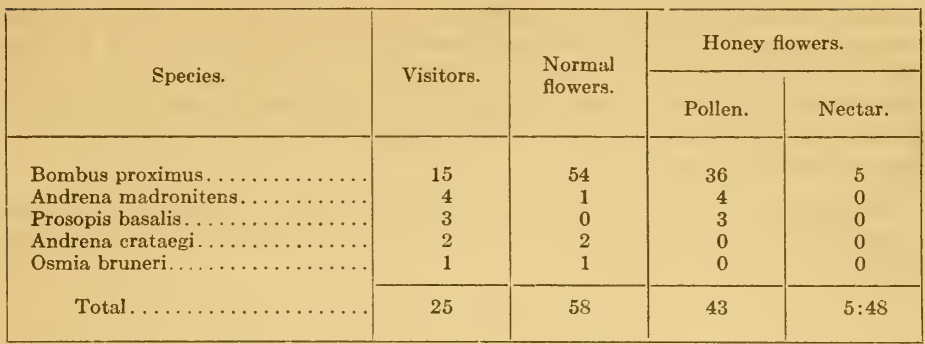

The results indicate that the honey did not constitute an added attraction, except possibly to Prosopis and Andrena.

Diluted honey was put on the stamens of half the flowers employed in experiment 1, while in experiment 2 the honey was placed in a circle around the base of the filaments and an additional drop at the center of the stamen mass; 10 normal and 10 honey flowers were used in each case, and the observation period was 2 hours.

TABLE 19.-Visitors to normal and honey flowers.

\begin{tabular}{|c|c|c|c|c|}
\hline \multirow[b]{2}{*}{ Species. } & \multicolumn{2}{|c|}{ Experiment 1.} & \multicolumn{2}{|c|}{ Experiment 2.} \\
\hline & $\begin{array}{l}\text { Normal } \\
\text { flowers. }\end{array}$ & $\begin{array}{c}\text { Honey } \\
\text { on } \\
\text { stamens. }\end{array}$ & $\begin{array}{l}\text { Normal } \\
\text { flowers. }\end{array}$ & $\begin{array}{c}\text { Honey } \\
\text { under } \\
\text { stamens. }\end{array}$ \\
\hline 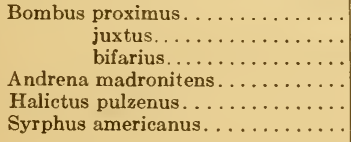 & $\begin{array}{r}17 \\
0 \\
1 \\
0 \\
6 \\
0\end{array}$ & $\begin{array}{l}3 \\
0 \\
0 \\
0 \\
0 \\
1\end{array}$ & $\begin{array}{r}13 \\
5 \\
0 \\
1 \\
0 \\
0\end{array}$ & $\begin{array}{r}27 \\
1 \\
0 \\
2 \\
0 \\
0\end{array}$ \\
\hline Total. . & 24 & 4 & 19 & 30 \\
\hline
\end{tabular}

Placing honey on the stamens reduced the number of visitors very greatly, the ratio being $24: 4$. This was due to interference with the usual collection of pollen. When the honey was placed at the base of the filaments, the visits of Bombus juxtus were likewise reduced, but those of B. proximus were doubled, without an evident reason. However, it landed and took honey in but 10 of these, leaving the others immediately after alighting, as though disturbed by the presence of the honey.

Honey and talcum powder.-Flowers were modified by the addition of pure or diluted honey, or talcum powder of the "Love me" and "Arbutus" brands. There were 10 of each type of modified flowers used and 40 normal ones were paired with them for comparison. Of the 49 visitors, 30 went to normal flowers, 4 to flowers with pure honey, 8 to flowers with diluted honey, 5 to those with "Love me" sachet, and 2 to those with "Arbutus" 
sachet. Clisodon terminalis flew above the flowers scented with "Arbutus" powder for some little time before landing, projecting its ligule, which was not its normal procedure when hovering above flowers. One Bombus juxtus landed on flowers powdered with both kinds of sachet, but quickly flew away. Syrphus opinator alighted on some with "Love me" sachet on them and worked as usual. It also landed on flowers with honey-drops but did not find the honey.

Camphor.-The response of the various species to flowers in which powdered "moth balls" had been sprinkled on the stamens and to normal flowers is shown in table 20.

TABLE 20.-Visitors to normal flowers and flowers scented with camphor.

\begin{tabular}{|c|c|c|c|c|c|}
\hline Species. & $\begin{array}{l}\text { Normal } \\
\text { flowers }\end{array}$ & $\begin{array}{l}\text { Scented } \\
\text { flowers }\end{array}$ & Species. & $\begin{array}{l}\text { Normal } \\
\text { flowers. }\end{array}$ & $\begin{array}{l}\text { Scented } \\
\text { flowers. }\end{array}$ \\
\hline \multirow{2}{*}{ 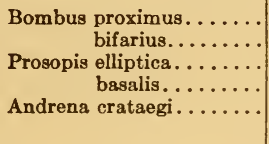 } & \multirow[t]{2}{*}{$\begin{array}{r}35 \\
2 \\
6 \\
2 \\
5\end{array}$} & \multirow[t]{2}{*}{$\begin{array}{r}23 \\
1 \\
1 \\
1 \\
3\end{array}$} & \multirow{2}{*}{$\begin{array}{l}\text { Halictus pulzenus........ } \\
\text { Monumetha albifrons.... } \\
\text { Anthophora simillima.... } \\
\text { Syrphus opinator........ } \\
\text { Total. ........... }\end{array}$} & $\begin{array}{l}3 \\
2 \\
1 \\
1\end{array}$ & $\begin{array}{l}0 \\
2 \\
0 \\
0\end{array}$ \\
\hline & & & & 57 & 31 \\
\hline
\end{tabular}

It is somewhat surprising to find that the flowers with an unpleasant odor attracted half as many visitors as the normal ones, but this is probably to be explained on the basis of habit.

Cotton perfumed with anise was wound around the pedicels under the sepals in 8 pairs of flowers, normal flowers adjoining the scented ones in each case, and the observations covering an hour. The response to anise was essentially the same as that to camphor.

TABLE 21.-Visitors to normal and anise-scented flowers.

\begin{tabular}{|c|c|c|c|c|c|}
\hline Species. & Normal. & Anise. & Species. & Normal. & Anise. \\
\hline Bombus juxtus..... & \multirow{6}{*}{$\begin{array}{r}27 \\
9 \\
5 \\
5 \\
4 \\
3\end{array}$} & \multirow{6}{*}{$\begin{array}{r}14 \\
4 \\
0 \\
0 \\
5 \\
2\end{array}$} & \multirow{6}{*}{$\begin{array}{l}\text { Anthrax nigra........... } \\
\text { Monumetha albifrons.... } \\
\text { Andrena crataegi ........ } \\
\text { Andronicus sp......... } \\
\text { Osmia fulgida......... } \\
\quad \text { Total ............ }\end{array}$} & 1 & 2 \\
\hline occidentalis. & & & & 1 & 0 \\
\hline Musca sp... & & & & 1 & 0 \\
\hline Syrphus americanus. & & & & 1 & 1 \\
\hline Prosopis elliptica........ & & & & 1 & 0 \\
\hline Erristanis la & & & & 58 & 28 \\
\hline
\end{tabular}

\section{SUMMARY.}

As would be expected from their similar size and structure, the rose and salmonberry yielded much the same experimental results. The reduction of the corolla decreased the visits to the one 3 and to the other 4 times, while in both cases flowers with stamens masked obtained but few visits. The visitors to paper flowers were much more numerous in the case of Rubus, but this was probably due in part at least to the more extensive experiments with it. The reverse was true in the case of flowers with added honey, the 
roses thus treated receiving a relatively large number of visitors. The difference between the two, however, was almost wholly a consequence of the preference of Bombus proximus for the honey-flowers of the rose. The addition of various odors to flowers of the rose regularly decreased the number of visitors about half, quite irrespective of whether the odor was one ordinarily regarded as pleasant. It seems evident that this decrease was due to the strange odor disturbing the habitual response of the pollinators.

\section{GERANIUM CAESPITOSUM.}

\section{NORMAL POLLINATION.}

Habit and structure.-The flowers of Geranium are regular and the five nectaries are so placed that the nectar in all is equally exposed and accessible. All the visitors except Halictus sp. usually come for nectar. The inner row of anthers dehisce first, followed by the outer row from 10 to 24 hours later (plate 7).

Behavior.-Bombus juxtus lands on the disk-shaped corolla and proceeds to circle the stamen group, taking nectar at each of the nectaries. It secures nectar from flowers in which all the anthers have dropped off, indicating that the flow continues while the stigmatic surface is receptive. A few individuals are satisfied to suck nectar from only one or two nectaries at each flower, and $B$. bifarius usually stops likewise at only a few of those in each flower, instead of making the complete round. Halictus pulzenus comes for both nectar and pollen. It visits each of the 5 nectaries, sometimes going around the circle twice in succession. After getting all the nectar available, it walks up the anthers, scrapes out pollen with its front legs, and packs it on the hind ones. This bee is so small that it can stand under the outwardly curved anthers. When in this position, pollen falls on its back, but it touches the stigma only as it flies away. Halictus was seen to pick up the pollen that had fallen on the corolla, brush its head well with the front legs, and then eat the pollen. Prosopis elliptica has a shiny body on which pollen does not collect easily. It is so small that in dipping into the nectaries only the lower shorter row of anthers or the recurved styles touch its abdomen. This species is probably not a very effective pollinator on this account.

Andrena madronitens is a pollen collector. It hangs suspended from the styles and filaments, and moves around them repeatedly, gathering pollen. It collects with its mouth and front legs and places the pollen on the hind ones. Monumetha albifrons lands with its head pointing toward the nectaries. It tips its abdomen upward as it goes from nectary to nectary, and this gives it the appearance of standing on its head. The tip of its abdomen rubs the anthers as it sucks nectar. A pis mellifica stops at all the nectaries and makes no effort to get pollen. The thoracic hairs become covered with the latter and scrape the anthers and style, dusting them with pollen as it moves about the nectar circle. Osmia bruneri and Sphex vulgaris also visit each nectary, where they appear to be standing on their heads. The head of the latter is hairy and serves to collect and deposit pollen. Pseudomasaris vespoides likewise goes to each nectary, the dorsal surface of the bee touching the anthers in one flower and the stigmas in the next. 
Merritt (1896:149) has studied the pollination of the closely related Geranium richardsoni in California, where the most frequent visitors are able to secure nectar without touching anthers or stigmas. However, larger bees also visit the flowers, namely, Apis, Anthophora, Coelioxys, Osmia, and Bombus californicus, and these readily effect pollination as they cling to the anthers or styles. Robertson $(1889: 229 ; 1893: 272)$ briefly describes the behavior of the flower in $G$. maculatum and G. carolinianum and gives a list of the visitors to each. The insect visitors of a large number of European species are given by Knuth (1908:218).

\section{CALENDARS.}

Fifty flowers were under observation on each of the five days for which the visitors are given in table 22 .

TABLE 22.-Visitors to normal flowers.

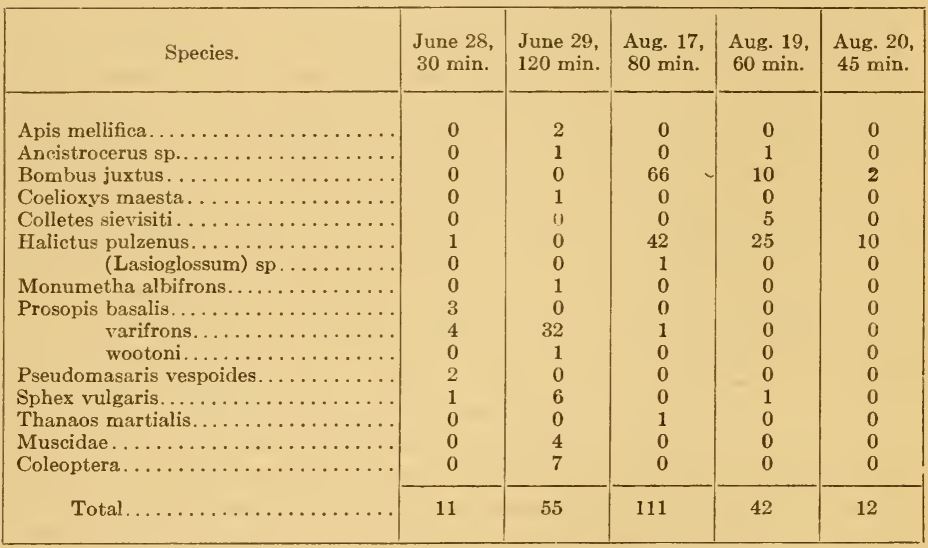

TABLE 23.-Visitors and visits to normal flowers.

\begin{tabular}{|c|c|c|c|}
\hline Species. & July 16. & July 16. & July 25 . \\
\hline Bombus bifarius. & $10: 186$ & $6: 44$ & $0: 0$ \\
\hline juxtus.. & $4: 45$ & $22: 97$ & $5: 36$ \\
\hline proximus...... & $1: 1$ & $2: 58$ & $0: 0$ \\
\hline Andrena madronitens............. & $0: 0$ & $0: 0$ & $1: 2$ \\
\hline Colletes sieverti............... & $0: 0$ & $3: 3$ & $0: 0$ \\
\hline Halictus pulzenus............... & $2: 2$ & $2: 2$ & $0: 0$ \\
\hline Megachile texana............ & $0: 0$ & $2: 2$ & $0: 0$ \\
\hline Monumetha albifrons............ & $0: 0$ & $0: 0$ & $1: 1$ \\
\hline Prosopis elliptica. . & $0: 0$ & $1: 1$ & $0: 0$ \\
\hline varifrons. & $9: 13$ & $1: 1$ & $0: 0$ \\
\hline Syrphus opinator.. & $1: 1$ & $1: 1$ & $0: 0$ \\
\hline Total. & $27: 24: 8$ & $40: 209$ & $7: 39$ \\
\hline
\end{tabular}


In the columns for July 16, 40 flowers were under observation for the two successive hour periods. On July 25, only 26 flowers were in the group observed during an hour period.

As would be expected, the records for two successive hours resemble each other closely, but depart much more widely from that made a number of days later. This record contains but three of the species present on July 16, and the number of visitors and visits is very low. The inversion of the number for Bombus bifarius and juxtus is the most striking feature of the two successive records. In table 23 the most important fact is the change of dominance from Prosopis at the opening of the flowering period to Bombus and Halictus near the close. This is to be explained by the fact that the latter were working on preferred species earlier and went to Geranium in abundance only when their choice became more restricted. This is likewise the explanation of the doubling of the average number of visitors per hour period in the later observations.

\section{EXPERIMENTS.}

\section{CHANGE OF POSITION.}

Flowers vertical or inverted.-When the face of the flower was turned so that it was vertical, Bombus juxtus found no difficulty in hanging on, and its behavior was practically the same as at a normal flower. In the case of inverted flowers, however, it experienced much trouble in keeping a foothold. One individual landed on the bottom of the flower, which was then uppermost, went over the edge to the face, but finally flew away without securing nectar. Another went to an inverted flower that was half-open, but did not succeed in opening it. It next went to another half-open inverted flower, landing on the calyx and looking for the opening to the nectaries among the sepals, and departed unsuccessful.

\section{MUTILATION.}

Cotton over nectaries. - A circle of cotton was placed at the base of the filaments so that it covered the opening to the nectaries. One individual of Prosopis varifrons flew around above the flowers without landing. Another individual alighted and poked around the edges of the cotton, but did not find the nectaries. A fly also landed and pushed out its ligule, but was unable to locate the nectar. Bombus juxtus secured nectar from 7 flowers by pushing aside the edge of the cotton until the nectary was exposed.

TABLE 24.-Visitors to normal and mutilated flowers.

\begin{tabular}{|c|c|c|c|c|c|}
\hline Species. & $\begin{array}{l}\text { Normal } \\
\text { flowers. }\end{array}$ & $\begin{array}{c}\text { Petals } \\
\text { removed. }\end{array}$ & $\begin{array}{l}\text { Petals } \\
\text { and } \\
\text { sepals } \\
\text { removed. }\end{array}$ & $\begin{array}{l}\text { Stamens } \\
\text { removed. }\end{array}$ & $\begin{array}{l}\text { Stamens } \\
\text { and } \\
\text { style } \\
\text { removed. }\end{array}$ \\
\hline $\begin{array}{r}\text { Bombus bifarius... } \\
\text { juxtus... } \\
\text { proximus. } \\
\text { Apis mellifica..... }\end{array}$ & $\begin{array}{r}15 \\
5 \\
0 \\
10\end{array}$ & $\begin{array}{l}1 \\
0 \\
0 \\
0\end{array}$ & $\begin{array}{l}1 \\
1 \\
0 \\
0\end{array}$ & $\begin{array}{r}15 \\
4 \\
3 \\
0\end{array}$ & $\begin{array}{r}12 \\
3 \\
2 \\
5\end{array}$ \\
\hline Total. & 30 & 1 & 2 & 22 & $22: 47$ \\
\hline
\end{tabular}


Excision.-The results of the experiments with the various types of mutilation are presented herewith. Flowers with the corolla gone closely resembled old flowers with the petals fallen and were probably mistaken for them (plate 17). Tables 24 to 28 give the results of observations in which 25 normal flowers and 5 flowers of each kind of mutilation were used, with the exception of the last, in which the numbers were equal. The period of observation was one hour in all cases but the second.

TABLE 25.-Visitors to normal and mutilated flowers.

\begin{tabular}{|r|r|r|r|r|r|r|c|}
\hline Species. & $\begin{array}{c}\text { Normal } \\
\text { flowers. }\end{array}$ & $\begin{array}{c}\text { Petals } \\
\text { removed. }\end{array}$ & $\begin{array}{c}\text { Petals } \\
\text { shortened. }\end{array}$ & $\begin{array}{c}\text { Petals } \\
\text { split. }\end{array}$ & $\begin{array}{c}\text { Stamens } \\
\text { and } \\
\text { style } \\
\text { excised. }\end{array}$ & $\begin{array}{c}\text { Cotton } \\
\text { over } \\
\text { stamens. }\end{array}$ & $\begin{array}{c}\text { Cotton } \\
\text { under } \\
\text { stamens. }\end{array}$ \\
\hline Bombus juxtus.... & 23 & 0 & 12 & 17 & 17 & 6 & 7 \\
Prosopis basalis... & 1 & 0 & 0 & 2 & 1 & 0 & 0 \\
Halictus pulzenus.. & 0 & 0 & 0 & 2 & 1 & 0 & 0 \\
\hline Total........ & 24 & 0 & 12 & 21 & 19 & 6 & $7: 65$ \\
\hline
\end{tabular}

TABLE 26.-Visitors to normal and mutilated flowers.

\begin{tabular}{|c|c|c|c|}
\hline Species. & $\begin{array}{l}\text { Normal } \\
\text { flowers. }\end{array}$ & $\begin{array}{c}\text { Petals } \\
\text { shortened. }\end{array}$ & $\begin{array}{c}\text { Style and } \\
\text { stamens } \\
\text { excised. }\end{array}$ \\
\hline 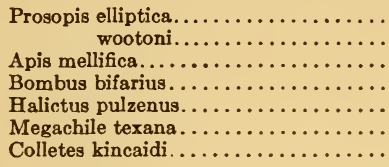 & $\begin{array}{l}6.6 \\
0: 0 \\
5: 6 \\
1: 4 \\
1: 1 \\
0: 0 \\
0: 0\end{array}$ & $\begin{array}{l}4: 4 \\
1: 1 \\
0: 0 \\
0: 0 \\
0: 0 \\
0: 0 \\
1: 1\end{array}$ & $\begin{array}{l}2: 5 \\
7: 7 \\
4: 10 \\
0: 0 \\
2: 3 \\
2: 6 \\
0: 0\end{array}$ \\
\hline Total. . & $13: 17$ & $6: 6$ & $17: 31$ \\
\hline
\end{tabular}

TABLE 27.-Visitors to normal and mutilated flowers.

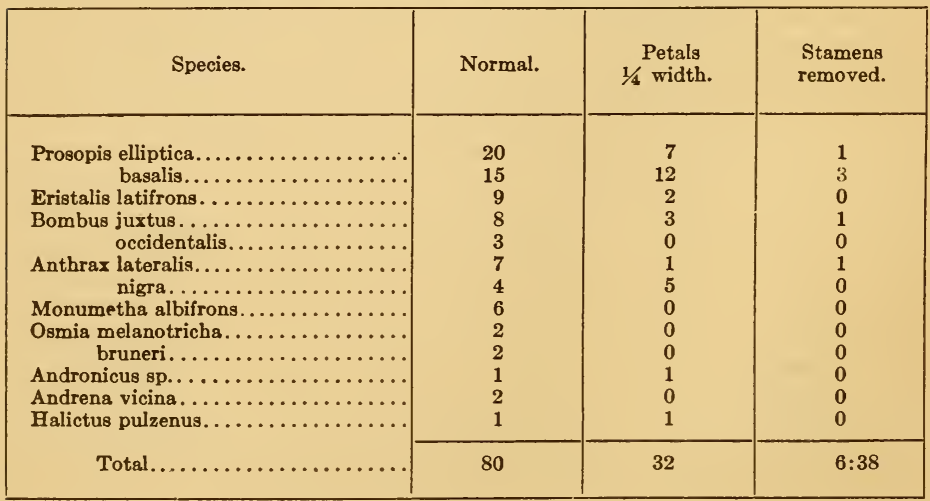


TABLE 28.- Visitors to normal and mutilated flowers.

\begin{tabular}{|r|r|r|r|r|c|}
\hline Species. & Normal. & $\begin{array}{r}\text { Corolla } \\
\text { shortened. }\end{array}$ & Species. & Normal. & $\begin{array}{c}\text { Corolla } \\
\text { shortened. }\end{array}$ \\
\hline Apis mellifica........ & 16 & 10 & Adrena prunorum.... & 1 & 0 \\
Bombus juxtus...... & 21 & 9 & crataegi..... & 1 & 0 \\
occidentalis.. & 8 & 1 & Osmia melanotricha... & 3 & 0 \\
Prosopis basalis...... & 15 & 15 & Halictus pulzenus.... & 1 & 2 \\
elliptica.... & 13 & 17 & Anthophora simillima. & 3 & 0 \\
Megachile wootoni... & 10 & 10 & Total.......... & 94 & 66 \\
\hline
\end{tabular}

In all cases where there were two or more mutilations, these received relatively twice as many visitors as the normal flowers. The removal of the petals practically eliminated visits, while shortening them decreased the number markedly. The excision of the stamens, or of these and the style, led to the greatest increase as a rule, probably because of the exposure of the nectar. The use of cotton to mask the stamens or nectar openings reduced the number of visitors in comparison with many of the other mutilations, but not below that for the normal flowers.

\section{ARTIFICIAL AND PAINTED FLOWERS.}

Crepe-paper corollas. - The corollas were replaced by crepe-paper ones of the same size and form as the normal and of the colors indicated in table 29. Four of each color or a total of 20 crepe corollas were used, together with 4 flowers with normal corollas.

TABLE 29.-Visitors to normal and crepe-paper flowers.

\begin{tabular}{|c|c|c|c|c|c|c|}
\hline Species. & Normal. & Red. & Blue. & Yellow. & White. & Green. \\
\hline 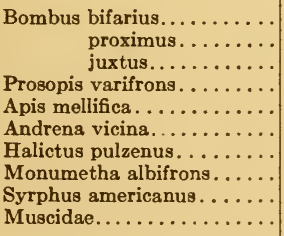 & $\begin{array}{r}34 \\
7 \\
4 \\
7 \\
4 \\
3 \\
2 \\
1 \\
1 \\
0\end{array}$ & $\begin{array}{l}1 \\
0 \\
0 \\
0 \\
0 \\
0 \\
1 \\
0 \\
0 \\
1\end{array}$ & $\begin{array}{l}6 \\
0 \\
0 \\
0 \\
0 \\
0 \\
1 \\
0 \\
0 \\
2\end{array}$ & $\begin{array}{l}3 \\
0 \\
0 \\
0 \\
0 \\
0 \\
6 \\
0 \\
0 \\
5\end{array}$ & $\begin{array}{l}5 \\
0 \\
0 \\
1 \\
0 \\
0 \\
0 \\
0 \\
0 \\
1\end{array}$ & $\begin{array}{l}2 \\
0 \\
0 \\
0 \\
0 \\
0 \\
2 \\
0 \\
0 \\
0\end{array}$ \\
\hline 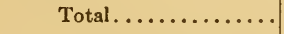 & 63 & 3 & 9 & 14 & 7 & $4: 37$ \\
\hline
\end{tabular}

In spite of the fact that the table shows 37 visits to artificial flowers to 63 for normal, the latter were only one-fifth as numerous and hence appear to have been about ten times as attractive. The contrast between red and green on the one hand and yellow, blue, and white on the other suggests that the bees were influenced in some degree by the brightness of the colors.

\section{ADDITION OF HONEY AND ODOR.}

Honey.-A drop of honey was put on the petals of half of the flowers. Bombus juxtus landed at a normal flower and then at one with the honey- 
drop in such a position that its head was just above the drop. It first walked around the filament column, then commenced to suck honey and continued for 90 seconds, until the drop was two-thirds gone. While sucking, it supported itself on a petal with the front and hind pairs of legs.

Diluted honey was placed in drops at the base of the filaments. Halictus pulzenus went from one nectary to the next, sucking nectar, as usual, and did not notice the honey. Bombus juxtus came and crowded Halictus away, but did not stay long enough to secure all the honey. At the next flower there was a drop at one point and it sucked at this until the honey was all gone. This took a minute; it then walked around the flower and dipped its ligule into each nectary. One individual stayed at a honey drop for more than 3 minutes. After this it walked around the flower, back to the honey-drop, and sipped more of it. The end of the ligule did not reach the nectary, as the tip was visible in the honey, moving in all directions. This bee flew to another flower that had a drop of honey in a similar position and walked around the column of anthers without stopping for nectar.

A circle of diluted honey was placed around the base of the filaments. Bombus juxtus took a few sips of this, but did not stay long. Another juxtus landed with its head pointed toward the outside of the flower and sucked honey from a drop that had run half way down the petals. It then went to the next flower which had honey in a similar position, took a sip, and flew away. When Bombus bifarius came to a flower on which there was diluted honey, it stayed and sipped, instead of trying to push the ligule into the nectaries. However, it did not remain until all the honey was gone, but flew to normal flowers and took nectar there. Halictus pulzenus went to a flower with a honey-drop, but worked at all the nectaries without finding it.

Diluted honey was put around the base of the stamens of 10 flowers, which were placed beside 10 normal ones. The results of an hour's observation are shown in table 30.

TABLE 30.-Visits to normal and honey flowers.

\begin{tabular}{|c|c|c|}
\hline Species. & $\begin{array}{l}\text { Normal } \\
\text { flowers. }\end{array}$ & $\begin{array}{l}\text { Honey } \\
\text { flowers. }\end{array}$ \\
\hline $\begin{array}{l}\text { Bombus hifarius........ } \\
\text { juxtus......... } \\
\text { Prosopis varifrons. . . . } \\
\text { Halictus pulzenus. . . . }\end{array}$ & $\begin{aligned} 13 & : 101 \\
2 & : 13 \\
2 & : 2 \\
3 & : 4\end{aligned}$ & $\begin{array}{c}10: 12 \\
0: 0 \\
0: 0 \\
0: 0\end{array}$ \\
\hline Total. & $20: 120$ & $10: 12$ \\
\hline
\end{tabular}

While there were one-half as many visitors to the honey as to the normal flowers, these averaged but one visit each in contrast to 6 each for the normal. In addition, 7 bumble-bees inspected the honey flowers. The effect of added honey in disturbing the normal response is well shown in the case of Bombus bifarius. The honey flowers received nearly as many visitors as the normal ones, but practically all of these made single visits, in contrast to an average of 8 for the normal flowers. 


\section{SUMMARY.}

Complete inversion of the flower did not deter bees from landing, but it did prevent their finding the nectaries. As a rule, they also alighted on flowers with the nectaries concealed by cotton, but Bombus alone succeeded in finding the nectar. The total number of visitors to the mutilated flowers was twice as great as the normal. This was due chiefly to the greater attractiveness of the flowers with stamens excised, since the removal of the petals almost completely destroyed the attraction and shortening them greatly reduced it. Paper flowers received a considerable number of visitors, but they were only about a tenth as attractive as the normal ones. The effect of honey on the flowers was to reduce the number of visitors a half and the number of visits six times.

\section{CHAMAENERIUM ANGUSTIFOLIUM.}

\section{NORMAL POLlination.}

Habit and structure.-These plants were present in the open spaces along Ruxton and Jack Brooks, where the communities are often so dense and extensive that they practically crowd out all other species where they exist. The blooming period is continuous from the beginning of July until the first of September, the lower flowers on the stalk maturing first, and then as the stalk elongates, the flowers above come into bloom. The long period of blooming and the numerous flowers that mature at any one time make this an admirable plant for study. The great number of visitors always present on bright days indicates that the bees find it a very desirable species. Nectar is abundant and there is a large amount of pollen. The pollen grains are large and of a blue-green color, and are held together by the sticky threads characteristic of the Onagraceae.

The corollas of the flowers lie in a more or less vertical plane with the style recurved and its branches held closely together, protecting the stigmatic surfaces, or in the later stage with the style projecting in front of the corolla and the stigmatic surfaces exposed on the outwardly coiled stylar branches. The stigmas are covered with blue-green pollen soon after they recurve. A large number of seeds develop, indicating that the method of pollination is unusually efficient. The petals of the flowers are about the size of the Bombus workers and so form a very convenient landing-platform for most of the visitors (plate 8).

Behavior.-Bombus juxtus is by far the most frequent visitor, although other species of Bombus and A pis are abundant. The former comes for nectar chiefly, although it usually collects some pollen in the process, while a few individuals collect pollen alone. Juxtus lands on a petal, pushes out its proboscis, and finds nectar at the openings between the bases of the two upper stamens. While sucking nectar, the hind legs move back and forth in such a way that much pollen accumulates in the corbiculae. This motion shakes the whole flower, and pollen from anthers and from the hairs covering the bee's body falls on the recurved stigmatic surfaces. The hairs on the dorsal and ventral sides of Bombus become dusted with pollen. One Bombus juxtus marked with white paint was found to return to the same group of flowers a number of times each hour, as well as day after day. 
It followed the same route each time among the flowers. The capacity to visit many flowers in succession varies in the different species. B. juxtus visited an average of 36 flowers in succession, while proximus came to an average of 17. One individual of juxtus visited 116 flowers in one circuit, and other individuals went respectively to 95,62 , and 52 flowers.

The queen of Bombus proximus lands and takes nectar, but it is so large that the under tip of the abdomen rubs the style branches and in that way leaves pollen on them. Much of the pollination is done, however, when the stamens are shaken. This queen goes from flower to flower for nectar without making any effort to get pollen. The drone of this species poises in the air and then lands on the stamens; it takes no nectar, but collects pollen alone. It scrapes this off with the second pair of legs and from these on to the third pair, where a heavy load of pollen soon accumulates. When poised in the air in front of the flowers, it is scraping pollen from the sides of its abdomen and putting it in the corbiculae. It works very nervously and rapidly at each flower, but flies deliberately from one to another.

Bombus bifarius, upon landing at a flower, takes a position in which the tip of the abdomen is between the style and the petals. It comes for nectar only and seldom touches the recurved styles because of the position of the abdomen. Apis mellifica lands below and then has to crawl to the opening of the nectary. It comes for both pollen and nectar, depending upon its needs at the time. Megachile pugnata, although a much less frequent visitor to these flowers, is a very effective pollinator. Its fewer visits are doubtless due to the fact that this species is not so common in this locality. The abdominal brushes are large and yellow and consist of unusually long, stiff bristles. It lands in the proper place for sucking nectar and straddles the style. This places the mouth-parts directly above the opening to the nectaries. It pushes out its proboscis and sucks nectar, while the hind legs move rapidly and scrape pollen on to the abdominal brushes. Halictus (Lasioglossum) sp. hangs on to the anthers with its front legs in some flowers, but usually twists its abdomen around the base of the filaments while sucking nectar. This places it in a position to have pollen fall on it, and as the bee flies away, pollen is jarred loose and falls on the stigmatic surface of the flower. The brushes on the legs collect pollen as when it hangs on the stamens. Vespa germanica stands on the petals, reaches in to the nectary, and sucks nectar. While sipping, Andrena madronitens elevates the tip of its abdomen in such a way that the scopa rubs the style branches in some flowers and the anthers in others. This makes it a very effective pollinator and one that uses the scopa in a different manner from other bees. There are also long blue-green pollen loads on its legs. Argynnis atlantis comes for nectar, the tip of its abdomen rubbing the recurved stigmas as it works.

The normal visitors to Chamaenerium are given in tables 31 to 33 . In the first case, 120 flowers on 20 racemes were observed for 30 minutes, in the second 80 flowers on 12 racemes for an hour, and in the third 140 flowers on 25 racemes for two s.jcessive hour periods.

For an hour period the number of visitors varied from 28 to 4 , and the number of visits from 158 to 728, the average number of visits per insect ranging from 6 to 50 . Bombus contributed 45 of the total of 60 visitors, and these made 1,391 of the 1,424 visits. A calendar of the normal visitors 
TABLE 31.-Visitors and visits to normal flowers.

\begin{tabular}{|c|c|c|c|c|c|}
\hline Species. & Visitors. & Visits. & Species. & Visitors. & Visits. \\
\hline \multirow{4}{*}{$\begin{array}{r}\text { Bombus juxtus...... } \\
\text { bifarius.... } \\
\text { appositus... } \\
\text { Megachile wootoni... } \\
\text { pugnata... } \\
\text { Prosopis basalis...... } \\
\text { Monumetha albifrons. } \\
\text { Syrphus americanus. . }\end{array}$} & \multirow{4}{*}{$\begin{array}{l}4 \\
1 \\
1 \\
2 \\
1 \\
3 \\
1 \\
1\end{array}$} & \multirow{4}{*}{$\begin{array}{r}56 \\
3 \\
1 \\
8 \\
3 \\
4 \\
3 \\
1\end{array}$} & \multirow{2}{*}{$\begin{array}{l}\text { Megachile wootoni... } \\
\text { Prosopis elliptica.... } \\
\text { Syrphus americanus. } \\
\text { Total. ........ }\end{array}$} & $\begin{array}{l}2 \\
2 \\
1\end{array}$ & $\begin{array}{l}9 \\
2 \\
1\end{array}$ \\
\hline & & & & 21 & 413 \\
\hline & & & & 9 to 10 & 10 to 11 \\
\hline & & & 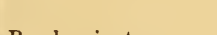 & a. m. & a. $\mathrm{m}$. \\
\hline Total. . & 14 & 79 & bifarius.... & $1: 27$ & $0: 0$ \\
\hline Bombus juxtus...... & $\begin{array}{l}6 \\
6\end{array}$ & $\begin{array}{l}163 \\
124\end{array}$ & $\begin{array}{l}\text { Syrphus americanus. } \\
\text { Thanaos martialis... }\end{array}$ & $\begin{array}{l}1: 1 \\
1: 1\end{array}$ & $\begin{array}{l}0: 0 \\
0: 0\end{array}$ \\
\hline & & & Total. . & $21: 728$ & $4: 204$ \\
\hline
\end{tabular}

to Chamaenerium during a half-hour period is given below, 9 stalks bearing 85 open flowers being observed.

\section{Calendar 1.-Visits to normal flowers.}

$8^{\mathrm{b}} 58^{\mathrm{m}}$ Apis mellifica 3.

900 Megachile relativa 8 .

902 Bombus juxtus 20.

906 Megachile vidua 6.

908 Megachile texana 15; Bombus occidentalis 11.

909 Megachile texana 3 ; relativa 16; wootoni 10. $9^{\mathrm{b}} 11^{\mathrm{m}}$ Apis mellifica 4 ; Bombus occidentalis 15 .

913 Apis mellifica 3.

915 Bombus juxtus 3; hunti 5.

917 Bombus juxtus 18; Selasphorus platycercus 7; Apis mellifica 5.

918 Apis mellifica 4; Bombus hunti 6.

935 Bombus bifarius 11 .

A summary of the above visitors is given in table 32 .

TABLE 32.-Visitors to normal flowers.

\begin{tabular}{|c|c|c|c|}
\hline Species. & $\begin{array}{c}\text { Visitors and } \\
\text { visits. }\end{array}$ & Species. & $\begin{array}{l}\text { Visitors and } \\
\text { visits. }\end{array}$ \\
\hline \multirow[t]{2}{*}{ 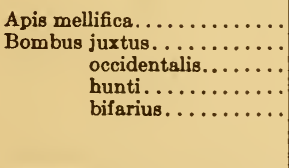 } & \multirow[t]{2}{*}{$\begin{array}{l}5: 19 \\
3: 41 \\
2: 26 \\
2: 11 \\
1: 11\end{array}$} & \multirow{2}{*}{ 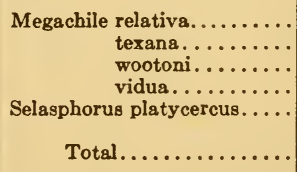 } & $\begin{array}{l}2: 24 \\
2: 18 \\
2: 16 \\
1: 6 \\
1: 7\end{array}$ \\
\hline & & & $21: 179$ \\
\hline
\end{tabular}

All the individuals of Bombus working on one group of flowers during an hour were collected, with the results given in table 33 .

TABLE 33.

\begin{tabular}{|c|c|c|}
\hline Species. & Workers. & Drones. \\
\hline $\begin{array}{r}\text { Bombus bifarius } \ldots \ldots \ldots \ldots \\
\text { juxtus } \ldots \ldots \ldots \ldots\end{array}$ & $\begin{array}{r}4 \\
11\end{array}$ & $\begin{array}{r}6 \\
32\end{array}$ \\
\hline Total............. & 15 & 38 \\
\hline
\end{tabular}


These results show that the drones of some species of Bombus gather nectar, while among the honey-bees this is not the case.

Merritt (1897:4) found the floral structure as described by Mueller (1883:261), except that she noted no lengthening of the style as the flower expanded. The style seemed unduly long, to such an extent that the lobes were often so high that the bee missed them. Only 1 honey-bee in 5 touched a stigma. Honey-bees and Osmia californica were the chief visitors. Knuth (1906:441) records a number of variations in the flower mechanism, and gives lists that show this to be primarily an apid flower.

\section{EXPERIMENTS.}

\section{CHANGE OF POSITION.}

Racemes inverted.-When the flower-stalk of Chamaenerium is inverted, the parts are reversed with respect to the position in which the bee is accustomed to find them. The style and the stamens now project upward, leaving only the petals and sepals of the lower half of the flower as a place to land. These often project backward in a such a way that it is difficult for an insect to stay on them. Three individuals of Bombus juxtus went to inverted flowers at different times and tried to discover the nectar, but flew away without finding it. In another experiment wet cotton was tied over the cut end of three racemes to keep the flowers from wilting, and each one inverted was fastened alongside a normal cluster. Table 34 gives the results of an hour's observation on two different days, an equal number of normal and inverted flowers being used in each case.

TABLE 34.-Visitors and visits to normal and inverted racemes.

\begin{tabular}{|c|c|c|c|c|c|c|}
\hline \multirow{3}{*}{ Species. } & \multicolumn{3}{|c|}{ Experiment 1.} & \multicolumn{3}{|c|}{ Experiment 2.} \\
\hline & \multirow[b]{2}{*}{ Normal. } & \multicolumn{2}{|c|}{ Inverted. } & \multirow[b]{2}{*}{ Normal. } & \multirow[b]{2}{*}{ Inverted. } & \multirow[b]{2}{*}{ Horizontal. } \\
\hline & & $\begin{array}{l}\text { Nectar } \\
\text { found. }\end{array}$ & $\begin{array}{c}\text { Nectar } \\
\text { not found. }\end{array}$ & & & \\
\hline Bombus juxtus.. & $6: 33$ & $3: 8$ & $3: 8$ & $3: 8$ & $6: 30$ & $8: 48$ \\
\hline & $0: 0$ & $1: 2$ & $0: 0$ & $0: 0$ & $0: 0$ & $1: 1$ \\
\hline Halictus pulzenus... & $2: 1$ & $0: 0$ & $0: 0$ & $0: 0$ & $0: 0$ & $0: 0$ \\
\hline Total. . & $8: 34$ & $4: 10$ & $3: 8$ & $3: 8$ & $6: 30$ & $9: 49$ \\
\hline
\end{tabular}

In the first experiment as many individuals of Bombus juxtus visited inverted as normal stalks, but the number of flowers visited was only half as great. In the second, the visitors to the changed clusters were four times as numerous and the number of flowers visited almost 10 times as great. However, this was due largely to the presence of the horizontal racemes, the visitors and visits to the inverted ones being much the same for the two cases.

\section{MUTILATION.}

Floral envelopes removed.- This mutilation makes the whole raceme much less conspicuous even than when in bud, and gives it a pale, feathery appearance not at all like the normal one. The 24 mutilated stalks were 4 feet away from those bearing normal flowers (plate 17). 
TABLE 35.-Visitors to flowers with floral envelopes removed.

\begin{tabular}{|c|c|}
\hline Species. & Visitors. \\
\hline Bombus juxtus. & $11: 136$ \\
\hline Halictus pulzenus. & $1: 1$ \\
\hline Prosopis elliptica... & $1: 1$ \\
\hline Megachile wootoni. . & $1: 1$ \\
\hline Syrphus americanus......... & $1: 1$ \\
\hline Total. & $15: 140$ \\
\hline
\end{tabular}

Bombus juxtus readily distinguished between buds and these mutilated flowers, for it never stopped at the former.

Upper petals and the included sepal removed.-This sepal is just behind the opening to the nectary and looks as if it might be a guide to it. Bombus juxtus went to flowers with these parts removed and to normal flowers indiscriminately, just as they happened to be in its path.

Stamens and style removed.-Bombus juxtus visited flowers with these parts removed and found the nectar at once. It went to three flowers in succession, but had some difficulty hanging on.

The following notes made during 5 minutes of observation indicate that Bombus juxtus took little notice of all the above changes. An equal number of normal and mutilated flowers were under observation.

$10^{\mathrm{h}} 20^{\mathrm{m}}$ Bombus juxtus flew over flowers with the corolla removed, but stopped at 2 with the stamens alone gone. A second one stopped at 2 flowers with the petals gone and at 3 normal ones.

1021 B. juxtus, 2 flowers with stamens gone. $10^{\mathrm{h}} 22^{\mathrm{m}}$ B. bifarius, 3 flowers with the upper 3 petals gone and 3 normal.

1023 B. juxtus, 4 normal and then 2 flowers with the upper petals gone.

1024 B. juxtus, 3 flowers with the upper petals gone and 2 normal.

1025 B. juxtus, 5 normal.

The relative numbers of visits made by the various species of bees to the different kinds of mutilated flowers, as well as to the normal ones, are shown in table 36. On July 17 and 18, 10 normal flowers and 5 mutilated ones of each type were used, one or more of each being placed in each raceme; the time of observation was 1 hour. For the next two periods of an hour and a half each, 4 flowers of one kind were arranged on each stalk.

The results obtained in this experiment relate chiefiy to the behavior of Bombus, as the other 4 genera made but 17 of the 210 visits recorded. Of the 193 visits by bumble-bees, $B$. juxtus made 173 and $B$. bifarius but 20. The actual number of visits to normal and mutilated flowers is nearly equal, but the normal flowers were a third as numerous and hence about twice as attractive. However, the contrast between the different types of mutilated flowers is so sharp as to indicate an intentional selection. Thus, flowers with the perianth, stamens, and styles removed received but 6 visits out of a total of 114 for mutilated flowers, while those with either stamens or styles excised obtained less than half as many as those with petals or both sepals and petals removed. On the other hand, the visits to both the latter were a third less than to the flowers with the stamens and styles excised but the perianth intact. While the results are not entirely 
in accord, it is significant that 166 visits were made to flowers with corollas in contrast to 44 to those without.

TABLE 36.-Visits to normal and mutilated flowers.

\begin{tabular}{|c|c|c|c|c|c|c|c|c|}
\hline Time. & Species. & Normal. & $\begin{array}{l}\text { Petals } \\
\text { off. }\end{array}$ & $\begin{array}{l}\text { Sepals } \\
\text { and } \\
\text { petals } \\
\text { off. }\end{array}$ & $\begin{array}{l}\text { Stamens } \\
\text { excised. }\end{array}$ & $\begin{array}{l}\text { Styles } \\
\text { excised. }\end{array}$ & $\begin{array}{l}\text { Stamens } \\
\text { and styles } \\
\text { excised. }\end{array}$ & $\begin{array}{l}\text { Perianth, } \\
\text { stamens, } \\
\text { and styles } \\
\text { off. }\end{array}$ \\
\hline \multirow[t]{2}{*}{$\begin{array}{l}\text { July } 17 \\
\text { July } 18\end{array}$} & $\begin{array}{c}\text { Bombus juxtus } \ldots \ldots \ldots \\
\ldots \ldots \ldots \text { Do } \ldots \ldots \ldots \ldots \ldots\end{array}$ & $\begin{array}{l}13 \\
55\end{array}$ & $\begin{array}{r}0 \\
12\end{array}$ & $\begin{array}{r}12 \\
0\end{array}$ & 1 & $\begin{array}{l}7 \\
0\end{array}$ & $\begin{array}{l}12 \\
17\end{array}$ & $\begin{array}{l}0 \\
0\end{array}$ \\
\hline & Total.. & 68 & 12 & 12 & 8 & 7 & 29 & $0: 68$ \\
\hline \multirow[t]{2}{*}{ July 21} & $\begin{array}{l}\text { Bombus juxtus......... } \\
\text { Monumetha albifrons... } \\
\text { Megachile wootoni..... }\end{array}$ & $\begin{array}{l}2 \\
4 \\
1\end{array}$ & $\begin{array}{l}0 \\
0 \\
0\end{array}$ & $\begin{array}{l}2 \\
1 \\
0\end{array}$ & $\begin{array}{l}0 \\
1 \\
0\end{array}$ & $\begin{array}{l}0 \\
0 \\
0\end{array}$ & $\begin{array}{l}2 \\
3 \\
0\end{array}$ & $\begin{array}{l}3 \\
0 \\
0\end{array}$ \\
\hline & Total. & 7 & 0 & 3 & 1 & 0 & 5 & $3: 12$ \\
\hline \multirow[t]{3}{*}{ July 25} & $\begin{array}{r}\text { Bombus juxtus......... } \\
\text { bifarius....... } \\
\text { Andrena madronitens... } \\
\text { Halictus pulzenus..... }\end{array}$ & $\begin{array}{r}18 \\
1 \\
0 \\
2\end{array}$ & $\begin{array}{l}5 \\
1 \\
1 \\
1\end{array}$ & $\begin{array}{l}3 \\
0 \\
0 \\
0\end{array}$ & $\begin{array}{l}0 \\
0 \\
0 \\
0\end{array}$ & $\begin{array}{l}0 \\
0 \\
0 \\
0\end{array}$ & $\begin{array}{r}2 \\
15 \\
1 \\
2\end{array}$ & $\begin{array}{l}0 \\
3 \\
0 \\
0\end{array}$ \\
\hline & Total. & 21 & 8 & 3 & 0 & 0 & 20 & $3: 34$ \\
\hline & Grand total... & 96 & 20 & 18 & 9 & 7 & 54 & $6: 114$ \\
\hline
\end{tabular}

In the following experiments one raceme was left normal and one mutilated by each of the various types of excision. In the tables the first number in each column represents the number of visitors, the second the number of flowers visited. The first observations were made on July 19 from $9^{\mathrm{h}} 05^{\mathrm{m}}$ to $10^{\mathrm{h}} 05^{\mathrm{m}}$ a.m. and the second on the same date from $10^{\mathrm{h}} 05^{\mathrm{m}}$ to $12^{\mathrm{h}} 05^{\mathrm{m}}$ a.m.

TABLE 37.-Visits to normal and mutilated flowers.

\begin{tabular}{|c|c|c|c|c|c|c|c|}
\hline Species. & $\begin{array}{l}\text { 㟧 } \\
\text { 总 } \\
\text { Z }\end{array}$ & 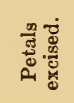 & $\begin{array}{l}\text { Petals } \\
\text { and } \\
\text { sera!s } \\
\text { excised. }\end{array}$ & 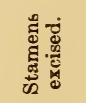 & 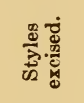 & $\begin{array}{l}\text { Stamens } \\
\text { and } \\
\text { styles } \\
\text { excised. }\end{array}$ & $\begin{array}{l}\text { Ovary } \\
\text { alone } \\
\text { left. }\end{array}$ \\
\hline $\begin{array}{r}\text { Bombus juxtus....... } \\
\text { proximus.... } \\
\text { Megachile wootoni... }\end{array}$ & $\begin{array}{l}43: 157 \\
3: 6 \\
2: 3\end{array}$ & $\begin{aligned} 20 & : 89 \\
0 & : 0 \\
0 & : 0\end{aligned}$ & $\begin{array}{c}22: 99 \\
0: 0 \\
1: 2\end{array}$ & $\begin{array}{l}40: 165 \\
2: 12 \\
3: 0\end{array}$ & $\begin{array}{l}49: 143 \\
4: 10 \\
0: 0\end{array}$ & $\begin{array}{l}38: 132 \\
1: 2 \\
0: 0\end{array}$ & $\begin{array}{c}212: 785 \\
10: 30 \\
3: 5\end{array}$ \\
\hline Total. & $48: 166$ & $20: 89$ & $23: 101$ & $42: 177$ & $53: 153$ & $39: 134$ & $225: 820$ \\
\hline $\begin{array}{r}\text { Bombus juxtus........ } \\
\text { proximus..... } \\
\text { Megachile wootoni.... } \\
\text { Monumetha albifrons.. }\end{array}$ & $\begin{array}{c}27: 179 \\
3: 18 \\
2: 8 \\
1: 3\end{array}$ & $\begin{array}{l}\cdots \cdots \\
\cdots \cdots \\
\cdots \cdots \\
\cdots \cdots\end{array}$ & $\begin{aligned} 14 & : 211 \\
1 & : 2 \\
0 & : 0 \\
0 & : 0\end{aligned}$ & $\ldots$ & $\ldots$ & & \\
\hline Total & $33: 208$ & & $15: 213$ & & & & \\
\hline
\end{tabular}

Bees flying to the community usually alighted upon flowers with corollas. Once landed, they passed on to the flowers in order, with little 
regard to the type of mutilation. It is significant that the removal of the petals or the perianth reduced the number of visitors more than half in every case, and with a single exception had a somewhat similar effect upon visits. The flowers with stamens or styles or both excised were treated essentially as normal ones, but those with ovary and nectary alone left received practically five times as many visitors and visits, probably owing to the greater fragrance and accessibility of the nectar.

\section{ARTIFICIAL AND PAINTED FLOWERS.}

Crepe-paper corollas.- Red, blue, green, white, or yellow corollas were made to simulate and replace the normal ones, leaving the stamens and style intact. No bees went to the flowers with crepe corollas, not even to those in which a drop of honey was placed on the nectary. At another trial of crepe corollas no visitors were attracted until a drop of diluted honey was put on the nectary, and even then but one bee, Bombus juxtus, came to the flowers for a chance visit. In another experiment, half of the flowers on the raceme were left normal and paper corollas were alternated, as it was thought that the habit of going from one flower to the next would cause some of the bees to stop at those with artificial corollas. In spite of this, not one bee stopped at a flower with crepe corolla, although they flew low to inspect them.

Painted corollas. - Natural corollas were painted with water-colors on the upper side. While the texture of the petal is such that the colors do not spread uniformly over the surface, they show up very well. Table 38 gives the results of these experiments, 5 flowers of each color and 10 normal ones being used in each case. The first observations were made on July 21 from 8 to $10 \mathrm{a}$. $\mathrm{m}$. and the second on the following day from 9 to $10 \mathrm{a} . \mathrm{m}$.

TABLE 38.-Visits to normal and painted flowers.

\begin{tabular}{|c|c|c|c|c|c|c|}
\hline Species. & Normal. & Red. & White. & Yellow. & Green. & Blue. \\
\hline $\begin{array}{l}\text { Bombus juxtus............ } \\
\text { Halictus pulzenus. . . . } \\
\text { Syrphus americanus. } \\
\text { Thanaos martialis. . . . }\end{array}$ & $\begin{array}{r}51 \\
0 \\
0 \\
0\end{array}$ & $\begin{array}{r}10 \\
0 \\
0 \\
0\end{array}$ & $\begin{array}{r}10 \\
1 \\
1 \\
1\end{array}$ & $\begin{array}{r}10 \\
0 \\
0 \\
0\end{array}$ & $\begin{array}{r}16 \\
0 \\
0 \\
0\end{array}$ & $\begin{array}{c}10: 56 \\
0 \\
0 \\
0\end{array}$ \\
\hline Total..... & 51 & 10 & 13 & 10 & 16 & $10: 59$ \\
\hline $\begin{array}{l}\text { Bombus juxtus............. } \\
\text { Halictus pulzenus.......... } \\
\text { Megachile wootoni......... } \\
\text { Monumetha albifrons..... } \\
\text { Syrphus americanus..... }\end{array}$ & $\begin{array}{r}48 \\
3 \\
1 \\
0 \\
0\end{array}$ & $\begin{array}{r}10 \\
0 \\
0 \\
0 \\
0\end{array}$ & $\begin{array}{l}6 \\
0 \\
0 \\
0 \\
0\end{array}$ & $\begin{array}{l}6 \\
2 \\
0 \\
1 \\
1\end{array}$ & $\begin{array}{l}7 \\
0 \\
0 \\
0 \\
0\end{array}$ & $\begin{array}{l}19: 48 \\
0 \\
0 \\
0 \\
0\end{array}$ \\
\hline Total. . & 52 & 10 & 6 & 10 & 7 & $19: 52$ \\
\hline Grand total.. & 103 & 20 & 19 & 20 & 23 & 29:111 \\
\hline
\end{tabular}

While there were a few more visits to the painted than to the normal flowers, the former were 2.5 times more numerous and the actual ratio of normal to painted is 103:44. Bombus juxtus made 203 of the total of 214 visits to all kinds of flowers. It showed no pronounced color preference, 
though blue led with 29 visits, followed by green 23 , red 20 , white and yellow 16 each. Oddly enough, white and yellow were the only colors sought by the other species, but the numbers are too small to be significant. The behavior of one Bombus juxtus was noted as it worked from flower to flower and the following course was observed: blue, normal, hovered over green, normal; next stalk, blue; third stalk, blue, normal, blue, normal.

\section{ADDITION OF NECTAR AND ODOR.}

Honey.-When a drop of honey was placed at the opening to the nectary in a group of normal flowers, Apis mellifica found it at once and stayed at the flower 6 minutes. In another experiment, honey was placed on every flower on one plant, but the number of visitors was no more numerous than to the normal plants adjoining. The bees merely happened to visit it and were not especially attracted by the honey. However, when Bombus juxtus did find the latter, it stayed at the drop until this was consumed. When the drop of honey was put on the style branches, Bombus sucked it up as readily as when it was over the openings to the nectaries.

Odor.-Flower perfumes were put on cotton-wads and these then wound around the several pedicels under the calyx. The groups of flowers on which the different odors were placed were arranged with respect to the direction of the wind so as to make the odor in each case as distinctive as possible. Twelve flowers of each odor were used in addition to 24 normal ones. The two sets of observations were made during succeeding hours on August 9.

TABLE 39.-Visitors and visits to perfumed flowers.

\begin{tabular}{|c|c|c|c|c|}
\hline Species. & Normal. & $\begin{array}{c}\text { Violet } \\
\text { perfume. }\end{array}$ & $\begin{array}{c}\text { Carnation } \\
\text { perfumę. }\end{array}$ & $\begin{array}{c}\text { Crab-apple } \\
\text { perfume. }\end{array}$ \\
\hline 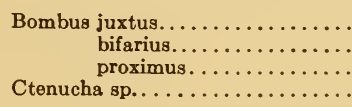 & $\begin{array}{l}8: 75 \\
7: 51 \\
4: 40 \\
1: 3\end{array}$ & $\begin{array}{l}7: 26 \\
3: 10 \\
4: 18 \\
0: 0\end{array}$ & $\begin{array}{l}1: 3 \\
1: 5 \\
1: 3 \\
0: 0\end{array}$ & $\begin{array}{l}\ldots \ldots \\
\cdots \ldots . \\
\cdots \cdots \\
\cdots \ldots\end{array}$ \\
\hline Total. & $20: 169$ & $14: 54$ & $3: 11$ & \\
\hline 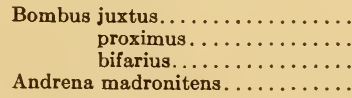 & $\begin{array}{c}15: 111 \\
11: 52 \\
9: 86 \\
0: 0\end{array}$ & $\begin{array}{l}5: 30 \\
2: 3 \\
0: 0 \\
0: 0\end{array}$ & $\begin{array}{c}16: 71 \\
8: 29 \\
4: 14 \\
1: 2\end{array}$ & $\begin{array}{l}1: 2 \\
9: 24 \\
1: 1 \\
0: 0\end{array}$ \\
\hline Total. & $35: 249$ & $7: 33$ & $29: 116$ & $11: 27$ \\
\hline Grand total.. & $55: 418$ & $21: 87$ & $32: 127$ & $11: 27$ \\
\hline
\end{tabular}

The flowers with carnation were shaded more than those with violet in the first part of the experiment, which probably accounts for the few visits. During the next hour of observation, carnation was in a different location and many more visitors came to it. The number of visitors per flower was practically the same for normal and for perfumed stalks, but these averaged only 4 visits each to the perfumed flowers in contrast to 8 each for the normal ones, indicating again something of the usual disturbance caused by strange odors. 
Perfumes.-Either "Love me," "Three flowers," "Poudre azure," or camphor-ball powder was sprinkled over the nectaries on half of the flowers on each of four stalks. Bombus juxtus was the only visitor during the hour of observation (table 40).

TABLE 40.-Visits of Bombus juxtus to scented flowers.

\begin{tabular}{|c|c|c|c|}
\hline Scented powder. & Normal. & Scented. & $\begin{array}{l}\text { Inspections } \\
\text { of scented. }\end{array}$ \\
\hline 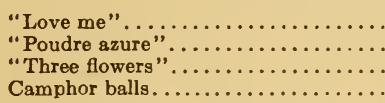 & $\begin{array}{l}5: 9 \\
2: 6 \\
1: 3 \\
0: 0\end{array}$ & $\begin{array}{l}1: 2 \\
0: 0 \\
0: 0 \\
0: 0\end{array}$ & $\begin{array}{l}4: 6 \\
3: 8 \\
1: 1 \\
1: 1\end{array}$ \\
\hline Total... & $8: 18$ & $1: 2$ & $9: 16$ \\
\hline
\end{tabular}

The difference in behavior as compared with that shown in table 39 is probably to be explained by the fact that the appearance of the flower was visibly changed by the powder. This also seems to furnish the reason for the large number of inspections indicated in the last column.

Flavoring extracts.-Extract of vanilla, lemon, almond, or peppermint was poured on absorbent cotton and a small wad wrapped around the ovary under the calyx. This changed the odor of the flower, but did not affect its appearance. Visitors to normal flowers were recorded only for the first experiment. All the observations were made on August 8, the first two

TABLE 41.-Visitors and visits to flowers scented with extracts.

\begin{tabular}{|c|c|c|c|c|c|}
\hline Species. & Normal. & Vanilla. & Peppermint. & Lemon. & Almond. \\
\hline 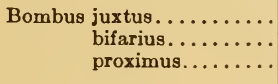 & $\begin{array}{l}9: 30 \\
7: 18 \\
1: 2\end{array}$ & $\begin{array}{l}1: 5 \\
0: 0 \\
1: 1\end{array}$ & $\begin{array}{l}5: 20 \\
1: 5 \\
1: 1\end{array}$ & $\begin{array}{l}3: 12 \\
3: 12 \\
1: 1\end{array}$ & $\begin{array}{l}3: 10 \\
0: 0 \\
1: 1\end{array}$ \\
\hline Total.. & $17: 50$ & $2: 6$ & $7: 26$ & $7: 25$ & $4: 11$ \\
\hline $\begin{array}{r}\text { Bombus juxtus. } \ldots \ldots \ldots \ldots \\
\quad \text { bifarius } \ldots \ldots \ldots \ldots \\
\text { morrisoni } \ldots \ldots \ldots\end{array}$ & 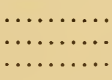 & $\begin{array}{l}1: 2 \\
0: 0 \\
1: 1\end{array}$ & $\begin{array}{l}1: 2 \\
0: 0 \\
0: 0\end{array}$ & $\begin{array}{l}0: 0 \\
0: 0 \\
0: 0\end{array}$ & $\begin{array}{l}4: 9 \\
2: 4 \\
2: 3\end{array}$ \\
\hline Total... & ....... & $2: 3$ & $1: 2$ & $0: 0$ & $8: 16$ \\
\hline $\begin{array}{l}\text { Bombus bifarius. . . . . . . . } \\
\text { morrisoni . . . . . } \\
\text { Monumetha albifrons..... }\end{array}$ & $\ldots \ldots \ldots$ & $\begin{array}{l}3: 7 \\
2: 5 \\
0: 0\end{array}$ & $\begin{array}{l}0: 0 \\
0: 0 \\
1: 1\end{array}$ & $\begin{array}{l}1: 2 \\
0: 0 \\
0: 0\end{array}$ & $\begin{array}{l}8: 10 \\
9: 10 \\
1: 2\end{array}$ \\
\hline Total. & $\ldots \ldots$ & $5: 12$ & $1: 1$ & $1: 2$ & $18: 22$ \\
\hline $\begin{array}{r}\text { Bombus bifarius. ........ } \\
\text { juxtus. . . . . . } \\
\text { morrisoni...... }\end{array}$ & , & $\begin{array}{l}2: 3 \\
0: 0 \\
0: 0\end{array}$ & $\begin{array}{l}1: 2 \\
2: 4 \\
3: 7\end{array}$ & $\begin{array}{l}0: 0 \\
0: 0 \\
0: 0\end{array}$ & $\begin{array}{l}1: 2 \\
0: 0 \\
6: 6\end{array}$ \\
\hline Total. & - & $2: 3$ & $6: 13$ & $0: 0$ & $7: 8$ \\
\hline Grand total. & & $11: 24$ & $15: 42$ & $8: 27$ & $37: 57$ \\
\hline
\end{tabular}


for hour periods from $9^{\mathrm{h}} 35^{\mathrm{m}}$ to $11^{\mathrm{h}} 35^{\mathrm{m}}$ in the morning and the next two for an hour period from 2 to 4 in the afternoon.

Both visitors and visits were slightly though not significantly greater to the scented flowers. The grand totals for the different odors are much alike, except in the case of almond. While visited least in the first experiment, its total was 2 to 4 times greater than for the others.

\section{SUMMARY.}

The inversion of the flower resulted in about half of the visits being fruitless at first, but later both inverted and horizontal flowers received many more visits than the normal. Mutilated flowers in general were about half as attractive as normal ones, but they differed greatly among themselves. The removal of the corolla reduced visits from a half to a fourth, in spite of the marked habit of Bombus in visiting Chamaenerium flowers in order from the bottom upwards. On the other hand the removal of all flower parts except the ovary and the nectary increased the visits 5 times over the normal, doubtless because the nectar was more fragrant and accessible, thus permitting the bees to work more rapidly. Artificial flowers of paper were often inspected, but they received only a single visit, in spite of the addition of honey. Painted ones were about half as attractive as normal flowers, suggesting that the neglect of artificial flowers was due to small differences in form and texture, since the colors were unnatural in both cases. Blue was the preferred color, but not decisively so. Honey did not attract greater numbers of bees, while scented powders almost eliminated visits, the number of inspections equaling the visits to normal flowers. The number of visitors was the same for blossoms perfumed with other flower odors and normal ones, but the visits were about half as many to the former. Flavoring extracts seemed to increase attraction slightly, but the significant fact was the marked effect of almond in augmenting the number of visitors.

\section{PACHYLOPHUS CAESPITOSUS.}

\section{NORMAL POLLINATION.}

Habit and structure. - This species possesses the largest and most fragrant flowers of any in the region. It is white in color the first evening, becoming pink the next morning. When the calyx is normal, the flowers open between 5 and 7 in the evening and the process usually requires but 2 to 7 minutes, the unfolding of the petals being so rapid that the movement is easily seen. The style and stamens are covered with very small black diptera when the flower opens. At this time the anthers are dehiscing and the stigmas are receptive. The under surface of the stigma lobes is covered with pollen, but the receptive surface is free from it. The tube of the calyx is about $10 \mathrm{~cm}$. long and is filled with nectar for more than half its length at the time of opening (plate 9). The amount of nectar varies considerably,

\begin{tabular}{|c|c|}
\hline Flower. & $\begin{array}{c}\text { Weight of } \\
\text { nectar. }\end{array}$ \\
\cline { 1 - 2 } & \\
1 & 0.0135 \\
2 & .0430 \\
3 & .0065 \\
4 & .0280 \\
5 & .0475 \\
6 & .0355 \\
\hline Av.... & .0290 \\
\hline
\end{tabular}
as is shown by its weight in several flowers. These were picked at 7 
o'clock in the evening just after opening, but before visitors were observed. The absence of pollen on the stigmas furnished additional evidence that they had not been visited. The nectar was blown out of the tube on a glass slide and weighed immediately.

Robertson (1892:272) has given a list of visitors to Oenothera biennis and $O$. fruticosa, and described the structure of the latter. The stigma exceeds the anthers and is inclined to the lower side so that it strikes the ventral surface of visiting bumble-bees. The tube measures 14 to $20 \mathrm{~mm}$. and can be drained only by the largest bees; though shorter-tongued ones can reach a little of the nectar when the tube is fullest. Hitchcock (1893: 362 ) has observed that the stigma in Oenothera missouriensis may protrude from the bud as early as 2 p. m., though the flower opens fully only during the latter part of the afternoon. The narrow calyx-tube, about $11 \mathrm{~cm}$. long, is often half filled with nectar. With the exception of ants, the only visitor was a sphinx-moth, Celerio lineata, which came in abundance just before 8 p. m., but ceased its visits at dark. The insect pushed its head into the throat as far as possible, but was able to reach only the upper portion of the nectar, and was caught in the flower by its endeavor to secure more. Merritt $(1897: 4)$ has noted that the flowers of 0 . biennis open about $6 \mathrm{p} . \mathrm{m}$. and close about $9 \mathrm{a} . \mathrm{m}$. While the stigmas are 2 to $6 \mathrm{~mm}$. beyond the anthers, a slight breeze is sufficient to bring them into contact. By $7^{\mathrm{h}} 30^{\mathrm{m}}$ p. m. pollen was found on nearly all the stigmas, though no night moths were seen. The odor is faint, but the large, pale flowers are conspicuous at night. In 0 . californica the flowers at 6,000 feet are always fully open by 5 p. m. and remain conspicuous and fragrant throughout the night. Honey-bees collect pollen as soon as the flowers open and usually strike the stigmas first, since the latter slightly exceed the anthers. Nectar is not abundant at night, but by morning it is sometimes an inch deep in the tube; the stigmas are visibly pollinated and the pollen is gone from the anthers. Longyear (1909:103) has described the opening of the flower and its pollination in Oenothera pinnatifida.

Behavior.-Three species of large hawk-moths come to the flowers very soon after they open each night, namely, Protoparce quinquemaculata, Hyloicus separatus, and Celerio lineata. The first two have a proboscis 9.5 to $10.5 \mathrm{~cm}$. long, which enables them to reach to the bottom of the deepest tube. It was found that each moth stays at a newly opened flower until it obtains all the nectar that it can reach. Protoparce worked as long as 38 seconds at such flowers, but only 3 to 10 seconds at those that had been previously visited. Celerio has a much shorter proboscis, about $4.5 \mathrm{~cm}$. long, and is limited to the nectar-supply in the upper half of the tube. These moths fly swiftly through the air to a group of evening primroses, when they stop over them, unroll the proboscis and hover in this position, gradually descending until the tip of the ligule is above the opening to the tube. After a few trials, the proboscis is gradually pushed down the tube until it reaches the nectar, after which it moves downward slowly as the nectar is sipped up. When it has exhausted the nectar, the moth rises above the flower and passes to the next. While poised in the air above the flower after a visit, its proboscis is covered with large masses of pollen and viscin threads at the point of contact with the anthers. When it dips 
into the next flower, these usually come in contact with the stigmatic surface, which acquires more and more pollen with each visit. The hawkmoths continue to come for an hour or so after dark, and perhaps later if nectar is still available. They are not frightened by lights being thrown on them and in consequence their movements can be readily followed by means of a flashlight.

\section{EXPERIMENTS.}

\section{ARTIFICIAL FLOWERS.}

Crepe-paper flowers.-Artificial flowers were made of crepe-paper and provided with calyx-tubes of glass. Some of these were coated with paraffin to stiffen them and others were shaped by stretching the paper. The calyx-tube was filled with a sirup made of beet-sugar, and a drop of nectar drawn from a flower placed at the top. The calyx-tubes of natural flowers from which the nectar had been taken were then filled to the top with sugar solution. In no case were the crepe-paper flowers visited or even inspected, a fact difficult to explain, since the moths stopped to inspect a white net and white pieces of paper lying near. The normal flowers filled with sugar sirup were popular, and this was sipped as far down as available.

Petals obscured.-Flowers were covered with disks of green crepe-paper with a hole cut at the center to allow the stamens and style to project and also to permit access to the nectary. Thus, while the disk covered the white petals, it did not confine the odor. No moths or other visitors stopped at these flowers, although the calyx-tube in each case was well supplied with nectar, while they came regularly to all the normal flowers among which the experimental ones were located. They also stopped at the disks of white paper that were grouped among the normal flowers. As the supply of flowers became greatly reduced at the end of the season, frequent inspections were made of the white-paper flowers.

\section{MENTZELIA MULTIFLORA.}

\section{NORMAL POLLINATION.}

Habit and structure.-This species differs from most of the others studied in that the flowers open at about 4 o'clock in the afternoon and close about 8 at night. There is a distinct advantage in opening at this time, since the nectar supply is running low in most of the flowers visited during the day. About the time these flowers should open, several species

TABLE 42.-Visitors and visits to normal flowers.

\begin{tabular}{|c|c|c|}
\hline Species. & $\begin{array}{l}\text { First } \\
\text { day. }\end{array}$ & $\begin{array}{l}\text { Second } \\
\text { day. }\end{array}$ \\
\hline $\begin{array}{r}\text { Apis mellifica............. } \\
\text { Bombus juxtus........... } \\
\text { bifarius......... } \\
\text { occidentalis..... }\end{array}$ & $\begin{array}{l}4: 42 \\
6: 55 \\
2: 16 \\
3: \quad 9\end{array}$ & $\begin{array}{l}5: 11 \\
5: 60 \\
7: 172 \\
2: \quad 9\end{array}$ \\
\hline Total. . & $15: 122$ & $19: 252$ \\
\hline
\end{tabular}


of Bombus and Apis are seen hovering around them, landing at the buds and inspecting them carefully. When the flowers open, the visitors appear at once in fairly large numbers and immediately commence collecting both pollen and nectar. The number grows less as the sun goes down, but persistent visitors are present and working until dark. This is particularly true of Bombus occidentalis. Table 42 gives the list of visitors to normal flowers on succeeding days, the first from $5^{\mathrm{h}} 00^{\mathrm{m}}$ to $6^{\mathrm{h}} 40^{\mathrm{m}}$ and the second from $5^{\mathrm{h}} 00^{\mathrm{m}}$ to $5^{\mathrm{h}} 55^{\mathrm{m}}$ in the afternoon.

\section{EXPERIMENTS.}

\section{CREPE-PAPER COROLLAS, AND COMPETITION.}

Crepe-paper corollas.-Red, white, yellow, green, and blue paper corollas were fastened below the stamens after the petals were cut off. This was done about 4 p. m., when the buds were beginning to open. Individual flowers of Chamaenerium and Geranium were also paired with these of Mentzelia in the group under observation, so that competition studies could be made at the same time. Before the calendar given below was made the flowers were observed as they opened. At that time the visitors were already in the vicinity, keeping watch of the flowers. In putting on the crepe corollas the stamens were exposed, and nectar and pollen made accessible. As a consequence, paper flowers of all colors were visited, yellow more than the others and green less often, doubtless because of the resemblance to the leaves. The yellow flowers so closely resembled the normal ones

\section{CALENDAR 1.-Visits to normal and crepe flowers.}

$5^{\mathrm{h}} 00^{\mathrm{m}}$ Apis mellifica 1 .

501 Bombus juxtus 1.

515 B. juxtus 1.

516 B. occidentalis 2 Mentzelia of Geranium pairs, 6 Mentzelia of Chamaenerium pairs.

521 B. juxtus 4 Mentzelia of Chamaenerium pairs.

525 B. occidentalis 1.

530 B. bifarius 32 ; inspects all crepe and paired flowers.

535 B. bifarius 27; inspects paired Chamaenerium. $5^{\mathrm{b}} 45^{\mathrm{m}}$ B. bifarius $50 ; 7$ Mentzelia of Chamae-

552 Apis 3. nerium pairs.

555 B. bifarius 48; inspects all crepe and paired flowers.

602 B. bifarius 1 .

615 B. juxtus 1; red crepe 1, Mentzelis $21,33$.

630 Apis 5.

640 B. bifarius 15 .

TABLE 43.-Summary of Mentzelia calendar.

\begin{tabular}{|c|c|c|c|c|}
\hline Species. & Normal. & $\begin{array}{c}\text { Geranium } \\
\text { pair. }\end{array}$ & $\begin{array}{l}\text { Chamae- } \\
\text { nerium } \\
\text { pair. }\end{array}$ & $\begin{array}{c}\text { Crepe } \\
\text { corollas. }\end{array}$ \\
\hline 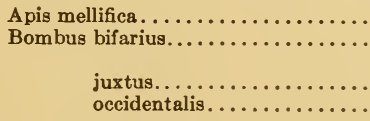 & $\begin{array}{l}3: 9 \\
6: 173 \\
5: 57 \\
1: 1\end{array}$ & $\begin{array}{c}0: 0 \\
2 \text { (i all) } \\
0: 0 \\
2 \text { Mentz. }\end{array}$ & $\begin{array}{l}\quad 0: 0 \\
3 \text { (i all) } \\
7 \text { Mentz. } \\
4 \text { Mentz. } \\
6 \text { Mentz. }\end{array}$ & $\begin{array}{ll} & 0: 0 \\
2 & \text { (i all) } \\
1 r & \\
0: 0\end{array}$ \\
\hline Total. . & $15: 240$ & $\begin{array}{l}2 \text { Mentz; } \\
2 \text { (i all) }\end{array}$ & $\begin{array}{l}17 \text { Mentz.; } \\
3 \text { (i all) }\end{array}$ & $1 \mathrm{r}: 2$ (i all) \\
\hline
\end{tabular}


that they were hard to find after these had opened, and this similarity doubtless explains the attraction of more visitors to them. After the normal flowers opened, those with artificial corollas were practically deserted, as the following calendar shows. Visits to normal flowers are indicated by the numeral alone.

\section{SUMMARY.}

In spite of the numerous visits to the normal flowers, but one crepe flower received a visit after the normal ones opened. Not a single one of the paired Geranium or Chamaenerium flowers was visited, though 19 Mentzelia flowers of such pairs were. Bombus bifarius was the only species to inspect the artificial or competing flowers, Apis not even visiting Mentzelia when paired with these. This experiment also included false flowers made by pasting petals of Geranium or Chamaenerium over those of Mentzelia, but as these were noticed only by one bifarius, which stopped at a false Chamaenerium, they were not included in calendar or table.

\section{FRASERA SPECIOSA.}

\section{NORMAL POLLINATION.}

Habit and structure.-The plants are 3 to 4 feet tall and wand-like, growing on sunny slopes or in open woods. The flowers form a close cluster often 2 feet long, but the number of those open at any one time is not large and they must be sought throughout the inflorescence. When the flower opens, the petals are curved so that the corolla is cup-shaped, but as the anthers mature, they are flattened. At first, the filaments are vertical or bend outward slightly, but they diverge as the anthers shed singly or by pairs. Two rows of hairs on a tongue-like projection extend over the nectaries and protect them (plate 10).

Behavior.-Bombus juxtus lands on the petals with its head pointing toward the pistil. Its ligule is pushed under the hairs above the nectary, and it sips in turn from each. In doing this the anther which extends between the two petals touches the side of its abdomen. Occasionally this bee stands with the abdomen over the style and its head pointing toward the outside of the flower. When the anthers are about through dehiscing, the petals close up, the corolla becomes cup-shaped again, and the stamens project between the closed petals. Nectar is still being produced, and in order to get it $B$. juxtus walks up the outside of the petals and dips its head into the inside of the cup. In doing this, the side of the abdomen and head, which have collected pollen from the dehiscing anthers, rubs pollen against the now receptive stigmas. Halictus pulzenus walks over the pistils, then up the filaments, and with its front legs and head collects pollen from the individual anthers. Clisodon terminalis also comes to this flower for pollen rather than nectar. It stands on its hind legs and collects with the front legs and head. A pis mellifica lands in such a manner as to reach and empty the nectaries in rapid succession. In one case a honey-bee took hold of the dehiscing anthers with the front legs, and, while suspended, opened each one, scraping out the pollen and placing it on the hind legs.

Fifty flowers were under observation on the three days recorded in table 44. 
TABLE 44.-Visitors to normal flowers.

\begin{tabular}{|c|c|c|c|}
\hline Species. & $\begin{array}{l}\text { Visitors, } \\
35 \text { min. }\end{array}$ & $\begin{array}{l}\text { Visitors, } \\
90 \text { min. }\end{array}$ & $\begin{array}{l}\text { Visitors, } \\
90 \text { min. }\end{array}$ \\
\hline 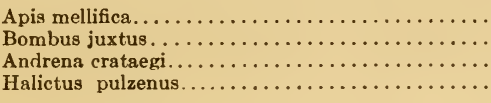 & $\begin{array}{r}14 \\
10 \\
4 \\
0\end{array}$ & $\begin{array}{r}51 \\
22 \\
0 \\
4\end{array}$ & $\begin{array}{r}37 \\
60 \\
0 \\
0\end{array}$ \\
\hline Total... & 28 & 77 & 97 \\
\hline
\end{tabular}

Robertson has discussed the pollination of Frasera carolinensis (1893:48) and given a list of visitors (1895:142).

\section{EXPERIMENTS.}

\section{MUTILATION.}

Types.-Flowers were modified in the following ways: (1) by removal of the stamens; (2) removal of petals to the nectary; (3) removal of nectary hairs; (4) removal of hairs and pads, leaving only the nectar pit; (5) removal of pistil; (6) by splitting the petals. Observation during an hour on July 28 gave the results shown in table 45 when 30 normal flowers and 5 of each type of mutilation were used.

TABLE 45.-Visits to normal and mutilated flowers.

\begin{tabular}{|c|c|c|c|c|c|c|c|}
\hline Species. & Normal. & $\begin{array}{l}\text { Nectary } \\
\text { intact; } \\
\text { petals } \\
\text { off. }\end{array}$ & $\begin{array}{c}\text { Stamens } \\
\text { off. }\end{array}$ & $\begin{array}{l}\text { Pistil } \\
\text { off. }\end{array}$ & $\begin{array}{l}\text { Hairs } \\
\text { and } \\
\text { sepals } \\
\text { off. }\end{array}$ & $\begin{array}{c}\text { Hairs } \\
\text { off. }\end{array}$ & $\begin{array}{l}\text { Petals } \\
\text { split. }\end{array}$ \\
\hline $\begin{array}{r}\text { Apis mellifica........... } \\
\text { Bombus juxtus......... } \\
\text { occidentalis.... } \\
\text { Andrena madronitens.... }\end{array}$ & $\begin{array}{l}8 \\
6 \\
0 \\
1\end{array}$ & $\begin{array}{l}2 \\
2 \\
0 \\
0\end{array}$ & $\begin{array}{l}3 \\
5 \\
0 \\
1\end{array}$ & $\begin{array}{l}1 \\
0 \\
0 \\
0\end{array}$ & $\begin{array}{l}0 \\
0 \\
0 \\
0\end{array}$ & $\begin{array}{l}3 \\
1 \\
3 \\
0\end{array}$ & $\begin{array}{l}2 \\
1 \\
0 \\
0\end{array}$ \\
\hline Total........... & 15 & 4 & 9 & 1 & 0 & 7 & $3: 24$ \\
\hline
\end{tabular}

While the number of visits is too small to permit definite conclusions, mutilation increased them somewhat, probably in consequence of making the nectar easier of access and allowing the odor to escape more readily.

\section{ARTIFICIAL AND PAINTED FLOWERS.}

Crepe-paper corollas.-The flowers of Frasera are gray-green with blackish lines on the surface. In color and form they are not conspicuous, though the upright brushes of hairs above the nectaries help to make them somewhat so. Crepe-paper corollas of red, green, blue, yellow, or white were used to disclose whether bright-colored petals would make them more attractive. The petals of the flowers were removed before the crepe-corollas were added, and the latter made to resemble them as closely as possible. The hairs above the nectaries were left intact, so that the general form of the flower was the same, although no nectar was present. Bombus juxtus stopped at the yellow crepe flowers and put out its proboscis 
at the place where the nectar should be. It felt around for the nectary, went to the next petal and did the same thing, then to a red-crepe flower and repeated this behavior. Apis mellifica avoided the artificial flowers altogether.

Painted corollas.-Flowers were painted blue, yellow, red, green, or purple with water-colors. The following calendars show the flowers visited by the different bees; visits to normal flowers are shown by number alone.

\section{Calendar 1.-Visitors to painted flowers.}

$10^{\mathrm{h}} 45^{\mathrm{m}}$ Apis mellifica, 1 , blue, 1 .

1051 Apis mellifica, yellow, yellow, 2, blue, 1.

1054 Andrena crataegi, 1, red, 3.

1058 Apis mellifica, 1; Bombus juxtus, 1, green.

1100 Apis mellifica, yellow, red, 1.

On the next day the same experiment was repeated with the following results:

$10^{\mathrm{h}} 27^{\mathrm{m}}$ Apis mellifica, blue, 4.

1028 A. mellifica, 6, 1, red, 3.

1030 A. mellifica, blue, 5; Bombus juxtus, 6.

1038 Bombus juxtus, yellow, blue, 1; Apis mellifica, 6 , blue, 1 , blue, 4 .

1041 Apis mellifica, green, red, 1.

1043 Apis mellifica, 3 .

1044 Halictus pulzenus, 3; Apis mellifica, blue, 5 . $11^{\mathrm{h}} 05^{\mathrm{m}}$ Apis mellifica, 2, blue.

1110 A. mellifica, 1, blue, 3, blue; Bombus juxtus, 1, 3, 2 yellow, 1, red, 2, green, 1, blue, green, blue, 1, green, 1 .

1120 Bombus juxtus, 1; Apis mellifica, red, 1.

\section{Calendar 2.}

The results shown by these two calendars are summed up in table 46 . The first section represents the visits during a 35-minute period and the second those made on the next day, but covering a period of 90 minutes; 20 normal flowers and 5 of each color were used.

TABLE 46.-Summary of visits to painted flowers.

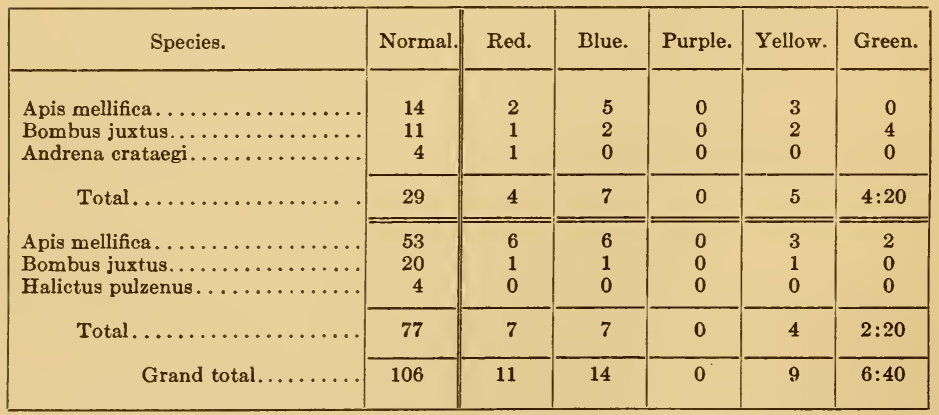

The total number of visits to the painted flowers was less than half that for the normal. The behavior was decidedly different for the two days, the bees making two-thirds as many visits to the painted as to the normal on the first, and only a fourth as many on the second. The most striking 
fact with reference to the selection of colors was that red stood next to blue, while purple, which often occupies this place, was completely ignored.

False corollas.-Blue corollas were made from petals of Campanula, which were cut to shape and glued on the sepals. The nectaries and protecting hairs were left intact, but the remaining portions of the Frasera petals were removed. Fourteen modified and 14 normal flowers were grouped on the stalk under observation. The first Bombus juxtus to visit the blue flowers had great difficulty in finding the nectary, as well as a place on which to stand. The next one landed on the blue petals and thrust out its ligule. At 9 successive flowers it pushed back the petals and tried to find the nectary between these and the sepals. At each flower visited it eventually found the nectar, but not readily, as it was accustomed to standing on the petal and facing the pistil, while with the normal petal cut away from around the nectary the visitor had to stand on a sepal. In three cases it finally straddled the pistil and dipped its ligule into the nectaries. Bombus juxtus showed no objection to the modified flowers, but Apis mellifica merely inspected them without landing.

Calendar 3.-Visits to flowers with Campanula petals.

\begin{tabular}{|c|c|}
\hline $9^{\mathrm{h}} 30^{\mathrm{m}}$ & Bombus juxtus, 1 blue. \\
\hline 942 & Apis mellifica, 4; Bombus juxtus, 3 . \\
\hline 943 & Bombus juxtus, 3 blue. \\
\hline 948 & Bombus juxtus, 4; Apis mellifica, 6 . \\
\hline 951 & $\begin{array}{l}\text { Apis mellifica inspects blue, } 3 \text {, inspects } \\
\text { blue, } 2 \text {. }\end{array}$ \\
\hline Do & Bombus juxtus, 4 blue. \\
\hline & $\begin{array}{l}\text { Bombus juxtus, } 6 \text { blue, } 1 \text {. This bee } \\
\text { had trouble finding the nectar; } \\
\text { it stood on the blue petal and } \\
\text { sipped at the adjoining nectar, } \\
\text { then walked around the pistil, } \\
\text { taking nectar from each of the } \\
\text { others. }\end{array}$ \\
\hline
\end{tabular}

$10^{\mathrm{b}} 05^{\mathrm{m}}$ B. juxtus, 2 blue; Apis mellifica, 1.

1012 B. juxtus, 2, 9, 6 blue, 4; Apis mellifica inspects blue.

1017 B. juxtus, 2, 5 blue.

1023 Apis mellifica, 6, inspects blue, 3 .

1027 A. mellifica; Bombus juxtus, 3.

1038 Bombus juxtus, 5 blue, 5,3 blue, 4 .

1042 B. juxtus, 2,4 blue, 1.

1045 B. juxtus, 5 blue, 2 .

1054 B. juxtus, 6 blue, 1,2 blue.

1058 B. juxtus, 3,2 blue, 6,2 blue; Apis mellifica 1 , inspects blue.

1104 Apis mellifica inspects blue.

1106 A. mellifica 4.

A summary shows that Bombus juxtus visited 60 normal and 56 blue flowers, while Apis mellifica visited 37 normal and inspected 6 blue flowers, but stopped to visit none of them.

\section{ADDITION OF NECTAR AND ODOR.}

Nectar.-Honey-drops were placed where the nectaries would be in normal flowers, and were also added to those with crepe corollas. Bombus juxtus and Apis mellifica were working constantly on the flowers in this location. In normal flowers they went directly to the nectaries, sipping nectar from all four, but the paper flowers were avoided, even though they had honey-drops on them. The honey-drops on normal flowers were visited by 2 A pis mellifica and 1 Bombus juxtus, but they were not sufficiently attractive to bring about a return visit.

\section{SUMMARY.}

Mutilation increased visits somewhat, owing chiefly to the behavior at the flowers with the stamens or the nectary hairs removed. The response of Bombus and Apis to artificial flowers was fairly typical, the one working on them industriously, the other ignoring them entirely. In the case of 
painted flowers, both went readily from these to the normal or the reverse, the ratio for Apis being 27:67 and for Bombus 12:31, or almost identical in value. The false flowers made of Campanula petals were treated like the paper ones, Bombus visiting practically as many of them as the normal and Apis merely inspecting them without landing. Honey received little attention from either, the paper flowers with honey-drops being entirely ignored.

\section{MERTENSIA PRATENSIS.}

\section{NORMAL POLLINATION.}

Behavior.-The flowers are pendant and have a tubular corolla with a bell-shaped expansion below (plate 11). The corolla-tube is only about $15 \mathrm{~mm}$. long, but both Vespa germanica and Bombus juxtus often bore holes at the base of the corolla and steal nectar. They land on the corolla-tube with their hind legs toward the corolla mouth. Juxtus carries yellow pollen on its legs, probably from Fragaria or Rubus strigosus previously visited, but it does not gather pollen at Mertensia. It comes to this for nectar, and upon landing it hangs on to the pendant corolla-tube, pushes out its ligule, and at once takes nectar. Edwardsi enters the flower, resting on the lower lobe of the corolla, and its head is pushed into the tube for the nectar. While the stigma comes in contact with the abdomen and receives the pollen found there, its head brushes against the dehiscing anthers and collects pollen. Osmia pentstemonis is so eager for nectar that it opens buds and pushes its head into the corolla-tube to secure it. Andrena madronitens usually rifles flowers of nectar when a hole has already been made. Otherwise, it pushes its head directly into the tube, bending at the thorax so that the abdomen is outside the corolla-tube and pointing upward. Halictus pulzenus lands at the corolla mouth, eats pollen, and then goes to the base of the corolla to puncture it for nectar. Other species of Halictus push far into the corolla tube, where they scrape pollen so vigorously with the hind legs that it flies out of the opening. While doing this, the head is very near the nectar, probably sipping it, and the hind legs are resting on the anthers. Halictus (Evylaeus) sp. bends over the edge of the corolla-tube, while its head is in contact with the stamens, and touches the stigma as it leaves the flower. Dejeania vexatrix lands and rests its legs on the lower edge of the petals, while it pushes its head into the corolla-tube and sucks

TABLE 47.-Visitors to normal flowers.

\begin{tabular}{|c|c|c|c|c|c|}
\hline \multirow{2}{*}{ Species. } & \multicolumn{2}{|c|}{ Observation. } & \multirow{2}{*}{ Species. } & \multicolumn{2}{|c|}{ Observation } \\
\hline & 1 & 2 & & 1 & 2 \\
\hline Halictus pulzenus. & 49 & 0 & Halictus (Evylaeus) sp.. & 1 & 0 \\
\hline Ceratina sp........ & 6 & 0 & Monumetha albifrons.... & i & 0 \\
\hline Andrena madronitens.... & 4 & 4 & Dejeania vexatrix..... & i & 0 \\
\hline Osmia phaceliae............. & 3 & 0 & Pseudomasaris vespoides..... & 1 & 0 \\
\hline coloradella ............ & 1 & 3 & Vespa germanica........ & 1 & 0 \\
\hline Bombus edwardsi... & 2 & 0 & & & \\
\hline bifarius. . & 0 & 1 & Total. & 70 & 8 \\
\hline
\end{tabular}


nectar. Acmaeops longicornis enters the corolla and eats pollen, which it also collects and deposits as it moves slowly about. Selasphorus platycercus visits and pollinates Mertensia as it flies very rapidly from flower to flower.

In table 47 two lists of visitors are given. The first represents those present during a two-hour period in the midst of the flowering season, the second those for an hour period at the end of the season. In each case 100 flowers were under observation.

During another hour's observation toward the end of the season, 15 individuals of Bombus juxtus made 167 visits to 140 flowers. The only other visitors were two wasps that robbed the flowers.

\section{EXPERIMENTS.}

\section{MUTILATION.}

Changes of corolla.-The petals were split apart, the corolla made irregular, or the upper petals were removed in various flowers. The only visitors during the period of observation were 4 individuals of Halictus sp., which went to the flowers with the front half of the petals removed. They paid no attention to the exposed stamens and nectar, but pierced the small corolla-tube in the usual place, as when robbing normal flowers.

\section{CASTILLEIA MINIATA.}

\section{NORMAL POLLINATION.}

Habit and structure. - The bracts inclosing the flowers are vermilion in color and arranged in a closely massed spike. As the individual flowers mature they elongate rapidly and take an ascending position. The first pair of anthers ripen while the flower is still very small, about one-third the mature size. The lower lip is much suppressed and serves to open the slit when pulled down. When the anthers are about through dehiscing, the style elongates, grows through the tip of the corolla-tube, and then bends downward. To obtain nectar, visitors must push into the slit of the corolla and reach to the base of the tube. In doing this the head comes in contact with the anthers in young flowers, while in the more mature ones the stigma bends downward so that it rubs the back of the visitor (plate 13).

Behavior.-Halictus (Evylaeus) sp. transfers pollen from the under part of its abdomen to the receptive stigma as it lands on the green tip of the corolla. It then turns upside down, opens the corolla, and exposes the stamens. With its front legs it scoops out the pollen and places it on the ventral surface of the abdomen. One individual stood with its head at the lower lip of the corolla and took out pollen with its front feet and mouth-parts. A second landed with the head toward the style and tried to open the corolla slit without success; it then turned toward the other end and scraped up the pollen on the outside with its front legs, placing it on the rear legs and abdomen. After turning again, it repeated its unsuccessful attempt to open the corolla, then turned its head downward, and at the lower lip succeeded in opening the corolla. It went into the latter until only the abdomen tip was visible outside the flower. A third bee of this species landed at the tip of the corolla and ate pollen found on the outside. The slit of this flower was inverted, i. e., faced up. The bee walked to the under 
side to the position in which it was accustomed to work, looked around, and found no slit. It had difficulty in holding on to the under side in the absence of the slit. It then moved to the dorsal side and found a few grains of pollen, but did not seem satisfied. Again it tried the ventral side of the corolla and looked all around for the slit and the lower lip. It went to the dorsal side again, but failed to locate the slit. For a third time it moved to the under side of the corolla, but not finding what it was looking for, flew away to a flower in a normal position and located the slit at once. A fourth one landed with its head toward the style, walked to the end of the latter and over it, the style touching the pollen loads on its legs, and then walked back again. It worked for several seconds with its head and the first pair of legs in the attempt to open the slit, and finally succeeded. A fifth individual alighted on the lower lip and immediately went down into the corolla and sucked nectar. Then it turned around, walked out to the end of the style, which swayed under its weight, and around it. It returned to the end of the corolla and then backed out onto the stamens, where it collected pollen, placing it on the hind legs before flying away.

Selasphorus platycercus landed upon a low tree branch and sucked nectar from the nearby Castilleia flowers, while resting its wings. Normally, it keeps its feet close to the body and sustains itself in the air by rapid wing motion while sucking nectar. In one flower the corolla tube was too small even for its slender bill. The bird found no trouble in thrusting the bill into the corolla, but was unable to pull it out again. It then lowered itself so that the corolla tube became pendant and sipped more nectar, finally freeing itself after further effort.

The normal visitors to Castilleia are not numerous, observations for a period of 2 hours and 20 minutes yielding only the following: Halictus pulzenus 6, Sphecodes sp. 2, Selasphorus platycercus 3.

Merritt (1897:21) states that the flowers of Castilleia affinis have abundant honey, and that pollination is usually effected before the flowers attain their full length. The exserted capitate stigma is struck by the visiting humming-bird, while the bill receives a fresh supply of pollen from the anthers just below in the galea. Longyear (1909:79) has described the structure and pollination of the flower of $C$. linarifolia.

\section{EXPERIMENTS.}

MUTILATION.

Upper lip removed, spike inverted.-The upper lip of the corolla was cut off even with the lower, the bract cut back to the same length, and the cluster then inverted so that the lower lip of the flower was turned up. Halictus pulzenus landed and remained quiet at the lower lip for some time, with its head inside the corolla. It was probably sucking nectar, but there was no movement of the abdomen to indicate this. It then walked out on the filaments to the anthers and ate the pollen that was still there. It next went to the end of the style, arching its body over in such a way that the stigma rubbed against the abdomen.

PAINTED FLOWERS.

Painted bracts.-The bracts of various clusters were painted purple, green, or yellow with water-colors. A humming-bird sucked nectar from 
such flowers in the normal fashion and Halictus pulzenus likewise gave no evidence of being disturbed by the change.

\section{PENTSTEMON GLABER.}

\section{NORMAL POLLINATION.}

Habit and structure.-The plants of this species usually grow in small communities on warm gravel-slides. The stems are about a foot high. several in number and ascending. The flowers are arranged in brilliant secund clusters. This is one of the large-flowered species, with not only a comparatively large corolla mouth, but also a tube of nearly the same size. Hence, its nectar is the most accessible of all the species of this genus in the region. The staminode is broadly spatulate and covered for nearly half its length with long hairs in two rows. The flowers are protandrous, the anthers on the longer filaments maturing first and arching above the entrance to the corolla mouth. The young stigma is straight, extending forward just behind the front pair of anthers. When the stigmas become receptive, the four anthers are nearly through dehiscing and the style elongates, its tip arching sharply downward between the front pair of anthers and almost touching the staminode. In older flowers the staminode coils inward, coming in contact with the stigmas (plates 12 and 17).

Behavior.-Osmia phaceliae works persistently at the tip of the bud, trying to gain entrance to the corolla. When the flower is about ready to bloom, the bee succeedsin opening it. In mature flowers it stands at the corolla entrance and scratches the dorsal surface of its thorax on the anthers, and then goes into the corolla-tube and secures nectar. Osmia pentstemonis lands where the lobes of the lower lip bend downward; it usually comes for pollen and enters the flower to the point where the anthers brush against the thorax. The latter is first well rubbed on the front pair of anthers and then on the rear ones. Its dorsal surface rubs back and forth against the anthers until the stigmas as well as the scopa become white with pollen. It rarely if ever seeks both pollen and nectar, but some individuals pass the anthers and take nectar only. Osmia melanotricha collects pollen in the same manner. ignoring the nectar, in spite of the fact that the corolla-tube is nowhere so narrow that it could not obtain this with its short tongue. Osmia densa is so large that its body fills the entire corolla, the tip of the abdomen reaching to the corolla mouth. It comes for nectar and the under surface of its abdomen rubs the staminode while it is sipping. In more mature flowers with a curved style, the stigma brushes closely against its back. In seeking nectar, Osmia coloradella lands on the lower petals and stands upright, bringing about pollination by contact with its dorsal surface.

Vespa germanica stands at the angle of the corolla mouth and rubs the thorax against the anthers so hard that a scratching sound is heard, while it moves back and forth 5 to 10 times during the process. The hairs on its head touch the anthers and stigma as it sucks nectar. Just before leaving the flower, it stands at the edge of the corolla mouth and with the front legs scrapes off and eats the pollen that has fallen on its head. Andrena madronitens goes into the flowers upside down and collects pollen only, while $A$. vicina enters for nectar alone and remains for a long time at each flower. 
Prosopis varifrons is very small in comparison with the size of the tube, and some individuals go directly to the nectary and depart without touching the anthers. Others work upside down and eat pollen as they hang suspended from the anthers, without making any attempt to find the nectary. Halictus pulzenus lands on the lower lip, then walks to the upper one and stands upside down on the anthers. The tip of its abdomen is just below these while it is removing pollen with its front legs. It also picks up and eats any pollen that has dropped on the lower lip.

Bombus juxtus lands in the normal way, turns upside down, and takes a position such that the anthers rub the thorax as it moves back and forth. It also scrapes pollen from the anthers with its front legs and transfers it to the hind ones. This bee often tries very hard to open buds and turns over and around in the attempt to do this. Bombus bifarius goes into a corollatube, turns upside down, and scrapes pollen from the anthers with its front legs, placing it on the hind ones. Monumetha albifrons lands and goes directly to the nectar. Its thoracic hairs brush the anthers as it sucks nectar and some pollen is collected accidentally, but it makes no effort to gather it. Titusella pronitens works on the anthers only, standing upside down as it collects pollen on its scopa.

TABLE 48.-Visitors to normal flowers.

\begin{tabular}{|c|c|c|c|c|c|c|}
\hline \multirow{2}{*}{ Species. } & \multicolumn{6}{|c|}{ Observations. } \\
\hline & 1 & 2 & 3 & 4 & 5 & 6 \\
\hline Pseudomasaris vespoides. . . . . . . . . . . & 63 & 42 & 1 & 6 & 2 & \\
\hline 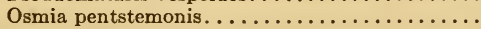 & 48 & 10 & 7 & 34 & 17 & 4 \\
\hline 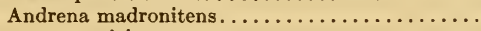 & 3 & 0 & 0 & 0 & 0 & 0 \\
\hline vicina........ & 1 & 0 & 0 & 0 & 0 & 0 \\
\hline prunorum........... & 1 & 0 & 0 & 0 & 0 & 0 \\
\hline Prosopis varifrons. ......... & 3 & 1 & 0 & 4 & 0 & 0 \\
\hline Halictus pulzenus...................... & 0 & 3 & 2 & 0 & 1 & 4 \\
\hline Melissodes fremonti..................... & 0 & 0 & 0 & 1 & 0 & 0 \\
\hline Clisodon terminalis $\ldots \ldots \ldots \ldots \ldots \ldots \ldots \ldots$ & 1 & 0 & 0 & 0 & 0 & 0 \\
\hline Bombus juxtus..................... & 0 & 1 & 0 & 1 & 1 & 1 \\
\hline Total.... & 120 & 57 & 10 & 46 & 21 & 11 \\
\hline \multicolumn{7}{|c|}{ COMPARATIVE VALUES. } \\
\hline Pseudomasaris vespoides........ & 21 & 16 & 2 & 4 & 4 & 1 \\
\hline Osmia penstemonis............... & 16 & 3 & 14 & 22 & 34 & 3 \\
\hline Total. ............... & 40 & 21 & 20 & 31 & 40 & 8 \\
\hline
\end{tabular}

Calendars. - Table 48 contains the results of observations on six different days. There were 150 open flowers under observation on the first date, 172 on the second, and 100 on the others. The records were made at the following times: (1) June 25, 8 to $10 \mathrm{a}$. m.; (2) June $27,1^{\mathrm{b}} 40^{\mathrm{m}}$ to $3^{\mathrm{h}} 18^{\mathrm{m}}$ p. m.; (3) June $28,10^{\mathrm{h}} 35^{\mathrm{m}}$ to $11^{\mathrm{h}} 04^{\mathrm{m}}$ a. m.; (4) July 13,10 to $11^{\mathrm{h}} 30^{\mathrm{m}}$ a. m.; (5) July $24,11^{\mathrm{h}} 06^{\mathrm{m}}$ to $11^{\mathrm{h}} 40^{\mathrm{m}}$ a. m.; (6) July $1,9^{\mathrm{h}} 15^{\mathrm{m}}$ to $10^{\mathrm{h}} 40^{\mathrm{m}}$ a. m. 
While the first part of table 48 contains the actual record of visits, the exact significance of these can be obtained only by reducing them to the same basis as to length of observation and number of flowers. This reveals a variation of five times in the total number of visits per hour. More suggestive, however, is the balance between Pseudomasaris and Osmia; the decrease of the one with the increase of the other indicates the effect of competition for the same species, either actually in progress or wrought out in the seasonal behavior.

Observations 1 and 2 in table 49 give the lists of visitors from 10 to $10^{\mathrm{h}} 40^{\mathrm{m}}$ on two mornings a week apart with 50 flowers concerned in each case. There were 19 flowers in number 3 , which was made on June 27 from $11^{\mathrm{h}} 20^{\mathrm{m}}$ to $12 \mathrm{a}$. m. Observation 4 was taken on July 10 from $9^{\mathrm{h}} 47^{\mathrm{m}}$ to $10^{\mathrm{h}} 26^{\mathrm{m}}$ on 20 flowers. 50 flowers were used for 5 , which was on July 12 from 10 to $11^{\mathrm{h}} 30^{\mathrm{m}}$ a. m. Number 6 was made July 18 from $10^{\mathrm{h}} 4^{\mathrm{m}}$ to $11^{\mathrm{h}} 40^{\mathrm{m}}$ and 50 flowers were in the group under observation. As usual, the first number in each column indicates the visitors, the second the visits made.

TABLE 49.-Visitors and visits to normal flowers.

\begin{tabular}{|c|c|c|c|c|c|c|}
\hline \multirow{2}{*}{ Species. } & \multicolumn{6}{|c|}{ Observation. } \\
\hline & 1 & 2 & 3 & 4 & 5 & 6 \\
\hline Osmia phaceliae. & $26: 65$ & $17: 20$ & $0: 0$ & $0: 0$ & $0: 0$ & $0: 0$ \\
\hline bruneri... & $2: 2$ & $0: 0$ & $4: 9$ & $1: 8$ & $27: 71$ & $17: 20$ \\
\hline Pseudomasaris vespoides. & $6: 18$ & $3: 4$ & $8: 51$ & $5: 113$ & $4: 17$ & $4: 4$ \\
\hline Clisodon terminalis....... & $6: 25$ & $3: 9$ & $0: 0$ & $0: 0$ & $6: 25$ & $1: 8$ \\
\hline Melissodes fremonti.. & $2: 4$ & $0: 0$ & $0: 0$ & $0: 0$ & $2: 2$ & $0: 0$ \\
\hline Andrena vicina....... & $2: 3$ & $2: 5$ & $0: 0$ & $0: 0$ & $0: 0$ & $1: 5$ \\
\hline Prosopis varifrons... & $2: 2$ & $0: 0$ & $1: 1$ & $1: 1$ & $2: 2$ & $0: 0$ \\
\hline elliptica. & $2: 2$ & $0: 0$ & $0: 0$ & $0: 0$ & $0: 0$ & $0: 0$ \\
\hline Apis mellifica.... & $1: 2$ & $0: 0$ & $0: 0$ & $2: 2$ & $1: 2$ & $0: 0$ \\
\hline Bombus juxtus.... & $1: 32$ & $2: 2$ & $2: 2$ & $1: 1$ & $1: 30$ & $4: 4$ \\
\hline Halictus pulzenus. & $0: 0$ & $2: 2$ & $0: 0$ & $1: 1$ & $0: 0$ & $0: 0$ \\
\hline Thanaos martialis... & $0: 0$ & $1: 1$ & $0: 0$ & $0: 0$ & $0: 0$ & $0: 0$ \\
\hline Total. & $50: 155$ & $30: 43$ & $15: 63$ & $11: 126$ & $43: 149$ & $27: 41$ \\
\hline \multicolumn{7}{|c|}{ COMPARATIVE VALUES. } \\
\hline Osmia phaceliae. & $39: 87$ & $25: 30$ & $0: 0$ & $0: 0$ & $0: 0$ & $0: 0$ \\
\hline bruneri... & $3: 3$ & $0: 0$ & $18: 40$ & $4: 36$ & $18: 47$ & $25: 40$ \\
\hline Pseudomasaris vespoides. & $9: 27$ & $4: 6$ & $36: 225$ & $22: 510$ & $3: 12$ & $8: 8$ \\
\hline Clisodon terminalis...... & $9: 37$ & $4: 13$ & $0: 0$ & $0: 0$ & $4: 17$ & $2: 16$ \\
\hline Bombus juxtus..... & $1: 48$ & $3: 3$ & 9:0 & $4: 4$ & $1: 20$ & $8: 8$ \\
\hline Total. & $75: 233$ & $45: 64$ & $66: 282$ & $48: 570$ & $30: 103$ & $40: 61$ \\
\hline
\end{tabular}

The reduction in the number of visitors and the great decrease in the visits made by them shown by the second observation were due entirely to the wind, the other factors being essentially the same. A similar decrease 
in the number of visits particularly occurred toward the end of the flowering period, as shown in columns 5 and 6 . The dominance of the species of Osmia alternates in a striking and suggestive manner. A similar alternation occurs in the case of Pseudomasaris and Clisodon, and the whole summary shows the extent to which the maxima for different species tend to fall at different times. The varying effectiveness of the genera is revealed by a comparison of Bombus and Osmia; 2 individuals of the former visited 30 and 32 flowers respectively on the same days that those of Osmia averaged but 2.5 visits each.

Merritt (1897:19) found that Pentstemon palmeri, P. barbatus labrosus, and $P$. bridgesi all have abundant nectar secreted by the bases of the two upper stamens. The filaments of these curve inward to meet each other and the other pair of filaments, and then rise to the upper wall. The staminode crosses the tube above this junction and lies for the rest of its length on the lower wall, thus excluding short-tongued visitors from the nectaries. Dehiscence of the anthers is not simultaneous, and it is continued for some time, the style lengthening only toward its close. The latter lies against the upper side, but is curved to bring the stigma down to the entrance, but out of the line of falling pollen. $P$. palmeri is constricted in the tube where the 4 filaments meet about $4 \mathrm{~mm}$. above the base, and the sterile filament crosses just above this. The throat and limb are wide enough to admit the largest bees. The anthers lie against the upper wall and the heavily bearded staminode forces insects against them, though one frequent guest, Osmia densa, appears to get nectar without touching them. The vivid scarlet of $P$. barbatus labrosus stamps it as a humming-bird flower. The anthers are exserted but protected by the upper lip, and serve to guard the entrance, as the stigma does later. Honey-bees and Anthophora sometimes collect pollen from the anther-slits. In P. bridgesi honeybees attempted to reach the nectar, but in vain, while the pollen is discharged too slowly to tempt bees.

\section{EXPERIMENTS.}

\section{CHANGE OF POSITION.}

Racemes inverted. - Table 50 gives a summary of the results of an experiment in which 23 racemes in the normal position and 3 inverted ones were under observation.

TABLE 50.-Visitors to normal and inverted racemes.

\begin{tabular}{|c|c|c|c|}
\hline Species. & Normal. & Inverted. & $\begin{array}{c}\text { Relative No. } \\
\text { inverted. }\end{array}$ \\
\hline Osmia phaceliae... & 51 & 9 & 69 \\
\hline $\begin{array}{r}\text { bruneri....... } \\
\text { Bombus juxtus.... }\end{array}$ & $\begin{array}{r}1 \\
28\end{array}$ & $\begin{array}{l}0 \\
3\end{array}$ & 23 \\
\hline Apis mellifica.... & 19 & 4 & 31 \\
\hline Pseudomasaris vespoides.............. & 18 & 1 & 8 \\
\hline Melissodes fremonti. . . . . $\ldots \ldots \ldots \ldots \ldots \ldots$ & 0 & 3 & 23 \\
\hline 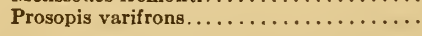 & 1 & 2 & 15 \\
\hline Total.. & 118 & 22 & 169 \\
\hline
\end{tabular}


Since there were about 7 times as many flowers in the normal position as inverted, the latter were relatively about a third more attractive, the ratio being 118:169.

In another series of observations the behavior of certain individuals was noted in detail, especially for Osmia, Vespa, and Apis. The first individual of Osmia phaceliae landed on the new lower lip, then climbed to the upper, went in upside down, and scratched its thorax back and forth on the stamens. At the next inverted flower it landed in the same way, looked around, and backed out. The second went to 4 inverted flowers, where it scraped its thorax against the inverted staminode and then pushed in to where the nectar should be. The third went straight in and tried to find the opening to the nectary, but did not succeed. The fourth individual entered the inverted flowers just as the normal ones and stayed the same length of time, while the fifth attempted to enter 3 inverted flowers without success. The sixth went into 3 inverted flowers and obtained nectar with but little more difficulty than in normal ones, but the seventh entered upside down, hence in its usual position with respect to the flower parts, and consequently worked as usual. Four others then did the same in succession. Osmia phaceliae often went into inverted flowers and scratched its thorax against the staminode, evidently without realizing that it was not touching the anthers. Some of this species at once recognized that the flowers were inverted and landed accordingly. Osmia melanotricha also went into such flowers upside down and secured nectar. It entered and scraped pollen as in normal flowers.

Vespa germanica twice tried unsuccessfully to find nectar in these flowers. It landed, but before entering noticed something different and went to the next flower, which was also inverted, where it behaved in the same way. A second individual entered hesitatingly in such a manner that it was upside down and then took nectar. A third one flew above and examined 6 inverted blossoms but did not land, while a fourth wasp entered the flower, and reached into the nectary, but did not stay long enough to get nectar. It then flew past the mouths of other inverted flowers, but did not land. A pis mellifica went into 2 inverted flowers, but departed at once. It stopped several times at such flowers later, but noticed the difference and flew away. Finally, it came back to a stem bearing inverted flowers and obtained pollen without standing upside down. Another individual stood upright and gathered pollen from the anthers underneath these flowers instead of standing upside down. Clisodon terminalis visited 10 normal flowers and 4 inverted ones, but obtained nectar in but 2 of the latter, while Andrena vicina secured it as usual.

When the two lobes of the lower lip in an inverted flower were cut into separate petals, Osmia melanotricha landed easily, but the stamens and style which projected in front of the flower confused it so that it could not find the entrance to the nectar. Osmia pentstemonis likewise landed on the inverted upper lip, but did not find the anthers and nectar. In the case of inverted flowers with the corolla mouth closed by wilting, it succeeded in opening the corolla with difficulty, but failed to find the anthers and so flew out at once. 
Racemes horizontal. - Bombus juxtus landed at the corner of the mouth, turned sideways, and then sucked nectar in the normal position with relation to the flower. Osmia pentstemonis tried to enter 3 flowers with the corolla tip pointing up, but after landing and starting in, it backed out each time without finding the anthers. The next individual went into these flowers apparently without noticing the change in position. O. melanotricha was puzzled by those that had the corner of the mouth pointing up. It landed by placing the right legs on the lower outside lobe of the upper lip and the left legs on one of the lower, thus straddling the angle of the mouth, which pointed down. The bee then moved back and forth, trying to rub, and some time elapsed before it discovered that the anthers were missing, when it flew away.

\section{MUTILATION.}

Cotton at the corolla mouth.-Absorbent cotton was placed in the corolla mouth, thus obscuring the anthers and blocking the entrance to the nectaries. The amount of cotton used was small and it was placed in position lightly, so that insects could easily push it aside and gain entrance to the flowers if they made any effort to do so. Half of the racemes were left normal and those with obstructed corollas were arranged at various places in the cluster. Two individuals of Osmia pentstemonis hovered at the corolla mouth, but did not try to force an entrance. Osmia phaceliae attempted repeatedly to get in past the corolla mouth but did not succeed, while Vespa germanica noticed the change just as it landed and did not try to enter.

Styles, stamens, and staminode removed.- In flowers thus modified, Bombus juxtus started to enter one, but before turning upside down noticed the difference and went to the next flower. Osmia bruneri flew to the corolla mouth, but noticed the change and did not enter, while $O$. phaceliae reached the point of getting its head in position to suck nectar before flying away. Another individual went into the flower, worked as usual, and left, apparently without having noted the change.

Corolla split.-When the corolla was deeply split between the lips, Andrena vicina visited 3 flowers without noting the difference. The first Halictus pulzenus that arrived walked around the flowers, but without entering. Another landed on the lowest lobe of the corolla and wandered back and forth over the edge. It then walked over the lowest lobe 5 times, trying to find the way into the corolla, and then flew away without entering at all. Some individuals of Bombus juxtus stopped and sucked nectar as if they noted no change, while others flew away at once as if frightened. Clisodon terminalis worked in the normal way, and both Vespa germanica and Pseudomasaris vespoides went directly to the nectary, took nectar, and departed. One Osmia pentstemonis landed and went at once to the nectary, but flew away without sipping. Another alighted on the lower petal and walked around, but since the anthers were projecting in front of the flower and the corolla lips were somewhat reflexed, it failed to find the anthers and the tip of the staminode, which it usually uses as a guide to the nectary. Osmia phaceliae went to 9 flowers, among which was one with the corolla lips separate. This bee advanced to the nectar, but suddenly 
flew away as if aware of the change. Another individual went into 3 of these flowers and inserted its ligule into the nectary, but left without taking nectar (plate 17).

Corolla lips separated and staminode raised.-In flowers of this type, Osmia phaceliae tried repeatedly to get on the lower lip of the corolla. but slipped off. Finally it landed and then bumped into the staminode. After doing this twice it went in at the side and obtained nectar. In normal flowers $O$. melanotricha has the habit of rubbing its back against the anthers, but in these it failed to find them, and went instead to the nectary.

Upper lip removed at the throat.-Osmia bruneri landed as usual and secured nectar, the style touching its back in the process.

Lower lip shortened half.-The lower lip constitutes the landingplatform, and this experiment was devised to find out the response of visitors when it was removed. Clisodon terminalis went into a flower without noting the change; it then flew to a normal flower, and afterward to one with the corolla mouth obstructed with cotton. When it did not succeed in entering this, it flew away. Vespa germanica sipped some nectar, but did not stay the usual time. Osmia phaceliae landed on the staminode, finding difficulty in balancing itself, but finally made its way along the staminode until it obtained a better foothold on the corolla-tube and was able to reach the nectar.

Lower lip removed.-Osmia melanotricha entered these flowers by straddling the staminode and was able to secure nectar.

Lower lip and part of tube removed.-The lobes of the lower lip were removed, as well as the tube for a distance of $4 \mathrm{~mm}$. Osmia bruneri succeeded in landing after repeated attempts by taking hold of the anthers with the front legs, turning upside down, and walking a short distance into the flower; it then turned right side up with the front legs on the remaining part of the lower lip. This gave it a sufficient foothold for gathering nectar.

Lips removed except lower lobe.-The median lobe thus left formed a landing-platform, so that Osmia phaceliae was able to obtain nectar in the usual fashion.

Corolla tube shortened half.-Clisodon terminalis poised in the air before these flowers, but did not land. Melissodes fremonti, Osmia phaceliae, and Andrena vicina entered them and obtained nectar. Some individuals of Pseudomasaris vespoides landed, but could not hang on and suck nectar, as too little of the corolla was left to serve as a platform for them.

Petals separated.-When the petals are separated to the base, they are long, slender, and recurved, since they lack mutual support. The stamens consequently spread out in all directions. Osmia phaceliae went directly to the nectar, instead of first standing at the corolla mouth and rubbing its thorax, as in the normal flower.

Lower lip split into three petals.-Osmia bruneri stood on the middle petal and continued to suck nectar, in spite of the fact that its weight caused this to bend down vertically. It did not come in contact with the anthers and style at all in these flowers. 
A second corolla slipped over the staminode.-This gives the flower an unusual appearance, as though it were doubled, and interferes with entrance to the corolla. Osmia melanotrich $a$ and $O$. pentstemonis landed and tried to enter, but failed.

Comparative relations.-An experiment in which normal, mutilated, and inverted flowers were placed in the same group was devised to determine the effect of competition. Three spikes of each type of mutilation and an inverted one were used with 11 normal spikes for comparison. Table 51 shows the results.

TABLE 51.-Inverted and mutilated flowers.

\begin{tabular}{|c|c|c|c|c|c|}
\hline Species. & Normal. & Inverted. & $\begin{array}{c}\text { Style } \\
\text { removed. }\end{array}$ & $\begin{array}{l}\text { Corolla } \\
\text { removed. }\end{array}$ & $\begin{array}{c}\text { Corolla } \\
\text { 2-divided. }\end{array}$ \\
\hline Osmia phaceliae. & 51 & 9 & 2 & 2 & 2 \\
\hline bruneri... & 1 & 0 & 0 & 0 & 0 \\
\hline Bombus juxtus. & 28 & 3 & 1 & 0 & 0 \\
\hline Apis mellifica... & 19 & 4 & 0 & 1 & 1 \\
\hline Pseudomasaris vespoides... & 18 & 1 & 0 & 0 & 0 \\
\hline Melissodes fremonti....... & 0 & 3 & 0 & 1 & 0 \\
\hline Prosopis varifrons.... & 1 & 2 & 0 & 0 & 0 \\
\hline Total... & 118 & 22 & 3 & 4 & 3 \\
\hline
\end{tabular}

ARTIFICIAL AND PAINTED FLOWERS.

The flowers of this species are bright blue in color and stand out conspicuously against the buff of the gravel-slides on which they grow. The racemes are 6 to 12 inches long and each plant has several, so that the color mass is large and conspicuous from some distance.

Crepe-paper corollas.-The corollas of half the flowers of 4 racemes (25 flowers) were removed and replaced by tubular paper corollas in red, blue, green, white, or yellow. Although the normal flowers were visited as usual during the morning, no insects even attempted to enter the artificial ones.

Corolla painted with water-colors.-Half of the flowers on 5 racemes were painted red, yellow, or green. One Vespa germanica passed by red and yellow to work on the normal ones adjacent. Another Vespa observed went to 2 flowers painted yellow, but passed by the neighboring red ones. Clisodon terminalis entered the normal flowers, but ignored the painted ones. Osmia pentstemonis was less discriminating and different individuals visited the yellow flowers repeatedly. They flew from yellow to normal flowers and then to red ones, etc., as they found the flowers in a convenient order, but they avoided the green ones to some extent. One individual inspected the green, but passed to work at yellow and red, and then returned to the green. It next went to yellow, to red, to a normal flower, and then back to red.

\section{HONEY AND ODOR.}

Sirup added.-Diluted Karo sirup was placed in various positions on the flower. One individual of Osmia pentstemonis entered blossoms with a drop 
of diluted Karo on the anthers without noticing its presence, and went directly to the anthers as usual. Another twice visited a flower with a drop at the right corner of the corolla mouth, and rubbed the anthers without discovering the sirup. Halictus pulzenus entered flowers with Karo on the anthers as it did normal ones, that is, upside down. It walked through one drop, turned around, and sipped it up before flying away. Vespa germanica visited every flower on the stalk except those with the Karo drop. Osmia melanotricha entered a flower with Karo at the right corner of the mouth, straddling the staminode in the usual manner, but before reaching the nectar turned around and came out at the left corner. Bombus juxtus almost entered such a flower, but suddenly flew to the next one.

\section{PENTSTEMON GRACILIS.}

\section{NORMAL POLLINATION.}

Habit and structure.-This is the smallest flowered species of Pentstemon found in the Pike's Peak region. The corolla-tube is narrow and comparatively long, 1 to $2 \mathrm{~cm}$., and the limb extends at right angles to the tubular portion. The racemes are erect, the color varying from delicate pink to pale blue. It grows on warm slopes and blooms earlier than the other species in the locality, and is sought particularly by various species of Osmia.

Behavior-O-Osmia bruneri and pentstemonis push the head into the corolla-tube, the anthers and stigma rubbing against the hairs on the dorsal surface of the thorax as the bee sucks nectar. 0 . phaceliae rests on the lower lip, and then enters the flower in a normal position. Its hind legs hang over the lip and the front pair rest in the corolla-tube. It goes from one flower stalk to the next and enters flowers at about the same level, in preference to visiting all the open flowers on one stalk. The same flower is visited repeatedly by different individuals and sometimes one bee returns several times. Prosopis elliptica enters in the normal position and turns so that it either stands upside down or sidewise within the corolla while collecting pollen. Halictus (Chloralictus) sp. lands on the lower lip in the normal position, and then turns upside down, hanging suspended from the upper lip. The tip of the abdomen touches the outer pair of anthers as it scrapes pollen on to the hind legs.

Bombus juxtus lands, thrusts its head in and places its front legs around the two outer lobes of the lower lip as it sips, the hairs on its head rubbing against the stigma meanwhile. It enters the flower upside down as well as in the normal position. This bee visited pink and blue flowers without discriminating between the two. In one plant with unusually small flowers, it could not get its head into the corolla-tube. However, it inspected these and tried to enter, even splitting the corolla-tube in the attempt. $B$. juxtus did not accumulate the heavy pollen loads exhibited by $B$. bifarius. The latter pushes its ligule into the flowers for nectar, the recurved part of the lobes extending past the thorax to the base of the abdomen. As it sips, the anthers rub against the dorsal side of the thorax. Most of the individuals carried heavy pollen loads on their legs, but they were not col- 
lecting pollen at the time. As B. bifarius leaves the flower, it scrapes pollen from the dorsal surface of its thorax with its front legs and places it on the hind ones. One individual started to suck nectar in the normal position, and then turned upside down and scraped pollen. Another individual behaved in the same manner on one flower and then visited the next flower in the normal way. The third landed, at once turned upside down, and commenced scraping pollen, working in the same fashion on three flowers in succession. The assumption of the normal or inverted position by $B$. bifarius apparently depended on whether it came for nectar or pollen.

Apis mellifica is so large that only its head and half of its thorax ean enter the corolla-tube. These parts are hairy, and after sucking nectar the bee comes out dusted with pollen. Titusella pronitens stands with its hind legs on the lower recurved petals and the front ones on the corollatube, while it pushes out its ligule and takes nectar. Anthophora simillima inspects these flowers, but none land. Systoechus vulgaris has a tongue as long as the corolla-tube, so long indeed that the head usually does not touch the anthers or stigma in sucking nectar. If pollination is accomplished by this fly, it is done by the ligule as it enters and leaves the corolla. Selasphorus platycercus is a very persistent visitor. In the course of a morning's observation the same bird sucked nectar once or twice from every open flower on the whole slope. This species worked so rapidly from flower to flower that even when there were only one or two visitors every flower in the locality was reached.

TABLE 52.-Visitors to normal flowers.

\begin{tabular}{|c|c|c|c|c|c|c|}
\hline \multirow{2}{*}{ Species. } & \multicolumn{6}{|c|}{ Observations. } \\
\hline & 1 & 2 & 3 & 4 & 5 & 6 \\
\hline Osmia bruneri... & 1 & 0 & 15 & 1 & 0 & 1 \\
\hline pentstemonis........... & 7 & 15 & 5 & 12 & 13 & 20 \\
\hline melanotricha. . & 12 & 2 & 0 & 0 & 1 & 6 \\
\hline Bombus morrisoni............. & 0 & 0 & 3 & 0 & 0 & 0 \\
\hline edwardsi................. & 0 & 1 & 0 & 0 & 0 & 0 \\
\hline Colletes sp........... & 7 & 0 & 0 & 0 & 14 & 10 \\
\hline Pseudomasaris vespoides. . & 2 & 1 & 1 & 0 & 0 & 2 \\
\hline Anthophora simillima............ & 0 & 1 & 0 & 0 & 0 & 0 \\
\hline Andronicus sp. $\ldots \ldots \ldots \ldots \ldots \ldots$ & 1 & 1 & 0 & 0 & 0 & 0 \\
\hline Halictus (Lasioglossum) sp........ & 1 & 1 & 0 & 0 & 0 & 1 \\
\hline (Chloralictus) sp........ & 0 & 1 & 0 & 0 & 0 & 0 \\
\hline Monumetha albifrons...$\ldots \ldots \ldots$ & 0 & 3 & 0 & 0 & 0 & 0 \\
\hline Titusella sp.......... & 4 & 1 & 0 & 0 & 0 & 0 \\
\hline Total. & 35 & 27 & 24 & 13 & 28 & 40 \\
\hline Relative total. & 9 & 2 & 24 & 13 & 19 & 26 \\
\hline
\end{tabular}

Calendars.-The normal visitors to this species as observed during an hour period on six different days are grouped in table 52. The first list was made at the entrance to Englemann Canyon on June 13, when the plants were past their prime and 212 open flowers on 30 spikes were in the group. The second list was made on 82 spikes, bearing 526 open flowers, 
found at Long's Ranch on the Ute Trail on June 19. The last four lists were made in the vicinity of the Alpine Laboratory; 50 flowers were under observation on the first two days, June 15 and 16; 85 open flowers on 169 spikes on the third, June 17; and 72 flowers on 175 spikes on the fourth, June 18.

\section{EXPERIMENTS.}

\section{CHANGE OF POSITION.}

Racemes inverted.-Bombus juxtus entered the inverted flowers as if it did not notice the difference. It stayed in the corolla for a shorter time than with normal flowers and probably did not find the nectar. Osmia phaceliae pushed into the corolla, thrust out its ligule, and, not finding the opening to the nectary, went to the next flower. It also failed to obtain nectar here and then visited a third flower that was in the normal position. The hairy thorax rubbed the mature pair of anthers, regardless of whether this was the front or rear pair. It also visited flowers with the pollen practically shed, the deflexed stigma scraping the thorax as the bee sipped nectar. O. pentstemonis ate the pollen that had fallen on the floor of the corolla, as also that on the staminode and anthers. Prosopis varifrons turned upside down in order to gain entrance to the flowers.

Raceme horizontal.-Bombus juxtus turned to take a horizontal position and entered at once in the usual relation to the parts.

\section{MUTILATION.}

Landing-platform removed.-The lower lip of the corolla was removed to destroy the landing-platform and in consequence Bombus and Apis were not able to enter such flowers. Osmia phaceliae did not need the lower lip for support, but straddled the staminode in such a position as to take nectar.

Brush of staminode removed.- There was no difference in the behavior of the visitors to these flowers.

Anthers and recurved portion of upper lip removed.-Halictus pulzenus entered the flowers upside down in the usual way and rubbed the upper surface of its body against the filaments, as if noting no change.

Upper lip partly removed.- This exposes the anthers to full view, but leaves the lower lip unchanged as a landing-platform. It also gives the observer a much better opportunity to view the interior of the flower while the bee is securing nectar. As Clisodon terminalis sucks nectar, it moves its head back and forth once or twice and the upper parts become covered with pollen, which is then removed by the stigma in older flowers. In the case of Bombus juxtus, the first pair of anthers rub the top of the abdomen and the second the top of the thorax, but only when mature. In these flowers the bee did not go to the exposed nectary directly, but always passed under the arch made by the stamens and style, as is its custom in normal flowers. When the style is mature, it is in position to touch the back of the abdomen.

Lobes of upper lip separated.-Osmia phaceliae goes into these flowers apparently without noticing any difference, the whole procedure being 
exposed to view. As the bee sucks nectar, the hairs of the thorax are brushed against the anthers or the stigma.

Petals split to the base.-Osmia phaceliae usually stands on the lower lip, and a single petal suffices to support it when the lobes are split. $O$. bruneri, on the contrary, is so heavy that a single petal will not support its weight, and hence it was unable to obtain a foothold. Bombus juxtus had even greater difficulty in landing because of its weight. It finally found a position in which it was supported by the two outer petals. It then felt around with its ligule until it found the arch under the stamens and went to the nectar in the usual manner. Vespa germanica entered these flowers, but stayed only a very short time, acting as though uneasy because of the unsteady foothold.

\section{PENTSTEMON GLAUCUS. NORMAL POLLINATION.}

Normal behavior.-Thanaos martialis lands on the lower lip of the corolla, where it feels around with its ligule until it finds the nectar, the anthers and stigma rubbing against the hairs of its back meanwhile. Bombus proximus and edwardsi enter the flowers by landing on the lower lip and going directly to the nectary. One bee tried to turn around and enter a half-open bud upside down, but was not successful. Osmia pentstemonis works on the anthers upside down, so that the ventral scopa rubs them. It comes out of the normal flower head first and, as it starts to fly, the back of its head comes in contact with the anthers or stigma tip.

\section{EXPERIMENTS.}

\section{MUTILATED.}

Upper lobes split to base.-Osmia pentstemonis, after trying to land on the projecting staminode, placed its front legs on the outer lobes of the lower lip and the others on the middle lobe and worked easily, reaching the nectar readily. The corolla mouth is so large that the bee does not usually come in contact with the anthers and the stigma. Its scopa rubs the hairs of the staminode, but pollination is not often effected by this visitor. Bombus morrisoni landed on some of the flowers, but flew away at once, while in other cases it inspected them without landing.

Lower lip removed.-Osmia pentstemonis had difficulty in landing, slipping back and forth and its head rubbing the anthers.

Outer lobes of lower lip removed.-Thanaos martialis normally places the front pair of legs on the outer lobes and the weight of its body on the middle one. With the outer lobes removed it finally succeeded in landing by putting its front legs at the edges of the middle lobe and the weight of its body on a bud under the flower.

Staminode removed.-Bombus juxtus landed, then moved from side to side, and backed out. It started into the flower again, stopped, and went directly to the nectar. In normal flowers it follows the staminode to the nectar at once. 
Middle lobe of the lower lip removed.-Bombus morrisoni went into 3 flowers of this type, apparently without noting any change, and $B$. juxtus behaved similarly.

Upper lip removed.-Bombus morrisoni noted no change.

\section{PENTSTEMON SECUNDIFLORUS.}

\section{NORMAL POLLINATION.}

Behavior.-Bombus proximus alights on the lower lip of the corolla and then turns around on to the upper lip, standing upside down while working. It flies from one open flower to another in a cluster and then to the next cluster. Vespa germanica stands on the lower lip and pushes its head far into the flower for nectar. It transfers the pollen collected on the head to its hind legs with the front ones. After visiting many flowers, it rests on the ground before going to others.

Calendar.-A calendar is given below of visits during a 42-minute period to 24 spikes bearing 125 open flowers. Holes had been bored by robbers at the base of the corolla on the upper side of many of these flowers. Pseudomasaris vespoides went to many flowers twice, collecting in the usual way from those previously robbed by some other insect. Anthophora simillima stopped at only 2 or 3 flowers at a time and was easily frightened. Systoechus vulgaris was a persistent visitor, going to as many as 59 flowers in rapid succession.

\section{Calendar 1.-Visits to normal flowers.}

$11^{\mathrm{b}} 06^{\mathrm{m}}$ Anthophora simillima, 1.

1110 Osmia melanotricha, 1; Prosopis wootoni, 1; Pseudomasaris vespoides, 15.

1113 Anthophora, 1.

1115 Anthophora, 2.

1116 Bombus juxtus, 1.

$11^{\mathrm{h}} 20^{\mathrm{m}}$ Osmia, 1.

1121 Bombus, 1; Systoechus vulgaris, 59.

1127 Anthophora, 5; Megachile wootoni, 3.

1130 Anthophora, 1.

1134 Osmia pentstemonis, 4.

1145 Andrena, 1.

1148 Monumetha albifrons, 1.

The variety of visitors to this species is shown by table 53 , column 1 giving the visitors during a 40 -minute period and column 2 during 48 minutes.

TABLE 53.-Visitors to normal flowers.

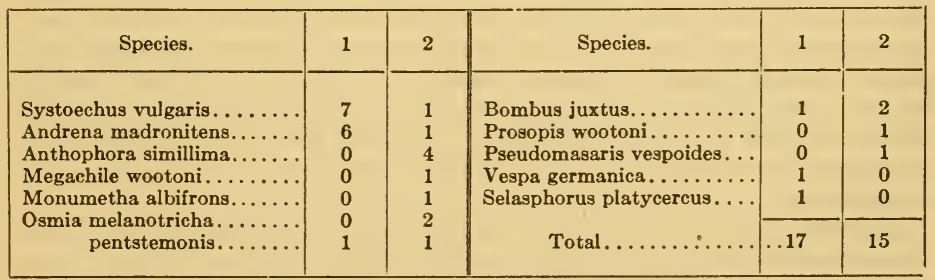

\section{EXPERIMENTS.}

ODOR.

Powders and extract.-Flowers were sprinkled with four kinds of talcum powder. Many individuals of Bombus juxtus landed on such flowers, 
but flew away immediately. Between such visits they stopped at normal flowers and sipped nectar. Halictus pulzenus behaved in a similar manner. Flowers sprinkled with talcum one day lost their odor during the night and the following day were visited normally by both Bombus juxtus and Halictus pulzenus for nectar.

Cotton-wads sprinkled with peppermint or almond essence were placed below the calyxes of 28 mature flowers, and 28 noimal ones were left for comparison, with the results shown in table 54 .

TABLE 54.-Visitors to normal and scented flowers.

\begin{tabular}{|c|c|c|c|}
\hline Species. & $\begin{array}{l}\text { Normal } \\
\text { flowers. }\end{array}$ & $\begin{array}{l}\text { Peppermint } \\
\text { scented. }\end{array}$ & $\begin{array}{l}\text { Almond } \\
\text { scented. }\end{array}$ \\
\hline Bombus juxtus. & $8: 38$ & $5: 5$ & $0: 0$ \\
\hline bifarius. & $6: 27$ & $0: 0$ & $0: 0$ \\
\hline proximus. & $0: 0$ & $1: 1$ & $0: 0$ \\
\hline Prosopis basalis... & $3: 4$ & $0: 0$ & $0: 0$ \\
\hline Andrena madronitens......... & $1: 1$ & $0: 0$ & $0: 0$ \\
\hline Osmia bruneri........ & $1: 1$ & $0: 0$ & $0: 0$ \\
\hline Total. . & $19: 71$ & $6: 6$ & $0: 0$ \\
\hline
\end{tabular}

\section{SUMMARY.}

Practically all visitors solved successfully the problems involved in changes of position, inverted flowers being visited as much as normal ones at least. On the other hand, a light plug of cotton rendered all visits unsuccessful. When the styles, stamens, and staminode were removed in Pentstemon glaber, most of the visitors left without securing nectar, while in the case of $P$. glaucus with the staminode excised, Bombus juxtus entered, backed out, and then went in again to the nectar. When the lips were separated in $P$. glaber, about half the visitors flew away as if disturbed. With the lobes split to the base, landing was modified to a marked degree, but it became impossible only in the case of one or two species. The removal of the upper lip produced no effect, but with the lower lip shortened or removed, the larger bees, such as Bombus and Apis, were unable to land on the small flowers of $P$. gracilis, while Osmia was obliged to make use of the staminode for landing. Splitting the upper lobes to the base in $P$. gracilis caused Bombus to inspect merely or to fly away without securing nectar, while splitting the lower ones in $P$. glaber caused difficulty in alighting even to smaller bees such as Osmia. When the interior of the flower was disarranged by slipping a corolla over the staminode, Osmia failed to find an entrance.

Artificial flowers of $P$. glaber secured no visitors whatever, but natural flowers painted with water-colors were well visited. The addition of honey had practically no effect, while essences greatly reduced the visits to $P$. secundiflorus. Flowers scented with peppermint received one-third as many visitors and one-twelfth as many visits as the normal ones. Those scented with almond were completely shunned, in marked contrast with the behavior in Chamaenerium. 


\section{MONARDA FISTULOSA.}

\section{NORMAL POLLINATION.}

Habit and structure.-This species grows in fairly dense groups on warm half-gravel slides, the numerous stems of each plant making a brilliant mass of color. This attractiveness is due in large measure to the capitate clusters of bright pink-purple flowers. The latter are erect or ascending, and consist of a slender tube with two long lips. The upper lip is subulate and protects the anthers and stigmas when young, while the lower is strapshaped and forms a landing-platform. The anthers are reduced to two, and the nectar is abundant, so that the flowers are visited almost wholly for nectar. Since the flowers bloom late in the summer, they constitute the chief attraction to the butterflies and larger bees at this time (plates 13 and 16$)$.

Behavior.-Bombus juxtus lands on the lower lip of the corolla and sucks nectar through the tube, pollinating the flower as its head rubs against the anthers or stigma. One $B$. juxtus was observed stealing nectar from the base of the corolla-tube, but this was not the normal procedure for the species. B. bifarius, proximus, and pennsylvanicus robbed Monarda through holes at the base of the tube during several seasons in succession, but in 1922 all the individuals observed secured nectar in the normal way. The year previous Bombus proximus was observed puncturing the corollas in one group without making a single normal visit, while in a second group a few yards away it just as regularly obtained nectar in the proper manner. Andrena crataegi is unable to make holes easily in the corolla-tube and consequently takes advantage of those made by other species. Prosopis elliptica stands on the lower lip of the corolla and eats the pollen fallen from the stamens. Halictus pulzenus alights, walks around on the anthers, and then goes down the filaments to the nectary. It gathers pollen from the anthers, but it does not come in contact with the stigma, except by accident.

Erynnis leonardus snowi alights on the corolla lip, unrolls its ligule, and tries to find the nectar. The ligule often slips along the outside of the tube, and even when it starts down the tube it is withdrawn occasionally as if the butterfly were uncertain. The latter does not have very good control of the ligule and its eyes are apparently so placed that it can not see down the tube to guide this by sight. The difficulty experienced by Erynnis is probably due to its landing at the margin of the head. This is indicated by the fact that Argynnis atlantis regularly alights in the center, the angle of the ligule approaching that of the corolla-tube and thus rendering the insertion of the ligule much easier. The control of the larger butterfly is perhaps greater also, as it has little difficulty in inserting the tongue in shortened corollas on the first trial. As a consequence, this species works on Monarda with something of the rapidity of Bombus. Selasphorus platycercus is a frequent visitor to these flowers, where it poises in the air in front of the flower-head and works very rapidly. It pushes its bill into every flower and is a very effective pollinator. The fluttering motion rubs the bill and feathers on the front of the head against the stigma and also collects pollen from the anthers. 
The visitors to normal flowers as observed for an hour on July 5 and 8 are given in table 55. There were 50 Monarda heads used on the first date and 80 on the second.

TABLE 55.-Visitors and visits to normal flowers.

\begin{tabular}{|c|c|c|}
\hline Species. & July 5. & July 8. \\
\hline Erynnis 1. snowi........ & $35: 35$ & $40: 70$ \\
\hline Argynnis atlantis........ & $13: 13$ & $6: 6$ \\
\hline Papilio turnus.......... & $0: 0$ & $1: 1$ \\
\hline Bombus proximus. . . . . . . & $25: 25$ & $0: 0$ \\
\hline juxtus.......... & $16: 16$ & $3: 6$ \\
\hline morrisoni........ & $9: 9$ & $0: 0$ \\
\hline bifarius.......... & $2: 2$ & $0: 0$ \\
\hline Clisodon terminalis. . . . . . & $0: 0$ & $5: 24$ \\
\hline Megachile texana........ & $0: 0$ & $1: 3$ \\
\hline wootoni... & $2: 2$ & $0: 0$ \\
\hline Total... & $102: 102$ & $56: 110$ \\
\hline
\end{tabular}

As would be expected from the form of the flower, more than half the visitors belonged to the two genera of butterflies, Erynnis and Argynnis. While all four species of Bombus are able to secure nectar in the proper way, this is sufficiently difficult so that they often avoid Monarda when Geranium or Aster are near, or they steal the nectar by puncturing the corolla at the base, as was done by all the visiting individuals of Bombus proximus and morrisoni in the present observations.

Meehan (1892:449) found that the anthers of Monarda fistulosa burst as the lips expand and while the stigma is still infolded by the curved portion of the upper lip. By nightfall of the second day the stamens begin to wither, the upper anther-cell shriveling first. In the morning the styles grow out beyond the upper lip and the stigmas separate. Keller (1892:452) observed that the anthers shed their pollen and the stigmas diverge widely in the closed buds, but this was probably a case of cleistogamy due to cold, as the observations were made in November. Longyear's observations (1909: 84) are in accord with those of Meehan, as is the detailed life-history (plate 13, figs. 11 to 16 ).

\section{EXPERIMENTS.}

\section{MUTILATION AND COMPETITION.}

Plan.-In order to permit a wider range of selection, mutilation and competition experiments were combined in the case of Monarda. The flowers of this plant lend themselves with especial readiness to studies of the effect of mutilation, owing to the pronounced zygomorphy. Moreover, the arrangement of the flowers in heads affords an opportunity to vary the kind of competition. Paper disks and paper composite flowers were also employed in some of the series. In order to determine in some degree the effect of place and time, two observers were employed to record the behavior in two separate clumps, distant 1 to 3 meters from each other, and the calendars were repeated a week apart and on two successive days. In consequence of the closing of the flowering period for many plants, the 
number of species and individuals visiting Monarda was large, comprising representatives of the three great groups. For the sake of brevity the clue name alone is given in the calendars, and the species are listed here:

Diptera:
Anthrax nigra
Aristatus montanus
Eristalis arbustorum
Syrphus americanus
Lepidoptera:
Argynnis atlantis
Atrytone taxiles
Chrysophanus sirius
Erynnis leonardus snowi
Gnophaela vermiculata

Diptera:

Eristalis arbustorum

Syrphus americanus

epidoptera :

Argynnis atlantis

Chrysophanus sirius

Gnophaela vermiculata

\author{
Hymenoptera-continued. \\ Clisodon terminalis \\ Colletes sp. \\ Halictus lasioglossum \\ pulzenus \\ Monumetha albifrons \\ Prosopis varifrons
}

In these more complicated calendars it seems desirable to use "normal" for such flowers, the number then indicating the number of flowers visited in each head. Visits were for nectar, unless otherwise indicated, but in the case of Clisodon, p. and n. are employed to denote those for pollen or nectar respectively. When the time is given in seconds or minutes, it applies to all the visits that precede.

First series.-The two records were made on August 8 in two adjacent clumps of Monarda. The installation consisted of approximately the same number of normal and modified heads. Crepe-paper corollas of the size of those of Rubus deliciosus were fastened below Monarda heads, making a composite; there were 2 each of red, yellow, blue, white, and green. The

\section{Calendar 1.}

$8^{\mathrm{h}} 45^{\mathrm{m}}$ Clisodon upper lip off 4 , normal 6 .

847 Argynnis lands and inspects Chamaenerium.

848 Prosopis Chamaenerium 2

849 Clisodon normal 2, inspects Chamaenerium, normal, $1,1,1$, corolla split 1, normal 2, corolla shortened $3 n$, inspects Chamaenerium.

851 Bombus occidentalis Geranium 4, inspects crepe Geranium.

853 Prosopis Chamaenerium 3.

855 Argynnis Chamaenerium 1, normal 2.

858 Bombus bifarius Geranium 5, inspects crepe Geranium.

900 Argynnis inspects most of the objects.

904 Atrytone normal 8, 2, Chamaenerium 2 , normal 3, upper lip off 1 , Chamaenerium 1 , normal 3 , rests on yellow composite, but does not take nectar.

$9^{\text {h }} 07^{\text {m }}$ Atrytone blue composite 1, upper lip off 1.

911 Argynnis corolla shortened 1, normal 1 , upper lip off 1.

913 Argynnis Geranium 2.

914 B. appositus normal 3; Atrytone blue composite 4 , white composite 3 , normal 5, Chamaenerium 3.

917 B. bifarius Geranium 2; Atrytone normal 3 , lower lip off 4 , rests on normal, normal 2.

922 Erynnis rests on yellow composite; Clisodon normal $3 p$, upper lip off $4 \mathrm{n}$.

926 Erynnis normal 2.

\section{Calendar 2.}

$9^{\text {h }} 29^{m}$ Atrytone, blue composite 1, white composite 1 , normal 1.

930 Atrytone, lower lip off 1.

931 Monumetha, normal 2; Syrphus, normal 1.

934 Clisodon, normal 4, lower lip off 2p; inspects both yellow composites and normal 3 .

937 Gnophaela, normal 4, 3; Atrytone, normal 1 , red composite 1 . $9^{\mathrm{h}} 44^{\mathrm{m}}$ B. bifarius, Geranium 2 ; B. occidentalis, Geranium 4, inspects crepe Geranium; Clisodon, normal 7n, 1p; B. appositus, normal 4 , lower lip off 1 .

950 Clisodon, normal 2p, 2 n.

951 B. occidentalis, Geranium 3; Atrytone normal 2, corolla shortened 3 .

952 Atrytone, lower lip off 3 , normal 3.

955 Atrytone, rests on yellow composite. 
corollas were removed from 2 heads and flowers of Chamaenerium substituted. Heads were also mutilated by shortening the corolla to half its length, leaving the stamens intact in one case and removing them in another,

TABLE 56.-Summary of calendars.

Calendar 1.

\begin{tabular}{|c|c|c|c|c|c|c|c|c|c|c|}
\hline Species. & $\begin{array}{l}\text { Norm. } \\
\text { Mon. }\end{array}$ & $\begin{array}{l}\text { Upper } \\
\text { lip } \\
\text { off. }\end{array}$ & $\begin{array}{c}\text { Lower } \\
\text { lip } \\
\text { off. }\end{array}$ & $\begin{array}{l}\text { Cor. } \\
\text { short. }\end{array}$ & $\begin{array}{l}\text { Cor. } \\
\text { short. } \\
\text { stam. }\end{array}$ & $\begin{array}{l}\text { Cor. } \\
\text { split. }\end{array}$ & $\begin{array}{l}\text { Mon. } \\
\text { comp. }\end{array}$ & $\begin{array}{l}\text { Chamae. } \\
\text { head. }\end{array}$ & $\begin{array}{l}\text { Norm. } \\
\text { Ger. }\end{array}$ & $\begin{array}{l}\text { Crepe } \\
\text { Ger. }\end{array}$ \\
\hline Clisodon......... & 16 & 8 & 0 & 3 & 0 & 1 & 0 & $2 \mathrm{i}$ & 0 & 0 \\
\hline Bombus appositus. . & 3 & 0 & 0 & 0 & 0 & 0 & 0 & 0 & 0 & 0 \\
\hline bifarius.... & 0 & 0 & 0 & 0 & 0 & 0 & 0 & 0 & 7 & $1 \mathrm{i}$ \\
\hline occidentalis & 0 & 0 & 0 & 0 & 0 & 0 & 0 & 0 & 4 & $1 \mathrm{i}$ \\
\hline Argynnis........... & 3 & 1 & 0 & 1 & 0 & 0 & 0 & $1: 1 \mathrm{i}$ & 2 & 0 \\
\hline Atrytone........... & 26 & 2 & 4 & 0 & 0 & 0 & $5 b: 3 w$ & 6 & 0 & 0 \\
\hline Erynnis............ & 2 & 0 & 0 & 0 & 0 & 0 & 0 & 0 & 0 & 0 \\
\hline Prosopis....... & 0 & 0 & 0 & 0 & 0 & 0 & 0 & 5 & 0 & 0 \\
\hline Total....... & 50 & 11 & 4 & 4 & 0 & 1 & $5 \mathrm{~b}: 3 \mathrm{w}$ & $12: 3 i$ & 13 & $2 i$ \\
\hline \multicolumn{11}{|c|}{ Calendar 2.} \\
\hline Clisodon... & $16: 3 i$ & 0 & 2 & 0 & 0 & 0 & yi & 0 & 0 & 0 \\
\hline Bombus appositus. . & & 0 & 1 & 0 & 0 & 0 & 0 & 0 & 0 & 0 \\
\hline bifarius.... & 0 & 0 & 0 & 0 & 0 & 0 & 0 & 0 & 2 & 0 \\
\hline occidentalis & 0 & 0 & 0 & 0 & 0 & 0 & 0 & 0 & 7 & $1 \mathrm{i}$ \\
\hline Monumetha....... & 2 & 0 & 0 & 0 & $\mathbf{0}$ & 0 & 0 & 0 & 0 & 0 \\
\hline Syrphus..... & 1 & 0 & 0 & 0 & 0 & 0 & 0 & 0 & 0 & 0 \\
\hline Atrytone. & 7 & 0 & 4 & 3 & 0 & 0 & bwr & 0 & 0 & 0 \\
\hline Gnophaela. & 7 & 0 & 0 & 0 & 0 & 0 & 0 & 0 & 0 & 0 \\
\hline Total. . & $37: 3 \mathrm{i}$ & 0 & 7 & 3 & 0 & 0 & bwr:yi & 0 & 9 & $1 \mathrm{i}$ \\
\hline Grand total.. & $87: 3 \mathrm{i}$ & 11 & 11 & 7 & 0 & 1 & $\begin{array}{l}\text { 6b4w } \\
\mathrm{r}: \mathrm{yi}\end{array}$ & $12: 3 \mathrm{i}$ & 22 & $3 \mathrm{i}$ \\
\hline
\end{tabular}

TABLE 57.-General summary.

\begin{tabular}{|c|c|c|c|c|c|c|c|}
\hline Species. & Normal. & $\begin{array}{l}\text { Muti- } \\
\text { lated. }\end{array}$ & $\begin{array}{l}\text { Other } \\
\text { flowers. }\end{array}$ & Species. & Normal. & $\begin{array}{l}\text { Muti- } \\
\text { lated. }\end{array}$ & $\begin{array}{l}\text { Other } \\
\text { flowers. }\end{array}$ \\
\hline Clisodon.... & 16 & 12 & 0 & Clisodon... & 16 & 2 & 0 \\
\hline Bombus appositus.... & 3 & 0 & 0 & Bombus appositus...... & 4 & 1 & 0 \\
\hline bifarius...... & 0 & 0 & 7 & bifarius........ & 0 & 0 & 2 \\
\hline occidentalis... & 0 & 0 & 4 & occidentalis... & 0 & 0 & 7 \\
\hline Argynnis............ & 3 & 2 & 3 & Monumetha........ & 2 & 0 & 0 \\
\hline Atrytone............ & 26 & 6 & 6 & Syrphus.......... & 1 & 0 & 0 \\
\hline Erynnis.............. & 2 & 0 & 0 & Atrytone......... & 7 & 7 & $\mathbf{0}$ \\
\hline Prosopis...... & 0 & 0 & 5 & Gnophaela... & 7 & 0 & 0 \\
\hline \multirow[t]{2}{*}{ Total.......... } & \multirow[t]{2}{*}{50} & \multirow[t]{2}{*}{20} & \multirow[t]{2}{*}{25} & \multirow{2}{*}{$\begin{array}{l}\text { Total. ......... } \\
\text { Grand total.... }\end{array}$} & 37 & 10 & 9 \\
\hline & & & & & 87 & 30 & 34 \\
\hline
\end{tabular}


by removing the lower lip or the upper one, and by splitting the tube for its entire length, each type being represented by 2 heads. The corollas of 5 Geranium flowers were replaced by crepe-paper ones representing the colors red, yellow, blue, green, and white, and these were grouped with 5 normal flowers.

Second series. -The two records were made on August 14 from $8^{\mathrm{h}} 20^{\mathrm{m}}$ to $10^{\mathrm{h}} 40^{\mathrm{m}}$ a. m., in two clumps of Monarda 3 meters apart. The number of normal and modified Monarda heads and normal Geranium flowers was approximately the same. Five heads were mutilated by shortening the corollas of one to half the normal length, by removing the upper lip in the second, the lower lip in the third, upper lip and stamens in the fourth, and both lips in the fifth. The flowers of one head and half of those of another were replaced by corollas of Gilia aggregata, while flowers of Chamaenerium angustifolium were substituted for half of those of a third head. In addition, two racemes of the latter species were inserted in bottles of water and placed in the clump.

\section{Calendar 1.}

$8^{\mathrm{h}} 20^{\mathrm{m}}$ Erynnis, normal 2

822 Erynnis, normal 1, 7, 2, 1; 70 seconds.

824 Clisodon, normal 7, 1, 4, 14.

826 Erynnis, normal 3, 2; Chamaenerium 2,$9 ; 80$ seconds.

829 Erynnis, normal 3; 60 seconds; Geranium $2,2,1$.

838 Erynnis, normal 3, 1, 4.

840 Erynnis, normal 4, upper lip off 4; Clisodon, normal 1.

842 Bombus juxtus, Chamaenerium 1.

844 Clisodon, normal 4,5 .

845 Erynnis, normal 1, 2, 3, 3, 5 .

848 Bombus morrisoni, normal 8 .

853 Erynnis, normal 2, touched Chamaenerium.

854 Clisodon, normal 1, 5, 3, 2.

855 Erynnis, upper lip off 3.

856 Erynnis, visits Chamaenerium 2, but takes no nectar, upper lip off 2 , normal 2, Jights on leaf.

857 Clisodon, normal 6.

859 Bombus appositus, 3 to 4 flowers each of 3 heads (total normal 10).

900 Erynnis, normal 3, upper lip off 2, leaf.

903 Erynnis, normal 2, 1, 1, 3; 55 seconds; upper lip and stamens off 4, upper lip off $5 ; \mathrm{B}$. juxtus, normal 5 , shortened corolla 3 , both lips off 1, upper lip off 1 .

907 Erynnis, upper lip off $12 ; 2$ minutes; Geranium, normal 2, 3; 30 seconds. Clisodon, normal 8 , $10,12,10$; upper lip off $5 ; 40$ seconds; normal 5,40 seconds.

914 Clisodon, normal 6, 6, inspected Chamaenerium.

915 Erynnis, normal 3, Gilia 1, Monarda, 1 in mixed head, tries Chamaenerium vainly.

919 Erynnis, Chamaenerium 3. $9^{\text {th }} 21^{\text {m }}$ Erynnis, Chamaenerium 2, normal 2.

923 Erynnis, normal 2, 1, Chamaenerium 1.

925 Erynnis, normal 4, Chamaenerium 1, normal 5, Gilia 2.

930 Bombus morrisoni, normal 5; Argynnis, normal 12, 30 seconds: Chamaenerium 6, 20 seconds.

933 Erynnis merely lands on 2 horizontal Monarda.

935 Erynnis, normal 3, Chamaenerium 2, both lips off 2, upper and stamens off 9; Clisodon, normal 10, 12, $3,9,5,6$.

950 Clisodon, normal 2, 3, 2, 4, 6, 7, 3, 5, $8,6,1,3$.

952 Bombus appositus, normal 6, 8, 5, 4, $7,8,5,8,4,4,3,8$; second individual normal 4, 4, upper lip off 12,2 minutes; third individual normal $8,10,12,6$ Monarda flowers of mixed Gilia head, normal 4, 8, Chamaenerium 8; Clisodon most flowers of 3 heads (total normal 25), all flowers of 4 heads, of ten twice (total normal 60), 5 heads some twice (total normal 53), 6 heads (total normal 58).

959 Bombus juxtus, normal $2,1,5,6$, $1,3,6,5$.

1004 Bombus juxtus, normal 6, 2, 1, 1, 1, $2,2,2,8,1,2,10,2$, upper lip and stamens off 6 , then goes vainly to shortened corollas; second individual normal 3,2 .

1009 Bombus appositus, normal 3, 2, 2, 4, $4,1,1,2,2,2,3,9,4,2$.

1013 Bombus appositus, both lips off 4 , upper lip and stamens off 7 , upper lip off 5 , normal $11,6,1$, $4,1,4,5,6 ; 1$ minute. 


\section{Calendar 1-Continued.}

$10^{\mathrm{h}} 15^{\mathrm{m}}$ Bombus appositus, normal 4; Erynnis, | $10^{\mathrm{h}} 32^{\mathrm{m}}$ Clisodon, upper lip and stamens off 6 ,

\section{normal $11 ; 2$ minutes.}

1020 Erynnis, Gilia 2, 7, 2.

1023 Argynnis, normal 1.

1025 Bombus juxtus, normal $3,4$.

1029 Bombus appositus, normal 5, 1, 1; Erynnis, normal 8, Chamaenerium 1, 5 .

1031 Bombus juxtus, normal 2, 6. normal $11,5,5$, Gilia 1 , normal 9 , inspects Chamaenerium, normal 4, 3, 4, 4, 15, inspects Chamaenerium and Gilia, normal 6, 14, thrice (total normal $60)$, shortened corolla 1, upper lip and stamens off 3 vainly, upper lip off 3 , inspected 6 for pollen; 4 minutes for all.

\section{Calendar 2.}

$9^{\mathrm{h}} 10^{\mathrm{m}}$ Bombus juxtus, Chamaenerium 1 in mixed and 3 in pure head; Erynnis, Monarda 2 in mixed Chamaenerium head.

923 Erynnis, lower lip off 1 .

927 Halictus pulzenus, normal 1.

929 Halictus pulzenus, normal 1.

940 Halictus pulzenus, normal 2; Clisodon, upper lip off 3 .

950 Bombus edwardsi, normal 1.

954 Bombus appositus, normal 1.

958 Bombus hunti, 9 normal on 3 heads, Chamaenerium 10 normal on 3 racemes, upper lip off 3 (total 31 , normal flowers on 4 heads. $10^{\mathrm{h}} 00^{\mathrm{m}}$ Bombus appositus, 26 normal flowers on 5 heads; Clisodon, normal 9 ;

B. appositus inspects 2 Geranium.

1020 Bombus juxtus, Geranium 5.

1024 Halictus (Lasioglossum) sp. Geranium 2; Halictus pulzenus, Geranium 1.

1026 Bombus juxtus, normal 13, Geranium 15; P. varifrons, Geranium 1.

1035 Bombus occidentalis, Geranium 14.

1036 Bombus juxtus, Geranium 2.

1041 Bombus morrisoni, Geranium 1.

TABLE 58.-Summary of calendars.

Calendar 1.

\begin{tabular}{|c|c|c|c|c|c|c|c|c|c|c|c|}
\hline Species. & घี่ & 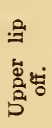 & 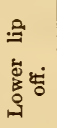 & 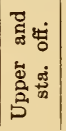 & 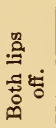 & ठ் & 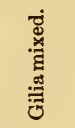 & 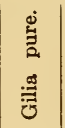 & 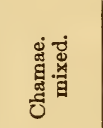 & 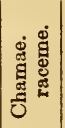 & 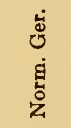 \\
\hline Clisodon.... & $621: 6 \mathrm{i}$ & 8 & 0 & $6: 3 \mathrm{i}$ & 0 & 1 & & $1: 1 \mathrm{i}$ & 0 & $2 \mathrm{i}$ & 0 \\
\hline Bombus appositu & 220 & 17 & 0 & 7 & 4 & 0 & 6 Mon. & 0 & 0 & 8 & 0 \\
\hline juxtus & 94 & 1 & 0 & 40 & 1 & 3 & 0 & 0 & 0 & 1 & 0 \\
\hline morri & 13 & 0 & 0 & 0 & 0 & 0 & 0 & 0 & 0 & 0 & 0 \\
\hline Argynnis. & 13 & 0 & 0 & 0 & 0 & 0 & 0 & 0 & 0 & 6 & 0 \\
\hline Erynnis... & 100 & 28 & 0 & 13 & 2 & 0 & 1 Mon. & 14 & 0 & $26: 3 i$ & 10 \\
\hline Total. & $1,061: 6 i$ & 54 & 0 & $66: 3 \mathrm{i}$ & 7 & 4 & 7 Mon. & $15: 1 \mathrm{i}$ & 0 & $41: 5 \mathrm{i}$ & 10 \\
\hline \multicolumn{12}{|c|}{ Calendar 2.} \\
\hline Clisodon. & 9 & 3 & 0 & 0 & 0 & 0 & 0 & 0 & 0 & 0 & 0 \\
\hline Bombus apl & 27 & 0 & 0 & 0 & 0 & 0 & 0 & 0 & 0 & 0 & $2 \mathrm{i}$ \\
\hline juxt & 13 & 0 & 0 & 0 & 0 & 0 & 0 & 0 & 1 & 3 & 22 \\
\hline ec & 1 & 0 & 0 & 0 & 0 & 0 & 0 & 0 & 0 & 0 & 0 \\
\hline $\mathrm{h}$ & 40 & 3 & 0 & 0 & 0 & 0 & 0 & 0 & 0 & 10 & 0 \\
\hline o & 0 & 0 & 0 & 0 & 0 & 0 & 0 & 0 & 0 & 0 & 14 \\
\hline & 0 & 0 & 0 & 0 & 0 & 0 & 0 & 0 & 0 & 0 & 1 \\
\hline Halictus(Lasioglossum) sp & 0 & 0 & 0 & 0 & 0 & 0 & 0 & 0 & 0 & 0 & 2 \\
\hline 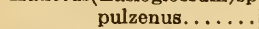 & 4 & 0 & 0 & 0 & 0 & 0 & 0 & 0 & 0 & 0 & 1 \\
\hline Prosopis varifrons & 0 & 0 & 0 & 0 & 0 & 0 & 0 & 0 & 0 & 0 & 1 \\
\hline Erynnis.......... & 0 & 0 & 1 & 0 & 0 & 0 & 0 & 0 & 2 Mon. & 0 & 0 \\
\hline Total.. & 94 & 6 & 1 & 0 & 0 & 0 & 0 & 0 & 1:2 Mon. & 13 & $41: 2 i$ \\
\hline Grand total. & 1,155 & 60 & 1 & $66: 3 \mathrm{i}$ & 7 & 4 & 7 Mon. & $\overline{15: 1 \mathrm{i}}$ & 1:2 Mon. & $54: 5 i$ & $51: 2 i$ \\
\hline
\end{tabular}


MONARDA FISTULOSA.

TABLE 59.-General summary.

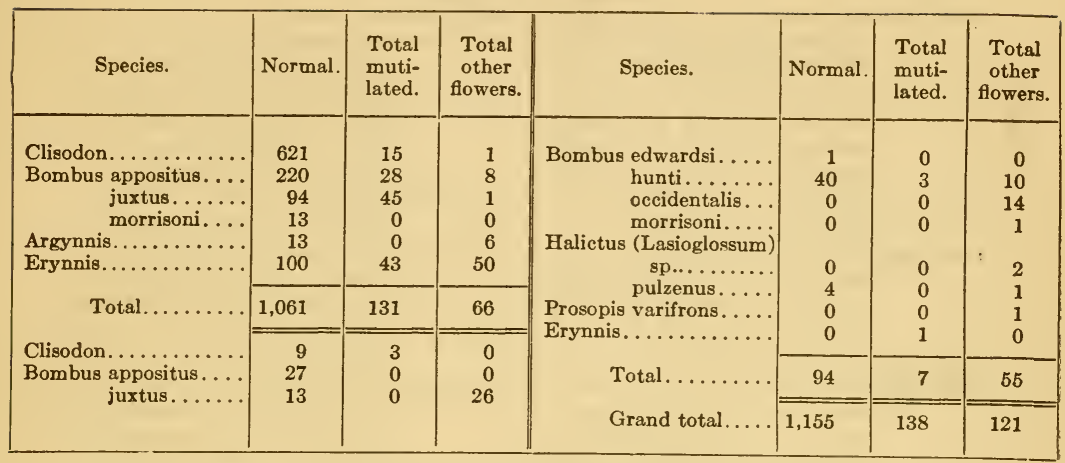

Third series.-The two calendars were recorded on August 15 between 8 and 11 a. m., the labor involved in installation causing the second to begin and end a half hour later than the first. The equipment consisted of 8 normal heads of Monarda, 3 racemes of Chamaenerium and 2 of Gilia, 8 heads of Aster bigelovi, and 8 flowers of Geranium caespitosum. The flowers of one head of Monarda were entirely replaced by those of Chamaenerium and of a second head by those of Gilia. In addition, there was one head of each type of mutilation, viz, upper lip removed, upper lip and stamens removed, lower lip removed, both lips cut off, corolla cut back to half its length in all but the marginal row. Finally, a few paper corollas of Geranium were still in place at some slight distance. The normal and mutilated heads of Monarda and the clusters of Chamaenerium and Gilia were intermingled, while Geranium and Aster were at one edge.

\section{Calendar 1.}

$8^{\mathrm{h}} 18^{\mathrm{m}}$ Clisodon, normal $1,1,1$.

822 Bombus appositus, normal 5, 2, 2, 8, 1; lands on Gilia merely.

830 Bombus juxtus, normal 1; Clisodon, normal $4,2,4$.

832 Argynnis, normal 12, 16, 10, 12, 14, 11; Erynnis, normal 4, 5 .

835 Bombus juxtus, normal 4, Geranium 2; Clisodon, normal 2, 1 .

836 Clisodon, upper lip off 8 ; unable to land on flower with upper lip and stamens off; upper lip off 2 ; normal 3, 8; touches Gilia; Chamaenerium 1.

837 Erynnis, normal 4; B. juxtus, normal 3, 2, 4, 1; Chamaenerium, 2, normal 1; Erynnis, normal 3, upper lip off 4 , both lips off 1 , upper lip and stamens off 1 ; Argynnis merely lights on flower with upper lip off.

844 Erynnis, normal 4, 5, leaf, normal 4, 8; Chamaenerium 1, leaf.

848 Erynnis, normal 2, 3, 1 .

850 Erynnis, upper lip and stamens off 1 , normal 1,3 .

851 Erynnis normal 4, 1, 1, 2. $8^{\mathrm{b}} 53^{\mathrm{m}}$ Clisodon, normal $1,3,7,8,4$; inspects Chamaenerium head, 4 normal flowers of head with middle flowers shortened, upper lip off 3 , inspects Chamaenerium.

855 B. appositus, normal $8,5,8,3,8,3,9$ 1 , rim flowers of shortened head 3 , Chamaenerium 1.

857 Clisodon, normal 6, 1; B. juxtus, normal 2.

900 Erynnis, normal 6, white paper Geranium 1.

901 Erynnis, normal 2, 1.

904 B. juxtus, normal 7, 2, Chamaenerium 5 , probing 1 from the bottom, normal 2, Chamaenerium 2, normal 6, 1, upper lip off 5, normal 3; Erynnis, normal 3, Gilia 1, 1, upper and stamens off 8 , upper off 3 .

907 Erynnis, normal 8, 4, 2 normal and 1 shortened corolla of the same head, upper lip and stamens off 9 .

910 B. appositus, normal $10,9,8,7,4,4$, 3,1 ; Erynnis, shortened corolla 1 , normal 12, Chamaenerium 2; normal 5, rests on Gilia. 


\section{Calendar 1-Continued.}

$9^{\mathrm{b}} 15^{\mathrm{m}}$ Clisodon, normal $2,1,4,1$ p. n., 7p, 7p, 3n; Chamaenerium 2, inspects 2 mutilated heads, normal 4, 6 p, 12 p twice (total 24), $2,4 \mathrm{p}$, shortened $1,5 \mathrm{p}, 2 \mathrm{p}$; B. juxtus, normal 3 , Chamaenerium 1, shortened 7 , inspects flowers with both lips off, normal 1,3,1, Chamaenerium 2, normal 6; Erynnis, upper and stamens off 4 , normal 3 .

922 Clisodon, normal 2 p, upper lip off 1 , normal $3 \mathrm{p}, 1 \mathrm{n}, 10$, inspects heads with upper lip and with this and stamens off, shortened 1 , normal 3 p. $3,4,6,2$.

925 Argynnis, upper off 8.

926 Apis lands on 3 normal heads but is unable to reach nectar; $B$. juxtus, normal 2, Chamaenerium 3, lower lip off 9 , working very rapidly, normal 3 ; B. appositus, normal 1, 3, 2, 5; Erynnis, upper lip off 7 .

930 Erynnis, normal 2.

931 Argynnis, normal 2, upper lip off 6.

933 Clisodon, normal 12, 12, 13, inspects Chamaenerium, shortened 3,15 normal of shortened head, Chamaenerium 3 , normal $1,5,8,2,4$; B. juxtus, normal 10, 11, 14, Chamaenerium 6, Chamaenerium 1 (next stalk), shortened 6, Chamaenerium head 2.

935 Argynnis, normal 3, 1, 14, 2, 4, 4; Erynnis, normal 1, touches Gilia and Chamaenerium, lower lip off 8 , leaf.

939 Erynnis, Chamaenerium 1; normal 1, lower lip off 3 , shortened 2 , Chamaenerium 1.

940 Erynnis, normal 5, 3, 4; Argynnis, normal 5, Chamaenerium 1 .

942 Argynnis, normal 2; Erynnis, shortened 1. upper lip and stamens off 2 , upper lip off 12 , normal 1 , Geranium 1, lower lip off 2, Chamaenerium 2. $9^{\mathrm{h}} 45^{\mathrm{m}}$ Argynnis, normal 4.

947 Argynnis, upper lip off 12, normal 8, tries all buds of young head, lights merely on Chamaenerium

949 B. juxtus, normal 1, 2, 1, 3, Chamaenerium 2; Clisodon normal 12 , 13 ; B. appositus, normal 4,5 , shortened 4, both lips off 3 .

950 Erynnis, Gilia 1, normal 3, 2; Argynnis, normal 2,5 .

952 B. appositus, normal $2,2,1,1,3,3$.

954 B. juxtus, small individual tries 4 heads but can not reach nectar.

955 Erynnis, normal 3, Gilia 1, normal 3, lower lip off 4 , normal 1.

956 B. appositus, normal 10; Erynnis, normal $10,11$.

959 Clisodon, normal 4 p, 2 p, 3 p, 3 p, 2 p, 3 n, 3 n, 2 p, Chamaenerium 1 , lower lip off $2 \mathrm{p}$, normal $2 \mathrm{p}$, upper lip off $2 \mathrm{p}, 1 \mathrm{n}, 1 \mathrm{p}, 3 \mathrm{p}$, $2 \mathrm{p}, 1 \mathrm{n}$.

1001 Erynnis, normal 2; Clisodon, normal $2 \mathrm{p}, 1 \mathrm{p}, 4 \mathrm{p}$, lower lip off $1 \mathrm{p}, 1 \mathrm{n}$, normal $1,5,1 \mathrm{p}, 1 \mathrm{p}$, shortened 1 and 3 normal of the same head, Aster 1, normal 4, 4.

1003 Erynnis, upper lip and stamens off 1 . B. morrisoni, Chamaenerium head 4, shortened 1, normal 2, Gilia 3 ; B. juxtus, normal 2 , upper lip and stamens off 3 , upper lip off 4 , upper lip and stamens off 3,2 normal of shortened head, Chamaenerium 1 , normal 4, 1, 6 .

1006 Clisodon, upper lip and stamens off 3 , shortened 3 , normal $3,4 \mathrm{p}, 3$, lower lip off $3 \mathrm{p}$, normal $4,1 \mathrm{p}$, 7, 2, shortened 1; Argynnis, normal 10, 4, 5; Erynnis, normal $3,4,3$.

1012 Argynnis, normal 14, 10, shortened 3.

1014 Erynnis, 8 normal of shortened head, upper lip off 2; Argynnis, normal 7,6 , shortened 2 , lower lip off 4

\section{Calendar 2.}

$8^{\mathrm{h}} 40^{\mathrm{m}}$ Bombus hunti, Chamaenerium raceme 68, inspects Aster, Chamaenerium raceme 16, Atrytone normal 2, 2, Chamaenerium raceme 2 .

845 Erynnis, normal 2, upper lip off 6.

846 Erynnis, upper lip off 2, normal 3.

850 Erynnis, normal 10.

853 Aristatus, normal 1; B. morrisoni queen, Chamaenerium raceme 2; Erynnis normal 6, Gilia 1, normal 5.

858 Erynnis, normal 3.

859 Eristalis, Chamaenerium raceme 1; Erynnis normal 2. $9^{\text {h }} 00^{\mathrm{m}}$ Erynnis, upper lip off 7.

902 Erynnis, upper lip off 6 .

908 Erynnis, Chamaenerium raceme 1; Clisodon, upper lip off 3 , normal 4. lower lip off 9 , normal 1 , shortened 5, upper lip off 10 , normal 3, 13, inspects mixed Gilia head, normal 6, 4, 5 .

914 Erynnis, normal 1; Clisodon, normal 1; Argynnis inspects 1.

918 Erynnis, normal 1.

921 Erynnis, normal 4, upper lip off 3 ; H. pulzenus, normal 2, Aster 30 florets in 1 head.

926 Erynnis, Chamaenerium raceme 3. 
Calendar 2-Continued.

$9^{\text {b }} 7^{\mathrm{m}}$ Erynnis, normal 6 , upper lip off 5 , normal $8 ; H$. pulzenus, Aster 16 florets in 1 head.

934 Erynnis, upper lip off 10.

937 Erynnis, Aster 12 florets in 1 head, Chamaenerium raceme 20; $\mathrm{Ar}$ gynnis, upper lip off 2.

944 B. juxtus, Chamaenerium raceme 9; Andrena same Chamaenerium raceme 9.

950 Erynnis, normal 2; H. pulzenus, Aster 2 florets 1 head.

953 Argynnis, normal 5, 2, upper lip off 4.

956 B. morrisoni, normal 2.

958 Erynnis, normal 4, 3, leaf; B. bifarius, Chamaenerium raceme 25, Geranium 1 , normal 6,2 .

1005 B. morrisoni, normal 3; Syrphus, normal 4, 8, 5; Erynnis, normal 6 . $10^{\mathrm{h}} 12^{\mathrm{m}}$ Erynnis, upper lip off 2.

1014 Erynnis, normal 4.

1017 Argynnis, normal 4.

1019 Argynnis, upper lip off $2 ;$ B. morrisoni, normal 4, 7.

1020 Clisodon, normal 1.

1022 Argynnis, normal 5.

$1024 \mathrm{H}$. pulzenus 3, Aster florets in 1 head; Erynnis, normal 2.

1026 Erynnis, normal 4, 4, 2, 2; B. hunti, Chamaenerium raceme 6 .

1029 Andrena, Aster 7 florets in 1 head.

1030 Erynnis, normal 2, 3, 4.

1034 Erynnis, normal 6.

1035 Erynnis, normal 3; Colletes, Aster 2 florets in 1 head.

1038 B. hunti, Aster 1; Erynnis, normal $8,3,5,6$; Argynnis, normal 5.

1042 Erynnis, normal 1.

TABLE 60.-Summary of calendars.

Calendar 1.

\begin{tabular}{|c|c|c|c|c|c|c|c|c|c|c|c|c|c|}
\hline 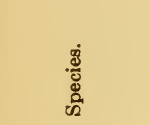 & 吾芒 & 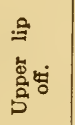 & 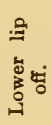 & 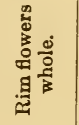 & 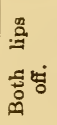 & 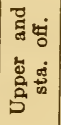 & 苛 & 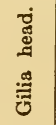 & 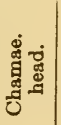 & 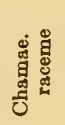 & 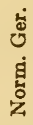 & 造要 & 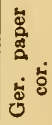 \\
\hline Clisodon & 309 & $24: 1 \mathrm{i}$ & 7 & $\begin{array}{c}22: 1 \mathrm{sh} \\
1 \mathrm{i}\end{array}$ & 0 & $3: 2 \mathrm{i}$ & 16 & 0 & $1 \mathrm{i}$ & $7: 2 \mathrm{i}$ & 0 & 1 & 0 \\
\hline B. appositus.. & 151 & 0 & 0 & & 3 & 0 & 4 & 0 & 0 & 1 & 0 & 0 & 0 \\
\hline juxtus. & 113 & 9 & 9 & 2 & $1 \mathrm{i}$ & 6 & 13 & 0 & 2 & 25 & 2 & 0 & 0 \\
\hline morrison & 2 & 0 & 0 & & 0 & 0 & 1 & 3 & 4 & & 0 & 0 & 0 \\
\hline Erynnis. . & 161 & 28 & 17 & $10: 1 \mathrm{sh}$ & 1 & 26 & 4 & $3: 2 \mathrm{i}$ & 0 & $7: 1 \mathrm{i}$ & 1 & 0 & $1 \mathrm{w}$ \\
\hline Argynnis... & 187 & $26: 1 \mathrm{i}$ & 4 & & 0 & 0 & 5 & 0 & 0 & & 0 & 0 & 0 \\
\hline Total. & 923 & $78: 2 \mathrm{i}$ & 37 & $\begin{array}{c}37: 2 \mathrm{sh} \\
1 \mathrm{i}\end{array}$ & $4: 1 \mathrm{i}$ & $35: 2 \mathrm{i}$ & 43 & $6: 2 \mathrm{i}$ & $6: 1 \mathrm{i}$ & $41: 2 \mathrm{i}$ & 3 & 1 & $1 \mathrm{w}$ \\
\hline
\end{tabular}

Calendar 2.

\begin{tabular}{|c|c|c|c|c|c|c|c|c|c|c|c|c|c|}
\hline Clisodon. & 38 & 13 & 9 & 0 & 0 & 0 & 5 & $1 \mathrm{i}$ & 0 & 0 & 1 & 0 & 0 \\
\hline B. juxtus. & 0 & 0 & 0 & 0 & 0 & 0 & 0 & 0 & 0 & 9 & 0 & 0 & 0 \\
\hline morrisoni... & 16 & 0 & 0 & 0 & 0 & 0 & 0 & 0 & 0 & 2 & 0 & 0 & 0 \\
\hline bifarius.... & 8 & 0 & 0 & 0 & 0 & 0 & 0 & 0 & 0 & 25 & 1 & 0 & 0 \\
\hline hunti. . & 0 & 0 & 0 & 0 & 0 & 0 & 0 & 0 & 0 & 90 & 0 & $1: 1 \mathrm{i}$ & 0 \\
\hline H. pulzenus. . & 2 & 0 & 0 & 0 & 0 & 0 & 0 & 0 & 0 & 0 & 0 & 51 & 0 \\
\hline Andrena...... & 0 & 0 & 0 & 0 & 0 & 0 & 0 & 0 & 0 & 9 & 0 & 7 & 0 \\
\hline Colletes........ & 0 & 0 & 0 & 0 & 0 & 0 & 0 & 0 & 0 & 0 & 0 & 2 & 0 \\
\hline Erynnis........ & 125 & 41 & 0 & 0 & 0 & 0 & 0 & 1 & 0 & 24 & 0 & 12 & 0 \\
\hline Argynnis.... & $21: 1 \mathrm{i}$ & 8 & 0 & 0 & 0 & 0 & 0 & 0 & 0 & 0 & 0 & 0 & 0 \\
\hline Atrytone....... & 4 & 0 & 0 & 0 & 0 & 0 & 0 & 0 & 0 & 2 & 0 & 0 & 0 \\
\hline Syrphus...... & 17 & 0 & 0 & 0 & 0 & 0 & 0 & 0 & 0 & 0 & 0 & 0 & 0 \\
\hline Aristatus...... & 1 & 0 & 0 & 0 & 0 & 0 & 0 & 0 & 0 & 0 & 0 & 0 & 0 \\
\hline Eristalis. . & 0 & 0 & 0 & 0 & 0 & 0 & 0 & 0 & 0 & 1 & 0 & 0 & 0 \\
\hline Total. & $232: 1 \mathrm{i}$ & 62 & 9 & 0 & 0 & 0 & 5 & $1: 1 \mathrm{i}$ & 0 & 162 & 1 & $73: 1 \mathrm{i}$ & 0 \\
\hline Grand total. & $1,155: 1 \mathrm{i}$ & $140: 2 \mathrm{i}$ & 46 & $37: 2 \mathrm{sh}$ & $4: 1 i$ & $35: 2 \mathrm{i}$ & 48 & $7: 3 i$ & $6: 1 \mathrm{i}$ & $203: 2 \mathrm{i}$ & 4 & $74: 1 \mathrm{i}$ & $1 \mathrm{w}$ \\
\hline
\end{tabular}


TABLE 61.-General summary.

\begin{tabular}{|c|c|c|c|c|c|c|c|}
\hline Species & Normal & $\begin{array}{l}\text { Total } \\
\text { muti- } \\
\text { lated. }\end{array}$ & $\begin{array}{l}\text { Total } \\
\text { other } \\
\text { flowers. }\end{array}$ & Species & Normal & $\begin{array}{l}\text { Total } \\
\text { muti- } \\
\text { lated. }\end{array}$ & $\begin{array}{l}\text { Total } \\
\text { other } \\
\text { flowers. }\end{array}$ \\
\hline Clisodon. . & 309 & 51 & 8 & Bombus hunti.. & 0 & 0 & 91 \\
\hline Bombus appositus. & 151 & 7 & 1 & Halictus pulzenus. & 2 & 0 & 51 \\
\hline juxtus. & 113 & 37 & 29 & Andrena... & 0 & 0 & 16 \\
\hline morrisoni.. & 2 & 1 & 7 & Colletes.... & 0 & 0 & 2 \\
\hline Erynnis............ & 161 & 77 & 11 & Erynnis.. & 125 & 41 & $3 \overline{7}$ \\
\hline Argynnis.......... & 187 & 35 & 1 & Argynnis...... & 21 & 8 & 0 \\
\hline Total. & 923 & 208 & 57 & Syrphus...... & $\begin{array}{r}4 \\
17\end{array}$ & 0 & 0 \\
\hline \multirow{3}{*}{ 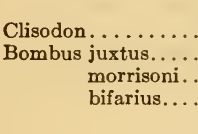 } & \multirow{3}{*}{$\begin{array}{r}38 \\
0 \\
16 \\
8\end{array}$} & \multirow{3}{*}{$\begin{array}{r}27 \\
0 \\
0 \\
0\end{array}$} & \multirow{3}{*}{$\begin{array}{r}0 \\
9 \\
2 \\
26\end{array}$} & Eristalis. . & $\begin{array}{l}1 \\
0\end{array}$ & $\begin{array}{l}0 \\
0\end{array}$ & $\begin{array}{l}0 \\
1\end{array}$ \\
\hline & & & & \multirow{2}{*}{$\begin{array}{r}\text { Total....... } \\
\text { Grand total. }\end{array}$} & 232 & 76 & 237 \\
\hline & & & & & 1,155 & 284 & 294 \\
\hline
\end{tabular}

TABLE 62.-Summary of tables; mutilations and totals.

\begin{tabular}{|c|c|c|c|c|c|c|c|c|}
\hline Species. & $\begin{array}{l}\text { Norm. } \\
\text { Mon. }\end{array}$ & $\begin{array}{l}\text { Upper } \\
\text { lip } \\
\text { off. }\end{array}$ & $\begin{array}{c}\text { Upper } \\
\text { and sta. } \\
\text { off. }\end{array}$ & $\begin{array}{l}\text { Lower } \\
\text { lip } \\
\text { off. }\end{array}$ & $\begin{array}{l}\text { Both } \\
\text { lips } \\
\text { off. }\end{array}$ & $\begin{array}{l}\text { Corolla } \\
\text { short. }\end{array}$ & $\begin{array}{c}\text { Total } \\
\text { mutila- } \\
\text { tions }\end{array}$ & $\begin{array}{c}\text { Total } \\
\text { compet- } \\
\text { itors. }\end{array}$ \\
\hline Clisodon.... & 1,009 & 56 & 18 & 9 & 0 & 25 & 110 & 9 \\
\hline Bombus appositus.. & 405 & 17 & 1 & 7 & 7 & 4 & 36 & 9 \\
\hline bifarius... & 8 & 0 & 0 & 0 & 0 & 1 & 1 & 35 \\
\hline edwardsi... & 1 & 0 & 0 & 0 & 0 & 0 & 0 & 0 \\
\hline hunti....... & 40 & 3 & 0 & 0 & 0 & 0 & 3 & 101 \\
\hline juxtus...... & 220 & 10 & 9 & 46 & 1 & 16 & 82 & 65 \\
\hline occidentalis. & 0 & 0 & 0 & 0 & 0 & 0 & 0 & 25 \\
\hline morrisoni... & 31 & 0 & 0 & 0 & 0 & 1 & 1 & 10 \\
\hline 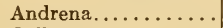 & 0 & 0 & 0 & 0 & 0 & 0 & 0 & 16 \\
\hline Colletes............. & 0 & 0 & 0 & 0 & 0 & 0 & 0 & 2 \\
\hline Halictus (Lasioglos- & & & & & & & & \\
\hline sum) sp.. & 0 & 0 & 0 & 0 & 0 & 0 & 0 & 2 \\
\hline pulzenus... & 6 & 0 & 0 & $\mathbf{0}$ & 0 & 0 & 0 & 52 \\
\hline Monumetha....... & 2 & 0 & 0 & 0 & 0 & 0 & 0 & 0 \\
\hline Prosopis..... & 0 & 0 & 0 & 0 & 0 & 0 & 0 & 6 \\
\hline Erynnis.... & 388 & 97 & 18 & 39 & 3 & 4 & 162 & 98 \\
\hline Argynnis............ & 224 & 35 & 4 & 0 & 0 & 6 & 45 & 10 \\
\hline Atrytone ............ & 37 & 2 & 8 & 0 & 0 & 3 & 13 & 8 \\
\hline Gnophaela.... & 7 & 0 & 0 & 0 & 0 & 0 & 0 & 0 \\
\hline Aristatus..... & 1 & 0 & 0 & 0 & 0 & 0 & 0 & 0 \\
\hline Eristalis...... & 0 & 0 & 0 & 0 & 0 & 0 & 0 & 1 \\
\hline Syrphus...... & 18 & 0 & 0 & 0 & 0 & 0 & 0 & 0 \\
\hline Grand total.. & 2,397 & 220 & 58 & 101 & 11 & 60 & 453 & 449 \\
\hline
\end{tabular}

\section{SUMMARY.}

Although the flowers of Monarda are in heads, they are sufficiently separated that bees and the smaller butterflies must fly from one to another, and are thus fairly comparable with those of other species. However, the detailed consideration of the relation to competing flowers is deferred to the succeeding chapter, the totals only being taken into account here for the sake of a view of the entire experiment. The number of visits to muti- 
lated flowers of Monarda and to flowers of other species was practically the same, though this is doubtless only a coincidence. The normal flowers were about thrice as attractive as these two groups, due in part to habit and in part to the mutilated ones being often less conspicuous and demanding unusual methods of approach.

The number of visits to the various mutilations were determined by four factors, namely, conspicuousness, ease of landing, accessibility, and exposure of nectar. Flowers with the upper lip removed were visited. most, since they were least changed in essential respects, the lower lip constituting the landing-platform and the attractive banner. The removal of the stamens in addition diminished the visits more than half, by affecting landing and eliminating the attraction of pollen, in the case of Clisodon especially. Visits to flowers without the lower lip were about a fourth as numerous as to those with the upper lip removed, due to their being less conspicuous and deprived of the landing-platform. Blossoms with the corolla shortened to half its normal length received an equal number of visits, a puzzling fact when taken in conjunction with the response to flowers with both lips cut off. The difference here is evidently to be explained by the greater readiness with which the odor of the nectar escapes, as well as by the greater ease of access for certain bees. The respective values of the upper lip, stamens, lower lip, and both lips in attraction and guidance are probably well indicated by the number of visits, viz, 220,101,58, and 11 .

While Monarda exhibits a wide range of visitors, only 8 of these are frequent and 5 important, namely, Clisodon, Bombus appositus, B. juxtus, Erynnis, and Argynnis. Clisodon paid nearly as many visits to the normal flowers as the total for the other four species, but it made only 1 visit in 10 to the mutilated flowers in contrast to about 1 to 2 for Erynnis and 1 to 3 for $B$. juxtus. Its large number of visits is to be explained chiefly by the fact that many of them were made for pollen alone and did not involve landing. It is interesting to note that the longer-tongued $B$. appositus visited nearly twice as many normal flowers as juxtus, while it went to only 1 mutilated flower in 9 to 1 in 3 for juxtus. Among the butterflies, Erynnis visited more than a half again as many normal flowers as Argynnis, but four times as many mutilated ones. In spite of its apparently less accurate movements, Erynnis was considerably more successful than $B$. juxtus and several times more so than Argynnis in solving the difficulties presented by the mutilated flowers.

\section{RÉSUMÉ.}

Variation in number of visits. - The special studies of the abundance of visitors and the frequence of visits made with Rubus deliciosus, Geranium caespitosum, Chamaenerium angustifolium, and Pentstemon glaber show that time, place, and conditions produce great fluctuations in the species and numbers of visitors and visits. Considerable differences in these respects between early, mid, and late season would be expected, but almost as great differences may be found between successive days or hours, as, for example, in the case of Chamaenerium, where the number of visitors and visits for two successive hours were $21: 728$ and $4: 204$, or of Rubus deliciosus, for which the figures for Apis were 22:127 and 5:5. The effect of even a 
small distance is shown in the Monarda calendars, which were made in areas but 3 meters apart. The flower group was essentially similar in both, but one calendar gave 1,061 visits to normal Monarda, 131 to the mutilated, and 66 to other species, while the other made simultaneously yielded 94 normal visits, 7 mutilated, and $\mathbf{5 5}$ to competing flowers. Essentially similar results were obtained the next day, the first area giving 923, 208, and 57 visits respectively, and the second 232,76 , and 237 . It is thus evident that a single record or calendar can not give an accurate or comprehensive picture of the numerical relations between a group of flowers and insects. It is evident also that similar variations must be more or less universal, and that they often explain the discrepancies between the results of different investigators.

Changes of position.--In general, the problem of alighting and securing nectar from flowers in inverted, horizontal, vertical, or other changed positions was solved with more or less readiness by the various bees. The general behavior is well illustrated by the response to such changes in Aconitum. Bombus juxtus and B. bifarius readily entered flowers with the hood pointed downward, though this involved using the side petals instead of the lower sepals as a landing platform. When the hood was turned to the side, $B$. juxtus first hovered over such flowers for a moment before landing successfully; in one case it slipped off, but tried again and succeeded. In the case of inverted flowers, some individuals passed over them, others hovered, and still others attempted to light and then flew away as though disturbed by the change. Some landed at the lower sepals, turned around, and entered upside down; at other inverted flowers they behaved in exactly the same way, apparently recognizing the changed position before landing. One individual landed three times at a group of inverted blossoms, tried to reach the nectary without turning upside down, and failed in every case. One $B$. bifarius mastered the problem readily and went to five inverted flowers in succession, turning upside down just after alighting.

A scrutiny of the behavior of various species of bees when confronted by changes in the position of flowers makes it certain that they usually recognize such changes at once. Since these are essentially changes in form, they demonstrate that such insects at least do distinguish forms. Differences in specific behavior are shown by table 50, in which Apis paid relatively almost twice as many visits to inverted as to normal flowers, Pseudomasaris about half as many, and Bombus went about equally to the two. Differences in individual behavior are exemplified by the instances given above for Bombus and they are revealed as well by practically all studies with changes of position. They permit no doubt of the remarkable intelligence of bees in problems that arise in situations with which they are familiar. It seems obvious also that many of the individual variations in response are not the result of differences in intelligence, but rather in what is called temperament in man.

Masking with cotton.-When the center of the flower was masked with cotton, or cotton plugs put over or in the nectaries, the bees were usually unsuccessful in reaching the nectar or pollen. Most of them landed and probed where the nectary or stamens should be, but were unable to reach 
these except where they found an entrance at the edge. After making vain attempts at one or two masked flowers, they usually hovered over others, apparently inspecting them in the light of their previous experience. The presence of a strange substance in the flower changed the relations so greatly and offered an obstancle so foreign to the experience of the bee that it could be solved in but few cases. Their behavior demonstrated the good memory of bees for position in the flower, and their ignoring of the masked flowers, both with and without experience of the cotton as an obstacle, indicated their perception of form.

Mutilation.-In more than three-fourths of the experiments mutilated flowers were visited to a greater extent than the normal ones, the outstanding exception being Monarda, to which the normal visits were five times more numerous than those to the mutilated flowers. The advantage enjoyed by the mutilated flowers as a whole was due chiefly to those in which both stamens and styles were excised or all parts removed but the ovary and nectaries. These changes not only permitted the odor of the nectar to escape more freely, but also made the nectar itself more readily accessible, with the consequence that the bees could work more flowers in the same time, and were also led to return to them sooner. Increasing the attractive surface of the perianth also augmented the number of visits; for example, splitting the hood of Aconitum and turning the sepals back rendered such flowers more than four times as attractive as the normal ones. On the contrary, reducing the expanse of the corolla to a half diminished its attraction from one-half to a tenth in practically all cases and demonstrated its paramount importance even in the case of habituated bees. When both lips were removed in Monarda, the number of visits was reduced to a fortieth of the total for all mutilations, though the difficulty of landing obviously played some part in the result. The removal of the lower lip alone decreased the visits to a fourth of those to flowers with the upper lip alone removed and to a tenth of the total visits to mutilations.

The accounts of the behavior of the different species and of the individuals of each species to the various mutilations naturally reveal similar specific and individual differences to those found for changes of position, and these are shown most clearly for Monarda in table 62 . Clisodon paid only 1 visit in 10 to the mutilated flowers in contrast to about 1 to 2 for Erynnis and 1 to 3 for Bombus juxtus. In contrast to the last, B. morrisoni made 1 visit in 30 to mutilated ones, while $B$. occidentalis went to neither normal nor mutilated Monarda, but only to flowers of competing species. There was no striking difference between the general behavior of Bombus on the one hand and the butterflies on the other. With respect to the type of mutilation most visited, Erynnis, B. appositus, and B. juxtus went to each of the 5 types, Clisodon to 4, and Argynnis to but 3. Of the mutilated flowers Clisodon gave the preference to those with the upper lip removed, as did $B$. appositus; $B$. juxtus preferred those with the upper lip and stamens cut away, while both Erynnis and Argynnis likewise went most often to the flowers without an upper lip, the removal of the latter obviously interfering least with attraction and access.

The evidence of this table, as well as that from the mutilation experiments as a whole, leaves no doubt that these pollinators were able to dis- 
tinguish the form of the different types and to adjust themselves to the changes with a great deal of ingenuity. What is now most needed is quantitative studies of marked individuals, both old and young, to determine differences in normal response and learning power.

Artificial flowers.-The artificial flowers employed were always composite in nature, consisting of crepe-paper corolla or perianth surrounding the natural center of the flower concerned, or more rarely of a natural flower or head with a paper disk below it. These imitations were at once rather more crude than those used by Plateau, Andreae,Wery, and others, in so far as the attractive corolla was concerned and much more natural with respect to stamens and pistil. As a rule, they were visited little or not at all, receiving but 257 visits in comparison with more than 2,000 to normal flowers, and a fifth of these were paid Frasera flowers provided with Campanula petals. In more than a half of the installations the imitations were completely ignored or received but 2 or 3 visits. The best success was obtained with Rosa, in which the relation between visits to natural and artificial flowers was $257: 78$, Rubus deliciosus, where it was $254: 49$, and Geranium, where it was $63: 37$, though the imitations were 5 times more numerous. In the case of the Frasera-Campanula composite, this received 56 visits to 97 for the normal, proving that the use of natural tissues was much less disturbing than that of paper. However, it is certain that the paper corollas did not in themselves actually repel the bees, since Bombus in particular went readily to paper Mentzelias in the early evening before the natural ones were open.

There was the usual wide range in the behavior of the various genera. Halictus pulzenus went indifferently to paper and natural roses, Bombus juxtus visited practically as many Frasera flowers with Campanula petals as normal ones, and $B$. bifarius went to more than half as many artificial as natural Geranium flowers. Osmia was likewise a frequent visitor to the imitations. On the other hand, no honey-bees were seen to visit artificial flowers, though they often were deceived until they came near, as shown by the fact that such flowers were much inspected. Prosopis and Andrena made very few visits to the paper flowers. Very few flies and butterflies were present in these experiments and the visits were too infrequent to indicate their response.

The significant fact is that crude paper composites were visited freely by a few species and that some flowers were frequently visited as imitations and others not at all. While the results as a whole approach more nearly those of Plateau and Forel than those of Andreae, Wery, Giltay, Detto, and others, it is clear that they constitute the explanation of the discrepancy between them, as is shown more fully in the final résumé in Chapter 4 . The artificial flowers were sufficiently plausible to cause a large number of inspections, which signifies that the marks differentiating them could not be distinguished until the insect was within a few centimeters. The case of Mentzelia shows that they did not repel visitors and that the difference is rather one of habit.

Painted flowers.-These were much more successful than artificial flowers in attracting visitors in competition with natural ones, receiving 
420 visits to 845 for the latter. In the case of Aconitum they obtained 154 visits to 116 for the normal flowers, though they were more numerous in the installation. This was likewise true of Chamaenerium, the numbers being 111 to 103 , though on the basis of the number of each the relation is 44:103. The painted flowers of Rubus deliciosus were visited as frequently as the natural ones, while in the case of Frasera the visits were a half and in that in Delphinium a fifth as many as for the natural.

The outstanding visitor to the painted flowers was Bombus juxtus, which made more than half the total number of visits. However, in two experiments it was exceeded by the honey-bee, which made 27 such visits to its 12 . The 27 visits were in contrast to 67 for the normal flowers, thus showing clearly how much more natural the painted flowers appeared than the paper ones, since A pis did not visit a single one of the latter. Of the four colors most employed, blue obtained a distinct preference, the visits being, blue 98 , green 84 , yellow 55 , and red 43 .

The painted flowers were approximately five times as successful in attracting bees as the paper ones. This was due to their identity with the natural ones in everything but color, and indicates that the artificial flowers were distinguished as such chiefly by small differences in form and by the texture, thus demonstrating an acute perception of form and texture by Bombus and Apis especially. The significance of this is further discussed in the final résumé.

Honey and odor.- In the majority of the species where it was employed, honey actually decreased the number of visits, often tenfold, while in a few it had no discernible effect. In no case did it increase the number of visits to natural flowers, and it had practically no effect upon those to artificial ones. The significant result of these experiments was to confirm the evidence of the exceedingly poor sense of smell in bees for honey. Often they would not discover the drop at a distance of a few millimeters and in some cases they even became entangled in it without recognizing it. This may have been due to the odor of the flower itself, but as it was true of all the flowers employed, it suggests that the odor of nectar plays a very small part in the attraction exerted by many species.

The addition of perfumes derived from other flowers or of other odorous substances decreased the total of visits 50 per cent in comparison with normal flowers. Even when honey was also added, a similar relation obtained, though it is certain if the bees had been trained to come for honey on flowers with a certain perfume that the latter would have seemed attractive. With odor, as with color, form, and texture, habit is the controlling factor, and this probably explains why the various perfumes appeared to repel. They disturbed the habitual response of the bee, and this was true whether perfumes, essences, or odors unpleasant to us were employed. The results certainly do not strengthen the rôle of odor in attraction, though undoubtedly it often plays a part in forming the habit of guidance. 


\section{COMPETITION AND CONSTANCY.}

Significance.-Although a number of studies have been made with special reference to the constancy of a particular species of pollinator to one species of flower, there has been little or no experimental work in this field. Competition between different species or genera of plants for the visits of insects has received practically no attention and no experiments are known that bear directly upon this problem. ${ }^{1}$ The early view that the bees in particular are constant or nearly so has been shown to be only partly true by Bulman, Plateau, and others, and the whole subject of habit in pollinators has been found to be much more complex than supposed. The idea that constancy was essential to the effective cross-pollination of a species, as well as to the prevention of hybridization, has necessarily been modified, and is now rather to be regarded as a matter for investigation in terms of habit and efficiency. Moreover, there have been several different concepts of constancy, as discussed later. In the present treatment, the experimental results of competition studies are first considered. This is followed by an account of the composition and weight of the pollen loads of various species, and the chapter is concluded with a résumé of the work of other investigators and a summary of the general principles involved.

\section{COMPETITION.}

General plan.-The methods employed in competition experiments have been discussed in detail in the introduction, the one most used in the present study being that of reciprocal bouquets. The primary objectives have been to throw light on the degree of habit fixation on the one hand and to furnish evidence as to the relative attractiveness of different flowers on the other. At the same time, questions of efficiency have been taken into account. For the most part, the species with regular corollas were used in order that visitors might not be excluded or handicapped by structural features, but a few zygomorphic flowers were employed in order to disclose the effect of structure.

The bouquet method was the one regularly used, though occasionally normal plants grew sufficiently close to each other that equal areas or equal numbers of flowers could be marked off for comparison. In all cases the natural plant was regarded as the standard, and the comparison was made by means of a bouquet placed in its midst or attached to the branches. The bouquet consisted in some cases of a mass of flowers or a group of branches and in others of single flowers or branches put in vials and attached to the stems. In practically all cases where this method was used, the records were made in the normal habitat of the standard plant. The bouquets were arranged among the stems or branches so that the insects would necessarily pass them in moving about. In a few instances the bouquet consisted of several species from other localities, in order to determine the reaction to species probably not seen previously but similar to those regularly visited.

\footnotetext{
${ }^{1}$ Knoll has made an incidental study of competition, which has just come to hand (1922: 215); he employed Pelargonium zonale or Satureia nepeta in competition with Linaria vulgaris in experiments with Macroglossa stellatarum.
} 


\section{RUBUS STRIGOSUS.}

General relations. - The raspberry is especially well fitted to serve as a standard plant for competition studies, owing to its abundant nectar and pollen, the duration of the flowering period, and its exceptional attractiveness for the honey-bee. While it is employed as the standard plant for the majority of the following experiments, certain reciprocal comparisons were made in which it was the bouquet. The various species with which it competed practically all possess open flowers, but exhibit a wide range in the size and color of the latter and the amount of nectar and pollen, as well as in the degree of relationship. With respect to the latter, Rubus deliciosus represents a related species, Rosa a related and Opulaster a more distant genus of the same family, while Geranium, Cleome, and Frasera are successively more remote, exemplifying a progressive decrease in the number of stamens and pistils, as well as striking differences in the nectaries. $\mathrm{Mer}$ tensia and Pentstemon afford more pronounced differences, though these are still within the range of effective competition. The order of treatment in the following pages is essentially that of degree of relationship, though the effect of size, color, and amount of nectar or pollen often obscures the significance of this.

\section{RUBUS STRIGOSUS AND RUBUS DELICIOSUS.}

Comparison.-The flowers of the raspberry are small and inconspicuous and more or less hidden by the leaves, so that they are hardly noticeable, while those of the salmonberry are large and showy and stand out clearly from the leaves on most of the branches. The flowers of both are white, but the corolla of Rubus strigosus is masked to a large degree by the green sepals. The flowers of the latter are often more numerous in an equal area, but they are so scattered as to be quite ineffective. Pollen is naturally abundant in both species, but there is approximately eight times as much in $R$. deliciosus. The petals of the latter are expanded at right angles to the pedicel, leaving the stamens much exposed, while in $R$. strigosus the petals are more or less erect and the pollen consequently less accessible. The nectar of $R$. deliciosus is formed at the base of the stamens and appears as minute drops in a circle; it is produced in the same place in $R$. strigosus, but much more abundantly, sometimes accumulating to an appreciable depth in the stamen-tube (plate 3).

Experiments.-Of the five studies made with these two species, Rubus strigosus was employed as the standard plant in the first three, and $R$. deliciosus in the last two. Two observers recorded the visitors in each case, and the numbers consequently are not only exact, but they are also maximum. In all cases where two figures are separated by a colon, the first indicates the number of insects and the second the number of visits made by them.

The differences arising out of the time-factor are revealed by the totals, the number of visitors being nearly twice as great in the first experiment. During the third period, Rubus deliciosus received several times as many visitors, due in part to the presence of the two species of flies. All told, A pis furnished 171 visitors to the raspberry in contrast to 5 for the salmon- 
berry, while Bombus yielded 7 and 6 respectively. The total number of visiting bees was 212 for the one and 21 for the other, while the flies went to $R$. deliciosus alone to the number of 6 .

TABLE 63.-Competition of Rubus strigosus and R. deliciosus.

Experiment 1, one hour, 10 to 11 a.m., July 6.

Experiment 2, one hour, $9^{\mathrm{h}} 30^{\mathrm{m}}$ to $10^{\mathrm{h}} 30^{\mathrm{m}}$ a.m., July 7 .

Experiment 3, one hour, $10^{\mathrm{h}} 10^{\mathrm{m}}$ to $11^{\mathrm{b}} 10^{\mathrm{m}}$ a.m., July 6 .

\begin{tabular}{|c|c|c|c|c|c|}
\hline Species. & $\begin{array}{l}\text { Plant, R. } \\
\text { strigosus. }\end{array}$ & $\begin{array}{c}\text { Bouquet, } R . \\
\text { deliciosus. }\end{array}$ & Species. & $\begin{array}{l}\text { Plant, R. } \\
\text { strigosus. }\end{array}$ & $\begin{array}{l}\text { Bouquet, } \mathbf{R} \text {. } \\
\text { deliciosus. }\end{array}$ \\
\hline First experiment: & \multirow{8}{*}{$\begin{array}{r}73 \\
5 \\
4 \\
2 \\
2 \\
2\end{array}$} & \multirow{8}{*}{$\begin{array}{l}0 \\
0 \\
1 \\
1 \\
0 \\
0\end{array}$} & \multirow{4}{*}{$\begin{array}{r}\text { Second experiment-Cont.: } \\
\text { Ancistrocerus sp....... } \\
\text { Calliphora vomitoria... } \\
\text { Syrphus americanus.... }\end{array}$} & & \\
\hline Apis mellifica. & & & & 1 & 0 \\
\hline Andrena crataegi. . & & & & 0 & 4 \\
\hline vicina.. & & & & 0 & 2 \\
\hline \multirow{4}{*}{$\begin{array}{r}\text { Bombus juxtus......... } \\
\text { proximus..... } \\
\text { Colletes oromontis..... } \\
\text { Halictus (Lasioglossum) }\end{array}$} & & & \multirow{7}{*}{$\begin{array}{l}\text { Total............ } \\
\text { One juxtus visited a } \\
\text { flower of deliciosus } \\
\text { thrice in succession } \\
\text { and later returned. } \\
\text { Third experiment: } \\
\text { Apis mellifica........... }\end{array}$} & \multirow{3}{*}{62} & \multirow{6}{*}{18} \\
\hline & & & & & \\
\hline & & & & & \\
\hline & & & & & \\
\hline sp............ & \multirow{3}{*}{$\begin{array}{l}1 \\
7 \\
0 \\
7\end{array}$} & \multirow{3}{*}{$\begin{array}{l}0 \\
0 \\
1 \\
0\end{array}$} & & \multirow[b]{3}{*}{48} & \\
\hline $\begin{array}{l}\text { Osmia densa..... } \\
\text { Prosopis basalis. }\end{array}$ & & & & & \\
\hline $\begin{array}{l}\text { varifrons } \\
\text { vanupis }\end{array}$ & & & & & \multirow{5}{*}{$\begin{array}{l}2 \\
2 \\
2 \\
0 \\
0 \\
0\end{array}$} \\
\hline Total. . & \multirow[t]{2}{*}{103} & \multirow{2}{*}{3} & $\begin{array}{l}\text { Bombus juxtus.......... } \\
\text { Halictus pulzenus...... }\end{array}$ & $\begin{array}{l}1 \\
2\end{array}$ & \\
\hline Second experiment: & & & Osmia bruneri..... & 1 & \\
\hline Apis mellifica. . & 50 & 3 & Pseudomasaris vespoides & 2 & \\
\hline Bombus juxtus......... & & 3 & Ancistrocerus sp....... & 2 & \\
\hline Halictus pulzenus. . & 2 & 4 & & & \\
\hline Osmia bruneri.......... & 3 & 2 & Total..... & 56 & 6 \\
\hline Pseudomasaris vespoides & 4 & 0 & & & \\
\hline
\end{tabular}

TABLE 64.-Competition of $R$. deliciosus and strigosus.

\begin{tabular}{|c|c|c|c|c|c|}
\hline \multicolumn{3}{|c|}{$\begin{array}{l}\text { First experiment, one hour, } 9 \text { to } 10 \text { a.m., } \\
\text { June } 27 \text {. }\end{array}$} & \multicolumn{3}{|c|}{$\begin{array}{l}\text { Second experiment, one hour, } 9 \text { to } 10 \text { a.m., } \\
\text { June } 28 \text {. }\end{array}$} \\
\hline Species. & $\begin{array}{l}\text { Plant, } \\
\text { R. deli- } \\
\text { ciosus. }\end{array}$ & $\begin{array}{l}\text { Bouquet, } \\
\text { R. stri- } \\
\text { gosus. }\end{array}$ & Species. & $\begin{array}{l}\text { Plant } \\
\text { R. deli- } \\
\text { ciosus. }\end{array}$ & $\begin{array}{l}\text { Bouquet, } \\
\text { R. stri- } \\
\text { gosus. }\end{array}$ \\
\hline Apis mellifica. . & 4 & 50 & Apis mellifica. . & $12: 53$ & $6: 39$ \\
\hline Andrena crataegi. & 4 & 0 & Bombus juxtus. & $6: 26$ & $3: 26$ \\
\hline vicina... & 1 & 3 & morrisoni. . & $2: 77$ & 0 \\
\hline \multirow{2}{*}{$\begin{array}{r}\text { Bombus bifarius..... } \\
\text { juxtus...... } \\
\text { proximus... }\end{array}$} & 10 & 7 & \multirow{8}{*}{$\begin{array}{l}\text { Syrphus americanus.. } \\
\text { Total......... }\end{array}$} & $1: 1$ & 0 \\
\hline & $\begin{array}{l}0 \\
1\end{array}$ & $\begin{array}{l}1 \\
6\end{array}$ & & \multirow[t]{7}{*}{$21: 157$} & \multirow[t]{7}{*}{$9: 65$} \\
\hline Halictus evylaeus.... & 2 & 0 & & & \\
\hline Monumetha albifrons. & 0 & 1 & & & \\
\hline Osmia bruneri........ & 6 & 10 & & & \\
\hline melanotricha.. & 1 & 0 & & & \\
\hline Melitaea sp......... & 1 & 0 & & & \\
\hline Total... & 30 & 78 & & & \\
\hline
\end{tabular}

In spite of the fact that it was the bouquet and hence out of place, the total number of visitors to $R$. strigosus was 87 in comparison with 51 for $R$. deliciosus. These were all bees, the single fly and butterfly going to 
$R$. deliciosus, as would be expected. Of Apis, 56 individuals went to the raspberry and 16 to the salmonberry, the preponderance of the former being reversed in the second experiment. The number of visitors belonging to Bombus was nearly the same for both experiments, viz, 17 and 19, and they were also more abundant on $R$. strigosus in the first case and on $R$. deliciosus in the second. The ratio of attraction to bees was almost exactly the reverse in the two instances. It is also interesting to note that they made an average of 7 visits to the raspberry to 4 for the salmonberry.

Summary,-Rubus strigosus is evidently much more attractive than $R$. deliciosus, as shown by the fact that the total number of visitors in the five periods was four times greater. However, this was true only for the bees, though they furnished nearly the entire number, since the flies and butterflies went only to the more visible and accessible flowers of the salmonberry. The raspberry held its advantage, whether used as the standard plant or the bouquet, except in the last experiment, where twice as many bees went to $R$. deliciosus. The constancy of the honey-bee was high in the first four cases, viz, 221 visitors for $R$. strigosus to 9 for $R$. deliciosus, but it was in abeyance in the last, in which twice as many went to the latter as to the former. As a whole, Bombus was inconstant, 24 going to the one and 23 to the other, while the numbers for the other bees were too small to be significant, twice as many preferring $R$. strigosus, however.

\section{RUBUS STRIGOSUS AND OPULASTER.}

Comparison.- The flowers of Opulaster are about half as large as those of the raspberry, but this is more than offset by their grouping in corymbs and the position of the latter at or near the ends of the branches. The spreading petals make the corymb very conspicuous, and at a distance it assumes a uniformly white appearance. The nectar is less abundant in Opulaster, but this is somewhat compensated by the large number of flowers in a cluster and by the open nature of the cup. The stamens are also less numerous and the amount of pollen available is considerably less.

Summary.-The total number of visitors was 138 for Rubus and 137 for Opulaster, indicating that they are equally attractive. However, the former was more than twice as attractive to bees, the ratio being 137:64, and overwhelmingly so to honey-bees, 85 of which visited the raspberry and only 1 the nine-bark. Andrena crataegi was the only bee that exhibited a marked preference for Opulaster, the ratio being 46:7. The behavior of the flies was exactly opposite to that of the bees, 73 going to the nine-bark and one to the raspberry. This appears to be readily explained by the fact that the flowers of the former were more easily seen and the nectar more accessible. The smaller amount of nectar and the ease with which it can be obtained make clear the reason why the bees and Apis in particular preferred the raspberry with its less conspicuous flowers and larger store of nectar less accessible to flies.

COMPETITION OF RUBUS WITH FRASERA, CLEOME, ETC.

Comparison.-The flowers of Jamesia americana resemble those of the raspberry, but differ in forming conspicuous white clusters at the ends of branches, and in having much less pollen and much more perfume. Those 
of Cleome serrulata are smaller, pink in color, and grouped in conspicuous spike-like racemes; nectar is abundant, but the odor of the plant is strong. The flowers of Geranium richardsoni are white and occur scattered at the ends of branches; they are somewhat larger than those of the raspberry, but contain much less nectar and pollen. Those of Chamaenerium angustifolium are about the same size, of a deep-pink color and arranged in a brilliant raceme often 2 or 3 feet long; the value in both nectar and pollen closely approaches that of the raspberry. The single flowers of Frasera speciosa are fairly inconspicuous, but the massive spike-like clusters are visible at considerable distances. The nectaries are highly differentiated and the flow abundant. Mertensia sibirica differs from all the others in having tubular flowers of a blue color; they produce a scanty amount of pollen and nectar (plates 3, 7, 8, and 10).

\section{TABLE 65.-Natural and bouquet competition.}

Experiment 1, 11/2 hours, $10^{\mathrm{h}} 30^{\mathrm{m}}$ to 12 a.m., June 27.

Experiment 2, 1 hour, $10^{\mathrm{h}} 10^{\mathrm{m}}$ to $11^{\mathrm{h}} 10^{\mathrm{m}}$, July 6 .

Experiment 3, 1 hour, $8^{\mathrm{h}} 30^{\mathrm{m}}$ to $9^{\mathrm{h}} 30^{\mathrm{m}}$, July 7 .

Experiment 4, 1 hour, $8^{\mathrm{b}} 30^{\mathrm{m}}$ to $9^{\mathrm{h}} 30^{\mathrm{m}}$, July 7 .

Experiment 5, 1 hour, 9 to 10 a.m., July 12 .

\begin{tabular}{|c|c|c|c|c|c|}
\hline Species. & $\begin{array}{l}\text { Plant, R. } \\
\text { strigosus. }\end{array}$ & $\begin{array}{c}\text { Plant, } \\
\text { Opulaster. }\end{array}$ & Species. & $\begin{array}{l}\text { Plant, R. } \\
\text { strigosus. }\end{array}$ & $\begin{array}{c}\text { Plant, } \\
\text { Opulaster. }\end{array}$ \\
\hline First experiment: & & & \multirow{8}{*}{$\begin{array}{l}\text { Third experiment- } \\
\text { Continued: } \\
\text { Pseudomasaris } \\
\text { vespoides........ } \\
\text { Diptera.......... } \\
\text { Lepidoptera ...... } \\
\quad \text { Total........ }\end{array}$} & & \\
\hline Apis mellifica..... & 25 & 0 & & & \\
\hline $\begin{array}{r}\text { Andrena crataegi.. } \\
\text { madroni- }\end{array}$ & 0 & 20 & & 1 & 0 \\
\hline & 0 & 1 & & 0 & 41 \\
\hline \multirow{5}{*}{$\begin{array}{r}\text { vicina.... } \\
\text { Bombus bifarius... } \\
\text { proximus. } \\
\text { Osmia bruneri..... } \\
\text { Prosopis elliptica.. } \\
\text { Diptera........... }\end{array}$} & 2 & 2 & & 0 & 1 \\
\hline & $\begin{array}{l}6 \\
2\end{array}$ & $\begin{array}{l}0 \\
0\end{array}$ & & 42 & 50 \\
\hline & 4 & 0 & & & \\
\hline & 3 & 0 & & Bouquet, & Plant, \\
\hline & 0 & 7 & \multirow{7}{*}{\begin{tabular}{|} 
Fourth experiment: \\
Apis mellifica..... \\
Andrena crataegi.. \\
Halictus pulzenus.. \\
Monumetha albi- \\
frons............. \\
Pseudomasaris ves- \\
poides............ \\
Diptera...............
\end{tabular}} & R. strigosus. & Opulaster \\
\hline \multirow[t]{2}{*}{ Total........ } & 42 & 30 & & 4 & 1 \\
\hline & Bouquet, & Plant, & & 0 & 3 \\
\hline \multirow{5}{*}{$\begin{array}{c}\text { Second experiment: } \\
\text { Andrena crataegi.. } \\
\text { Halictus pulzenus.. } \\
\text { Osmia bruneri..... } \\
\text { Diptera......... }\end{array}$} & R. strigosus. & Opulaster. & & 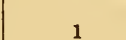 & 0 \\
\hline & 6 & 18 & & & \\
\hline & 1 & 1 & & 0 & 1 \\
\hline & 1 & 0 & & 0 & 9 \\
\hline & 1 & 16 & \multirow{2}{*}{ Total........ } & 6 & 17 \\
\hline Total. . & 9 & 35 & & $P$ & Opulaster \\
\hline \multirow{9}{*}{$\begin{array}{r}\text { Third experiment: } \\
\text { Apis mellifica...... } \\
\text { Andrena crataegi.. } \\
\text { Bombus juxtus.... } \\
\text { Megachile wootoni. } \\
\text { Osmia bruneri..... } \\
\text { densa..... }\end{array}$} & \multirow{2}{*}{$\begin{array}{l}\text { Plant, R. } \\
\text { strigosus. }\end{array}$} & \multirow{2}{*}{$\begin{array}{l}\text { Bouquet, } \\
\text { Opulaster. }\end{array}$} & \multirow{9}{*}{$\begin{array}{r}\text { Fifth experiment: } \\
\text { Apis mellifica..... } \\
\text { Andrena crataegi.. } \\
\text { Bombus bifarius... } \\
\text { juxtus.... } \\
\text { proximus.. } \\
\text { Osmis densa...... } \\
\text { Prosopis varifrons. } \\
\text { Total........ }\end{array}$} & strigosus. & in vials. \\
\hline & & & & 20 & 0 \\
\hline & 36 & 0 & & 0 & 1 \\
\hline & 0 & 5 & & 14 & 0 \\
\hline & 3 & 0 & & 1 & 0 \\
\hline & 0 & 1 & & 0 & 2 \\
\hline & 0 & 2 & & 3 & 1 \\
\hline & & 0 & & 1 & 1 \\
\hline & & & & 39 & 5 \\
\hline
\end{tabular}


Experiments.-In the first case all three plants were rooted in position, affording a test of natural competition. In the others, Rubus strigosus was the standard and its competitors were arranged in bouquets or vials.

TABLE 66.-Rubus and Frasera, Cleome, etc.

\begin{tabular}{|c|c|c|c|c|c|c|}
\hline \multicolumn{4}{|c|}{ Expt. 1, 1 hour, 11 to 12 a.m., June 23.} & \multicolumn{3}{|c|}{ Expt. 2, 2 hours, 10 to 12 a.m., July 13.} \\
\hline Species. & $\begin{array}{l}\text { Plant, R. } \\
\text { strigosus. }\end{array}$ & $\begin{array}{l}\text { Plant, M. } \\
\text { sibirica. }\end{array}$ & $\begin{array}{l}\text { Plant, J. } \\
\text { americana. }\end{array}$ & Species. & $\begin{array}{l}\text { Plant, R. } \\
\text { strigosus. }\end{array}$ & $\begin{array}{l}\text { Geranium } \\
\text { in vials. }\end{array}$ \\
\hline \multirow{4}{*}{$\begin{array}{l}\text { Bombus } \\
\text { bifarius... } \\
\text { Colletes } \\
\text { oromontis. } \\
\text { Diptera...... } \\
\text { Total..... }\end{array}$} & $\begin{array}{l}5 \\
0 \\
3\end{array}$ & $\begin{array}{l}1 \\
1 \\
4\end{array}$ & $\begin{array}{l}1 \\
0 \\
1\end{array}$ & \multirow{4}{*}{ 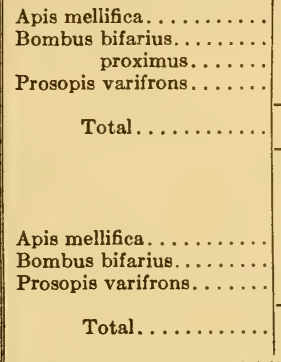 } & $\begin{array}{r}15 \\
14 \\
2 \\
5\end{array}$ & $\begin{array}{l}0 \\
0 \\
0 \\
0\end{array}$ \\
\hline & \multirow[t]{3}{*}{8} & \multirow[t]{3}{*}{6} & \multirow[t]{3}{*}{2} & & 36 & 0 \\
\hline & & & & & $\begin{array}{r}26 \\
37 \\
1 \\
\end{array}$ & $\begin{array}{c}\text { Chamae- } \\
\text { nerium in } \\
\text { vials. } \\
0 \\
0 \\
0 \\
\end{array}$ \\
\hline & & & & & 64 & 0 \\
\hline \multicolumn{4}{|c|}{ Expt. 3, 1 hour, 10 to 11 a.m., July 14 . } & \multicolumn{3}{|c|}{ Expt. 4, 1 hour, 11 a. m., to 12 m., July 18.} \\
\hline \multicolumn{2}{|c|}{ Species. } & $\begin{array}{l}\text { Plant, R. } \\
\text { strigosus. }\end{array}$ & $\begin{array}{c}\text { Bouquet, F. } \\
\text { speciosa. }\end{array}$ & Species. & $\begin{array}{l}\text { Plant, R. } \\
\text { strigosus. }\end{array}$ & $\begin{array}{c}\text { Bouquet, C. } \\
\text { serrulata. }\end{array}$ \\
\hline \multirow{10}{*}{\multicolumn{2}{|c|}{ 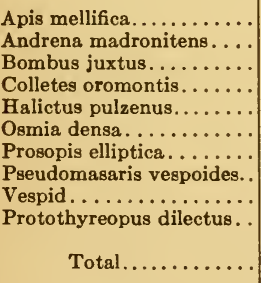 }} & $57: 62$ & $37: 62$ & Apis mellifica & 22 & 1 \\
\hline & & $1: 1$ & $0: 0$ & Bombus juxtus.. & 2 & 0 \\
\hline & & $0: 0$ & $2: 5$ & Halictus pulzenus. & 0 & 1 \\
\hline & & $\begin{array}{l}0: 0 \\
1: 1\end{array}$ & $\begin{array}{l}1: 2 \\
3: 3\end{array}$ & (Lasioglossum) & & 0 \\
\hline & & $\begin{array}{l}1: 1 \\
8: 9\end{array}$ & $\begin{array}{l}3: 3 \\
0: 0\end{array}$ & $\begin{array}{r}\text { sp............... } \\
\text { Megachile wootoni...... }\end{array}$ & 0 & 1 \\
\hline & & $11: 16$ & $2: 2$ & Osmia bruneri............. & 3 & 0 \\
\hline & & $6: 6$ & $1: 1$ & melanotricha........ & 4 & 0 \\
\hline & & $2: 2$ & $4: 4$ & Prosopis elliptica........ & 2 & 0 \\
\hline & & $1: 1$ & $1: 1$ & Pseudomasaris vespoides.. & 3 & 0 \\
\hline & & $87: 98$ & $51: 80$ & Total & 37 & 3 \\
\hline
\end{tabular}

Summary. - The total number of visitors to Rubus was 232 , in contrast with 62 to all its competitors, though the raspberry was undoubtedly favored by being the plant in each case. With the flowers in vials, Geranium and Chamaenerium exerted no competition whatever and that of Cleome was negligible. Mertensia approached Rubus in attractiveness and Frasera apparently exceeded it, as suggested by the relatively greater number of visits per insect. This was especially true of the honey-bee.

\section{RUBUS STRIGOSUS AND TWO OR MORE COMPETITORS.}

Comparison.-The flowers of the two species of Pentstemon are much larger than those of the raspberry, but they contain much less pollen and 
nectar. P. secundiflorus possesses a pink-purple corolla with a wide throat, while that of $P$. barbatus is a flaming scarlet with a narrow throat and hence excludes the larger bees. The flowers of Scrophularia nodosa are small and of a dull mottled color, but these disadvantages are offset by the abundant nectar. Those of Aquilegia coerulea are large and showy, the sky-blue color making them exceedingly conspicuous; they contain much pollen and nectar, but the latter is unavailable to many of the visitors. The deep-blue flowers of Mertensia alpina are relatively small, with a narrow throat, and are borne in small clusters. However, they possess a delightful fragrance, which is indicated by their local name, "forget-me-nots." Table 67 contains the record for 1 hour 15 minutes, from $10^{\mathrm{h}} 45^{\mathrm{m}} \mathrm{a} . \mathrm{m}$. to $12 \mathrm{~m}$. on July 4 , and table 68 for an hour, $10^{\mathrm{h}} 20^{\mathrm{m}}$ to $11^{\mathrm{h}} 20^{\mathrm{m}}$ a. m. on July 12 .

TABle 67.-Rubus, Pentstemon, and Scrophularia.

\begin{tabular}{|c|c|c|c|c|}
\hline Species. & $\begin{array}{l}\text { Plant, R. } \\
\text { strigosus. }\end{array}$ & $\begin{array}{l}\text { Bouquet, P. } \\
\text { secundiflorus. }\end{array}$ & $\begin{array}{c}\text { Bouquet, } P . \\
\text { barbatus. }\end{array}$ & $\begin{array}{l}\text { Bouquet, } \mathrm{S} . \\
\text { nodosa. }\end{array}$ \\
\hline 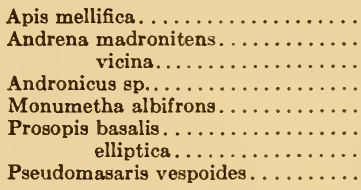 & $\begin{array}{l}\text { Many. } \\
0: 0 \\
1: 4 \\
0: 0 \\
1: 2 \\
0: 0 \\
2: 5 \\
4: 12\end{array}$ & $\begin{array}{l}1: 1 \\
1: 3 \\
0: 0 \\
4: 12 \\
0: 0 \\
2: 3 \\
5: 14 \\
4: 5\end{array}$ & $\begin{array}{ll}0: & 0 \\
0: 0 \\
0: 0 \\
0: 0 \\
0: 0 \\
0: 0 \\
0: 0 \\
0: 0\end{array}$ & $\begin{array}{l}0: 0 \\
1: 3 \\
0: 0 \\
0: 0 \\
0: 0 \\
0: 0 \\
0: 0 \\
4: 21\end{array}$ \\
\hline Total & $8: 23$ & $17: 38$ & $0: 0$ & $5: 24$ \\
\hline
\end{tabular}

TABLe 68.-Rubus, Aquilegia, and Mertensia.

\begin{tabular}{|c|c|c|c|}
\hline Species. & $\begin{array}{l}\text { Plant, R. } \\
\text { strigosus. }\end{array}$ & $\begin{array}{l}\text { Bouquet, A. } \\
\text { coerulea. }\end{array}$ & $\begin{array}{l}\text { Bouquet, } M \\
\text { alpina. }\end{array}$ \\
\hline Apis mellifica... & Countless. & 1: 1 & $0: 0$ \\
\hline Andrena crataegi. & $1: 1$ & $0: 0$ & $0: 0$ \\
\hline madronitens & $1: 1$ & $0: 0$ & $0: 0$ \\
\hline Andronicus sp......... & $1: 1$ & $1: 1$ & $0: 0$ \\
\hline Bombus juxtus. & $4: 7$ & $20: 66$ & $0: 0$ \\
\hline Halictus pulzenus. . & $0: 0$ & $7: 9$ & $0: 0$ \\
\hline Megachile texana.. & $0: 0$ & 1: 1 & $0: 0$ \\
\hline Monumetha albifrons................ & $0: 0$ & $1: 2$ & $0: 0$ \\
\hline Osmia densa. . . . . . . . . . . . . & $0: 0$ & $0: 0$ & $1: 1$ \\
\hline Prosopis sp.......... & 1: 1 & $0: 0$ & $6: 6$ \\
\hline 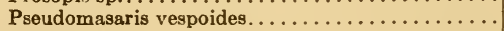 & $8: 9$ & $0: 0$ & $0: 0$ \\
\hline Muscidae...... & $0: 0$ & 4: 4 & 2: 2 \\
\hline Atrytone taxiles. . & $0: 0$ & 1: 1 & 1: 1 \\
\hline .....(Apis) & $16: 20$ & $36: 85$ & $10: 10$ \\
\hline
\end{tabular}

Summary. - In both cases the honey-bees were so numerous that they could not be counted at the same time that the other visitors were noted. In the first experiment Pentstemon secundiflorus was nearly twice as attrac- 
tive to the other bees as the raspberry and Scrophularia was about equal to the latter. It is interesting that $P$. barbatus received neither visits nor inspections from bees to most of which it was new, but this probably is to be ascribed partly to color and partly to habit. In the second experiment the honey-bee was again almost perfectly constant to Rubus, while the other bees preferred Aquilegia in the ratio of 2:1. Bombus juxtus showed a decisive preference for the latter, as Prosopis did for Mertensia; on the contrary, the wasp Pseudomasaris went only to the raspberry. Taking all bees into account, Rubus was much the most attractive, but, ignoring the honey-bee, the attractive features of Pentstemon secundiflorus and Aquilegia coerulea proved more potent than the control exerted by habit.

\section{RUBUS DELICIOSUS.}

Experiments.-In the studies with this species it was compared with two plants of the same family, viz, Rosa acicularis and Prunus demissa. The flower of the rose resembles that of the salmonberry closely in form, size, and grouping, but contrasts sharply in color. On the other hand, the flowers of the chokecherry, though white, are several times smaller and arranged in close racemes. The color area is much the same in the three, but in Prunus it is broken by the spaces between the flowers; the raceme is much the most fragrant and produces more nectar, while the amount of pollen appears to be much the same as in the single flowers of the other two species. Since the plants grew in juxtaposition, it was only necessary to bring the branches together to form an effective competition group, though in the last case a bouquet of Rubus was used (table 69).

Summary.-Of the total of 434 visitors, 302 went to Prunus, 120 to Rubus, and 12 to Rosa. While this indicates the relative attractiveness, it must be considered with reference to the fact that 387 of the total were contributed by Andrena and Diptera. Had either Apis or Bombus been abundant in the area at this time, the results would have been very different. The marked preference of Andrena for Prunus is shown by the fact that the latter obtained 225 visitors to 43 for Rubus and 4 for Rosa, all of the four species exhibiting the same behavior. The preference was less marked in the case of the flies, 75 going to Prunus and 40 to Rubus. The honey-bee was all but perfectly constant to Rubus, 26 visiting this in contrast to one to Rosa and none to Prunus. All told, the rose received less than a tenth of the total number of visitors in the experiments concerned, affording clear-cut evidence of the effect of habit in the face of greater total attraction.

\section{ROSA ACICULARIS}

Comparison.-Of the competitors employed, Rubus deliciosus most nearly resembles the rose in size and form, but contrasts sharply with its white color. Rubus strigosus and Opulaster opulifolius, though likewise belonging to the same family and white in color, differ greatly in form, size, and arrangement. Geranium caespitosum and Chamaenerium angustifolium approach closely in color, but they are much smaller and yield much less pollen, and this is largely true also for Cleome serrulata. Aquilegia coerulea equals the rose in pollen production and excels it in the attractiveness of the bright blue corolla, while the flowers of both species of Mertensia are rela- 
tively small and produce little pollen, but are readily visible by virtue of their deep blue color (plates $3,7,8$, and 11).

TABLe 69.-Rubus, Rosa, and Prunus.

\begin{tabular}{|c|c|c|c|c|c|c|}
\hline \multicolumn{3}{|c|}{ Expt. 1,2 hours, $9^{\mathrm{h}} 45^{\mathrm{m}}$ to $11^{\mathrm{b}} 45^{\mathrm{m}}$ a.m.June 23 . } & \multicolumn{4}{|c|}{ Expt. 3,1 hour, 10 to 11 a.m., June 28.} \\
\hline Species. & 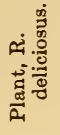 & 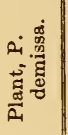 & Species. & 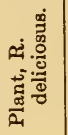 & 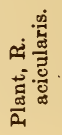 & 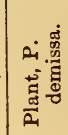 \\
\hline \multirow{2}{*}{ 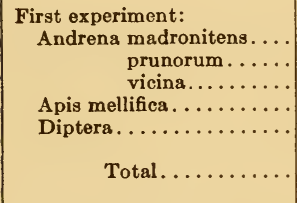 } & $\begin{array}{r}0 \\
0 \\
5 \\
3 \\
21\end{array}$ & $\begin{array}{r}7 \\
4 \\
25 \\
0 \\
45\end{array}$ & \multirow{4}{*}{ 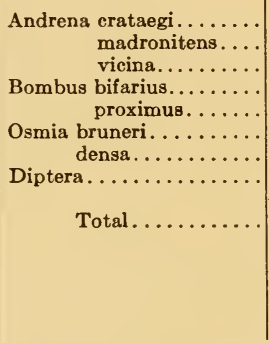 } & $\begin{array}{r}10 \\
0 \\
0 \\
0 \\
0 \\
1\end{array}$ & $\begin{array}{l}3 \\
0 \\
1 \\
2 \\
1 \\
0\end{array}$ & $\begin{array}{r}85 \\
2 \\
2 \\
1 \\
0 \\
0\end{array}$ \\
\hline & 29 & 81 & & $\begin{array}{l}0 \\
1\end{array}$ & $\begin{array}{l}1 \\
0\end{array}$ & 3 \\
\hline \multicolumn{3}{|c|}{ Two hours, $8^{\text {h }} 30^{\mathrm{m}}$ to $10^{\mathrm{h}} 30^{\mathrm{m}}$ a.m., June 25 . } & & 12 & 8 & 93 \\
\hline \multirow{4}{*}{ 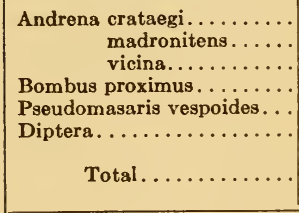 } & \multirow{3}{*}{$\begin{array}{l}6 \\
1 \\
6 \\
1 \\
0 \\
5\end{array}$} & \multirow{3}{*}{$\begin{array}{r}22 \\
6 \\
12 \\
0 \\
1 \\
23\end{array}$} & & & & \\
\hline & & & \multicolumn{4}{|c|}{ Expt. 4,2 hours, $9^{\mathrm{b}} 48^{\mathrm{m}}$ to $1^{\mathrm{b}} 48^{\mathrm{m}}$ a.m., July 3 . } \\
\hline & & & \multirow{3}{*}{ Species. } & \multirow{3}{*}{ 离 } & \multirow{3}{*}{\multicolumn{2}{|c|}{ 粮莺 }} \\
\hline & 19 & 64 & & & & \\
\hline \multicolumn{3}{|c|}{ Expt. 2, 1 hour, 10 to 11 a.m., June 28.} & & & & \\
\hline Species. & 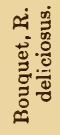 & 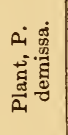 & \multirow{3}{*}{ 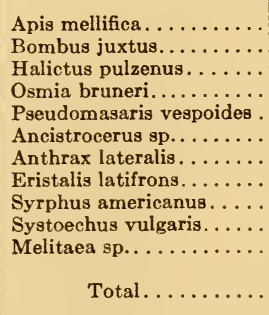 } & $\begin{array}{r}23 \\
2 \\
2 \\
1 \\
2\end{array}$ & \multirow{2}{*}{\multicolumn{2}{|c|}{$\begin{array}{l}1 \\
1 \\
2 \\
0 \\
0 \\
0 \\
0 \\
0 \\
0 \\
0 \\
0\end{array}$}} \\
\hline 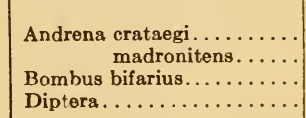 & $\begin{array}{r}13 \\
2 \\
1 \\
1\end{array}$ & $\begin{array}{r}54 \\
6 \\
0 \\
4\end{array}$ & & $\begin{array}{l}1 \\
3 \\
4 \\
3 \\
1\end{array}$ & & \\
\hline Total. .......... & 17 & 64 & & 43 & & 4 \\
\hline
\end{tabular}

Experiments.-In order to save space some of the less important details of installation are omitted and others are given in the discussion that follows tables 70 and 71 . As always, an equal number of flowers was used as a rule or an endeavor was made to have the attractive surfaces equal.

Summary.-Rosa acicularis proved to be less attractive than its competitors taken collectively, the ratio being $327: 420$. Rubus strigosus 
TABle 70.-Rosa, Rubus, Geranium, etc.

\begin{tabular}{|c|c|c|c|c|c|}
\hline \multicolumn{3}{|c|}{ Expt. 1,1 hour, $8^{\mathrm{h}} 45^{\mathrm{m}}$ to $9^{\mathrm{h}} 45^{\mathrm{m}}$ a.m., July 6 . } & \multicolumn{3}{|c|}{ Expt. 3,1 hour, $8^{\text {b }} 50^{\mathrm{m}}$ to $9^{\mathrm{h}} 50^{\mathrm{m}}$ a.m., July 6.} \\
\hline Species. & $\begin{array}{l}\text { Plant, } R \text {. } \\
\text { strigosus. }\end{array}$ & $\begin{array}{l}\text { Bouquet, } R . \\
\text { acicularis. }\end{array}$ & Species. & $\begin{array}{c}\text { Bouquet, } \mathrm{R} . \\
\text { acicularis. }\end{array}$ & $\begin{array}{l}\text { Plant, } 0 . \\
\text { opulifolius. }\end{array}$ \\
\hline \multirow{2}{*}{ 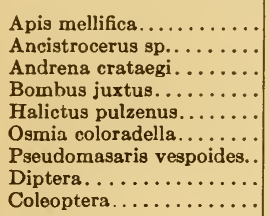 } & \multirow{2}{*}{$\begin{array}{r}50 \\
1 \\
2 \\
1 \\
0 \\
3 \\
4 \\
0 \\
0 \\
\end{array}$} & \multirow{2}{*}{$\begin{array}{l}3 \\
0 \\
0 \\
0 \\
1 \\
5 \\
0 \\
2 \\
1\end{array}$} & \multirow[t]{2}{*}{$\begin{array}{r}\begin{array}{r}\text { Andrena crataegi......... } \\
\text { madronitens.... }\end{array} \\
\text { Halictus pulzenus........ } \\
\text { Prosopis varifrons....... } \\
\text { Diptera................ } \\
\text { Total............ }\end{array}$} & $\begin{array}{l}0 \\
0 \\
0 \\
0 \\
0\end{array}$ & $\begin{array}{r}20 \\
1 \\
2 \\
1 \\
26 \\
\end{array}$ \\
\hline & & & & 0 & 50 \\
\hline Total. .......... & 61 & \multirow[b]{2}{*}{ m., July 7 . } & \multicolumn{3}{|c|}{ Expt. $4,11 / 2$ hours, $9^{\text {h }} 30^{m}$ to 11 a.m., July 8.} \\
\hline \multicolumn{2}{|c|}{ Expt. 2,1 hour, $10^{\mathrm{h}} 40^{\mathrm{m}}$ to $11^{\mathrm{b}} 40^{\mathrm{m}}$ a.m., July 7.} & & Species. & $\begin{array}{l}\text { Plant, } \mathrm{R} \text {. } \\
\text { acicularis. }\end{array}$ & $\begin{array}{l}\text { Plant, G. } \\
\text { caespitosum }\end{array}$ \\
\hline Species. & $\begin{array}{l}\text { Plant, R. } \\
\text { strigosus. }\end{array}$ & $\begin{array}{c}\text { Bouquet, } R . \\
\text { acicularis. }\end{array}$ & $\begin{array}{r}\text { Prosopis episcopalis....... } \\
\text { elliptica........ } \\
\text { basalis }\end{array}$ & $\begin{array}{c}10: 10 \\
0: 0 \\
1: 1\end{array}$ & $\begin{array}{c}33: 36 \\
2: 2 \\
0: 0\end{array}$ \\
\hline $\begin{array}{l}\text { Apis mellifica ............. } \\
\text { Ancistrocerus sp......... } \\
\text { Halictus evylaeus....... } \\
\text { Megachile wootoni...... } \\
\text { Pseudomasaris vespoides.. } \\
\text { Diptera............... }\end{array}$ & $\begin{array}{r}42 \\
1 \\
2 \\
2 \\
5 \\
0\end{array}$ & $\begin{array}{l}0 \\
0 \\
4 \\
0 \\
0 \\
2\end{array}$ & $\begin{array}{r}\text { Andrena crataegi........ } \\
\text { sp............... } \\
\text { Bombus juxtus......... } \\
\text { occidentalis..... } \\
\text { Anthophora simillima.... } \\
\text { Halictus (Evylacus) sp... } \\
\text { pulzenus....... } \\
\text { (Lasioglossum) }\end{array}$ & $\begin{array}{l}9: 15 \\
1: 4 \\
9: 30 \\
4: 13 \\
4: 15 \\
4: 4 \\
1: 1 \\
1: 1\end{array}$ & $\begin{array}{l}0: 0 \\
0: 0 \\
0: 0 \\
0: 0 \\
0: 0 \\
1: 1 \\
8: 8 \\
0: 0\end{array}$ \\
\hline $\begin{array}{r}\text { Diptera......................... } \\
\text { Total. }\end{array}$ & 52 & 6 & \multirow{3}{*}{ 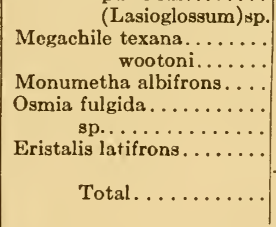 } & $\begin{array}{l}1: 1 \\
5: 11 \\
4: 9\end{array}$ & $\begin{array}{l}0: 0 \\
0: 0 \\
0: 0\end{array}$ \\
\hline \multicolumn{3}{|c|}{ Expt. 3,1 hour, $10^{\mathrm{h}} 40^{\mathrm{m}}$ to $11^{\mathrm{h}} 40^{\mathrm{m}}$ a.m., July 7.} & & $\begin{array}{l}5: 16 \\
1: 1 \\
1: 1 \\
5: 5\end{array}$ & $\begin{array}{l}0: 0 \\
0: 0 \\
0: 0 \\
0: 0\end{array}$ \\
\hline Species. & $\begin{array}{c}\text { Bouquet, } R . \\
\text { strigosus. }\end{array}$ & $\begin{array}{l}\text { Plant, R. } \\
\text { acicularis. }\end{array}$ & & $65: 137$ & $44: 47$ \\
\hline \multirow{4}{*}{$\begin{array}{l}\text { Anthophora simillima.... } \\
\text { Apis mellifica.......... } \\
\text { Halictus (Evylaeus) sp... } \\
\text { Monumetha albifrons.... } \\
\text { Osmia phaceliae........ } \\
\text { Syrphus americana....... } \\
\text { Total. .......... }\end{array}$} & \multirow{2}{*}{$\begin{array}{l}2 \\
0 \\
1 \\
1 \\
1 \\
2\end{array}$} & \multirow{2}{*}{$\begin{array}{l}0 \\
4 \\
1 \\
0 \\
0 \\
0\end{array}$} & \multicolumn{3}{|c|}{ Expt. 5,2 hours, $10^{\mathrm{h}} 05^{\mathrm{m}}$ to $12^{\mathrm{h}} 05^{\mathrm{m}}$ a.m., July 18.} \\
\hline & & & Species. & $\begin{array}{l}\text { Plant, R. } \\
\text { acicularis. }\end{array}$ & $\begin{array}{l}\text { Bouquet, C } \\
\text { serrulata. }\end{array}$ \\
\hline & 7 & 5 & $\begin{array}{r}\text { Bombus juxtus.......... } \\
\text { occidentalis..... } \\
\text { Andrena madronitens.... } \\
\text { vicina.......... } \\
\text { Prosopis elliptica........ } \\
\text { Megachile wootoni....... } \\
\text { Anthrax nigra........... } \\
\text { Syrphus a mericanus...... } \\
\text { Muscidae............... }\end{array}$ & $\begin{array}{l}15: 22 \\
1: 4 \\
2: 2 \\
0: 0 \\
2: 3 \\
1: 2 \\
0: 0 \\
5: 8 \\
0: 0\end{array}$ & $\begin{array}{l}8: 15 \\
0: 0 \\
5: 6 \\
1: 1 \\
1: 1 \\
1: 4 \\
1: 1 \\
2: 2 \\
1: 3\end{array}$ \\
\hline & & & Total. & $26: 41$ & $20: 33$ \\
\hline
\end{tabular}


TABLE 71.-Rosa, Chamaenerium, Aquilegia, etc.

Expt. 1, 11/2 hours, $10^{\mathrm{h}} 30^{\mathrm{m}}$ a.m. to $12 \mathrm{~m}$. , July 11.

Expt. $4,11 / 2$ hours, $8^{\mathrm{h}} 30^{\mathrm{m}}$ to 10 a.m., July 12 .

\begin{tabular}{|r|c|c|}
\hline Species. & $\begin{array}{c}\text { Plant, } \\
\text { R. } \\
\text { acicularis. }\end{array}$ & $\begin{array}{c}\text { Vials, } \\
\text { C. } \\
\text { angusti. }\end{array}$ \\
\hline Bombus proximus........ & 5 & 0 \\
Andrena crataegi....... & 2 & 0 \\
Halictus pulz nus....... & 0 & 1 \\
Prosopis basalis........ & 1 & 0 \\
Syrphus opinator....... & 1 & 0 \\
\hline Total........... & 9 & 1 \\
\hline
\end{tabular}

Expt. $2,1 \frac{1}{2}$ hours, $10^{\mathrm{h}} 30^{\mathrm{m}}$ a.m. to $12 \mathrm{~m}$., July 12 .

\begin{tabular}{|c|c|c|c|}
\hline Species. & $\begin{array}{l}\text { Plant, } \\
\text { Rosa. }\end{array}$ & $\begin{array}{l}\text { Vials, } \\
\text { Rosa. }\end{array}$ & $\begin{array}{l}\text { Vials, } \\
\text { Chamae. }\end{array}$ \\
\hline Bombus proximus. . & 72 & 41 & 7 \\
\hline bifarius. . & 2 & 2 & 0 \\
\hline juxtus... & 1 & 1 & 0 \\
\hline Halictus pulzenus & 3 & 1 & 0 \\
\hline man tonellus. & 1 & 1 & 0 \\
\hline Megachile wootoni.... & 1 & 0 & 0 \\
\hline Total.. & 80 & 46 & 7 \\
\hline
\end{tabular}

Expt. 3,3 hours, $7^{\text {h }} 30^{\mathrm{m}}$ to $10^{\text {h }} 30^{\mathrm{m}}$ a.m., June 27 .

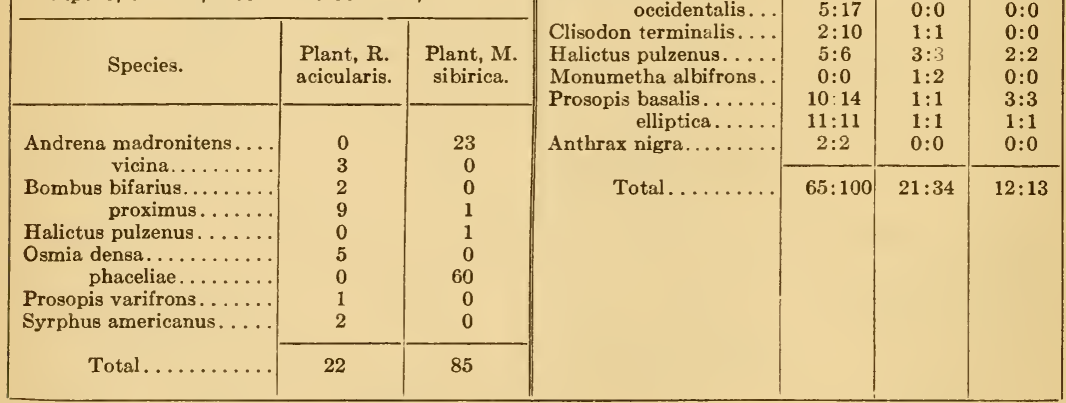

greatly exceeded it in attractive power, in the ratio of $120: 23$, though this was due chiefly to the habitual preference of the honey-bee. When Rosa was the standard and Rubus the bouquet, the difference was slight, owing to the fact that $A$ pis then visited the first alone. In competition with Opulaster, the rose received no visitors, a consequence explained by the fact that practically all the visitors present were flies and species of Andrena. The rose was most effective in competition with flowers of similar color but smaller size, the ratio being 65:44 for Geranium, 26:20 for Cleome, and 
9:1 for Chamaenerium. When a flower of rose or of fireweed in a vial was paired with rose flowers on the bush, the latter yielded 85 visitors to 49 for the first and 7 for the second. When Rosa as the standard competed with Aquilegia, the latter received nearly twice as many visitors and more than twice as many visits, but when both were in the form of bouquets, the number of visitors and visits to the rose was thrice as great. This exception to the general rule for standard and bouquet was due chiefly to the reversal of the behavior of Bombus juxtus and the greater abundance of Prosopis. The success of Mertensia sibirica in securing nearly four times as many visitors as the rose was the result of the constant preference of Andrena madronitens and Osmia phaceliae for it, all the other species choosing the rose. The small number of visitors for Mertensia alpina is partly to be explained by its being removed a long distance from its native habitat in terms of climate and vegetation.

Competition with normal and mutilated Aquilegia.-In this experiment were employed 50 normal flowers of the rose and columbine, and 10 flowers of each of the three kinds of mutilation. In addition, a pile of loose petals 6 inches in diameter was placed on the ground. The period of observation was one hour, $9^{\mathrm{h}} 15^{\mathrm{m}}$ to $10^{\mathrm{h}} 15^{\mathrm{m}}$, July 13 .

TABLE 72.-Competition of Rosa with normal and mutilated Aquilegia.

\begin{tabular}{|c|c|c|c|c|c|c|}
\hline \multirow{2}{*}{ Species. } & \multicolumn{2}{|c|}{ Normal. } & \multicolumn{4}{|c|}{ Mutilations. } \\
\hline & $\begin{array}{l}\text { Plant, } \\
\text { Rosa. }\end{array}$ & $\begin{array}{l}\text { Bouquet, } \\
\text { Aquilegia. }\end{array}$ & $\begin{array}{l}\text { Sepals and } \\
\text { petals off. }\end{array}$ & $\begin{array}{c}\text { Petals } \\
\text { off. }\end{array}$ & $\begin{array}{l}\text { Petals and } \\
\text { spurs off. }\end{array}$ & $\begin{array}{l}\text { Loose } \\
\text { petals. }\end{array}$ \\
\hline Bombus juxtus........ & $5: 5$ & $28: 31$ & $7: 10$ & $6: 6$ & $5: 6$ & $2: 2$ \\
\hline occidentalis... & $6: 9$ & $1: 1$ & $0: 0$ & $0: 0$ & $0: 0$ & $0: 0$ \\
\hline Andrena crataegi..... & $9: 10$ & $0: 0$ & $0: 0$ & $1: 1$ & $0: 0$ & $0: 0$ \\
\hline Halictus pulzenus..... & $0: 0$ & $1: 1$ & $0: 0$ & $0: 0$ & $0: 0$ & $0: 0$ \\
\hline Megachile texana...... & $0: 0$ & $1: 1$ & $0: 0$ & $0: 0$ & $0: 0$ & $0: 0$ \\
\hline w. calogaster & $5: 5$ & $0: 0$ & $0: 0$ & $0: 0$ & $1: 1$ & $0: 0$ \\
\hline Monumetha albifrons. . & $1: 1$ & $1: 1$ & $0: 0$ & $0: 0$ & $0: 0$ & $0: 0$ \\
\hline Osmia densa.......... & $1: 1$ & $0: 0$ & $0: 0$ & $0: 0$ & $0: 0$ & $0: 0$ \\
\hline Prosopis elliptica. . . . . & $1: 1$ & $0: 0$ & $0: 0$ & $1: 1$ & $0: 0$ & $0: 0$ \\
\hline sp $\ldots \ldots \ldots \ldots$ & $0: 0$ & $0: 0$ & $0: 0$ & $1: 1$ & $0: 0$ & $0: 0$ \\
\hline Syrphus americanus... & $0: 0$ & $1: 1$ & $0: 0$ & $1: 1$ & $0: 0$ & $0: 0$ \\
\hline Muscidae........... & $0: 0$ & 1: 1 & $0: 0$ & $1: 1$ & $0: 0$ & $0: 0$ \\
\hline Total... & $28: 32$ & $34: 37$ & $7: 10$ & $11: 11$ & $6: 7$ & $2: 2$ \\
\hline
\end{tabular}

While the rose was more attractive to Bombus occidentalis, Andrena crataegi and Megachile $w$. calogaster, the greater number of visitors of $B$. juxtus gave the preference to the columbine. The mutilations were relatively more visited than the normal flowers, this exception.to the rule for decorollate flowers being explained by the bright-colored stamen mass and the blue color of the sepals.

\section{GERANIUM.}

Comparison.-The flowers of Geranium caespitosum and G. richardsoni are almost identical except for the color, the former being pink-purple and 
the latter practically white. In nature, $G$. caespitosum is much more visited, as it is a plant of open sunny slopes. Its flowers are larger and much more conspicuous than those of Rubus strigosus, but are only about one-fourth the size of the rose. They are also much smaller than the flowers of Aquilegia coerulea and the color somewhat less attractive, while the pollen is much less abundant. Mertensia alpina possesses the advantage of blue flowers, but the cluster is rather less conspicuous than a single geranium. In the group of natural competitors, the heads of Aster bigelovi resemble the flowers of geranium in size and color, but they yield more nectar and pollen. Campanula rotundifolia, in spite of its deep blue color, produces little pollen or nectar and most pollinators ignore it. In both Allium recurvatum and Heracleum lanatum, the smallness of the flowers is compensated by their grouping in umbels, though even this is little effective in Heracleum. The pink flowers of Allium produce an amount of nectar and pollen that is out of proportion to their size. Of the competitors with zygomorphic flowers, Pentstemon secundiflorus and $P$. barbatus have larger and more brilliant flowers, and the cluster is larger and more vivid in Castilleia miniata, while the chief asset of the small, dull flowers of Scrophularia nodosa lies in the abundant nectar (plates, $37,11,12,13$, and 14).

Experiments.-Table 73 deals with the competition between the two species of Geranium in various installations, table 74 with competition between Geranium and other genera, and tables 75, 76, and 77 with group competition.

Although Geranium caespitosum yielded 277 visitors to 155 for G. richardsoni, in competition with each other, they are more nearly equal in attractiveness than this would indicate. This difference is more than accounted for in the behavior of Prosopis, which preferred caespitosum in the ratio of $184: 28$, chiefly when this species was the standard. The two were practically equal when both were used in the form of bouquets, and they changed rank in two successive periods in which they alternated as standards, the respective ratios being $88: 9$ and $83: 10$. This equality is further indicated by their behavior in competition with Rubus strigosus, though the conditions were not precisely comparable in the different experiments. When plants were compared, Apis was perfectly constant to the raspberry, but in all other cases it exhibited a practically exclusive preference for the standard plant, going to richardsoni, caespitosum, or strigosus as each took this role. Between richardsoni and strigosus as plants, Prosopis gave a ratio of 42:1, while between bouquets of $G$. caespitosum and Rosa the ratio was 28:0. The honey-bee behaved similarly in the latter choice, while for Bombus the preference was reversed, namely, 0:29, as it was likewise for Megachile and Anthophora. However, Aquilegia in a mixed boquet was as attractive as standard G. caespitosum, while the associated Mertensia alpina received but one visit. It is interesting to note that Andrena crataegi was the only visitor to both Geranium and Aquilegia in this experiment.

The size of the flowers differs so much in this group that exact comparisons are difficult. In spite of the size of the clusters, however, the pinkish or white flowers of Allium and Heracleum were obviously at a disadvantage. The flowers of Geranium and Campanula and the heads of Aster are somewhat 
TABLE 73.-Competition of Geranium caespitosum and G. richardsoni.

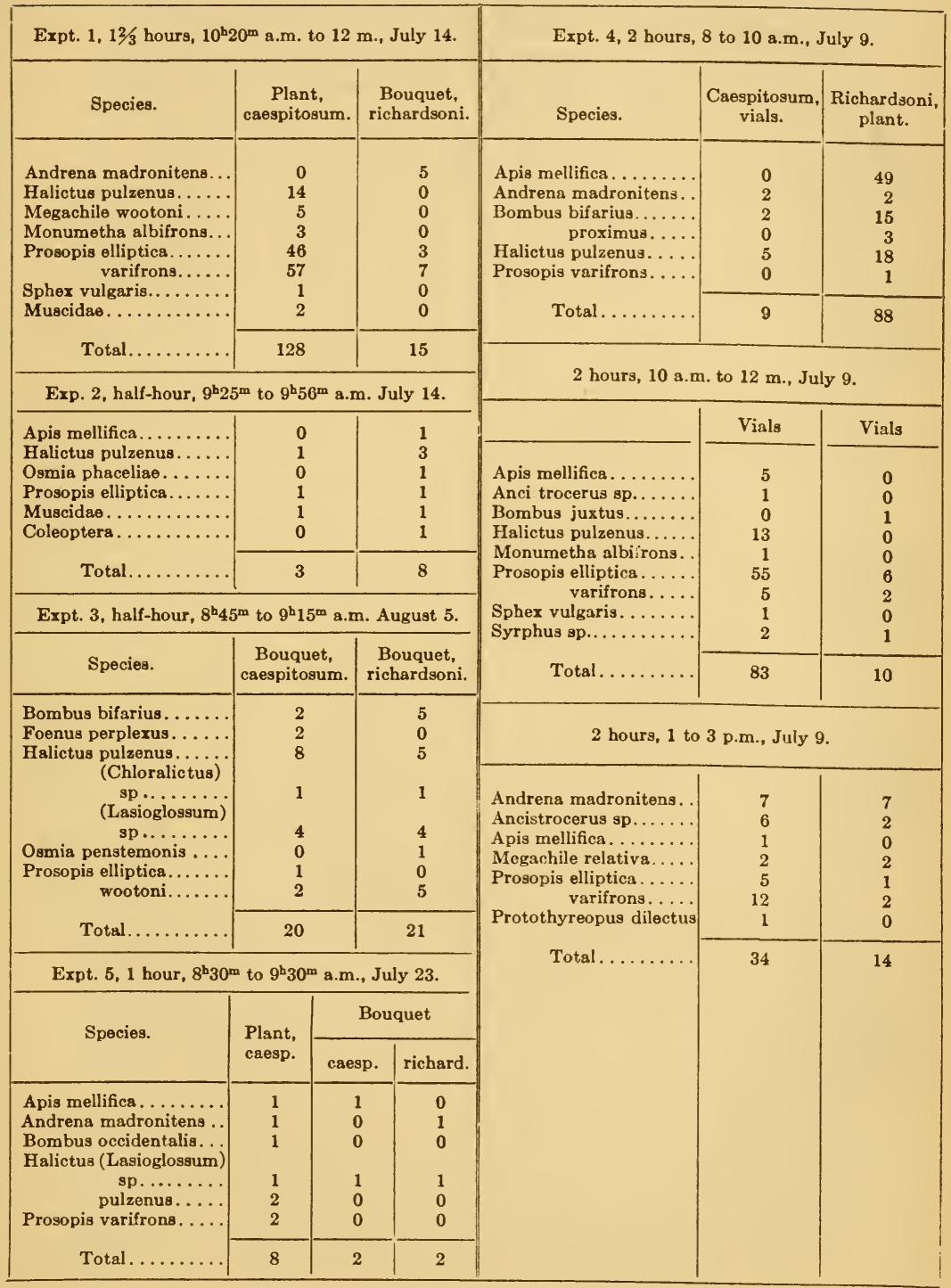


Table 74.-Geranium, Rubus, Rosa, Aquilegia, etc.

\begin{tabular}{|c|c|c|c|c|c|c|}
\hline \multicolumn{3}{|c|}{ Expt. 1,1 hour, $9^{\mathrm{b}} 20^{\mathrm{m}}$ to $10^{\mathrm{h}} 20^{\mathrm{m}}$ a.m., July 2.} & \multicolumn{4}{|c|}{ Expt. 3,1 hour, $2^{\mathrm{h}} 50^{\mathrm{m}}$ to $3^{\mathrm{h}} 50^{\mathrm{m}}$ p.m., July 11 . } \\
\hline \multirow[b]{2}{*}{ Species. } & \multirow{2}{*}{$\begin{array}{l}\text { Plant, G. } \\
\text { richard. }\end{array}$} & \multirow{2}{*}{$\begin{array}{l}\text { Plant, } R \text {. } \\
\text { strigosus. }\end{array}$} & \multirow{2}{*}{ Species. } & \multicolumn{3}{|c|}{ Mixed bouquet. } \\
\hline & & & & \multicolumn{2}{|c|}{ Ger. caes. } & Rosa acic. \\
\hline Apis mellifica. & 0 & 29 & \multirow{12}{*}{ 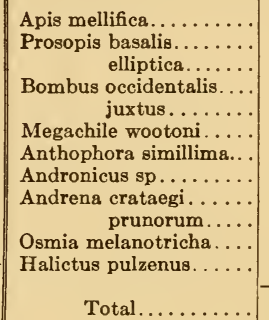 } & \multirow{12}{*}{\multicolumn{2}{|c|}{$\begin{array}{r}16 \\
15 \\
13 \\
0 \\
0 \\
0 \\
0 \\
2 \\
0 \\
0 \\
3 \\
1\end{array}$}} & 0 \\
\hline Andrena madronitens. . & 0 & 1 & & & & 0 \\
\hline Osmia bruneri......... & 1 & 0 & & & & 0 \\
\hline densa................ & 1 & 0 & & & & 8 \\
\hline Prosopis basalis....... & 40 & 1 & & & & 21 \\
\hline elliptica...... & 2 & 0 & & & & 8 \\
\hline Psammophila violace- & & & & & & 3 \\
\hline pennis.............. & 1 & 0 & & & & 0 \\
\hline Sphex vulgaris....... & 1 & 0 & & & & 1 \\
\hline Glypta sp............ & 1 & 0 & & & & 1 \\
\hline Muscidae....... & 1 & 0 & & & & 0 \\
\hline Total & 48 & 31 & & & & 0 \\
\hline \multirow{2}{*}{\multicolumn{3}{|c|}{ Expt. 2, 1 hour, 11 a.m. to $12 \mathrm{~m}$, July 10.}} & & \multicolumn{2}{|l|}{50} & 42 \\
\hline & & & \multirow{2}{*}{\multicolumn{4}{|c|}{ Expt. 4, half-hour, $11^{\mathrm{b}} 30^{\mathrm{m}}$ a.m. to $12 \mathrm{~m}$., July 12 . }} \\
\hline \multirow{2}{*}{ Species. } & \multirow{2}{*}{$\begin{array}{c}\text { Plant, G. } \\
\text { caespitosum. }\end{array}$} & \multirow{2}{*}{$\begin{array}{c}\text { Bouquet, } \mathrm{R} . \\
\text { strigosus. }\end{array}$} & & & & \\
\hline & & & \multirow[b]{3}{*}{ Species. } & \multirow{3}{*}{$\begin{array}{l}\text { Plant, G. } \\
\text { caesp. }\end{array}$} & \multirow{2}{*}{\multicolumn{2}{|c|}{ Mixed bouquet. }} \\
\hline Apis mellifica..... & 11 & 0 & & & & \\
\hline $\begin{array}{l}\text { Halictus pulzenus..... } \\
\text { Osmia bruneri......... } \\
\text { Prosopis basalis....... }\end{array}$ & $\begin{array}{l}2 \\
0 \\
0\end{array}$ & $\begin{array}{l}0 \\
1 \\
1\end{array}$ & & & A. coer. & M. alp. \\
\hline Total......... & 13 & 2 & Andrena crataegi... & $0: 0$ & $1: 1$ & $0: 0$ \\
\hline \multicolumn{3}{|c|}{1 hour, 11 to 12 , July 11 . } & $\begin{array}{l}\text { Apis mellifica............. } \\
\text { Bombus juxtus...... }\end{array}$ & $\begin{array}{l}0: 0 \\
0: 0\end{array}$ & $\begin{array}{l}1: 1 \\
1: 1\end{array}$ & $\begin{array}{l}0: 0 \\
0: 0\end{array}$ \\
\hline \multirow{5}{*}{$\begin{array}{r}\text { Apis mellifica......... } \\
\text { Halictus pulzenus..... } \\
\text { Osmia bruneri........ } \\
\text { Prosopis basalis....... } \\
\text { Total........... }\end{array}$} & 48 & 0 & occidentalis... & $0: 0$ & $2: 2$ & $1: 1$ \\
\hline & $\begin{array}{r}40 \\
2\end{array}$ & 0 & & $\begin{array}{l}0: 0 \\
0: 0\end{array}$ & 4: 4 & $\begin{array}{l}0: 0 \\
0: 0\end{array}$ \\
\hline & 0 & 1 & $\begin{array}{l}\text { Monumetha albifrons. . } \\
\text { Prosopis episcopalis... }\end{array}$ & $\begin{array}{l}0: 0 \\
1: 1\end{array}$ & $\begin{array}{l}1: 1 \\
0: 0\end{array}$ & $\begin{array}{l}0: 0 \\
0: 0\end{array}$ \\
\hline & 0 & 1 & Protothryreopus dilec- & $1: 1$ & & \\
\hline & 50 & 2 & $\begin{array}{l}\text { tus.......................... } \\
\text { Arctophila flagrans.... }\end{array}$ & $\begin{array}{l}1: 1 \\
1: 1\end{array}$ & $\begin{array}{l}0: 0 \\
0: 0\end{array}$ & $\begin{array}{l}0: 0 \\
0: 0\end{array}$ \\
\hline \multicolumn{3}{|c|}{1 hour, 10 to 11 a.m., July 8 . } & $\begin{array}{l}\text { Symmorphus sp......... } \\
\text { Syrphus americanus... }\end{array}$ & $\begin{array}{l}1: 4 \\
2: 4\end{array}$ & $\begin{array}{ll}0: 0 \\
0: 0 \\
0: 0\end{array}$ & $\begin{array}{l}0: 0 \\
0: 0 \\
0: 0\end{array}$ \\
\hline Species. & $\begin{array}{l}\text { Bouquet, G. } \\
\text { caespitosum. }\end{array}$ & $\begin{array}{l}\text { Plant, R. } \\
\text { strigosus. }\end{array}$ & Total... & $13: 13$ & $11: 11$ & $1: 1$ \\
\hline \multirow{5}{*}{ 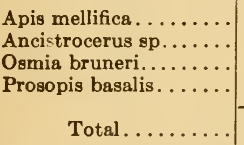 } & 0 & 24 & & & & \\
\hline & 4 & 0 & & & & \\
\hline & 1 & $\begin{array}{l}1 \\
1\end{array}$ & & & & \\
\hline & & & & & & \\
\hline & 6 & 26 & & & & \\
\hline
\end{tabular}


similar in color and size. As there were 25,10 , and 5 respectively, the corresponding numbers for visitors and visits are $11: 26,45: 90$, and $10: 10$, the much larger nectar supply of $A$ ster giving it a great advantage.

TAвLE 75.-Natural competition: Geranium, Aster, Allium, Campanula, Heracleum.

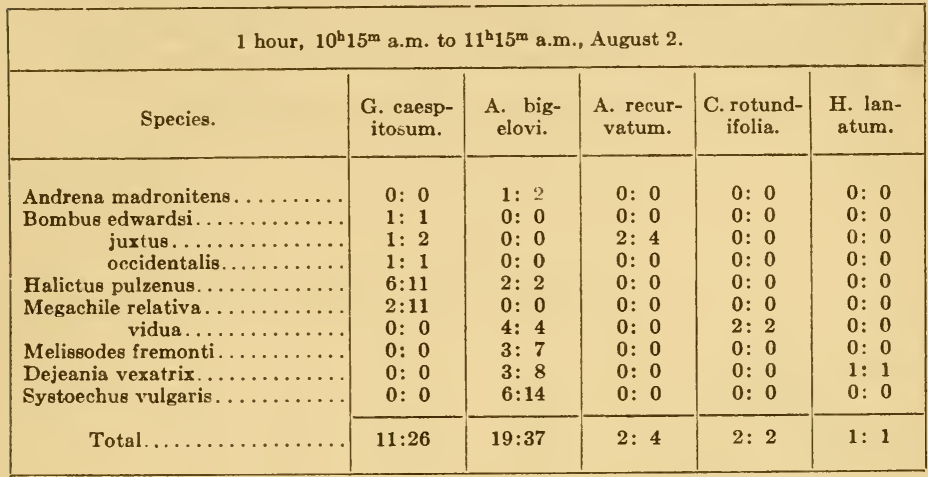

Summary.-In these two experiments the preferences of most of the visitors were so pronounced that the usual difference between plant and bouquet is hardly to be seen. Anthophora, Bombus, and Osmia were the only visitors to work on both standard and bouquet, the first two giving preference to the rose and the last to Pentstemon secundiflorus. Andrena and Megachile likewise preferred the rose, while Apis selected Geranium. The competition between Geranium and Castilleia was conclusive as to the marked specialization of the latter, the broad-tailed humming-bird being the regular pollinator and Osmia the only insect to visit it. As in former experiments, Pentstemon barbatus was entirely ignored, perhaps because of its narrow vermilion corolla, and the difference between $P$. secundiflorus and Scrophularia was less than would be expected from the size and color of the former. In both experiments more individuals of Pseudomasaris went to Scrophularia, but they made a larger number of visits to Pentstemon. Osmia, however, showed an all but exclusive preference for the latter. In the second experiment the bouquet was later turned so that the flowers of $P$. barbatus were in the position formerly occupied by Scrophularia. Pseudomasaris returned to the original position of the latter, recognized its mistake, and then flew through the red flowers of the Pentstemon to the figwort. Andrena crataegi flew 7 times within $0.5 \mathrm{~cm}$. of Scrophularia and 4 times around $P$. secundiflorus, but ignored $P$. barbatus; it then flew to Ros $a$ and alighted.

Since there were four times as many roses and twice as many castilleias as geraniums, the latter was relatively as attractive as the others, receiving more visitors but fewer visits than the rose. The three species in the bouquet were represented by an equal number of spikes. Pentstemon secundiflorus was about 50 per cent more attractive than Scrophularia, probably owing to its much larger size and brilliant color. 
The results are interesting only in showing the behavior of Bombus juxtus on two successive and similar mornings. On the first the bouquet of Chamaenerium approached the Geranium plant in attraction, but there was a great discrepancy on the second day. Monarda received a few visits on one and inspections only on the other, in spite of the fact that $B$. juxtus can reach the nectar when it chooses. Gilia was not even inspected, the visitors evidently knowing that the nectar is inaccessible to them.

TABLE 76.-Plant and bouquet competition of several species.

\begin{tabular}{|c|c|c|c|c|c|}
\hline \multicolumn{6}{|c|}{ Expt. 1,2 hours, 8 to 10 a.m., July 3 . } \\
\hline \multirow{2}{*}{ Species. } & \multicolumn{2}{|c|}{ Plant. } & \multicolumn{3}{|c|}{ Mixed bouquet. } \\
\hline & Geranium & Rosa. & Pent. sec. & Pent. barb. & Scroph. nod. \\
\hline 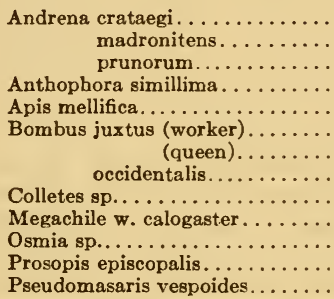 & $\begin{array}{ll}0: & 0 \\
0: & 0 \\
0: & 0 \\
0: 0 \\
9: 27 \\
0: 0 \\
0: 0 \\
0: 0 \\
3: 0 \\
0: 0 \\
0: 0 \\
1: 1 \\
0: 0\end{array}$ & $\begin{array}{lr}4: & 7 \\
1: & 6 \\
1: & 2 \\
4: & 28 \\
1: & 8 \\
3: & 9 \\
1: & 22 \\
6: & 37 \\
0: & 0 \\
8: & 34 \\
2: & 3 \\
0: & 0 \\
0: & 0\end{array}$ & $\begin{array}{l}0: 0 \\
0: 0 \\
0: 0 \\
1: 2 \\
0: 0 \\
1: 1 \\
0: 0 \\
0: 0 \\
0: 0 \\
0: 0 \\
2: 10 \\
0: 0 \\
5: 59\end{array}$ & $\begin{array}{ll}0: & 0 \\
0: & 0 \\
0: & 0 \\
0: & 0 \\
0: & 0 \\
0: & 0 \\
0: & 0 \\
0: & 0 \\
0: & 0 \\
0: & 0 \\
0: & 0 \\
0 & 0 \\
0: & 0\end{array}$ & $\begin{array}{ll}0: & 0 \\
0: 0 \\
0: 0 \\
0: 0 \\
0: 0 \\
0: 0 \\
0: 0 \\
1: 7 \\
0: 0 \\
0: 0 \\
1: & 1 \\
0: & 0 \\
8: & 54\end{array}$ \\
\hline Total. . & $13: 34$ & $31: 156$ & $9: 72$ & $0: 0$ & $10: 62$ \\
\hline \multicolumn{6}{|c|}{ Expt. 2,2 hours, 10 a.m. to $12 \mathrm{~m}$., July 3 . } \\
\hline Species. & Geranium & Castilleia & \multicolumn{3}{|c|}{ Mixed bouquet. } \\
\hline 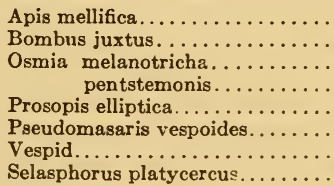 & $\begin{array}{l}6: 16 \\
1: 1 \\
0: 0 \\
0: 0 \\
1: 2 \\
0: 0 \\
0: 0 \\
0: 0\end{array}$ & $\begin{array}{cc}0: & 0 \\
0: & 0 \\
0: & 0 \\
1: & 2 \\
0: & 0 \\
0: & 0 \\
0: & 0 \\
19: 39\end{array}$ & $\begin{array}{l}0: 0 \\
0: 0 \\
6: 19 \\
6: 21 \\
0: 0 \\
6: 75 \\
0: 0 \\
0: 0\end{array}$ & $\begin{array}{ll}0: & 0 \\
0: & 0 \\
0: & 0 \\
0: & 0 \\
0: & 0 \\
0: & 0 \\
0: & 0 \\
0: & 0\end{array}$ & $\begin{array}{ll}0: & 0 \\
0: & 0 \\
0: & 0 \\
0: & 0 \\
0: & 0 \\
8: 39 \\
2: & 9 \\
0: & 0\end{array}$ \\
\hline Total.... & $8: 19$ & $20: 41$ & $18: 115$ & $0: 0$ & $10: 48$ \\
\hline
\end{tabular}

\section{CHAMAENERIUM ANGUSTIFOLIUM.}

Comparison.-The flowers of Geranium caespitosum resemble those of the fireweed in form and color, but are somewhat larger. Perhaps the chief difference between them lies in the fact that they are scattered in the one and grouped in a conspicuous raceme in the other. The fireweed produces more nectar, and the pollen is not only more abundant but is also 
available in each flower for a much longer period. Both Aconitum columbianum and Delphinium scopulorum afford a striking contrast to the fireweed in the form and color of the flower. The blue or purple color and the great abundance of pollen would seem to make them more attractive, but this is offset by the more constant flow of nectar in Chamaenerium. Frasera speciosa is similar to the latter in the form and size of the flower, but the corolla is dull green. It would seem to be greatly handicapped by the color and the small number of stamens, but the nectar is abundant and apparently very palatable, a fact that more than compensates for the larger size, brighter color and more abundant pollen of Aquilegia coerulea (plates 2, 7, 8, and 10).

TABLE 77.-Plant and bouquet competition of several species.

\begin{tabular}{|c|c|c|c|c|c|}
\hline \multicolumn{6}{|c|}{ Expt. 1,1 hour, 47 minutes, $8^{\mathrm{h}} 10^{\mathrm{m}}$ to $9^{\mathrm{h}} 57^{\mathrm{m}}$ a.m., August 15 . } \\
\hline \multirow{2}{*}{ Species. } & \multicolumn{3}{|c|}{ Plant. } & \multicolumn{2}{|c|}{ Bouquet. } \\
\hline & Geranium. & Monarda. & Aster. & $\begin{array}{l}\text { Chamaener- } \\
\text { ium. }\end{array}$ & Gilia. \\
\hline \multirow{2}{*}{$\begin{array}{l}\text { Bombus juxtus..... } \\
\text { Halictus pulzenus... } \\
\text { Erynnis } 1 . \text { snowi .... } \\
\text { Total........ }\end{array}$} & $\begin{array}{rr}34: 107 \\
1: & 2 \\
1: & 1\end{array}$ & $\begin{array}{l}2: 5 \\
0: 0 \\
0: 0\end{array}$ & $\begin{array}{l}6: 8 \\
0: 0 \\
0: 0\end{array}$ & $\begin{array}{r}23: 77 \\
2: 14 \\
0: 0\end{array}$ & $\begin{array}{l}0: 0 \\
0: 0 \\
0: 0\end{array}$ \\
\hline & $36: 110$ & $2: 5$ & $6: 8$ & $25: 91$ & $0: 0$ \\
\hline \multicolumn{6}{|c|}{ Expt. 2,2 hours, 15 minutes, $8^{\mathrm{b}} 15^{\mathrm{m}}$ to $10^{\mathrm{h}} 30^{\mathrm{m}}$ a.m., August 14 . } \\
\hline Bombus juxtus...... & $\begin{array}{r}24: 151 \\
2: 8\end{array}$ & $\begin{array}{c}15 \mathrm{i} \\
0\end{array}$ & & $\begin{array}{c}7: 34 \\
0\end{array}$ & \\
\hline Total. & $26: 159$ & $15 \mathrm{i}$ & & $7: 34$ & \\
\hline Grand total. . & $62: 269$ & $2: 5: 15 i$ & $6: 8$ & $32: 125$ & $0: 0$ \\
\hline
\end{tabular}

Experiments.-In table 78 the first record is one of natural competition between fireweed and geranium, the next two are experiments in which the former was the standard plant and the last is an isolated one with Frasera, a flower of similar form but very different color.

Summary. - Chamaenerium proved many times more attractive than either Aconitum or Delphinium; it received fewer visitors than Geranium, though this was only exceptionally true, and was due to the absence of Bombus. The usual efficiency of the columbine was lacking in competition with Frasera, in consequence of the great attraction of the latter for Apis and Bombus.

\section{PENTSTEMON.}

Comparison.-Of the five species of Pentstemon employed, $P$. glaber, glaucus, and gracilis grow native in the area, barbatus and unilateralis were brought from the foothills, and halli from the alpine meadows. The 
flowers of all are variously blue or blue-purple in color, with the exception of $P$. barbatus, in which they are vermilion. The flowers of $P$. glaber are the largest, decreasing through unilateralis, glaucus, and halli to gracilis; those of $P$. barbatus have a narrow tube as in the last, but they are much longer. The secund clusters are most conspicuous in $P$. unilateralis and $P$. glaber and the open few-flowered one of $P$. barbatus is the least so, in spite of the brilliant flowers. The pink-purple corollas of Elephantella groen-

TABLE 78. - Natural and bouquet competition of Chamaenerium, and Frasera.

\begin{tabular}{|c|c|c|c|c|c|}
\hline \multicolumn{3}{|c|}{ Expt.1, half-hour, $11^{\mathrm{h}} 23^{\mathrm{m}}$ to $11^{\mathrm{h}} 53^{\mathrm{m}}$ a.m., July 15 . } & \multicolumn{3}{|c|}{ Expt. 3,1 hour, $10^{\mathrm{h}} 35^{\mathrm{m}}$ to $11^{\mathrm{b}} 35^{\mathrm{m}}$ a.m., July 24} \\
\hline Species. & $\begin{array}{l}\text { Plant } \\
\text { Chamae. }\end{array}$ & $\begin{array}{l}\text { Plant } \\
\text { G. caesp. }\end{array}$ & Species. & $\begin{array}{l}\text { Plant } \\
\text { Chamae. }\end{array}$ & $\begin{array}{l}\text { Bouquet } \\
\text { Aconitum. }\end{array}$ \\
\hline \multirow{10}{*}{ 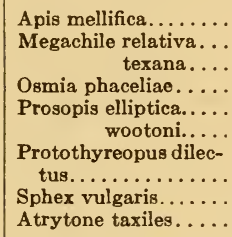 } & \multirow{10}{*}{$\begin{array}{l}0: 0 \\
4: 13 \\
2: 6 \\
1: 1 \\
6: 6 \\
2: 2 \\
0: 0 \\
0: 0 \\
1: 1\end{array}$} & \multirow{10}{*}{$\begin{aligned} & 7: 9 \\
& 0: 0 \\
& 0: 0 \\
& 1: 4 \\
& 13: 13 \\
& 1: 1 \\
& 2: 4 \\
& 1: 1 \\
& 0: 0\end{aligned}$} & \multirow{10}{*}{\begin{tabular}{|r|} 
Bombus appositus... \\
juxtus...... \\
proximus.... \\
Megachile pugnata... \\
texana... \\
Vespa germanica.... \\
Atrytone taxiles..... \\
Total ........
\end{tabular}} & \multirow{8}{*}{$\begin{array}{r}42 \\
140 \\
7 \\
4 \\
10 \\
2 \\
47\end{array}$} & \multirow{8}{*}{$\begin{array}{l}0 \\
4 \\
0 \\
0 \\
0 \\
0 \\
0\end{array}$} \\
\hline & & & & & \\
\hline & & & & & \\
\hline & & & & & \\
\hline & & & & & \\
\hline & & & & & \\
\hline & & & & & \\
\hline & & & & & \\
\hline & & & & \multirow{2}{*}{252} & \multirow{2}{*}{4} \\
\hline & & & & & \\
\hline Total.. & $16: 29$ & $25: 32$ & \multicolumn{3}{|c|}{ Expt. 4,1 hour, $9^{\mathrm{h}} 40^{\mathrm{m}}$ to $10^{\mathrm{h}} 40^{\mathrm{m}}$ a.m., July 14} \\
\hline \multicolumn{3}{|c|}{$\begin{array}{c}\text { Expt. 2, 21/2 hours, } 8 \text { to } 10 \text { and } 10 \text { to } 11 \text { a.m., } \\
\text { August } 17 .\end{array}$} & Species. & $\begin{array}{l}\text { Plant, } \\
\text { Frasera. }\end{array}$ & $\begin{array}{l}\text { Bouquet, } \\
\text { Aquilegia. }\end{array}$ \\
\hline Species. & $\begin{array}{l}\text { Plant, } \\
\text { Chamae. }\end{array}$ & $\begin{array}{l}\text { Bouquet, } \\
\text { Delphin. }\end{array}$ & \multirow{10}{*}{$\begin{array}{r}\text { Apis mellifica........ } \\
\text { Andrena madronitens } \\
\text { Bombus juxtus...... } \\
\text { morrisoni.... } \\
\text { Colletes sp.......... } \\
\text { Osmia bruneri...... } \\
\text { melanotricha } \\
\text { Prosopis episcopalis } \\
\text { Vespid............. } \\
\text { Muscidae........... } \\
\text { Totals........ }\end{array}$} & \multirow{7}{*}{$\begin{array}{rr}73: & 101 \\
3: & 4 \\
30: & 49 \\
1: & 1 \\
0: & 0 \\
0: & 0 \\
0: & 0 \\
1: & 1 \\
2: & 2 \\
4: & 4\end{array}$} & \multirow{7}{*}{$\begin{array}{l}0: 0 \\
1: 2 \\
1: 1 \\
0: 0 \\
1: 3 \\
1: 3 \\
1: 1 \\
0: 0 \\
0: 0 \\
0: 0\end{array}$} \\
\hline & & & & & \\
\hline Bombus bifarius & 133 & 11 & & & \\
\hline & 46 & 0 & & & \\
\hline \multirow{2}{*}{$\begin{array}{r}\text { Prosopis varifrons..... } \\
\text { Total......... }\end{array}$} & 3 & 0 & & & \\
\hline & 182 & 11 & & & \\
\hline \multirow{3}{*}{$\begin{array}{r}\text { Bombus justus...... } \\
\text { bifarius..... } \\
\text { Monumetha albifrons }\end{array}$} & 1 & & & & \\
\hline & 16 & 0 & & \multirow{3}{*}{$114: 162$} & \multirow[t]{3}{*}{$5: 10$} \\
\hline & 4 & 0 & & & \\
\hline Total. & 141 & 1 & & & \\
\hline
\end{tabular}

landica are individually inconspicuous, owing to the slender coiled tube, but they are massed in a compact cluster that has a considerable degree of visibility. The amount of both nectar and pollen is much less than in the various species of Pentstemon. The flowers of Dodecatheon meadia are bright pink and of about the size of the smaller pentstemons; usually but one or two are in bloom in a cluster at the same time and the amount of nectar and pollen is small. The other species concerned have been previously described (plates 7,8 , and 12). 
Experiments. - These dealt largely with single and mixed bouquets, though both natural and plant-bouquet competition were also concerned.

TABLE 79.-Bouquet competition of species of Pentstemon.

\begin{tabular}{|c|c|c|c|c|c|c|c|c|}
\hline \multicolumn{4}{|c|}{ Separate bouquets. } & \multicolumn{5}{|c|}{ Single bouquet. } \\
\hline \multicolumn{4}{|c|}{ Expt. 1, 1 hour, 9 to 10 a.m., June 19.} & \multicolumn{5}{|c|}{ Expt. 4,2 hours, 9 to 11 a.m., July 21 . } \\
\hline Species. & Glaber. & Halli. & Gracilis. & Species. & Glab. & Hall. & Glauc & c. Eleph. \\
\hline Anthophora simillima.. & 0 & 1 & 0 & Bombus bifarius... & 22 & 0 & 1 & 25 \\
\hline Halictus pulzenus..... & 1 & 1 & 0 & juxtus.... & 1 & 0 & 0 & 0 \\
\hline Monumetha albifrons.. & 0 & 0 & 1 & Halictus (Chloralictus) & & & & \\
\hline Osmia bruneri......... & 3 & 0 & 2 & sp........ & 1 & 1 & 0 & 0 \\
\hline densa........... & 10 & 15 & 2 & Osmia bruneri........ & 2 & 0 & 0 & 0 \\
\hline phaceliae....... & 1 & 14 & 13 & \multirow{5}{*}{$\begin{array}{r}\text { melanotricha... } \\
\text { pentstemonis... } \\
\text { Prosopis elliptica...... } \\
\text { Pseudomasaris vespoi- } \\
\text { des............... } \\
\text { Total.......... }\end{array}$} & 5 & 7 & 4 & $3 \mathrm{i}$ \\
\hline \multirow{2}{*}{$\begin{array}{r}\text { Prosopis basalis....... } \\
\text { Total......... }\end{array}$} & 0 & 3 & 9 & & 8 & 0 & 0 & 0 \\
\hline & 15 & 34 & $: 7$ & & & & & \\
\hline \multicolumn{4}{|c|}{ Expt. 2, 1 hour, 10 to 11 a.m., June 19.} & & & & & \\
\hline \multirow{2}{*}{ Species. } & \multirow{2}{*}{ Glaber. } & \multirow{2}{*}{$\begin{array}{l}\text { Unilat- } \\
\text { eralis. }\end{array}$} & \multirow{2}{*}{$\begin{array}{c}\text { Bar- } \\
\text { batus. }\end{array}$} & & & & & \\
\hline & & & & \multicolumn{5}{|c|}{ Expt. 5,1 hour, 9 to 10 a.m., July 14 . } \\
\hline Anthophora simillima.. & 1 & 0 & 0 & \multirow[b]{2}{*}{ Species. } & \multirow{2}{*}{$\begin{array}{l}\text { Pent. } \\
\text { glab. }\end{array}$} & \multirow{2}{*}{\multicolumn{2}{|c|}{$\begin{array}{l}\text { Geran. } \\
\text { caesp. }\end{array}$}} & \\
\hline $\begin{array}{l}\text { Bombus juxtus......... } \\
\text { Halictus pulzenus. }\end{array}$ & 4 & 2 & 0 & & & & & meadia \\
\hline Monumetha albifrons. . & $\begin{array}{l}2 \\
1\end{array}$ & $\begin{array}{l}0 \\
0\end{array}$ & $\begin{array}{l}0 \\
0\end{array}$ & \multirow{12}{*}{$\begin{array}{r}\text { Anthophora simillima.. } \\
\text { Apis mellifica......... } \\
\text { Halictus (Chloralictus) } \\
\text { sp........ } \\
\text { Osmia bruneri........ } \\
\text { pentstemonis.... } \\
\text { Prosopis varifrons.... } \\
\text { Total. ......... }\end{array}$} & \multirow{4}{*}{$\begin{array}{l}2 \\
1\end{array}$} & \multirow{4}{*}{\multicolumn{2}{|c|}{$\begin{array}{r}0 \\
19\end{array}$}} & \\
\hline Osmia phaceliae...... & 2 & 0 & 0 & & & & & 0 \\
\hline Vespa germanica...... & 1 & 0 & 0 & & & & & 0 \\
\hline \multirow{2}{*}{$\begin{array}{r}\text { Atry tone taxiles...... } \\
\text { Total......... }\end{array}$} & 2 & 0 & 0 & & & & & \\
\hline & 13 & 2 & 0 & & \multirow{2}{*}{$\begin{array}{l}0 \\
1 \\
5 \\
1\end{array}$} & \multirow{2}{*}{\multicolumn{2}{|c|}{$\begin{array}{l}1 \\
0\end{array}$}} & 0 \\
\hline \multicolumn{4}{|c|}{ Expt. 3, 1 hour, 11 a.m. to $12 \mathrm{~m}$., June 19.} & & & & & 0 \\
\hline Bombus juxtus & 6 & 10 & 0 & & \multirow[t]{6}{*}{10} & \multirow{6}{*}{\multicolumn{2}{|c|}{20}} & 0 \\
\hline Halictus pulzenus. & 0 & 3 & 0 & & & & & \\
\hline Osmia phaceliae. & 3 & 3 & 0 & & & & & \\
\hline Prosopis varifrons.. & 1 & 0 & 0 & & & & & \\
\hline Vespa germanica... & 1 & 1 & 0 & & & & & \\
\hline Total. . & 11 & 17 & 0 & & & & & \\
\hline
\end{tabular}

There were no visitors to the $P$. secundiflorus flowers when that bouquet was placed 6 inches from the $P$. gracilis plants. However, when these flowers were mixed in the same cluster, Osmia went from $P$. gracilis to $P$. secundiflorus and behaved in the same way at both species. It probably visited $P$. secundiflorus in this case without noticing that it had gone to a different flower. Although the corolla mouth of the $P$. secundiflorus flower is very large, Halictus went into it upside down just as in $P$. gracilis.

Summary. - In the competition with separate boquets, Pentstemon halli and gracilis were about twice as attractive as glaber, owing to the preference shown by Osmia and Prosopis. P. barbatus again received no visits, while the ratio between $P$. glaber and $P$. unilateralis was $24: 19$, this similarity being suggested by the resemblance of the flowers. The extra-regional 
species, $P$. halli and $P$. unilateralis, fared as well or better than the others, the neglect of the third, $P$. barbatus, obviously being due to its color or shape. When combined in one bouquet, $P$. glaber was several times more attractive than both $P$. halli and $P$. glaucus and about twice as attractive as Elephantella. While Osmia and Prosopis were both attracted by the latter, the one merely hovered and the other was unable to probe the

TABLE 80.-Natural and bouquet competition of Pentstemon gracilis.

\begin{tabular}{|c|c|c|c|c|c|}
\hline \multicolumn{3}{|c|}{ Expt. 1,8 to $10^{\mathrm{h}} 50^{\mathrm{m}}$ a.m., July 1 . } & \multicolumn{3}{|c|}{ Expt 3,9 to 10 a.m., June 17.} \\
\hline Species. & $\begin{array}{l}\text { Plant, P. } \\
\text { gracilis. }\end{array}$ & $\begin{array}{l}\text { Plant, G. } \\
\text { caespito- } \\
\text { sum. }\end{array}$ & Species. & $\begin{array}{c}\text { Plant, P. } \\
\text { gracilis. }\end{array}$ & $\begin{array}{c}\text { Bouquet, } \mathbf{R} \\
\text { deliciosus. }\end{array}$ \\
\hline \multirow{3}{*}{ 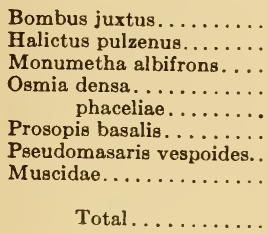 } & \multirow{2}{*}{$\begin{array}{r}1 \\
7 \\
0 \\
16 \\
9 \\
5 \\
0 \\
0\end{array}$} & \multirow{2}{*}{$\begin{array}{l}0 \\
4 \\
1 \\
1 \\
0 \\
0 \\
1 \\
1\end{array}$} & \multirow[t]{2}{*}{$\begin{array}{l}\text { Halictus pulzenus........ } \\
\text { Osmia pentstemonis...... } \\
\text { Prosopis varifrons....... } \\
\text { Syrphus americanus..... } \\
\quad \text { Total............. }\end{array}$} & $\begin{array}{l}5 \\
1 \\
1 \\
2\end{array}$ & $\begin{array}{l}0 \\
0 \\
0 \\
0\end{array}$ \\
\hline & & & & 9 & 0 \\
\hline & 38 & 8 & \multicolumn{3}{|c|}{ Expt. $4,10^{\mathrm{h}} 35^{\mathrm{m}}$ to $11^{\mathrm{h}} 35^{\mathrm{m}}$ a.m., June 17.} \\
\hline \multicolumn{3}{|c|}{ Expt. 2,8 to $11^{\mathrm{b}} 20^{\mathrm{m}}$ a.m., July 6 . } & Species. & $\begin{array}{c}\text { Bouquet, } P . \\
\text { gracilis. }\end{array}$ & $\begin{array}{l}\text { Plant, R. } \\
\text { deliciosus. }\end{array}$ \\
\hline \multirow{4}{*}{ 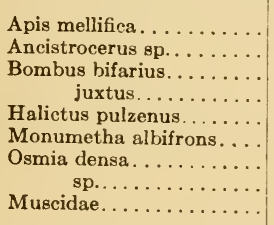 } & \multirow{4}{*}{$\begin{array}{l}0 \\
0 \\
7 \\
5 \\
0 \\
4 \\
0 \\
0 \\
0\end{array}$} & \multirow{4}{*}{$\begin{array}{l}4 \\
1 \\
0 \\
0 \\
1 \\
7 \\
1 \\
1 \\
1\end{array}$} & \multirow{2}{*}{$\begin{array}{r}\text { Colletes oromontis....... } \\
\text { Diptera.............. } \\
\text { Total........... }\end{array}$} & $\begin{array}{l}0 \\
0 \\
\end{array}$ & $\begin{array}{r}24 \\
1 \\
\end{array}$ \\
\hline & & & & 0 & 25 \\
\hline & & & \multicolumn{3}{|c|}{ Expt. 5,2 to 3 p.m., July 12.} \\
\hline & & & \multirow[b]{2}{*}{ Species. } & \multirow{2}{*}{$\begin{array}{l}\text { Plant, P. } \\
\text { gracilis. }\end{array}$} & \multirow{2}{*}{$\begin{array}{l}\text { Vials, C. } \\
\text { angustif. }\end{array}$} \\
\hline \multirow[t]{3}{*}{ Total. . } & \multirow[t]{3}{*}{16} & \multirow[t]{3}{*}{16} & & & \\
\hline & & & $\begin{array}{r}\text { Bombus bifarius......... } \\
\text { Osmia melanotricha...... } \\
\text { phaceliae......... } \\
\text { Prosopis elliptica....... }\end{array}$ & $\begin{array}{r}1 \\
10 \\
8 \\
7\end{array}$ & $\begin{array}{l}0 \\
0 \\
0 \\
1\end{array}$ \\
\hline & & & Total. . & 26 & 1 \\
\hline
\end{tabular}

tightly coiled beak. Though $P$. glaber attracted more species than geranium, the preference of $A$ pis for the latter gave it the lead. In the natural competition of Pentstemon gracilis and Geranium caespitosum the ratios were $38: 8$ and $16: 16$ on days about a week apart. This was due chiefly to the practical dropping out of Osmia and Prosopis in the second case. The results with bouquets and vials followed the rule, neither Pentstemon nor Rubus being visited when it was the bouquet and Chamaenerium flowers in 
vials receiving but 1 visit to 26 for those of $P$. gracilis in the natural position. The latter as the standard was about twice as attractive as $P$. secundiflorus, P. barbatus, and Scrophularia in a mixed bouquet.

TABLE 81.-Competition of Pentstemon gracilis standard and a mixed bouquet.

\begin{tabular}{|c|c|c|c|c|}
\hline \multicolumn{5}{|c|}{ Expt. 1, 1 hour, 11 a.m. to $12 \mathrm{~m}$., July 3 . } \\
\hline Species. & $\begin{array}{c}\text { Plant, } \\
\text { P. gracilis. }\end{array}$ & $\begin{array}{l}\text { Bouquet, } \\
\text { P. secund- } \\
\text { iflorus. }\end{array}$ & $\begin{array}{l}\text { Bouquet, } \\
\text { P. barbatus. }\end{array}$ & $\begin{array}{l}\text { Bouquet, } \\
\text { S. nodosa. }\end{array}$ \\
\hline 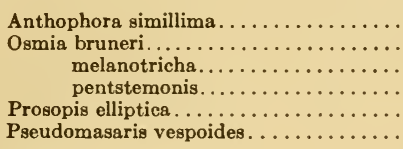 & $\begin{array}{l}0: 0 \\
0: 0 \\
6: 25 \\
6: 45 \\
1: 4 \\
2: 3\end{array}$ & $\begin{array}{l}1: 3 \\
3: 9 \\
0: 0 \\
2: 4 \\
1: 1 \\
1: 3\end{array}$ & $\begin{array}{l}0: 0 \\
0: 0 \\
0: 0 \\
0: 0 \\
0: 0 \\
0: 0\end{array}$ & $\begin{array}{ll}0: & 0 \\
0: & 0 \\
0: & 0 \\
0: & 0 \\
1: & 4 \\
3: 18 & \end{array}$ \\
\hline Total. & $15: 77$ & $8: 20$ & $0: 0$ & $4: 23$ \\
\hline \multicolumn{5}{|c|}{ Expt. 2,1 hour, $10^{\mathrm{h}} 40^{\mathrm{m}}$ to $11^{\mathrm{h}} 40^{\mathrm{m}}$ a.m., June 22 . } \\
\hline $\begin{array}{l}\text { Bombus juxtus } \ldots \ldots \ldots \ldots \ldots \ldots \ldots \ldots \ldots \ldots \\
\text { Halictus pulzenus } \ldots \ldots \ldots \ldots \ldots \ldots \ldots \ldots \ldots \\
\text { Osmia pentstemonis } \ldots \ldots \ldots \ldots \ldots \ldots \ldots \ldots \\
\text { Syrphus opinator. } \ldots \ldots \ldots \ldots \ldots \ldots \ldots\end{array}$ & $\begin{array}{l}0: 0 \\
1: 1 \\
8: 8 \\
1: 1\end{array}$ & $\begin{array}{l}1: 1 \\
1: 1 \\
1: 1 \\
1: 1\end{array}$ & $\begin{array}{l}0: 0 \\
0: 0 \\
0: 0 \\
0: 0\end{array}$ & $\begin{array}{ll}0: & 0 \\
0: 0 \\
0: & 0 \\
1: & 1\end{array}$ \\
\hline Total.... & $10: 10$ & 4: 4 & $0: 0$ & 1: 1 \\
\hline Grand total.... & $25: 87$ & $12: 24$ & $0: 0$ & $5: 23$ \\
\hline
\end{tabular}

\section{MONARDA FISTULOSA.}

Comparison.-A large number of species were used in competition with Monarda, in natural, bouquet, and group installations. The only one to resemble it at all closely was Gilia aggregata, with long, tubular pink corollas in an elongated cluster. The gamopetalous flowers of Gentiana parryi and Campanula rotundifolia departed widely in shape, color, and arrangement, as did also the zygomorphic Delphinium and the actinomorphic Geranium, Chamaenerium, and Calochortus gunnisoni. This was essentially true also of the three composites Achillea millefolium, Aster bigelovi, and Erigeron macranthus, the first with white rays and the last two with purple ones (plates $6,7,8$, and 10).

Experiments.-These include natural and bouquet competition, and the competition results of the Monarda calendars given in the preceding chapter.

Summary.-In natural competition with Geranium caespitosum, Campanula rotundifolia, and Achillea millefolium, Monarda was slightly less attractive than Geranium, owing to the decided preference of Bombus and Halictus for the latter. When Monarda was the standard in competition with a bouquet of Gentiana, Erigeron, and Calochortus, it was about twice 
TABLE 82.-Natural and bouquet competition.

\begin{tabular}{|c|c|c|c|c|c|}
\hline \multicolumn{3}{|c|}{ Expt. $1,11 / 2$ hours, 8 to $9^{\text {b }} 30^{\mathrm{m}}$ a.m., July 3 . } & \multicolumn{3}{|c|}{ Expt. 3,2 hours, $8^{\mathrm{h}} 57^{\mathrm{m}}$ to $10^{\mathrm{h}} 57^{\mathrm{m}}$ a.m., July 20 . } \\
\hline Species. & $\begin{array}{l}\text { Plant, } \\
\text { Mon. }\end{array}$ & $\begin{array}{l}\text { Plant, } \\
\text { Ger. }\end{array}$ & Species. & $\begin{array}{l}\text { Plant, } \\
\text { Mon. }\end{array}$ & $\begin{array}{l}\text { Bouquet, } \\
\text { Chamae. }\end{array}$ \\
\hline $\begin{array}{r}\text { Bombus juxtus...... } \\
\text { bifarius.... } \\
\text { proximus.... } \\
\text { Colletes oromontis... } \\
\text { Argynnis atlantis.... } \\
\text { Thanaos martialis.... }\end{array}$ & $\begin{array}{c}17: 44 \\
0 \\
0 \\
0 \\
1: \\
1: \\
1\end{array}$ & $\begin{array}{r}74 \\
85 \\
5 \\
2 \\
0 \\
0\end{array}$ & \multirow{6}{*}{ 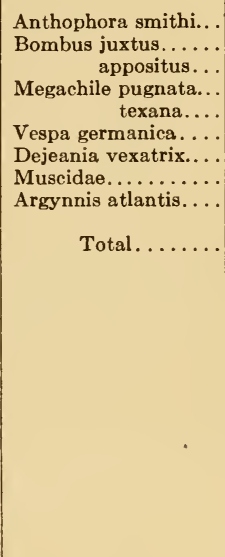 } & \multirow{2}{*}{$\begin{array}{c}0 \\
12: 169 \\
0 \\
0 \\
0 \\
1: 3 \\
0 \\
0 \\
1: 3\end{array}$} & \multirow{2}{*}{$\begin{array}{c}1: 2 \\
35: 222 \\
3: 8 \\
2: 4 \\
1: 2 \\
0 \\
1: 9 \\
3: 4 \\
0\end{array}$} \\
\hline Total.. & $19: 46$ & 166 & & & \\
\hline \multicolumn{3}{|c|}{ Expt. 2, 1 hour, 11 a.m. to 12 m., August 17.} & & \multirow[t]{4}{*}{$14: 175$} & \multirow[t]{4}{*}{$46: 251$} \\
\hline Species. & $\begin{array}{l}\text { Plant, } \\
\text { Mon. }\end{array}$ & $\begin{array}{c}\text { Bouquet, } \\
\text { Delph. }\end{array}$ & & & \\
\hline $\begin{array}{r}\text { Bombus proximus..... } \\
\text { morrisoni... } \\
\\
\text { edwardsi.... } \\
\text { juxtus..... } \\
\text { bifarius.... }\end{array}$ & $\begin{array}{r}134 \\
19 \\
46 \\
14 \\
11\end{array}$ & $\begin{array}{r}0 \\
96 \\
17 \\
6 \\
0\end{array}$ & & & \\
\hline Total... & 224 & 119 & & & \\
\hline
\end{tabular}

TABLE 83.-Natural competition of a group.

\begin{tabular}{|c|c|c|c|c|}
\hline \multicolumn{5}{|c|}{ One and one-half hours, 9 to $10^{\mathrm{h}} 30^{\mathrm{m}}$ a.m., August 2 . } \\
\hline Species. & Monarda. & Geranium. & Campanula. & Achillea. \\
\hline Bombus bifarius. & 0 & 50 & 0 & 0 \\
\hline $\begin{array}{l}\text { Bombus birarius. } \\
\text { hunti... }\end{array}$ & 4 & 0 & 0 & 0 \\
\hline occidentalis & 0 & 9 & 0 & 0 \\
\hline Clisodon terminalis.. & 30 & 1 & 0 & 0 \\
\hline Halictus (Lasioglossum) sp...... & 0 & 13 & 0 & 0 \\
\hline pulzenus................... & 0 & 10 & 0 & 0 \\
\hline Monumetha albifrons.............. & 0 & 2 & 0 & 0 \\
\hline Osmia phac liae.......... & 2 & 0 & 0 & 0 \\
\hline Prosopis wootoni.......... & 0 & 2 & 0 & 0 \\
\hline basalis......... & 0 & 1 & 0 & 0 \\
\hline Anthrax nigra........ & 0 & 0 & 0 & 3 \\
\hline Argynnis atlantis.......... & 4 & 0 & 0 & 0 \\
\hline Atrytone taxiles..... & 33 & 0 & 0 & 0 \\
\hline Total. & 73 & 88 & 0 & 3 \\
\hline
\end{tabular}

as attractive. In a test of plants of Monarda and Geranium, the latter was more than three times as attractive, Bombus bifarius going to it alone, and $B$. juxtus giving it a marked preference. Similar behavior of $B$. bifarius was the chief factor in causing a bouquet of Chamaenerium to be preferred 
to a plant of Monarda. However, while the latter obtained only a third as many visitors, these averaged 12 visits to it in contrast to 6 for the former.

In the three related series, the total number of visits to normal Monarda flowers was 2,397 , to mutilated ones 452 , and to the various competing flowers 449. There were outstanding differences between the different

TABLE 84.-Bouquet competition of a group.

\begin{tabular}{|c|c|c|c|c|}
\hline \multicolumn{5}{|c|}{ Two and a half hours, 9 to $11^{\mathrm{h}} 30^{\mathrm{m}}$, August 5 . } \\
\hline Species. & $\begin{array}{l}\text { Plant, } \\
\text { Monarda. }\end{array}$ & $\begin{array}{l}\text { Bouquet, } \\
\text { Gentiana. }\end{array}$ & $\begin{array}{l}\text { Bouquet, } \\
\text { Erigeron. }\end{array}$ & $\begin{array}{c}\text { Bouquet, } \\
\text { Calochortus. }\end{array}$ \\
\hline Bombus bifarius. . . . . . . . . . . & 0 & 0 & 3 & 0 \\
\hline juxtus..................... & 26 & 0 & 0 & 0 \\
\hline morrisoni .............. & 24 & 0 & 0 & 0 \\
\hline Halictus pulzenus. . . . . . . . . & 0 & 0 & 9 & 9 \\
\hline Prosopis elliptica. . . . . . . . . . & 1 & 0 & 1 & 2 \\
\hline Pseudomasaris vespoides. . . . . . . . & 0 & 0 & 0 & 1 \\
\hline Argynnis atlantis............ & 1 & 0 & 2 & 0 \\
\hline 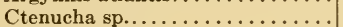 & 2 & 0 & 0 & 0 \\
\hline 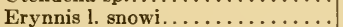 & 16 & 0 & 2 & 0 \\
\hline Coleoptera. .................. & 0 & 0 & 11 & 0 \\
\hline Total. ...... & 70 & 0 & 28 & 12 \\
\hline
\end{tabular}

TABLE 85.-Competition of normal and mutilated Monarda and other species.

First Series.

\begin{tabular}{|c|c|c|c|c|c|c|}
\hline Species. & $\begin{array}{c}\text { Normal } \\
\text { Monarda. }\end{array}$ & $\begin{array}{c}\text { Total } \\
\text { mutilated } \\
\text { Monarda. }\end{array}$ & $\begin{array}{l}\text { Monarda } \\
\text { composite. }\end{array}$ & $\begin{array}{l}\text { Chamae- } \\
\text { nerium } \\
\text { head. }\end{array}$ & $\begin{array}{c}\text { Normal } \\
\text { Geranium. }\end{array}$ & $\begin{array}{c}\text { Total } \\
\text { competi- } \\
\text { tors. }\end{array}$ \\
\hline Clisodon . . . . . . . . . . . . & 16 & 12 & 0 & 0 & 0 & 0 \\
\hline 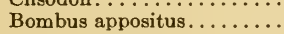 & 3 & 0 & 0 & 0 & 0 & 0 \\
\hline bifarius.. & 0 & 0 & 0 & 0 & 7 & 7 \\
\hline occidentalis... & 0 & 0 & 0 & 0 & 4 & 4 \\
\hline Argynnis $\ldots \ldots \ldots \ldots \ldots$ & 3 & 2 & 0 & 1 & 2 & 3 \\
\hline Atrytone............. & 26 & 6 & $5 \mathrm{~b}: 3 \mathrm{w}$ & 6 & 0 & 6 \\
\hline Erynnis.... & 2 & 0 & 0 & 0 & 0 & 0 \\
\hline Prosopis... & 0 & 0 & 0 & 5 & 0 & 0 \\
\hline Total..... & 50 & 20 & $5 \mathrm{~b}: 3 \mathrm{w}$ & 12 & 13 & 20 \\
\hline Clisodon. . & 16 & 2 & 0 & 0 & 0 & 0 \\
\hline Bombus appositus..... & 4 & 1 & 0 & 0 & 0 & 0 \\
\hline bifarius...... & 0 & 0 & 0 & 0 & 2 & 2 \\
\hline occidentalis... & 0 & 0 & 0 & 0 & 7 & 7 \\
\hline Monumetha......... & 2 & 0 & 0 & 0 & 0 & 0 \\
\hline Syrphus............... & 1 & 0 & 0 & 0 & 0 & 0 \\
\hline Atry tone......... & 7 & 7 & bwr & 0 & 0 & 0 \\
\hline Gnophaela........ & 7 & 0 & 0 & 0 & 0 & 0 \\
\hline Total... & 37 & 10 & bwr & 0 & 9 & 9 \\
\hline Grand total. . & 87 & 30 & $6 \mathrm{~b}: 4 \mathrm{w}: \mathrm{r}$ & 12 & 21 & 34 \\
\hline
\end{tabular}


TABLE 85-Competition of normal and mutilated Monarda and other species-Continued.

Second Series.

\begin{tabular}{|c|c|c|c|c|c|c|c|c|}
\hline Species. & $\begin{array}{c}\text { Normal } \\
\text { Monarda. }\end{array}$ & $\begin{array}{l}\text { Total } \\
\text { muti- } \\
\text { lated. }\end{array}$ & $\begin{array}{c}\text { Gilia } \\
\text { heads. }\end{array}$ & $\begin{array}{c}\text { Chamae. } \\
\text { head. }\end{array}$ & $\begin{array}{l}\text { Total } \\
\text { heads. }\end{array}$ & $\begin{array}{l}\text { Norm. } \\
\text { Chamae. }\end{array}$ & $\begin{array}{l}\text { Norm. } \\
\text { Ger. }\end{array}$ & $\begin{array}{c}\text { Total } \\
\text { competi- } \\
\text { tors. }\end{array}$ \\
\hline Clisodon.... & 621 & 15 & 0 & 0 & 0 & 0 & 0 & 1 \\
\hline Bombus appositus... & 220 & 28 & 6 Mon. & 0 & 6 Mon. & 8 & 0 & 8 \\
\hline juxtus...... & 94 & 45 & 0 & 0 & 0 & 1 & 0 & 1 \\
\hline morrisoni... & 13 & 0 & 0 & 0 & 0 & 0 & 0 & 0 \\
\hline Argynnis.. & 13 & 0 & 0 & 0 & 0 & 6 & 0 & 6 \\
\hline Erynnis.... & 100 & 43 & $\begin{array}{l}1 \mathrm{Mon} . \\
14 \mathrm{p} .\end{array}$ & 0 & 1 Mon. & 26 & 10 & 50 \\
\hline Total. & 1,061 & 131 & 7 Mon. & 0 & 7 Mon. & 41 & 10 & 66 \\
\hline Clisodon. & 9 & 3 & 0 & 0 & 0 & 0 & 0 & 0 \\
\hline Bombus appositus... & 27 & 0 & 0 & 0 & 0 & 0 & 0 & 0 \\
\hline juxtus. . & 13 & 0 & 0 & 1 & 1 & 3 & 22 & 26 \\
\hline edwardsi.... & 1 & 0 & 0 & 0 & 0 & 0 & 0 & 0 \\
\hline hunti.. & 40 & 3 & 0 & 0 & 0 & 10 & 0 & 10 \\
\hline occidentalis. & 0 & 0 & 0 & 0 & 0 & 0 & 14 & 14 \\
\hline morrisoni... & 0 & 0 & 0 & 0 & 0 & 0 & 1 & 1 \\
\hline H. (Lasioglossum) sp. & 0 & 0 & 0 & 0 & 0 & 0 & 2 & 2 \\
\hline pulzenus......... & 4 & 0 & 0 & 0 & 0 & 0 & 1 & 1 \\
\hline P. varifrons... & 0 & 0 & 0 & 0 & 0 & 0 & 1 & 1 \\
\hline Erynnis.. & 0 & 1 & 0 & 2 Mon. & 2 Mon. & 0 & 0 & 0 \\
\hline Total. & 94 & 7 & 0 & 1:2 Mon. & 1:2 Mon. & 13 & 41 & 55 \\
\hline Grand total... & 1,155 & 138 & 7 Mon. & 1:2 Mon. & 1:9 Mon. & 54 & 51 & 121 \\
\hline
\end{tabular}

Third Series.

\begin{tabular}{|c|c|c|c|c|c|c|c|c|c|}
\hline Species. & $\begin{array}{l}\text { Nor- } \\
\text { mal. }\end{array}$ & $\begin{array}{l}\text { Total } \\
\text { muti- } \\
\text { lated. }\end{array}$ & $\begin{array}{l}\text { Gilia } \\
\text { head. }\end{array}$ & $\begin{array}{c}\text { Chamae. } \\
\text { head. }\end{array}$ & $\begin{array}{l}\text { Total } \\
\text { heads. }\end{array}$ & $\begin{array}{c}\text { Norm. } \\
\text { Chamae. }\end{array}$ & $\begin{array}{c}\text { Norm. } \\
\text { Ger. }\end{array}$ & $\begin{array}{l}\text { Norm. } \\
\text { Aster. }\end{array}$ & $\begin{array}{c}\text { Total } \\
\text { competi- } \\
\text { tors. }\end{array}$ \\
\hline Clisodon.... & 309 & 51 & 0 & 0 & 0 & 7 & 0 & 1 & 8 \\
\hline Bombus appositus.. & 151 & 7 & 0 & 0 & 0 & 1 & 0 & 0 & 1 \\
\hline juxtus.. & 113 & 37 & 0 & 2 & 2 & 25 & 2 & 0 & 29 \\
\hline morrisoni.. & 2 & 1 & 3 & 4 & 7 & 0 & 0 & 0 & 7 \\
\hline Erynnis... & 161 & 77 & 3 & 0 & 3 & 7 & 1 & 0 & 11 \\
\hline Argynnis........ & 187 & 35 & 0 & 0 & 0 & 1 & 0 & 0 & 1 \\
\hline Total. & 923 & 208 & 6 & 6 & 12 & 41 & 3 & 1 & 57 \\
\hline Clisodon.. & 38 & 27 & 0 & 0 & 0 & 0 & 0 & 0 & 0 \\
\hline Bombus juxtus. & 0 & 0 & 0 & 0 & 0 & 9 & 0 & 0 & 9 \\
\hline morrisoni.. & 16 & 0 & 0 & 0 & 0 & 2 & 0 & 0 & 2 \\
\hline bifarius... & 8 & 0 & 0 & 0 & 0 & 25 & 1 & 0 & 26 \\
\hline hunti.. & 0 & 0 & 0 & 0 & 0 & 90 & 0 & 1 & 91 \\
\hline H. pulzenus. & 2 & 0 & 0 & 0 & 0 & 0 & 0 & 51 & 51 \\
\hline Andrena..... & 0 & 0 & 0 & 0 & 0 & 9 & 0 & 7 & 16 \\
\hline Colletes........ & 0 & 0 & 0 & 0 & 0 & 0 & 0 & 2 & 2 \\
\hline Erynnis... & 125 & 41 & 1 & 0 & 1 & 24 & 0 & 12 & 37 \\
\hline Argynnis........ & 21 & 8 & 0 & 0 & 0 & 0 & 0 & 0 & 0 \\
\hline Atrytone.... & 4 & 0 & 0 & 0 & 0 & 2 & 0 & 0 & 2 \\
\hline Syrphus... & 17 & 0 & 0 & 0 & 0 & 0 & 0 & 0 & 0 \\
\hline Aristatus. . . . . . & 1 & 0 & 0 & 0 & 0 & 0 & 0 & 0 & $\mathbf{0}$ \\
\hline Eristalis... & 0 & 0 & 0 & 0 & 0 & 1 & 0 & 0 & 1 \\
\hline Total.. & 232 & 76 & 1 & 0 & 1 & 162 & 1 & 73 & 237 \\
\hline Grand total. . & 1,155 & 284 & 7 & 6 & 13 & 203 & 4 & 74 & 294 \\
\hline
\end{tabular}


series as well as between the two calendars made at the same time, as shown in table 86 .

The greatest difference is shown by the two calendars of series 3 , in which the marked constancy of Clisodon and Bombus appositus and their vastly greater abundance in the one place furnishes the explanation. Corresponding differences may also be noted with respect to the response to the several competitors. Normal Geranium flowers and composite heads of Chamaenerium were twice visited equally, though as a rule these artificial heads were neglected. A marked exception occurred in the second series, where 14 flowers of a pure Gilia head were visited by Argynnis. As between normal Chamaenerium and normal Geranium, the former was thrice as attractive all told, though the relative positions were reversed in the calendars of the second series. In this competition B. bifarius and $B$. hunti were partial to Chamaenerium and $B$. occidentalis to Geranium, while $B$. juxtus preferred Geranium in one series and Chamaenerium in the other.

TABLE 86.-Summary of normal and competing flowers by series and calendars.

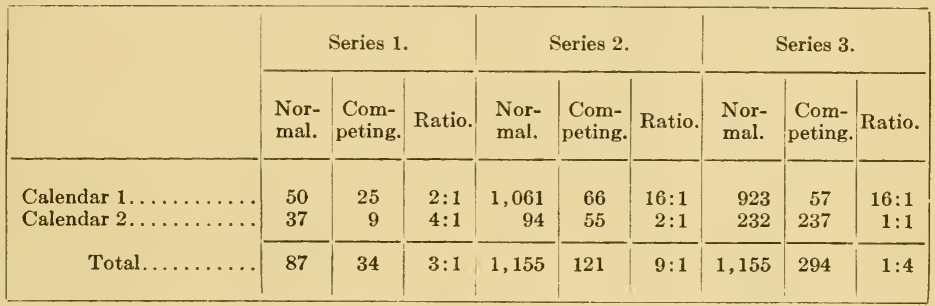

\section{COMPOSITION AND WEIGHT OF POLLEN LOADS.}

Value and methods. - While occasional observations of the purity of pollen loads have been recorded (Bennett, 1874; Perez, 1903), no previous microscopical analysis of loads seems to have been made. The latter were undertaken in the first place as a check upon the habits observed in the field, and were extended to include the weight of the bee and its pollen load as a measure of its efficiency in collecting and in flight. Unfortunately, it was not until these preliminary studies were practically finished that it was realized that the time of flight should have been recorded, since the degree of constancy varies much between morning or evening on the one hand and mid-day on the other. There is also an evident difference in individual efficiency, which can be determined only by the use of marked bees.

As a rule the bees were weighed immediately after being caught, the load completely removed by means of a needle, and the body weighed again. In a few cases the bees were dry, and corresponding allowance must be made with respect to the percentage weight of the load. In the tables the name of the species on which the insect was captured is given first in each case; when the bee had collected none of this pollen, it is indicated. For a number of specimens previously collected (designated by a letter), the pollen was examined, but the weight of the load was not determined. 
TABLE 87.-Composition and weight of pollen loads.

ApIs MellificA.

\begin{tabular}{|c|c|c|c|c|c|}
\hline Date. & $\begin{array}{c}\text { Catalogue } \\
\text { No. }\end{array}$ & $\begin{array}{c}\text { Weight of } \\
\text { bee. }\end{array}$ & $\begin{array}{c}\text { Weight of } \\
\text { load. }\end{array}$ & $\begin{array}{l}\text { Load, p. ct. } \\
\text { of bee's } \\
\text { weight. }\end{array}$ & Composition of load. \\
\hline $\begin{array}{c}\text { June } 21 \\
\text { Do. } \\
\text { Do. } \\
\text { Do. } \\
\text { Do. } \\
\text { Do. } \\
\text { Do. } \\
\text { Do. } \\
\text { Do. } \\
\text { Do. } \\
\text { Dry. } \\
\text { June } 7 \\
\text { Do. } \\
\text { Do. } \\
\text { Do. } \\
\text { Do. } \\
\text { Do. } \\
\text { Do. } \\
\text { Do. } \\
\text { Do. } \\
\text { Do. } \\
\text { Do. } \\
\text { Do. } \\
\text { July } 23 \\
\text { Do. } \\
\text { July } 28 \\
\text { Do. } \\
\text { July } 30 \\
\text { Do. } \\
\text { Do. }\end{array}$ & $\begin{array}{r}1 \\
2 \\
3 \\
4 \\
5 \\
6 \\
7 \\
8 \\
9 \\
10 \\
49 \\
50 \\
51 \\
52 \\
99 \\
100 \\
101 \\
102 \\
103 \\
104 \\
105 \\
106 \\
123 \\
125 \\
167 \\
\\
169 \\
170 \\
171 \\
172 \\
\\
\\
\text { A } \\
\text { B } \\
\text { C }\end{array}$ & $\begin{array}{c}g m . \\
0.0780 \\
.0800 \\
.0710 \\
.0858 \\
.0930 \\
.0820 \\
.0738 \\
.0800 \\
.0725 \\
.0670 \\
.0262 \\
.0315 \\
.0250 \\
.0250 \\
.0250 \\
.0275 \\
.0300 \\
.0275 \\
.0280 \\
.0230 \\
.0260 \\
.0335 \\
.0750 \\
.1020 \\
.0760 \\
.0900 \\
.1015 \\
.0950 \\
.0950 \\
\text { Number } \\
\text { examined. } \\
1 \\
1 \\
1 \\
\end{array}$ & $\begin{array}{c}g m . \\
0.0168 \\
.0190 \\
.0188 \\
.0210 \\
.0120 \\
.0190 \\
.0120 \\
.0250 \\
.0235 \\
.0200 \\
.0113 \\
.0125 \\
.0095 \\
.0120 \\
.0200 \\
.0145 \\
.0108 \\
.0135 \\
.0145 \\
.0045 \\
.0040 \\
.0065 \\
.0085 \\
.0090 \\
.0190 \\
.0080 \\
.0185 \\
.0245 \\
.0130\end{array}$ & $\begin{array}{r}p . c t . \\
21.4 \\
24.0 \\
26.5 \\
24.5 \\
13.0 \\
23.2 \\
16.2 \\
31.2 \\
32.4 \\
30.0 \\
44.0 \\
39.0 \\
38.0 \\
50.0 \\
8.0 \\
52.0 \\
36.0 \\
49.0 \\
52.0 \\
19.0 \\
16.0 \\
19.0 \\
11.0 \\
9.0 \\
25.0 \\
9 \\
9.0 \\
18.0 \\
26.0 \\
14.0\end{array}$ & $\begin{array}{l}\text { Rubus deliciosus, pure. } \\
\text { Do. } \\
\text { Do. } \\
\text { Do. } \\
\text { Do. } \\
\text { Do. } \\
\text { Do } \\
\text { Do. } \\
\text { Do. } \\
\text { Do. } \\
\text { Do. } \\
\text { Do. } \\
\text { Do. } \\
\text { Do. } \\
\text { Do. } \\
\text { Do. } \\
\text { Do. } \\
\text { Do. } \\
\text { Do. } \\
\text { Do. } \\
\text { Do. } \\
\text { Do. } \\
\text { Geranium caespitosum, pure. } \\
\text { Geranium caespitosum, } 1 \text { p. ct. } \\
\text { Holodiscus dumosus, } 99 \text { p. ct. } \\
\text { Chamaenerium angustifolium, } \\
\text { pure. } \\
\text { Do. } \\
\text { Do. } \\
\text { Do. } \\
\text { Do. } \\
\\
\text { Geranium caespitosum, } 99 \text { p. ct. } \\
\text { R. acic. and P. gracilis, } 1 \text { p. ct. } \\
\text { Solidago, } 95 \text { p. ct.; ?5. } \\
\text { Petalostemon purpureus, } 99 \text { p. ct. }\end{array}$ \\
\hline \multicolumn{6}{|c|}{ ANDRENA CRATAEGI. } \\
\hline $\begin{array}{c}\text { June } 22 \\
\text { Do. } \\
\text { Do. } \\
\text { Do. } \\
\text { July } 3 \\
\text { July } 6 \\
\text { Do. } \\
\text { Do. } \\
\text { July } 23\end{array}$ & $\begin{array}{r}30 \\
31 \\
40 \\
41 \\
68 \\
78 \\
79 \\
80 \\
128\end{array}$ & $\begin{array}{c}g m . \\
0.0469 \\
.0537 \\
.0520 \\
.0687 \\
.0520 \\
.0490 \\
.0470 \\
.0500 \\
.0395 \\
\\
\text { Number } \\
\text { examined. } \\
2 \\
7\end{array}$ & $\begin{array}{r}g m . \\
0.0058 \\
.0053 \\
.0075 \\
.0095 \\
.0090 \\
.0070 \\
.0055 \\
.0050 \\
.0035\end{array}$ & $\begin{array}{c}p . c t . \\
12 \\
10 \\
14 \\
14 \\
17 \\
5 \\
11 \\
10 \\
8\end{array}$ & $\begin{array}{l}\text { Rubus deliciosus, } 99.5 \text { p. ct.; } ? .5 \text {. } \\
\text { Rubus deliciosus, pure. } \\
\text { Do. } \\
\text { Do. } \\
\text { Rosa acicularis, pure. } \\
\text { Rubus deliciosus, pure. } \\
\text { \{ubus deliciosus, } 25 \text { p. ct. } \\
\text { Rubus strigosus, } 75 \text { p. ct. } \\
\text { Rubus strigosus, pure. } \\
\text { Garanium caespitosum, } 10 \text { p. ct. } \\
\text { Holodiscus dumosus, } 90 \text { p. ct. } \\
\\
\text { Prunus demissa, pure. } \\
\text { Rubus strigosus, pure. }\end{array}$ \\
\hline
\end{tabular}


POLLEN LOADS.

TABLE 87.-Composition and weight of pollen loads-Continued.

Andrena edwineaE.

\begin{tabular}{|c|c|c|c|c|c|}
\hline Date. & $\begin{array}{c}\text { Catalogue } \\
\text { No. }\end{array}$ & $\begin{array}{c}\text { Weight of } \\
\text { bee. }\end{array}$ & $\begin{array}{c}\text { Weight of } \\
\text { load. }\end{array}$ & $\begin{array}{c}\text { Load, p.ct. } \\
\text { of bee's } \\
\text { weight. }\end{array}$ & Composition of load. \\
\hline & C & $\frac{o m .}{1}$ & $g m$. & $\begin{array}{l}p . c t . \\
\cdots \cdots \cdots\end{array}$ & Jamesia americana, pure. \\
\hline \multicolumn{6}{|c|}{ ANDRENA MADRONITENS. } \\
\hline $\begin{array}{l}\text { July } 23 \\
\text { July } 24 \\
\text { July } 25\end{array}$ & $\begin{array}{r}135 \\
148 \\
\text { D }\end{array}$ & $\begin{array}{c}g m . \\
0.0320 \\
.0365 \\
.0380 \\
2\end{array}$ & $\begin{array}{r}g m . \\
0.0045 \\
.0050 \\
.0080\end{array}$ & $\begin{array}{l}\text { p. ct. } \\
14 \\
14 \\
21\end{array}$ & $\begin{array}{l}\text { Geranium caespitosum, } 1 \text { p. ct. } \\
\text { Holodiscus dumosus, } 97 \text { p. ct. } \\
\text { Oenothera biennis, } 2 \text { p. ct. } \\
\text { Frasera speciosa, } 97 \text { p. ct. } \\
\text { Geranium caespitosum, } 3 \text { p. ct. } \\
\text { Frasera speciosa, } 5 \text { p. ct. } \\
\text { Sedum stenopetalum, } 95 \text { p. ct. } \\
\text { Rubus deliciosus, pure. }\end{array}$ \\
\hline \multicolumn{6}{|c|}{ ANDRENA VICINA. } \\
\hline $\begin{array}{c}\text { June } 23 \\
\text { Do. }\end{array}$ & $\begin{array}{l}28 \\
29 \\
\\
\mathrm{E} \\
\mathrm{F}\end{array}$ & $\begin{array}{c}g m . \\
0.1045 \\
.0700 \\
\text { Number } \\
\text { examined. } \\
2 \\
1\end{array}$ & $\begin{array}{c}g m . \\
0.0065 \\
.0100\end{array}$ & $\begin{array}{c}\text { p. ct. } \\
6 \\
13\end{array}$ & $\begin{array}{l}\text { Rubus deliciosus, pure. } \\
\text { Do. } \\
\text { Rosa acicularis, } 99 \text { p. ct.; ?1. } \\
\text { Rubus deliciosus, } 99 \text { p. ct.; ?1. }\end{array}$ \\
\hline \multicolumn{6}{|c|}{ ANTHOPHORA SIMILLIMA. } \\
\hline $\begin{array}{l}\text { June } 23 \\
\text { July } \\
\text { July } 8\end{array}$ & $\begin{array}{l}62 \\
94 \\
\text { A } \\
\text { B }\end{array}$ & $\begin{array}{c}.1275 \\
.1400 \\
. \text { Number } \\
\text { examined. } \\
1 \\
1\end{array}$ & $\begin{array}{c}g m . \\
0.0079\end{array}$ & $\begin{array}{r}\text { p. ct. } \\
5.0\end{array}$ & 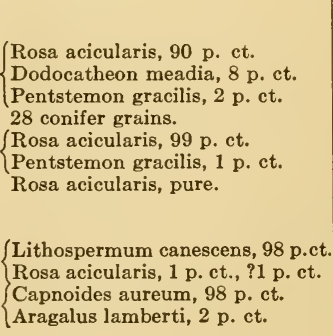 \\
\hline \multicolumn{6}{|c|}{ BOMBUS APPOSITUS. } \\
\hline & A & $\begin{array}{c}\text { Number } \\
\text { examined. } \\
1\end{array}$ & & p. ct. & $\begin{array}{l}\text { Petalostemon purpureus, } 70 \text { p. ct. } \\
\text { Compositae, } 30 \text { p. ct. }\end{array}$ \\
\hline
\end{tabular}


TABLE 87.-Composition and weight of pollen loads-Continued.

BombUs BIFARIUs.

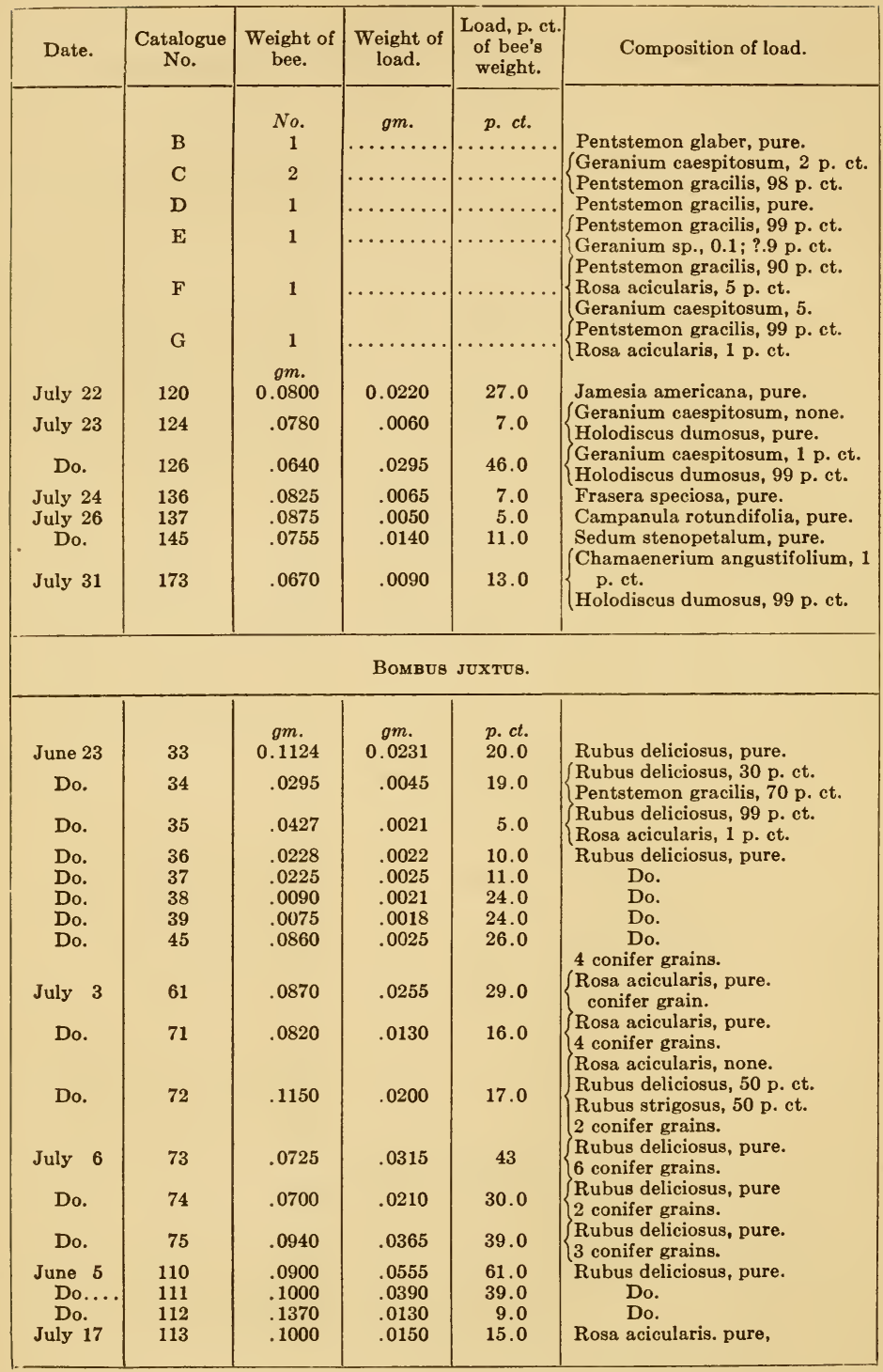


TABLE 87.-Composition and weight of pollen loads-Continued.

Вомвus Juxtus-Continued.

\begin{tabular}{|c|c|c|c|c|c|}
\hline Date. & $\begin{array}{c}\text { Catalogue } \\
\text { No. }\end{array}$ & $\begin{array}{c}\text { Weight of } \\
\text { bee. }\end{array}$ & $\begin{array}{l}\text { Weight of } \\
\text { load. }\end{array}$ & $\begin{array}{c}\text { Load, p. ct. } \\
\text { of bee's } \\
\text { weight. }\end{array}$ & Composition of load. \\
\hline July 17 & 114 & $\begin{array}{c}g m . \\
0.0850\end{array}$ & $\begin{array}{c}g m . \\
0.0050\end{array}$ & $\begin{array}{c}\text { p. ct. } \\
3.0\end{array}$ & \multirow{6}{*}{ 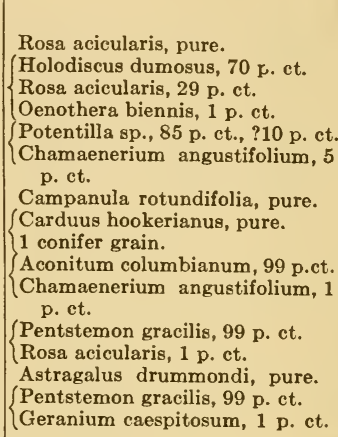 } \\
\hline July 21 & 116 & .0915 & 0.0110 & 12.0 & \\
\hline July 22 & 117 & .0880 & .0125 & 1.0 & \\
\hline July 26 & 138 & .1010 & .0045 & 4.0 & \\
\hline July 25 & 147 & .0955 & .0135 & 14.0 & \\
\hline & $\begin{array}{l}\mathrm{m} \\
\mathrm{n} \\
\mathrm{0}\end{array}$ & & & & \\
\hline
\end{tabular}

BOMBUS KIRBYELLUS.

\begin{tabular}{|c|c|c|c|c|c|}
\hline July 3 & 70 & 0.5940 & 0.0275 & 4 & Frasera speciosa, pure. \\
\hline July 25 & 149 & .2395 & .0065 & 12 & Castilleia p. occidentalis pure. \\
\hline Do. & 150 & .1000 & .0200 & 20 & Do. \\
\hline Do. & 151 & 1470 & .0190 & 13 & Do. \\
\hline Do. & 152 & .1030 & .0100 & 9 & Do. \\
\hline Do. & 153 & .0720 & .0140 & 20 & Do. \\
\hline Do. & 154 & .0700 & .0100 & 13 & Do. \\
\hline Do. & 155 & 1480 & .0140 & 9 & Do. \\
\hline Do. & 156 & .2700 & .0380 & 14 & $\left\{\begin{array}{l}\text { Pedicularis parryi, none. } \\
\text { Castilleia p occidentalis }\end{array}\right.$ \\
\hline Do. & 157 & .0600 & .0050 & 8 & Castilleia p occidentalis, pure. \\
\hline Do. & 158 & .1020 & .0315 & 30 & $\{$ Pentstemon glaber, 95 p. ct. \\
\hline $\begin{array}{l}\text { Do. } \\
\text { Do. }\end{array}$ & $\begin{array}{l}159 \\
160\end{array}$ & $\begin{array}{l}.1045 \\
.0800\end{array}$ & $\begin{array}{l}.0095 \\
.0220\end{array}$ & $\begin{array}{r}9 \\
20\end{array}$ & $\begin{array}{l}\text { Castilleia p. occidentalis, pure. } \\
\text { Do. }\end{array}$ \\
\hline Do. & 161 & 1200 & .0090 & 8 & $\{$ Castilleia p. occidentalis, 90 p. ct. \\
\hline Do. & 162 & .1450 & .0250 & 17 & Castilleia p. occidentalis, pure. \\
\hline Do. & 163 & 1800 & .0200 & 11 & $\left\{\begin{array}{l}\text { Trifolium dasyphyllum, } 50 \text { p. ct. } \\
\text { Castilleia p. occidentalis, } 48 \text {; } \\
\text { ?2 p. ct. }\end{array}\right.$ \\
\hline Do. & 164 & .1050 & .0220 & 12 & $\left\{\begin{array}{l}\text { Trifolium dasyphyllum, } 50 \text { p. ct. } \\
\text { Castilleia p. occidentalis, } 50 .\end{array}\right.$ \\
\hline Do. & 165 & .0805 & .0085 & 11 & $\left\{\begin{array}{l}\text { Trifolium dasyphyllum, } 97 \text { p. ct. } \\
\text { Composite, } 3 \text { p. ct. }\end{array}\right.$ \\
\hline
\end{tabular}

BombUs OCCIDENTALIS.

\begin{tabular}{|c|c|c|c|c|c|}
\hline June 30 & 48 & 0.1400 & 0.0250 & 18.0 & $\left\{\begin{array}{l}\text { Rosa acicularis, } 99 \text { p. ct. } \\
\text {. }\end{array}\right.$ \\
\hline July 3 & 63 & .1330 & .0530 & 40.0 & Rosa acicularis, pure. \\
\hline Do. & 64 & .1400 & .0390 & 28.0 & $\left\{\begin{array}{l}\text { Rosa acicularis, } 95 \text { p. ct. } \\
\text { Rubus deliciosus, } 5 \text { p. ct. }\end{array}\right.$ \\
\hline
\end{tabular}


TABLE 87.-Composition and weight of pollen loads-Continued.

Bombus occidentalis-Continued.

\begin{tabular}{|c|c|c|c|c|c|}
\hline Date. & $\begin{array}{c}\text { Catalogue } \\
\text { No. }\end{array}$ & $\begin{array}{l}\text { Weight of } \\
\text { bee. }\end{array}$ & $\begin{array}{l}\text { Weight of } \\
\text { load. }\end{array}$ & $\begin{array}{c}\text { Load, p. ct. } \\
\text { of bee's } \\
\text { weight. }\end{array}$ & Composition of load. \\
\hline & & $g m$. & gm. & p. ct. & \multirow{15}{*}{ 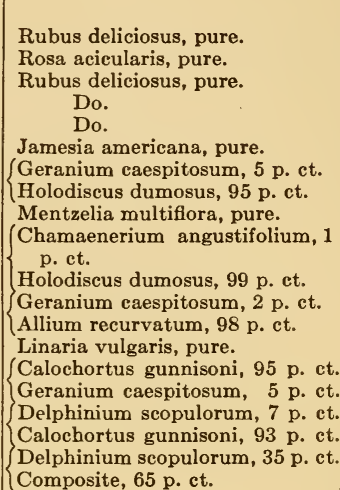 } \\
\hline July 6 & 76 & 0.1060 & 0.0080 & 7.0 & \\
\hline July 8 & 90 & .1650 & .0420 & 25.0 & \\
\hline June 5 & 107 & .1385 & .0650 & 47.0 & \\
\hline Do. & 108 & .1620 & .0727 & 45.0 & \\
\hline Do. & 109 & .1590 & .0730 & 46.0 & \\
\hline July 22 & 119 & .2450 & .0625 & 25.0 & \\
\hline July 23 & 122 & .1750 & .0465 & 26.0 & \\
\hline July 22 & 134 & .1580 & .0300 & 19.0 & \\
\hline July 31 & 174 & .0955 & .0045 & 4.0 & \\
\hline \multirow[t]{5}{*}{ Aug. 5} & 175 & .1435 & .0355 & 24.0 & \\
\hline & $\mathrm{H}$ & & & & \\
\hline & $\mathbf{I}$ & & & & \\
\hline & $\mathbf{J}$ & & & & \\
\hline & & & & & \\
\hline
\end{tabular}

Bombus occidentalis:

Percentage composition Cat. No. L (Delphinium scopulorum. ................ 95

$\left\{\begin{array}{l}\text { Composite. . . . . . } \ldots \ldots \ldots \ldots \ldots \ldots \ldots \ldots \ldots \ldots \ldots \ldots \ldots \ldots \\ 5\end{array}\right.$

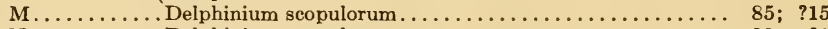

N. . . . . . . Delphinium scopulorum . . . . . . . . . . . . . . 99 ;1

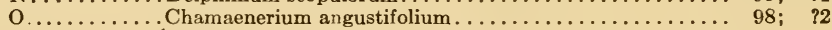

P........ $\{$ Chamaenerium angustifolium ................ 95

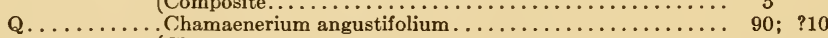

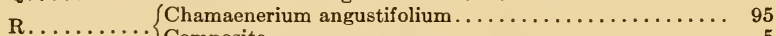

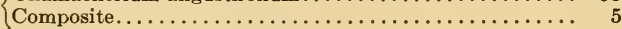

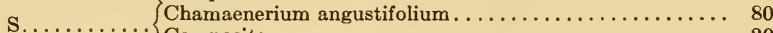

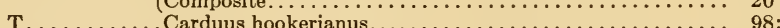

Bombus centralis:

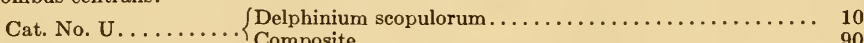

Bombus edwardsii:

Cat. No. V..........Petalostemon purpureus.................. 99

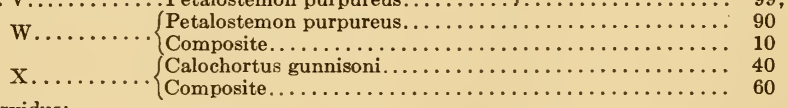

Bombus fervidus:

Cat. No. Y .........Petalostemon purpureus................. 98;

Bombus flavifrons:

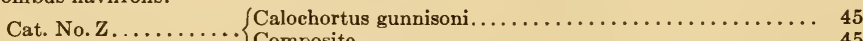

$\left\{\begin{array}{l}\text { Calochortus gunnisom } \ldots \ldots \ldots \ldots \ldots \ldots \ldots \ldots \ldots \ldots \ldots \ldots \ldots \ldots \ldots \ldots \ldots \ldots \ldots \ldots \ldots \ldots \ldots \ldots \ldots \\ \text { Composite } \ldots \ldots \ldots \ldots \ldots \ldots \ldots\end{array}\right.$

Bombus hunti:

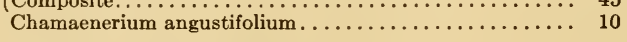

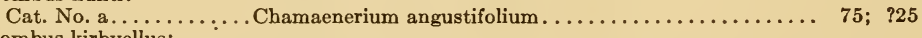

Bombus kirbyellus:

Cat. No. b. . . . . . Rubus deliciosus. . . . . . . . . . . . . . . . 99 ; 
TABLE 87.-Composition and weight of pollen loads-Continued.

Bombus morrisoni:

Percentage composition of load.

Cat. No. c..

Bombus proximus:

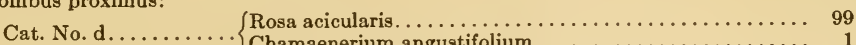

Chamaenerium angustifolium................ 1

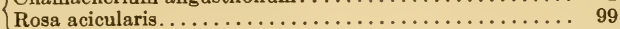

$\left\{\begin{array}{l}\text { Rosa acicularis } \ldots \ldots \ldots \ldots \ldots \ldots \ldots \ldots \ldots \ldots \ldots \ldots \ldots \ldots \\ \text { Chamaenerium angustifolium. }\end{array}\right.$

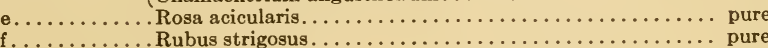

Rosa acicularis. . . . . . . . . . . . . . . . . . . . . . 99

Bombus rufocinctus:

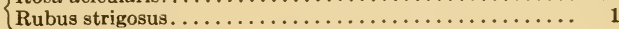

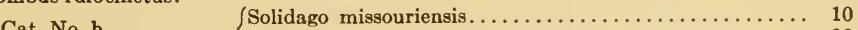

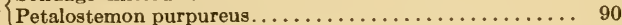

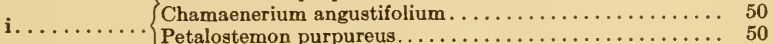

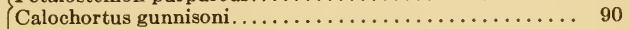

j. ........ $\left\{\begin{array}{l}\text { Geranium caespitosum } \ldots \ldots \ldots \ldots \ldots \ldots \ldots \ldots \ldots \ldots \ldots \\ 2\end{array}\right.$

$\left\{\begin{array}{l}\text { Geranium caespitosum } \ldots \ldots \ldots \ldots \ldots \ldots \ldots \ldots \ldots \ldots \ldots \ldots \ldots \ldots \ldots \ldots \ldots \ldots \ldots \ldots \ldots \ldots \ldots \ldots \ldots \ldots \ldots \ldots \ldots \ldots \ldots \\ \text { Composite } \ldots \ldots \ldots \ldots \ldots \ldots \ldots \ldots \ldots\end{array}\right.$

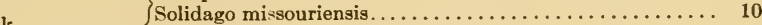

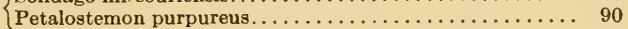

Clisodon terminalis

\begin{tabular}{|c|c|c|c|c|c|}
\hline Date. & $\begin{array}{l}\text { Catalogue } \\
\text { No. }\end{array}$ & $\begin{array}{l}\text { Weight of } \\
\text { bee. }\end{array}$ & $\begin{array}{l}\text { Weight of } \\
\text { load. }\end{array}$ & $\begin{array}{l}\text { Load, p. ct. } \\
\text { of bee's } \\
\text { weight. }\end{array}$ & Composition of load. \\
\hline July 17 & 115 & $\begin{array}{c}g m . \\
0.1010\end{array}$ & $\begin{array}{l}g m . \\
0.0040\end{array}$ & $\begin{array}{l}\text { p. } c t \text {. } \\
4.0\end{array}$ & $\left\{\begin{array}{l}\text { Rosa acicularis, } 70 \text { p. ct. } \\
\text { Mertensia sibirica, } 29 \text { p. ct. } \\
\text { Geranium caespitosum, } 1 \text { p. ct. }\end{array}\right.$ \\
\hline \multicolumn{6}{|c|}{ Colletes oromontis. } \\
\hline July 23 & 133 & $\begin{array}{c}g m . \\
0.0045\end{array}$ & $\begin{array}{c}g m . \\
0.0015\end{array}$ & $\begin{array}{l}\text { p. ct. } \\
33.0\end{array}$ & $\left\{\begin{array}{l}\text { Geranium caespitosum, } 1 \text { p. ct. } \\
\text { Holodiscus dumosus, } 99 \text { p. ct. }\end{array}\right.$ \\
\hline \multicolumn{6}{|c|}{ Halictus medionitens. } \\
\hline $\begin{array}{lr}\text { June } & 23 \\
& \\
\text { July } & 8 \\
\text { July } & 8 \\
\text { July } & 23\end{array}$ & $\begin{array}{r}96 \\
97 \\
130\end{array}$ & $\begin{array}{c}g m . \\
0.0011 \\
.0320 \\
.0058 \\
.0060\end{array}$ & $\begin{array}{c}g m . \\
0.0003 \\
.0030 \\
.0012 \\
.0020\end{array}$ & $\begin{array}{r}\text { p. } c t . \\
27.0 \\
9.0 \\
21.0 \\
33.0\end{array}$ & $\begin{array}{l}\left\{\begin{array}{l}\text { Rubus deliciosus, } 70 \text { p. ct. } \\
\text { Rosa acicularis, } 25 \text { p. ct. } \\
\text { Potentilla pulcherrima, } 5 \text { p. ct. } \\
\text { Rosa acicularis, } 95 \text { p. ct. } \\
\text { Rubus deliciosus, } 5 \text { p. ct. }\end{array}\right. \\
\text { Rosa acicularis, pure. }\end{array}$ \\
\hline \multicolumn{6}{|c|}{ Halictus pulzenus. } \\
\hline & $\begin{array}{l}\text { A } \\
\text { B } \\
\text { C } \\
\text { D }\end{array}$ & & & $\begin{array}{l}\ldots \ldots \ldots \cdots \\
\cdots \cdots \cdots \cdots \\
\cdots \cdots \cdots\end{array}$ & $\begin{array}{l}\left\{\begin{array}{l}\text { Geranium caespitosum, none. } \\
\text { Unknown, pure. }\end{array}\right. \\
\text { Geranium richardsoni, pure. } \\
\text { Rosa acicularis, pure. } \\
\text { Rubus strigosus, pure. }\end{array}$ \\
\hline
\end{tabular}


TABLE 87.-Composition and weight of pollen loads-Continued.

Megachile pUonata.

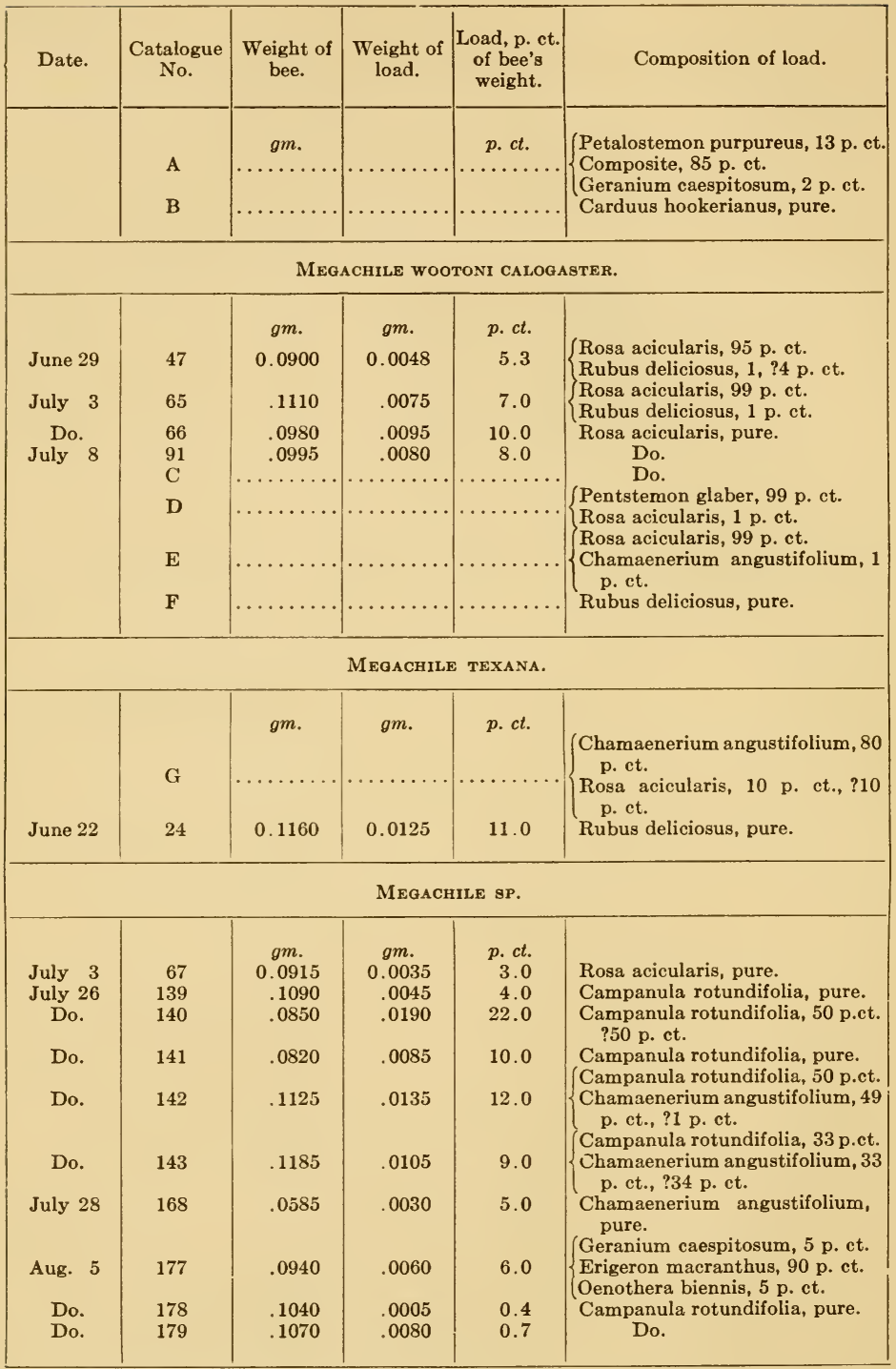


TABLE 87.-Composition and weight of pollen loads-Continued.

MONUMETHA ALBIFrons.

\begin{tabular}{|c|c|c|c|c|c|}
\hline Date. & $\begin{array}{c}\text { Catalogue } \\
\text { No. }\end{array}$ & $\begin{array}{l}\text { Weight of } \\
\text { bee. }\end{array}$ & $\begin{array}{c}\text { Weight of } \\
\text { load. }\end{array}$ & $\begin{array}{c}\text { Load, p. ct. } \\
\text { of bee's } \\
\text { weight. }\end{array}$ & Composition of load. \\
\hline June 22 & 26 & $\begin{array}{c}g m . \\
0.1135\end{array}$ & $\stackrel{g m .}{0.0035}$ & $\begin{array}{c}\text { p. } c t . \\
2\end{array}$ & $\begin{array}{l}\text { Rubus deliciosus pure; } 1 \text { conifer } \\
\text { grain. }\end{array}$ \\
\hline $\begin{array}{l}\text { July } 8 \\
\text { Do. }\end{array}$ & $\begin{array}{l}92 \\
93\end{array}$ & $\begin{array}{l}.0995 \\
.0800\end{array}$ & $\begin{array}{l}.0055 \\
.0050\end{array}$ & $\begin{array}{l}5 \\
6\end{array}$ & $\begin{array}{l}\text { Rosa acicularis, pure. } \\
\text { Do. }\end{array}$ \\
\hline \multicolumn{6}{|c|}{ Osmia meLANOTRICHA. } \\
\hline July 8 & $\begin{array}{l}95 \\
\text { A }\end{array}$ & $\begin{array}{c}\stackrel{g m .}{ } . \\
0.0247 \\
\ldots \ldots \ldots\end{array}$ & 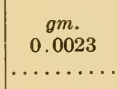 & $\begin{array}{c}p . c t . \\
9.0 \\
\ldots \ldots \ldots\end{array}$ & $\begin{array}{l}\text { Rosa acicularis, pure. } \\
\text { Pentstemon gracilis, pure. }\end{array}$ \\
\hline \multicolumn{6}{|c|}{ Panurginus sp. } \\
\hline & A & & & & Calochortus gunnisoni, pure. \\
\hline \multicolumn{6}{|c|}{ Prosopis Varifrons. } \\
\hline July 23 & 131 & $\begin{array}{c}g m . \\
0.0045\end{array}$ & $\begin{array}{c}g m . \\
0.0015\end{array}$ & $\begin{array}{l}\text { p. ct. } \\
33.0\end{array}$ & $\left\{\begin{array}{l}\text { Geranium caespitosum, } 10 \text { p. et. } \\
\text { Holodiscus dumosus, } 90 \text { p. ct. }\end{array}\right.$ \\
\hline \multicolumn{6}{|c|}{ Psithyrus consultus. } \\
\hline & A & & & & $\begin{array}{l}\text { Solidago missouriensis, } 95 \text { p. ct., } \\
\text { ?5 p. ct. }\end{array}$ \\
\hline
\end{tabular}

Discussion.--Of the total of 207 bees, 121 carried pure loads of pollen, i. e., from a single species of flower, while 86 had mixed loads. Three-fourths of the latter consisted of 2 species, and one-fourth of 3 species, a single load containing as many as 4 species. Pollen grains of conifers are not considered as constituting a mixture, since they were purely incidental. They may have been taken with the pollen sought or picked up separately, but in no case did they involve a visit to the species from which they originated. With the exception of Halictus pulzenus, no species represented by 4 or more individuals was perfectly constant in its choice of pollen. Apis mellifica and Andrena crataegi were the most constant of these, Bombus occidentalis and Anthophora simillima among the least so. The 4 genera represented by 2 or more species gave the following ratios between pure and mixed loads: Andrena 19:10, Bombus 50:36, Halictus 6:2, Megachile $12: 10$. Each of these contained species that were largely or entirely constant on the one hand, and those that were 50 per cent or more inconstant on the other. 
The only bees able to carry a pollen load amounting to approximately half of their own weight were species of Bombus; Apis, Colletes, Halictus, and Prosopis coming next with a load a third of their body-weight.

TABLE 88.-Summary.

\begin{tabular}{|c|c|c|c|c|c|c|c|}
\hline \multirow{2}{*}{ Species. } & \multirow{2}{*}{$\begin{array}{l}\text { Maximum } \\
\text { load. }\end{array}$} & \multirow{2}{*}{$\begin{array}{l}\text { No. } \\
\text { bees. }\end{array}$} & \multirow{2}{*}{$\begin{array}{l}\text { Pure } \\
\text { load. }\end{array}$} & \multicolumn{4}{|c|}{ Mixed load. } \\
\hline & & & & 2 spp. & 3 spp. & 4 spp. & Total. \\
\hline Apis mellifica.... & $\begin{array}{c}\text { p. ct. } \\
32\end{array}$ & 32 & 28 & 3 & 1 & & 4 \\
\hline Andrena crataegi.......... & 14 & 18 & 15 & 3 & & & 3 \\
\hline edwiniae. & & 1 & & 1 & & & \\
\hline madronitens...... & 21 & 4 & 1 & 2 & 1 & & 3 \\
\hline vicina...$\ldots \ldots \ldots$ & 13 & 5 & 2 & 3 & & & 3 \\
\hline Anthophora simillima. . & 8 & 5 & 1 & 3 & 1 & & 4 \\
\hline Bombus appositus. . . . . . . & & 1 & & 1 & & & \\
\hline bifarius. & 46 & 14 & 7 & 5 & 2 & & 7 \\
\hline juxtus........... & 61 & 27 & 19 & 6 & 2 & .. & 8 \\
\hline occidentalis....... & 47 & 26 & 9 & 17 & & & 17 \\
\hline centralis......... & ...... & 1 & … & 1 & & & \\
\hline edwardsi.......... & 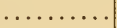 & 3 & & 3 & & & \\
\hline flavifrons.. & $\cdots$ & 1 & & & 1 & & \\
\hline hunti............ & $\cdots$ & 1 & & 1 & ... & $\cdots$ & \\
\hline kirbyellus......... & ... & 1 & & 1 & ... & & \\
\hline morrisoni. . & ... & 1 & & 1 & ... & & \\
\hline proximus......... & & 4 & 2 & 2 & & & \\
\hline rufocinctus. & & 4 & & 3 & & 1 & 4 \\
\hline spp............ & 30 & 18 & 13 & 4 & 1 & & 5 \\
\hline Clisodon terminalis......... & 4 & 1 & & & 1 & & \\
\hline Colletes oromontis......... & 33 & 1 & & . & 1 & & \\
\hline Halictus madronitens....... & 33 & 4 & 2 & 1 & 1 & ... & 2 \\
\hline pulzenus... & 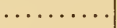 & 4 & 4 & $\cdots$ & & & \\
\hline Megachile pugnata...... & & 2 & 1 & ... & 1 & & \\
\hline texana. & 11 & 2 & 1 & ... & 1 & & \\
\hline w. cologaster.... & 10 & 8 & 4 & 3 & 1 & $\ldots$ & 4 \\
\hline sp. $\ldots \ldots \ldots \ldots \ldots$ & 22 & 10 & 6 & 1 & 3 & & 4 \\
\hline Monumetha albifrons...... & 6 & 3 & 3 & .... & ...... & $\ldots$. & \\
\hline Osmia melanotricha... & 9 & 2 & 2 & .... & $\ldots \ldots$ & ... & \\
\hline Panurginus sp... & & 1 & 1 & .. & & & \\
\hline Prosopis varifrons.. & 33 & 1 & $\ldots$ & 1 & .. & & \\
\hline Psithyrus consultus... & . & 1 & & 1 & $\cdots$ & $\cdots$ & \\
\hline Total.. & & 207 & 121 & 67 & 18 & 1 & \\
\hline
\end{tabular}

\section{CONSTANCY.}

Definitions.-Loew (1884) employed the term monotropic to designate those apids that visit flowers of a single species, oligotropic for those visiting only a few allied species, and polytropic for those that go indifferently to very diverse flowers. Robertson further restricted the terms, designating as oligotropic only those bees the females of which collect pollen from a single species or from those of the same genus or family and as polytropic those that secure pollen from flowers of different families. Following the English naturalists, Plateau (1901) denoted by constancy the behavior of a polytropic hymenopter such as the honey-bee, which visits various species of flowers during the season, but limits its activity 
to the flowers of a single species during one journey from the hive or nest. Detto (1905) pointed out that constancy may be used to refer to the fact that a bee visits only flowers of one species on a journey, or to fidelity to one species until it obtains nothing more from it, when it goes to another. It must also be recognized that single individuals seem to visit only certain portions of very large or very floriferous plants and that they do not go to other plants of the same species, but to a new species when a particular portion has been exhausted. Moreover, nothing is known as to whether a bee gives the preference to flowers of the same color or shade as those upon which it began to collect. The term "monodrome constancy" may be applied to the cases where the bee visits the flowers of but one species during a single flight, and "polydrome constancy" to those where successive flights are always directed to the same species as long as this yields nectar or pollen. An insect that then goes to another species is "temporarily constant" in contrast to one that confines itself chiefly to one species.

Early observations of constancy.-Two chance observations only have been recorded for the period before Darwin, one by Aristotle and the other by Dobbs (1736). Aristotle stated that during each flight the honeybee does not settle upon flowers of different kinds, but flies, as it were, from violet to violet and touches no other species till it returns to the hive. With respect to constancy, Darwin (1876:415) says:

"All kinds of bees and certain other insects usually visit the flowers of the same species as long as they can, before going to another species. It may be observed by any one, both with hive and humble bees, in every flower garden; not that the habit is invariably followed. Humble and hive bees are good botanists, for they know that varieties may differ widely in the color of their flowers and yet belong to the same species. Some species of diptera or flies keep to the flowers of the same species with almost as much regularity as do bees, and when captured they are found covered with the pollen. I do not know whether lepidoptera generally keep to the flowers of the same species, but I once observed many minute moths apparently eating the pollen of Mercurialis annua. I then went to a female plant some yards off and saw three of these moths light on the stigmas. It must not be supposed from these several statements that insects strictly confine their visits to the same species. They often visit other species when only a few plants of the same kind grow near together. That insects should visit the flowers of the same species as long as they can is of great importance to the plant, as it favors the cross fertilization of distinct individuals of the same species, but no one will suppose that the insects act in this manner for the good of the plant. The cause probably lies in the insects being thus enabled to work quicker; they have just learnt how to stand in the best position on the flower, and how far and in what direction to insert their proboscides."

Kerner (1876) stated that the bumble-bee always devotes itself to the plunder of a single species at one time, but in commenting on this, Weed (1884) said that he had observed one bumble-bee fly back and forth from Pedicularis canadensis to Vicia americana, another from hyacinth to columbine, a third from Solomon's seal to dandelion, and a fourth from vetch to honeysuckle. Forbes (1878) recorded 30 visits in succession of Bombus to Lamium, during which it ignored all other flowers, while Syrphus visited Rubus to the complete neglect of Lamium. Kronfeld (1888:785) observed a honey-bee that returned for 10 visits to a bed of cucumbers after being 
driven off, though many species were in bloom in the adjacent beds. Three other individuals worked solely on Zinnia, though the same bed contained 7 other species in bloom, while a bumble-bee visited exclusively 28 heads of Tragopogon in a 10-minute period, in spite of the competition of 10 other kinds of flowers.

Bennett's studies of constancy.-Bennett (1874, 1884:175) was apparently the first to make an extensive study of the visits made by an insect in one journey from the hive, in the hope of confirming or confuting Aristotle's statement. The 66 observations made concerned only the butterflies, the syrphids, and apids, and they appeared to indicate very different degrees of constancy. On the whole, the butterflies manifested but a small degree of fidelity; they preferred yellow or pink flowers and showed a marked tendency to adhere to one of these colors after starting with it. In the case of Eristalis, it exhibited little constancy in two instances, while in two others it confined its visits to a single though different flower. On the other hand, four observations of Syrphus gave only one case of constancy.

Of 33 observations made on various species of Bombus, 4 showed visits to 3 distinct species, while in 6 others the number of species noted while the insect was in sight was 2 . In 23 instances the bumble-bee visited but a single species while under observation, but these were of the most diverse kinds and colors. It was quite obvious that at the same spot different bees of the same species were visiting different kinds of flowers. Pollen masses were examined, in two cases and found to consist wholly of the pollen of the flower on which the bee was taken. The honey-bee was constant to one species for 5 out of 6 observations, the exception consisting of 1 visit to Scabiosa and 9 successive ones to Centaurea. It was concluded that the butterflies exhibit little constancy, the flies greater constancy, while this is much greater for the bumble-bees and all but absolute in the honey-bee. Constancy appeared to increase in proportion to the part performed by the insects in carrying pollen from flower to flower.

Christy's studies of methodic habits.-Christy (1884:186) adopted Bennett's methods and corroborated his general results. The honey-bee was found to be perfectly methodic, not one individual changing from one species of flower to another, even in mixed groups. Among the bumblebees one individual was seen to visit no less than 5 different species, 3 visited 4 species, 4 went to 3 species, 18 to 2 species, and 29 were constant to a single species. The Lepidoptera were found to be much more constant than in Bennett's observations, only 3 of the 12 individuals going to a second species. It was observed that bees were less constant in early spring and autumn, probably because fewer flowers were out, a honey-bee in spring going twice from Anemone to Ranunculus. Bumble-bees proved more methodic when visiting blue flowers than those of other colors, though the results were not regarded as conclusive.

Mueller's results.-Mueller (1876) reached the same conclusions as Darwin with reference to the causes of constancy. With respect to the differences in the behavior of male and female bees (1881), he found that 
pollen flowers are visited almost solely by the females. Many fragrant honey-flowers are visited by the males of certain bees with especial fondness, but little or not at all by the females of the same species. In cases where the females of a certain species have restricted themselves to a particular flower form or even species for the sake of rapid and certain profit, the males are not affected by such restriction but visit also other flowers. Among those species of bees that visit many flower forms, the females go to the most profitable flowers, the males to the easiest or most fragrant. His demonstration of the presence of the greatest individual differences in color preference also revealed one of the factors involved in constancy (1883:275).

Bulman's studies.-In a series of papers $(1890,1892,1897,1899)$ Bulman dealt especially with exceptions to the supposed rule of constancy.

"It is pretty generally believed that the bee is very constant in its visits to flowers, and that when it begins with any particular species it keeps to that until it has obtained its load. But while it is true that bees do show a considerable amount of constancy and often visit a large number of flowers of the same species in succession, they are far from possessing that amount of constancy required by the theory. But it is a well-established fact that bees pass readily from variety to variety of the same species in our gardens. They do not even confine themselves in a single journey to varieties of the same species. In numerous cases I have seen bees visit two, three, or even four species in the course of a minute or two. Hive bees are much more constant than wild bees, yet they pass freely from variety to variety, and not by any means rarely from species to species. As to the latter, take any wild bee, and if you can follow its movements for twenty visits or more, the chances are something like ten to one that it will be seen to change its species of flower."

Among the numerous cases of inconstancy cited, the most striking were those of a bee that made 10 changes in 27 visits to four different species of geranium and of a group of bees that passed from Lavandula to Geranium, Leycesteria, Epilobium, Antirrhinum, and Oenothera.

Ord's conclusions. - Ord (1897) observed the following routes for two honey-bees: (1) Cytisus 2 visits, Primula 1, Tremandra 1, Eupatorium, rose 2, white 2; (2) Caltha 7, Ficaria 2, Caltha 3, Ficaria 2, Caltha 3. Bombus made the following journeys: (1) red Tropaeolum 1, yellow 2, red 1, Viola 1, red Tropaeolum 2, yellow Calceolaria 1, red 2; (2) Geum rivale 2, intermedium 1, rivale 1 , intermedium 2 , urbanum 2 , rivale 6 , rivale 6 , intermedium 3 , urbanum 1. The majority of the apids observed seemed constant to a single species, though this was not true of all the individuals followed for a long time. Few bees were able to resist the temptations offered by a garden. The hive-bee appeared to be fully as inconstant as the wild humble-bees. The most remarkable examples of constancy were observed for Salix, Tilia, Calluna, Mercurialis, and Ajuga. The transfers seemed especially frequent when a number of related plants grew together.

Plateau and Pérez. - The general results of Plateau's studies of constancy (1901) have already been given (p. 157). Anthidium and Apis were found to be very constant, the latter affording but 14 examples of inconstancy during three summers, while Bombus often flew from one species to another and even to a third. Pérez (1903:24) objected to Plateau's re- 
striction of the term constancy to polytropic hymenoptera and he extended it to apply to polytropic and oligotropic bees that visit but one species of flower during a flight. For the honey-bee constancy is the usual rule at any moment, as it is for the social bees generally, a fact shown by the pollen stored up in the hives. It is likewise the rule that the pollen-baskets of bumble-bees contain the pollen of a single species. The fidelity of bees in general to a single species of flower is far from absolute, but it may be very frequent. Within the limits of observation it appears only with respect to the collection of pollen and not at all with that of nectar. Consequently, it rarely exists with the males. For the same reason, doubtless, it is hardly to be found in hymenoptera other than the bees. It appears to exist in relation to the gathering of pollen because the larva is less tolerent to differences of food than the adult (cf. also Pérez 1889, 1894.)

Constancy in Bombus.-Wagner (1907:38) has recorded the following observations which show an exceptional degree of constancy in several species of Bombus. Four individuals of Bombus lapidarius made respectively $31,28,34$, and 20 visits to Vicia sepium without going to other flowers, and a fifth sought Lamium album exclusively. Bombus terrestris flew 15 times to Dianthus carthusianorum to the neglect of Vicia, another individual ignored all flowers but those of red clover, and four others paid attention only to those of Scabiosa; while the last visited similarly Melampyrum nemorosum. Bombus muscorum went only to Salvia pratensis on one day, in spite of the presence of Melampyrum, while on the next it flew back and forth from Trifolium to Melampyrum. For a whole day Bombus terrestris and silvarum worked only on species of lilac-colored flowers, ignoring all others. As a result of his study of the detailed path followed by the bumble-bees in these and other visits, Wagner reached the conclusion that at a certain distance they are guided to flowers by vision exclusively, the distance at which the species can be discriminated being determined by the size of the flower, the inflorescence, or the plant group itself.

Lovell's conclusions.-Lovell (1914:202) reaches the following conclusions as to the various types of constancy:

"There are still in existence many intermediate stages between monotropic, oligotropic and polytropic bees. While many bees visit a great variety of flowers, others visit only one family, as the Compositae or Nymphaeaceae, others only a single genus, as Salix, and others only a single species, as the violet, strawberry or spring beauty. Many exceptions no doubt occur and will be recorded when the habits of these bees have been more carefully observed. For instance, I have often seen the loosestrife bee on the umbels of the prickly sarsaparilla. It is evident that if a monotropic bee extends into a region where the flower it visits elsewhere does not occur, it must of necessity visit other flowers. Evidently this habit did not originally exist among bees, but has gradually been acquired.

"We may sum up the matter as follows. All bees including the honey-bee show a strong tendency in collecting both nectar and pollen to be constant to one species of flower. This is manifestly for the advantage of both insects and flowers. In the case of a number of bees flying for only a small part of the season, this habit has become so specialized that they visit only one or a few allied species of flowers, which offer an abundance of pollen and nectar. As the honey-bee for a time restricts its visits to 
the white clover, so in like manner a monotropic bee visits but a single kind of flower. But in the former case the bee flies throughout the whole season, while in the latter when the flower fades the bee's period of flight is over."

Kranichfeld's observations.-Kranichfeld (1915:39) has carried out two series of field observations on the constancy of the honey-bee to color and species. Of the 18 fields studied, 15 were being visited by honeybees and 10 of these contained plants of Cirsium oleraceum. In these Cirsium was sought exclusively in five cases and chiefly in all the others, the only visits to other flowers being to Lathyrus in one case, Cirsium palustre in another, and to Centaurea and Heracleum in the third. As the flowers were almost wholly white or dull in color, it was concluded that color was not decisive in the choice of the flowers. In the second series the constancy was greater, both as to color and species, the exceptions being regarded as due to the behavior of the young and inexperienced bees. The other cases of inconstancy appeared to be due to the confusion of the honey-bees and bumble-bees by the presence of the same color in two or three species. While the results were not entirely harmonious, they strengthened the probability that sense of color serves to guide bees and hence is a factor in constancy.

Origin of oligotropism.--Robertson (1914) ascribes the assumption of the oligotropic habit to competition, maintaining that "the bee fauna is all that the flora will support, that there is constant competition between bees, and that natural selection favors those which are the least competitive in food habits. The early maximum flight, the non-competitive phenological distribution, and the frequent oligotropic habits indicate that these bees have managed to hold their own only by dividing up the remaining field and occupying the most favorable corners left by their polytropic competitors." On the contrary, Lovell $\left(1914^{2}\right)$ believes that only a part of the available flower food is gathered by bees, many plants producing nectar far in excess of the needs of the tributary bee population. If severe competition were to occur, the oligotropic habit would be undesirable, since such a bee would be at a disadvantage in comparison with polytropic species, unless it were always certain to find the requisite food supply. In the genus Perdita, the tube-length of the flower, and not competition, is the factor that limits the visits of the various species. It is concluded that "certain bees have become oligotropic because of the direct advantage gained, combined with the fact that their flight was synchronous, or nearly so, with the period of inflorescence of the plant to which they restricted their visits. This theory offers an explanation of the rise of oligotropism by the observation of existing conditions. There may be and often are accessory factors, but they are of secondary importance." It appears fairly certain that Lovell is correct in assigning the chief importance to the limiting action of structure and to the coincidence of flight and flowering period, though there are doubtless cases in which competition enters to some degree, as apparently he would admit. Special studies are greatly needed in the case of each oligotropic species to determine the exact relations, and these will afford further opportunity for the use of experiment. 


\section{RÉSUMÉ.}

Experimental results in competition.-In the case of adult insects, especially bees, habit is the controlling factor in competition. This is shown by the fact that the standard plant, which is the one that the insect was in the habit of visiting, was favored in 36 cases, while the bouquet, consisting of flowers out of their natural position, had the advantage in but 11 cases. Moreover, the difference between the number of visitors in each experiment was regularly much greater when the plant was preferred than when the bouquet was. The reversals of choice were caused by flowers with a large amount of nectar, mostly members of the rose family, such as Rubus strigosus, Prunus demissa, and Opulaster opulifolius, or by regular flowers well-supplied with nectar and pollen, such as Chamaenerium, in competition with specialized ones such as Monarda. In a few cases, the abundance of pollen was the deciding factor, as when Rubus deliciosus or Rosa acicularis proved more attractive, doubtless owing to a shift in the nutrition requirements at the time. Flowers in vials obtained very few visitors, even in comparison with bouquets, probably because of the strangeness of the vial itself. The effect of the vial is well exhibited in the experiment where the two species of Geranium were employed reciprocally as standard plants and in vials. With G. richardsoni as the standard the respective figures were 88 and 9 ; with $G$. caespitosum as the standard, 83 and 10. When standard roses were in competition with roses and with Chamaenerium in vials, the figures were 85,49 , and 7 . The vials alone reduced visits nearly a half, and a strange flower in addition further decreased them seven times. In the case of natural competition, or competing bouquets, habit is partly eliminated, and the relative attractive power of the species is the chief factor. This varies, however, with respect to the composition of the visiting population, and a decisive test is possible only with young insects in which habits have not yet been fixed.

A pis mellifica gave the preference to the standard plant in 24 instances and to the bouquet in 4 ; in 15 experiments it went to the plant alone. The total number of visitors to the standard was 972 , to the bouquet, 153 . Bombus bifarius preferred the standard in all of the 9 experiments where it was an important visitor, and went to it alone in 6 cases, the total number of visitors to standard and bouquet being 206 and 20 . B. proximus chose the plant in 7 experiments out of 8 , visited it alone in 6 instances, and 222 bees went to it in contrast to 48 to the bouquets. B. juxtus was far less faithful to the standard, giving it the preference in 13 cases out of 19 , visiting it exclusively but twice, and yielding 564 visitors to the bouquets for 920 to the standards. The preference as to species naturally shifted with the progress of the season, but during the respective flowering periods the marked preferences were as follows: Apis for Rubus strigosus, Bombus for Rubus deliciosus, Rosa, Geranium, and Chamaenerium, Clisodon for Monarda, Andrena for Opulaster and Prunus, and Osmia for Pentstemon.

Effects of competition.-The final outcome oî competition for pollinators in terms of the setting of fruit and the production of seeds is difficult to determine in nature, owing to the wide range of preferences among the many species of insects usually present. The only direct study of this so 
far made seems to be that of Dodel-Port (1882:294), though Lovell (1912, 1914) mentions a number of observations by bee-keepers, which belong in this general category. Dodel-Port found that two beds of the scarletrunner bean, though blooming profusely, failed to set fruits with the exception of a single legume, in spite of the fact that elsewhere in Zürich it fruited abundantly. During this period repeated observation failed to reveal a single pollinating insect on these flowers, though honey-bees, bumble-bees, butterflies, wasps, and flies were numerous on the adjacent flowers of Cerinthe, Calendula, Centaurea, Bidens, Cichorium, etc., which exercised a greater selective power upon them. Just as long as these flowers that were richer in honey continued to bloom, the bean was at a complete disadvantage in the competition, but after the middle of August they began to disappear and the brilliance of the beans then brought the visitors to them and fruits began to develop frequently. A comparison with the plants of this species in other gardens led to the inevitable conclusion that it formed no fruits in the Botanical Garden as a direct consequence of the diversion of the bumble-bees through the other more attractive flowers.

Constancy as shown by pollen loads.-The composition of pollen loads can only reveal the behavior of bees in the collection of pollen. Too little is known of the detailed habits of the various species of bees with respect to the gathering of pollen and nectar, and more exact knowledge of constancy must await upon this among other matters. The analysis of pollen loads showed that 86 individuals carried mixed loads in comparison with 121 carrying pure pollen. With respect to species, none represented by 5 or more individuals was characterized by pure loads, the latter being found only on 4 bees belonging to Halictus pulzenus, on 3 of Monumetha albifrons, and 2 of Osmia melanotricha. In Apis the relation of pure loads to mixed was 28:3, in Andrena crataegi 15:3, in Bombus juxtus 19:6, and in bifarius 7:5. Variation in behavior within a genus is shown by the fact that for $B$. occidentalis the ratio was $9: 17$, Andrena madronitens $1: 3$, and A. vicina $2: 3$, while for Halictus medionitens it was $2: 2$. It is clear that bees in general are no more constant in the collection of pollen than in the gathering of nectar.

Determination and designation of constancy.-Our present knowledge of the habits of bees is inadequate to a comprehensive and accurate treatment of constancy. Nearly all those interested in the subject have defined constancy in different terms and the studies that bear directly on this relation have been so few and fragmentary that further advance must await special investigations which are at once extensive and intensive. These must take account of behavior with respect to both pollen and nectar, the differences between individuals, sexes, ages, species, etc., single flights and those made on the same day, and on different days and at different parts of the flowering period of preferred species. Furthermore, they must employ experiment to vary conditions in a definite manner in order to test habit under new circumstances and to furnish quantitative results, which will permit the expression of the degree of constancy for individual or species in numerical terms. 


\section{PRINCIPLES AND CONCLUSIONS.}

\section{INTRODUCTORY.}

Nearly the entire history of experimental pollination is reflected in the writings of Plateau and the papers called forth by his results. His were the first researches in this field and for thirty-five years his classic experiments were the outstanding features of its development. Indeed, he and his critics occupied the stage until the last decade, which has been marked by researches not genetically related to his. Thus, while Plateau is the dominant figure almost throughout, it is helpful to divide the period of development into four stages, as follows; (1) early experiments of Plateau and others, (2) main researches of Plateau, (3) related studies and critiques, (4) recent investigations. In the hope of providing a comprehensive and exhaustive account of experimental pollination, abstracts are given in detail of all experimental studies, and of such critical discussions as those of Knuth, Kienitz-Gerloff, and others. Because of their significance and their frequent inaccessibility, the papers by Plateau have been summarized with especial fullness. The historical section is followed by an extended résumé of results and conclusions, examined in the light of the present researches.

\section{EARLY EXPERIMENTS OF PLATEAU AND OTHERS.}

Artificial flowers. - The stimulus for Plateau's first experiments came from an observation reported by Vallete (1875), according to which an individual of Macroglossa stellatarum, which had entered through the window, tried vainly to plunge its tongue in the flowers of a tapestry, "passing from one bouquet to another and choosing skillfully the flowers that it sought to probe." The unfavorable comments called forth by this statement léd Plateau to come to its defense with his study of response to artificial flowers $(1877: 535)$. The latter consisted of red and yellow roses, yellow Ranunculus, and variegated Convolvulus, which were made to resemble natural flowers as closely as possible. They were placed in the garden among plants of Viola, Pulmonaria, Primula, Fritillaria, Crocus, Hyacinthus, and Arabis, of which the latter was almost alone in being visited by insects, chiefly Vanessa and Apis. During two hours of observation no visitor came to the artificial flowers, though a butterfly passed near one. When the same artificial flowers were placed in a bed of Hyacinthus or of Arabis, or the latter mixed with artificial flowers of its own kind, the results were the same, only a single honey-bee hesitating for a moment above them. Moreover, when a drop of honey was placed in the center of each false Arabis, no visitors alighted on the flowers, although Anthophora frequently poised above them as though drawn by the odor. Two showy beds of artificial flowers of violets, pansies, marsh marigolds, roses, buttercups, etc., were placed in a sunny sward, but of the Anthophora, Apis, Bombus, Pieris, and Vanessa flying about, only the latter noticed them in the least and then but momentarily. On the same day branches of a cherry in full bloom were provided with flowers made to resemble the cherry and white lilac, but the bees visited only the natural ones. When imitation roses, white, pink, and red in color, were mixed with natural ones, Apis, Bombus, Trichius, and various flies showed complete indifference to the 
former, though Syrphus poised for some time above a false rose and Pieris wheeled to make a small circle above a group. A shoot of Aucuba without natural flowers was furnished with artificial ones of a lively color, but drew no visitors during a half-hour of observation. In the final experiment, a large number of brilliant artificial flowers was placed in one group in the center of a lawn surrounded by a garden in full bloom. Although many bees, butterflies, and flies were working on the latter, but two individuals of Pieris came to inspect the imitation flowers.

In conclusion, Plateau stated that the bright colors of flowers attract but a small number of insects, chiefly diurnal Lepidoptera, a group in which instinct is but feebly developed. Insects are able to perceive differences between natural and artificial flowers that escape the observer who is not forewarned, differences sufficiently great to permit no error and even to excite distrust. In their flight from a distance to the flower sought, insects are probably guided by some other sense than sight alone. Thus, he was led to draw conclusions which were exactly the opposite of what he expected. He disclaimed any desire to render a final judgment, but regarded the methods employed as worthy the attention of those engaged in the study of pollination.

Nectaries.-Bonnier (1878:5) challenged the prevailing view of the fundamental importance of floral nectaries in pollination, scrutinizing in detail the evidence adduced by the enthusiastic students of floral biology. He pointed out that the development of spurs in flowers is not necessarily in accord with the presence of nectar, and that this is likewise true of scales, hairs, and other devices for protecting the nectar. A considerable list was given of flowers of inconspicuous color that are abundantly visited by insects, and a reciprocal list of bright-colored flowers little or not at all visited because of the lack of nectar. The view of Mueller that the visibility of the flower is proportional to insect visits and to the development of floral adaptation was tested by means of related species of different color. The greenish-white flowers of Teucrium scorodonia were visited by 13 honey-bees in the same time that 3 went to the red ones of $T$. chamaedrys, while 4 species of Allium with a nearly equal attractive surface received respectively $6,4,5$, and 15 visits. In the case of Althea rosea an equal number of red, rose, and white flowers gave 14, 13, and 13 visits by honey-bees and 4, 3, and 4 visits by bumble-bees respectively. Observations were reported for a number of other species, and a special test of response to color was made by means of rectangles colored red, green, yellow, and white, provided with an equal amount of honey and placed at equal distances from the hives. The maximum number of visits for any one minute was 78 for yellow during the ninth minute, 90 and 93 respectively for red and green during the tenth minute, and 85 for white during the eleventh minute, the totals being 549,621, 640, and 652. The conclusion was reached that there is no agreement between the development of colors and that of nectar, that in the same conditions the flowers with brightest colors are not the most visited by insects, and the visibility of flowers is not proportional to their adaptation to cross-fertilization; in short, insects go in greatest number where the nectar is most abundant, the richest in sugars, and easiest to obtain. 
The view that the male flowers are more visible than the female in diclinic nectariferous flowers was tested by observations of Salix, Ribes, Asparagus, and Bryonia. The number of visitors was so nearly equal that it was stated that in such flowers the bees do not go first to the staminate and then the pistillate, and that the former do not possess a greater visibility. The development of spots and stripes on the corolla was thought not to be correlated with the nectar or the presence of a large corolla, which is independent of the frequent visits of insects. The development of perfume in the flower and that of nectar are not in agreement. The same flower can be visited in several different ways by the same insect, indicating that there is no reciprocal adaptation between them, as is shown also by the fact that insects continue to visit flowers after the corolla has fallen. Insects are able to secure nectar from the flower without effecting fecundation, as is especially true of the large number of flowers that are robbed by bees. The visitors to the same species differ in accordance with the variations in the amount of nectar. Furthermore, undesirable visitors are not excluded by odor, form, or by the time or place of blooming. In summarizing it was stated that it is impossible to admit that all the features of flowers are designed to attract insects in furnishing them nectar, and thus bringing about cross-fertilization. One can not admit that there may be reciprocal adaptation between flowers and insects, since the observed facts do not accord with the imaginary hypotheses. Finally, the modern theory as to the rôle of the nectary seems to be inadequate.

It is obvious that Bonnier's conclusions were much more sweeping than his evidence warranted, and hence it is not strange that he should have been severely criticized by Mueller (1880:219), who declared that Bonnier, in his blind and presumptuous endeavor to destroy one of the most comprehensive and best-grounded of theories by childish weapons, had only succeeded in bringing to it new support. In spite of this, however, he deserves much credit for pointing out some of the serious weaknesses of a theory which attempted to explain the most insignificant features of the flower as both cause and effect of insect pollination.

Color sense of bees.-Lubbock (1882:291) studied the response of honey-bees to color by means of paper slips and glass slides provided with honey. The latter was placed on blue and on orange paper and a bee brought to the former. After she had returned twice the papers were transposed, but she still went to the blue paper, as she did also when the papers were again transposed after three visits to the blue. Similar results were obtained two days later, in which, as the bee returned to the usual place, now occupied by the orange slip, she started to alight and then darted off to the blue. Experiments of the same sort were made at various times, and agreed in showing that bees return to the color to which they have been accustomed.

To determine whether there was a preference for one color over another, Lubbock made use of microscope slides on which were pasted slips of paper colored respectively blue, green, orange, red, white, and yellow. These were placed on a lawn about a foot apart and on top of each was put a second slide with a drop of honey; with them was also placed a slide of plain glass with honey. After a marked bee, trained to come for honey, 
had sipped for a quarter of a minute, the slide with honey was moved so that she flew to another slide. This was next taken away, and so on, until she was induced to visit all the drops before returning to the hive. While she was absent, all the upper glasses with honey were transposed and the colored slips also moved, so that position could not influence selection by the bee. The record was made by noting the order in which the bee went to the different colors. The experiment was repeated a hundred times with the use of two different hives at different places and the observations extended over some time in order to work with different bees and under varied conditions. The first day's results gave a decided preference for blue; white, yellow, and green were nearly equal, followed by orange and red also about equal, with the plain glass last. In the next series, bees had been trained for three weeks to come to a particular spot on the lawn by placing honey on a piece of plain glass. In spite of the advantage thus given the latter, blue was again first, followed at some distance by white, and this by yellow, red, green, orange, and plain glass.

Bonnier's results to the contrary were regarded as inconclusive, since the colors were largely covered up by the bees and since the presence of so many would attract their companions. Moreover, he omitted blue and his squares were all colored, the absence of colorless checks being especially serious.

Response to detached petals.-Mueller (1883:273) regarded Lubbock's results as inconclusive, since he did not use the natural colors of the flower and did not give the bee a distinct choice between two plates differing in color alone. To obviate these difficulties Mueller made use of detached petals placed between glass slides which were cemented at the edges, so that the odor could not be effective. A drop of honey was placed on each test-object thus prepared. As a rule, petals of two distinct colors were submitted to the choice of bees that had been marked and accustomed to coming for honey on glass slides. In their color preference different honey-bees exhibited marked individual response, one showing equal liking for both colors, another a preference for one, and a third for the other. Thus, while the total number of visits made by a group of 6 bees to the purple of a rose and the blue of a cornflower was the same for each, only three bees were equally sympathetic to them, the other three visiting them in the following ratios: $10: 14,5: 3$, and $3: 1$. In the case of the fire-red of nasturtium and the violet of the pansy, seven of eight bees preferred the latter, most of them very decisively, and but one the former, also very distinctly, viz, 10:3. Individual bees also differed in the constancy of their response to related colors, two preferring honey-yellow to brilliant yellow throughout the period of experiment, and the other two choosing the one in the first half and the other in the second. Bright colors, brilliant yellow and orange, fire-red, scarlet, are less pleasing to the honeybee than the softer colors with which the bee-flowers are adorned, viz, white, honey-yellow, rose, pink-red, violet, and blue. The preference for bright yellow and honey-yellow was 48:78, for the former and white $21: 48$, for brilliant orange and rose $22: 71$, and $26: 77$, for fire-red and violet $29: 80$, for scarlet and rose $9: 55$, for scarlet and pink $34: 69$, and for scarlet and blue 13:78. 
The least attractive of all the colors of true bee-flowers is glaring yellow, the ratio between this and yellow-white being $35: 68$, with pink-red $27: 74$, with purple $42: 62$, with indigo-blue $28: 56$, and with violet $24: 78$, while chrome-yellow and cobalt-blue gave 11:40. White and yellowish-white were visited about as readily as many shades of purple or even more so, but less readily than blue or violet; for example, white against darkpurple gave a ratio of $7: 30$, and against sky-blue $36: 64$, while yellowishwhite and purple gave $52: 49$, with blue 18:25, and with violet $11: 24$. Blue is either preferred to red, or the two are equally attractive, in accordance with the particular shades employed; thus, violet-blue in competition with dull-purple gave $61: 31$, sky-blue and bright purple $45: 36$, sky-blue and rose $57: 54$, cornflower blue and purple 52:52, and impure violet-blue and dark-purple 57:57. A pure deep blue excels violet in attraction in the proportions, 50:35 and 81:67. In its attraction for the honey-bee violet excels all other flower colors except blue. Among the brilliant flower colors, bright yellow is the most attractive to bees, giving with scarlet the ratio $50: 29$, and with bright orange $42: 31$. The green of leaves is less pleasing to honey-bees than the colors of bee-flowers, giving in competition with rose $75: 33$, but it is more attractive than scarlet, $45: 40$ or orange $57: 46$. As a result of field observations, Kranichfeld (1915:40) has come to the conclusion that the color preference demonstrated by Mueller's experiments does not obtain in the normal visits of bees to flowers (see p. 133).

Color preference of nocturnal moths.-Gratacap (1883:791) made cylinders of variously colored tissue-papers and drew them over common kerosene lamps with gas chimneys in order to test the color perceptions of night-flying insects. The colored lights were first placed in a row at long distances from each other, but this arrangement seemed defective by reason of the fact that the brilliancy of the light first visited interfered with the visitor's freedom of choice between that color and another that reached it but dimly. The lights were next arranged in a square, at first in such manner that the circles of light touched each other, but later so that they overlapped. Since this did not permit an exactly equal choice, the final plan was to make use of but two lamps at a time. The need of causing the insect to choose instantly between the colors before it reached either arose from the infatuation produced by the lights, preventing the insect from freeing itself except in an accidental manner. The results indicated the absence of marked preference for certain colors over others, and demonstrated the almost invariably greater charm of the white lantern, which on account of its translucency appeared more brilliant than the colored ones.

Response to color without antennæ.-Forel (1886:24) considered that the ingenious and patient studies of Lubbock had demonstrated the ability of bees and wasps to distinguish colors and at the same time a feeble sense of smell in the former. While this seemed to be contradicted by the experiments of Plateau with artificial flowers, such negative results were regarded as of less value, especially since other factors rendered the investigation incomplete. Above all, it is possible and even probable that an imitation exact to our eyes may affect those of an insect so that 
it will perceive differences not apparent to us. Moreover, Plateau failed to take odor into account, though this is of less importance, and finally, Lubbock has shown that bees and wasps are so controlled by habit that new flowers would attract them less than those to which they were habituated. To determine the attraction exerted by color, Forel cut the antennæ of 6 individuals of Bombus terrestris at the base and released them. At the end of 5 minutes a male returned and visited 10 flowers of bindweed in succession, each time flying directly to the flower without hesitating a second. It was caught, the antennæ examined to confirm their complete absence, and then released, when it made a single circuit in the air and returned immediately to the flowers, to visit them as before. In the case of other bumble-bees the front of the head was cut away as far as the compound eyes and the remainder of the lower lip and the entire pharynx removed. Nevertheless, the bees thus mutilated flew actively, saw, and moved their antennæ; when released they returned to the flowers, but remained only an instant in each, since they were unable to suck nectar. At the same time several of the bees without antennæ came again to the bindweeds, flying from one to the other with more precision if possible than those with the antennæ intact. Two days later several of the mutilated bees were again found on the flowers, visiting them with an astonishing rapidity and precision. When the antennæ, the front part of the head and the pharynx were removed from males of Bombus pratorum, one of these made a turn and flew directly back to the Veronica it had been visiting, seeking vainly to secure nectar from it as well as from the bindweed. A second shortly returned and behaved in the same manner, while the small females thus treated did not come back, apparently because of their greater intelligence. A wasp, Polistes gallicus, treated in the same way, behaved similarly, returning to the mignonette in a fruitless quest.

Forel noted that the loss of the antennæ in these cases seemed to increase instead of decreasing the precision of flight. The insects no longer balanced to the right and left before alighting, but flew in a straight line to the flower and landed immediately, the difference in behavior before and after the removal of the antennæ being especially striking in Vespa. All this seems to indicate that the balancing in flight enables these insects to smell certain substances with their antennæ, which explains why this movement is more marked with the wasps which smell readily and see less well than with the bees, where the reverse is true. The experiments were regarded as demonstrating clearly that it is the compound eyes alone that direct flies, butterflies, beetles, dragon-flies, bumble-bees, and wasps in their flight. It is by means of these organs alone that these insects distinguish colors on the wing, as well as objects, especially when they are moving, distances, and pathways through the air. Odor can attract certain winged insects in a certain direction, but without eyes they could not find their way.

Perception of form.-An individual of Vespa germanica was placed by Forel on a circle of white paper $3 \mathrm{~cm}$. wide, spread with honey. After taking its fill, the wasp flew away, but returned at once directly to the white circle and again sipped the honey. The white paper was then re- 
placed by one without honey, while it was moved to one side at a distance of 2 inches. The wasp returned to the original place occupied by the disk without honey, and finding nothing there, rose a little, balanced two or three times, and went to the paper with honey. During its absence honey was placed upon a cross of white paper about $11 \mathrm{~cm}$. long, and this with the empty white disk was placed near the spot last visited. Upon returning the wasp soon found the honey, probably because the cross was not sufficiently different, and it was replaced by a white band. On the next, visit the wasp flew direct to the white disk and searched a long time for honey, and then went to the original place in vain. It repeated this before it was able to find the honey in consequence of repeated searching. On the morrow the wasp came twice to take nectar from the cross, when it was caught and the antennæ removed. It flew away, but returned in a halfhour to sip upon the same cross. After its departure a similar cross without honey was placed at one side, and on the other a band with honey, the original cross then being taken away. The wasp returned, flew directly to the cross, and alighted in the middle, hunting vainly during a rather long time. Then it began to search, apparently remembering that the papers had been frequently transposed, and after passing two or three times within a few millimeters of the honey, finally found it after the tongue practically touched it.

A bumble-bee, trained to take honey from a blue disk, first flew to one without honey, but taken again to the former, returned to it several times without error. The blue disk was next replaced by a blue band, and a disk alone put at a distance of three inches. The bee then flew straight to the disk, but made only one turn before going to the band with nectar. He was returned to the disk with nectar, which he visited several times. Two hours later this was replaced by the band with honey, and a disk without was put at $6 \mathrm{~cm}$. This time the bee came first to the original place now occupied by the band, but scarcely hesitated, failing to note the honey, and flew to the empty disk, which he searched thoroughly two or three times, finally going to the band with the honey. When a red disk with honey was substituted for the blue, and an empty blue one placed at 4 or 5 inches, the bee each time went straight to the latter and could not find the honey on the red disk, even though it was in the original place. Once found by chance, he hardly tasted it, so much was he obsessed by the association of "honey and blue," before he again began his search upon the blue disk, without returning to the honey on the red one. This was explained by the fact also that bumble-bees have much poorer memories than wasps, since several visits are necessary to enable them to find a place without hesitation, while one suffices for the wasp.

Consequently, the influence of color was regarded as of the greatest significance. The bee did not know enough to find the honey on the red disk when he was brought to touch it; he still sought it on the blue with a perseverance but little intelligent. It is evident that he perceived the color in a fashion infinitely more intense than the form of the paper. On the contrary, as Lubbock has shown, while the bumble-bees and honeybees distinguish colors especially well, wasps pay little attention to them, but recognize places admirably, the one employed going direct to a red 
disk in the place formerly occupied by the blue one, and paying no heed to the latter at one side. On the other hand, when the disk is moved a foot from the former place, the wasp is usually unable to find it, while the bee locates it quickly by the color. The fact that wasps guide themselves so well when deprived of antennæ, without distinguishing colors very clearly, is one of the best proofs that they see the forms and contours of objects, further evidence being afforded by the fact that they can not direct themselves when their eyes are covered with varnish.

Response of wasps to color.-In their classic experiments with wasps (1887:105), the Peckhams carried out experiments upon the response to color, largely with the idea of verifying Lubbock's conclusions. Their results were somewhat at variance with his, however, as they tended to prove that wasps rely very greatly upon color for their guidance. This divergence may be explained in part by the fact that they worked with large numbers, 500 sometimes passing into and out of the nest in 5 minutes, and that the presence of two observers increased the accuracy. At the outset a hole 4.5 inches in diameter was cut in a sheet of bright-red paper about 24 by 20 inches in extent, and the latter was placed above the nest in such a way that the entrance was not at all impeded and could be plainly seen from above. The returning wasps did not enter, but circled over the paper, seeming greatly excited, until one more intelligent or venturesome flew in and the others gradually followed. In the course of 3 hours all of them became accustomed to the paper and worked as usual. Two days later a blue paper was substituted and this produced as much confusion as before, though the wasps became used to it in a little more than 2 hours. The next day the blue paper was removed and a cage full of wasps released at some distance; an hour afterward 25 or 30 wasps were found buzzing about, apparently not knowing how to get into the nest, though they entered at once as soon as the blue paper was replaced. When a yellow paper was substituted for the blue, 130 wasps noticed the change within a period of 10 minutes, circling around the nest several times before entering, while 8 seemed not to notice it. After an hour's exposure, 70 out of 100 wasps recognized the change, but after the paper had been over the nest for 3 working hours, only 8 out of 200 hesitated before entering. The substitution of a light-green paper with yellowish reflections for the yellow one produced a response, but it was not nearly so marked, 100 out of 172 wasps noting it, but to a smaller degree.

When three dark-red nasturtiums were placed on yellow paper 2 inches from the hole, 46 of 146 wasps noticed them by flying to them and almost alighting during a period of 5 minutes, while 29 of 126 noticed them in the next 5 minutes. With the substitution of California poppies of a yellow color for the red nasturtiums, the number was much smaller, being but 5 per hundred for 10 minutes instead of 28 per hundred, the previous rate. Replacing the dark-red flowers brought the rate again to 18 per hundred. To eliminate the effect of perfume, 3 light yellow nasturtiums, which matched the paper even more closely than the poppies, were employed; these received but 3 notices per hundred, proving that the differences observed were due to color and not to odor. 
Being satisfied that the wasps distinguished colors and were disturbed by a change from one to another, an endeavor was made to determine more exactly the impression made by a particular color. After the red paper had been over the nest for $\mathbf{2 4}$ hours, it was moved a foot and half to the south and a blue one put in its place, in order to determine whether any of the returning wasps would enter the hole in the red paper, to which they were accustomed, instead of going to the real entrance through the blue paper. For convenience the blue was designated as the true and the red as the false entrance. In the first 10 minutes, 76 wasps went into the true entrance, of which 54 first hovered over the false and about half of which actually entered it and explored the grass below. Some of the latter, not finding the entrance here, flew away entirely, and most of those that entered the true one directly did not pass above the red paper in so doing. In the next 5-minute period 50 of 78 wasps went first to the false entrance and afterward found the true, but after 4 hours only 15 out of 125 were deceived. The blue paper was then left over the nest for 48 hours, when it was moved a foot and a half to the west to put it directly in the line of flight and its place taken by a yellow paper, which gave a more decided contrast than the blue had to the red. In the first 7 minutes 270 wasps returned, none of which flew straight into the true entrance, although many passed directly over it; all hovered first over the false, many of them going in and some going in and out seven or eight times, so closely was the blue color associated with the idea of the nest. Three minutes later, during a 5-minute period, 205 wasps first entered the false and then the true hole; not one flew straight to the true, though 6 hesitated over it and then entered without going to the false. An hour later 184 went into the false hole and 202 into the true one, but after 2 hours more, only 76 entered the false hole to 191 for the true one, while 5 hours later still only 5 out of 49 visited the false entrance. The next morning only an occasional wasp entered the false hole, though one came and searched in the grass after the blue paper was finally removed.

A similar test was made with yellow paper, one of slightly darker color being substituted after an exposure of 3 days. During the first period nearly a third of the wasps were deceived, but during the 4 succeeding ones only about one-eighth of them, while 2 hours later this dropped as low as one-twentieth. The original paper was replaced and 2 days later it was moved 10 inches to the south, leaving the ground about the nest exposed after it had been covered with different papers for 16 days. During the first 5 minutes not one flew straight to the hole, but of the 130 that entered the false hole 61 finally found the true one. When the false paper was moved 2 feet to the south, 107 entered the true hole and 103 the false, but when the opening in the yellow paper was put 6 inches from the hole and a red one placed over the latter, three or four times as many entered the true hole as the false one. Somewhat similar results were obtained when green paper was substituted for the red, the mistakes growing fewer with increasing experience. When the green paper blew over the hole and the wasps could not get in, at least 100 gathered and many settled in the false hole. The green paper was taken away, exposing the ground about the nest, but only 3 or 4 entered. As soon as it was replaced with 
the hole above the entrance, they swarmed in 6 or 7 at a time and in a moment all had disappeared; it was plainly the color that had directed them.

Response of wasps to odor.-In studying the attractive effect of odor, the Peckhams surrounded the nest with paper saturated with oil of peppermint or wintergreen. When the latter was employed, a third to a fourth of the wasps noticed the odor, as shown by starting back and circling about. A plate of maple sirup placed 6 inches from the nest received no attention from the wasps, though visited by many ants and flies and one bumble-bee. Fresh warm chicken bones were wrapped in several thicknesses of gauze of the same color as the paper around the nest and placed 4 inches to one side of the entrance, while a control bundle without bones was put on the other side. In 15 minutes 25 different wasps visited the first bundle, some working over it for a minute or two, but none went to the second. This test was twice repeated with the same results; in the last case 3 wasps worked on the bundle with bones for 15 minutes and then had to be driven away. When the bones were cold, fewer wasps noticed them and only 2 alighted, and 2 days later after they had become dry and relatively inodorous, but 2 out of 129 wasps landed on them. A dead wasp, hidden completely in the grass, attracted 5 others, one of which carried it away. Three or four others afterward visited the spot, probably attracted by the scent of blood. At another time 2 were killed and the ground smoothed over after they had been thrown away; in 15 minutes 9 wasps came to the spot. It was concluded that wasps have a strong sense of smell, but that they pay little attention to odors, however powerful, that do not indicate food.

\section{main ReSEarches of plateau.}

Masked flowers.- In the first paper of the main series (1895:466), Plateau set himself the task of evaluating the attractive power of color and odor by masking simple heads of Dahlia with colored paper or green leaves. The dahlias grew in a garden with petunias, stocks, nasturtiums, morning-glories, zinnias, phlox, marigolds, etc., all of which were being visited by species of Bombus, Megachile, Vanessa, and Pieris. In the preliminary experiments the ray-flowers were covered with squares of paper, red, violet, white, and black in color, the yellow disk projecting through a hole in the center. During an hour the 4 masked heads, which were on different plants, received visits as follows:

TABLE 89.

\begin{tabular}{|c|c|c|c|c|c|}
\hline & Red. & Violet. & White. & Black. & Total. \\
\hline 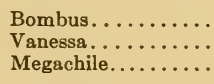 & $\begin{array}{l}2 \\
8 \\
1\end{array}$ & $\begin{array}{l}0 \\
6 \\
0\end{array}$ & $\begin{array}{l}9 \\
3 \\
0\end{array}$ & $\begin{array}{l}0 \\
1 \\
0\end{array}$ & $\begin{array}{r}11 \\
18 \\
1\end{array}$ \\
\hline Total......... & 11 & 6 & 12 & 1 & 30 \\
\hline
\end{tabular}


While the heads with red and white squares seemed to be much more attractive, this was shown not to be wholly true by the next test, in which the application of white or green disks to the center of the heads resulted in masking the latter entirely. In spite of this, a total of 29 visits was recorded, of which the black square with white disk received 7. However, the red square with white disk still yielded the largest number, and a direct comparison between black and white was lacking, as no white square was employed in this series. Similar results were obtained with a disk masking the tubular flowers alone, and with a central cylinder and a black square.

In order to avoid objections arising from the use of paper, the latter was replaced by leaflets of Ampelopsis in the remaining experiments. When the rays of 20 heads much sought by insects and well distributed among normal heads were covered with leaflets, with only the yellow disk in evidence, 36 visits were noted in an hour, 18 by Bombus, 11 by Vanessa, and 7 by Megachile. To determine whether the yellow disk still furnished the necessary attraction, this was effectively concealed in each of the 20 heads by a smaller leaflet. In spite of this an hour period yielded 58 visits, of which 28 were made by Bombus, 6 by Vanessa, 5 by Pieris, and 1 by Megachile. The following day the small leaflet was placed in contact with the disk-flowers in 16 heads and these were disposed among a larger number of normal heads. Of the 30 visits made, Bombus afforded 19, of which 13 were successful and 6 in vain, while the butterflies made 6 unsuccessful to 3 successful ones. In the fourth series 37 heads were completely covered with leaflets and the remaining ones were removed. In an hour's time 70 visits were recorded, distributed as follows.

\begin{tabular}{|r|c|c|c|}
\hline & Total. & $\begin{array}{r}\text { Suc- } \\
\text { cessful. }\end{array}$ & $\begin{array}{r}\text { Unsuc- } \\
\text { cessful. }\end{array}$ \\
\hline Bombus......... & 36 & 29 & 7 \\
Vanessa......... & 21 & 10 & 11 \\
Pieris......... & 13 & 2 & 11 \\
\hline Total..... & 70 & 41 & 29 \\
\hline
\end{tabular}

The author contended that the experiments of Bert, Lubbock, and others gave misleading results, since it was impossible to give two different colors the same absolute intensity. This conclusion was derived from the researches of Graber (1884), who found that leucophile, i. e., light-seeking, invertebrates preferred the more refrangible rays, while the leucophobe chose the less refrangible, red producing to them the effect of obscurity. He also cited the observations of Forel (1887) and others to the effect that the sense of smell is much better developed among insects than in man, and that the perception of odors is very different. From these facts he reached the conclusion that nothing in our present knowledge proves that insects distinguish colors as the human eye does, and also that they perceive odors that can not be recognized by the olfactory nerve of man. His final conclusions were as follows: 
(1) Insects visit actively heads in which form and color are masked by green leaves.

(2) Neither the form nor bright colors of flower heads seem to possess attractive power.

(3) The colored ray-flowers of simple dahlias, and in consequence those of other radiate composites, do not have the vexillary, or signal, rôle attributed to them.

(4) Since form and color appear to have no attractive rôle, insects are evidently guided to composite heads by another sense than sight. This is probably the sense of smell.

Removal of corolla.-Plateau removed the corolla or ray-flowers in several species in order to determine the rôle in attraction (1896:505) The first experiment was made with Lobelia erinus, with which Darwin had already made a test of this response $(1876: 420)$. The latter cut off all the petals of certain flowers and only the lower striated lip of others and found that not a single honey-bee visited them, although bees were abundant on the normal flowers. The removal of the small upper lip had no effect. Plateau used two pots of this species, one with 30 and the other with 40 flowers. These were placed near groups of Dahlia, Petunia, and Tagetes in order to afford a wider choice to visitors. The corollas of one pot were cut back to the tube, and the behavior recorded for three different periods of 1 to 2 hours. The total number of visitors to the whole flowers was 33 against 25 to the mutilated ones, Eristalis tenax giving much the largest number, while there were 29 inspections to the former and 16 to the latter. Thus, while there was a larger number of visitors to the normal flowers, it was pointed out that the suppression of the corolla did not prevent them, as in Darwin's results. In the case of Oenothera biennis, one honey-bee was seen to take nectar from 14 mutilated flowers in succession, and other individuals made respectively 10,3 , and 15 visits to them, the last one returning to flowers already visited. When the corolla of I pomoea purpurea was cut back to the sepals, Bombus muscorum visited successively 5 mutilated flowers, and $B$. terrestris in like manner 2,3 , and 5 respectively.

Kurr (1833:135) removed the floral envelopes of Delphinium ajacis and $D$. consolida and found that the flowers produced seeds, a fact that astonished Darwin (l. c.). Plateau made a similar test with $D$. ajacis, removing all the petaloid parts except the nectary, but the only visit was made by a bumble-bee. In the next test only part of the flowers of a spike were mutilated; $B$. terrestris visited the intact flowers and two of the mutilated ones. The mutilation experiment made by Bonnier (1878:61) with Digitalis purpurea was also repeated, 5 out of 19 clusters having the corolla cut back to a tube $1 \mathrm{~cm}$. long, and the plants being intermingled. Anthidium and Bombus made 12 and 1 visits and 11 and 5 inspections respectively of the mutilated flowers. With 3 mutilated spikes out of 5,4 individuals of $B$. terrestris merely inspected the cut flowers, while 2 visited 5 and 6 of them respectively. The next day the same setting was visited by 4 bumble-bees of the same species, the first going only to intact flowers, the second merely inspecting the mutilated ones, the third visiting 6 of the latter in succession after normal ones, and the last, 9 in similar manner. Antirrhinum majus was mutilated by cutting the corolla back to $1 \mathrm{~cm}$. in 8 spikes out of 25 . Of 5 bumble-bees observed, 3 merely whirled about the cut clusters, while the other two flew near them and then left for the entire flowers. The 
author remarked that if he had worked only with Antirrhinum he would have been persuaded of the attractive role of the corolla, but regarded this difference in response to two related genera to be due to the fact that the cut flowers of Digitalis are still directed downward, while in the snapdragon the stub is erect and much more difficult to reach.

One experiment was carried out on Centaurea cyanus to determine the value of the sterile marginal flowers of the head, which were regarded as attractive parts by Mueller and others. The show flowers were removed from 10 heads scattered among many normal ones. During an hour and a half, 1 honey-bee visited a mutilated head, while Megachile revisited them to a total of 19 heads, behaving exactly as at the normal ones, and passing readily from one kind to the other. Observations of Darwin, Mueller, Bonnier, and Van Tieghem were cited to show that insects visit flowers of which the corolla has fallen, while Van Tieghem had similar results with Nicotiana, from which he had cut the upper part of the corolla. The conclusion of Errera and Gevaert $(1878: 141)$ that bees are guided by the odor of the nectar was extended to include all pollinating insects and to be true even when there were no normal flowers to assist in the attraction.

The effect of masking flowers was further tried on a very fragrant Heracleum, the single plant available being several kilometers from any others and thus apparently eliminating the possible action of habit. An umbel was covered with leaves of rhubarb, but in spite of this received 7 visits in a half-hour. Several umbels were brought close together and covered with leaves in a similar fashion, receiving 45 visits during the period of observation. The evidence furnished by this umbellifer was in entire accord with that obtained from Dahlia and was regarded as proving that the insects were guided by the sense of smell.

Response to different colors.-In connection with his experiments on color, (1897:17), Plateau emphasized the importance of the work of Graber $(1884,1885)$. In the case of the honey-bee, the latter found that the choice of color depended upon the degree of refrangibility. When the bee was given a choice between bright red and deep blue, it went to the latter, which is more refrangible though less luminous; between bright red and deep yellow it chose the latter, which is likewise more refrangible. Between dark green and bright yellow it exhibited no preference, owing to the similar refrangibility of the two colors, in spite of the fact that the yellow is more luminous. In consequence, Plateau concluded that insects do not see color as such at all, in the way that we do, but that they respond to the different ones merely in relation to differences in refrangibility. His observations as to choice of color were made upon several species with flowers of various colors. In the case of Centaurea cyanus he grew blue, rose, white, and dark-purple varieties in mixture. Both Apis and Megachile were observed to pass readily from one color to another, though 22 of the 30 visits were to blue or purple, and this was explained by the greater number of the blue heads. Unfortunately, the number of each kind was not counted, and no endeavor was made to arrange the installation so that the number of each would be the same. With Dahlia variabilis the colors were scarlet, purple, rose, salmon, and white, among which the visiting 
bees, butterflies, and syrphids showed not the least choice, though no figures were given. During one period of observation pollinators went more frequently to purple heads of Scabiosa purpurea and during another to the rose ones, the explanation being that this was due to the greater number of heads in each case. Observations by Darwin, Bonnier, and Errera and Gevaert were also cited in confirmation of these results, and the conclusion was reached that, contrary to the general view, insects exhibit the utmost indifference to the diverse colors to be found in the same species or the same genus.

Addition of honey to vivid nectarless flowers. - In the same paper were reported the results of experiments made upon showy flowers with little or no nectar, in confirmation of the views of Darwin, Bonnier, and Perez, who had found that nectar brought visitors in abundance. The flowers of a border of Pelargonium zonale were observed to be completely disdained by Apis and Bombus. A drop of honey direct from the hive was placed in each flower of 17 umbels on plants arranged in a continuous series and marked to prevent confusion with normal ones. Bombus terrestris made 8 visits in an hour to the honeyed flowers, entirely neglecting the neighboring nasturtiums. After sipping at several, he would fly toward the normal flowers, but only to inspect them without alighting. The next day honey was taken from these flowers by $3 \mathrm{Apis}$, 5 Bombus, and $3 \mathrm{Vespa}$, as well as several Diptera, and a little later by 18,5 , and 5 individuals respectively of the same genera, but no further visits were seen for the normal flowers. Flowers of Phlox paniculata, which were but little visited by diurnal insects, were provided with honey, a drop being placed in 20 flowers of the violet and white varieties. The latter, being in the shade at the time, received no visits, while 6 were made to the former by Apis, Pieris, and Vespa, the two bees also making 9 visits during the next period to both colors. Honey was placed on 6 out of 29 white flowers of Anemone japonica, which were ordinarily little visited except by Diptera. During the hour 100 visits were made to intact flowers and 94 to those with honey, making an average of 4.5 for each of the former and $\mathbf{1 5 . 6}$ for the latter. A single flower of Convolvulus sepium, which had been completely neglected, received 29 visits after being supplied with honey, though few of these were made by bees.

The effect of removing the supply of nectar was determined in Dahlia by excising the disk-flowers of 8 heads and replacing them by a small disk cut from a yellowed leaf of cherry. No insect alighted on the mutilated heads, though Bombus and Megachile inspected them frequently. This behavior determined, the disks were coated with honey and the visitors immediately returned, Bombus making 26 visits, Vespa 12, and Megachile 2 during a half-hour. Two days later the artificial disks were dry and the mutilated heads were again entirely neglected. The disks were removed and a little honey placed in the greenish cup of the receptacle, when visitors came in abundance. The summary stated that insects go without hesitation to flowers habitually neglected by reason of the absence or paucity of nectar, when they are supplied with artificial nectar in the form of honey. They cease their visits, even in the presence of the showy ray-flowers, when the nectariferous part is removed, and begin them again when honey is added. 
Anemophilous flowers.-In his study of the attraction of anemophilous flowers (1897:601), Plateau enumerated Chenopodium album, Rumex obtusifolius, Corylus avellana, Carex, Anthoxanthum, Agrostis, Poa, Festuca, Bromus, Brachypodium, and Secale as already known to be visited by insects for their pollen, and cited also a number of cases in which extrafloral nectaries and fruits were visited by bees and butterflies. His own experiments were carried out on green or brownish flowers belonging to the Chenopodiaceae, Urticaceae, Polygonaceae, Typhaceae, Juncaceae, Cyperaceae, and Poaceae, to which honey was added. The great majority of the visitors were Diptera, which usually came within a few minutes, while the bees appeared much later. It is perhaps significant that Apis went to 12 of the 17 species, the wasps Odynerus and Vespa to but 4, and Bombus to but 1. Rheum tataricum, which combines the two methods of pollination to some degree, gave somewhat similar results with honey, but Apis was entirely absent and 2 species of Bombus made one visit each.

Entomophilous flowers of dull color.-After citing the frequent neglect of such flowers by Darwin and Mueller, and the emphasis upon their significance by Bonnier and MacLeod, Plateau (1897:613) gave a complete summary of his own and other observations upon flowers of this type, grouped as green, greenish, brown, or brownish. In the first group he listed 43 species belonging to 18 families, frequented chiefly by Diptera, especially the muscids; 8 species were visited by $A$ pis, 4 by Bombus, and 8 by other bees, usually the same ones. In the group with greenish flowers or inflorescences were placed 38 species belonging to 20 families, of which 10 were visited by Apis, 4 by Bombus, and 6 by other bees, the vast majority of visitors being flies. The flowers with brown or brownish color numbered 12 and were distributed in 9 families, 6 of the species being visited by honeybees.

In the matter of anemophilous flowers the conclusion was reached that it was only necessary to add honey in order to attract insects in large numbers. Moreover, insect visits were abundant to 91 species of entomophilous plants that lack striking color in the corolla. In short, insects concern themselves little with the presence or the absence of bright floral parts; what they desire is pollen or nectar. They are guided to these in a very secondary degree by sight, but on the contrary in a sure manner by another sense, which can only be that of smell.

Artificial flowers, second series.-The first experiments of Plateau, made by means of artificial flowers in 1876, were augmented 20 years later by studies with the flowers of 8 different families (1897:847). In all cases the flowers were copied with the utmost fidelity, even to the details of stamens, calyx, etc. With Ribes sanguineum 10 clusters of artificial flowers were placed among normal ones, but of 5 individuals of Bombus, 3 of Apis, and 3 of Osmia, not one was seen to pay the slightest attention to them. Two branches of artificial flowers of the peach were suspended among the natural ones and observed for three different periods two days apart. The bees showed complete disdain for the imitation flowers, even when they were supplied with a drop of honey, as on the last day. With flowers of the cherry the results were the same, bumble-bees and honey-bees both passing 
them without the slightest notice. Similar results were obtained with the apple, except that the flowers with a drop of honey were visited by one wasp and many flies. No visitors came to the artificial flowers of Myosotis alpestris, even with the addition of honey, while with those of Saxifraga umbrosa 2 individuals of $A$ pis and 1 of Andrena gave them a hurried inspection.

A more comprehensive study was made of Digitalis purpurea, in which the habit of the inflorescence, the form of the corolla, its color, and markings were copied from nature with great care. Among 6 natural spikes were disposed 3 artificial ones, on one of which honey was placed in the flowers. On its two visits Megachile paid no attention to the false flowers, while 4 of 10 individuals of Bombus inspected them, 1 repeating this three times. In the second experiment, 3 natural spikes were interspersed with 3 false ones, 1 of which was provided with honey. Anthidium ignored the artificial flowers on 38 visits, but inspected them briefly during 11 others, while one Oxybelus actually entered a false corolla containing honey, as did one Odynerus also. In the next test, made when the natural flowers were few, Megachile again ignored the false flowers, Anthidium inspected them on 9 visits out of 31, and two individuals of Musca alighted, but without entering the corolla. To eliminate the competition of the natural flowers of Digitalis, 3 clusters of artificial ones were placed at a distance, but among Dianthus and Tagetes. Of the many visitors to the latter, but 3 individuals inspected the false flowers for an instant. To check this behavior an old trunk of a conifer, a few feet in height, was placed in the spot occupied before by the imitation clusters, with the result that 3 different. insects were observed to inspect it on two different occasions, indicating the precautions that must be taken in interpreting mere inspections.

Three clusters of false flowers were suspended in a mass of normal ones of Lathyrus latifolius, the mimicry being so close that it would not have been suspected by one not forewarned. One individual of Stelis and one of Bombus gave an instant's attention to an artificial cluster, while Megachile inspected it in 10 of 17 visits. To test the significance of this, 3 pieces of pole were placed where artificial clusters had been, when it was found that Megachile made 9 inspections of them in the course of 36 visits. When the imitation clusters were placed $4 \mathrm{dm}$. in front of the main group, Bombus ignored them and Odynerus merely alighted for a moment on one of the artificial leaves. In 50 visits $M$ egachile hovered above the false flowers in but 8 cases, paying no attention whatever to them in the others.

Artificial flowers of green leaves.-To avoid the objection arising from the use of something other than vegetable tissue and to further test the response to green objects furnished with honey, leaves of Ribes rubrum and Acer pseudoplatanus were rolled into cups, the free edges trimmed, and honey placed in the center. Six flowers of this type were attached to several branches of Symphoricarpus racemosus, where they were almost invisible in the mass of foliage. In a half-hour the leaf flowers had received 19 visits, chiefly from flies; the bees were represented by two visits of Apis. In the next test $A$ pis made 8 visits, 1 more than by the other insects, and in the third, Bombus furnished 2 of the 15 visits, again chiefly due to flies. The 
bumble-bees attempted to pierce the leaf with their mandibles, but desisted after several minutes, as the thickness was too great. Finally, two leaf flowers were fastened to the peduncles of simple heads of Dahlia, the one made from the leaf of maple being erect, the other from the currant, hanging. The first received 14 visits, of which 5 were by Bombus, and the second but 4 visits, none of them from bees.

Incidentally, Plateau made a series of tests with various essences, such as lavender, sage, thyme, mint, etc., but found that they exerted little attraction. Thyme and sage alone afforded a feeble attraction, while the effect of mint was to repel the insects.

Conclusions as to artificial flowers.-From the above results, Plateau came to the following conclusions:

(1) In general, the insects observed paid no attention to artificial flowers of bright color, whether empty or provided with honey; they even seemed to avoid them.

(2) In the few cases where they seemed to notice the presence of the artificial flowers, they merely hovered about them, a behavior also exhibited before other bodies without any resemblance to flowers.

(3) The insects did not attempt to enter the flowers made of paper or cloth, even when furnished with honey.

(4) On the contrary, the leaf corollas, marked by the natural plant odor, and normal green color, and provided with honey, received numerous visits.

(5) The attractive influence of bright artificial colors can consequently be regarded as practically null.

General summary.-In completing the series of five papers on the way in which flowers attract insects, Plateau enunciated the following principles.

Insects seeking pollen or nectar are guided to the flowers that contain these substances in only a subordinate degree by sight. In fact:

(1) Neither the form nor the bright colors of flowers seem to have an important attractive role.

(2) Insects visit actively the heads of composites and the umbels of umbellifers not mutilated but with the forms and colors masked by green leaves.

(3) Insects continue to visit flowers or inflorescences in which practically all the brightcolored organs are removed, such as petals, corolla, disk-flowers, etc.

(4) They exhibit neither preference nor antipathy for the different colors afforded by the flowers of different varieties of the same species or of related species, passing from a white flower to a blue one, then to purple, rose, etc., without appreciable choice.

(5) Insects easily discover and actively visit numerous green or greenish flowers, which are but slightly visible in the midst of the leaves.

(6) They ordinarily pay no attention to artificial flowers of paper or cloth, even though brightly colored and well-executed, and provided with honey. They even seem to avoid them.

(7) On the contrary, artificial corollas made of green leaves receive numerous visits when provided with honey.

Insects are guided in an accurate manner to flowers with pollen or nectar by some other sense than vision and this can only be the sense of smell:

(1) They go without hesitation to those flowers habitually neglected because of the lack or paucity of nectar, just as soon as one provides them with an artificial nectar in the form of honey. 
(2) Insects cease their visits when, without disturbing the bright-colored parts, one removes the nectar-bearing part of the flower, and they begin them again if the missing nectar is replaced by honey.

(3) It is sufficient to put honey in or upon inconspicuous green or brownish anemophilous flowers rarely visited, to attract numerous insects.

(4) The rôle of the sense of smell is also demonstrated by leaf flowers filled with honey.

Rôle of vexillary organs. - The attractive value of colored bracts and show-flowers furnished the theme of the first investigation in a new series of studies on the relations between insects and flowers, begun by Plateau in 1897 (1898:339). The vexillary rôle of the terminal group of vivid bracts of Salvia horminum was first studied, making use of a bed of this species more than a square meter in extent. This resembled a rose carpet as seen from above, while the flowers themselves were hardly visible, except at the edge. The numerous bees present, chiefly Apis and Anthidium, went directly to the flowers upon their arrival, noticing the colored bracts only as they flew upward from flower to flower or when the folded bracts simulated the flowers. The butterflies were more easily deceived, 1 Pieris and 3 Rhodocera landing on the bracts and trying to probe them with the proboscis. Six honey-bees were observed to make but one visit and one inspection of the bracts to 388 visits to the flowers. In order to eliminate the possibility that this behavior was due to habit arising from the fact that Salvia had been grown for several years in the same spot, plants were transferred to another garden more than $2 \mathrm{~km}$. distant, where they were placed in a circle within another of Dianthus barbatus. Thus, the visiting insects were offered three choices, between the flowers of Dianthus, those of Salvia, and the bracts of the latter, the last two being presumably new to them. The insects that hovered without landing on either Dianthus or Salvia were 106 in number, all butterflies or moths, with the exception of 3 individuals of Bombus. During the period, 26 individuals of bees, 49 butterflies, 48 flies, and 16 beetles visited Dianthus alone, without paying any attention to Salvia. Of 21 individuals that visited Dianthus and were also confused by Salvia, all were Lepidoptera, with the exception of one Andrena. Three out of 6 individuals of Macroglossa hovered over the colored bracts of Salvia, one making this mistake 3 times. In the case of the insects visiting Salvia alone, the bees observed numbered 250, but only 24 of these made even a slight mistake, while there was on an average one error for each butterfly and each fly.

With reference to the attraction exerted by show-flowers, Plateau employed two species of $H y d r a n g e a$, the one native and with a clear distinction between the small fertile flowers of the center of the umbel and the large sterile ones of the margin, the other cultivated and exhibiting umbels with large sterile flowers alone. The number of visitors to the native species was small, a few bees and syrphids coming for pollen alone. The behavior of these was characteristic, for, instead of alighting first on the large marginal flowers as demanded by the theory of their attractive rôle, they flew by or above them as though they did not exist, in order to land directly on the fertile central ones. The number of mistakes made was but 1 for the bees out of 79 visits, while for the less intelligent flies it was 1 for 18 umbels visited. In the case of the cultivated species neither the brilliance of the 
umbels nor their large number served to attract honey-bees, bumble-bees, or butterflies, except for rare visits or inspections. The sole visitors were Syrphus and Melanostoma, which went almost exclusively to the flowers with stamens. The total number of errors for the bees was 5 in 397 , for the flies 5 in 93 . The author dismissed the possibility that this was due to habit, partly because of the short life of the individuals and partly because of the way he assumed this would affect the numbers found on the umbels. He regarded these results as proving conclusively that the vexillary organs studied actually attracted the majority of insects so little and the higher bees to such a minimum degree that the fertilization of these species would in no wise suffer by their absence, and that they could no longer be considered as organs of attraction.

Choice of colors by insects. - The first half of this second paper of the series $(1899: 336)$ is devoted to a critical résumé of experiments by others made by means of colored objects and by means of natural intact flowers, together with an account of desirable and undesirable methods to be employed in such studies. The first experiments were made with the two varieties of Salvia horminum, one of which had pale-rose flowers and brightrose bracts, while the other possessed violet-blue flowers and deep-blue bracts. These grew in contiguous beds and were trimmed back to give the same dimensions to the two groups. The observations were made during an hour each day for 12 days, a representative record giving 125 visits to rose and 131 to blue, with 5 abrupt changes from rose to blue and 7 from blue to rose. The addition of the numbers series by series gave the predominance alternately to rose and blue, the final totals being 1,085 rose and 847 blue, and this was regarded as explaining the preference obtained by Lubbock for blue and Bennett for rose. The equality of the two colors was further shown by the fact that Anthidium and Megachile flew suddenly from rose to blue in 64 cases and from blue to rose in 75 , while one individual of the former visited first 5 blue, then 2 rose, 4 blue, 4 rose, 1 blue, and 4 rose.

For a number of insects and flowers the percentages of each color and of the visits were computed and the results expressed in table 90 .

In further experiments it was found that the honey-bee went to scarlet without the least repugnance. Pieris brassicae eagerly visited the red and yellow heads of Zinnia, while the related Goniopteryx seemed to neglect these colors. One individual of Pieris visited indifferently the red, rose, and yellow heads of Zinnia, but another went only to rose heads of Scabiosa.

In his conclusions, Plateau emphasized the fact that he had at no time said that insects did not see the colors of flowers. He affirmed, however, that we have no practical means of assuring ourselves that they perceive colors and that this perception is the same as with man. The results of all experiments made with colored papers, cloths, or glass, or with isolated petals or normal flowers can be explained either by differences in the amount of light reflected, or by differences in the refrangibility of the rays transmitted or reflected. Whatever may be the visual perception of insects, the question whether the insects that visit flowers are guided in their choice by the colors that flowers present to the human eye must be answered in the negative. In studying the response of insects to varieties of the same 
species, which eliminates the effect of differences of form, perfume, and the abundance and accessibility of nectar or pollen, it has been seen that they show a complete indifference to color, when the relative number of the flowers of each color available is taken into account. Finally, it was admitted that insects perceive flowers from a distance, either because they see colors as we do or because they perceive a certain contrast between the flowers and their surroundings, and that concurrently with the sense of smell, although to a considerably smaller degree, this visual perception can direct them toward the mass of flowers. Once arrived there, however, if the flowers differ from each other in color alone, they are perfectly indifferent whether the corollas are blue, red, yellow, white, or green.

TABLE 90.-Color preferences.

\begin{tabular}{|c|c|c|c|}
\hline Species. & Color. & $\begin{array}{l}\text { No. of } \\
\text { flowers. }\end{array}$ & $\begin{array}{l}\text { No. of } \\
\text { visits. }\end{array}$ \\
\hline $\begin{array}{l}\text { Bombus terrestris: Althea rosea.......... } \\
\text { Bombus terrestris: Delphinium ajacis...... }\end{array}$ & 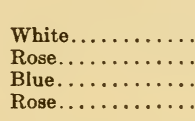 & $\begin{array}{l}\text { p. ct. } \\
60.9 \\
39.0 \\
55.2 \\
44.7\end{array}$ & $\begin{array}{l}\text { p. ct. } \\
60.1 \\
39.8 \\
49.1 \\
50.8\end{array}$ \\
\hline & Color. & Heads. & Visits. \\
\hline $\begin{array}{l}\text { Bombus terrestris: Scabiosa atropurpurea... } \\
\text { Apis mellifica: Centaurea cyanus......... } \\
\text { Eristalis tenax: Zinnia elegans.......... } \\
\text { Papilio machaon:Zinnia elegans......... }\end{array}$ & 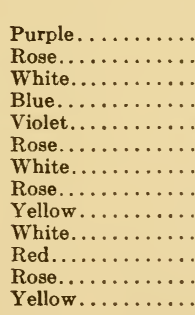 & $\begin{array}{r}\text { p. ct. } \\
56.4 \\
33.8 \\
9.6 \\
69.6 \\
12.9 \\
8.9 \\
8.4 \\
70.6 \\
18.6 \\
10.6 \\
27.8 \\
54.0 \\
18.0\end{array}$ & $\begin{aligned} \text { p. ct. } \\
52.6 \\
42.1 \\
5.2 \\
76.4 \\
13.5 \\
7.3 \\
2.7 \\
75.0 \\
21.8 \\
3.1 \\
25.0 \\
42.8 \\
32.0\end{aligned}$ \\
\hline
\end{tabular}

Errors made by Anthidium.-Plateau $\left(1899^{2}: 452\right)$ concluded that the female of Anthidium manicatum was directed to the flowers of Salvia horminum by the odor, since these were much smaller and much less conspicuous than the group of terminal bracts. In following her behavior it is seen that she makes many mistakes; she often returns to a flower already visited, goes to partly faded flowers with the upper lip brownish, and even to completely faded ones which fall with her, and finally alights uselessly upon the buds. The male is frequently unable to see the female when the latter is immobile, but perceives her instantly when she flies. Moreover, he is often unable to recognize the same individual again, sometimes returning to her twice. So much does he depend upon movement that more than once he was seen to fly to females of other genera even, such as Megachile, Anthophora, Apis, and an ichneumon fly. However, he did not disturb 
females of Pieris, recognizing them as different by their staccato flight and large white surface. It was concluded that the observations given for this one species, belonging apparently to those better endowed mentally, show how necessary it is to distrust statements as to the perfect clearness of the vision of Hymenoptera.

Admiration of syrphids for bright flowers.-In the third and last paper of this series $(1900: 266)$, Plateau discussed the current views as to the admiration exhibited by syrphids for bright-colored flowers. To refute this view he listed 35 species with green or greenish flowers for which characteristic visits by syrphids were recorded, and gave a large number of observations in which species of Syrphus in particular hovered in the usual fashion over leaves and other objects. In addition, he showed by experiment that these flies could be made to respond as usual by means of a variety of objects, such as a finger, the tip of a cane, etc., His conclusions were as follows:

(1) The number of cases clearly described of supposed shows of admiration for the color of flowers is very limited and may be reduced to seven altogether out of the thousand described by naturalists.

(2) The only insects noted are the dipterous syrphids, with limited faculties inferior to those of the bees.

(3) The syrphids regularly exhibit their so-called admiration before flowers not only without bright colors, but also before green and greenish ones.

(4) They frequently hover before other plant parts than flowers, such as green leaves, green buds, and fruits, green and brown stems.

(5) Syrphids also exhibit their characteristic stationary flight before objects having no resemblance to flowers, such as a finger, a cane, a marble, or a string.

(6) As a consequence, admiration for the color of flowers does not exist among insects.

Attraction of colored cloths and brilliant objects.-Plateau employed banner-like pieces of colored cloth to determine the attraction of color when not associated with flowers $\left(1900^{2}: 174\right)$. In the first experiment the colors used were bright red, yellow, bright violet, and sky-blue, the cloths being suspended on leafy branches at about a meter above the soil. The sole response to the banners was made by a single individual each of Musca, Calliphora, and Megachile, which seemed to rest on the yellow cloth as on any object. However, 7 individuals of Eristalis and 1 honey-bee hovered over a fringe of blue wool. The position of the colors was then changed, but the results were similiar; Pieris was attracted slightly by the blue, one Eristalis and Bombus rested on the violet piece, while 11 Eristalis, 4 Syrphus, and 1 Pieris hovered over the blue fringe. Two further tests were made with much the same results, the entire series yielding 30 cases of probable and 8 of doubtful attraction. All but 2 of the first were caused by the blue fringe, as well as 4 of the latter. Of the total, 5 visits were made by bees, 29 by flies, chiefly syrphids, and 4 by butter flies.

To determine the effect of brilliant objects, four spheres of metallic luster and 4 to $6 \mathrm{~cm}$. in diameter were employed. One of these was red above and blue below, the second had these colors reversed, while the other two were glass silvered within. These were suspended on stakes at the usual height of the flowers visited. All told, there were 24 cases of evident attraction and 10 doubtful ones, the silvered spheres furnishing 14 of the 
former. The bees comprised 19 of the evident attractions, of which Apis and Bombus each made 4 to the silvered spheres, and Bombus 7 to the colored ones.

Plateau repeated the experiment of Pérez, who found that insects were attracted to pieces of colored cloth when these were hung among masked flowers. Pieces of the colored cloths and the blue fringe previously used were hung among 13 masked heads of Dahlia and 3 of Rudbeckia and at the same level. The visiting insects paid practically no attention to the shreds of cloth, in spite of the fact that they hovered over both buds and fruits. One honey-bee and 2 Eristalis inspected the blue fringe, and two of the latter and one Lucilia alighted for a moment on the yellow piece.

In general, brightly colored pieces of cloth attracted so few insects that it is impossible to deduce from this an argument in favor of the attraction of insects by the colors of flowers. Pieces of colored cloth suspended near flowers masked with leaves attracted no more insects than when they were placed near normal flowers. Brilliant objects with metallic luster seemed to exercise a slightly greater attraction than colored cloth. From this it may be concluded that the attraction produced by certain objects other than flowers is probably related to the amount of light reflected. In certain flowers supposed to be without odor, such as Dahlia for example, a real odor can be disclosed by a simple process.

Constancy among bees.-After citing the observations of Bennett, Christy, Bulman, and Ord on the constancy shown by insects as to the flower visits made during each flight from the nest or hive (1901:56), Plateau gave"the results obtained from his own studies. A tabular exposition was made of the visits of 42 individuals belonging to 4 species of Bombus, in which the bee flew from one species to another and in 13 instances to a third, showing complete indifference to structure and color. In contrast to Bombus, Anthidium was found to be very constant, and it was only with difficulty that 8 cases of inconstancy were observed, two of them comprising 3 species. As shown by the results of earlier investigators, the honey-bee proved also very constant, though not completely so. In three successive summers Plateau found only 14 instances of inconstancy, and but 2 of these concerned a third species.

None of the apids observed exhibited an absolute constancy. Bombus was much the most inconstant, rarely remaining faithful even for a short time to the same species. Anthidium and Apis presented a remarkable fidelity, which, however, suffered certain clear exceptions. In all the cases observed, the bees passed from the flowers of a certain species and color to those of other species, often of a different color and family, thus giving proof of a complete indifference to flower structure and coloration. The acquisition of pollen and nectar is their sole motive.

Mistakes made by bees.-Plateau recorded in detail the mistakes made by 7 species of Hymenoptera in visiting 37 species of flowers belonging to 19 different families. The time involved was rather more than 6 hours scattered through 22 days. The results are given in table 91 .

It was concluded that probably no pollinating hymenopter is exempt from error and that the honey-bee is deceived as frequently as others. 
TABLE 91.

\begin{tabular}{|c|c|c|c|}
\hline Species. & $\begin{array}{c}\text { No. of } \\
\text { individuals. }\end{array}$ & $\begin{array}{l}\text { No. of } \\
\text { errors. }\end{array}$ & $\begin{array}{l}\text { Proportion per } \\
\text { individual. }\end{array}$ \\
\hline Apis mellifica.. & 46 & 87 & 1.8 \\
\hline Bombus hortorum. & 39 & 60 & 1.5 \\
\hline muscorum. & 14 & 31 & 2.2 \\
\hline lapidarius. & 2 & 2 & 1.0 \\
\hline Megachile centuncularius............. & 1 & 1 & 1.0 \\
\hline 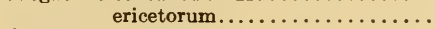 & 1 & 1 & 1.0 \\
\hline Odynerus quadratus................... & 4 & 4 & 1.0 \\
\hline Total.. & 107 & 186 & \\
\hline
\end{tabular}

Removal of the antenna of bumble-bees.-In the introduction to this paper $\left(1902^{2}: 414\right)$, Plateau stated that up to that time he had attributed a secondary rôle to sight and a preponderant one to smell, and likewise called attention to the results of many investigators, including Forel and himself, who had shown that with the insects the sense of smell resides chiefly if not exclusively in the antennæ. Forel $(1901: 53)$ cut the antennæ of 6 individuals of Bombus at the base and set the bees free again. At the end of 5 minutes a male returned to visit 8 to 10 flowers of Convolvulus in succession, each time flying directly to the flower without a second's hesitation. He was caught to confirm the complete absence of the antennæ and then released, when he made a single turn in the air and came back at once to the flowers to visit them as before. At the same time, several of the bumble-bees deprived of their antennæ returned to the bindweed flowers, flying from one to the other with even more precision if possible than those with the antennæ intact. Two days later several males and small females with the antennæ cut were found flying from flower to flower with an astonishing rapidity and precision.

Plateau repeated the experiments of Forel on two occasions. In 1899 the antennæ were cut from 10 individuals of Bombus terrestris and 1 ot $B$. muscorum, on four nearly successive days. These at once flew away, but one returned the first day to the same flowers, and on the following days, and in 3 cases shortly after the operation, 6 bees without antennæ were captured, including the $B$. muscorum. Although more than half of the multilated bees had found their way back to the flowers, the experiment was repeated in 1902 to remove certain doubts, especially with respect to the thoroughness with which the antennæ were removed. The latter were consequently cut at the level of the head and the bees released. The results were as follows: 4 neuters of $B$. terrestis never returned; of $11 \mathrm{~B}$. hortorum, 10 females and 1 neuter, only 1 female returned; 1 male and 1 female came back out of 7 individuals of $B$. lapidarius; finally, of 8 B. hypnorum, 5 returned shortly after the operation. Thus, 8 bumble-bees out of 30 returned accurately to the preferred species of flower after the antennæ had been completely removed and guidance by smell was impossible. 
Evidence of the attractive rôle of odor.-Plateau properly insisted that the above results did not indicate that the sense of smell played no part in attraction, and he brought forward a number of facts to prove this and in particular the investigations of Mayor and Gorka.

(1) Flowers that seem to man to have no odor may be shown to possess it by the proper method, and these would be perceived by insects with the sense of smell well developed.

(2) Many champions of the importance of the corolla in attraction have admitted that in certain cases odor can attract insects more strongly than color.

(3) The apids are much more attracted by odor than is ordinarily believed. Honeybees and bumble-bees seek actively the extrafloral nectar of stipules, petioles, and leaves, while the former, with many flies and wasps, visit fallen and dry fruits.

(4) The olfactory sense of many insects is extraordinary and guides them from considerable distances to objects that frequently they can not see, as in the case of saprophilous flies and beetles. Wasps readily find such desired food as cooked meat, and, like bees, are often attracted in great numbers to fruits, preserves, etc. Numerous observations have been made of the attraction from the fields of male moths by a captive female inclosed in a room or in a box.

(5) Moths are captured at night by means of perfumed sugar solutions placed on tree trunks, cords, apples, etc.

Mayor (1900) clearly demonstrated the unique importance of the sense of smell in connection with the sex attraction in Callosamia promethea. Males of this species when released more than 30 meters from a glass vase covered with mosquito netting and containing 5 females, flew directly to the vase and hovered about the opening. When the vase was inverted in sand so that the females could be seen but no emanation could escape, the males flew away, only to return when the vase was placed again in the original position. When the female was wrapped up in loose cotton, the males flew to the latter and gathered on it. After the females were inclosed in a box with a paper chimney at one end and a lattice at the other, the males flew to the opening of the former, through which the odor was drawn. When the abdomens of the females were detached and placed on a table and the winged thorax placed near by, the males went only to the former. If the antennæ of the male were covered with varnish, glue, paraffin, or other substances capable of excluding the odor, it no longer sought the female or even noticed it at a distance of a few centimeters. Plateau pointed out that the experiments of Gorka $(1900: 57)$ seemed to demonstrate that odor should be taken into account as well as sight, since the individuals of Deiliphila with the eyes covered with black varnish immediately found the flowers of Borrago and Malva, and shortly afterward, the preferred ones of Phlox. He further stated that, if he had been incorrect in assigning an exaggerated importance to smell, his many observations and experiments proved, as Knuth had admitted, that the sense of smell played a much more important rôle in the attraction of insects by flowers than had been admitted up to that time.

Decorollate poppies and insect visits.-In repeating Giltay's experiments with flowers of Papaver from which the petals had been removed (p. 171), Plateau pointed out two errors in the method that he regarded 
as serious $\left(1902^{3}: 657\right)$. In order to remove the petals before the flowers were visited by insects, Giltay excised them before the corolla expanded, which led to the flowers being handled for too long a time. He also paid no attention to the behavior of the insects on the mutilated and on the intact flowers. Hence, Plateau took precautions to work on Papaver orientale, a species more abundantly visited and easier to observe than $P$. rhoeas, to remove the petals with the minimum of disturbance, and to observe the number and behavior of the insects in minute detail. In addition some buds were enclosed in netting and the stems tied to stakes to prevent the access of insects and the transfer of pollen in consequence of being shaken by the wind. During a typical period there were 1 fresh and 18 old decorollate and 13 normal flowers under observation. The single fresh mutilated flower received 20 visits, of which 17 were made by $A$ pis and 3 by Halictus. During this time the 13 normal flowers yielded 56 visits, or an average of 4.3 to 20 for the mutilated one. While frequent visits were made to old decorollate flowers, these were always brief, the insect quickly recognizing its error. The total number of visits to 30 multilated flowers was 137, Apis making 97 and Halictus 19, while 70 normal flowers received 172 visits, of which Apis contributed 121 and Halictus 18. The former received an average of 4.5 , the latter of 2.4 visits. As to the weight of seed, the 70 capsules of the intact flowers produced $21.07 \mathrm{gm}$., and those of the mutilated ones $6.5 \mathrm{gm}$.; the respective averages per capsule were 0.30 and $0.21 \mathrm{gm}$., giving a ratio of $1: 1.39$ in favor of the normal flowers. In the matter of germination no difference was found between the two kinds of flowers.

In conclusion, the removal of the petals reduced the number of seeds per flower, as Giltay had shown. This result probably did not come from the removal of the attractive corolla, since the mutilated flowers received as many or even more visits than the normal ones. It was really due to the different behavior of the insects on the two flowers in their quest for pollen. They hang from the stamens of the decorollate flowers and pull them below the ovary, with the consequence that they neither carry pollen to the stigmas nor shake any upon it. On the contrary, in the normal flower they pass between the corolla and the crown of stamens, which they shake vigorously by the movements; they also wander over the stigmatic disk. As a consequence, the mutilated flower is reduced to the less effective autogamy, while the normal benefits by the action of allogamy.

New experiments with artificial flowers.-In reply to a number of his critics, Plateau performed a much more comprehensive series of tests with artificial flowers in 1904 and 1905, in the course of which he made 66 experiments of an hour's duration with 10 different genera, 5 of which were composites $\left(1906^{2}: 3\right)$. His criticisms of the methods of Andreae, Reeker, Wery, and others are considered later under the authors concerned, and the present account is restricted to his own investigations and the consequent conclusions. In making the artificial flowers especial pains were taken to avoid the use of any attractive material whatsoever, as well as to copy the flower faithfully as to habit, size, and color. Translucid colored papers of the usual kind were employed alone for the flowers of thinner texture, while for others the paper was first pasted upon tarlatan cloth, but without alter- 
ing the transparence. For an adhesive, pure gum arabic alone was used, since it never attracts insects, and for stuffed parts, only cork, wadding, or tow. Paste anthers were avoided and all delicate parts, such as disk flowers, were made of paper cut into a fringe. At the time of each experiment, all artificial flowers were provided with natural foliage.

When 21 artificial flowers of Crocus, 10 yellow and 11 white, were placed in a bed of normal flowers of $C$. luteus and vernus, they received but one visit, that of a muscid, and two inspections from Osmia, in the course of three experimental periods, in spite of abundant visits to the normal flowers. In the case of Viola odorata, the imitations received two visits from Vanessa and 11 inspections from $O s m i a$ in 47 visits, while Apis ignored them entirely. Paper flowers of Althea rosea were provided in one series with stamens of commerce, afterwards found to contain much starch and some dextrinlike substance, while in the second series, fringed paper was employed for the stamens to avoid the possibility of attraction by the starch. Two artificial stems with 6 white and 7 rose flowers were attached to 2 out of 4 plants with the buds still closed. Eight insects landed on the imitation flowers, 7 merely inspected them, and 15 ignored them. When the artificial clusters were placed near natural ones the latter yielded 55 visits to 3 inspections of the former in one case and 50 visits to but 4 inspections in the other. In the experiment given from the second series an artificial cluster of 6 flowers was placed 4 meters in front of natural ones bearing 20 flowers. One Apis and Bombus and 5 Prosopis inspected the false clusters.

Three cloth flowers of Papaver orientalis were arranged among unopened buds, but out of 45 insects, only 3 individuals of Pieris inspected them. When placed in competition with a bed of Myosotis alpestris, 3 such flowers secured no attention from the honey-bee. A mixture of 4 normal flowers with 3 artificial ones yielded 51 visits to the former and 1 visit and 4 inspections by $A$ pis to the latter, while in the five experiments there were but 10 inspections or visits to the artificial flowers as compared with 198 visits to normal ones. Six artificial heads of Scabiosa atropurpurea were placed at the edge of a cluster containing more than 60 natural heads, receiving 4 inspections to 53 visits to the latter. When the imitations were placed a meter in front of the cluster, they received 5 inspections to 36 visits. When imitation heads of Dahlia variabilis were attached at the proper level to stalks not yet in bloom, 4 individuals of Apis, 1 of Megachile, 4 small bees, 2 muscids, and 1 Lucilia inspected them, out of the host of insects in the garden. The 9 artificial heads were next fastened on stalks bearing 3 normal heads in full bloom, with the result that 28 insects visited the latter directly and 10 passed near the imitations without noticing them. Twelve insects went directly to the latter and 3 visited them after a normal head, all of these merely making an inspection, with the exception of 3 butterflies. The same 9 imitations were placed 2 meters before 8 plants bearing 18 heads, and the number of inspections was considerably decreased, namely, to 4 out of 51 , as would be expected from the distance between the two groups.

The effect of grouping on the response to artificial flowers was especially well shown by the experiments with Zinnia elegans. When 20 imitations were placed 3 meters from a plot of this plant, they received 2 inspections 
and 11 visits, at 2 meters 1 inspection and 9 visits, while the mixture of artificial and natural heads yielded 23 visits. When 2 imitation heads of Helianthus annuus were placed on stems with closed buds, they received 2 inspections by Bombus and 13 incidental visits from muscids chiefly, while 33 insects ignored them entirely. The number of inspections was increased when the 2 imitations were placed among 15 normal heads, 9 insects coming to inspect and 2 to alight, among them being Apis and Bombus. With 3 normal and 2 artificial heads, 27 insects ignored the latter as they flew past, and 5 inspected them. In order to test the attraction exerted by the materials used in ordinary artificial flowers, a head bought in a store was added to the two previously used. The result was that the 10 inspections observed either took place before this one head or began with it, indicating that the starch or dye employed in it served as the attraction. Twelve heads of Leucanthemum vulgare bought in the trade were attached to a plant bearing 1 open head and 25 to 30 buds, but received a single incidental visit and no inspections. The next experiment was organized by placing 5 imitations among 30 open heads of the same plant and putting a group of 7 artificial heads at a distance of a meter. No visits were made to the latter, in contrast to 3 to those on the plant and 53 to the normal ones, thus indicating that the natural flowers furnished the attraction for the others.

The most comprehensive series of experiments was made with Centaurea cyanus, in which both bought and specially constructed artificial flowers were employed. Six clusters of 3 heads each of the former were attached to plants with the buds still closed, which grew near groups of Melandrium and Anchusa actively visited by bees. Apis and Bombus inspected the false heads 30 times and extended the ligule before them 5 times. When artificial heads made for the purpose were employed, Apis made 1 inspection and Bombus 5 only. However, these were made a year later and under different conditions of weather and competition. The author admitted that the bees frequenting the adjacent flowers gave evident attention to the imitation heads, but stated that they perceived them only from a short distance, attraction from a distance seeming not to exist or to be very feeble so far as the artificial heads were concerned. When 18 of the commercial flowers were put at $2 \mathrm{dm}$. from a group of normal ones, they obtained 15 inspections and 2 extensions of the ligule in comparison with 54 visits to the latter, while the special imitations when placed in and about a nearly equal number of natural heads received but 9 inspections. In a series of 5 comparative studies with both kinds of artificial heads the figures were essentially similar, though the inspections were more marked with the commercial heads. Altogether, the cornflowers attracted insects somewhat more than the other artificial flowers.

Conclusions as to artificial flowers.-Because of their value in summing up the results of his three investigations with artificial flowers and giving his final views on the subject, Plateau's conclusions are here stated in detail:

"With respect to the solution of the question whether insects are or are not seriously attracted by artificial flowers, these new and extensive experimental studies are almost useless, since they serve only to confirm in full the results of my earlier re- 
searches. They confirm these all the more, since, advised by the criticisms, I have endeavored to avoid everything that could lead to objections: it has been said that the imitations employed were too few in number compared with the normal flowers; this time I have used numerous examples and in several cases the numbers of the real flowers and of the copies were essentially the same; it has been objected that I have not tried the attraction of imitations completely isolated; I have now done this repeatedly; the erroneous objection has been made that my artificial flowers have been nothing but gross imitations; I have continued to use only the most careful imitations possible and have frequently employed the very same species utilized by my critics.

"I can then only repeat the conclusions that I have formulated earlier, modifying the words alone a little in order to avoid all ambiguity, and emphasizing the necessity of good experimental conditions:

"1. In much the greater number of cases insects pay no attention to artificial flowers of vivid color and frequently treat them merely as obstacles in their way.

" 2 . In the relatively small number of cases where they perceive the presence of the imitations, they usually show only a brief hesitation, which is revealed by a turn or a crochet before or around them.

"3. Insects never seek pollen or attempt to suck nectar in a flower truly artificial and containing no attractive material of any sort.

"4. The attractive influence of bright artificial colors can in consequence be regarded as nearly null.

"However, if this laborious study has ended only in the demonstration of the accuracy of my earlier results, it has permitted what is perhaps more important, the discovery of most of the errors committed by my opponents and the reasons why they have believed in good faith in the actual attraction of artificial flowers. Such errors are as follows:

"A. To cover, conceal, cut or suppress in any manner the natural flowers and to replace them with artificial ones. In this case, insects, and especially the bees, not finding pollen or nectar where it was on former visits, fly in seeking it about any object occupying the place or located near it.

"B. To place artificial flowers near or among natural ones. Under such conditions it happens occasionally that insects which start by going directly to the real flowers, in passing from one flower to another or in leaving, hesitate before an artificial one as one sees them stop before faded flowers or even closed buds.

"C. To make studies with artificial flowers in places where they have already been performed with natural ones, since such places might have become habitually visited by bees, for example.

"D. Not to have taken into account the significant difference between a direct flight and simple turns or crochets of inspection.

"E. To disregard the well-known details of behavior, thus to forget that syrphids may hover before any object whatsoever, that the muscids alight constantly upon the most diverse surfaces, chiefly to expose themselves to the sun, that Pieris whirls about all kinds of plants and projecting objects, that small Hymenoptera such as Stelis and Prosopis fly about and land upon anything; finally, to take for visits the momentary or accidental presence upon artificial flowers of carnivorous insects or others that are not attracted by real flowers.

"F. To employ the artificial flowers of commerce or those made by florists. Such imitations may contain parts taken from natural flowers; they are nearly always impregnated with starch; they are sometimes dyed with chlorophyll or other plant colors; the stamens and pistils are always represented by small balls of paste more or less attractive to certain insects, faults whose importance I do not wish to exaggerate, but which probably explain the cases noted of an apparent search for pollen, of attempts to suck pollen, and of visits to the flowers of ladies' hats." 
Macroglossa and false flowers.-In order to throw light upon the numerous observations of visits by Macroglossa stellatarum and other insects to artificial and painted flowers, Plateau (1906:141) collected all the known cases of this sort, commented on them critically, and carried out several series of experiments to show the slight value pertaining to the observations. The significance of the latter and of Plateau's objections is discussed later (p. 189), the experiments alone being taken up at this point. The flight of Macroglossa is astonishingly swift, Bedel noting an average of 50 flowers of jasmine visited per minute, and Plateau observing 301 flowers of Phlox paniculata sought in succession. In the experiments with colored eloths, rectangles of silk, wool, etc., varying in size from a $12 \mathrm{mo}$. to a 4 to. page and ranging from red through yellow to blue, and rose, were attached to four stakes placed at the corners of a large bed of Delphinium ajacis. The 7 experiments with varying combinations gave the following results: (1) the 12 hawk-moths observed always flew directly to the flowers, never to the cloths; (2) no moth paid any real attention to the cloths, two only making a rapid exploratory curve about the blue woollen fringe; (3) none of the other insects noticed the colored cloths, not even the blue fringe. In the next series, the objection raised earlier by Pérez was met by using small pieces of cloth $4 \mathrm{~cm}$. square, which were hung near the flowers of Dianthus and Phlox. In no case did the hawkmoths go to the bits of cloth, even bounding over them as so many obstacles to visiting the flower. Similar results were obtained by employing pieces of colored paper, 14 by $10 \mathrm{~cm}$., a single Macroglossa, and one of Papilio and Bombus merely inspecting the papers. When screens covered with paper on which bright flowers were painted were employed, no hawkmoth gave them the slightest attention, and this was true of a large number of bees and butterflies. Two butterflies, two bees, and a wasp merely alighted on the screen for a moment's repose, as shown by the fact that one of them landed on the unpainted side, while one Apis and one Vespa flew up and down along the screen. Four experiments were made with a large number of artificial flowers, which permitted the study of the behavior of 6 individuals of Macroglossa. At least 100 such flowers were placed in two groups near a mass of Anchusa, and at a distance of a meter, and in the second experiment they were scattered in and about a border of Dianthus. While 99 flowers of Anchusa and 110 of Dianthus were visited by hawk-moths, no notice was taken of the imitations, and a similar result was obtained in the final experiment.

Plateau refrained from giving formal conclusions at the end of this paper, partly because his studies, though prolonged and laborious, were rendered incomplete by the destruction of the gardens in the midst of which he worked.

"New researches, by means of other methods, will be necessary and I hope there will somewhere be found a serious investigator to undertake them, rather than a superficial observer content with approximations. I have conscientiously endeavored to deceive Macroglossa by means of colored paper, large and small pieces of cloth, flowers painted upon wall-paper, artificial flowers, and the colored bracts of Salvia horminum. 
It is possible, it is even probable that several of my experiments have been defective; I believe, however, that it is impossible that all of these observations and experiments, made during five successive summers, are absolutely bad. A single consideration diminishes my regret at not being able to carry them further, namely, that the present work contains a number of documents which it. will be neceessary to take into account in writing the history of Macroglossa stellatarum."

Entomophilous flowers little visited by insects. - The final memoir by Plateau (1910:3) was devoted to experiments with entomophilous flowers with bright colors but without nectar. The investigations were made in the spring and summer of 1907, 1908, and 1909, and comprised 55 experiments upon a dozen species. The substances employed to render the flowers attractive were anisette, composed of very dilute alcohol, sugar sirup, and a small amount of essence of anise, brown-sugar sirup with rum, sugary juice of cooked cherries, and sugar sirup with a decoction of $A n$ gelica. The first two species employed were Fumaria officinalis and Polygonum convolvulus, both with very small inconspicuous flowers. When anisette was placed upon these by means of a brush, insects were immediately attracted to them, the visitors being chiefly flies. The experiments dealt chiefly with large flowers of a vivid color, which are normally little or not at all visited by insects. When Lilium candidum was supplied with anisette or brown-sugar sirup, visitors appeared almost at once, the total number reaching 28 in an hour, of which 25 were honey-bees. As a check, flowers were supplied with sirup alone, but these were visited by only a small number of flies, no bees noticing them. A single flower of Passiflora with the corolla moistened with anisette received 34 visits by flies, while another was supplied with brown-sugar sirup with rum a few days later and yielded 40 visits in an hour, of which 1 was by Apis, 2 by Bombus, and several by Vespa. Five experiments were made with Oenothera speciosa, the first one with anisette showing visits by Halictus and Prosopis chiefly, while the second, on the afternoon of the same day, yielded 20 visits, 19 by $A$ pis and 1 by Prosopis. Similarly treated, Pisum sativum received 30 visits, chiefly of Bombus and Megachile, and Linum perenne, 15 visits, 11 of which were by flies, 3 by bees, and 1 by a hawk-moth. The juice of cooked cherries was put in the flowers of 3 umbels of Pelargonium zonale and anisette in those of another two. While the natural clusters were not visited at all, those treated received a number of visitors, practically all flies. Clematis jackmanni perfumed with anisette gave 20 visits in an hour, of which 14 were made by Bombus, and Convolvulus sepium received numerous visits from 4 genera of Hymenoptera, 5 of Diptera, and 1 of Lepidoptera. In the case of Petunia hybrida provided with cherry juice, 40 honey-bees came during a period of an hour, and visits continued actively for a day or more, even to flowers completely faded, as long as the juice was available. In the second experiment, cherry juice was placed in the flowers of a group situated at a distance of 5 meters from the first one, but no visits occurred for more than 4 hours, and the number then was much smaller than in the previous case. 
The results of this series of experiments were summarized in the following conclusions:

1. These observations confirm the fact, already known but not sufficiently emphasized, of the existence of a considerable number of entomophilous flowers of large size and bright color that attract diurnal insects little or not at all.

2. Two corollaries may be derived from this fact: the first is that the attractive rôle of the form and color of the floral envelopes is either null or nearly so; the second is that other causes than the attraction of colored surfaces is necessary to bring pollinators to flowers and to cause them to return, such as an odor pleasing to insects and a sugary liquid.

3. The addition of these two attractions to nectarless flowers that are little visited has the practically certain consequence of causing insects to come to them, frequently in large numbers.

4. This type of experiment, previously made by means of honey, succeeds just as well when sugar sirup perfumed with an odor properly chosen is employed, a fact which proves that the criticisms directed against the use of honey are not well founded.

5. To obtain good results it is necessary to avoid the use of most of the pure essences of commerce and of artificial perfumes, and to employ substances already known to attract insects, others of which will doubtless be discovered. It is also necessary to work on clear days and during the warmest part of the day, as well as to renew the solution from time to time so that the odor will continue to attract.

6. The immediate or nearly immediate arrival of insects, not only flies but frequently bees as well, at flowers thus treated demonstrates clearly the olfactory sensitiveness of insects and, in spite of all the objections raised, proves the importance of the rôle of smell in the attraction of insects by flowers.

7. In résumé, the present investigation but confirms the thesis advanced in 1897 in the following words: "Insects seeking pollen or nectar are guided to the flowers that contain these substances in only a subordinate degree by sight. They are guided in an assured manner to such flowers by some sense other than vision, and this can only be the sense of smell."

\section{RELATED STUDIES AND CRITIQUES.}

Comparative importance of odor and color.-As a consequence of Plateau's first paper, Pérez (1894:245) brought together the results of a number of observations and several experiments to show that both color and odor serve for attraction, as Lubbock had already demonstrated. With reference to the attraction of red flowers, he found that Salvia splendens was not visited by honey-bees while in the shade, but as soon as the sun reached it a number of visitors came almost immediately. This was explained as being due to the effect of the sun's rays in favoring the excretion of nectar or freeing its perfume, and not to the greater visibility, but the latter seems much more probable. When honey was placed on the corolla of flowers of a scarlet Pelargonium, honey-bees working on neighboring heliotropes were at once attracted by its odor and went directly to the flowers, which they continued to visit until evening. They even returned in the morning, although the honey had been exhausted the evening before, when they also went to flowers that had not received honey and examined them thoroughly. Perrez concluded that at a distance where vision could not be an aid, bees and the great majority of insects are di- 
rected by the odors carried by currents of air and thus reach the flowers that exhale them. As soon as they approach sufficiently near for sight to intervene, they fly directly to the flowers in response to guidance by vision. Color likewise serves to attract, in the absence of odor previously perceived, when the chances of the flight bring them near a flower. They then visit the latter if the odor is pleasing, or disdain the flower if the odor is unpleasant.

In a more extensive paper (1903:1), Pérez communicated the results of further experiments and discussed at some length the points of difference between Plateau and himself. When fallen flowers of Glycine were interspersed with bits of paper of the same color, a honey-bee inspected them, but flew away before landing, to seek nectar in some of the flowers. Small balls of rose paper were strung on a pin, which was fixed on the end of a leafy shoot of Symphoricarpus or on a shoot from which the flowers had been removed, and in some cases all the open flowers of a cluster were replaced by similar balls of paper. Two honey-bees inspected the paperballs for a moment, while a bumble-bee gave them more extended attention. When the rose flowers of a currant were hidden by means of green leaves and bits of cloth of the same color placed near them, several honey-bees were deceived by the latter, though they finally found the masked clusters. Similar results were obtained from a small orange tree ornamented with small pieces of white paper. The addition of honey to the branches of a laurustine ornamented with squares of white and blue paper quickly attracted honey-bees, which went first to the colored papers. Disconcerted, they began an agitated search for the honey and finally found it.

Pérez's critique of Plateau's work.-Pérez pointed out that the use of large surfaces of colored cloth by Plateau to demonstrate the indifference of insects to color was incapable of furnishing actual evidence on this point, since insects care nothing for color in itself, but only as a sign of the food they are seeking. The same failure to recognize the significance of the resemblance of small bits of cloth to flowers in contrast to large pieces was regarded as vitiating Plateau's results with bright standards placed near masked composite heads. A just criticism of the latter's statement that all the results obtained with colors were illusory because of Graber's discovery, was based upon the fact that this showed insects, like man, to receive different impressions from the light of different parts of the spectrum, and that it is immaterial whether their perceptions are the same as ours, since they possess a scale of luminous sensations. Experiment based upon the use of colored objects is legitimate in every respect and to proscribe it would be only to carry one's scruples to excess. Attention was also called to the obvious discrepancy of Plateau's own conclusions as to the importance of color, involved in the two statements, "Neither form nor color seems to have any attractive rôle" (1895), and "I admit that this vague visual perception can guide the insect toward the flower mass, concurrently with smell but to a much less degree" (1899).

In regard to the errors committed by pollinators, Pérez noted that Plateau invoked smell to explain the attraction of flowers containing nectar, 
but said nothing about the rôle of this when it was a question of flowers already visited, or of faded flowers, buds, or fruits. The mistaken visits to these were said to be directed by the form, poorly seen, the attraction of which had been previously denied. In the case of withered flowers it was thought clear that these were really visited because of the usual similarity in color and not because of the form, as was likewise true in the case of many buds. Imperfect vision of form can not serve to explain the majority of the errors noted by Plateau, and form is to be regarded as the least important of the features that effect attraction.

Effect of colors at the hive.-Theen (1896:101) summarized the results of a number of investigators on the color sense of bees, including the little known ones of Wüst and of Dönhoff. In Wüst's apiary the thresholds of the hives were painted with bright colors, which stood out sharply against the deep-green of the Ampelopsis surrounding them on three sides. On one occasion the supply of bright colors was inadequate and some thresholds were painted black, red, or blue. The consequence was that the bees required a longer time for recognition and were able to recognize the proper hive at once only after the second day; at first it was necessary for them to orient themselves for a much longer time in order to determine the right hive. He also found that queen-bees were best equipped with the sense of location and color. When a red petal of a poppy was placed on the yellow threshold of a hive, a returning queen approached ten times as though to enter and even alighted twice; it then quickly flew back, showing that she recognized the place accurately, but found something there that was not present when she flew out. Suddenly she flew away and was lost to view, and the red petal was removed. After a few minutes she flew directly to the threshold without hovering about and immediately disappeared. Dönhoff pasted blue paper before a hive and 14 days later replaced it with a yellow one. Bees returning from the field hesitated long before flying to the hive and finally most of them flew to another part of the hive rather than to the entrance. Theen also cited three observations of Darwin, in which honey-bees flew directly from a tall larkspur in full bloom to one of another species at a distance of 10 to 12 feet, though none of the flowers were open and the buds showed but a tinge of blue.

Critiques of Kienitz-Gerloff.-In a series of four reviews, KienitzGerloff considered the results and conclusions adduced in the five papers of Plateau's first series. With reference to the response to masked Dahlia heads he pointed out that the insects were readily guided by the sense of smell, and that this did not warrant the assumption that the color of the normal heads played no part in attraction, especially since no comparative number of visits was given for the two kinds of heads. He cited the many and varied experiments of Lubbock and of Mueller, and in particular those of Forel with insects deprived of their antennæ to show that the experiments with Dahlia were not to be regarded as adequate. In opposition to the conclusion of Graber that weakly refrangible light gives leucophobe animals the impression of darkness, he brought forward the fact that all nocturnal winged animals fly to lighted windows, indicating that they are drawn by the contrast (1896:123). In discussing the experiments in which the corolla 
was removed, he emphasized the fact that the mutilated flowers were always near normal ones and the insects attracted by the latter were guided by odor to the former. Moreover, control numbers were lacking in most cases and in that of Lobelia were mostly against the assumption. The fact that a honey-bee flew to faded flowers and buds, and even to fallen petals, gave evidence of the effect of color, the fact that it took nectar only from the mutilated flowers being explained perhaps by the greater odor and accessibility. It was further remarked that the results with flowers of different colors of the same species indicated just the opposite conclusion to that drawn, as shown especially in the case of Centaurea. The small number of experiments were regarded as having little weight in comparison with the observations of Mueller on 5,674 visits by 841 species of insects to 422 alpine flowers. Whether insects see the various colors as we do or not is immaterial, if in general they distinguish them $(1897: 84,108)$.

Plateau was further criticized for not being familiar with Mueller's results and for opposing a single observation on Listera to the many made by the latter, as well as for not distinguishing between insects of different orders and diverse intelligence, although Mueller had frequently emphasized the importance of this. Moreover, he should have repeated the experiments of Lubbock and of Mueller, which showed that insects possessed a clear perception of color, instead of trusting too much to the evidence drawn from artificial flowers. Likewise, he contradicted himself when he explained the visit of a cabbage butterfly to an artificial flower on a lady's hat by saying that it sought the flower for its protective white color and not for nectar. The critic also found unconvincing the use of artificial flowers made from leaves and provided with honey, owing to the superior attraction of honey, irrespective of the object on which it may be placed. The final conclusion was reached that Plateau had proved nothing against the color sense of insects, although it was admitted that odor played an important rôle, as Mueller had long before insisted.

Knuth's critique.-The results of Plateau's first series were reviewed by Knuth (1898, 1906:204), who pointed out that they permitted another interpretation than that given. In the case of umbels of Heracleum covered with green leaves, the visits of a variety of insects were regarded as indicating that insects are attracted also by odor, but that this was alone effective was not proved, since there was no comparison with the visitors of the umbels not masked. The evidence that color is not attractive, afforded by behavior to the differently colored varieties of the same species, is inconclusive and it can only be concluded that color is immaterial in flowers of the same form. The experiments in which honey was added to bright flowers that are normally little visited merely prove the well-known fact that the odor of honey is a powerful lure. Since both honey-bees and bumble-bees distinguish readily in many cases between flowers visited and unvisited, it is not strange that they distinguished the artificial from the natural flowers in Plateau's tests and left them alone, even when supplied with honey. Neither the paper flowers nor those made from green leaves and provided with honey prove that color is unattractive to insects, but both merely emphasize the powerful attraction exerted by the odor of honey. 
Since other odors were unattractive or actually repellent, with the exception of thyme and sage, which were weakly attractive, Plateau's theory is refuted by his own experiments.

The discovery that bees still visited flowers rendered inconspicuous by removing the petals or the colored part of the corolla seemed at first to overthrow the accepted principle of attraction by color. However, careful consideration of these experiments led to the conclusion that Plateau's inferences were not justified and that another explanation was permissible. The mutilation of Digitalis by cutting away the corolla, together with the stamens and style, to leave a stump only $1 \mathrm{~cm}$. long seemed to warrant the conclusion that neither color, size, nor form was essential to their attraction. Knuth argues, however, that the nectar is more exposed and the fragrance more widely diffused and that this compensates for the loss of the corolla; moreover, the visits should thus have been more numerous than to the normal flowers, which was not the case. With other species the mutilated flowers were visited less than the normal ones, a fact that Knuth regarded as proving that the corolla also plays a part in attraction. In the case of Antirrhinum majus the lack of visitors to the cut flowers seems to indicate that the odor is not effective and that the form and color of the corolla play the chief part. Moreover, the frequent visits of Megachile to heads of Centaurea cyanus deprived of ray-flowers, explained by Plateau as due to the odor, may be equally well explained by the memory of the bee as applied to the honey-bearing disk-flowers.

Plateau has given a one-sided meaning to his experiments, without regard to the work of earlier investigators. Thus, he has entirely overlooked the experiments of Forel, who showed that blinded insects are unable to recognize the landing-place of the flower, while those that have the antennæ cut away fly confidently from flower to flower. He further ignores the results of Mueller, Loew, MacLeod, and Knuth himself, which have established the following principles:

1. Other things being equal, a flower is visited by insects in proportion to its conspicuousness. Among related species that agree closely in form and color as well as in floral mechanism, the most conspicuous receive the most visits and the least conspicuous the smallest number.

2. In a number of cases odor has more to do with the attraction of insects than the color and size of the corolla.

3. Dull yellow flowers are not visited as a rule by beetles, while nearly related flowers that are white or of some other conspicuous color attract these insects even when nectarless. Reddish-blue or violet flowers are preferred by bees, butterflies, and hoverflies, which are highly specialized, while the most frequent visitors to white or yellow flowers are less intelligent insects with a short proboscis. Bumble-bees appear least dependent upon the color of flowers, and as Mueller indicated, are influenced more by food-value than by the external appearance of flowers.

4. Strong-smelling flowers attract flies more particularly, while those with sweet aromatic odors attract bees strongly without excluding other insects. The delicate odor, strongly exhaled toward evening, of many white flowers with long corolla-tubes attracts hawk-moths especially, as well as other nocturnal Lepidoptera. 
"Plateau's experiments only show that the sense of smell perhaps guides insects to a greater extent than has hitherto been supposed. Apparently there is need of further experiments to decide questions as to the attraction of insects to flowers by means of the senses of smell and sight. Meanwhile, the following law may be provisionally accepted: Attraction from considerable distances is certainly effected for the most part by the odor of flowers, which fills the air as with invisible clouds and indicates the direction for flight: when the insects approach near (1 to 2 meters), the colors of flowers undertake the task of attracting them further, and when they finally settle, the lines and points long since described by Sprengel under the name of 'Saftmal' (i. e., sapmark) serve to point the way to the nectar."

Reeker's experiments with artificial flowers.-Reeker (1898:105) made a critical review of Plateau's first series of investigations, in which he brought forward essentially the objections advanced by Kienitz-Gerloff and by Knuth. Of especial interest was an extract from Graber which showed that Plateau was not justified in citing Graber's views in support of his conclusions, since the latter was actually an exponent of the color sense of insects (p. 215). In the first experiment Reeker employed artificial flowers of Centaurea cyanus, 4 of which were grouped in a square against a green background, at a distance of 6 to 8 meters from other flowers. During an hour of observation, 11 individuals of Pieris inspected the imitations and 4 actually alighted. Honey-bees were very scarce, only one coming near the cornflowers, and this landed and probed for nectar for 2 seconds; 3 syrphids came to seek pollen and 6 to 8 small flies flitted from one head to another in an assiduous search for pollen or nectar. For the second experiment four artificial flowers of Ranunculus acris were added to the cornflowers in a fairly compact group, placed at a distance of 12 meters from natural flowers. Five Pieris made inspections and 3 others alighted, while one bumble-bee also landed on a cornflower and probed for nectar, and 2 honey-bees visited nearly every flower in the group. A dozen small flies made long stays at several flowers and flew back and forth from the blue to the yellow.

Reeker stated that these experiments gave such uniformly positive results that further investigation seemed unnecessary, an unfortunate conclusion in view of the much more extensive studies of Plateau. He regarded them as furnishing incontrovertible proof that the color and form of flowers serve to attract insects. Granting that the odor of flowers constitutes a very powerful means of attraction, it must also be conceded that color likewise has a share in the attraction of pollinating insects. However, Plateau (1906:87) considered it very probable that the visits noted by Reeker were due to the materials entering into the composition of the artificial flowers, such as starch, etc.

Decorollate poppies.-In order to demonstrate the importance of the corolla, Giltay (1900) grew Papaver rhoeas in two beds of about equal extent and separated 50 meters from each other, and in a third bed covered by a screen impenetrable to pollinators. In the first two the number of flowers was equalized, and in one the flowers were left to develop normally, while in the other the corolla was removed before the flowers opened. A portion of the latter were later fertilized artificially with other pollen to determine whether the mutilation itself could influence the production of seed. The 
plants in the wire cage produced only a very small amount of seed, viz, $0.004 \mathrm{mg}$. per flower, although they had been artificially pollinated. The 215 decorollate flowers yielded $10.77 \mathrm{gm}$. of seed or $0.05 \mathrm{gm}$. per fruit, while 215 normal ones produced $25.23 \mathrm{gm}$. or 0.117 per fruit. The 28 decorollate flowers that had been artificially fertilized gave $0.115 \mathrm{gm}$. of seed per fruit.

The criticisms of Plateau as to the methods and conclusions of Giltay have already been given (p. 159). These brought in return a critique of Plateau's studies, in addition to a new series of experiments with mutilated poppies, in which especial attention was devoted to the insect visitors (1904:368). The first emphasized the discrepancy between Plateau's earlier and later conclusions as to the importance of color, as Pérez had already done, and summarized the experiments of Forel with masked Dahlia heads, which gave results very different from those obtained by Plateau ( $p$. 145). Papaver rhoeas was again used by Giltay for his studies, owing to its many advantages, such as complete sterility to its own pollen, the ease of cultivation, the abundance of flowers and of insect visitors, and the readiness with which the corolla may be removed. To insure better manipulation the plants to be used were transferred to pots and kept in a screened cage until needed. Checks were employed in connection with the removal of the calyx and corolla to show that this in no wise affected the visits of insects and that Plateau's fears were consequently groundless. In the first series of 1902 two potted plants were placed on a greensward 2 meters apart, and the corollas removed from the flowers of one of them. For an equal number of flowers the normal ones received 96 visits and the mutilated 9 visits, while the second series with the plants near each other and with but one or two flowers each gave 38 and 1 visits respectively. In the third series the intact flowers obtained 34 visits, those with the calyx removed and the corolla still folded 14, ordinary buds 1 , and young fruits 2 . When flowers were so masked by pots that they could not be seen but any odor present was free to escape, they received no visits, but bees came readily as soon as the pot was removed. When the pot was so placed that the flower was visible, it received frequent visits, thus showing that the odor of the pot was not a factor in the preceding case. The relative importance of color and odor was further demonstrated by placing petals in a dish and covering them with a pot so that they were invisible but the odor could escape. These were never visited, but when the pot was removed, bees alighted on them, sometimes immediately.

Several additional series of experiments were carried out in 1903, in which the response to the two kinds of flowers was shown to be greatly influenced by habit. At first when one or more pots of mutilated flowers were placed among normal ones, the visitors gave the former practically no attention. In the case of two flowers of each sort the intact received 15 visits, the mutilated, none, while on the next day a honey-bee was seen that went to mutilated flowers as often as to normal ones. Three days later an observation on 4 each of intact and decorollate flowers yielded 12 visitors to the former and none to the latter, and 1 flower of each on the same plant gave respectively 8 and 4 . However, 1 marked honey-bee went to 18 intact and 13 mutilated flowers. When all the flowers in the experimental plot were picked and 2 pots with equal numbers of the two sorts of flowers were placed at 
a distance of several meters, the bees came first to the habitual place and flew about it for some time before finding the potted plants, on which they went only to the normal flowers. When the latter were picked and placed in water or wet sand near the plot, there were several times as many visitors to them as to the mutilated flowers. As the visitors to the latter increased, the two kinds were separated about 2 meters, with the result that 24 honeybees and 23 bumble-bees went to intact flowers and 15 and 10 to the mutilated ones. When the flower groups were again brought near each other, the number of visitors to normal flowers alone was 1 honey-bee and 9 bumble-bees, to mutilated alone 16 honey-bees, while 11 bees and 1 Bombus went first to a normal flower and 2 of the latter first to a decorollate one. The 12 mutilated flowers were then removed to a distance of 2 meters and in their place was put a new group of 5 similar ones; the latter received 8 visits, while a single bee alone found the flowers in the new position. Finally, the position of a single flower of each was changed each time, with the results that 14 visitors came to the intact flower to 3 for the decorollate one, the latter being visited first but a single time. When the intact flower alone was shifted it still received all the visits, but when the two were again brought together the sole visiting bee went 10 times to the intact flower and then directly to the mutilated one. The normal flower was then taken away, and the bee now visited the mutilated one.

In the second series of experiments, Giltay (1906:468) extended the work of Pérez on the response of bees to red flowers, employing geranium and corn-poppy for this purpose. A special instrument was devised for catching and marking bees, and practically all the studies were made with bees so treated. The results of the experiments are expressed in a number of résumés, as well as in the final summary. Trained bees came to the usual place even when the plant used was not provided with honey; however, they did not alight or for but a moment, though they landed in the normal manner as soon as honey was placed on the flowers. When a plant without honey was substituted for one with it, and the latter placed at a distance of 1 to 2 meters, most of the first visits were made at the usual place, but the honey plant was quickly found again. The honey-free plant was put 2.5 meters to one side of the usual place and the honey-bearing one the same distance to the other side; several bees flew about the experimental spot, but visited neither pot, until the honey-bearing plant was replaced, when Nos. 5 and 4 visited it again. Five leaves were spread with honey and placed on the ground below the honey-bearing plant. Within a few minutes, three visits were made to the latter and later these were repeated, without the other plant or the honey-bearing leaves being perceived. This indicated that the odor of the honey was not sufficiently strong to be attractive at the short distance represented by the height of the geranium plant. When a cork with honey and a dish of the same were placed near the two plants, both the latter were frequently visited, but the honey alone was not noticed. In the next experiment, a blue flower of iris and a bud of poppy with the calyx removed were put a meter distant on opposite sides of a honey-bearing geranium, but neither was visited. The iris was then replaced by a full-blown poppy, which was visited by both bees. When Brassica was employed, it was also visited, though to a less degree than the geranium. 
In the studies with Pelargonium, 22 honey-bees were concerned, 20 of which were marked and brought to a flower provided with honey, while 2 made independent visits. Of the 22 , only 4 returned to the place of experiment and one of these, No. 4, more often than all the others. The visitors to the honey-bearing flowers clearly exhibited place-memory, as well as a preference for these over those without honey, and the ability to remember Pelargonium after they had once learned it. During 14 days of experiment no case was found of a marked bee bringing others, the only doubtful instance being that of a bee that seemed to come by mere chance. Pérez explained the visits ultimately made to flowers without honey as due to the memoryassociation of honey and color, and Giltay also found such visits to be numerous. Moreover, he thought that, while form and fragrance might play a part in this, it was improbable that these could be perceived as quickly and accurately as was the case. His conclusion was that the bees saw the flowers of Pelargonium as standing out against the background of different color and consequently could easily find them at a certain distance.

The experiments with Papaver were designed to demonstrate the relative attraction of decorollate flowers or of paper ones, usually with a natural center, in competition with normal flowers. These were organized in such a manner as to bring out clearly the effect of memory of place. In all cases of competition between decorollate and intact flowers, the latter were always much more visited. The method of exposure exerted an evident influence upon the ratio, since the decorollate were first sought after the normal flowers had been brought near them. As in the experiments of 1903 , it was found that flowers covered with a pot were not visited when they were not visible from the outside. In the case of paper flowers with natural centers, one bee visited practically all of these, independently of their position, while another was much more timid, flying to some of them, but rarely alighting. However, in a second series, the first bee behaved in a wholly inexplicable manner, going to both the normal and artificial flowers, but stopping at none, until it finally landed on a yellow composite one. By means of a particular grouping it was possible to bring the bees to visit decorollate flowers readily, though to see the latter it was almost necessary for them to pass very close. After the bees had been attracted to the decorollate flowers, the latter were exposed with an intact one, but this was then alone visited.

In the case of Papaver, 27 bees were marked, of which 13 returned and 5 served for experimental purposes. These showed place-memory in a high degree. Of their own accord they found the decorollate flowers not at all or only by chance, when these were not exposed in a most conspicuous manner. Once attracted to them, they later found them more easily, and often returned to the spot where the flowers had stood earlier. Likewise, artificial flowers with natural centers were not readily visited, but they were frequently sought after the bees had first been attracted to them. Marked individual differences were exhibited by the bees employed in the experiments, and the same bee sometimes behaved in two opposite ways.

It was concluded that bees are certainly attracted by the corolla in Pelargonium and Papaver, and that it is very improbable that a special odor 
constitutes the attraction of this organ. Since a single petal or a bud deprived of its calyx exerts this attraction, it can not depend upon the form of the flower. Hence, it must be due to the color, which must also stand out sharply from the background to the bee's eye, although it can not be said that they see the color red as we do. Small amounts of honey had relatively little effect, at equal distances a single corolla exercising a much stronger power of attraction than a quantity of honey much greater than that ever found in a single flower.

Response to color and odor by a hawk-moth.-The experiments performed by Gorka (1900:57), though few in number, are among the most important of all, as they were carried out with newly hatched moths in which either the antennæ or the eyes were rendered useless. He noted that Deiliphila elpenor, which was frequent in a garden in upper Hungary, sought the flowers of Phlox paniculata and drummondi with especial fondness, but ignored the other flowers, such as Dianthus, Malva, Borrago, etc. As a preliminary test, a butterfly was released from its pupal case, when it flew straightway to Phlox. On this he based his experiments to determine whether this flower attracted hawk-moths by means of its color or its fragrance. For this purpose he had at his disposal about 40 pupæ. The antennæ of three hawk-moths that had just emerged were covered with collodion and thus deprived of the sense of smell. These were freed in the evening, when they flew directly to the Phlox at a distance of about 2 meters and at once began to suck the nectar. Four days later the eyes of 4 hawkmoths just hatched were covered with shellac, but the antennæ were not disturbed. In the evening when released, these flew to the flowers of Borrago and Malva, which they immediately left; they finally landed on those of Phlox, where they remained for some time. They then flew away, but only to return for six different visits. These two experiments were repeated 12 times, and always with the same results. In three cases the blue flowers of Borrago were sprinkled with essence of jasmine, when it was found they were no longer disdained, but were visited by several of the moths.

Gorka's results prove conclusively that the hawk-moth is guided by both sight and smell, and indicate that the former is more directive at a distance. Taken in conjunction with the similar experiments of Forel (p. 140), and Mayor (p. 159), they afford convincing evidence of the importance of both senses in regard to attraction.

Vexillary nature of the plume in Muscari.-In order to test the value of Plateau's conclusion as to the rôle of vexillary organs, Ferton (1901:96) mutilated racemes of Muscari comosum by removing the sterile flowers, which form a vivid violet-blue plume at the top of the inflorescence. The fertile flowers are brownish and rather inconspicuous, but they emit a pleasant fragrance. Andrena vetula flew indifferently to the fertile or sterile portion of normal clusters, but when the fertile flowers were cut off, it went to the sterile plume direct, then dropped to the level of the fertile ones, only to find them gone. It twice hovered for some time before the mutilated stem, and also visited two or three such clusters in succession. Bombylius fimbriatus likewise went to the vivid sterile group first and then descended slowly along the stem, with the ligule extended, but finally dis- 
appeared as though disconcerted. Osmia tricornis and some males of Anthophora acervorum were not deceived by the change, but one male visited in succession four mutilated clusters before flying away. In the following experiment the colored plume was removed from most of the plants and placed on the ground near normal ones. A female of this species passed by the latter in spite of their fragrance and went directly to one of the detached clusters. However, it quickly recognized its error and departed after visiting one of the fertile flowers. These results were thought to confirm the vexillary rôle of the plume, which was regarded as a better guide than the perfume which diffused in all directions. When the essential organs were excised from flowers of Cistus, such blossoms were visited by Anthophora, in spite of the fact that the fragrance had disappeared, one individual going to three or four after failing to find pollen in the first (cf. Knoll, 1921).

Forel's experiments with covered dahlias and with artefacts. Forel (1901:26, 1904:22) repeated Plateau's experiments with concealed dahlia heads in order to check his conclusions. A bed of variously colored dahlias, much visited by honey-bees, contained about 43 heads, of which 28 were covered with grape leaves fastened below by pins; in 4 heads the yellow center alone was covered, while in a single one the center was free and the rays masked. Forthwith the bees ceased to visit the completely concealed heads, but went to the one with the rays covered just as to the normal. They also flew frequently to the heads with masked disk, but soon forsook them, though a few succeeded in crawling beneath the leaf. Just as soon as the leaf was removed from a red dahlia the bees returned to it, and a poorly covered head was also discovered and visited. Later one bee found an entrance to a concealed head, to which it repeatedly returned. Various individuals continued to seek the dahlias that had so suddenly disappeared and late in the afternoon some of them had discovered the hidden flowers. They were soon imitated by the others and in a short time the concealed heads were again regularly visited. As soon as a bee had discovered the entrance to a masked head, it flew without hesitation to it on subsequent journeys. Single bees were not noticed by the others, but a successful visit by several brought the others after them. It was concluded that Plateau's methods were faulty and his results erroneous, due to the fact that he had failed to reckon with the bee's memory and attention.

Three days later crude imitations of dahlia heads were made by putting yellow Hieracium heads in Petunia flowers and these were placed among the dahlias. Neither Petunia nor Hieracium was visited by the bees, though at first nearly as many flew to the artefacts as to the normal heads. They left them immediately, however, upon finding their error, obviously through the sense of smell. They behaved in the same manner at dahlias with the center replaced by a Hieracium head. As a check a beautiful fragrant dahlia disk was placed among some white and yellow Chrysanthemums neglected by the bees. For a half-hour this remained unnoticed by the many bees, but came to be visited like the normal ones as soon as one or two had discovered it.

In confirmation of Plateau's results, Forel found that the most carefully made artificial flowers were entirely neglected when placed among the 
dahlias. He then made a series of crude paper flowers as follows, placing a drop of honey on each; $(a)$ red, $(b)$ white, $(c)$ blue, $(d)$ blue with yellow center made from a dead leaf, (e) rose-colored with a dry dahlia disk, together with an $(f)$ unchanged green dahlia leaf. During the first hour the honey was removed from the blue flower alone. The red flower was then brought repeatedly to the attention of a bee resting on a dahlia, when it began to sip the honey. This bee was marked with blue, and those led to sip from the white and the rose flower were painted yellow and white respectively. Upon returning from the hive, the blue bee flew at once to the red flower and hovered over it doubtfully, then visited the blue, and went again to the red but not to the dahlias. The yellow bee next revisited the white flower, then visited the red and the blue, but gave no heed to the normal ones. It was followed by the white bee, which, failing to find the rose flower at once, began to work on the dahlias, but remained only a moment on each. It returned to the artefacts without finding the honey, until it encountered a corner of the rose-colored flower and began to sip. After this the three painted bees, and no others, returned regularly to the artefacts and ceased to visit the dahlias. It is significant that they discovered the other artificial flowers by themselves, doubtless through an instinctive inference from analogy, in spite of the fact that these were somewhat distant from each other and differently colored. The blue bee went to red, white, and both blue flowers, the yellow to white, red, blue, and blue composite, and the white to rose, red, white, and blue composite, the green not being found, evidently because of its color.

Finally, a new bee came to the blue composite and was marked with carmine, after which she drove the blue bee from the red flower. Another bee came to the rose flower and was painted with orange, and still another to the white flower and was painted green. The experiment had now lasted more than three hours and but six bees had come to know the artefacts, the great number continuing to visit the dahlias. Soon, however, the others began to come and it was necessary to replenish the honey constantly, a swarm finally removing the last traces and one bee discovering it on the green leaf. After vainly searching the empty artefacts, the bees began to return to the dahlias; at this moment the red and white flowers were replaced by red and white paper entirely free from any odor of honey. These pieces of paper were visited and examined by various bees, still possessed with the idea of honey, the white bee carefully searching the white paper for three or four minutes. This could only be explained by an association of space, form, and color memories with memories of taste. When the artefacts were carried away, several bees followed and tried to alight on them, in response to color and form alone, the space-image having changed.

This and other experiments were considered to demonstrate the space, form, and color perceptions of the honey-bee, its memory particularly with respect to vision and taste, the power of associating gustatory and visual memories, the instinctive ability to draw inferences from analogy, a poor olfactory sense, a one-sided and narrow range of attention, the rapid formation of habits, and the limited imitation of bees by each other. Further experiments designed to lead the bees to distinguish between disks of dif- 
ferent color were vitiated by the bees' power of memory, the marked bees placed on the blue disks beginning at once to investigate all the other colors with and without honey, and being followed by a swarm that even besieged the paint-box.

Response of Syritta.-Schröder (1901:181) recorded 12 cases in which a honey-bee approached to within $2 \mathrm{dm}$. of heads of Chrysanthemum leucanthemum and then flew to a bush of jasmine at a distance of 4 meters, the strong fragrance of which was carried across the former. He clipped the rays from half a group of 12 heads and found that Syritta pipiens in the course of a half-hour visited 37 normal heads, while it completely ignored the mutilated ones. Syritta hovered over the latter a longer time than usual, but without alighting. During the afternoon, 4 visits were made to the clipped heads and 21 to the normal, and on the next day 19 to 46 , the fly no longer showing the hesitation before the former. This indicated that the insect recognized the difference in the heads in spite of the similar odor, and that it learned rather rapidly to accustom itself to the mutilated ones. Two days later the latter were cut off and a flat piece of white paper the size of the head, provided in the middle with another piece the size and color of the disk, was fastened on the end of the stem. In spite of visits to the normal flowers, no Syritta paid the slightest attention to these crude imitations, which lacked the form and fragrance of real flowers. They were then furnished with a few drops of an infusion of Chrysanthemum heads, but, while they were inspected during the next half-hour, no Syritta visited them. However, when three of them were provided with honey, they received 10 visits during the half-hour to 12 for the normal ones. The other three were also visited four times, indicating that Syritta had again profited by experience. Three artificial flowers made of cloth were fastened on the stem ends, and one received a visit, but it was thought this might be due to the odor of the adjacent normal heads. To give them a distinctive odor they were soaked in the infusion of normal heads, dried, and again attached, when they received 7 visits in comparison to 24 for the normal. Thus, the question of the means by which flowers attract insects seemed not solved in the direction of Plateau's views.

Andreae's experiments with artificial flowers.--In a comprehensive examination of Plateau's results, Andreae carried out many experiments with artificial flowers, some of these being made at Jena and some at Lake Como (1903:427). In the first series yellow artificial flowers were placed 2 meters from a bed of Eranthis nivalis and these were visited during an hour by 10 honey-bees. As a check a bell-glass was put over one plant to eliminate the influence of odor, but in spite of this 4 honey-bees came to the glass. When the imitations were replaced they were visited 8 times within the hour. A further check was obtained by putting 10 decorollate flowers in one beaker, 10 normal ones in a second, and the detached perianths in a third. One honey-bee flew into the first glass and 2 hovered about it, 14 into the second and 10 about it, and 9 into the beaker with perianths alone and 4 about it. When a dark paper was placed upon a small group of Crocus and an artificial flower placed 2 meters away, bees went to the latter, to Crocus, and again to the imitation before flying away to the snow- 
drop. A bell-glass was next put over the Crocus flowers and 5 honey-bees came to it within an hour. At a distance of a meter from a bed of yellow Crocus was placed a striking artificial flower of the same color and at the same distance a beaker with 5 normal flowers, while a meter further away stood one with 10 similiar flowers. The latter was surrounded by dark paper with a fairly large opening above, so that the odor might easily escape. However, not a single bee came to this during two and a half hours, though 10 visited the imitation during the first hour. The open glass with normal flowers was constantly visible, but only one bee entered it. The next installation consisted of a beaker filled with blue Crocus 2 meters from the bed, another with white Crocus at 4 meters, and an artificial flower at 7 meters. During a quarter of an hour these received respectively 11,9 , and 2 visits by honey-bees; when the beakers were turned down they still received 9 and 7 visits respectively.

In the first experiment with Rhododendron ciliatum a large empty beaker was placed 2 meter's from the bush and a smaller one filled with normal flowers of this species at a distance of 3 meters, the first designed to show the effect of the brightness of the glass, the second that of color. During a half-hour but 2 bees went to the empty beaker, while 12 flew to the red flowers in the other, and 10 flew directly against the glass itself. When this beaker was inverted, 7 bees went to it in 5 minutes. The second installation consisted of three beakers placed 8 meters from the bush and likewise distant from each other, one containing honey, another slightly perfumed water, and the third was the inverted one with normal flowers, designed to show the relative attraction of honey, perfume, and color. The visits made by Musca and Apis were respectively 15 and 4, 12 and 3, and 16 and 10, during an hour. An inverted beaker with normal flowers gave 60 visits to a single one for an empty beaker. The bush was then shaken and 20 bees flew directly to the normal-flower beaker, and during three repetitions not a single bee went to the empty glass. This showed conclusively that the bees were not attracted by the brightness of light but only by the color itself. Moreover, the honey-bee must be able to see color for a distance of 8 to 10 meters at least. When the attraction of honey alone was tested, a single bee came to the beaker as though by accident.

Parallel to a bed of primroses were installed a yellow primrose made of cloth, an inverted beaker containing blue primroses, a glass of honey, and an upright beaker filled with the same flowers freshly picked. The last two were surrounded with dark-gray paper to conceal their contents, and all were placed a meter from the bed. The artificial flower received a total of 18 visits, of which 10 were made by the honey-bee, the inverted beaker 13 , the glass of honey none, and the open beaker 1, giving a ratio of $31: 1$ in favor of color. In the check a glass with diluted honey was surrounded with paper and placed at a meter from the bed, while at 2 meters were located an imitation flower and an inverted beaker. This yielded 26 visits, 14 by Apis, to the artificial flower, 2 to the beaker, and 3 to the honey glasses, or 28 to 3 in favor of color. The second check consisted of four glasses, one filled with honey and the other three with primroses and all wrapped with dark paper, placed at a meter from the bed. At 3 meters were located a false flower and an inverted beaker of red primroses. The imitation 
received 38 visits, 25 by bees, the inverted beaker 17 , and the four "odor" glasses but one, giving a ratio of 55:1 in favor of color. Even when the artificial primrose was placed 5 meters from the flower-bed, it received 13 visits from bees to none for the more accessible "odor" glasses. To determine the effect of a difference in form the artificial primrose was replaced by a peony of the same material and color, which was placed 7 meters from the bed of primroses. One meter from the latter stood four glasses, one filled with honey, the other three faintly perfumed with jasmine, mignonette, and violet respectively. However, the latter obtained no visits in contrast to 41 for the imitation flower.

Twelve meters from a bush of Doronicum caucasicum, a yellow composite actively sought by various insects, was located an artificial flower-bed composed of the primrose and peony already used and an orange-red and a dark-red poppy, all of which were a meter apart. As an additional attraction, artificial cornflowers and snowballs were placed in the center of the square. The yellow peony received 31 visits, the orange-red poppy 9, the dark-red one 3 , the central group 7 , and the primrose but 1 , showing a clear relation between conspicuousness and attractiveness. A further test of the effect of odor was made by filling an inverted beaker with fresh primroses, so that they were plainly visible, while a bell-glass was likewise filled with several hundred fragrant flowers of the same species, but these rendered invisible by means of dark paper. In spite of the advantages given the latter, it received but 3 visits to 35 for the former.

When 5 funnels were filled with fragrant flowers of the peony and surrounded with paper, and placed above the bush, now past blooming, they received but 3 visits in competition with a bell-glass in which several flowers were visible, this yielding 40 visits. To test the effect of the glass itself, the same bell-glass full of peonies was placed 15 meters away, while a small empty one was put but a meter distant. The latter received no visits to 5 for the former. In the next trial two artificial flowers were made of bright-yellow and rose-red tissue paper, provided with dark-green below to furnish a contrast, and attached to stakes 2 meters high. Within a period of 2 hours 17 visitors went to one and 16 to the other, the total of 33 including 12 bees. When a yellow, a dark-yellow, and a purple-red cloth flower were employed, the yellow obtained 21 visits and the red 9, during 3 hours. In the next case, 3 flowers of Papaver orientalis were placed in a funnel so that the odor could escape without their being seen, while to the single normal flower left on the plant was added a larger artificial one of cloth, in order to determine whether conspicuous color, color and odor, or the latter alone would be most effective. The results showed 81 visits to the imitation, chiefly by Osmia and Apis, 56 to the normal flower, and none to the funnels. In the control the last normal flower was added to those in the funnel and this placed 5 meters distant against the wind. In spite of this it received no notice from the bees, which meanwhile made 43 visits to the imitation.

Experiments with flowers of dull color but nectar-bearing showed that the color was often attractive, sometimes more attractive than the odor of nectar or honey. Studies were also made of flowers with dull color and marked perfume, such as Reseda, Dahlia, etc. When stems of the former 
were put in a dark-brown bag of gauze and hung above the bed, they were visited by Prosopis and Andrena, but Apis continued to work only on the plants in the bed. In the case of bell-glasses filled with mignonette and one of them inverted, Prosopis and Andrena went only to the one with the opening, thus exhibiting the reverse response to odor and color from that of the higher apids. When artificial flowers of Paeonia and Primula were placed in a meadow, 8 Apis went directly to the more conspicuous peony and one each of Apis and Bombus to the primrose. A box was covered on the four sides with differently colored cloths, through which a large opening permitted the air to move. When linden flowers were placed on the inside, about 20 individuals of Prosopis went directly in, while 3 Eristalis went first to the color before entering, and 10 to 20 Apis flew against the color alone, especially on the lighted side. With buckwheat substituted for linden, the results were the same, Apis flying to the color and Prosopis entering the box, but when the latter was empty, Prosopis failed to appear, Apis, however, behaving as before. In the case of a choice between the colored bracts of Salvia horminum and artificial cornflowers attached to the plant, the former received 20 visits to 9 for the latter.

A few weeks later experiments with Dahlia variabilis were made in a garden at Cadenabbia on Lake Como. Four heads were cut off and laid in a pot wrapped with green paper, which was kept covered until the odor had time to collect, and at the same time a large bright-yellow paper flower was fastened to the stem. The pot received no visits, while 19 were made to the imitation, and the results were similar when other paper flowers were employed. When red-brown plums were placed in a pot and also on the ground, the latter alone were visited by honey-bees; with those on the ground removed and the pot in full sunshine the odor of the plums attracted but one bee in the course of an hour. Near a plum tree sought by hundreds of bees was placed a pot wrapped with bright paper and filled with crushed ripe plums, and a paper flower with contrast colors. The latter received 16 direct flights, while the former was visited only by young bees that grazed it in flight. In the last experiment with diurnal insects, 50 paper flowers of various colors were fastened to stems of Zinnia elegans, and the normal ones inclosed in wire-gauze to permit the attraction of fragrance alone. However, the latter received no visits, while the former had 49, of which Apis made 30, Argynnis 14, Pieris 3, and Vanessa 2, showing that the butterflies behaved essentially like the higher bees.

Andreae's conclusions.- It is evident that running insects will have the sense of smell better developed, while flying ones that possess an extended life-period have sight developed in proportion to their rapidity of flight. Thus, it is necessary to distinguish between high and low types, the one characterized by long direct flight, a relatively long life-period, and a keen sense of sight, the other by short flight, short life-period, marked sense of smell and a poorer vision. Consequently, the various inflorescences and corollas with bright colors are chiefly adapted to the biologically highly differentiated insects, and the fragrant flowers without bright colors are designed to attract the lower ones. Thus, Prosopis and Andrena react to odors very differently from the higher apids, for, while colors attract Apis, Osmia, Anthophora, and Anthidium from considerable distances, as 
can be determined by their direct and rapid flight to them, the flight by the lower types is quite different. The latter change in direction and each time toward the side from which the fragrance comes. Such insects also perceive colors, but only when they are near at hand. Similar differences also occur among Diptera; Eristalis responds differently to a color than a gnat does, and Bombylius and Volucella, two highly developed flies, show but very slight response to odor, as Forel has already shown.

The conclusion that color attracts the biologically higher insects from a distance and odor when near at hand is supported not only by the experiments recorded, but also by the following facts. A brightly colored object does not change its position, and, if forced out of it, becomes more or less conspicuous only as a result of changes in lighting, while odor behaves very differently. In the first place, its intensity varies from time to time, in the second its conveyance depends upon a variable wind direction, and in the third its perception is determined by the amount of humidity in the air, since the antennæ are much more sensitive in moist than in dry air. There are constantly many odors in the atmosphere which pervade and replace each other, and are constantly changing their position in response to the slightest breeze. Thus, the view of Sprengel and of Darwin that color attracts insects from a distance is rehabilitated.

Andreae's criticisms of Plateau's work.-In connection with Plateau's statement that we have no means of knowing that the perception of color by insects is the same as with man, Andreae pointed out that this was equally true of odor, declaring that the whole question was an idle one and that the only thing of importance was to determine whether what we call color exerts an attractive effect upon insects or not. He also emphasized the fact that many of Plateau's experiments were excellent in demonstrating choice among colors, but they had no value for the question of the relative merits of color and odor. The chief error in his investigations lay in the fact that he failed at the outset to organize his queries properly. In the first place all possible factors that bring about attraction must be considered, and in the second as many of these as possible must be tested at the same time. In this way alone can comparative results be obtained that will lead to an objective conclusion as to the importance of form, luster, brightness, and color, honey-odor, or fragrance. Many of Plateau's results were to be ascribed to the effect of habit, and the others were not organized to yield a definite decision as to color and odor. However, Andreae's statement that the greater proportion of visits to the decorollate poppies did not change the essential facts with respect to the attraction of the corolla does not seem valid. Finally, it was stated that Plateau had not sufficiently distinguished the behavior of various insects in regard to color and odor, since the lower apids gave results directly opposite to those obtained with the higher ones.

Plateau's criticisms of Andreae's work.-Plateau stated (1906:13) that it was probable that the artificial flowers of Andreae and of Reeker would have exhibited the same sources of error as those employed by Wery (p. 185). With respect to the experiments with Crocus in which the flowers were covered, it was objected that the bees upon returning to the habitual 
place and not finding the flowers precipitated themselves upon the imitation, as upon any object whatsoever. The same objection was raised to the experiments with the poppy, the results of which were regarded as illusory because of this fact, as well as because the flowers were cut off and handled, and to those with Dahlia. The experiments with Zinnia were also regarded as demonstrating nothing whatsoever, since the artificial flowers were attached to the stems to which the bees were accustomed to come to visit the natural ones. Moreover, it was supposed that the meshes of the wire-gauze were so small that the odor could escape little if at all. Both of these objections were also urged against the results obtained with Salvia horminum, but their validity does not seem to be great, and they can not apply to the many cases in which the artificial flowers were placed at distances of several meters.

Wery's experiments with decorollate and artificial flowers.-At the suggestion of Errera and Massart, and under their supervision, Wery (1904:1211) made a series of investigations to determine whether color exerted an attraction upon insects and whether this was greater or less than that due to odor. An interesting historical introduction is given, but no direct criticism of Plateau's work is made, except to point out that this investigator modified his earlier conclusions as to odor and color in 1899, and in 1902 he admitted that he had ascribed an exaggerated importance to odor. The first experiments with decorollate flowers demonstrated that different insects behaved differently in response to color and odor, the higher bees, A pis and Bombus, visiting the normal flowers in much greater number, Eristalis showing a marked but slighter preference, and the flies and other small Diptera exhibiting little difference. This showed that it was not permissible to group such various insects together in studies of attraction and consequently the visits of honey-bees alone were taken into account in these experiments, a fact that explained in part their disagreement with those of Plateau. A further explanation of this difference was afforded by the fact that the bouquets were always separated by a distance of several meters and sufficiently isolated to avoid errors due to any other attractive object. Moreover, the flowers were changed about in order to eliminate errors arising from the habits of the bees. The experimental area was stripped of all other flowers and the space between these and the hive was cleared of all plants, so that the bees flew straight from the hive in direct response to attraction and the visits were not the result of hazard. The bouquets were not exposed between experiments and the artificial flowers were put away to make sure that the bees would not ignore them in consequence of vain visits. An endeavor was made to count only the visits of bees coming from the hive or from a distant flight during which they had gone to other flowers. In removing the corolla care was taken not to injure the nectaries and great care was also given to following the precautions laid down by Plateau, such as washing the hands, avoiding the use of perfume, not touching the flowers with the hands and using the scissors for no other purpose. The objection of Plateau that insects would not visit cut flowers was not confirmed, except when the temperature was unfavorable, as at other times they were abundantly visited by insects of diverse species. 
The first experiments were carried out by means of a bouquet each of normal and decorollate flowers of Epilobium spicatum and Malva silvestris, placed 10 meters apart. The normal flowers of these received respectively 14 and 4 visitors, of which 7 and 2 were honey-bees, while the mutilated ones yielded 12 and 3 , of which 5 and 1 were bees, the totals for the former being 18 and 9, and for the latter 15 and 6 . When Epilobium and Antirrhinum majus were employed, there were 19 visitors to the intact and 13 to the mutilated flowers, the number of bees being twice as great in the former. Symphytum officinale was added in the next test, which gave 27 visitors to normal and 24 to mutilated flowers, while the respective numbers for the bees were 20 and 6 . The next installation consisted of two bouquets of Centaurea cyanus, Papaver rhoeas, and Pyrethrum leucanthemum separated by a distance of 25 meters and 500 meters from two hives. The flowers of one bouquet were left intact, while the petals or the rayflowers were cut off in the other. The former received 43 visits, 29 of them by the honey-bee, and the latter 27 , of which 10 were made by the bee. The following year the visits of the honey-bee alone were counted, the installation comprising two bouquets, one intact, the other decorollate, which were exchanged after each series. The results of 6 observations gave a total of 72 bees for the normal flowers to 28 for the mutilated ones. The total for the two years was respectively 138 and 46, the bees being much more attracted by the normal flowers, in the ratio of $3: 1$.

When a dish of honey was placed at 6 meters from a bouquet of normal flowers, the latter gave 49 visitors, the former none, while the totals for two further observations were 25 and 0 . When a bouquet of artificial flowers of Eschscholtzia and Dahlia was placed 6 meters from one of normal ones, it was visited by 15 bees, to 17 for the latter, the visitors scarcely landing before perceiving their error. The final results of the series gave almost equal numbers, showing that the artificial flowers were equally attractive. Two experiments were made with the normal bouquet in a closed globe in order to suppress the perfume, resulting in 5 visitors in contrast to 6 for the artificial one. In competition with a bouquet of natural flowers deprived of the corolla, the artificial flowers received 11 visitors in contrast to 6 . Hiding a bouquet of normal flowers under the foliage resulted in but 7 visitors to it in comparison with 32 to a similar one freely exposed. In a check with artificial flowers entirely visible and normal ones hidden in the foliage, 19 bees went to the first and but 4 to the last, demonstrating that odor is much less effective than color.

The remaining experiments made use of honey or fragrant flowers, the installation for the first consisting of bouquets of normal and artificial flowers fully visible, normal flowers hidden under leaves, and a dish of honey, all 2 meters apart. The respective numbers of bees were 25, 20, 7 , and 1 . The check, which differed only in having 2 artificial dahlias stuck in the honey, gave respectively, $15,11,3$, and 8 bees, the dahlias having greatly increased the attractiveness of the dish with honey. When yellow pollen flowers (Eschscholtzia) were placed in a dish of honey 6 meters away from honey alone, no bees went to the latter, while 14 flew directly to the flowers and for the most part to the stamens, only 3 going to the honey. A bouquet of brilliant flowers with little odor was placed 6 meters from 
another containing mignonette, with marked perfume and dull color; the former was visited by 35 bees, the latter by 6 . When the bouquet of normal blossoms was replaced by one of artificial flowers, equally brilliant, the figures were 25 and 6 . In the final installation, made first on a day with few bees flying, 6 bees went to a dish of honey to which natural flowers were added, 4 to one with artificial flowers, and none to honey alone or with green leaves merely. In the check, the dish with natural flowers gave 14 visitors, that with artificial ones 15 visitors, and the honey with leaves or honey alone, none. Finally, the author endeavored to give a numerical expression to attraction by means of a table of her own results, as well as one for those of Andreae and Giltay. The conclusions drawn were as follows:

1. Flowers provided with brightly colored parts have a much greater attraction for the honey-bee than those of the same species when deprived of these parts.

2. Honey attracts bees very little.

3. Under the conditions given, artificial flowers attracted honey-bees readily, to the same degree as normal flowers placed in a globe.

4. Perfume alone attracts bees but feebly, while bright color and form taken together, but detached from odor, exercise a very manifest attraction upon them.

5. From the juxtaposition of the three principal factors, form, color, and odor, associated in the memory, results the most marked attraction.

6. For the honey-bee the attraction exerted by the form and color of flowers is approximately four times greater than that of their pollen, perfume, and nectar taken together. Thus, if the total attraction exerted by the most attractive flowers is taken as 100 , that of form and color will be represented by about $\$ 0$ and that of the other three factors by about 20 .

Plateau's criticisms of Wery's experiments.--In discussing the discrepancy between his results and those of Wery and Andreae in particular, Plateau (1906:11) thought it probable that this was due to certain disturbing factors. In order to discover these, it appeared necessary to secure conclusive evidence as to the nature of the materials employed by his opponents, and to repeat their experiments and add new ones surrounded by all possible precautions. A preliminary examination showed that certain artificial flowers of commerce are only partly artificial; thus the yellow disk of oxeye daisies consisted of the natural receptacle dried and dyed, the involucre of the cornflower was simply the natural one dried, etc. Moreover, the stiffness of the petals in artificial flowers for hats is secured by means of a large amount of starch and the anthers are composed of balls of paste, which are eaten by small Hymenoptera. He then obtained samples of the flowers used by Wery and found his suspicions to be confirmed. In all the flowers their rigidity was due to the presence of starch. The yellow color of Helianthus and Eschscholtzia was derived from a saffron dye obtained from the stigmas of Crocus sativus and containing a yellow glucoside accompanied by a volatile odor attractive at least to certain insects. The disk flowers of Dahlia were made of yellow fibers, some of which were covered with gum and rolled in flour. Balls of wheat flour colored yellow constituted the yellow center of Aster, and the anthers of Eschscholtzia were made of similar starchy material colored blue by iodin. Although it was not supposed that the presence of such substances explained all the differences, it was thought to be responsible for them in part. Finally, the 
artificial flowers used by Miss Wery were regarded as imitations of very mediocre value.

In the experiments where Dahlia was used, Plateau stated that the figures probably did not really indicate that the artificial flowers were practically as attractive as the natural ones, for three reasons. The first was the error committed in carrying out these tests where a series of 8 experiments with bouquets had been made during the preceding two weeks, giving an opportunity for the exercise of place-memory by the bees. The second was the fact that the majority of the insects barely landed on the artificial flowers, these visits to be interpreted rather as hesitations, curves, or crochets made in flight, and the third dealt with the materials used in the artificial flowers.

Experiments of Weismann and Errera.-Weismann (1902:219) placed an artificial Chrysanthemum in the midst of normal flowers actively visited by butterflies. He found that most of the latter passed near the imitation without stopping, but he saw two alight on it and probe actively with the ligule before flying away. It seemed evident that they sought the nectar which they had found in the normal flowers and that they flew off only after having determined its absence. Errera (Wery, 1904:1224) placed two bouquets made up of the same number of flowers of the same species in similar vases at a considerable distance from each other in the midst of an extensive greensward at Brussels. In one the flowers were normal, in the other they were deprived of their corollas in such a way as not to injure the nectaries. The decorollate bouquet was still rather conspicuous, owing to the colored stamens of Rhododendron, the white calyx of Hesperis, and the yellow disks of Chrysanthemum. The two bouquets were visited at the rate of 46 per hour for the normal and 24 for the decorollate, the majority of the visitors being flies.

Orientation of the honey-bee at flowers of the same species.Detto (1905:424) carried out a number of experiments to determine the relative importance of color and odor in the attraction of the honey-bee, as well as to throw light upon the rapidity with which it learned. The first series dealt with the manner in which the bee is led from one flower to another of the same plant or different plants of the same species. When flowers were mutilated by removing the anther mass or half the corolla, they were visited like the normal ones, but when the corolla was completely suppressed, visits ceased immediately, to begin again as soon as it was replaced. Visits also stopped at once as soon as the corolla was replaced by one of yellow tissue-paper, but were resumed when the normal corolla was put in position again. Shortening the corolla to a third did not affect its attraction, and finally, after a few hours the decorollate flowers began to receive visitors, but in a smaller degree than the normal ones. These tests show how important a guide the colored corolla is in the near-flight of habituated honeybees, and the visits to decorollate flowers merely prove that they are able to form new associations in consequence of the stimulus afforded by the abundant nectar. If flowers with excised anther column were provided with a colored paper disk with a hole in the center, thus cutting off the lower third of the flower, part of the bees avoided such flowers and others 
alighted for but a moment. Many, however, rushed about on the disk and some succeeded in passing under the edge or through the opening to the nectaries. In three other flowers the anther column was replaced by a staminate flower of Bryonia and the results were similar, some bees shunning the artefacts and others succeeding after persistent endeavor in finding the nectar. It was concluded that in Anoda triloba the colored corolla is the guide in the flight from flower to flower and that near-flight is determined by optical orientation to color.

In the case of Bryonia dioeca, flowers provided with a ring of colored paper were readily visited, the visits to the different colors being, yellow 12, blue 8 , green 6 , and red 1 . When the anthers were concealed by colored disks, the visits were fewer than to normal flowers, yellow again leading, and visits continued at about the same rate when the anthers were excised. The complete removal of the perianth greatly decreased the number of visits. The conical disk of three heads of Rudbeckia laciniata was covered with a thin glass tube, with the result that numerous bees flew against the glass, some crawling all over it and others flying about it several times. In two heads the cone was replaced by the similar one of Heliopsis levis; some bees hovered over this and others crawled about on it, but none sipped nectar from it. Heads of Echinacea purpurea placed between those of Rudbeckia were not visited, but they were sought when the disk was replaced by that of Rudbeckia. In order to determine the effect of the yellow ray-flowers, the cones of two heads were completely removed; bees coming from higher heads or those on the same level paid little attention to these, but those coming from below alighted on them for a moment or darted over the middle. When the disk was covered with blue or yellow paper, bees arriving on the same level or from below alighted on the paper before perceiving their mistake. Bees coming from above visited the green disk after the ray-flowers had been covered with colored paper, but the visits decreased in cases where the rays were all removed. These results were considered to prove that visits are determined by optical signals, and that either ray-flowers or disk suffice for attraction, though the green disk is naturally less effective in this respect.

From this series of experiments it was concluded that the colored corolla is the normal guide to the individual flowers of a cluster or group, but other guides may be utilized with the result that decorollate flowers may continue to be visited. In consequence no conclusion as to the absence of the colorsense can be drawn from habituated bees. The means of orientation in the flight from flower to flower is optical in nature. Since the different attractive parts of the flower can bring about visits when present alone, it is easily seen that partly concealed flowers may be visited. This also explains why the differently colored varieties of a species are visited indifferently by bees; this is possible whenever the flowers agree in the possession of one important guide for the insects, which may be some other part than the corolla.

Discrimination between similar species of flowers.-In further studies Detto placed clusters of Deutzia flowers in umbels of Crataegus. The bees behaved differently on them, some sipping nectar, others not, but they all flew or crawled to the neighboring flowers of Crataegus. When 
umbels of Crataegus were placed between clusters of Deutzia, the behavior was the reverse. A similar discrimination was found in the case of heads of Rudbeckia provided with disks from Heliopsis, and these results led to the conclusion that flowers of similar color are distinguished on near approach by means of the odor of the nectar or the flower itself. The approach of bees habituated to a particular species to the flowers of a similar species intermingled with it attests their color-sense, since they perceive the difference only in the immediate vicinity of each, through the perception of the strange odor. Detto considered it unwarranted to ascribe this ability to discriminate to the perception of form, as was done by Forel, Buttel-Reepen, and Knuth, but this conclusion is contradicted by his earlier statement that pistil and anthers serve as guides in decorollate flowers. He called attention to the conflict between the views of Knuth and Andreae as to the attraction sequence of color and odor, and agreed with the latter that far-flight in the case of newcomers is due to color and near-flight to odor, though this was not true of all groups of insects.

Orientation of the bee within the flower.-In order to determine whether bees are guided by vision or smell in going from one nectary to another, Detto made use of flowers of Althea rosea, in which the deep comate nectaries are about $9 \mathrm{~mm}$. apart. Honey-bees and bumble-bees go from one nectary to the next with the greatest accuracy, without feeling with the antennæ or probing with the ligule. The anther column was removed and a paper disk put in place in such a manner that it covered the nectaries; it was perforated in a way to permit the nectaries to be closed or opened by a turn. Some bees avoided such flowers, while others entered and quickly found the nectar through the openings, going to them all in normal fashion. As one bee went from the first to the second nectary, the disk was turned to bring the openings between the nectaries; he went to the next perforation. In repeated trials, some of the insects flew away after the first futile attempt, others went to several openings, and still others kept probing until they were able to reach the nectar by oblique movements of the ligule. Finally, some forced up the edge of the disk and crawled beneath it. When the disk had no perforations, the bees sought to force the head under the edge at all points and not merely in the direction of the nectaries. With holes $1 \mathrm{~mm}$. in diameter directly above the nectaries, the bees made no attempt to reach the nectar. While these results were not regarded as entirely conclusive, they seemed to indicate that vision was the decisive factor in directing the insect to each nectary. An ingenious check was constructed by cutting out a disk from a hollyhock flower in such a manner that the nectaries were without a bottom and could be brought above or between the nectaries of a normal flower at will. As a further precaution the false nectaries were thoroughly washed out to free them of odor in so far as possible. When the false nectaries were directly above the true ones, the bees visited the latter in the normal way, but when they were brought into the intervals the bees continued to go to the false nectaries without success. Although it was impossible to be certain that the latter were entirely without odor, it seems highly probable that the nectar journey is controlled by vision. If odor be regarded as chiefly directive, it must be assumed that its intensity decreases with the distance from each nectary, as otherwise the bee 
could not go directly to each one. However, several facts argue against this assumption. The bees behave in the normal manner even when the flowers sway back and forth in a strong wind. Spraying menthol in the nectaries does not change the behavior, except that the bees fly away after probing such a nectary or go rapidly to the next. Moreover, the layering and the concentration of the nectar odor above the nectaries must be obliterated by its mixing with the odor of the flower itself.

Detto also gave an interesting account of the training of an individual bee, which was effected by covering a flower cluster with glass. The cluster was thus changed by the addition of the glass, the greater accumulation of nectar in consequence of fewer visits, and a corresponding increase of fragrance. The abundance of nectar appeared to be the chief factor in the association through which the bee gradually accustomed itself to the new marks of the cluster and finally came to gather nectar from it almost exclusively, so that it might be said to know it.

The following general statements were made with respect to the sigificance of color in the attraction of bees:

1. The assumption of Sprengel, Darwin, Mueller, Buttel-Reepen, and others that the color of the flower brings about the attraction of the higher bees, Apis and Bombus, has been established by the investigations of Forel, Andreae, and Giltay.

2. However, since flowers with inconspicuous corollas are often abundantly visited by honey-bees and bumble-bees (Ampelopsis, Vitis, Rhamnus frangula, Cotoneaster acutifolius, etc., with greenish flowers), the bright color of corolla or inflorescence is not an indispensable condition. Still, color must play a significant part in the competition of species for the visits of the most dependable pollinators, since striking colors are more easily found than dull ones and since these insects orient themselves in flight exclusively with their eyes (ButtelReepen, Forel).

3. The return of a habituated bee to the plant is independent of the color signal, probably indeed after the first visit, since the bees are able to refind the place of the desired plant through optical orientation to the surroundings (ButtelReepen, Giltay, etc.).

4. Guidance to the individual flowers of an inflorescence takes place by means of vision. Normally the color of the corolla is the chief factor in guiding the bees to the single flowers. Sometimes other features of the flower have a share in this, and the removal of the corolla does not necessarily cause a cessation of visits.

5. The distinction of flowers of the same color but different species by the honey-bee is very probably due to the perception of odor when near at hand.

6. It is very probable that honey-bees and bumble-bees locate the nectaries of large flowers by means of vision.

Chance observation of visits to imitations.-Plateau (1906:148) has collected the records of the great majority of accidental observations of visits to artificial flowers on hats, flower designs on tapestry or wall-paper, and bits of colored paper or cloth. To these a few others are added here to make the record complete and to permit a discussion of their significance in the light of Plateau's criticisms. The first recorded instance of such visits appears to have beeen made by Houzeau (1872:132), who stated that Trevillian saw an individual of Sphinx convoluta fly along wall-paper orna- 
mented with brilliant flowers and try to probe the fanciful corollas. A similar observation by Vallete (1875) had the fortunate consequence of stimulating Plateau to undertake his first experiments, as already indicated (p. 136), and this was followed by another one made on artificial flowers:

"After the experiments of Plateau, I watched for an opportunity to renew my observations, the occasion for this presenting itself while I was at La Roche-sur-Yon last October. An individual of Macroglossa stellatarum entered the room and perceiving two baskets of artificial flowers, roses, violets and others, that decorated the mantel-piece, flew precipitately toward them. But I must confess that he had barely unrolled the ligule before the baskets when he flew away. He had recognized his error, or at least this seems to be the explanation to be given. Led into error by the sense of sight, the mistake was rectified by means of the sense of smell" (1878).

Burton recorded a corresponding observation the same year (1878:162):

"In going by steamboat from Como to Maggiore in September, 1875, I saw a Macroglossa stellatarum dart towards some brightly colored flowers in a lady's hat, hover a short time above them, and then fly away. It remained long enough to convince me that it had examined the flowers and had recognized its error."

In a discussion of the mistakes marle by animals, Romanes (1884:167) cited the following cases:

"Again, the Rev. Mr. Beran and Miss C. Shuttleworth write me independently that they have seen wasps and bees visiting representations of flowers upon the wallpaper of rooms and Trevillian saw the same mistake made by a sphinx-moth. Swainson in his 'Zoological Illustrations' gives an analogous case in a vertebrated animal; an Australian parrot, whose food is taken from the flowers of the Eucalyptus, was observed endeavoring to feed on the representations of flowers on a cotton-print dress. Likewise, Professor Moseley, F. R. S., informs me that he has noticed honey-seeking insects mistake for flowers the bright-colored salmon flies stuck in his hat while fishing, and Mr. F. M. Burton, writing to Nature, says that he has observed the hummingbird hawk-moth (Macroglossa stellatarum) mistake artificial flowers in a lady's hat for real ones. Still more curiously, the naturalist Couch observed a bee mistake a sea-anemone (Tealia crassicomis), which was 'covered merely by a rim of water,' for a flower, darting to the center of the disk, 'and though it struggled a good deal to get free, was retained till it was drowned and was then swallowed."

Blanchard (1891), upon entering a hotel room in Adelsberg in September, 1890 , found a sphinx-moth fluttering about, apparently deceived by the seeming twilight. It successively examined each of the flowers, painted in blue, violet, yellow, and dull red, that formed the cluster at the center of the ceiling. The proboscis was extended, as though it were dealing with real flowers. Disappointed by a lack of success, it left the ceiling to explore, one after another, a large number of the yellowish flowers crudely figured on the wall. It then went back to the ceiling, but visited only a few flowers to make sure that it was not deceived the first time, and then returned to the wall. After a number of fruitless visits to the flowers here, it sought refuge in the hangings. Blanchard also reported a statement of Alphonse DeCandolle to the effect that he had frequently seen sphinxmoths dart to the flowers found on wall-paper.

The studies of J. Pérez on Macroglossa led to those of Plateau on the same insect, which were designed to correct the impression that this was due to an actual attraction by color. An earlier observation by his brother, B. Pérez, was reported as follows: 
"A diurnal sphinx (Macroglossa stellatarum) entered my room, in which there is a tapestry with a clear background strewn with bouquets of white and rose flowers with green stems and leaves. For two minutes the insect flew from bouquet to bouquet, stopping before 5 of them with the ligule unrolled as if visiting real flowers. Afterwards he disappeared suddenly, possibly because I moved in the hope of observing him more closely."

Pérez himself saw an individual of this same species fly abruptly from a pot of flowers in a window to a small piece of rose-colored paper on the pavement, but the mistake once recognized the moth disappeared like a flash (1894). Several years later (1897), he stated that he had frequently deceived this moth by placing bits of bright-colored paper on shrubs, and that Eristalis also exhibited a similar response.

Lesne (1895) saw a fly of the genus Bombylius alight without hesitation on an artificial violet of his sister's hat and insert the ligule in the corolla. Not finding nectar, it passed at once to a second and then to a third in the same manner before flying away a few paces to rub its tongue as though it had been roughly treated. It was concluded that smell in the case of the Bombylidae does not play the rôle ordinarily assumed, but that vision alone enables them to discover the flowers that provide their food. However, this was not intended in an absolute sense, since it was later stated that the bee-flies are guided by both senses acting together in most cases. This discrepancy was pointed out by Gazagnaire (1895) in the paper immediately following, and it was contended that either or both senses acting together could enable these flies to distinguish the flowers sought and that errors would be frequent only when they were flying indifferently and not in need of food. Schnabl (1896) related an experience of Schuch, who saw a Macroglossa flying before a tapestry in a hotel room, on which were represented flowers of Tropaeolum majus. It went to the flowers from time to time in the endeavor to plunge its ligule into the corolla.

Bedford (1897), while walking down a street in London, noted a butterfly (Pieris brassicae) following a lady's hat, which was ornamented with artificial lilies of the valley. It made repeated attempts to light on the flowers, but was prevented by the abrupt movements of the wearer and finally gave up the endeavor. Parkin (1897) related the observations of his friend Winstaley with respect to a honey-bee that entered his room. This flew at first to some paintings on the wall opposite the window, passed from one to the other in making the round of the room, stopping for an instant before those with color, and then disappeared through the open door. It returned and flew to the gas-globes, returned to the paintings, went again to the globes, visited four glass objects on the mantelpiece, and finally, after five minutes in all, departed through the window. Thornley (1897), on one or two occasions when driving a pony whose head was decorated with blue rosettes, saw a Macroglossa fly straight to one of the rosettes and hover above it for several seconds, although the pony had begun to trot.

Knuth $\left(1898^{2}\right)$ recorded the case of Syrphus that flew to the flowers on his wife's hat in a railway station at Leipsic. The flowers were greenishbrown with a velvet sheen, but in spite of their inconspicuous character and lack of fragrance, the fly hovered over them for several minutes, per- 
forming its characteristic evolutions. Gorka (1898) noted two individuals of Deiliphila elpenor that flew along the walls of a pavilion painted with crude flowers of Phlox and Verbena and attempted to plunge the proboscis in the corollas. Lack of success did not discourage them, for they returned after a moment to renew the attempt. In the instance cited by Motelay (1898), a cabbage butterfly fluttered against the window of a florist's shop, trying for 10 or 15 minutes at all.parts of the pane to reach the flowers on the inside. It appeared certain that it was attracted by vision and not by smell, since the door of the shop was open but 6 or 8 feet away, and especially since the butterfly passed the door as it flew away. Benary (1900) stated that a bumble-bee, which entered a room through the open door, flew at first to some natural flowers. After it had examined all of these, it sought for nearly a minute to insert the ligule in one of the flowers of the carpet. According to Aigner-Abafi (1900), Langhoffer saw a bee fly through the open window of his lecture-room and go directly to a colored botanical wall-chart. It flew to one cluster, working upward and then to another flower, but finding itself again deceived it flew away.

Charlier observed that the males of Rhodocera rhamni were greatly attracted by a piece of green paper 10 by $20 \mathrm{~cm}$. moving gently in the sunshine. They alighted on it several times and moved about in an agitated manner. Errera noticed a number of Hymenoptera flying about the hat of a country-woman for fully a half-hour. The hat was trimmed with artificial flowers, full-blown yellow roses and pansies, but the bees flew to the former and neglected the latter. They were so numerous and their behavior so striking that it was remarked by several people. He also reported an observation communicated by Strasburger, who saw Macroglossa stellatarum light on the red oleander flowers of the wall-paper of a room; the hawk-moth sought to visit the flowers one by one exactly as though they were natural (Wery, 1904:1224, 1226). Van Bembeke, while walking in a park at Ghent, saw a cabbage butterfly dart toward a piece of red paper, light on it for an instant and then depart abruptly (Wery, l. c.).

In supporting his opinion that these isolated observations were without value, Plateau cited the case of a Rhodocera that appeared to follow a bicyclist in a dark costume, who was mounted on a wheel without bright colors, pointing out that the presence of bright colors would have led to the fallacious assumption of a real attraction. Instances of visits to bits of paper were regarded as fortuitous and without significance, and it was emphasized that butterflies often light on objects having neither the form nor the color of flowers, but provided with an odor. With respect to attraction by the colored designs of wall-paper or tapestry, he remarked that several of the accounts were given at second-hand and that some of these were merely verbal, while as to those given by the observer himself, the latter was often taken by surprise. This fact, together with the poor light and the rapid movements of the insects, made it probable that the findings would be very difierent from those of an investigator prepared to follow the insect's behavior. Moreover, Macroglossa and other insects were found to fly along vertical walls without flower designs, the extension of the ligule being without significance, since Breyer stated that this moth and the sphinx-moths always fly with the ligule unrolled. Furthermore, if paint- 
ings of flowers were to attract insects, colored posters bearing flowers should do this in an evident degree, which is obviously not the case. Finally, Plateau gave a list of eight objects, mostly dull in color, on which a bumblebee alighted in his study. Likewise, as to attraction by the artificial flowers of hats, he regarded the cases as too isolated to be of value, those of an actual attraction being explained by the presence of some dye possessing an odor evident at least to certain insects.

Knoll's critique of Plateau's study of Macroglossa.-Knoll (1922: 363) points out that Plateau's failure to interpret the behavior of Macroglossa properly was due largely to not recognizing that the "darkness flight" of the hawk-moth is a peculiar response of this insect. He was also in error in thinking that the hawk-moth always flies with the ligule unrolled, and was thus not in position to observe the finer details of its behavior. As Pérez contended earlier, the pieces of cloth and paper used by Plateau were too large, as were also his artificial flowers. Moreover, the colored objects often belonged to a different optical group from the flower visited shortly before by the hawk-moth, so that the latter had no predilection for them, contrary to the case when the color group was the same. Since the depth of color plays an important part, it is not strange that the few moths observed by Plateau did not notice the artificial objects in which the color was less saturated than in the flowers. This was especially true in the experiments with Anchusa italica, owing to its remarkable deep-blue color. Finally, Plateau's arrangement of his test objects was not a happy one. It has proved undesirable to place artificial objects in competition with large plants in full bloom, as the insects fly directly to the latter and visit the artefacts only by chance, and much better results have been secured by intermingling the test objects and plants with few flowers. The same effect can be obtained by removing the flowers in part or, better still, by installing a path of flight in which the artefacts are placed.

With respect to the vexillary rôle of the bracts of Salvia horminum, Knoll remarks that the visits of three out of six hawk-moths to such clusters constituted a positive result and not an error, and that this is to be explained by the fact that Dianthus and Salvia belong to the same color group. He also found these colored bracts without honey to be sought by the moths in just the same manner as the usual violet honey containers and a similar response was obtained in nature. He concludes that the bracts greatly increase visibility at a distance and hence possess a definite vexillary function, contrary to the views of Plateau (cf. Frisch, 1914:4, 1919:3).

\section{RECENT INVESTIGATIONS.}

The color sense of the honey-bee.-Lovell was the first to carry out extensive experiments on pollination in America, in which he had the unusual advantage of bringing to the problem the experience gained by years of observation in this field. The first three papers of the series deal with the color sense of the honey-bee, the fourth with conspicuous flowers rarely visited, and the fifth with constancy. As indicated in the first (1909: 338 ), his investigations were stimulated by Plateau's conclusions that color and form are unimportant and odor alone attractive to pollinators. In 
order to determine whether conspicuousness is an advantage to flowers, the petals were removed from a cluster of 7 blossoms of Pirus communis, which had received 8 visits in 15 minutes. No visits were paid to it in the first 15 minutes after this, and but 2 in the second. When the petals were removed from one of two adjacent clusters of 8 flowers, the normal received 11 visits in the 15-minute period to none for the mutilated one. Two groups of flowers of Borago officinalis 6 inches apart received 15 and 13 visits in 10 minutes; after the corolla and anthers were removed from one, no bees came to it, while the normal yielded 7 visits. Although bees did not go to the decorollate flowers, they twice flew to withered corollas on the ground. In the case of a staminate flower of Cucurbita maxima, 12 visits were made in 10 minutes, 4 of them by Bombus terricola. The removal of the perianth decreased the number of visits for the unit period to a single one made by a bumble-bee, although a flower wilted and nearly closed received 5 visits. Two staminate flowers with their corollas touching were used in the next test; one received 6 visits, the other, 13 during a unit period. The calyx-lobes and corolla were cut from the more attractive flower, which then received no visits in contrast to 12 for the other.

Lovell explains the visits to the mutilated flowers of Digitalis purpurea in Plateau's experiments as due primarily to memory of place, though the corolla stump itself was not entirely inconspicuous, and cites in illustration the visits of bees for a month and a half afterward to a window where they had obtained honey. Bees were trained to visit a red-glass slide with honey, and this was put in various positions, and a plain slide added. All of these were found in 6 to 20 minutes as a consequence of the reflected light, the color, and the odor, and this is regarded as explaining why bees readily passed under the green leaves used by $\mathrm{Pla}-$ teau for masking dahlia heads. These experiments were not well adapted to the purpose and afford an insufficient basis for the conclusion that bright colors are not advantageous to flowers.

Can bees distinguish colors? - In order to test the statement of Plateau that flowers might as well be green as bright-colored and that of Bethe that bees have no ability to acquire experiences or to modify them, Lovell has repeated and extended the experiments of Lubbock with colored strips of paper (1910:673). After a bee had been accustomed to visit a blue strip with honey, strips of other color were added or exchanged with it in various ways. Given a choice between blue and red, the bee went 4 times to the former and once to the latter. When blue, red, and yellow were employed, blue alone was visited. With a wider range of choice the bee went to blue 8 times, black twice, and once to red, yellow, and white, the choice of some other color than blue occurring only after the slides had been exchanged or the color changed. Out of the total of 21 visits, 15 were made to blue and not more than 2 to any other color, the bee endeavoring to be constant to blue in spite of loss of time and effort. When a yellow and a plain slide were used, the bees made 20 visits to the first in 30 minutes, entirely ignoring the second; flies went alone to the yellow, and the wasps went to it in all but two cases. These results indicate that Plateau was in error in assuming that artificial colors appear different from natural ones to the bee. 
Lovell has also repeated the experiments of Mueller with colored corollas, making use of the yellow rays of sunflower, the blue perianth of larkspur, and the red corolla of balsam. A bee accustomed to the sunflower yellow made 9 visits to it and one to blue, and in other experiments with these slides the bees discriminated readily between the colors. When bees trained to red were given a choice between a red slide and a plain one, they made 46 visits to the one and but 8 to the other. To determine the effect of habit in this case, a blue slide was substituted for the plain one; the first visits were 8 to red and 2 to blue, but at the end this had changed to 3 for red and 7 for blue, the respective totals being 22 and 24 . A number of instances are cited from the experience of practical apiarists to show that bees distinguish colors readily, and it is stated that "it may well be doubted whether they would ever have been capable of making long journeys afield for nectar and pollen, if this visual power had been wanting."

When a bee trained to blue was given a choice between seven or eight colors, it remained constant to blue or purple for several visits, but its fidelity to them was weakened by repeated transpositions, until similarity of form, honey, and odor prevailed over the difference in color and visits were then made indiscriminately. In nature a bee usually finds in one flower only a part of a load of nectar and is compelled to go to other blossoms; if these are alike in form they will then be visited regardless of differences in color, especially when a number of bees are present. In conclusion, Lovell states that bees easily distinguish colors whether artificial or natural and are more strongly attracted by a colored than a plain slide. Bees trained to a certain color tend to return to it habitually, but they quickly learn to ignore the color differences when it is to their advantage.

The pollination of green flowers.-Lovell $(1912: 83)$ discusses the relation of insects to green flowers and points out that the phylogeny of such flowers as developed by Bessey $(1897,1907)$ strongly supports the view that they are not well adapted to pollination by insects. He admits that bees will collect sweet liquids from green or dull-colorea surfaces, after they have once been found, but states that this does not prove that bright colors are not an advantage to flowers. When a bouquet of Gerardia purpurea was placed in front of a hive, it received little attention, but when two clusters, one normal and the other decorollate, were provided with honey, the former received many visits and the latter none, until later, when the bees discovered the honey on them. In order to vary the conditions under which the objects were exposed, bees were trained to visit a small dull-gray board bearing a small quantity of honey, raised on a support 2 feet high. A slide prepared from the blue perianth of a larkspur and provided with honey was placed on the grass 3 feet from the support and honey was also placed on a dandelion leaf 5 feet away and 3 feet from the support. As soon as the honey on the feeder was exhausted, the bees began to circle in the air. In a few minutes 1 bee had found the blue slide and in 25 minutes 5 bees found it, though none had discovered the honey on the leaf. Two days later the experiment was repeated, 3 bees finding the blue slide within 2 minutes after the honey had disappeared from the feeder. In 7 minutes there were 8 bees on the slide and none on the green leaf, 1 bee finding the latter 5 minutes later. Two poles 4.5 feet 
high were then placed 6 feet from the support and 6 feet apart; the top of one was covered with a large amount of honey, while to the top of the other was attached a cluster of yellow immortelles many years old. Within 3 minutes after the honey disappeared from the feeder there were 3 bees and a fly on the flowers, but none on the free honey; later there were 6 bees and $1 \mathrm{fly}$ on the flowers and 1 bee on the free honey, the total number of visitors to the flowers being three times greater than to the free honey. When the poles were transposed and a single immortelle placed on the one that had the supply of honey previously, both being provided with honey, the cluster showed 10 insects at the same time that the single flower gave 4 .

In later experiments a yellow immortelle with honey was placed 9 feet from the feeder and a considerably larger apple-leaf with honey at a equal distance on the opposite side. Three bees came to the flower and none to the leaf, the small number apparently due to the fact that they were looking for sugar sirup which they had been eating on the feeder. The number of visitors was larger in other cases, but in spite of this the leaf did not receive a single visit. When a head of golden glow and the end of a spike of Amarantus were used, the head yielded 18 visits to 8 for the spike, but when they were laid side by side, there were 15 visits to the golden glow to 3 to the spike in one case, and 18 to 5 in another. In further studies with a green and bright-colored object placed on a green background or with conspicuous and inconspicuous objects, which extended over three seasons, there were no visits to the inconspicuous objects in 6 cases, while in the others the number of visits to the conspicuous object was usually two or three times greater. The preference was sufficiently marked to account for the development of color contrast in flowers and shows that the experiments and observations of Plateau on green or greenish flowers were fallacious.

Conspicuous flowers rarely visited by insects. - In testing Plateau's conclusion that bright color is without significance because certain conspicuous flowers are commonly neglected, Lovell (1914:147) made observations and experiments on some of the same species, in addition to others. The nectarless flowers of Clematis jackmanni were not only found to be visited, but the number of visitors was greatly increased by putting sugar sirup on some of them, showing that the presence of an agreeable odor was unnecessary, contrary to Plateau's assumption. It was determined that the real reason for the general absence of visits to the garden pea and the sweet pea is the inability of most pollinators to depress the keel and open the flower. In these flowers neither color nor odor will induce frequent visits, since nothing is to be gained by them, but the addition of an odorless sirup causes bees to go to them in large number. Similar results were obtained in the case of petunia, the addition of sugar sirup bringing many bees and small Diptera, and the honey-bees continuing to come for many days after the sirup was gone. In the case of a variety of Pelargonium zonale with neither nectar nor pollen, no insect visits were observed to the normal flowers, but the application of sugar sirup ultimately brought them, the bees repeatedly searching the normal umbels after the supply was exhausted. Later they flew to a bed of Portulaca grandiflora, 
which is habitually ignored, and inspected flower after flower, but rarely alighting. The use of sugar sirup also brought visitors to other flowers ordinarily neglected, such as zinnia and the scarlet runner.

Interesting instances are given of the rôle played by variations in the length of the corolla of red clover and the amount of nectar in alfalfa in determining the visits of honey-bees, and many cases are cited to show that the latter occasionally make careful examination of flowers commonly neglected. Such visits are infrequent because the bees remember their inability to obtain food. In the aggregate they waste much time in fruitless visits to flowers that yield no booty for one reason or another, but this waste is reduced to a minimum by their ability to learn from experience. Thus, insects do perceive the colors and forms of neglected flowers, and the rarity of their visits is the result of recalling the absence of nectar or pollen and not because the flowers lack an agreeable odor, which, moreover, is often not the case.

\section{Response of honey-bees to colored artefacts.-Turner (1910:257) has carried out investigations-}

"To see if, in the field, bees can be trained to respond to colored artefacts, and, after a bee has thoroughly learned to collect honey from an artefact of a certain color, to see if it can select those of that color from numerous others of a different color; first, when the artefacts to be selected contain honey and the others do not; second, when some of each kind contain honey; third, when none of the artefacts contain honey; fourth, when the brightness content of the artefact to be selected is changed without altering the hue. In furthering the first aim, honey was placed on disks of a certain color and exposed in a field from which a large number of bees were collecting honey. At first these disks were not attended to; but after a lapse of several hours a few bees began to collect from them. After a few bees had acquired the habit of collecting from disks of a certain color, three different series of experiments were conducted; one with disks, one with cornucopias, and one with small boxes, each provided with a small opening. In each of these series a large number of artefacts of two colors, half of which were of the color of the disks from which the bees had learned to collect honey, were scattered promiscuously among the flowers from which the bees were foraging. The artefacts of the color from which the bees had learned to collect honey were supplied with honey, the others were not. All of the artefacts containing honey were visited by numerous bees; no bees visited the others. Control artefacts of the color from which the bees were collecting honey were well supplied with the latter and placed in portions of the field where the bees had not been trained to feed from artefacts. Although the bees were numerous, these artefacts were not visited. At intervals artefacts of the color from which the bees had not been trained to forage were supplied with honey and scattered among the others. As a rule these were not visited. At the close of both the second and third series of experiments, all of the artefacts were removed from the field; and two artefacts, one of each color, both new and neither containing honey, were exposed in the field. In a few minutes, the artefact of the color that had formerly marked those that contained honey was completely packed with struggling bees. No bees entered the other artefact. In each series the artefacts were distributed in both the sunshine and the shadow. All were equally visited by bees. Since the brightness content in the two cases was different while the color was the same, it was concluded that the bees were reacting to color as such. It is thought that these experiments prove that bees can discriminate between colors." 


\section{Pattern vision in the honey-bee.-In experiments on this subject, Turner (1911:249) -}

"Made use of pasteboard boxes like those employed in his experiments on color vision in the same insect. He constructed artefacts showing seven different color patterns. Bees which had been trained to gather honey from one pattern were tested to see if they could choose this pattern from one or more of the others. In some cases the artefact of the pattern to be chosen contained honey, while the rest had none; in other cases there was honey on some of the artefacts of all patterns, and in still others there was no honey on any of the artefacts. Five hundred and eight correct selections out of 518 were made, indicating that color patterns are perceived by bees. Since they can distinguish both color and pattern, no evidence can be drawn from the visual powers of bees against the hypothesis that colors and patterns in flowers are adapted to secure the visits of insects."

Experiments with cotton blossoms.-Allard (1911:607) has made a large number of interesting experiments with single cotton blossoms. The normal flower, modified flower, and control were disposed at the corners of a triangle and about 4 feet apart, or in a line in the same row. Petals pinned to a stem received as many inspections as the normal flower, almost all of them being made by Melissodes. The number of entrances was less than one-fifteenth the number of inspections, and at all times the actual visits were few. When the petals of one of the same group of flowers were removed, the inspections dropped from 81 to 4, though they actually increased for the other normal flower. Replacing the petals brought the inspections up to those for the normal, but when cloth petals from an artificial rose were employed, the number dropped to 4 in comparison with 48 for the normal control and 65 for the petals alone. Five cotton petals were then placed over the cloth ones and the number of inspections again rose to a point slightly above that for the control. The next installation consisted of a normal blossom in situ, one pinned in position, and an artificial half-opened bud made by pinning normal petals together and wrapping a piece of green cotton leaf about the base. The latter received practically the same number of inspections as the most visible control. This was next modified by concealing one of the normal flowers so that it was visible only from above; this yielded 1 inspection to 12 for the control and 40 for the artificial bud. Removing the disguise caused the flower to be inspected twice as often as the control. The substitution of crepepaper petals led to the reduction of inspections to 2 in contrast to 16 for the control, while placing three real petals on the paper ones increased them to 11 in comparison to 7 for the control and 21 for the artificial bud.

The following installation comprised a single real petal pinned to a stem, an artificial bud made by wrapping a portion of a cotton leaf about the base of 5 petals rolled together and a normal in situ; these received 2,8 , and 3 inspections respectively. A single petal in competition with a normal blossom alone obtained 16 inspections to 26 for the latter. In the following experiments the flowers were on 3 consecutive plants in the same row. The first consisted of a flower of bindweed between two normal flowers pinned in position, which attracted attention as often as the normals, but was entered less frequently. When the petals were removed from one of the controls, this received no inspections to 19 for the bindweed 
and 20 for the normal control. When a single petal was placed on the decorollate flower, the latter yielded 8 inspections to 9 for a single petal pinned to the stem and 27 for a normal flower; changing the relative position of the three gave 27,8 , and 22 inspections. Placing the smaller brighter yellow blossom of an Asiatic cotton between two normal flowers of the American variety resulted in 14 inspections for the former and 20 and 29 for the latter in one case, and 10,16, and 20 in another, while putting the foreign flower at one end of the series gave 3,10, and 11 respectively in one instance and 11, 12, 9 in the other. A day-old blossom of a deep reddish-purple color received 12 visits to 26 for a recently opened creamcolored one. Four experiments with two controls and a normal blossom with honey added at the base of the petals, arranged in varying order, gave respectively 62,64 , and 66 inspections, the actual visits being but 2 for the flower with honey to 27 for the other two.

The petals of a normal bloom were covered on both sides with cotton leaves cut to match and a drop or two of honey added. When this was exposed with a control with honey and one without, the inspections were respectively 0,34 , and 25 , the actual entrances being 0,2 , and 6 . In the next installation the pieces of leaf were removed from the outside of the corolla and this was exposed with a normal flower and one with the petals removed. The respective inspections were 9,11 , and 1 , while the actual visits were negligible. When one bud due to open the next day was pulled fully open and another but partly so, the first was inspected 15 times to twice for the latter and 24 for the normal, the latter receiving 14 visits to none for the other two. To entirely eliminate the effect of odor, a glass plate was fixed before a flower and leaves drawn in about the edges to conceal most of the plate but leave the flower fully visible. This received 18 inspections in contrast to 37 for the normal. When a flower was placed in a box with a glass face, it was inspected twice to 5 times for the control. With a crepe-paper blossom of the proper color added, the boxed flower was inspected once, the normal 8 times, and the imitation 3 times. In the final experiments, detached petals were usually inspected, but the numbers were too small to be very significant.

The simplicity and variety of Allard's experiments, coupled with the use of single flowers and constant controls, give his results an exceptional value. They emphasize the attractive value of the color at the expense of odor and suggest that the latter merely guides bees from a distance or from one field to another. The discrimination between artificial flowers and normal ones is thought to depend upon perceptible differences in color and texture rather than to the presence of repellent odors from the material and support the view that bees develop keen powers of discernment as to the structural details of flowers.

Color sense and memory in the honey-bee.-Dobkiewicz (1912:664) carried out three series of experiments dealing respectively with the color- sense, memory, and learning ability of the honey-bee. The first series employed crude artificial flowers of yellow or red paper placed at the same spot in a clover field. No visits were made to installations of 10 yellow or 10 red artefacts without honey, or at first to 5 of each color with and without honey. For the next experiment the blue artefacts were removed, 
after which a single bee appeared, soon followed by two others. A half hour later the honey flowers were actively sought, while those without honey were completely neglected. When the yellow flowers were more widely separated and the blue ones so interspersed that one with honey occupied the former position of a similar yellow one, the blue imitations were neither inspected nor visited, though the yellow were busily probed. Placing the two kinds of yellow artefacts in pairs caused those without honey to be often inspected, but the bees quickly learned the position of the honey ones and paid no further attention to the others. Further experiments likewise showed that when the bees did not at first know all the honey artefacts, it was necessary for them to make orienting flights over the two kinds. However, the flights of inspection over the flowers without honey gradually diminished to the point of disappearance. With respect to memory, the second series of experiments indicated that colored objects do not attract bees that are busily at work if they have had no previous experience with imitations. However, when they have repeatedly found honey in an artefact of a certain color in one spot, the color continues to exert attraction even when honey is absent, and small displacements of position are immaterial. It was also demonstrated that bees habituated to gather from honey artefacts at a certain time, namely, 11 to 1 o'clock, did not react to them at a different time, showing that they take note of time as well as of color and place. Further experiments showed that the bees were able to make use of two colors in adjusting themselves to new conditions and that they utilize their sense of color in different and unexpected relations. In short, they are not reflex machines, but their behavior has the stamp of purposeful, intentional acts.

Frisch's researches.-Sense of color and form in the honey-bee.Frisch has discussed the color and form sense of the honey-bee in a monograph of fundamental importance (1914), as well as in shorter articles $(1913,1919)$. At the present time it is possible only to indicate the scope of his treatment and the general method, and to give his conclusions. The original itself must be studied by all those who wish to carry on accurate work under controlled conditions. The treatise is divided into the following main sections: (1) demonstration of a color sense; (2) nature of the color sense; (3) the color sense of the honey-bee and flower colors; (4) sense of form and its significance in flower visits; (5) unsuccessful training experiments with unnatural forms; (6) biological notes; (7) practical significance of painting hives in color. The method of experiment consisted essentially in training bees to come to a watch-glass of honey placed on a particular color and following their behavior when such colored squares were variously arranged among gray ones, ranging through all possible shades from white to black and likewise provided with glasses of honey. After two days training with two papers of dull yellow disposed among 30 gray ones, two new yellow papers and watch-glasses, unused and hence free from the odor of bees, were placed in a different position from the first two, which were removed and gray ones substituted. All the watch-glasses were then filled with sugar solution, thus making the conditions on all the papers identical, except for color and brightness. Thus, if the bees were entirely color blind they would see yellow only as a certain degree of brightness without 
color and would visit the corresponding shade of gray in similar number. If they saw color as such, the yellow papers should receive more visits than all the gray ones. This is what actually happened. The bees flew without hesitation to the yellow papers and crowded together on these about the sugar-solution, while the watch-glasses of this solution on the gray papers remained neglected. Frisch's conclusions were as follows:

1. Bees possess a sense of color. This is proved by the fact that if they were totally color-blind they would see each color, for example, blue, only as gray of a certain brightness. In a series of gray papers that grade insensibly from white to black must occur a gray paper that would be identical to the bee with a blue one in form, extent, and surface character. Once trained, however, it is able to distinguish the blue paper with certainty from all the shades of gray. The gradations of the gray series were sufficiently fine, as demonstrated by the fact that training for a particular shade of the series was unsuccessful. The objection that the bees may have recognized the colored paper by means of a particular odor imperceptible to us is removed by the fact that the experiments gave the same results when the colored and gray papers were covered with a glass plate or sealed in a glass tube.

2. The bee confuses red with black and blue-green with gray. It distinguishes only "warm" and "cold" colors and mixes orange-red with yellow and with green, blue with violet and purple-red. Thus, its color sense shows a close agreement with that of a man color-blind to red and green (protanopic).

3. The colors that are not seen as such by the bee, such as blue-green and pure red, are extraordinarily rare in the flowers of our flora. This supports the view that the colors of flowers have developed in adaptation to their pollinators, and all the more since, in exotic flowers adapted to pollination by birds, scarlet-red blossoms predominate and blue ones are strikingly infrequent. In many flowers are found several colors combined which contrast strongly. Such "contrast colors" have been regarded as adaptations to insect visits, especially when they appear in the form of nectar guides. However, our new knowledge indicates that color differences which are conspicuous to our eyes can not be assumed to be such for the eyes of the insects, but closer examination shows that this presents no serious difficulty. We find that the varicolored flowers combine almost exclusively such colors as stand out distinctly from each other in the bee's eye. On the other hand, the biological significance ascribed to changes of color during anthesis is not to be accepted in the fullest sense.

It has appeared a striking fact to students of flower biology that blossoms with the most complete adaptation to allogamy and particularly fitted to the visits of honey-bees and bumble-bees should be blue or red-purple. This has been explained by the assumption that such colors are the favorite ones of bees. On the contrary, my experiments show that for the bee's eyes blue and red-purple contrast most strongly with the green of leaves, and hence range themselves readily with the other characters by which the bee flowers reveal their greater adaptation to insect pollination in contrast with the more primitive flowers of this kind.

4. From the observations on constancy it follows that bees recognize the flowers of one species as belonging together and hence distinguish them certainly from those of another species. Since they possess no finer sense of discrimination for color nuances, they must consequently utilize other features than flower color. Thus it may be shown that form and combinations of color serve bees as indicators, and the significance of nectar guides is partly to be sought in this connection.

5. It is of psychological interest that the training of bees is unsuccessful when it demands of them the discrimination of forms that are completely unknown to them in nature, e. g., geometric figures.

6. The question whether color striping of the hive facilitates the return of the bees to the proper hive must be answered in the affirmative. How closely the bees observe hive-color and use it as a guide is shown by the fact that returning bees can all be decoyed into a wrong empty hive by a change of color. Misled by the color of the hive, they even seek to enter occupied hives, where they are received in the most unfriendly manner.

The supposed color sense of the honey-bee.-In a series of papers (1913-1919), Hess has imitated Plateau in challenging all the studies and 
conclusions as to the ability of bees to distinguish colors as such. It is now impossible to deal with his experiments and criticisms in detail, and it must suffice to give the summaries of the two papers that treat this question directly. These will serve also to reveal the attitude of the author, who goes far beyond Plateau in rejecting unqualifiedly the results of those who do not agree with him.

"It has been demonstrated that the earlier conclusions of Lubbock and Forel, as well as the later ones of Frisch, in accordance with which it is possible to train bees to discriminate a particular color, are incorrect. If the colors are presented under conditions otherwise identical, the bees find it wholly impossible to habituate themselves to a certain color and to respond to it. The errors of the earlier investigators are in part to be ascribed to the fact that they either ignored the contributing factors emphasized by me or failed to take them sufficiently into account.

"Up to the present time not a single fact has been adduced that makes even probable the assumption that bees possess a color sense comparable with ours. On the contrary, my earlier researches with spectral and other rays as well as the later ones with colored papers refute this opinion conclusively. In virtue of the results contributed by me, which are readily demonstrable, the view of Sprengel as to the significance of flower color in insect attraction can no longer be maintained." (1913:105.)

"It has been demonstrated that every training experiment with bees, which has been thought to prove their color sense, affords complete support to my researches which show their total color-blindness. Moreover, Frisch's record shows, in entire agreement with mine, that bees supposedly trained to blue or yellow were unable to distinguish the two colors, but much more frequently confused one with the other or with gray.

"The inadequacy of the method of training experiments is forcibly exhibited by these new observations and measurements. Furthermore, the objections recently raised from the zoological side to my investigations are vitiated by the results given here. Finally, even Frisch himself has removed the last prop from the concept of color sense in the bees by his training experiments and the Freiburg results." (1918:365.)

Frisch (1919:122) has made an effective rejoinder to Hess's statements, as is indicated by the following excerpts:

"Hess begins his real objections with the surprising assertion that my record shows that the bees were unable to distinguish blue and yellow from gray, and also blue from yellow. I wish to ask him how he can advance such a statement when he must have seen from my record that the bees trained to yellow discerned the latter and discriminated between it and all the shades of gray in all seven experiments in which a yellow paper was exposed in the gray series; that further, the bees trained to blue selected this color and distinguished it from the gray shades in the entire 15 experiments with blue similarly exposed; that bees trained to yellow sought this in overwhelming majority in competition with blue and purple in all eight experiments, and finally that bees trained to blue chose blue and purple just as decisively in 25 of the 26 tests with the complete color series, the exception being readily explained by the circumstances (p. 126).

"I have shown that bees trained to blue for two days were able to distinguish with certainty a blue paper, which, according to Hess, they see as a colorless gray of a particular shade, from gray papers of any shade. In order to remove the objection that they directed themselves to the blue paper by virtue of an odor imperceptible to us, all the papers were covered by a glass plate. When the mass of bees above the blue paper were brought upon a gray one by moving the glass plate, the mass dissolved within $1 / 4$ to $1 / 2$ minute and a new one formed upon the blue" (p. 135).

Seasonal change in the response to honey.-Zander (1913:711) found that, while honey exposed in summer stood day after day without visits from honey-bees, in agreement with the results of Forel, it was sought by hosts of them in September. This led him to make similar tests at intervals of about two weeks from the end of April to the beginning of October. 
The honey was placed in a small porcelain dish covered with gauze, so that the odor could escape but the honey itself could not be reached and thus exhausted. This was exposed on the threshold or the top of a hive and observed for a quarter to a half hour during the period of the best morning flight, the temperature, humidity, wind direction, and condition of the sky being recorded, as well as the honey increase of a test hive and the kind and condition of the flowers available. On June 1 and July 6 no bees were attracted to the honey, while on April 30, May 15, June 15, July 15, and August 1, the respective numbers were 7, 3, 6, 7, and 1. On August 15, 13 bees were noted, 23 on August 30, a host on September 16, and 15 to 20 on the 30th. The most striking relation was the inverse one to the number and abundance of nectariferous species and the nectar flow. The visitors to the honey were few or none until the flowers decreased greatly or disappeared altogether, when they increased from two to several fold. Zander regarded the observations of June 1 and July 6 as the only ones that supported Forel's view as to the bee's feeble sense of smell for honey, but it would appear that all the observations that yielded but 1 to 7 visits should also be considered as evidence for this, if those that gave 20 to many visitors be adduced in proof of a keen sense of smell. Interesting as the experiments are, they fail to reckon sufficiently with the effect of habit on the one hand and the tendency of bees to attract others on the other, to be entirely conclusive. They do show, however, that the sense of smell is psychic as well as physical, in that the stimulus of the odor of honey is much less effective in the midst of the obsession produced by an abundant flow of nectar.

The sense of smell in the honey-bee.-Frisch has supplemented his studies of the attraction exerted by color by a second outstanding research on the sense of smell in the honey-bee $(1919: 1)$. As this likewise became available only after the present book was in type, it must suffice to indicate the main heads of his treatment and to give the essence of his summary. The main divisions of his treatise, which has the proportions of a book, are as follows: (1) exposition of the experimental technique, and discussion of the question whether bees are attracted by the odor of flowers; (2) ability of the honey-bee to discriminate between different odors; (3) odor and color; (4) memory of the honey-bee for odor and color; (5) do scentless inconspicuous flowers that are much visited by bees have a fragrance imperceptible to us? (6) the odor of honey; (7) the fineness of the sense of smell in the honey-bee (the "minimum perceptibile"); (8) experiments with mixed odors; (9) the biological significance of the fragrance of flowers; (10) experiments with odorous substances of different chemical composition but similar odor; (11) training with lysol, skatol, etc., a contribution to the psychology of the honey-bee; (12) summary.

The first questions to be decided were whether the honey-bee perceives the odor of flowers and whether it is guided by such perception in its visits to flowers. The answer in both cases is affirmative, since training for flower odors has always met with complete success. But in addition to odor itself, its quality must be taken into account. Bees trained to the fragrance of acacia visit this alone and are not in the least attracted by the odor of the rose or lavender. Bees trained to the odor of the oil from orange-peel 
distinguish this by smell from 43 other essential oils with the greatest certainty, and are attracted only by a similar oil of different origin and by bergamot and cedar oils. It is not especially noteworthy that the essential oils which are similar to our sense of smell should be the very ones confused by the bees, since they are related in origin and chemical composition. Comprehensive experiments with paired odorous substances of different chemical constitution but smelling alike to us have shown that many of them are also confused by the bee, and that a similar grade of likeness appears to exist also for it. This indicates that the physiological basis of the sense of smell in man and in bees has more in common than has previously been supposed for organs that are anatomically so different. However, in detail the two show considerable departures. Many odorous substances, very similar to us but easily distinguishable, were mixed by the bees, and on the contrary the latter distinguished with great accuracy others that can not be discriminated by us.

When bees trained to both odor and color were exposed to the two separately, the behavior was complex, but it was regularly the case that the color was perceived at considerable distances and the odor only near at hand, even when strong odors were borne toward the bee by a gentle wind. This and other observations support the assumption that the sense of smell in bees is not materially keener than in man. It might be supposed that the perception of odors related to their life activities would be greatly enhanced in bees, and that they would perceive the odor of nectar or honey at great distances. However, this is not supported by the results. A honey fragrance that is little or not at all perceptible to man also gives no positive results with bees. With a stronger honey odor an actual training can be effected, but the observations of other investigators that have led to the assumption of its attractive effect at a distance can be otherwise explained. The honey odor is probably nothing more than the fragrance of the flower that has been absorbed by the nectar, and it is understandable that it should affect the bee like any weak fragrance of this sort.

Some evidence exists for the assumption that many flowers which are scentless for us have a strong odor for bees, and this has been assumed for the wild grape especially. However, it can be demonstrated that these flowers have just as little odor for bees as for us, and this is true likewise for the bilberry and the red currant. Outside of these three species there are but few whose blossoms are both inconspicuous and scentless, and yet visited by bees. These are trees or shrubs, or plants that grow in extensive closed masses, with the consequence that they are easily found by bees. The experiments with mixed odors show that the fragrance of scattered flowers, even when marked, can be effective only in the immediate vicinity, where it is pure and unmixed.

While fragrance has been regarded as a means of attracting pollinators, this is not wholly correct; at least, it does not fully characterize its function. When a bee has found the food desired in a particular species, it brings its companions with it and these then haunt the plant with great persistence, distinguishing it with the greatest assurance from all others. Inasmuch as they see only "yellow," "blue," and white flowers out of the entire series of shades, they must make use of other characters to discriminate between 
the various species. Thus, flower fragrance is a distinguishing mark for bees, and perhaps the most important one that the flower possesses. In the light of this fact, it is readily understood how bees can remember for days or even weeks an odor to which they have been trained for a short time only.

It seems significant of the psychic processes in these highly organized insects, which are able to perceive flower odors so quickly and to make use of them, that they refuse almost completely to respond to training experiments with foul-smelling substances, and that certain other odorous substances give only poor training results. There seems no other explanation of this than the assumption that there are odors which had been without significance for bees through countless generations and to which they habituated themselves not to respond. In like manner they readily learn to distinguish forms which suggest those of flowers, while training them to geometric figures is completely unsuccessful.

In their entire behavior bees show in their sense of smell an agreement with that of man which is as far-reaching as it is unexpected. All of the 32 odors to which they were trained are effective for them, as for us. All the substances tested that are inodorous for us are equally so for them. Substances with strong odor for us are likewise strong for bees and the reverse, just as those that are similar for the one are alike for the other. Thus, it is possible to evaluate the biological significance of flower odors with far greater certainty than heretofore.

Bombylius and the colors of flowers.-Knoll has presented the results of his investigations of the behavior of Bombylius and Macroglossa in two comprehensive monographs, which must be ranked with those of Frisch with respect to the detail and accuracy of the treatment. The first deals primarily with the response of Bombylius fuliginosus to the flowers of Muscari, under the following headings: (1) main objects of the experiments; (2) experiments, $(a)$ choice and preparation of the experimental area, $(b)$ determination of the optical attraction of flowers, $(c)$ studies of the chemical attraction of flowers, $(d)$ experiments with Frisch's methods, (e) near-by attraction of Muscari; (3) constancy of Bombylius in its visits to certain flowers and the behavior of other species of the genus to the same flowers; (4) general considerations on the color sense of Bombylius and that of the honey-bee. The experimental results showed that the flowers of Muscari attracted this fly at a distance by color and form and that fragrance had no part in this. It was also found that Bombylius possessed the ability, though probably in smaller degree than in the honey-bee, to associate the color of a flower and the presence in it of an easily accessible store of nectar. Further, since this fly visits the brightest or pure white flowers as well as the less bright ones of the blue group, but ignores the deep yellow, which are also very bright, it seems that the attraction is determined by the quality of the color rather than by its intensity. It may be assumed that the color vision of insects and of vertebrates has been developed independently on the basis of the independent evolution of the sense organs and the related nerve systems. A consideration of the structure of the sensory apparatus and the central organ of the two groups confirms us in the assumption that 
a more or less different expression of physiologically similar functions must result from organs so differently constituted.

As a consequence of what has been said, a part of the teaching of Sprengel as to the ecological significance of the color of flowers can be accepted by modern flower biology without modification. One reservation must be made, however, to the effect that the two insects so far investigated, the honey-bee and the bombyliad, possess a different optical perception of what appears to us as pure red or blue-green in color and that in consequence neither of these colors can exert an attractive action on these insects in connection with pollination. However, the questions as to the nature of insect vision and the ecological significance of the details of color and marking in flowers can not be conclusively answered with our present knowledge.

Vision and flower behavior of Macroglossa stellatarum.-The second half of Knoll's monograph on insects and flowers treats of the response of the hawk-moth to light and color, as well as to flowers, under the following main captions: (1) observations on the life-history of Macroglossa; (2) experiments on the vision of Macroglossa; (3) the food instinct in Macrogloss $a$ and its evaluation for the study of the color sense; (4) experiments with freshly hatched moths; (5) the behavior of the female during the period of egg deposit; (6) flower visits and fragrance; (7) critique of the experiments of Plateau (p. 164); (8) notes on other Lepidoptera; (9) summary.

In its flights for nectar, Macroglossa observes objects of a certain optical quality, but not those of a different one. In addition to the dark colors, it often visits also the paler ones and pure white, but takes no notice of green plant parts, and just as little of the gray, black, or brown objects of its environment. With the hawk-moth, as with the honey-bee and the bombyliad, two groups of colors come into especial consideration, namely, blue and yellow. When it has obtained its nectar for some time solely from an object of a definite optical character, under certain conditions there appears an association with such an object. In the attraction of this moth from a distance the fragrance of flowers plays no part, as this appears to be true also for the immediate proximity of the flower. This result was entirely unexpected, as it has been generally assumed in flower biology that the marked fragrance of many flowers was a direct adaptation to the hawk-moths. However, this particular species does not lack the faculty of perceiving plant odors, since the odor of Galium leads the female to deposit her eggs upon it.

A newly hatched hawk-moth flies directly to certain flowers, in spite of the fact that it has had no individual experience with them. In doing this it distinguishes the color of the blue and yellow groups from green and the various grays. Thus, there is present in the inexperienced moth a predilection for objects of a certain optical effect. This effect is given in nature only by flowers, so that the young insect may go quickly to its food in consequence. The action of certain optical stimuli in the process of flying to the flowers and the consequent possibility of acquiring experience by means of vision furnishes the basis for a part of the constancy of the hawk-moth. This utilization of animal experience has already been made by other investigators in this field, notably by Frisch with the honey-bee. A comparison of the results shows that there is no essential difference be- 
tween the color sense of the honey-bee and that of the hawk-moth, as is equally true for the latter and Bombylius.

Since attraction from a distance is a matter of vision, the hawk-moth will regularly visit only those flowers that belong to its particular color groups. This is supported by the records of visits, which show that the flowers commonly sought are blue or purple in color, though in southern Europe the yellow flowers of Linaria vulgaris may be exclusively visited. This difference in behavior in various regions may be regarded as a passing stage of the natural association, and therefore as a consequence of the insect's experience. To effect pollination it is desirable that the hawk-moth visit the flowers of one species for as long a period as possible. Therefore, all the features of the flower are of significance that produce and fix the association of the moth with this particular species. Of paramount importance in this are those optical features which guide the moth to adequate supplies of nectar. In connection with such optical associations the nectar guides may play an important rôle.

The above results confirm in large measure the views of the earlier flower biologists as to the significance of the optical features of flowers for the visits of the hawk-moth. The importance of nectar guides was somewhat overemphasized by them, though the essential facts of the older concept can be maintained. However, no support has been found for the view that the odor of flowers plays the important part in the attraction of the hawk-moth heretofore assigned to it.

Response of bees to spectral bands. - The studies of Kühn and Pohl (1921:738) mark a distinct advance in the technique employed for the analysis of color vision in insects. They have utilized the spectral bands obtained by means of the mercury spectrum in order to extend their experiments into the region of the ultra-violet and have consequently had the advantage of working with pure colors. The bees were habituated to fly in a room in which a $\mathrm{Hg}$ spectrum was thrown on a horizontal table-top, upon which it could be turned and shifted at will. To human eyes the lines at $578 \mu \mu$ (yellow), $546 \mu \mu$ (green), and $436 \mu \mu$ (blue) appeared brilliant; $405 \mu \mu$ (violet) was distinctly and $492 \mu \mu$ (blue-green) still noticeably to be seen in the daylight of the room. The line $365 \mu \mu$ (ultra-violet) could be recognized in weaker light as a sensible bluish glow on the white paper of the table. In training the bees all the lines were eliminated except one, which was directed upon a small elongated combustion dish filled with sugar solution. In doing this the position of the line was frequently shifted to avoid any association with a particular portion of the table. In the tests without food a new sheet of paper was spread and the particular wavelength presented in proper sequence with the remaining lines of the spectrum. After a training period of an hour the bees always gave a constant response.

After training to $578 \mu \mu$ (yellow) the bees concentrated regularly upon this band. When this was covered, they went in almost equal number to $546 \mu \mu$ (green). Lines of shorter wave-length were not noticed, and variations in the brightness within wide limits had no effect. After feeding upon $436 \mu \mu$ (blue) a dense mass of bees formed on this; violet (405 $\mu \mu)$ was equally strong in effect after uncovering from $436 \mu \mu$. After eliminating $436 \mu \mu$ and $405 \mu \mu$, there was a marked movement to the ultra-violet line 
$365 \mu \mu$. The region of greater wave-length was completely avoided after training to $436 \mu \mu$ and $405 \mu \mu$. The wave-lengths of ca. 400 to $440 \mu \mu$ on the one hand and ca. 540 to $580 \mu \mu$ on the other were consequently discriminated from each other by the eyes of the bee. The flight to the ultraviolet line $365 \mu \mu$ after training to $436 \mu \mu$ or $495 \mu \mu$ (blue or violet) may be explained by the action of the weak bluish fluorescence or by a sensitivity of the bee's eye to this part of the spectrum. Further studies indicate a particular specific sensitivity to ultra-violet. When trained to $365 \mu \mu$, the bees sought ultra-violet alone out of the entire spectrum, and even after concealing this line, blue and violet were without effect. Unbroken light rays received no visits, but the interpolation of an ultra-violet filter which cut out wave-lengths above $400 \mu \mu$ and removed the disturbing influence of whiteness brought about many visits. Light-waves in the region of $365 \mu \mu$, or ultra-violet, were distinguished qualitatively from unrefracted light as well as from the regions of ca. 400 to $440 \mu \mu$ and ca. 540 to $580 \mu \mu$.

Further experiments showed that the line $492 \mu \mu$ (blue-green) was also distinguished from the other lines of the $\mathrm{Hg}$ spectrum as well as from unrefracted light. The bees were then trained to a bright band from a continuous spectrum between $480 \mu \mu$ and $500 \mu \mu$. Checking with the Hg spectrum gave a massing upon the blue-green mercury line of $492 \mu \mu$, which is faint to our eyes and which always remained free in the training to all the other wave-lengths. In order to test the discrimination of the region 480 to $500 \mu \mu$ from unrefracted light, a "white" band of the same size was exposed alongside of or instead of the "blue-green" one. The bees left this unnoticed, even though its brightness was varied greatly, and gathered always on the blue-green strip ( 480 to $500 \mu \mu$ ). To this region of the spectrum corresponds Hering's paper No. 10 approximately for our eyes. In the experiments of Frisch the bees were unable to distinguish this pigment from the shades of gray, but the explanation of this discrepancy seems obvious. Pigment No. 10 has been measured photo-electrically and found to reflect from $492 \mu \mu$ to $365 \mu \mu$ downwards in increasing measure. Consequently, there must have been present for the bee's eyes a marked veiling by white.

\section{EVAluation OF PLATEAU'S RESEARCHES.}

Forel's estimate.-The most comprehensive critique of Plateau's work was made by Forel (1901, 1908:142). As a complete summary of this would involve too much repetition of Plateau's results, it appears best to quote Forel's general statements and conclusions, and to deal with certain contradictions which affect the significance of some of his criticisms.

\footnotetext{
"It is with reluctance that I have decided to undertake the eriticism of this author, not, indeed, that it will be difficult, but because of the space it demands, and because it is painful to me to have to bring to light the false conclusions of a colleague whose patience, work, honour, and good faith I esteem. But the considerable confusion that Plateau has thrown on the question which occupies us, in spite of and in part by his long and patient researches, and the fact that his conclusions have been accepted all too easily by certain authors who consider themselves to be very superior to all that has preceded them, demands that we examine the matter closely.

"Before starting, I must, to simplify matters, lay down in anticipation certain general theses at which I have long arrived and which agree in short with the results
} 
of Darwin, Romanes, Lubbock, and all investigators who have gone deeply into the psychology of insects. But these theses require to be definitely formulated.

" (a) Granted that there is often a principal directing sense, the rule is nevertheless that insects combine the impressions of several senses for their own guidance.

"(b) Attention plays a considerable part in the manner in which insects guide themselves. When it is strongly directed toward a goal or object, they are often profoundly oblivious of everything else, somewhat like an absorbed savant (bee eating honey; ants fighting).

" $(c)$ The memory of insects varies much according to the species. It is connected with various sensory impressions. It is much better than one would imagine a priori in insects with complicated instincts and especially in social hymenoptera, but it is extremely weak in the small-brained forms.

" $(d)$ As Lubbock and H. Mueller have shown, impulse plays a great part. Attracted by the sensations of sight or of smell or of both combined, the insect ends by fixing its attention on an object or on an instinctive coordinated act, connected with a purpose. When this fact is accomplished it may be seen to repeat its journey or other instinctive acts with a rapidly increasing precision.

"(e) Insects have sentiments or emotions more or less developed according to the species, genera, and families. Rage, fright, discouragement, jealousy are very marked among the social hymenoptera; similarly affection and temerity based on success. It is necessary to take them into account accurately to judge their acts. Emotional states of the nerve centers are very general in the animal series and are therefore related to danger, success, defeat, fruitless efforts, pain, attack, defence, as much in the individual as in the society.

" $(f)$ Nothing is so dangerous as premature generalizations, or $(g)$ to draw illegitimate conclusions from experiments."

"Attraction of insects by flowers.-Color preferences.-It is well known that Hermann Mueller has insisted on the part played by the colors of flowers as a cause of attraction, and has upheld the opinion that certain lively colors of flowers of themselves attract insects, i. e., that the attraction for such and such a lively color will tend to direct the insect towards them rather than towards less apparent colors. These preferences of color thus serve indirectly for the fertilization of flowers by insects, so that selection will induce the flowers for this reason to become more and more colored. Lubbock has made experiments whence it resulted that bees and bumblebees had, for example, a marked preference for blue. Let us say once for all that this question is extremely complex, and that the results of observations made without prejudice are not of a nature to confirm in a satisfactory manner the theories of Mueller. The results of Lubbock are similarly not very conclusive on this point. It has often appeared to me also that blue was especially apt to attract and to direct bees and bumble-bees to a spot; they find honey placed on blue more easily, for example, than if on red. But as insects distinguish the colors on the side of the ultra-violet better than those on the side of the infra-red, the preference might thus be accounted for. White attracts them in my opinion as much as blue, everything else being equal. In this question, distinction of colors must not be confounded with preference for one or another color. Though the distinction of colors is useful to insects which visit flowers, to enable them to distinguish and find them rapidly, the attraction of a special color will be equally detrimental to them in preventing them from going to flowers quite as rich in nectar or pollen, but differently colored, or in attracting them toward flowers or other objects colored with the hue of predilection, but offering neither nectar nor pollen, or even having poisonous qualities. For these simple reasons, self-evident to the common-sense of a practical entomologist, I have never been able to participate in the theories of Mueller and Lubbock on this subject.

"I am happy to find myself in perfect agreement with Plateau on this point; his numerous experiments all tend to prove clearly what would be expected, i. e., that 
insects direct themselves toward flowers which provide them with the nourishment that they need, and that they find them as well when they are as green as the leaves, as when they are blue, red, or yellow. Inversely, they ignore the most beautiful flowers with striking colors, when these have nothing to give them. Plateau gives himself unnecessary trouble to show that there are green flowers and that insects visit them as much as others. Every one knows the first of these facts, and the second has escaped no entomologist; in my opinion, his long comparative tables refute Mueller. Nevertheless, do there exist any preferences of color beside the fundamental fact that we have enunciated? This is so difficult and so delicate to decide that I dare not express an opinion.

"But Plateau has completed his old experiments on another very interesting point. I refer to artificial flowers. He has taken enormous trouble to obtain the best and most artistic imitations of natural flowers. To one who knows modern art in this branch this means much, for even man needs all his attention to enable him to distinguish these artificial products from true flowers. Here again I am pleased to be able to confirm Plateau by several experiments that I have been able to make. That which deceives us never deceives insects, or hardly ever, and then only for an instant. The insect passes to one side of artificial flowers without paying them attention, without stopping at them, without hesitating. and goes straight to natural flowers situated beside them, and which we do not distinguish from them. Ought we to conclude therefrom that the colors which we use, and which are not chlorophyllic, are distinguished by insects from chlorophyllic colors? This appears very probable from Plateau's experiments, and I shall believe it until I have proof to the contrary. That which to our eyes is a good imitation of color appears not to be so to the insect eye. These facts will appear less astonishing to us if we remember that among men some are color-blind, while others are artists who render and appreciate colors in many various shades. Then we must not forget that artificial imitations of flowers are made by the help of human vision and for it.

"I shall not enlarge upon the researches of Mueller, Bennett, Bonnier, Gratacap, Christy, Bulman, Scott Elliot, Delpino, Kuntze, Knuth, and Plateau on the truly hairsplitting question regarding the possibility of insects having preferences for certain colors or not. Here I am in agreement, as I have said, with Plateau (and Bulman). What is astonishing is that so many authors can waste so much ink in proof of the obvious, clearly summed up by Bulman when he says, 'It matters not one iota to a bee whether the flower is blue, red, pink, yellow, white, or green, so long as there is honey, that is sufficient.' Only the fact that any color does not attract specially by itself some insect is no proof that the latter cannot distinguish other colors.

"But here my agreement with Plateau ceases. Here again he has drawn erroneous conclusions from his experiments. In the case of masked dahlias, he concludes that shape and color do not attract, but forgets that the insect remembers the place where the flower was. Plateau's observations and inferences are both faulty. First, his dahlias were insufficiently masked, being covered only in the uppor part; bees flying around a group of flowers must perceive the uncovered colored sides by their peripheral vision. This seems to be evident from the figures of Plateau, which shows the vine leaf lying flat on the flower. In the second place his bees had consequently discovered his trick sooner than mine; he probably took no account of their behavior at the beginning of his experiment, or had not noted it. But it is only at such a time that conclusions can be drawn as to vision alone, independently of memory. Further, our results show that bees have a poor sense of smell at a distance.

"Plateau also worked with bees that were visiting Oenothera biennis with its beautiful yellow potals. On September 3rd he cut the corollas, leaving only the stamens. I give the results in his own words:- 'The bees visiting the plant flew in every direction, toward the faded flowers, towards the buds, even to the fallen petals on the ground, which they examined with some attention in walking over them; nevertheless, 
they alighted to forage only on the mutilated blossoms deprived of corollas.' [The italics are Plateau's!] And Plateau concludes that it is smell and not vision that guided them! Is it possible to prove better to oneself the contrary of what his experiment says? That bees do not forage where there is nothing, is obvious to a child. But that they should seek the flowers, wherever they perceived them, by their bright yellow color, that they should see the dry rudiments or the buds on the plant, this agrees so admirably with our experiments that I pass no comment.

"The last conclusions of Plateau are somewhat curious. He begins by declaring that he has 'never said that insects do not see the colors of flowers; that would be absurd' (nevertheless, he uses the title: On the so-called distinction of colors by insects). Then he adds that the differences in the quantities of reflected light or in the refrangibility of luminous rays transmitted or reflected by the transparent media can explain the results hitherto obtained. And finally he pretends that the question to be solved is: do the insects which visit flowers allow themselves to be guided in their choice by the colors which these flowers present to the human eye? I protest against the manner in which Plateau now puts the question. I do not believe any more than he does that insects see colors subjectively as we do, and I believe further with him that there are objective differences in the manner in which their eyes and ours are stimulated by the different forms of light, i. e., by colors and shades. But the experiments of Lubbock, of Peckham, of other authors, and my own indicate that certain insects distinguish not only flowers, but colored objects, by their coloration, i. e., by the kind of refrangibility of the luminous rays which they reflect or transmit, and recognize them in this particular when the other senses are eliminated, and even when such objects are found surrounded by light of the same intensity.

"In saying that bees distinguish colors, We have never wished to assume that they vee them exactly as man does, and so much the less since, as I have already emphasized, all men do not see them absolutely the same.

"In recapitulation, we see that the facts are very complex, and this is why I abstain from general conclusions on 'all insects' seeing or not seeing 'forms and colors, etc.,' for such generalization would necessarily be false. If one wishes to understand it, one must take the trouble to follow the details. Nevertheless, I am constrained to repeat that Plateau's interpretation of his so-called non-distinction of forms among insects, after the restrictions which he has himself gradually introduced, finally approaches more or less to the opinion of Exner, which has always agreed with my own. The greatest error of fact into which Plateau falls, is that by which he attributes what really belongs to vision in certain insects (in bees in particular) to their sense of smell. Nevertheless, in the final paper of the series, he finally recapitulates the way insects guide themselves, in a manner which in its general characteristics approaches nearly to the truth. As we have seen, the causes of the erroneous judgments with which Plateau has obscured the question at issue are errors of interpretation, inadmissible and continual generalizations, and the almost total neglect of the psychical faculties of the insect, especially with regard to memory and association."

Although Forel's criticisms of Plateau's work are often too severe, they are on the whole fairly well justified. They err in making the differences between their general conclusions greater than it actually was, as Plateau himself pointed out $\left(1902^{2}: 424\right)$. Moreover, Forel was not free from the contradictions for which he takes Plateau to task, and it is evident that his own knowledge of the behavior of anthophilous insects was much smaller than for many other groups. After dismissing the views of Mueller and Lubbock on color preference as unsatisfactory or inconclusive, he states that "this problem is so difficult and delicate to decide that I dare not express an opinion," only to express a very positive 
one a moment later (p. 210) and to rebuke Mueller, Plateau, and others for proving the obvious. He is far from clear as to the practical difference between the distinction of colors and the preference for certain ones, and fails to realize that the marked constancy of many bees indicates that distinction and preference are often the same thing. He apparently did not know the careful work of Mueller as to color preferences for petals, which, like that of Lubbock, is corroborated by the later researches of Lovell, Turner, Frisch, and others. Lovell in particular has shown that green flowers and green objects are visited much less than bright-colored ones and often not at all, and this has been confirmed by Allard in his work with cotton blossoms. The results of Plateau and of Forel with respect to artificial flowers are contradicted by those of Andreae, Wery, Detto, and others, and it is evident that time, place, and other factors often play a controlling part in the behavior of insects to such imitations. Moveover, if insects can distinguish chlorophyllic colors from others in the case of artificial flowers that deceive human vision, it is impossible to believe that they are unable to distinguish the strikingly different forms of various flowers. The evidence for the perception of form by bees is given later, and it is only necessary to point out here that Forel himself speaks of their seeing the dry remains of flowers and the buds of Oenothera.

Contradictory nature of Plateau's later conclusions.-While several critics have pointed out that Plateau materially modified his earlier statements as to the relative rôle of color and odor in attraction, the greater contradictions involved in his later ones have been overlooked. These are contained in the four extracts that follow, which represent the last ten years of his work, 1899 to 1910.

"I have never said, in my previous studies or the present memoir, that insects do not see the colors of flowers. This assertion would be absurd. But I insist that we have no practical means of assuring ourselves whether there exists a perception of color and whether this is the same as our own. The question to be resolved is this: whatever may be the visual perceptions of insects, are those that visit flowers guided in their choice by the colors that the flowers present to the human eye. The reply can only be negative [1899:368]. I admit fully that the insect can perceive flowers at some distance, whether it be because he sees their colors in the same manner that we do or because he perceives a certain contrast between the flowers and their surroundings, I admit that concurrently with the sense of smell, although to a much less degree, this vague visual perception can guide the animal to the whole floral mass; but once arrived there, if the flowers differ among themselves by color alone, he will prove by his behavior that it is entirely indifferent to him, as Bulman says, whether the corollas are blue, red, yellow, white, or green" (370).

As a result of his experiments with bumble-bees deprived of their antennæ $\left(1902^{2}: 418\right)$, Plateau said:

"The results of A. Forel are thus shown to be accurate; I state it with the satisfaction of having been able to contribute to the demonstration of a scientific truth. However, it is not necessary to draw from this the exaggerated conclusion that the sense of smell plays no part in the attraction of insects by flowers." "What is to be drawn as a conclusion from all this? It is that, if I have been wrong in attributing an exaggerated preponderance to the sense of smell in the relations between insects and flowers, my numerous observations and experiments prove, as Knuth admitted, that the olfactory sense plays a much more important rôle in the search for flowers by insects than has hitherto been admitted. 
"I could quote further from the work of Forel, but limit myself to the preceding. I thank him for giving me the opportunity to prove that, even in supposing all the criticisms of which he is not sparing to be absolutely well founded, the results of my studies on the relations between insects and flowers are not as worthless as some pretend and that they do lead to the refutation of this part of the floral theory of Hermann Müller and his school, who attribute to the brilliance of flowers, to their colors more or less striking, an important rôle in the attraction of insects and consequently in fecundation (1902:424).

"Two corollaries may be derived from this fact: the first is that the attractive rôle of the form and color of the floral envelopes is either null or nearly so; the second is that other causes than the attraction of colored surfaces is necessary to bring pollinators to flowers and to cause them to return, such as an odor pleasing to insects and a sugary liquid." "In résumé, the present investigation but confirms the thesis advanced in 1897 in the following words: 'Insects seeking pollen or nectar are guided to the flowers that contain these substances in only a subordinate degree by sight. They are guided in an assured manner to such flowers by some other sense than vision and this can only be the sense of smell" "(1910:51).

Conclusions as to Plateau's views. - The admiration felt for Plateau's frank admission that he had been wrong in assigning an exaggerated importance to the sense of smell in attraction is more or less eclipsed by the fact that this was never again referred to in his later papers, in which he returned finally to his original view that the attractive rôle of color is null or nearly so. In spite of Plateau's originality, industry, and patience, the bias in favor of odor and against color pervaded all his researches, blinding him to many faults of execution and leading him to unwarranted conclusions. How dominant this prejudice was is shown by the fact that within six pages after his apology for exaggerating the rôle of smell in attraction, he states that his studies refute the view of Mueller that color plays an important part in this process. This also led him frequently to overlook facts and results that were not in accord with his views, and to make gratuitous assumptions as to the work of other investigators. A second great fault of his experiments was the failure to insist upon the regular use of controls, with the consequence that the results were often open to any interpretation desired. With this went the failure to realize that time, place, and conditions work great differences in response, and that this was usually the explanation of the discrepancies between his results and those of his critics, rather than carelessness or lack of thought on their part. Finally, as Forel in particular insisted, he paid practically no attention at first to the importance of habit and memory, and gave them too little consideration throughout. In spite of all this, he deserves great credit as the pioneer in experimental pollination, as an indefatigable investigator, and a good-natured and courteous opponent.

\section{SENSES OF INSECTS.}

\section{SIGHT.}

The mosaic theory.-Forel (1886:10) emphasized the fact that the structural studies of Grenacher (1874) and the physiological ones of Exner (1875) led them to revive the earlier theory of Müller. This was not that each facet formed an image, as Gottsche thought to have demonstrated, but that the insect perceives a more or less clear image of the 
object in the form of a mosaic, due to the fact that each facet receives a different part of the light rays coming from the object. It follows necessarily, as Müller pointed out, that, since the clearness of vision, the localization of the light rays, is rendered possible only by the combination of the separate action of each facet, it is the number of facets that will determine the degree of definition. The smaller the facet, the longer the crystalline, the fewer the rays the retinule will receive and the smaller or more localized will be the external object from which the rays proceed. On the contrary, the larger the facet and the shorter the crystalline, the more light the retinule will receive and it will see in a manner more intense and diffuse, that is, less clearly. Thus, many small facets will diminish the intensity of the light, but will increase the clearness of vision. When in addition the entire eye is not flat but strongly convex, it will receive light from more diverse points, which increases the common field of vision. If this be true, it ought to be possible to prove by observation that insects with many small facets and with the compound eyes strongly convex have the best vision.

Forel brought forward a number of observations to support this view, the most significant, perhaps, being with reference to eyes of male and female ants. The eyes of the former are more convex and may contain twice as many facets, since they require greater vision to discern and follow the females in flight. He also confirmed the opinion of many investigators that the loss of the ocelli was without effect, but that this was not the case with the compound eyes. When the latter were varnished in the case of flies, these no longer flew if placed on the ground and once in the air they flew about aimlessly. Wasps and bumble-bees similarly treated behaved in like manner, flying even more rarely and finding their way on the ground more slowly. They searched for cracks in which to hide, as though it were night.

The following summary was given of the existing knowledge of vision in insects.

1. Insects guide themselves almost wholly in flight and partly on the ground by means of their compound eyes. The antennæ and the sensory organs of the mouth can not serve for direction in the air, their extirpation in no wise diminishing the ability to guide themselves on the wing.

2. The mosaic theory of vision proposed by Müller is alone sound. Each retinule of the compound eye does not receive an image, but merely a pencil of light rays more or less distinct from that of its neighbors.

3. The greater the number of facets and the length of the crystallines, the more distinct the sight, as well as further.

4. Insects perceive the movements of objects particularly well, that is, the displacements of the visual image relative to the compound eye. They thus see better in flight than at repose, for the image of immobile objects is then displaced with respect to the eye. Perception of the mobility of objects decreases as the distance becomes greater.

5. Insects distinguish the contours and form of an object only in a manner more or less indistinct, as much more indistinct as the number of facets is less, the crystallines shorter, the object more distant or smaller. Those insects that have large eyes with several thousand facets see quite distinctly.

6. In flight insects recognize the direction and distance of objects very clearly by means of their compound eyes; at least this is true for short distances. Even when in repose they can also recognize the distance of immobile objects. 
7. Certain insects, the honey-bee and bumble-bee, clearly distinguish colors and they recognize colors better than forms. With the wasps on the contrary the perception of colors appears to be very rudimentary.

Criticisms of Plateau's views as to vision.-Forel stated (p. 43) that-

"Plateau began by assuming that the theory of Müller as to mosaic vision is finally rejected and this in consequence of the work of Exner of which we have spoken! This is completely in error. On the contrary we have seen that Exner, as well as Grenacher, has entirely rehabilitated the theory of Müller. Plateau appears to have failed to understand the works of Exner, because he also adds that this author has concluded theoretically that insects do not see the form of objects, which is wholly inexact as well. Plateau says in the text, 'The earlier hypothesis of J. Müller, consisting in the production of a mosaic image formed by the juxtaposition of a series of minute partial images each of which occupies the base of one of the distinct elements of the compound eye is definitely rejected.' But this is the theory of Gottsche and not at all that of mosaic vision of Müller. The theory of mosaic vision does not admit of minute images in each facet, but a single image in mosaic formed by the juxtaposition of light rays of different quality perceived by each facet."

As to the experiments of Plateau upon the perception of form by insects, Forel declared that these did not in the least demonstrate that they could not distinguish form, but merely that they would fly to the more luminous of the two orifices without regard to the form. He also pointed out that while Plateau first spoke only of the non-perception of form, he concluded by saying that "insects do not distinguish the form of objects or distinguish it very badly."

\section{Sensibility to color.-Graber said (1875):}

"I understand very well that a brain relatively small and simple in construction is in general less capable than a more highly differentiated central organ and that both the number and the coordination of perceptions is limited by the simplicity of structure, but I can not admit offhand that when an animal, let us say a bee for example, exhibits actual color perceptions, these must necessarily be different from ours, or that we then know, since the sensory organ for color perception in the bee is essentially different than with us, that the nerve tissues concerned can not call forth the same sensations that they do with us. Disregarding the fact that insects possess very complex eyes and that they appear to react clearly to small differences of color, such as orange, yellow-green, etc., other evidence testifies to the great sensibility of their sense of color. I have especially in mind the fact that many insects have no other means of recognizing their own species than certain differences in color and it is well known that related species of ten differ outwardly only in coloring or marking. Moreover, it is hardly to be assumed that mutual recognition takes place by means of other attractions, imperceptible to us, such as odor or sound. But if I ascribe a very delicate sense of color to certain insects on the basis of these relations, I do not however go so far as Allen, who asserts that the ability of insects to distinguish color may be more marked than with man."

Perception of form and movement by insects.- In a series of six papers appearing from 1885 to 1888, Plateau dealt with a comprehensive investigation of vision in the Arthropoda. Some of these were made upon other groups than the insects and others had little or no relation to the problem of insect attraction. In consequence, the following account of his conclusions is confined to those that have to do with the perception of form or movement. Diurnal insects require a fairly strong light and 
are unable to direct themselves in semi-obscurity. Insects with compound eyes pay no heed to differences of form existing between two illuminated openings and are deceived either by excess of luminous intensity or of apparent surface. In short, they do not distinguish the forms of objects at all, or do so very poorly (1885:251).

Plateau (1888:437) stated that Exner, Notthaft, Carrière, Forel, and Bleuler had all concluded from theoretical considerations, often supported by observations, that the majority of insects see the movements of bodies much better than they do the bodies themselves. He regarded his own experiments as fully confirming this opinion and permitting the following conclusions. The faculty of perceiving the displacement of mobile objects is very well developed in many insects with compound eyes, those best endowed in this respect being the Lepidoptera, Hymenoptera, Diptera, and Odonata. However, the distance at which the movements of an object of small volume are perceived does not exceed 2 meters. On the average it is 1.5 meters for the butterflies, $58 \mathrm{~cm}$. for the bees, and $68 \mathrm{~cm}$. for the flies. The perception of movement plays a great rôle as the determining cause in the behavior of insects. It explains how, without a clear vision of form, the dragon-flies pursue their victims in the air, how different insects fly about among leaves moved by the wind, and why those with slow movement often escape their enemies. On the other hand, insects may be readily touched or caught if the movements are sufficiently slow. For them an object that ceases to move merges at once into the vague background.

Discrimination of form.-As a result of simple experiments with a spider, bee, and fly, Dahl $(1889: 243)$ found himself in agreement with Lubbock and Forel as to the ability of insects to distinguish forms, and in opposition to the conclusions of Plateau. He regarded the statement of the latter that insects often deceive themselves by flying to unopened flowers as indicating that they are attracted primarily by color rather than form, and not that they are unable to distinguish forms. He also observed (Knuth, 1898:45) that in spring young bees light on flowers whose nectar is too deep-seated for them and make vain endeavors to reach it, while the older bees merely come near and fly away without landing. This indicates that the latter recognize the flower on sight as one with unavailable honey, since guidance by odor would make it unnecessary for them to approach the flower.

Vision in honey-bees.-Buttel-Reepen stated that bees do not find their way home when thrown up into the air at dusk, not far from the hive; they make several small circles and fall to the ground completely lost. Their flight is often strongly influenced by dark clouds, especially during the honey-flow, when the approach of a storm sends thousands of bees scurrying back to the hives. In their haste many blunders are made in entering, which would not be true if they were drawn to the proper hive like a magnet by the "unknown force." It was also observed that when they went to the wrong hive, they tried to enter as at their own, even when no entrance was present, showing that they had a memory picture of their hive, though they had mistaken it. He also cited an in- 
stance of bees flying against a gable painted sky-blue that they had regularly avoided before, and one of young bees issuing from a blue hive and flying on their return to other blue ones by mistake, but never to those painted in other colors.

Vision in ants.-Fielde (1902:599), whose studies of vision in ants were in agreement with those of Lubbock and Forel, stated that-

"The ants manifested no liking for any of the rays of light. If obliged to stay in light rays of some sort, the rays of longer wave-lengths are preferred to those of shorter wave-lengths. Dividing the spectrum, as we know it, into red, green, and violet, we may say that to the ants' eyes red and green are most like the darkness that they prefer and that violet is to them most luminous; or that the red and green are less visible to them than is violet. In this regard the eyes of the ant appear to be the reverse of our own. Our eyes perceive in the spectrum three fundamental colors-red, green, and violet. The eyes of the ant perceive there only two fundamental colorsone made up of the red and green rays, the other of the violet and ultra-violet rays.

"It appears that the eye of the ant is not well adapted to the reception of light-rays whose wave-length is longer than in the violet rays; that it receives blue and indigo more perfectly than red, orange, yellow, and green; and that there is a sudden increase of luminosity in the light rays at that point in the spectrum where violet begins for our eyes. The ants may discern colors, and yet have no preferences among the colors discerned. Color is determined by the wave-length in the light-ray, and since ants discriminate between rays of different wave-lengths, they probably perceive color in the rays. Sensitivity to the length of the wave indicates perception of color."

The role of ultra-violet in attraction.-Richtmyer (1922) has determined the ultra-violet reflection of a number of Colorado flowers with reference to a possible influence in attraction. He considers that the effect of ultra-violet in attraction involves two questions: (1) do insects "see" ultra-violet in the sense that they seem to "see" the rays visible to us? (2) is the ultra-violet reflected by flowers present in sufficient degree to play an important part in rendering flowers visible to insects? It was found that few of the flowers reflected any considerable proportion of ultra-violet, only 4 of the 25 studied reflecting more than 10 per cent of radiation shorter than $0.38 \mu \mu$. These were Laciniaria punctata, Oenothera biennis, Rudbeckia laciniata, and Solanum rostratum. Certain yellow flowers showed a distinct ultra-violet reflection band, particularly well marked in Rudbeckia, but others such as Solidago and Ratibida gave no trace of such a band. The flowers differed from each other in the reflection of ultraviolet just as much and as erratically as in that of the visible spectrum. It might be expected that a white flower, which reflects the visible rays in approximately equal proportions, would also reflect a considerable amount of ultra-violet, but this is not the case. They gave a high reflection of light longer than 0.42 or $0.43 \mu$, but none of them reflected more than 4 per cent of $0.39 \mu$. The most striking case was that of Argemone platyceras, with a relative coefficient of reflection of more than 75 per cent at $0.41 \mu$ and of only 4 per cent at $0.39 \mu$.

THE HOMING FACULTY IN BEES AND WASPS.

Fabre's experiments with bees and wasps.- In his "Souvenirs Entomologiques" (1879:299, 1882:99), Fabre recounted his studies of the hom- 
ing of bees belonging to two species of Chalicodoma. In the first series the insects were released at $4 \mathrm{~km}$. from their nests; of the first 2, one returned the next morning, but the other never reappeared, while in the second case, 3 of the 5 were noted the following morning. In the third experiment 40 bees were freed, but only half of these flew away from the spot. Once free, the bees fled as though frightened, some in one direction and some in the other. The first 2 returned to the nests in three-quarters of an hour and 3 others toward sundown, while 10 more were observed the next morning, making a total of 15 to return out of the 20 released. All told, 19 found their way home out of 27 , disregarding those thought to be injured. These were supposed to have found their way back in spite of the contrary winds and their ignorance of the places to which they were carried. It is obvious, however, that the assumption that the bees had never wandered so far from home and had never seen these places was a gratuitous one. It afforded exceedingly tenuous support for the conclusion that they were certainly not guided by memory on the homeward journey, but by some special faculty, not to be explained but recognizable by its astonishing effects.

In the second series, 10 bees of the same genus were placed in a bag and carried a kilometer distant, where the bag was whirled rapidly about. They were then taken in the opposite direction to a distance of $4 \mathrm{~km}$. from their home and again whirled around before they were released one at a time. The first bee traversed the distance in a quarter of an hour and 2 others returned several hours later, but the remaining 7 did not reappear. The following day the first bee reached home in 5 minutes and 2 more in about an hour, while the other 7 failed to appear. When 49 bees were released, the majority started in the right direction, the first arriving in 15 minutes and 11 within an hour and a half; 6 more appeared within the next 5 hours, making a total of 17 out of 49 , while in the next test 7 bees out of 20 found the way back. The bees in the next experiment were taken over 2 miles away, 2 returning in an hour and a half and 7 more in 3 hours and a half, making 9 out of the total of 40 . Finally, 15 bees were marked with rose and carried by a roundabout route of over 5 miles, while a second 15 were marked with blue and taken directly to the spot, a distance of a mile and a half. All were released at noon, and by 5 o'clock 7 "rose" and 6 "blue" bees had returned, the long detour making no appreciable difference. Fabre regarded these results as conclusive, neither the whirling of the sack, the obstacles of hill and forest, nor the devious route being able to hinder Chalicodoma from returning to the nest.

Lubbock's and Forel's critiques of Fabre's conclusions.-Lubbock's discussion of Fabre's results is so detailed and conclusive that quotation alone can do it justice $(1888: 264)$ :

\footnotetext{
"I am not ashamed to confess that, charmed with M. Fabre's enthusiasm, dazzled by his eloquence and ingenuity, I was at first disposed to adopt his view. Calmer consideration, however, led me to doubt, and though his observations are most ingenious and are very amusingly described, they do not carry conviction to my mind. There are two points especially to be considered: (1) the direction taken by the bees when released; (2) the success of the bees in making good their return home.

"As regards the last point, it will be observed that the successful bees were in the following proportion, viz, 3 out of 10,4 of 10,17 of 49,7 of 20,9 of 40,7 of 15 , or a total of 47 out
} 
of 144. This is not a very large proportion. Out of the whole number no less than 97 appear to have lost their way. May not the 47 have found theirs by sight or by accident? Instinct, however inferior to reason, has the advantage of being generally unerring. When 2 out of 3 bees went wrong, we may, I think, safely dismiss the idea of instinct. Moreover, the distance from home was only $11 / 2$ to 2 miles. Now, bees certainly know the country for some distance around their home; how far they generally forage $I$ believe we have no certain information, but it seems not unreasonable to suppose that if they once came within a mile of their nest they would find themselves within ken of some familiar landmark. Now, if we suppose that 150 bees are let out 2 miles from home and that they flew away at random, distributing themselves equally in all directions, a little consideration will show that some 25 of them would find themselves within a mile of home and consequently would know where they were. I have never myself experimented with Chalicodomas, but I have discovered that if a hive-bee is taken to a distance, she behaves as a pigeon does under similar circumstances; that is to say, she flies round and round, gradually rising higher and higher and enlarging her circle, until I suppose her strength fails or she comes within sight of some known object. Again, if the bees had returned by a sense of direction, they would have been back in a few minutes. To fly $11 / 2$ or 2 miles would not take 5 minutes. One bee out of the 147 did it in that time, but the others took $1,2,3$, or even 5 hours. Surely, then, it is reasonable to suppose that these lost some time before they came in sight of any object known to them.

"Fabre observes that the great majority of his Chalicodomas at once took the direction home. He confesses, however, that it is not always easy to follow bees with the eye. Admitting the fact, it seems to me far from impossible that the bees knew where they were; and at any rate, this does not seem so improbable that we should be driven to admit the existence of a new sense, which we ought to assume only as a last resource. Moreover, Fabre himself says: 'When the rapidity of flight permitted me to note the direction taken,' which seems to imply doubt. Indeed, some years previously he had made a similar experiment with the same species, but taking them direct to the point rather over 2 miles from the nest and not whirling them round his head. In this case some went in one direction, some in another. It certainly would be remarkable if bees which were taken direct missed their way, while those which were whirled round and round went straight home. Moreover, it appears, after all, as a matter of fact, that they did not fly straight home. If they had done so, they would have been back in 3 or 4 minutes, whereas they took far longer. Even then, if they started in the right direction, it is clear that they did not adhere to it.

"Romanes's experiments, likewise, as he himself says, entirely confirm the opinion I have ventured to express, that there is no sufficient evidence among insects of anything which can justly be called a 'sense of direction."'

Forel $(1900,1908: 72,215)$ also emphasized the discrepancy between Fabre's results and his conclusions.

"Instead of attributing these facts to an instinct of direction, I explain them as follows: aerial insects and aerial beings in general, soaring above terrestrial objects ought to have,and have, a knowledge of places very different from that of wingless ones. If we reflect on the geographical coup d'oeil 'as the crow flies' that one obtains on the summit of a hillock, we shall have a feeble idea of what the vision of an aerial being can be, with this difference, that in the twinkling of an eye it moves and alters its horizons, which we can not do. In 20 minutes the Chalicodoma of Fabre had travelled over their 3 kilometers! This experiment simply proves to me the very instructive and interesting fact that the Chalicodoma knew the places within a radius of a league, at any rate. Those which did not find their way were probably newly hatched and had not pushed their reconnaissances so far.

"If a mysterious sense of direction had guided them, all that started would have returned. Weismann thinks rightly that the bees, set free in this unknown and to them distasteful place, would have been attracted by the sight of the hill. Once there, the oldest, those that knew the surroundings best, would have found a landmark and a road. Indeed we see even pigeons often go off in various directions at first. Is it not significant thus to see mason-bees, placed under the same conditions, conduct themselves in miniature like carrier-pigeons, without possessing however any vestibular or otolithic apparatus? The circle of their knowledge of places does not appear to go beyond 4 kilometers; that of highly trained pigeons appears to reach 500 . There is no striking disproportion therein. 
"I hope to prove that any mystic or mysterious theory of special sense, sixth sense, magnetism, etc., is as superfluous as false for the whole animal series. The known senses, their variations, and the memories which are derived from them explain everything" (p. 196).

As a result of experiments of his own (1895; cf. Rau, 1918:278), Weismann concluded also that "the only correct solution of the enigma of path-finding by Chalicodoma is that the insects find their way back with their eyes." (See also Pérez, 1895.)

Homing faculty of bees.-Romanes $(1885: 630)$ conducted observations to determine whether honey-bees find their way home by means of landmarks or by means of a mysterious sense. A hive of bees was placed in a basement room of a house situated several hundred yards from the coast, with flower gardens on each side and lawns between the house and the sea. A definite number of bees was used in each experiment and those that returned were caught by means of birdlime. The first score of individuals were taken out to sea, whence none of them returned; the second lot was liberated on the shore, but none returned. The same result was obtained when the next lot was released on the lawn between the shore and the house, although the distance to the hive was not over 200 yards. Finally, when bees were freed in different parts of the garden, they were always found stuck in the birdlime within a few minutes, often arriving before the observer could reach the hive. As the garden was a large one, many of these bees had to fly a longer distance than those released on the lawn and their uniform success in reaching home quickly was due to their special knowledge of the garden. The results convinced Romanes that bees depend entirely upon their special knowledge of a district or landmarks and not upon any general sense of direction.

Sense of direction in ground-wasps.-The Peckhams (1887:113) performed a number of experiments to determine whether wasps possess a mysterious sense that enables them to fly in a straight line to any desired point, even though they have never been over the line before. When 63 workers were carried 200 yards west to the top of a hill in sight of the nest and 10 released, they flew off in all directions, not taking the east toward the nest oftener than the other directions. Three, after circling about, settled again on the stump, but after some hesitation started off. When 20 wasps, 10 of which were marked, were set free on a lake, nearly all flew in the direction of the wind, toward the nest, but in the next test with 26 individuals, 6 took a direction opposite to that of the nest, 10 returned to the boat and seemed loath to leave, while several seemed to change their minds and altered their courses. Two days later 32 wasps were released on the lake a half-mile north of the nest; 8 of these returned to the boat, some of them twice, 6 or 7 flew in a straight line against the wind and over the lake to the nest, while 17 or 18 flew toward the shore. A second group of 40 was released, to fly in all directions, but most of them returned to the boat. Of the 135 wasps set free, it seemed fairly certain that they did not fly toward their nest as frequently as in an opposite direction. It also appeared that they were at a loss to know which way to go, since they often returned once or twice for a new start. Of 55 wasps released in a later experiment, 39 returned to the nest in about an hour's time. When 38 workers were set free in a room with opposite windows, 
22 flew through the window away from the nest, 16 through the one toward it; the majority returned in the first 15 minutes, but they continued to arrive for another quarter of an hour.

The experiments all served to show that the two species of wasps employed have no sense of direction in the form of a mysterious second sense or of an ability to keep track of the turns and changes in a journey. In spite of the fact that the wire cage permitted the use of sight, they frequently started in a wrong direction as they flew out. In many instances, however, these wasps returned to the nest and it seems probable that they did this by rising higher and higher in the air and discovering some objects that served them as landmarks.

Disturbance of memory in wasps. - In their study of the homing in solitary wasps (1898:367), the Peckhams concluded that if these had an innate sense of direction they would not need to make a study of the surroundings of the nest in order to find the way back, but in the absence of such a sense common prudence would require the careful inspection of the location before the outward flight. After days spent in flying about the garden, it would seem that further study of the precise locality might be superfluous, but the wasps did not find it so. They made repeated and detailed studies of the surroundings of the nests, and when their prey was laid down for a moment on the return, they noted the place carefully before leaving it. If the scrutiny of the objects about the nest makes no impression on the wasp, she should not be bothered or misled when weeds and stones are removed and the ground smoothed, but this is just what happens. Aporus fasciatus lost her way entirely when a leaf that covered the nest was broken off, but found it readily when this was replaced. All the species of Cerceris were extremely annoyed by new objects placed near the nests, and Ammophila refused to make use of her burrow after deep lines were drawn in the dust before it. The same annoyance was exhibited when any change whatever was made near the spot where the prey was placed, and experience showed how important it was not to disarrange the grass or other plants on such occasions. Marchal (1900:1113) has given an account of the errors made by Pompilus in the return to the nest and reaches a similar conclusion to the effect that it is not guided by a special sense of direction, but solely by vision and memory.

Observations on the homing of Bembex and Pompilus.-Stimulated by the observations of Fabre on Bembex (1879:261), which led to the conclusion that neither memory of place, sight, nor smell guided the insect, Bouvier (1900:874) investigated the behavior of Bembex labiatus. His first results were in agreement with those of Fabre to the effect that the wasp always returned close to the entrance of its nest, regardless of the substances used to mask this. However, when the objects have a considerable size, the insect is completely lost and sometimes spends hours seeking here and there before relocating its burrow. When the latter was covered with a flat stone about a decimeter in size, the wasp lighted on the stone, scratched it, hunted beneath it, and found the entrance only after much effort. The next day the stone was displaced about $2 \mathrm{dm}$. from the new entrance that had been made, with the result that the insect flew at once to the edge of the stone and began to dig as though at the right place. $\cdot \mathrm{He}$ 
was twice driven away, only to return and start digging. Finally, the rock was restored to its original position, and the wasp found the entrance immediately. Clearing away the plants and smoothing the sand about a burrow for a space of 7 or 8 square decimeters sufficed to mislead Bembex entirely, and it was only after a long time spent in digging here and there that the entrance was rediscovered. Bouvier concluded that memory of place and vision play an essential if not exclusive rôle in the wonderful facility with which Bembex returns to the entrance to its nest. Bouvier has also given an admirable discussion of the faculty of orientation with insects and other articulates (1922:230, 251).

Marchand (1900:248) found that when a plant growing about $5 \mathrm{~cm}$. from the burrow of Bembex was displaced about the same distance, the insect was unable to relocate the entrance and hunted vainly in all directions for several minutes. The plant was then restored to the original position, and upon its return the wasp flew close to it and soon found the entrance to his nest.

Memory of place in Osmia.-Ferton (1905:89) has made observations on Osmia rufohirta which indicate that this solitary bee possesses the same remarkable power of memory for place as the social bees and the wasps. After closing its nest in a shell of Helix, an individual of this species moved it to a new position a dozen centimeters away and then went to the plant the leaves of which it was using to make a paste. On its return flights it first flew to position A, slackened its speed without alighting, and then went directly to position B, a path that it followed for a quarter of an hour or more. The observer moved the shell to a new position at $\mathrm{C}$, where the bee found it after some trouble. On leaving, the latter made several vertical flights of orientation above the nest before returning to the plant. On coming back it took the path $\mathrm{ABC}$, though when it went to another plant growing near C, it returned directly to the latter. Soon afterward it carried the shell back to $\mathrm{A}$ and again began to work on the original plant. On its return it passed $A$ and, making a slight turn toward $B$, reached the point $\mathrm{C}$, whence it returned to $\mathrm{A}$, after determining the absence of the nest at C. This experiment, with others that were repeated several times, demonstrated that this species is guided by its memory of place. The results obtained with Osmia ferruginea led to the same conclusion, but as this species does not have the habit of moving its shell, it is less skillful in relocating it and consequently has a poorer memory.

The manner in which Osmia searches for its nest when displaced indicates that it is guided chiefly by vision. It lands upon all the shells found in its exploration, which would not be the case if it were guided by smell alone. However, the bees of this genus also employ the sense of smell, especially that of contact. Moreover, they can make use of this sense at a distance, as when it is used to guide them to their favorite flowers. It is unnecessary to have recourse to the unlikely hypothesis of an unknown sense, since vision, smell at a distance and in contact, and memory suffice to explain all the observed facts (1906:29).

Ferton (1908:578) has also discussed Pieron's contention that the homing of Osmia is due to muscular memory and rejects this except for movements repeated a great many times. 
The field and nest flights of the bumble-bee.-Wagner (1907:51) has considered the sense of direction of Bombus under the following captions: (1) observations on the return to the nest by running; (2) observations on the field and the nest flight; (3) observations in cages; (4) homing in nature. When the wings were cut off, Bombus was unable to return to the nest, showing that it was not guided by a mysterious sense of direction. Each flight of this bee consists of two separate acts, the field flight and the return to the nest. These are impressed upon the memory and retained by it in a different manner, though this holds much more fully for the nest flight. The bumble-bee finds its way on the nest flight through the careful inspection of a few objects in the proximity of the nest or with the aid of the main points in memory. This inspection, as well as the correlated impression on the memory, can result only from the position of the body as taken on the return journey to the nest. The inspection of objects, which leaves recollections of their features, demands a special behavior, namely, a zig-zag flight near the object; objects not observed in this manner are not impressed on the memory of the bee. Such a zig-zag flight continues only so long as the bee can see the objects about the nest, which is within a radius of a meter at most. Beyond this sphere of vision lies one of orientation, which includes neither nest nor the small objects about it, but only such large ones as can be distinguished vaguely at a distance greater than 10 meters. Beyond this the flight back and forth is guided by the sense of direction. Even within the sphere of vision the sight of the bumble-bee is incomplete in so far as it distinguishes only a few guide-points, which are rather impressions of positions than of definite objects. As a consequence, only a decreasingly small portion of the way to and from its nest remains fixed in its memory, and hence the sense of direction plays an important rôle in the field flight and the return to the nest.

The homing of the mud-dauber wasp.-In studying the homing habits of the mud-dauber $(1908: 215)$, Turner noticed that the wasp never flew directly to its nest, but always alighted on a certain crack. It ascended this crack to the height of the nest and then turned and walked to the latter, its behavior suggesting that the crack served as a landmark. The method of experiment and the nature of the evidence may be obtained from the account of the first experiment:

\footnotetext{
"The lower shade of window number one was raised halfway and the top shade as far as it would go. While the wasp was out of the room all the blinds of windows number two to six were closed, except the upper shade of window number four, which was raised as far as possible.

"The wasp on entering through window number one flew obliquely upwards across the beam of light from window number four to the upper third of upright C. (This line of flight was convex towards the east.) It then flew vertically upwards almost to the ceiling, then leftward about a foot (this is a little more than the distance of the nest from upright B) and examined carefully the moulding. Not finding the nest, it began flying first to the right and then to the left in constantly elongating ellipses with very short minor axes. All this time it was carefully examining the moulding. Occasionally the mud-dauber would fly downward into the beam of light and then resume its search. In its lateral flights the wasp sometimes flew as far to the east as upright D and to the west almost as far as upright B. At the end of three minutes it had not found the nest, although under former conditions of illumination it required only half a minute to fly from window number one to the nest.
} 


\begin{abstract}
"While the wasp was still searching for the nest, the top shade of window number four was lowered and the corresponding shade of window number three raised as far as possible. This reproduced the conditions under which the wasp had originally worked. Almost immediately the wasp found the nest!

"From these experiments it is evident that in finding its way back to its nest, the muddauber is guided neither by what is known as a homing instinct nor by what Pieron has called a kinesthetic reflex; for if either assumption were true, a manipulation of the light should not have altered the wasp's behavior. Evidently light plays a prominent rôle in the homing of wasps, yet the behavior of the mud-dauber is not a phototropism, for in no case did the wasp so orient itself as to have the major axis of its body parallel to the rays of light. Neither is the wasp's behavior merely a reflex response either to brightness or to the direction of the rays of light; for if that were the case, in experiment six, when all the shades of windows number two to four were lowered except the top shade of window number two, the wasp should have flown, not to the wall to the west of window number three, but to window number two. But brightness is not the only factor which influences the movements of this wasp; else, when all the shades of windows number two to six were lowered, it would have been impossible for it to rediscover the nest. This series of experiments warrants the induction that, in the wasp's memory, the nest is located in a certain direction and at about a definite distance from a bright patch which is situated at a known elevation in a peculiar environment.

"The above statement predicates to wasps memory and an awareness of space relations. As to the existence of memory, these experiments furnish unequivocal evidence, and they warrant the conclusion that the flying mud-dauber, like the creeping ant, is guided by certain landmarks, and that light plays a prominent rôle in furnishing such landmarks."
\end{abstract}

Experiments on the orientation of bees in homing.-Frisch $(1914: 86)$ has summarized the results of others as to the practical value of painting hives in color and has contributed the details of some of his own experiments in this field. All of these support the conclusion that honey-bees, when their hive is set apart from the neighboring ones by means of color in a striking manner, utilize this as the chief means of orientation in finding their home. They further show that bees observe not only the color of their own hive, but also the color and relative position of neighboring ones. In consequence the bee-keeper can hardly devise a better and more certain way of enabling bees to locate their own hive than that of painting it in colors. For this, however, it is desirable to paint the entire outside and not merely the landing-board or the entrance. Care should be taken not to employ for neighboring hives colors that are distinct for our eyes but not for those of the bee, such as blue and purple, or black and scarlet-red. As a result, when hives are numerous, it is better to use color combinations for each, such as one-half red and the other yellow, rather than too many colors or shades which may merely be distinct to us.

Homing ability in Polistes.-The Raus (1918:273) have made a number of experiments on the homing ability of the wasp, Polistes pallipes, which they summarize as follows:

"Out of 33 queens which were taken for various distances from one-eighth mile to 2.7 miles, 24 returned to the nest. Of the 22 taken out for the first time, 17 reached home; of the 11 which had made previous test flights, 7 successfully returned. With the workers, the results were quite different. Of 112 workers that were used, only 28 returned, and those that returned did so only in the short flights. The long distance tests always gave negative results. Out of the 17 new workers that were experimented upon, none returned; of the 33 old workers, 14 came back; of the 62 workers of unknown age, 14 returned. According to the law of chance, it is easily possible that these 14 out of the 62 workers of unknown age may have been old ones. 
Previous experience is not necessary to successful flights; 27 successful returns out of 96 were made by wasps used for the first time, but only 1 out of 16 wasps that had previous flights made a successful second trip. Not one of the 17 males returned to their former nests, even though the distance for 16 of them was only one-eighth mile. The function of the antennæ is not the sole factor in bringing them home, for out of 24 mutilated wasps, 18 successfully returned. Thus, by the elimination of other faculties, the evidence grows stronger that vision is the sense whereby the insects regain their homes."

\section{SMELL.}

Sense of smell in insects deprived of antenna.-Forel $(1886: 184)$ insisted that the experiments of Graber (1885) with strong odors merely proved whether these were irritating or not to the insects concerned and that evidence of smell could be obtained only by causing the insect to recognize a certain substance and especially to distinguish it from others in a constant and indubitable manner. As an example, he cited the case of a swarm of males of Saturnia carpini that besieged the window of his room after some females had hatched out, which he regarded, together with many previous observations of others, as demonstrating in insects a special sense that corresponds to that in man. Further demonstration may be furnished by the removal of the antennae whenever the loss of these organs carries with it the loss of the sense of smell, as proved to be the case in many of the experiments he carried out.

When the antennæ were removed from individuals of four different genera of ants, they mingled readily without harming each other, and they recognized honey only when the mouth touched it by chance. If the antennæ were removed in Formica fusca and the ants placed in a globe with their larvæ, cocoons, and soil, they did not attempt the slightest digging or give the larvæ the least care. When ants of another species were added, they did them no harm, but when the anterior tarsi were cut off above the spine in the same species, they immediately killed other ants given them, and made futile efforts to dig and to care for the larvæ. A repetition of these experiments eight years later gave similar results, except in the case of Myrmica ruginodis, which killed other ants as well as its own kind. In the case of Sarcophaga vivipara with both eyes excised, the female readily found a dead mole on which it fed, but after the antennæ were removed, it paid no more attention to the mole, even when placed beside it. A blue fly which also fed upon the mole and deposited eggs in it paid no attention whatever to it after the antennæ had been removed, in spite of the use of its eyes. Two other individuals of Sarcophaga behaved in similar manner, while a very active Lucilia caesar, though placed on the mole, ceased eating and depositing eggs as soon as the antennæ were gone. In like manner, beetles of several genera were unable to rediscover putrid objects after the removal of the antennæ. Males of Bombyx mori, which perceived the females at a distance and ran to them directly, were no longer able to determine the direction of the female after the antennæ had been removed.

In an experiment with a wasp, Polistes gallicus, three individuals were employed, one having the antennæ removed, the second the front of the head with the sense-organs of the mouth, and the third was left intact. In repose the latter was able to recognize honey at a distance of a centi- 
meter and followed it as the pin covered with it was withdrawn. The second wasp behaved in identical fashion, though it was unable to sip the honey, while the first was absolutely unable to perceive the honey until the latter was put in contact with its mouth or to follow as it was moved away. To determine how acute the sense of smell is in bees, Forel placed some hungry honey-bees in a glass box with a drop of honey covered with a disk of wire screen with large meshes, through which the honey could be readily reached. In spite of this they walked back and forth over the screen, passing a hundred times within 2 or $3 \mathrm{~mm}$. of the honey, without stopping or suspecting the presence of the food they sought. As soon as the screen was removed, they found the honey by chance and sipped it with avidity. In agreement with Lubbock, it was concluded that honey-bees guide themselves almost exclusively by sight, their antennæ being very short, without clubs, and having olfactory terminations only on the internal dorsal face.

The following conclusions were deduced with reference to smell:

1. With many insects that guide themselves primarily by vision, as with dragonflies and cicadas, the antennæ are rudimentary and the sense of smell likewise. At night such insects are immobile and by day all their acts are guided by sight (the cicadas also perhaps by hearing).

2. The sense of smell, notwithstanding the objections and the experiments of Graber, resides in the antennæ, especially in the swollen or perfoliate part in which the antennal nerve ramifies.

3. With certain insects, especially the majority of the Diptera, the antennæ are stiff and probably serve solely or almost so as an organ of smell.

4. But with other insects they are mobile and serve at the same time to smell at a distance and to feel near at hand. This is true of Hymenoptera in the highest degree.

Forel's criticisms of Graber's results.-Emphasis was placed by Forel upon the fact that we regard as odorous substances those that are odorous for us, in spite of the fact that the study of animals shows enormous differences between them in this respect, a substance extremely odorous for one species being little or not at all for another. This general fact was recognized by Graber, but his simple and uniform method of experimentation failed to take account of it. Graber placed different insects in the middle of a box divided into two compartments open below. He put an odorous substance in the top of one of them and observed at the end of a certain time the number of insects in each part. He employed especially substances with strong and often corrosive emanations, and in many cases found that insects deprived of their antennæ behaved like normal ones. But this was not always the case, Asphodius, for example, ceasing to gather under cow-dung when the antennæ were removed. This was because Graber had made the proper choice, that of an substance sought by this insect in nature. Moreover, he finally stated that a certain degree of smell resided in the antennæ.

In the case of Lucilia caesar, Graber found that 169 normal flies collected under putrid meat, while 92 were found on the other side, but with the antennæ cut off the respective figures were 101 and 39 , which he thought proved irrefutably that they had smelled the meat without the aid 
of antennæ. Forel pointed out that the numbers were not sufficiently different to prove much, and this is confirmed by the fact that the respective percentages for meat were 64 and 72 . In addition, the odor of putrid meat in a box was regarded as sufficiently strong to provoke tactile or gustatory reactions quite apart from smell, while flies inclosed in a box are far from normal in their response. With Formica rufa, Graber found that essence of rose was not liked, 515 ants collecting in the empty division. and but 42 in that containing the essence, while with the antennæ cut off the respective numbers were 299 and 165, figures which Forel regarded as insufficient to prove that ants have other organs of smell than antennæ. However this may be, he declared that Graber had absolutely not proved that ants with or without antennæ were in a state to recognize the essence of rose as such, to distinguish it from another substance, or to find it when hidden. Finally, in another place Graber seemed to be of the opinion that these responses were rather of the nature of reaction to irritation than smell. In the case of Silpha thoracica, while essence of rosemary quickly produced a reaction in the absence of antennæ, asafetida did not, but with the antennæ present the response to both was equally prompt.

In summarizing, Forel declared that the experiments of Graber exhibited a very superficial knowledge of the habits of insects, often lacked controls, and were too little varied, and that the means and the reagents employed were frequently too strong and took no account of the habits or needs of each species. Moreover, after seeking the location of the sense of smell in various places in contradictory fashion, Graber finally stated that "there are insects in which the antennæ play a preponderant rôle in the distinction of weaker odors, food, etc."

In a later paper $(1887: 13)$ Graber himself stated that the stronger odors usually repel insects and that this response is not due to the sense of smell, but to a generally very painful excitation of the sense of feel, which is often extraordinarily developed. As a consequence of a number of carefully controlled experiments, he reached the conclusion that Plateau's results with the cockroach (1876) were untrustworthy, though he was able to confirm the statement that the sense of smell is located in the antennæ.

Hauser's experiments.-Hauser $(1880: 367)$ determined the effect of removing the antennæ in a wide range of insects from beetles to bees. The loss of the antennæ caused many individuals to become sick and die, though some lived for weeks afterward. Coating the antennæ with paraffin gave the same results as extirpation. Beetles made no response to a clean glass-rod, but when this was dipped in carbolic acid, the effect was noticed at 4 inches and the insect moved away quickly as the rod was brought nearer. It reacted even more strongly to turpentine and acetic acid. The experiments were repeated on the second day after the removal of the antennæ, but no response occurred. This was in spite of the fact that the beetles ate more heartily after the operation and some lived more than two months. Species of various genera gave similar results, but a few continued to respond slightly. Beetles of the genus Silpha lost the power of finding putrid meat after the amputation of the antennæ, and the same result was obtained with different species of flies. Male and 
female beetles or butterflies that mated freely when normal did so only occasionally after the antennæ were lost.

Olfactory pores.-Hicks (1857-1860) was the first to discover the pores now termed olfactory by McIndoo, who summarizes the former's results as follows $\left(1914^{2}: 38\right)$.

"To summarize Hicks's three papers, he discovered these pores on the halteres and on the bases of the wings of all Diptera examined; on the bases of all four wings of the four-winged tribes; on the trochanter and femur of all insects, and occasionally on the tibia. He examined many species representing various insect orders and found the pores even on the lower insects, such as the earwig. In such wingless insects as the worker and soldier ants, he infers that these pores are much more abundant on the legs than they are on these appendages in the winged insects. Hicks suggested an olfactory function for all of these pores, whether on the wings or legs, but he performed no experiments of any kind. In regard to smell in insects and the function of the pores on the legs, he says: 'The delicacy with which odors are perceived by many insects argues an olfactory apparatus of considerable perfection; and it seems to me not impossible that these latter-named organs (those on the legs) may be in some way connected with the sense of smell, or perhaps with some sense not to be found in the Vertebrata."'

McIndoo mentions the work of about a dozen other investigators on these pores, two of whom regarded them as olfactory in function.

McIndoo's own studies (1914) of the pores are much the most detailed and comprehensive, and his experiments upon their function appear to be the most extensive in the entire field of olfaction. The Hicks vesicles or olfactory pores consist of inverted flasks in the chitin and of fusiform sense-cells lying beneath the mouths of the flasks. The sense fiber pierces the bottom of the cone and enters the pore aperture, thus coming in direct contact with the air containing odorous particles, contrary to the condition in the antennæ, where the odors must pass through a hard membrane in order to stimulate the sense-cells. In the case of the honey-bee the pores are found on the bases of the wings, on the legs, and on the sting of worker and queen. They also occur on the mouth-parts of all Hymenoptera, while they are lacking on the antennæ of the honey-bee and probably all other Hymenoptera. For the legs of ants the number varies from 211 to 356 and for the winged ants the total number varies from 463 to 1,090 . In the honey-bee the queen has an average of 1,860 , the worker 2,268 , and the drone 2,604 ; the averages for all four wings are $1,310,1,510$, and 1,998, and for all six legs, 450,658, and 606 respectively, the sting having an average of 100 . The total number for a bumble-bee was 1,627 and for a wasp 1,957; the number of isolated pores is approximately one-half the number in groups, except in the worker honey-bee, where it is somewhat less.

Experiments with antennæ removed, mutilated, or coated.McIndoo (1914: 291) finds that worker bees with the left antennæ pulled off at the base reacted to the three essential oils, peppermint, thyme, and wintergreen, in an average of 4.6 seconds in contrast to 2.3 seconds for intact individuals. When 2 to 8 joints of the other antennæ were removed, the reaction-time rose proportionately from 15 seconds for the first case and 88 for the last. Bees with both antennæ pulled off or covered with celloidin failed entirely to respond to these oils. Drones with 4 or 5 joints of one 
flagellum missing responded to 6 of the 10 odors used in an average reaction-time of 3.16 seconds in contrast to 2.9 seconds for unmutilated ones. When both antennæ were removed from workers, none responded to oil of peppermint held within a half inch or to smoke, while all the normal bees reacted quickly and markedly. Similar experiments with other oils yielded no reaction in the case of 50 mutilated bees, though the normal ones never failed to react.

In the case of immature bees the results were quite different. When both the antennæ of workers were burned off, they responded readily to the three essential oils by moving slightly and vibrating the stubs of the antennæ. Frequently, however, they did not react to odors or anything else. When the antennæ were covered with glue and the tarsi of the front legs burned off to prevent the removal of the glue, most of the bees died in a few days, but a score were fairly normal and responded to the oils without failure.

\section{Experiments with wings, legs, and stings mutilated.-}

"To determine the function of these pores, the wings, legs, and stings of many worker bees were mutilated (McIndoo, 1914: 47 ). The behavior of the mutilated bees was carefully studied, and they were tested with odors in the same manner as were the unmutilated ones. The stings of 100 workers were pulled out. These bees lived 30 hours on an average. Twenty of them were tested with odors. They responded only slightly more slowly than unmutilated bees. The wings of 28 workers were pulled off. When tested with odors, these bees responded one-eighth as rapidly as normal bees. The bases of the wings of 20 workers were covered with liquid glue. When tested, these bees also responded one-eighth as rapidly as unmutilated ones. The pores on the legs of 20 workers were covered with a mixture of beeswax and vaseline. When tested, these bees responded two-fifths as rapidly as unmutilated workers. The wings were pulled off and the pores on the legs of 20 workers were covered with the beeswax-vaseline mixture. When tested with odors, these responded one-twelfth as rapidly as unmutilated ones. All of the workers with mutilated wings and legs lived just as long in the observation cages as did unmutilated workers, and they were absolutely normal in all respects, except that they reacted to odors more slowly."

With the oils and other odors four dealated females of Formica gave a reaction-time of 2.89 seconds in contrast to 2.45 seconds for winged females of the same species. Pulling off the wings of 7 males removed 92 per cent of the pores and increased the reaction-time from 2.63 to 3.6 seconds. When the wing bases of female ants were covered with liquid glue and the legs with beeswax-vaseline mixture, the reaction-time was about doubled, and similar results were obtained with Camponotus. When males of the latter had the wings pulled off, leaving but 12 per cent of the pores, they gave a reaction-time of 3.49 seconds, which is one and a fourth times that of the normal insects. Worker hornets similarly treated gave nearly thrice the reaction-time for normal ones.

\section{McIndoo's criticisms of experiments with deantennate insects.-}

"The following criticisms concerning the physiological experiments performed with the antennæ of the various insects may be offered $\left(1914: 342,1914^{3}: 54\right)$. Most of the previous investigators have studied the behavior of the insects investigated in captivity for only a short time, while the remainder have paid no attention at all to the behavior of their unmutilated insects. They cut off either a few joints of both 
antennæ, or these entire appendages, or varnished them with paraffin, rubber, and so forth. When a few joints are severed, the sense of smell is apparently weakened. This is true for bees also. When both antennæ are amputated or varnished, the insects as a rule fail to respond to substances which normally affect the olfactory sense. They generally fail to respond to odors held near them and fail to find food in captivity, and do not return to putrid meat and dead bodies when removed from such food. Males so mutilated as a rule do not seek females and show no responses when females are placed near them. Such experiments were seriously criticised until Hauser in 1880 presented his apparently conclusive results. Many of the insects on which he experimented with the antennæ amputated became sick and soon died. Most of them failed to respond when the antennæ were mutilated, although Carabus, Melolontha, and Silpha responded slightly, while all the Hemiptera that he used responded almost as well with their antennæ off as they did with them intact. Only 40 per cent of the ants from which Miss Fielde cut the antennae recovered from the effect of the shock. Not one of these observers has studied the behavior of the species under observation sufficiently to know exactly how long they live in captivity with their antennae either intact or mutilated. No one, except Miss Fielde, has kept a record of the death of the mutilated and normal insects so accurate that one might know what percentage died from the operation. To cut off some other appendage or even the lower part of the head, as Forel did, is not a fair test, because such operations seldom expose sense-cells and never any nerve equal in size to that of the antennæ, unless one pulls off the wings. When the wings are pulled off, the large nerve is severed between the masses of sense-cells and the thorax, and the sense-cells are not exposed to the air, as they are when antennæ are removed. Even if the antennæ are cut through the scape, the large masses of sense cells belonging to Johnston's organs are severed. When the lower part of the head or the tarsi are cut off, as Forel did, no nerves are exposed to the air except ends of small nerves. From the foregoing it is only reasonable to assume that when the antennæ of any insect are injured in the least degree, the insect is no longer normal and if it fails to respond to odors placed near it, this negative response may be due to the shock of the injury."

Present status as to the seat of the olfactory sense.-In spite of the obvious merits of McIndoo's studies, it is evident that further investigations will be necessary to decide the respective claims of the antennæ and the olfactory pores as the organs of smell. The results of more than a score of investigators, some of them, such as Forel, Graber, Hauser, and Plateau, of the first rank, are in accord as to the olfactory function of the antennæ, and it is certain that their conclusions can not be rejected without a repetition of their most decisive experiments. On the other hand, many of McIndoo's are similarly decisive, and at present it seems quite possible that both antennæ and pores have to do with smell. The burden of proof rests upon the latter, however, since they lack the confirmation given by successive investigators to the function of the antennæ. McIndoo has given a practically complete list of those who have based their conclusion as to the olfactory function of the antennæ upon experimental evidence $\left(1914^{3}: 14\right)$. They are Dugés (1838), Lefebvre (1838), Küster (1844), Perris (1850), Cornalia (1856), Dönhoff (1861), Balbiani (1866), Forel (1874, 1878, 1886, 1901), Trouvelot (1877), Layard (1878), Slater (1878), Chatin (1880), Hauser (1880), Porter (1883), Graber (1885, 1887), Plateau (1886, 1902), Dubois (1895), Mayor (1900), Gorka (1900), Fielde (1901, 1903), Barrows (1907), and Kellogg (1907). The most extensive and significant studies have been those of Forel, Hauser, Graber, 
Plateau, and Mayor, since the extirpation of the antennæ in most cases destroyed the sense of smell without rendering the insects otherwise abnormal. Graber's second series of experiments is especially important, since they led him to abandon his former view that the antennæ were not olfactory organs. (See also Schenk, 1903: 573.)

A scrutiny of McIndoo's conclusions shows that they are not in entire accord, though this may be due to a desire to avoid overstatement. The statements concerned are as follows:

"These results indicate that the olfactory organs are located elsewhere. At most it can be claimed only that the antennæ may assist in the receiving of odor stimuli" (1914: 297). "It may now be assumed that these pores constitute the olfactory organs in the honey-bee, and perhaps in insects in general" (Ib., 341). "Then it will be realized that the antennæ can no longer be regarded as the seat of the sense of smell in insects" (Ib. 345). "In conclusion, it seems that the organs called olfactory pores by the author are the true olfactory apparatus in Hymenoptera and possibly in all insects and that the antennæ play no part in receiving odor stimuli" $\left(1914^{3}: 56\right)$.

The mature bees used in experiments with the antennæ cut off gave either greatly delayed reactions or none at all, but when these were burned off, the reaction-time was but slightly increased. However, the latter lived an average of $51 / 2$ days, while the former in some cases lived an equal period, indicating that both were equally abnormal and that the discrepancy must be sought elsewhere. Forel long ago criticized Graber's results because of the strong odors employed, insisting that natural odors to which the various insects are accustomed should be used, and this objection may hold in some measure for the essential oils. Moreover, it seems possible that reactiontime experiments do not furnish such decisive tests as those made by Forel, Hauser, Mayor, and others. Furthermore, the use of a stop-watch would appear almost imperative, especially for short intervals.

McIndoo frequently finds a relation between the number of pores and the reaction-time. "If the reaction-time of each caste of the honey-bee is compared with the total number of olfactory pores, a consistent ratio is obtained. A drone has 2,600 pores and responds in 2.9 seconds; a worker posesses 2,200 pores and responds in 3.4 seconds, and a queen has 1,800 pores and responds in 4.9 seconds." This, however, is only a qualitative relation, since the worker with 400 pores less than the drone requires but 0.5 second longer, while the queen with 800 pores less takes 2 seconds longer. The absence of a definite quantitative relation is further shown by the fact that removing the wings of workers with 1,510 pores increased the reaction-time 8 times, while coating the 658 pores of the legs increased it but 2.5 times. Finally, although wasps are generally regarded as having a keener sense of smell than bees, the one species studied possessed only 1,957 pores.

On theoretical grounds it is difficult to reconcile the large number of pores and their distribution with the high development of the sense of smell in insects. This is often much more highly developed than vision, and one would expect a highly differentiated organ to correspond and one in immediate connection with the "brain," as is the compound eye. On the contrary, there are hundreds of pores, some of them as far away from the central ganglion as possible and several times as far as others. Moreover, 
their position on the tarsi and the sting casts grave doubt upon their effectiveness as olfactory pores. Their localization on the bases of the wings, the legs, and the sting suggests that they have to do with the sense of touch or feel in the wide sense and that their response to chemical stimuli is somewhat similar to that of all exposed nerve-ends. ${ }^{*}$ However, it is idle to speculate upon this until the results of new investigations, which take into account the experiments of both McIndoo and his predecessors, are made available.

Turner (1916:385) states: "These experiments of McIndoo are painstaking and his anatomical studies of what he calls olfactory pores are excellent, but the serious student, who is acquainted with the experiments of Forel and others who 'claim that the antennae are the organs of smell' will not be convinced that the last word has been said on the subject. They do not seem to have met the criticisms raised by Forel" (1878, 1886, 1908), as indicated above.

\section{INTELLIGENCE.}

Relation between the senses and mental faculties of insects.Forel (1886:233) considered that insects possess our five senses, with the possible exception of hearing, in a well-differentiated degree and with a special energy that we consider analogous to our own. The quality of their vision is different from that of ours in certain respects, as certain of them see the ultra-violet rays. Many insects have besides a kind of odor by contact, which enables the ants in particular to distinguish their companions from enemies. The development of each sense and of each of its kinds of special energy (color, odor) varies enormously, not only for families and genera, but even with related species and with the sexes of the same species. Insects naturally combine their different senses in their acts, but in general the principal sense is that of direction, just as sight is with man. Sight assumes this rôle with the aerial insects, especially the dragon-flies and the butterflies. With the workers among ants, it is in general smell, with the spiders, touch, and with the beetles it is touch and taste combined.

It is evident that insects possess the faculty of the so-called voluntary movements which are not merely reflex or simply automatic, but very well coordinated and nearly all dictated by combinations of instinctive reason with the aid of sensory impressions, and admirably adapted to their end. They frequently have an excellent memory of places, of things, and perhaps of persons. Thus, insects reason, and the most intelligent of them, the social Hymenoptera, reason much more than one thinks when he observes the mechanism due to instinct, but to properly observe and comprehend these reasoning processes, it is necessary to put instinct out of commission. Instinct is organized, systematized, and automatic reasoning, that is, it has become unconscious. Instinct and reason are not in inverse proportion to each other, as Pouchet has remarked, and the insects with the most intelligence are generally those with the largest number of varied instincts, though this is not always true. Finally, insects exhibit passions that are more or less bound up with their instincts, and these vary enor-

\footnotetext{
* Since this was written, it has been found that Graber ascribed the sensitiveness of the "afterborsten" and the legs to relatively strong odors to the sense of feel and not to that of smell.
} 
mously with the species. Among the ants the traits of character recognizable are anger, hate, devotion, activity, perseverance, greediness, boldness, discouragement, and fear. Thus, in studying the habits of insects it is necessary to take into consideration their mental faculties as well as their organs of sense.

Memory and general intelligence of wasps.-The Peckhams (1887:121) concluded that wasps have a very good memory, remembering for ten days the characteristics of the glass of a window through which they were accustomed to fly. The memory varied greatly in different individuals; in the color experiments many wasps would fly into the false entrance several times, while others would fly in but once, and still others would only hover over it before turning to the true opening. When blades of grass were placed across the entrance to the nest, not one of more than 300 wasps made any attempt to remove them, in spite of the fact that they seriously hindered them and were less than a usual load in weight. Even when going out without loads no endeavor was made to get rid of the obstacle. They noted two classes of intelligent action among the Hymenoptera, which are sufficiently distinct to be considered separately (1905:301). The first includes those acts performed by large numbers in a similar fashion under like conditions, while in the second each act is an individual affair. The first is exemplified by Fabre's experiment with Osmia, in which he took 2 dozen nests in shells from a quarry, where the bees had been nesting for centuries, and placed them in his study along with some empty shells and hollow stems. When the bees came out in the spring, nearly all chose the stalks as better suited to build in than the shells, thus evidencing an intelligent adaptation to new conditions. The second case is illustrated by a wasp (Pompilus scelestus) which tried to drag its prey into the opening of a nest that was too small. After several vain tugs, it was carried to a place of safety up among some clover blossoms, and after some fifteen minutes of walking and brushing herself, the wasp set about making the hole larger. During this period she must have carried in mind the idea of doing a necessary act outside of the ordinary routine, and it is also suggestive that the hole when enlarged was exactly what was needed.

Memory of place in bees.-In an extended critique of Bethe's paper (1898:15) which endeavored to establish the hypothesis that bees are merely reflex machines, Buttel-Reepen $(1900: 96,1907)$ discussed the evidence chiefly under three heads, namely, (1) the hive odor and the reactions resulting from it, (2) the means of communication in bees, and (3) memory of place in bees. The latter alone is directly connected with the present inquiry and hence summarized here. Bethe assumed that-

\footnotetext{
"Bees are led back to the hive by a force entirely unknown to us. This force does not adhere to the hive itself, and it does not lead bees back to the hive itself, but to the place in space which the hive usually occupies. It does not act at boundless distances. It is an old experience of bee-keepers that they can take a colony to another stand without fearing that the bees will return to the old place, if the new spot is only more than six kilometers from the old. It follows, then, that this force acts at most at a distance of six kilometers, since the impulse to return to the hive is the strongest of all impulses in bees. But I believe that the zone of action of the force is not a
} 
circle with a radius of six kilometers, but of only three or four kilometers. If the circle had had a radius of six kilometers, then the bees of the transposed hive would be back into the circle of action if they got more than half that distance near the old position in foraging, and would have to return to the old place. But this only happens if the old position is less than six kilometers away from the new. We must; therefore, accept something near three kilometers as the boundary for this circle of action for this force."

When Bethe freed 8 marked bees at each of three distances from the hive, namely, 350,400 , and 650 meters, they found their way back in 1.5 to 3.5 , 5 to 10 , and 4.75 to 10.5 minutes respectively. Buttel pointed out that at the normal velocity for bees, doubled because they were carrying loads, the unknown force should have led them all back in 1 minute 12 seconds, 1 minute 36 seconds, and 2 minutes 36 seconds, for the respective distances. This discrepancy can only be explained on the assumption that the bees had to orient themselves with their eyes and that they made errors in doing so, and thus lost time. Since the unknown force does not bring bees back to the hive but only to the place where it stands or usually stood, it must be memory of location. When bees are stupefied with chloroform, ether, saltpeter, etc., memory of location entirely disappears, and they no longer recognize their home or the place where it stands. As soon as they become normal, they again begin to orient themselves with regard to the home, gathering new memory pictures of the sources of nectar and pollen as well as of the new hive. This also shows their capacity for learning, a fact disputed by Bethe. Buttel also emphasizes the discrepancy between Bethe's assumption that all the bees set free within the circle of action of the "unknown force" must return to the place that "draws them like a magnet," and the actual results obtained by him in the box experiment. When the bees were released from the box, most of them, after a few circles in the air, went in the direction of the institute, but "two mounted to a height of about 3 meters, made a few circles of 4 or 5 meters in diameter, and then alighted on the box. I drove them away into the air again. They flew in large circles about it, and then again alighted on the box. I then took the box away and put it on another stone, having driven the bees into the air once more. Both bees flew so high that I could no longer see them, but a few seconds later they reappeared and slowly flew about the place where the box had stood." Thus some bees were influenced by the "unknown force" and others were not, a fact that Bethe did not attempt to explain. Buttel carried out similar experiments with the same results and all of them furnished evidence of memory for locality, though he regarded the conditions as abnormal in comparison with those carried on at the apiary. Although Bethe gave no explanation of why the "unknown force" operates at a distance of but 3 or $4 \mathrm{~km}$., it is really very simple, since this supposedly mysterious force operates only within the space in which the bees have made flights of orientation and stored up memory pictures.

The identity of this unknown force with memory of location is further proved by the following facts: If young bees are let fly not far from the apiary before they have had their flight of orientation, none of them find their way back to the hive, but if old bees are released at a much greater distance they all return. If a colony is brought from a place more than 
7 kilometers away and the old bees released only 30 or 40 meters from the hive before they have been able to make their flight of orientation, none find their way back in case trees or houses intervene. Memory of locality may be lost through artificial swarming, by the influence of buckwheat honey; by the effect of dark or cold; by throwing bees into water, and by the lapse of time. Memories also disappear quickly by new impressions obliterating the old. In their first flight from the hive, bees turn their heads toward the latter and survey the hive, the neighboring hives, and the general surroundings. After this short preliminary flight, small and then larger orientation flights are taken and the landmarks impressed on the memory. It is evident that bees also orient themselves in special ways. If the height of a hive is changed so that the entrance is suddenly made $30 \mathrm{~cm}$. higher or lower, the bees fly exactly to the level where the entrance was before, and hours or even days pass before a smooth flight is made to the new height. The ability to judge distances even goes so far that bees normally fly in and out of the same corner of the hive-entrance. If the entrance is closed to about the breadth of an inch, they will try to enter at the usual spots and find the open part only after considerable search. A bee flies to the point of entrance without being able to see it or the nearest surroundings of the entrance, on the basis of its orientation in the neighborhood. As it comes closer, it generally notices the surroundings of the entrance, for it becomes aware of any changes in the outside of the hive.

Forel $(1900,1908: 217)$ has dealt with Bethe's results and conclusions in similar detail. He says:

"When writing the preceding, I was ignorant of the work of Buttel-Reepen. If on the one hand I regret it, on the other it has the advantage of having rendered my criticism of Bethe independent of his, and the reader of both will be astonished to see to what extent our results agree.

"I am obliged to combat Bethe's conclusions as preconceived, one-sided, and of an absolutism quite contrary to logic and the scientific spirit."

Memory of time and association of impressions. - Buttel-Reepen stated that where colonies stand in fields of buckwheat the flight is lively until about 10 o'clock, then becomes entirely quiet for the rest of the day, to begin again vigorously the next morning. Buckwheat nectar is abundant only in the early morning; as the nectaries dry up, the bees fly out once or twice and then cease their vain flight. In spite of the sea of flowers and the strong fragrance, few bees are found in the field after 10 o'clock. Regardless of the constant attraction of color and scent and the habit of daily flight to the fields, the processes of learning and remembering play the directive rôle.

Association of impressions is illustrated by the behavior of bees that found a honeycomb in a room, after flying through the open window. More and more came, some of them being kept out at the second window, which was closed. To prevent this the honeycomb was placed in the open window, and a half-hour later the bees were driven away and the window closed. Twenty minutes later the room above, the windows of which were open, was found full of bees. In order to observe their behavior accurately, the bees were driven out, the windows closed, and Buttel went into the garden. Here the bees were seen trying to enter at the window from which they had been 
fed, then flying to the next window and afterward to the other windows until they had tried them all. It was then assumed that the existence of an actual association of honey with the form of a window would lead them to extend the search to the neighboring house, which they did. He also cited in confirmation the observation that, when a dish of honey is placed on the trunk of a tree, bees afterward search for honey at the same place on all the trees in the neighborhood.

Memory of time and memory association in honey-bees.-Forel (1907:459) reported the behavior of bees which were led to visit an out-door dining table, on which it was the habit to place preserves at breakfast, from $7^{\mathrm{h}} 30^{\mathrm{m}}$ to $9^{\mathrm{h}} 30^{\mathrm{m}}$ a. m., and at tea, from 4 to $5 \mathrm{p}$. m. Drawn by the odor of cooked cherries, one or two bees first found the preserves and in a day or two a whole swarm came to feast on them. However, after having sought for them at mid-day also and having found nothing, they entirely ceased coming at this time and confined their visits to the hours of breakfast and tea. After this habit had been confirmed, the table was set as for breakfast, but no preserves were placed on it. A large number of bees came to it as usual and searched everything in vain. They stopped coming at 10 o'clock and only a single one appeared at noon and but one or two at 4 o'clock. The next morning a much smaller number than usual was observed and they did not stay long. More appeared at noon than before, as if driven to make the search for the sweets at other hours. When they returned at 4 o'clock they were given some preserves, and this led others to come. The next day the same behavior occurred at breakfast time, the bees flying against an inverted glass containing preserves but paying no attention to the edge where the odor could be perceived. At 10 o'clock all had again disappeared. After several days a supply of sirup and preserves was made constantly available, and the bees ceased to come at stated hours. These facts were regarded as clearly proving that bees not only have place memory but also that of time. In short, they returned to the same place and examined the same or similar objects only at the hours when they had found them before, and, after several deceptions, but once at mid-day, the hour at which they found nothing. Bees were found peculiarly adapted to the experiment on account of their poor sense of smell, visual and gustatory memory operating alone. The visual memory of colors and forms guided them and also enabled them to distinguish the preserve container and similar objects, the sense of smell coming into action at the very short distance of $1 \mathrm{~cm}$.

Intelligence of honey-bees.-In his conclusions (1907:44) ButtelReepen stated:

"It is unquestionable to me that the senses of bees are similar to those of men, and that especially the senses of sight, hearing, and smell play an important part. As Wundt has already shown, we certainly are 'referred essentially to outer observations in animals; what they teach us is not a total dissimilarity in the capacity of mind, but the most essential conformity with the psychic processes that we observe in man, and know chiefly from observation of ourselves.' The anthropomorphic apprehension relative to the question of consciousness has brought it about that there has been ascribed to bees a consciousness similar to human consciousness, and accordingly 
the most varied human feelings. On the basis of my observations I am of the opinion that bees possess either no consciousness at all, or one of only the lowest degree of development. The question of consciousness is left to subjective estimates, but the question whether an animal learns and can acquire experience or not may be determined objectively. We see that bees show signs of an admirable memory in their orientation and also in other activities; further I believe I have shown that the bee possesses a perception for color and form, and develops a rich capacity for communication by means of its well-developed 'language'; that, further, it is able to gather experiences, to learn and to form associations of impressions, etc. I can not agree with Bethe, therefore, in his denial that the bee has capacity to gather experience and thereby to modify its action. The bee is evidently much more than a reflex machine."

The psychic powers of insects.-Forel summed up his conclusions as to the intelligence of insects as follows $(1901: 25 ; 1904: 20 ; 1908)$ :

"It ensues from the concordant observations of all the experts that sensation, perception, association, inference, memory, and habit in the social insects follow the same fundamental laws as in the vertebrates and ourselves. Moreover, attention is strikingly developed in insects, often assuming the nature of an obsession that is hard to divert. On the other hand, inherited automatism manifests an immense preponderance, and the faculties mentioned are exhibited in but excecdingly feeble form beyond the limits of the instinct-automatism fixed in the species.

"The senses of insects are our own. Only the sense of hearing remains doubtful in so far as its location and interpretation are concerned. A sixth sense has not yet been shown to exist, and a special sense of direction and orientation is certainly lacking. Reflexes, instincts, and plastic individually adaptive central nervous activities pass over into one another by gradations. Without becoming antagonistic, the central nervous activity in the different groups and species of animals becomes complicated in two fashions: (1) through inheritance by natural selection, etc., of complex purposeful automatic responses, or instincts; (2) through the manifold possibilities of plastic, individually adaptive activities, in combination with the faculty of gradually developing secondary individual automatic responses, or habits. In social insects the correlation of more developed psychic powers with the volume of the brain may be directly observed. In these animals it is possible to demonstrate the existence of memory, associations of sensory images, perception, attention, habits, simple powers of inference from analogy, the utilization of individual experiences and hence distinct, though feeble, plastic individual deliberations or adaptations.

"It is also possible to detect a corresponding, simpler form of volition, i. e., the carrying out of individual decisions in a more or less protracted time sequence, through different concatenations of instincts; furthermore different kinds of discomfort and pleasure emotions, as well as interaction and antagonisms between these diverse psychic powers. In insect behavior the activity of the attention is one-sided and occupies a prominent place. It narrows the scope of behavior and renders the animal temporarily unresponsive to other sense-impressions.

"Even to-day I am compelled to uphold the seventh thesis which I established in 1877 in my habilitation as privat-docent in the University of Munich: 'All the properties of the human mind may be derived from the properties of the animal mind.' I would merely add to this: 'And all the mental attributes of higher animals may be derived from those of lower animals.' In other words: The doctrine of evolution is quite as valid in the province of psychology as it is in all the other provinces of organic life. Notwithstanding all the differences presented by animal organisms and the conditions of their existence, the psychic functions of the nerve-elements seem nevertheless to be everywhere in accord with certain fundamental laws, even where this would be least expected on account of the magnitude of the differences." 


\section{GENERAL RÉSUMÉ.}

TREATMENT.

Plateau focussed attention so exclusively upon attraction that it has remained the chief theme of experimental pollination for 45 years. While the present series of studies has endeavored to deal with the whole field in a more comprehensive fashion, attraction is necessarily the central theme of a resume that attempts to summarize all the experimental results in brief. This is considered with respect to color, odor, form and size, distant and near attraction, and competition. The first is discussed under the captions of mutilation, artificial flowers, painted flowers, inclosing in glass, green and showy nectarless flowers, color preference, and the second under those of masking and concealing flowers, honey, perfumes and scents, and relative values. The remaining major divisions are learning and habit, memory and intelligence. For the treatment of these there is much less definite and accurate experimental material, and an adequate exposition of them must await extensive experimentation under the quantitative conditions afforded by control and measurement.

\section{ATTRACTION.}

COLOR.

Mutilation.-Here it is necessary to take into account only those experiments in which the corolla, perianth, ray-flowers, or bracts were removed or reduced in expanse by shortening or otherwise. Covering the attractive part produced essentially the same effect, but such cases are considered under masking or artificial flowers in accordance with the device employed. In Plateau's first experiments with decorollate flowers (1896), his results in general failed to confirm his conclusion as to the insignificant rôle of the corolla in attraction. In the case of several species of flowers and insects, the mutilated flowers were visited less than the normal, for example, $24: 44,4: 10,250: 330$, and 16 inspections to 29 , and in others no comparison was possible because the visits to normal flowers were not noted. Moreover, no account was taken of habit and the effect of removing the corolla on the diffusion of the odor, especially of the nectar. In the studies of decorollate poppies $\left(1902^{3}\right)$, he obtained an average of 4.5 visits to the mutilated flowers to 3.4 for the normal. These were wholly exceptional and are negatived by the results of all other workers. They serve to illustrate the variations in behavior that may be expected, but in this case they are doubtless to be explained on the basis of habit and accessibility.

In working with decorollate poppies and geraniums (1904), Giltay regularly obtained such ratios between normal and mutilated flowers as $96: 9$, and $38: 1$, while in the later studies of 1906, the intact flowers were always much more visited likewise. On the second day of an installation, the ability of the bees to learn changed such ratios as 15:0 and 12:0 to 18:13, but they were rarely if ever reversed. Similarly, Schröder (1901) secured ratios of $37: 0$ and 21:4 with Syritta pipiens on the first day, but by the second day experience increased the visits to the mutilated to almost half, viz, 19 to 46 . Andreae (1903) found decorollate flowers to be several times less attractive than normal ones (3:24), and Errera (1904), about half as 
attractive (24:46). Wery (1904) regularly obtained more visits to the normal flowers; the difference was often small with a heterogeneous group of visitors, such as $19: 13,27: 24,43: 27$, but when the honey-bees alone were counted the ratios were 11:6, 29:10, and 20:6. The totals for one series was 138 normal and 46 mutilated for all visitors, and 72 to 28 for the bees. Detto (1905) observed that the removal of the corolla stopped visits completely, and that replacing the petals caused them to be resumed. Lovell (1909) secured decisive results as a rule by the removal of the corolla, as shown by the following ratios for normal and mutilated, 15:0, 12:0, 7:0, and 12:1. In Allard's experiments (1911) the loss of the corolla caused the inspections to drop from 81 to 4 , while a single petal received 16 inspections to 26 for the normal. Placing a single petal on a decorollate flower yielded 8 inspections to 9 for such a petal pinned to a stem and 27 for the normal; replacing the petals regularly brought the inspections back to the usual number.

In the present studies, the removal of the corolla has rarely eliminated visitors entirely, but it has usually decreased them from three to ten times, depending upon the flower and the habit of the visitors. Reducing the size of the corolla was somewhat less effective as a rule, the decrease ranging from a half to a tenth. With both lips removed in Monarda, visits were reduced to a fortieth of the total for all mutilations and with the lower lip gone, to a tenth. The most striking exception occurred in Chamaenerium, where the excision of all the flower parts but the ovary and nectar ring resulted in nearly 5 times as many visitors and visits as to the normal. This was apparently due to the marked effect of habit in responses to this flower, as well as to the exposure of the nectar. This probably also explains the discrepancy involved in Detto's results, in which the reduction of the corolla was without effect. Experiments with newly hatched insects will be required to evaluate the effect of habit, but practically all the existing experimental results are in accord in demonstrating that the loss or reduction of the corolla has a significant and usually a decisive effect in decreasing visitors and visits. This applies with greatest force to the bees, and is somewhat modified by the type of flower and especially its fragrance.

Artificial flowers.-Plateau devoted four papers to the attraction exerted by artificial flowers, in which he insisted upon the perfection of his imitations and ascribed the abundant visits obtained by other investigators to the presence of materials attractive by their odor or to imperfections in the method. Neither the presence of attractive substances nor the effect of habit can explain the frequent initial visits obtained by the great majority of workers, and the proper explanation seems to be that of the variation to be expected in consequence of differences in time, place or installation. In his preliminary studies (1877), Plateau obtained few visits to artificial flowers and these were made chiefly by butterflies, but visits and inspections were much more numerous in the experiments of 1897, though as a rule far below those to normal flowers. Bombus gave 4 inspections out of 10 to imitations, Anthidium 11 out of 38 , and Megachile 10 out of 17 ; in some cases of those reported in the series of 1906, artificial flowers received as many as 8 visits and 7 inspections to 15 visits to normal ones. Forel agreed with Plateau's conclusions as to the ineffectiveness of artificial flowers, but his results likewise were not at all in harmony with each other. Bees dis- 
dained imitations placed in the midst of dahlias, but visited artefacts of Petunia and Hieracium. Moreover, it proved possible to train bees to come to artificial flowers and ignore the dahlias.

Reeker (1898) found that artificial flowers were visited so regularly and frequently when placed at 6 to 12 meters from the natural ones that he found it undesirable to carry his experiments further, and Schröder (1901) induced Syritta to visit them almost as abundantly as the normal by the addition of honey. In an admirable series of experiments that rivaled those of Plateau, Andreae (1903) obtained numerous visits to artificial flowers, in one instance 81 visits being made to the latter and but 56 to the normal. In the competition between color and odor as represented by artificial flowers on one hand and masked natural ones on the other, the results were uniformly in favor of the former, as shown by such ratios as $55: 1,41: 0,31: 1$, and 28:3. Wery's results (1904) were equally conclusive, the artificial flowers often equaling or exceeding the normal ones in attractiveness and regularly surpassing honey in this respect. They attracted honey-bees readily and to the same degree as normal flowers placed in a globe. Lovell (1912) employed dry yellow immortelles in competition with honey, and obtained three times as many visits to them as to the latter. Allard (1911) found that the placing of cloth petals over the natural ones of cotton usually decreased inspections, but a crepe-paper blossom of the proper color received 3 inspections to 8 for the normal. Detto (1905) also found that replacing the corolla with one of yellow paper stopped visits, which began again as soon as the petals were replaced. On the other hand, flowers with a ring of colored paper were readily visited.

In the present experiments artificial flowers were visited about an eighth as much as natural ones. In more than half the installations they were completely ignored or visited but little. In several instances the total number of visits to imitations was large, though the ratio rarely reached one-half. The highest relative number of visits was in the case of a Frasera supplied with Campanula petals, namely, 56:97, but this was doubtless owing to the naturalness of the living tissue. The fact that Bombus went readily to paper Mentzelias before the natural ones were open appears to prove that the paper flowers were not repellent in themselves, but that the habit response to the natural flowers was a very definite one, as would be expected. While our results are more nearly in accord with those of Plateau and Forel, there is sufficient variation in them with respect to the various species of flowers and insects, as indeed there is in those of these two investigators, to make it unnecessary to question the observations of Andreae, Wery, and others. It has been repeatedly demonstrated that insects are not repelled by paper or cloth flowers or by composite imitations, and it is no longer possible to uphold Plateau's contention that insects do not go to artificial blossoms because odor is more powerful than color in attraction. In the major number of investigations they have been found to visit such flowers abundantly and repeatedly, and to prefer them all but exclusively to honey or odor alone, as Andreae and Wery in particular have shown.

Painted flowers.-While painted flowers are artificial in a sense, this is true to a much smaller degree than of paper or cloth ones, as is shown by the relative number of visits. They have been modified as to color 
primarily, and perhaps slightly as to surface texture and odor. Their greater naturalness is attested by the fact that they received about five times as many visitors as the paper composites employed. With respect to total response they were half as attractive as normal blossoms, though in the case of particular species they were equally or even more attractive. Thus, painted flowers of Rubus deliciosus were visited as readily as normal ones, and in the installations of Aconitum and Chamaenerium they received a larger number of visits absolutely. The greatest number of visits to such flowers was made by Bombus juxtus, but in two experiments the honey-bee made twice as many visits to them. The behavior of the latter was especially significant, since it ignored paper flowers altogether, but visited about half as many painted as normal ones. On the whole, it seems clear that changing the color of flowers as well as giving a wider range in color disturbed the response of bees, but to a much smaller degree than artificial flowers proper. The results secured by painting the white flowers of Rubus suggest that making these more conspicuous overcomes the disturbance arising from the addition of the water-colors, and indicate that white flowers should be preferred for experiments of this kind.

Inclosing flowers in glass.-Glass containers, such as beakers, tubes, and globes, have been employed by several investigators to eliminate odor and determine the response to color alone. Andreae placed flowers under bellglasses or beneath inverted beakers and found that they received many visits, in spite of the absence of odor. Wery also found out that cut flowers in a closed globe exerted nearly normal attraction. The conical disk of three heads of Rudbeckia was covered with a glass tube by Detto, with the consequence that numerous bees flew against the glass. Allard made use of boxes with a glass face and found that the inspections of the cotton blossoms were reduced about half. These experiments show conclusively that color by itself serves to attract insects in quantity, and to a degree equaling or exceeding that of odor. This is confirmed by the experiments in masking and covering discussed in the next section, the effect being to eliminate color and to render odor the sole attractive force.

Green flowers and showy nectarless flowers.-Plateau contended that green or dull-colored flowers which are visited by insects demonstrate that color is unnecessary and hence ineffective in attraction. Andreae showed that the color of inconspicuous flowers was often more attractive than either odor or honey, and Lovell has proved that green leaves with honey are much less attractive than yellow immortelles. When a head of golden glow and a green spike of Amarantus were placed in competition, the former obtained all told 51 visits to 16 for the latter. Plateau likewise insisted that the failure of showy nectarless flowers to attract insects proved that color was unimportant, and that it was necessary to supply them with a sweet fragrant liquid to induce bees to come. Pérez observed that bees did go to showy flowers without nectar, but that they soon learned the futility of this and ignored such blossoms. They came readily to geranium flowers supplied with honey, and not only returned to them after the honey was exhausted, but also went to others that had received no honey. Giltay found that bees trained to come to geranium flowers with honey went read- 
ily to flowers without it when these occupied the same place, although they were unable to find honeyed leaves. Lovell noted visits to showy nectarless flowers and was able to increase these by the addition of sugar sirup with odor, thus negativing Plateau's assumption. In the case of petunias, honey-bees continued to come for several days after the honey was gone, while with geranium they not only behaved similarly, but also went to a bed of Portulaca, which is regularly ignored, and inspected the flowers repeatedly.

Thus, it is evident that the positive response to dull flowers with nectar and the negative one to showy nectarless blossoms are largely matters of experience and habit, in the case of adult insects. The nectar or pollen reward being equal, bright flowers are visited more than green ones, and, conversely, the size and color being equal or approximately so, flowers are visited in proportion to the amount and accessibility of their nectar, the nectarless ones, no matter how showy, receiving no visits after the bees have determined the absence of nectar. Here, as elsewhere, it is desirable to work with flowers of each sort that are entirely unknown to a particular insect community, and with newly hatched bees, which are necessarily without experience.

Color preference.-The view that bees do not discriminate between colors has been advanced by Bonnier, Bulman, Plateau, Forel, MacLeod, and others. Bulman stated that "it matters not one iota to a bee whether the flower is blue, red, pink, yellow, white or green; so long as there is honey, that is sufficient," a statement approved by both Plateau and Forel. They have failed to reckon with intelligence and habit, however, as well as with the fact that odor and form doubtless enable the bee to recognize that the difference in color is immaterial to him. Darwin appreciated the significance of this when he said, "humble and hive bees are good botanists, for they know that varieties may differ widely in the color of their flowers and yet belong to the same species" (1876:416), and Lovell in particular has confirmed the view of Lubbock and Mueller that bees easily distinguish colors and go to some in preference to others. Mueller (1883:275) pointed out that it is necessary to keep in mind certain characteristics of the honey-bee in connection with its color preferences, if one is to avoid hasty conclusions. Chief among these are their shyness and lack of cleverness in unaccustomed surroundings. However, their shyness and desire for freedom are overruled by the all-powerful impulse for honey. The shyness and lack of skill of bees in unaccustomed places are in marked contrast to their prompt decisions and shrewdness at flowers. On flowers to which they are not especially adapted, various individuals often behave very differently, and they also show great individual differences in their color preferences.

Bonnier decided that bees exhibited no choice between red, yellow, green and white, but his results were regarded as inconclusive by Lubbock, since his squares were largely covered by the bees, and since he omitted blue and used no uncolored checks. Lubbock made most extensive experiments, which disclosed a decided choice for blue, with white and yellow usually next. To avoid artificial colors, Mueller employed detached petals, but obtained similar results. While there were marked individual differences, there were but few cases in which one or more individuals reversed 
the preference (p. 139). The least attractive of all colors was glaring yellow; white and yellowish-white were visited about as readily as many shades of purple, but less readily than blue or violet. Violet excelled all other flower colors except blue, a pure deep shade of the latter having the advantage indicated by the ratios $81: 37$ and 50:35. Among the brilliant flower colors, bright yellow was the most attractive. The green of leaves was less than half as attractive as rose, but slightly more so than scarlet or orange. Forel found that Bombus exhibited a distinct preference for blue over red, though he appears to have forgotten the inability of the bee to find honey on red or to have felt that this had no relation to the behavior of bees at flowers. Plateau showed that insects made no choice between the differently colored flowers of the same species or variety, but entirely overlooked habit as an explanation of this. He did prove, however, that in his experiments at least the so-called admiration of syrphids for bright colors, mottling, etc., was little different from their behavior before colorless or inanimate objects.

Contrary to the results of Lubbock and Forel with wasps, the Peckhams found that wasps rely very greatly upon color for their guidance, a change in the color of paper about the nest often causing all of them to hesitate or go to the misplaced color. This is in harmony with the instances cited by Theen, Buttel-Reepen, and Lovell of the effect of changing the color of hives or their thresholds. Lovell corroborated the preference of bees for blue, 15 going to this and but 1 or 2 to any other color. A bee trained to red first gave a ratio of $8: 2$ for red and blue, but finally this shifted to $3: 7$. Turner showed that as a rule bees did not visit artefacts of the color from which they had not been trained to forage when these were supplied with honey and scattered among the others. Frisch found that bees paid no attention to gray in competition with blue or yellow, but that they visited red, dark gray, and black disks indifferently. He concluded that bees are color-blind to red and a certain shade of blue-green, in agreement with the views of Ladd-Franklin. Since there are many records of visits to both these colors, which must have appeared in varying shades, and since several shades of green have been much visited in the course of the present investigation, it is clear that further experimentation by means of colors of known value is needed in this field (cf. Frisch, Knoll, Kühn and Pohl, pp. 200 to 207 ).

While the different colors of the same variety or species may have no significance for insects, it is evident that this is not true of the changes in color shown by flowers in maturing or withering. Such colors are helpful in guiding the insect and saving his time, and he regularly takes advantage of them. Mueller (1883:81) observed that in a field of red and blue Pulmonaria females of Anthophora pilipes visited almost exclusively the red blossoms and those just beginning to change toward blue, but only rarely the blue ones. F. Mueller (1877:17) found that Lantana flowers were visited by butterflies on the first and second day when they were yellow and orange-red, but never on the third when they were purple; some species in fact visited the yellow flowers alone. Here the perferences were naturally not for the colors as such, but as indicators of the availability of nectar (cf. Ludwig, 1885, 1887). In conclusion, it may be affirmed that trained bees exhibit a 
marked and often persistent choice for the proper color, but that there is a general preference for blue. In field and garden, differences in color are of great importance in attraction, but the bee discriminates among them only when it is to its advantage to do so, as between species, or between partly open buds or old flowers on the one hand and fresh ones on the other. When the flowers differ in color alone, the bee has learned that this is unimportant in comparison with odor and form. When a new factor is interjected, however, as in the case of flowers habitually visited which are changed by painting them with water-colors, a preference is manifested until experience again shows that it is undesirable or unnecessary.

\section{ODOR.}

Masking or covering flowers to conceal color.-Plateau thought to have demonstrated by masking flowers and heads with paper or green leaves that color is of little or no value in attraction and that odor alone is sufficient. Most of his experiments lacked checks or controls, and were contradicted by those of Forel, who found that flowers completely masked received no visits. Wherever a slight gap permitted entrance, bees soon found their way in and then returned regularly by the same route. Moreover, after the lapse of several hours they discovered the flowers and then visited them normally. Andreae frequently employed beakers masked with dark paper to determine the effect of odor alone; in three representative cases the ratios for color and odor were $10: 0,31: 1$, and $35: 3$, indicating that odor is much less effective than color as a rule. Wery noted 32 visitors to normal flowers to 7 for similar ones hidden in foliage, and 19 to artificial flowers fully exposed to but 4 for those concealed in leaves. Giltay repeatedly masked flowers with pots so that no color was visible, but the odor could regularly escape; such blossoms received no visits, but bees came readily as soon as the pot was removed. When petals were placed in a dish and covered with a pot so that they were invisible but the odor could escape they were never visited, but after the pot was removed, bees alighted on them, sometimes immediately. Allard concealed a cotton blossom so that it was visible only from above; this obtained but 1 visit to 12 for the control. When the disguise was taken away, the flower was inspected more than the control.

These experiments leave no question that for the flowers concerned at least the rốle of color in attraction is usually several times and often many times greater than that of odor.

Odor of honey.-While honey has a strong attractive power, this is due chiefly to its sweetness and but little to its odor, especially in the case of bees. Even Plateau had remarked the fact that bees have a weak sense of smell for honey, and this inability has been emphasized by Forel, Buttel-Reepen, Giltay, Wery, Detto, Lovell, and others. Bombus and Apis have repeatedly been observed to pass within a few millimeters of honey in both natural and artificial flowers without perceiving it. In some cases they have even become entangled in it and tried to clean it oft without recognizing it. Moreover, sugar sirups and other sweet liquids without odor have often been found to be quite as attractive as honey. Once found, honey is a powerful incentive to return until it is exhausted. In our experiments it never in- 
creased the number of visits to natural flowers and had practically no effect upon those to artificial ones. In the majority of cases it actually decreased the number of visits, often as much as ten times. Wery found that honey remained practically untouched in competition with natural or artificial flowers, obtaining such ratios as 49:0 and 25:0, and emphasized the fact that honey attracts bees very little.

Effect of added odors. - In his first studies of the effect of adding odors to flowers Plateau obtained no conclusive results. Thyme and sage appeared to attract feebly, lavender not at all, and mint to repel. In his later studies, he stated that it was indispensable for good results to avoid essences and to employ substances known to attract. With these he had marked success with but one or two, such as anisette, a sugar sirup flavored with anise. On the other hand, our experiments showed a decrease of 50 per cent in the number of visits when various perfumes and essences were added, even in the presence of honey. With occasional exceptions, perfumes in themselves have no effect in increasing attraction, though they may serve as indicators of the presence of honey or sirup and thus seem to be attractive, as in Plateau's results. It is possible that positive results would be secured by using perfume from flowers that bees had been visiting in other areas or earlier in the season, and such experiments are now under way.

Relative value of color and odor.-Wery has endeavored to give quantitative expression to the respective parts played by color, form, odor, and food in the attraction of insects, and her values seem to be fair approximations of the various rôles. Her general conclusion in this respect was formulated as follows:

"For the honey-bee the attraction exerted by the form and color of flowers is approximately four times greater than that of their pollen, perfume, and nectar taken together. Thus, if the total attraction exerted by the most attractive flowers is taken as 100 , that of form and color will be represented by about 80 and that of the other three factors by about 20."

In view of the faint sense of smell for honey and pollen exhibited by bees, this seems a conservative figure except for flowers with a marked perfume, which are still to be adequately investigated. It is these flowers that have given rise to contradictory opinions as to the relative share of color and odor in attraction from a distance and guidance near at hand.

\section{FORM.}

Distinction and role.-Following the views of Exner as to vision, both Plateau and Forel were of the opinion that insects distinguish forms more or less vaguely, except when in motion. When one recalls the incessant activity of bees on flowers, this exception is nearly tantamount to the admission that insects do distinguish forms and make use of them in determining their visits. Although Pérez regarded form as less important than color or odor, he pointed out the contradiction involved in Plateau's contention that insects could not distinguish colors, but that they were guided to buds, withered flowers, and fruits by their form. Moreover, Forel stated that wasps readily recognize the forms and contours of objects, and he demonstrated that wasps and bumble-bees could distinguish bands from 
disks. He also declared that his experiments with artefacts demonstrated that honey-bees possess the perception of space, form, and color. Practically all other students of experimental pollination have agreed that insects are guided in some degree by form, though Giltay thought that visits to a single petal indicated that form could not be concerned. This does not follow, however, since it is evident that color is often more potent than form. Detto was also doubtful of the ability of bees to see forms, but he explains certain of his results on the assumption that the bees were able to recognize the stamens and pistil of a flower. The Peckhams, Dahl, Andreae, Wery, Frisch, and Turner have shown that insects distinguish forms or patterns, and some of Lovell and Allard's results permit no other conclusion. Additional proof is furnished by the readiness with which they go from one color to another of flowers of the same species or variety, whether fragrant or not, and especially by their response to painted flowers. The minuteness with which they can distinguish forms and structures is proved by the ease with which they solve the problems presented by inverted and mutilated flowers, as well as by the ingenious experiments of Detto on the relative importance of vision and smell in enabling insects to locate the nectary openings. Finally, it appears that insects can distinguish differences in surface and texture sufficiently small to escape man. This conclusion seems unavoidable, when one recalls the readiness with which bees often distinguish between the best of artificial or painted flowers and normal ones. In fact, it is a curious paradox that Plateau, who thought insects distinguish neither form nor color, and that Forel, who thought they had but a vague vision of form, should have believed that they were able to discriminate between artificial and natural flowers by means of other differences not visible to the eyes of man.

\section{ATTRACTION AT A DISTANCE AND NEAR AT HAND.}

It is unfortunate that no definite experiments have been made as to the distance at which various colors and odors as represented in flowers exert attraction, but it is hoped that the experiments now contemplated will yield accurate quantitative results. The general opinion has been that odor attracts from a distance and color near at hand, and Plateau has definitely stated that insects do not perceive objects at a greater distance than 2 meters and many of them only when much nearer. On the other hand, Wery believed that color could attract for a distance of 6 meters, since insects were able to recognize artificial blossoms placed this far from natural ones, and Andreae stated that honey-bees could see 8 to 10 meters at least, basing this upon similar grounds.

The careful consideration of previous experiments confirms the evidence derived from the present investigation. This indicates as the best working hypothesis for further studies the conclusion that odor attracts for distances beyond 10 meters, color in mass for the intermediate ones, and color and form in detail within a meter or so, depending greatly upon the size and color of the flower or cluster. For the majority of flowers without a marked fragrance, odor can be effective only when near at hand and the effect is probably small even then. It is hardly necessary to point out that this must be true of color also in the case of green or dull flowers and especially 
those of small size. Since the senses of sight and smell differ greatly in the various groups of insects, the relative importance of the three attractive factors will be modified accordingly. In a group of plants or a floriferous individual or even in the midst of a cluster of flowers, odor can have little effect, except in the rare instances when very fragrant flowers or clusters are widely separated in such groups. The odor is not only general, but it is naturally most powerful at the flower or cluster on which the insect is working. Such conditions would not permit it to go straightway and without an instant's hesitation to the next flower or head, and guidance by color and form alone can explain the assured and rapid flight of bees in the midst of flowers. This is confirmed by their behavior when the wind is blowing, for they fly most easily with the wind, though this carries the fragrance of the next flower sought away from them. Moreover, the readiness with which they often drop from the midst of a plant or bush to fallen corollas on the ground a foot or more below further supports the view that odor is rarely a guide among flowers. However, it must be kept in mind that such studies have so far been incidental and concerned with bees already habituated to the flowers concerned, except in some of the competition studies already given in chapter 3.

\section{LEARNING AND HABIT.}

It is possible at present to deal with learning and habit only in the general qualitative manner so admirably exemplified in the work of Lubbock, Mueller, Forel, Peckham, Buttel-Reepen, Detto, Lovell, Turner, Frisch, and Knoll. The time has come for a comprehensive quantitative attack on the learning process and its relation to the fixation and modification of habit, and one of the primary objects of the present book is to clear the way for such investigation, as indicated earlier. In view of their generalized mental organization, the ability of insects, and especially the bees, to learn by experience is remarkable. This has been widely recognized by experimenters in this field, though it has been doubted by some who failed to take into account the qualities emphasized by Mueller, namely, the shyness and lack of cleverness in unusual surroundings and the all-powerful obsession for honey. The ease and rapidity with which habits of landing and securing nectar are modified under changed conditions indicate a great power of learning and a corresponding plasticity of habit that is surprising. These qualities will probably be found to be even more marked in the case of newly hatched or young insects, and it is possible that the training of these will disclose new possibilities of learning and adjustment. As the work of Giltay shows, the selection of marked individuals on the basis of different types of response opens a new vista in this field, and permits the extension and refinement of our knowledge of the mental powers of the species and group by means of the psychology of the individual.

\section{MEMORY AND INTELLIGENCE.}

The Peckhams concluded that wasps have a very good memory, and Forel stated that bees not only have memory for place but also for time, a statement in accord with the views of Buttel-Reepen. Probably the 
most remarkable instance of memory is that recorded by Hoffer (1886:11), who found that bumble-bees remembered the place in which their nest had been put, from the middle of October when they disappeared to the beginning of April when they returned. It is evident also that wasps in particular have a remarkable memory for forms and outlines along the path of their flights, as shown by their ability to find their way back for several miles, a faculty only less developed in the bees.

Both Buttel-Reepen and Forel have shown that bees are capable of memory and other associations, and the former stated:

"We see that bees show signs of an admirable memory in their orientation and in their other activities; further, I believe I have shown that the bee possesses a perception for color and form, and develops a rich capacity for communication by means of its well-developed 'language'; that, further, it is able to gather experiences, to learn and to form associations of impressions, etc."

Forel independently declared that-

"It ensues from the concordant observations of all the experts that sensation, perception, association, inference, memory, and habit in the social insects follow the same fundamental laws as in the vertebrates and ourselves. In these animals it is possible to demonstrate the existence of memory, associations of sensory images, perception, attention, habits, simple powers of inference from analogy, the utilization of individual experiences and hence distinct, though feeble, plastic individual deliberations or adaptations. It is also possible to detect a corresponding, simpler form of volition, i. e., the carrying out of individual decisions in a more or less protracted time sequence, through different concatenations of instincts; furthermore, different kinds of discomfort and pleasure emotions, as well as interactions and antagonisms between these diverse psychic powers."

As early as 1877, Forel said that all the properties of the human mind may be derived from the properties of the animal mind and a quarter of a century later he merely added the statement that all the mental attributes of higher animals may be derived from those of lower animals.

With the development of more exact methods in comparative psychology has gone a more critical spirit, which has discarded practically all the observational and anecdotal material so long utilized. The same feeling for accuracy and objectivity has led to the present endeavor to place the study of the relations of flowers and insects upon a purely experimental basis. In spite of this, however, the work of Forel, Lubbock, the Peckhams, Buttel-Reepen, Ferton, and others was so largely experimental that their general conclusions have remained true and still constitute much of the essential foundation for the study of insect psychology, as is evident from the recent and more exact researches of Frisch, Knoll, and Kühn and Pohl [see also Holmes (1911), Thorndike (1911), Smith (1915), and Bouvier (1922)]. 


\section{POLLINATORS AND FLOWERS VISITED.}

Acmaeops longicornis: Carduus hookerianus. Mertensia sibirica. Prunus demissa. Rosa acicularis. Rubus deliciosus.

Acmaeops pratensis: Prunus demissa. Rosa acicularis. Rubus deliciosus.

Agapostemon coloradensis: Stanleya pinnatifida. Taraxacum officinale.

Agapostemon splendens: Malvastrum coccineum. Pentstemon glaber. Rosa acicularis. Taraxacum officinale.

Agapostemon sp.:

Prunus demissa.

Stanleya pinnatifida.

Agathis vulgaris:

Achillea millefolium.

Ancistrocerus sp.:

Geranium caespitosum. richardsoni.

Jamesia americana.

Mertensia sibirica.

Rubus deliciosus. strigosus.

Andrena apacheorum:

Erigeron macranthus.

Geranium caespitosum.

Andrena braccata:

Geranium caespitosum.

Andrena canadensis:

Prunus demissa.

Rubus deliciosus.

Andrena crataegi:

Carduus hookerianus.

Frasera speciosa.

Holodiscus dumosus.

Monarda fistulosa.

Opulaster opulifolius.

Prunus demissa. virginiana.

Rosa acicularis.

Rubus deliciosus. strigosus.

Andrena edwiniae:

Jamesia americana.

Prunus demissa.

Andrena gardineri:

Astragalus drummondi.

Andrena imitatrix:

Astragalus drummondi.

Andrena lewisi:

Rubus strigosus.

Andrena madronitens:

Frasera speciosa.

Geranium caespitosum. richardsoni.

Holodiscus dumosus.

\author{
Andrena madronitens-Con. \\ Mertensia sibirica. \\ Onagra biennis. \\ Opulaster opulifolius. \\ Pentstemon glaber. \\ Prunus demissa. \\ secundiflorus. \\ Rosa acicularis. \\ Rubus deliciosus. \\ strigosus.
}

Sedum stenopetalum. Andrena placida:

Rubus deliciosus.

Andrena prunorum:

Pentstemon glaber.

Prunus demissa. virginiana.

Rubus deliciosus.

Andrena vicina:

Astragalus drummondi

Geranium caespitosum.

Pentstemon glaber.

Potentilla arguta.

Prunus demissa. virginiana.

Rosa acicularis.

Rubus deliciosus. strigosus.

Stanleya pinnatifida.

Andrena washingtoni:

Pentstemon gracilis.

Rosa acicularis.

Andrena ep.

Prunus demissa. virginiana

Rosa acicularis.

Andronicus sp.:

Carduus hookerianus.

Geranium caespitosum.

Pentstemon gracilis.

Rubus deliciosus.

Anthidium tenuiflorae:

Sedum stenopetalum.

Anthophora bomboides:

Pentstemon glaber.

Anthophora occidentalis:

Chamaenerium angustifolium.

Anthophora neomexicana:

Pentstemon gracilis.

Anthophora simillima:

Aragalus lamberti.

Capnoides aureum.

Dodocatheon meadia.

Lithospermum canescens.

Pentstemon glaber. gracilis.

halli.

secundiflorus. unilateralis.

Rosa acicularis.

Rubus strigosus.
Anthophora smithi:

Campanula rotundifolia.

Chamaenerium angusti-

folium.

Monarda fistulosa.

Anthrax alternata:

Holodiscus dumosus.

Anthrax fulviana:

Erigeron macranthus.

Anthrax halcyon:

Solidago missouriensis.

Anthrax hypomelas:

Heracleum lanatum.

Potentilla gracilis.

Anthrax lateralis:

Rosa acicularis.

Anthrax nigra:

Rosa acicularis.

Anthrax sinuosa:

Sedum stenopetalum.

Tradescantia virginiana.

Anthrax tegminipennis:

Erigeron macranthus.

Anthomyia sp.:

Clementsia rhodantha.

Apanteles sp.:

Geranium caespitosum.

Apis mellifica:

Aretostaphylus uva-ursi.

Asclepias halli.

$$
\text { speciosa. }
$$

Chamaenerium angustifolium.

Frasera speciosa.

Geranium caespitosum. richardsoni.

Holodiscus dumosus.

Jamesia americana.

Linaria vulgaris.

Mentzelia multiflora.

Opulaster opulifolius.

Pentstemon glaber. unilateralis.

Petalostemon candidus. purpureus.

Rosa acicularis.

Rubus deliciosus. strigosus.

Solidago missouriensis.

Stanleya pinnatifida.

Taraxacum officinale.

Thalictrum fendleri.

Tradescantia virginiana.

Archytas sp.:

Geum rivale.

Arctophila flagrans:

Rosa acicularis.

Argynnis atlantis:

Chamaenerium angustifolium.

Erigeron macranthus.

Monarda fistulosa.

Pentstemon secundiflorus. 
Argynnis eurynome:

Geranium caespitosum.

Helianthus petiolaris.

Rydbergia grandiflora.

Sedum stenopetalum.

Atrytone taxiles:

Capnoides aureum.

Chamaenerium angustifolium.

Monarda fistulosa.

Pentstemon glaber.

Basilarchia weidemeyeri:

Linaria vulgaris.

Bembex spinolae:

Asclepias halli.

Bombomelecta fulvida:

Capnoides aureum.

Mertensia sibirica.

Pentstemon glaber. gracilis.

Bombus americanorum:

Pentstemon unilateralis.

Rubus deliciosus.

Thermopsis montana.

Bombus appositus:

Aconitum columbianum.

Carduus hookerianus.

Chamaenerium angustifolium.

Delphinium occidentale.

Gentiana parryi.

Geranium caespitosum.

Ibidium strictum.

Monarda fistulosa.

Pentstemon glaber. gracilis.

Petalostemon candidus.

Rubus deliciosus. purpureus.

Rydbergia grandiflora.

Rosa acicularis.

Bombus bifarius:

Aconitum columbianum.

Carduus hookerianus.

Chamaenerium angustifolium.

Delphinium scopulorum.

Dodocatheon meadia.

Elephantella groenlandica.

Erigeron macranthus.

Geranium caespitosum. richardsoni.

Holodiscus dumosus.

Jamesia americana.

Mentzelia multiflora.

Mertensia sibirica.

Monarda fistulosa.

Pentstemon glaber.

$$
\text { glaucus. }
$$

gracilis.

secundiflorus.

Rosa acicularis.

Rubus deliciosus. strigosus.

Stanleya pinnatifida.
Bombus centralis:

Chamaenerium angustifolium.

Delphinium scopulorum.

Monarda fistulosa.

Pentstemon glaber. gracilis.

Bombus dorsalis:

Capnoides aureum.

Bombus edwardsi:

Aconitum columbianum.

Allium recurvatum.

Aretostaphylus uva ursi.

Aster foliaceus.

Astragalus drummondi.

Calochortus gunnisoni.

Campanula rotundifolia.

Carduus hookerianus.

Chamaenerium angustifolium.

Chrysopsis villosa.

Cleome serrulata.

Delphinium scopulorum.

Dodocatheon meadia.

Drymocallis fissa.

Erigeron macranthus.

Fragaria vesca.

Frasera speciosa.

Geranium caespitosum.

Holodiscus dumosus.

Jamesia americana.

Lathyrus ornatus.

Mertensia sibirica.

Opulaster opulifolius.

Pedicularis racemosa.

Pentstemon glaber.

glaucus.

gracilis. secundiflorus.

Petalostemon candidus. purpureus.

Rosa acicularis.

Rubus deliciosus. strigosus.

Rydbergia grandiflora.

Sedum stenopetalum.

Sieversia ciliata.

Solidago missouriensis.

Bombus fervidus:

Astragalus drummondi.

Monarda fistulosa.

Pentstemon unilateralis.

Petalostemon candidus. purpureus.

Rubus deliciosus.

Bombus flavifrons:

Aconitum columbianum.

Aster foliaceus.

Calochortus gunnisoni.

Chamaenerium angustifolium.

Dasyphora fruticosa.

Delphinium scopulorum.

Dodocatheon meadia.

Frasera speciosa.

Mertensia sibirica.

Monarda fistulosa.
Bombus flavifrons-Con

Prunus demissa.

Rosa acicularis.

Rubus deliciosus. strigosus.

Rydbergia grandiflora.

Solidago missouriensis.

Bombus fulvida:

Mertensia sibirica.

Bombus hunti:

Aquilegia brevistyla. coerulea.

Astragalus drummondi.

Campanula rotundifolia.

Carduus hookerianus.

Castilleia miniata.

Chamaenerium angustifolium.

Erigeron macranthus. uniflorus.

Frasera speciosa.

Geranium caespitosum. richardsoni.

Helianthus petiolaris.

Holodiscus dumosus.

Jamesia americana.

Monarda fistulosa.

Pedicularis parryi.

Pentstemon glaber. gracilis.

Petalostemon candidus. purpureus.

Potentilla gracilis.

Rosa acicularis.

Rubus deliciosus. strigosus.

Rydbergia grandiflora.

Sedum stenopetalum.

Solidago missouriensis.

Stanleya pinnatifida.

Thermopsis montana.

Trifolium dasyphyllum.

Bombus juxtus:

Aconitum columbianum.

Astragalus drummondi.

Campanula rotundifolia. Capnoides aureum.

Carduus hookerianus.

Chamaenerium angustifolium.

Chrysopsis villosa.

Delphinium scopulorum.

Frasera speciosa.

Gentiana parryi.

Geranium caespitosum.

Holodiscus dumosus.

Jamesia americana.

Mentzelia multiflora.

Mertensia sibirica.

Monarda fistulosa.

Onagra biennis.

Pentstemon glaber. glaucus. gracilis. secundiflorus.

Potentilla arguta. 
Bombus juxtus-Con.

Rosa acicularis.

Rubus deliciosus. strigosus.

Thermopsis montana.

Bombus kirbyellus:

Castilleia miniata.

Pedicularis parryi.

Pentstemon glaber.

Potentilla arguta. pulcherrima.

Rubus deliciosus.

Trifolium dasyphyllum.

Bombus morrisoni:

Astragalus drummondi.

Delphinium scopulorum.

Ibidium strictum.

Monarda fistulosa.

Pentstemon glaber. glaucus. gracilis.

Rosa acicularis.

Rubus deliciosus. strigosus.

Scutellaria resinosa.

Stanleya pinnatifida.

Bombus nevadensis:

Carduus hookerianus.

Chamaenerium angustifolium.

Gentiana parryi.

Opulaster opulifolius.

Bombus occidentalis:

Aconitum columbianum.

Allium recurvatum.

Aquilegia coerulea.

Calochortus gunnisoni.

Capnoides aureum.

Carduus hookerianus.

Castilleia miniata.

Chamaenerium angustifolium.

Delphinium scopulorum.

Erysimum asperum.

Erigeron uniflorus.

Geranium caespitosum. richardsoni.

Heracleum lanatum.

Holodiscus dumosus.

Jamesia americana.

Linaria vulgaris.

Mentzelia multiflora.

Mertensia sibirica.

Monarda fistulosa.

Opulaster opulifolius.

Pedicularis racemosa.

Pentstemon glaber. glaucus. secundiflorus.

Petalostemon purpureus.

Potentilla pulcherrima.

Prunus demissa.

Rosa acicularis.

Rubus deliciosus. strigosus.

Sieversia ciliata.

Solidago missouriensis.
Bombus pennsylvanicus: Monarda fistulosa.

Bombus rufocinctus:

Aconitum columbianum.

Calochortus gunnisoni.

Chamaenerium angustifolium.

Geranium caespitosum.

Pentstemon glaber. gracilis.

Petalostemon candidus.

Rosa acicularis. purpureus.

Rubus deliciosus.

Solidago missouriensis

Stanleya pinnatifida.

Bombylius atriceps:

Rosa acicularis.

Brachyopa notata:

Prunus demissa.

Rubus deliciosus.

Bracon helena:

Erigeron macranthus.

Bracon vulgaris:

Stanleya pinnatifida.

Brenthis triclaris:

Dasyphora fruticosa.

Prunus demissa.

Calliphora vomitoria:

Prunus demissa.

Celerio lineata:

Pachylophus eaespitosus.

Pentstemon glaber.

Cenis uhleri:

Geranium caespitosum.

Cerastomia lignaria:

Pentstemon gracilis.

Ceratina sp.:

Mertensia sibirica.

Pentstemon gracilis.

Stanleya pinnatifida.

Chilosia petulca:

Prunus demissa.

Chilosia tristis:

Prunus demissa.

Chionobis macouni

Draba aurea.

Iris missouriensis.

Potentilla pulcherrima.

Chrysogaster parva:

Rubus deliciosus.

Chrysophanus helloides

Achillea millefolium.

Erigeron macranthus.

Oreochrysum parryi.

Chrysophanus rubidus.

Campanula rotundifolia.

Carduus hookerianus.

Phacelia heterophylla.

Chrysophanus sirius: Monarda fistulosa.

Chrysotoxum integrum:

Holodiscus dumosus.

Rosa acicularis.

Chrysotoxum upsilon: Polygonum bistorta.
Chrysotoxum ventricosum:

Potentilla pulcherrima.

Clisodon terminalis:

Aquilegia coerulea.

Carduus hookerianus.

Chamaenerium angustifolium.

Frasera speciosa.

Geranium caespitosum.

Holodiscus dumosus.

Mertensia pratensis.

Monarda fistulosa.

Pentstemon glaber.

glaucus.

gracilis.

secundiflorus.

Petalostemon purpureus.

Rosa acicularis.

Rubus strigosus.

Clisodon sp.:

Carduus hookerianus.

Mertensia sibirica.

Pentstemon glaber.

gracilis.

Coelioxys moesta:

Chamaenerium angustifolium.

Geranium caespitosum.

Coenonympha pamphiloides:

Dasyphora fruticosa.

Erigeron macranthus.

Prunus demissa.

Colias alexandra:

Potentilla pulcherrima.

Colias edwardsi:

Carduus hookerianus.

Colias keewaydina:

Castilleia miniata.

Colias scudderi:

Carduus hookerianus.

Colletes americanus:

Rosa acicularis.

Solidago missouriensis.

Colletes kincaidi:

Geranium caespitosum.

Pentstemon gracilis.

Petalostemon purpureus.

Prunus demissa.

Colletes oromontis:

Capnoides aureum.

Geranium caespitosum.

Holodiscus dumosus.

Mertensia pratensis. sibirica.

Monarda fistulosa.

Rubus deliciosus. strigosus.

Solidago missouriensis.

Colletes sieverti:

Geranium caespitosum.

Ctenucha sp.:

Chamaenerium angustifolium.

Monarda fistulosa.

Curtipogon leucozona:

Calochortus gunnisoni. 
Dasyllis fernaldi:

Calochortus gunnisoni.

Chamaenerium angustifolium.

Dejeania vexatrix:

Chamaenerium angustifolium.

Mertensia sibirica.

Opulaster opulifolius.

Dolichovespula arctica:

Chamaenerium angustifolium.

Delphinium scopulorum.

Dolichovespula diabolica:

Chamaenerium angustifolium.

Echinomyia algens:

Chamaenerium angustifolium.

Chrysopsis villosa.

Heracleum lanatum.

Echinomyia decias:

Asclepias speciosa.

Ectemius montanus:

Geranium richardsoni.

Ectemius muricatus:

Heracleum lanatum.

Eliphilus latifrons:

Cleome serrulata.

Epalpus bicolor:

Carduus hookerianus.

Polygonum bistorta.

Solidago missouriensis.

Epalpus rufus:

Carduus hookerianus.

Valeriana edulis.

Epeolus helianthi:

Geranium caespitosum.

Erebia epipsodea:

Dasyphora fruticosa.

Geranium caespitosum. Potentilla pulcherrima. Prunus demissa.

Eristalis arbustorum: Prunus demissa. Rubus strigosus.

Eristalis dimidiatus: Prunus demissa.

Eristalis flavipes: Rubus deliciosus.

Eristalis latifrons: Opulaster opulifolius.

Rosa acicularis.

Rubus deliciosus.

Eristalis meigeni: Potentilla gracilis.

Eristalis temporalis:

Prunus demissa.

Rubus deliciosus.

Rydbergia grandiflora.

Eristalis tenax:

Jamesia americana.

Erynnis leonardus snowi:

Chamaenerium angusti-

folium.

Monarda fistulosa.
Erizoa olivalis:

Carduus hookerianus.

Exoprosopa caliptera:

Rubus deliciosus.

Exoprosopa divisa:

Sedum stenopetalum.

Exoprosopa volucris:

Silene acaulis.

Foenus perplexus:

Geranium caespitosum.

Geocoris bullatus:

Potentilla pulcherrima.

Glypta sp.:

Geranium caespitosum.

Gnophaela vermiculata:

Achillea millefolium.

Polygonum bistorta.

Potentilla pulcherrima.

Rubus strigosus.

Solidago missouriensis.

Gonochrysis densa:

Pentstemon glaber.

Grapta hylas:

Carduus hookerianus.

Halictus (Chloralictus) sp. :

Asclepias halli.

Castilleia miniata.

Geranium caespitosum.

Gilia aggregata.

Mertensia sibirica.

Monarda fistulosa.

Opulaster opulifolius.

Pentstemon glaber.

Prunus demissa. gracilis.

Halictus (Evylaeus) sp.:

Apocynum androsaemifolium.

Astragalus drummondi.

Castilleia miniata.

Chamaenerium angustifolium.

Mertensia sibirica.

Pentstemon gracilis.

Prunus demissa.

Rosa acicularis.

Tradescantia virginiana.

Halictus fendleri:

Thalictrum fendleri.

Halictus (Lasioglossum) sp.:

Asclepias speciosa.

Castilleia miniata.

Chamaenerium angustifolium.

Geranium caespitosum.

Monarda fistulosa.

Opulaster opulifolius.

Prunus demissa.

Rubus deliciosus. strigosus.

Halictus lerouxi:

Frasera speciosa.

Halictus medionitens:

Geranium caespitosum.

Holodiscus dumosus.
Halictus medionitens-Con. Potentilla pulcherrima.

Rosa acicularis.

Rubus deliciosus.

Halictus manitonellus:

Monarda fistulosa.

Rosa acicularis.

Halictus pulzenus:

Castilleia miniata.

Chamaenerium angustifolium.

Frasera speciosa.

Geranium caespitosum. richardsoni.

Gilia aggregata.

Mertensia sibirica.

Monarda fistulosa.

Opulaster opulifolius.

Pentstemon glaber. gracilis.

halli. secundiflorus.

Prunus demissa.

Rosa acicularis.

Rubus deliciosus. strigosus.

Halicyoides mamus: Achillea millefolium.

Hammerschmidtia ferruginea: Geranium caespitosum.

Heracleum lanatum.

Holodiscus dumosus.

Heriades gracilior:

Fragaria vesca.

Pentstemon glaber. gracilis.

Heringia salix :

Rubus deliciosus.

Hyloicus separatus:

Pachylophus caespitosus.

Irbisia brachycerus: Caltha leptosepala.

Drymocallis fissa.

Geranium caespitosum.

Jamesia americana.

Malvastrum cocineum.

Lemonias nubigena wheeleri:

Geranium caespitosum.

Helianthus petiolaris.

Rydbergia grandiflora.

Leptura chrysocoma:

Sambucus racemosa.

Lithargus apicalis opuntiae:

Stanleya pinnatifida.

Lycaena glaucon:

Galium borealis.

Lycaena pseudargiolus:

Geranium caespitosum.

Lygus pratensis:

Ibidium strictum.

Mallota flavoterminata:

Rosa acicularis.

Megachile gemula albula: Chamaenerium angustifolium.

Megachile pugnata:

Carduus hookerianus. 
Megachile pugnata-Con. Chamaenerium angustifolium.

Erigeron macranthus. Geranium caespitosum. Petalostemon purpureus.

Megachile relativa:

Chamaenerium angustifolium.

Geranium caespitosum. richardsoni.

Rosa acicularis.

Megachile texana:

Chamaenerium angustifolium.

Rosa acicularis.

Megachile vidua:

Chamaenerium angustifolium.

Megachile wootoni:

Astragalus drummondi.

Campanula rotundifolia.

Carduus hookerianus.

Chamaenerium angustifolium.

Monarda fistulosa.

Opulaster opulifolius.

Pentstemon glaber. glaucus. gracilis.

Rosa acicularis.

Rubus deliciosus. strigosus.

Thermopsis montana.

Megachile wootoni calogaster:

Chamaenerium angustifolium.

Pentstemon glaber.

Rosa acicularis.

Rubus deliciosus.

Melitaea whitneyi:

Rydbergia grandiflora.

Melitaea sp.:

Rubus deliciosus.

Melissodes aurigenia:

Chamaenerium angustifolium.

Melissodes fremonti:

Monarda fistulosa.

Pentstemon glaber.

Melissodes sp.:

Carduus hookerianus.

Geranium caespitosum.

Mesogramma marginata:

Potentilla gracilis.

Microdon cothurnatus:

Prunus demissa.

Monumetha albifrons:

Apocynum androsaemifolium.

Astragalus drummondi.

Carduus hookerianus.

Chamaenerium angustifolium.

Frasera speciosa.

Geranium caespitosum.

Mertensia sibirica.
Monumetha albifrons-Con.

Pentstemon glaber. glaucus. gracilis. halli.

Rosa acicularis.

Rubus deliciosus.

Monumetha argentifrons:

Chamaenerium angustifolium.

Mordella melaena: Solidago missouriensis.

Myopa clausa:

Rubus deliciosus.

Nathalis iole:

Potentilla pulcherrima.

Nomada sp. :

Prunus virginiana.

Rubus deliciosus.

Odynerus annulatus:

Campanula rotundifolia.

Stanleya pinnatifida.

Omalus sp.:

Pentstemon glaber.

Ophion sp.:

Caltha leptosepala.

Osmia abnormis:

Iris missouriensis.

Osmia albolateralis:

Mertensia pratensis.

Osmia bella:

Iris missouriensis.

Osmia brevi.s:

Mertensia pratensis.

Osmia bruneri:

Elephantella groenlandica.

Geranium caespitosum.

Opulaster opulifolius.

Pentstemon glaber. gracilis.

Rosa acicularis. secundiflorus.

Osmia coloradella:

Mertensia sibirica.

Pentstemon glaber.

Osmia densa.:

Capnoides aureum.

Geranium caespitosum.

Mertensia pratensis. sibirica.

Opulaster opulifolius.

Pentstemon glaber. gracilis. halli.

Rosa acicularis.

Osmia fulgida:

Fragaria vesca.

Geranium richardsoni.

Rosa acicularis.

Rubus deliciosus.

Osmia hypoleuca:

Mertensia pratensis.

Pentstemon gracilis.

Silene halli.

Osmia megacephala:

Rydbergia grandiflora.
Osmia melanotricha:

Mertensia pratensis.

Pentstemon glaber.

glaucus.

gracilis.

halli.

Rosa acicularis.

Osmia nigrifrons:

Mertensia pratensis. sibirica.

Osmia pentstemonis:

Mertensia sibirica.

Pentstemon glaucus. gracilis. secundiflorus.

Osmia phaceliae:

Geranium caespitosum.

Mertensia sibirica.

Pentstemon glaber. gracilis. halli.

Osmia propinqua:

Geranium caespitosum.

Rosa acicularis.

Rubus deliciosus. strigosus.

Taraxacum officinale.

Osmia pusilla:

Mertensia pratensis.

Osmia rohweri:

Mertensia pratensis.

Osmia wardiana:

Chamaenerium angustifolium.

Osmia sp.:

Geranium caespitosum.

Monarda fistulosa.

Thermopsis montana.

Oxybelus sp.

Pentstemon glaber.

Panurginus cressoniellus:

Erigeron macranthus.

Geranium caespitosum.

Ibidium strictum.

Rosa acicularis.

Rubus deliciosus.

Panzeria radicum:

Achillea millefolium.

Erigeron macranthus.

Papilio rutulus:

Pentstemon glaber.

Paragus bicolor:

Sieversia turbinata.

Parnassius clodius:

Carduus hookerianus.

Erigeron macranthus.

Parnassius smintheus:

Allium recurvatum.

Drymocallis fissa.

Geranium caespitosum.

Iris missouriensis.

Pentstemon secundifforus.

Potentilla pulcherrima.

Peleteria robusta:

Erigeron macranthus.

Phorbia fusciceps:

Erigeron macranthus. 
Phorbia fusciceps-Con. Holodiscus dumosus. Potentilla pulcherrima.

Phormia regina:

Pentstemon gracilis. Tradescantia virginiana.

Phyciodes camillus:

Rubus deliciosus.

Sedum stenoptetalum.

Pieris protodice:

Sedum stenopetalum.

Pieris sisymbri: Carduus hookerianus.

Pipiza vanduzeei:

Rubus deliciosus.

Pipiza sp.:

Rosa acicularis.

Rubus deliciosus.

Pompiloides sp.:

Pentstemon glaber.

Stanleya pinnatifida.

Prosopis basalis:

Chamaenerion angustifolium.

Geranium caespitosum.

Pentstemon gracilis.

halli.

secundiflorus.

Rosa acicularis.

Rubus deliciosus.

Prosopis coloradensis:

Rosa acicularis.

Prosopis cressoni:

Rubus deliciosus.

Prosopis elliptica:

Apocynum androsaemifolium.

Chamaenerium angustifolium.

Dasyphora fruticosa.

Erigeron macranthus.

Geranium caespitosum. richardsoni.

Monarda fistulosa.

Pentstemon glaber.

glaucus. gracilis. secundiflorus.

Rosa acicularis.

Rubus deliciosus.

Prosopis episcopalis:

Galium boreale.

Pentstemon glaber.

Rubus strigosus.

Prosopis tridentula:

Geranium caespitosum.

Prosopis varifrons:

Apocynum androsaemi-

folium.

Geranium caespitosum. richardsoni.

Holodiscus dumosus.

Opulaster opulifolius.

Pentstemon glaber.

gracilis. unilateralis.

Rubus deliciosus.
Prosopis varifrons-Con. Rubus strigosus. Rosa acicularis.

Prosopis wootoni:

Geranium caespitosum.

Pentstemon glaber.

Rosa acicularis.

Rubus deliciosus.

Prosopis sp.

Solidago missouriensis.

Protoparce quinquemaculatus Pachylophus caespitosus.

Protothyreopus dilectus: Geranium caespitosum.

Psammophila violacepennis: Geranium caespitosum.

Pseudomasaris vespoides:

Calochortus gunnisoni.

Geranium caespitosum.

Mertensia sibirica.

Monarda fistulosa.

Opulaster opulifolius.

Prunus demissa.

Pentstemon glaber. glaucus. gracilis.

Rubus deliciosus. strigosus.

Pseudomelecta californica miranda:

Asclepias halli.

Psithyrus ashtoni:

Chamaenerium angustifolium.

Geranium caespitosum.

Psithyrus consultus: Delphinium scopulorum.

Monarda fistulosa.

Solidago missouriensis.

Psithyrus fernaldae:

Carduus hookerianus.

Psithyrus insularis:

Aquilegia coerulea.

Carduus hookerianus.

Chamaenerium angustifolium.

Dasyphora fruticosa.

Gentiana parryi.

Geranium caespitosum.

Ptilodexia harpasa:

Prunus demissa.

Pyrameis atlanta:

Carduus hookerianus.

Linaria vulgaris.

Satyrus charon:

Carduus hookerianus.

Erigeron macranthus.

Sedum stenopetalum.

Scaba opinator:

Mertensia sibirica.

Selasphorus platycercus:

Castilleia miniata.

Iris missouriensis.

Mertensia sibirica.

Monarda fistulosa.

Pentstemon gracilis. secundiflorus.
Solenius sp.:

Chamaenerium angustifolium.

Specomyia vittata:

Prunus demissa.

Spegina infuscata:

Prunus demissa.

Sphaerophoria cylindrica:

Rosa acicularis.

Sphecodes sophiae:

Chamaenerium angustifolium.

Lappula floribunda.

Potentilla arguta. gracilis.

Prunus pennsylvanica. virginiana.

Valeriana edulis.

Sphex vulgaris:

Geranium caespitosum.

Sterictophora sp.:

Petalostemon candidus.

Synanthedon albicornis:

Achillea millefolium.

Rubus strigosus.

Syritta pipiens:

Prunus demissa.

Syrphus amalopis:

Geranium caespitosum.

Syrphus americanus:

Asclepias halli.

Chamaenerium angustifolium.

Frasera speciosa.

Geranium caespitosum.

Pentstemon gracilis.

Rosa acicularis.

Rubus deliciosus. strigosus.

Tradescantia virginiana.

Syrphus disgregus:

Prunus demissa.

Syrphus nitens:

Rubus deliciosus.

Syrphus opinator:

Gentiana parryi.

Geranium caespitosum.

Pentstemon gracilis. secundiflorus.

Rosa acicularis.

Systoechus vulgaris:

Pentstemon gracilis.

Rosa acicularis.

Rubus deliciosus.

Tabanus rhombicus:

Geranium caespitosum.

Temnostoma aequale:

Rubus deliciosus.

Tenthredella unicincta:

Erigeron macranthus.

Pentstemon glaber.

Tenthredella flavomarginis:

Heracleum lanatum.

Tetrachrysis lauta:

Pentstemon glaber. 
Tetraopes sp.:

Asclepias halli.

Thanaos martialis:

Chamaenerium angusti-

folium.

Delphinium scopulorum.

Erigeron macranthus.

Geranium caespitosum. richardsoni.

Mertensia sibirica.

Monarda fistulosa.

Pentstemon glaber.

Thanaos propertius:

Capnoides aureum.

Theventimtia muricatus:

Prunus demissa.

Thyreocorisanthracina:

Frasera speciosa.

Physaria didymocarpa.
Titusella pronitens:

Pentstemon glaber. gracilis.

Trichius affinis:

Calochortus gunnisoni.

Trichodes ornatus:

Rubus deliciosus.

Trichopticus septentrionalis:

Rubus deliciosus.

Triepeolus helianthi grandior: Asclepias halli.

Trypeta occidentalis: Achillea millefolium.

Vespa germanica: Chamaenerium angustifolium.

Jamesia americana. Mertensia sibirica.

Monarda fistulosa. Opulaster opulifolius. Pentstemon glaber. unilateralis.
Vespa occidentalis:

Erigeron macranthus.

Linaria vulgaris.

Volucella rufomaculata:

Castilleia miniata.

Rubus deliciosus. strigosus.

Volucella satur:

Rubus deliciosus.

Stanleya pinnatifida.

Xylota angustiventris:

Heracleum lanatum.

Xylota flavitibia:

Holodiscus dumosus.

Rosa acicularis.

Rubus deliciosus.

Xylota nigra:

Rosa acicularis.

Zodion pygmaeum:

Prunus demissa. 


\section{FLOWERS AND THEIR VISITORS.}

Achillea millefolium:

Agathis vulgaris.

Chrysophanus helloides.

Gnophaela vermiculata.

Halicyoides mamus.

Panzeria radicum.

Synanthedon albicornis.

Trypeta occidentalis.

Aconitum columbianum:

Bombus appositus. bifarius. edwardsi. flavifrons. juxtus. occidentalis. rufocinctus.

Allium recurvatum:

Bombus edwardsi. occidentalis.

Parnassius smintheus.

Apocynum androsaemifolium: Halictus (Evylaeus) sp.

Monumetha albifrons.

Prosopis elliptica. varifrons.

Aquilegia brevistyla: Bombus hunti.

Aquilegia coerulea:

Bombus hunti. occidentalis.

Clisodon terminalis.

Psithyrus insularis.

Aragalus lamberti:

Anthophora simillima

Arctostaphylus uva-ursi :

Apis mellifica.

Bombus edwardsi.

Asclepias halli:

Apis mellifica.

Bembex spinolae.

Halictus (Chloralictus) sp.

Pseudomelecta miranda.

Syrphus americanus.

Tetraopes sp.

Triepeolus helianthi grandior.

Asclepias speciosa:

Apis mellifica.

Echinomyia decisa.

Halictus(Lasioglossum)sp.

Astragalus drummondi:

Andrena gardineri. imitatrix. vicina.

Bombus edwardsi. fervidus. hunti. juxtus. morrisoni.

Halictus (Evylaeus) sp. Megachile wootoni. Monumetha albifrons.
Aster foliaceus:

Bombus edwardsi. flavifrons.

Calochortus gunnisoni:

Bombus edwardsi. flavifrons. occidentalis. rufocinctus.

Curtipogon leucozona.

Dasyllis fernaldi.

Panurginus sp.

Pseudomasaris vespoides.

Trichius affinis.

Caltha leptosepala:

Irbisia brachycerus.

Ophion sp.

Campanula rotundifolia:

Anthophora smithi.

Bombus edwardsi. hunti. juxtus.

Chrysophanus rubidus.

Megachile wootoni.

Odynerus annulatus.

Capnoides aureum:

Anthophora simillima.

Atrytone taxiles.

Bombomelecta fulvida.

Bombus dorsalis. juxtus. occidentalis.

Colletes oromontis.

Osmia densa.

Thanaos propertius.

Carduus hookerianus:

Acmaeops longicornis.

Andrena crataegi.

Andronicus sp.

Bombus appositus. bifarius. edwardsi. hunti. juxtus. nevadensis. occidentalis.

Chrysophanus rubidus.

Clisodon terminalis. sp.

Colias edwardsi. scudderi.

Epalpus bicolor. rufus.

Erizoa olivalis.

Grapta hylas.

Megachile pugnata. wootoni. sp.

Melissodes sp.

Monumetha albifrons.

Parnassius clodius.

Pieris sisymbri.

Psithyrus fernaldae. insularis.
Carduus hookerianus-Con.

Pyrameis atlanta.

Satyrus charon.

Castilleia miniata:

Bombus hunti. kirbyellus. occidentalis.

Colias keewaydinus.

Halictus (Chloralictus) sp.

(Evylaeus) sp.

(Lasioglossum)

sp.

pulzenus.

Selasphorus platycercus.

Volucella rufomaculata.

Chamaenerium angustifolium:

Anthophora occidentalis. smithi.

Apis mellifica.

Argynnis atlantis.

Atrytone taxiles.

Bombus appositus.

bifarius.

centralis.

edwardsi.

flavifrons.

hunti.

juxtus.

nevadensis.

occidentalis.

rufocinctus.

Clisodon terminalis.

Coelioxys moesta.

Ctenucha sp.

Dasyllis fernaldi.

Dejeania vexatrix.

Dolichovespula arctica. diabolica.

Echinomyia algens.

Erynnis leonardus snowi.

Halictus (Evylaeus) sp.

(Lasioglossum)

sp.

pulzenus.

Megachile gemula albuls.

pugnata.

relativa.

texana.

vidua.

wootoni.

wootoni calo-

gaster.

Melissodes aurigenia.

Monumetha albifrons. argentifrons.

Osmia wardiana.

Prosopis basalis.

$$
\text { elliptica. }
$$

Psithyrus ashtoni insularis.

Solenius sp.

Sphecodes sophiae.

Syrphus americanus. 
hamaenerium angustifolium

-Con.

Thanaos martialis.

Vespa germanica.

Chrysopsis villosa:

Bombus edwardsi. juxtus.

Echinomyia algens.

Cleome serrulata:

Bombus edwardsi.

Eliphilus latifrons.

Clementsia rhodantha:

Anthomyia sp.

Dasyphora fruticosa:

Bombus flavifrons.

Brenthis triclaris.

Coenonympha pamphiloides.

Erebia epipsodea.

Prosopis elliptica.

Psithyrus insularis.

Delphinium scopulorum:

Bombus appositus.

bifarius.

centralis.

edwardsi.

flavifrons.

juxtus.

morrisoni. occidentalis.

Dolichovespula arctica.

Psithyrus consultus.

Thanaos martialis.

Dodocatheon meadia:

Anthophora simillima.

Bombus bifarius. edwardsi. flavifrons.

Draba aurea:

Chionobis macouni.

Drymocallis fissa:

Bombus edwardsi.

Irbisia brachycerus.

Parnassius smintheus.

Elephantella groenlandica:

Bombus bifarius.

Osmia bruneri.

Erigeron macranthus:

Andrena apacheorum.

Anthrax fulviana. tegminipennis.

Argynnis atlantis.

Bombus bifarius. edwardsi. hunti.

Bracon helena.

Brenthis helena.

Chrysophanus helloides.

Coenonympha pamphiloides.

Megachile pugnata.

Parnassius clodius.

Panurginus cressoniellus.

Panzeria radicum.

Peleteria robusta.

Prosopis elliptica.
| Erigeron macranthus-Con. Satyrus charon.

Tenthredella unicincta.

Thanaos martialis.

Vespa occidentalis.

Erigeron uniflorus:

Bombus hunti. occidentalis.

Erysimum asperum: Bombus occidentalis.

Fragaria vesca:

Bombus edwardsi.

Heriades gracilior.

Osmia fulgida.

Frasera speciosa:

Apis mellifica.

Andrena crataegi. madronitens.

Bombus edwardsi. flavifrons. hunti. juxtus.

Clisodon terminalis.

Halictus lerouxi. pulzenus. sp.

Misnumetha albifrons.

Syrphus americanus.

Thyreocoris anthracina.

Galium boreale:

Lycaena glaucon.

Prosopis episcopalis.

Geum rivale:

Archytas sp.

Gentiana parryi:

Bombus appositus. juxtus. nevadensis.

Psithyrus insularis.

Syrphus opinator.

Geranium caespitosum:

Ancistrocerus sp.

Andrena apacheorum.

braccata. madronitens. vicina.

Andronicus sp.

Apanteles sp.

Apis mellifica.

Argynnis eurynome.

Bombus appositus. bifarius. edwardsi. hunti. juxtus. occidentalis. rufocinctus.

Cenis uhleri.

Clisodon terminalis.

Coelioxys moesta.

Colletes kincaidi. oromontis. sieverti.

Epeolus helianthi.

Erebia epipsodea.

Foenus perplexus.
Geranium caespitosum-Con.

Glypta sp.

Halictus (Chloralictus) sp.

(Lasioglossum)

$8 p$.

medionitens.

pulzenus.

Hammerschmidtia ferruginea.

Irbisia brachycerus.

Lemonias nubigena wheeleri.

Lycaena pseudargiolus.

Megachile pugnata. relativa.

Melissodes sp.

Monumetha albifrons.

Osmia bruneri.

densa.

phaceliae. propinqua. sp.

Panurginus cressoniellus.

Parnassius smintheus.

Protothyreopus dilectus.

Prosopis basalis. elliptica. tridentula. varifrons. wootoni.

Psammophila violacepennis.

Pseudomasaris vespoides.

Psithyrus insularis.

Sphex vulgaris.

Syrphus amalopis. americanus. opinator.

Tabanus rhombicus.

Thanaos martialis.

Geranium richardsoni:

Ancistrocerus sp.

Andrena madronitens.

Apis mellifica.

Bombus bifarius. hunti. occidentalis.

Ectemius montanus.

Halictus pulzenus.

Megachile relative.

Osmia fulgida.

Prosopis elliptica. varifrons.

Thanaos martialis.

Gilia aggregata:

Halictus (Chloralictus) sp. pulzenus.

Helianthus petiolaris:

Argynnis eurynome.

Bombus hunti.

Lemonias nubigena wheeleri.

Heracleum lanatum:

Anthrax hypomelas. 
Heracleum lanatum-Con.

Bombus occidentalis.

Echinomyia algens.

Eclimus muricatus.

Hammerschmidtia ferruginea.

Tenthredella flavomarginis.

$\mathrm{Xylota}$ angustiventris.

Holodiscus dumosus:

Andrena crataegi. madronitens.

Anthrax alternata.

Apis mellifica.

Bombus bifarius.

edwardsi.

hunti.

juxtus.

occidentalis.

Chrysotoxum integrum.

Clisodon terminalis.

Colletes oromontis.

Halictus medionitens.

Hammerschmidtia ferruginea.

Phorbia fusciceps.

Prosopis varifrons.

Xylota flavitibia.

Ibidium strictum:

Bombus appositus. morrisoni.

Halictus sp.

Lygus pratensis.

Panurginus cressoniellus.

Iris missouriensis:

Chionobis macouni.

Osmia abnormis. bella.

Parnassius smintheus.

Selasphorus platycercus.

Jamesia americana:

Andrena edwiniae.

Ancistrocerus sp.

Apis mellifica.

Bombus bifarius. edwardsi. bunti.

juxtus. occidentalis.

Eristalis tenax.

Irbisia brachycerus.

Vespa germanica.

Lappula floribunda:

Sphecodes sophiae.

Lathyrus ornatus:

Bombus edwardsi.

Linaria vulgaris:

Apis mellifica.

Basilarchia weidemeyeri.

Bombus occidentalis.

Pyrameis atlanta.

Vespa occidentalis.

Lithospermum canescens: Anthophora simillima.

Malvastrum coccineum: Agapostemon splendens. Irbisia brachycerus.
Mentzelia multiflora:

Apis mellifica.

Bombus bifarius.

juxtus. occidentalis.

Mertensia pratensis: Clisodon terminalis.

Colletes oromontis.

Osmia albolateralis.

brevis.

densa.

hypoleuca. melanotricha.

nigrifrons.

pentstemonis. pusilla.

rohweri.

Mertensia sibirica:

Acmaeops longicornis.

Ancistrocerus sp.

Andrena madronitens.

Bombus bifarius.

edwardsi.

flavifrons.

fulvida.

juxtus.

occidentalis.

Bombomelecta fulvida.

Ceratina sp.

Clisodon sp.

Colletes oromontis.

sp.

Dejeania vexatrix.

Halictus (Chloralictus) sp. (Evylaeus) sp. pulzenus.

Monumetha albifrons.

Osmia coloradella.

densa.

nigrifrons.

pentstemonis. phaceliae.

Pseudomasaris vespoides.

Scaba opinator.

Selasphorus platycercus.

Thanaos martialis.

Vespa germanica.

Monarda fistulosa:

Andrena crataegi.

Anthophora smithi.

Argynnis atlantis.

Atrytone taxiles.

Bombus appositus.

bifarius.

centralis.

fervidus.

flavifrons.

hunti.

morrisoni.

occidentalis. pennsylvanica.

Chrysophanus sirius.

Clisodon termininalis.

Colletes oromontis.

Ctenucha sp.

Erynnis leonardus snowi.
Monarda fistulosa-Con.

Halictus (Chloralictus) sp.

(Lasioglossum)

sp.

manitonellus.

pulzenus.

Megachile wootoni.

Melissodes fremonti.

Osmia sp.

Prosopis elliptica.

Pseudomasaris vespoides.

Psithyrus consultus.

Selasphorus platycercus.

Thanaos martialis.

Vespa germanica.

Onagra biennis:

Andrena madronitens.

Bombus juxtus.

Megachile sp.

Opulaster opulifolius:

Andrena crataegi. madronitens.

Apis mellifica.

Bombus edwardsi. nevadensis. occidentalis.

Dejeania vexatrix.

Eristalis latifrons.

Halictus (Chloralictus) sp. (Lasioglossum) sp. pulzenus.

Megachile wootoni.

Osmia bruneri. densa.

Prosopis varifrons.

Pseudomasaris vespoides.

Vespa germanica.

Oreochrysum parryi:

Chrysophanus helloides.

Pachylophus caespitosus:

Celerio lineata.

Hyloicus separatus.

Protoparce quinquemaculatus.

Pedicularis parryi:

Bombus hunti. kirbyellus.

Pedicularis racemosa:

Bombus edwardsi. occidentalis.

Pentstemon glaber:

Agapostemon splendens.

Andrena madronitens. prunorum. vicina.

Anthophora bomboides. simillima.

Apis mellifica.

Atry tone taxiles.

Bombus appositus. bifarius. centralis. edwardsi. hunti.

juxtus.

kirbyellus. 
Pentstemon glaber-Con.

Bombus morrisoni. occidentalis. rufocinctus.

Bombomelecta fulvida.

Celerio lineata.

Clisodon terminalis. sp.

Gonochrysis densa.

Halictus (Chloralictus) sp. pulzenus.

Heriades gracilior.

Megachile wootoni. wootoni calogaster.

Melissodes fremonti.

Monumetha albifrons.

Omalus sp.

Osmia bruneri. coloradella. densa. melanotricha. phaceliae.

Oxybelus sp.

Panurginus sp.

Papilio rutulus.

Pompiloides sp.

Prosopis elliptica. episcopalis. varifrons. wootoni.

Pseudomasaris vespoides.

Tetrachrysis lauta.

Tenthredella unicincta.

Thanaos martialis.

Titusella pronitens.

Vespa germanica.

$\mathrm{Xylota}$ angustiventris.

Pentstemon glaucus:

Bombus bifarius. edwardsi. juxtus. morrisoni. occidentalis.

Clisodon terminalis.

Megachile wootoni.

Monumetha albifrons.

Osmia melanotricha. pentstemonis.

Prosopis elliptica.

Pseudomasaris vespoides.

Pentstemon gracilis:

Andrena washingtoni.

Andronicus sp.

Anthophora neomexicana.

Anthophora simillima.

Bombus appositus. bifarius. centralis edwardsi. hunti. juxtus. morrisoni. rufocinctus.

Bombomelecta fulvida.
Pentstemon gracilis-Con.

Ceratina sp.

Cerastomia lignaria.

Clisodon terminalis. sp.

Colletes kincaidi.

Halictus (Chloralictus) sp. (Evylaeus) sp. pulzenus.

Heriades gracilior.

Megachile wootoni calogaster.

Monumetha albifrons.

Osmia bruneri.

densa.

hypoleuca.

melanotricha.

pentstemonis. phaceliae.

Phormia regina.

Prosopis basalis. elliptica. varifrons.

Pseudomasaris vespoides.

Selasphorus platycercus.

Syrphus americanus. opinator.

Systoechus vulgaris.

Titusella pronitens.

Penstemon halli:

Anthophora simillima.

Halictus pulzenus.

Osmia densa. melanotricha. phaceliae.

Monumetha albifrons.

Prosopis basalis.

Penstemon secundiflorus:

Andrena madronitens.

Anthophora simillima.

Argynnis atlantis.

Bombus bifarius. edwardsi. juxtus. occidentalis.

Clisodon terminalis.

Halictus pulzenus.

Osmia bruneri. pentstemonis.

Parnassius smintheus.

Prosopis basalis. elliptica.

Selasphorus platycercus. Syrphus opinator.

Pentstemon unilateralis:

Anthophora simillima.

Apis mellifica.

Bombus americanorum. fervidus. juxtus.

Prosopis varifrons.

Vespa germanica.

Petalostemon candidus:

Apis mellifica.

Bombus appositus. edwardsi. fervidus.
Petalostemon candidus-Con.

Bombus hunti. rufocinctus.

Sterictophora sp.

Petalostemon purpureus:

Apis mellifica.

Bombus appositus. edwardsi. fervidus. hunti. occidentalis rufocinctus.

Clisodon terminalis.

Colletes kincaidi.

Megachile pugnata. sp.

Phacelia heterophylla:

Chrysophanus rubidus.

Physaria didymocarpa:

Halictus sp.

Thyreocoris anthracina.

Polygonum bistorta:

Chrysotoxum upsilon.

Epalpus bicolor.

Gnophaela vermiculata.

Potentilla arguta:

Andrena vicina.

Bombus juxtus. kirbyellus.

Sphecodes sophiae.

Potentilla gracilis:

Anthrax hypomelas.

Bombus hunti.

Eristalis meigeni.

Mesogramma marginata.

Sphecodes sophiae.

Potentilla pulcherrima:

Bombus kirbyellus. occidentalis.

Chionobis macouni.

Chrysotoxum ventricosum.

Colias alexandra.

Erebia epipsodea.

Geocoris bullatus.

Gnophaela vermiculata.

Halictus medionitens. sp.

Nathalis iole.

Parnassius smintheus.

Prunus demissa:

Acmaeops longicornis. pratensis.

Agapostemon sp.

Andrena canadensis. crataegi. edwiniae. madronitens. prunorum. vicina. sp.

Bombus flavifrons. occidentalis.

Brachyopa notata.

Brenthis triclarius.

Calliphora vomitoria. 
Prunus demissa-Con.

Chilosia petulca. tristis.

Coenonympha pamphiloides.

Colletes kincaidi. oromontis.

Erebia epipsodea.

Eristalis arbustorum. dimidiatus. temporalis.

Halictus (Chloralictus) sp. (Evylaeus) sp. (Lasioglossum) sp. pulzenus. sp.

Microdon cothurnatus. Pseudomasaris vespoides. Ptilodexia harpasa.

Specomyia vittata.

Spegina infuscata.

Syrphus disgregus.

Syritta pipiens.

Thevenetimyia muricatus.

Zodion pygmaeum.

Prunus pennsylvanica:

Sphecodes sophiae.

Prunus virginiana:

Andrena crataegi. prunorum. vicina. sp.

Nomada sp.

Sphecodes sophiae. Rosa acicularis:

Acmaeops longicornis. pratensis.

Agapostemon splendens.

Andrena crataegi. madronitens. vicina. washingtoni. sp.

Anthrax lateralis. nigra.

Anthophora simillima. Apis mellifica. Arctophila flagrans.

Bombus appositus. bifarius. edwardsi. flavifrons. hunti. juxtus. morrisoni. occidentalis. rufocinctus.

Bombylius atriceps.

Chrysotoxum integrum.

Clisodon terminalis.

Colletes americanus.

Eristalis latifrons.

Halictus (Evylaeus) sp. manitonellus. medionitens. pulzenus.

Mallota flavoterminata.
Rosa acicularis-Con.

Megachile relativa. texana. wootoni. wootoni calogaster.

Monumetha albifrons.

Osmia bruneri. densa.

fulgida. melanotricha. propinqua.

Panurginus cressionellus.

Pipiza sp.

Prosopis basalis. coloradensis. elliptica. varifrons. wootoni.

Sphaerophoria cylindrica. Syrphus americanus. opinator.

Systoechus vulgaris.

Xylota flavitibia. nigra.

Rubus deliciosus:

Acmaeops longicornis. pratensis.

Ancistrocerus sp.

Andrena canadensis. crataegi. madronitens. placida. prunorum. vicina.

Andronicus sp.

Apis mellifica.

Bombus americanorum. appositus. bifarius. edwardsi. fervidus. flavifrons. hunti.

juxtus.

kirbyellus. morrisoni. occidentalis. rufocinctus.

Brachyopa notata. Chrysogaster parva.

Colletes oromontis.

Eristalis flavipes. latifrons. temporalis.

Exoprosopa caliptera.

Halictus (Lasioglossum) sp. medionitens. pulzenus. sp.

Heringia salix.

Megachile wootoni. wootoni calogaster.

Melitaea sp.

Monumetha albifrons.

Myopa clausa.
Rubus deliciosus-Con.

Nomada sp.

Osmia fulgida. propinqua.

Panurginus cressionellus. $\mathrm{sp}$.

Phyciodes camillus.

Pipiza vanduzeei. $\mathrm{sp}$.

Prosopis basalis. cressoni. elliptica. varifrons. wootoni.

Pseudomasaris vespoides.

Systoechus vulgaris.

Syrphus americanus. nitens.

Temnostoma aequale.

Tricopticus septen-

trionalis.

Trichodes ornatus.

Volucella rufomaculata. satur.

Xylota flavitibia.

Rubus strigosus:

Ancistrocerus sp.

Andrena crataegi. lewisi. madronitens. vicina.

Anthophora simillima.

Apis mellifica.

Bombus bifarius. edwardsi. flavifrons. hunti. juxtus. morrisoni. occidentalis.

Clisodon terminalis.

Colletes oromontis.

Eristalis arbustorum.

Gnophaela vermiculata.

Halictus (Lasioglossum) sp. pulzenus. sp.

Megachile wootoni.

Osmia propinqua.

Prosopis episcopalis. varifrons.

Pseudomasaris vespoides.

Synthedon albicornis.

Syrphus americanus.

Volucella rufomaculata.

Rydbergia grandiflora:

Argynnis eurynome.

Bombus appositus. edwardsi. flavifrons. hunti.

Eristalis temporalis.

Lemonias nubigena wheeleri.

Melitaea whitneyi.

Osmia megacephala. 
Sambucus racemosa:

Leptura chrysocoma.

Scutellaria resinosa:

Bombus morrisoni.

Sedum stenopetalum:

Andrena madronitens.

Anthidium tenuiflorae.

Anthrax sinuosa.

Argynnis eurynome.

Bombus edwardsi. hunti.

Exoprosopa divisa.

Phyciodes camillus.

Pieris protodice.

Satyrus charon.

Sieversia ciliata:

Bombus edwardsi. occidentalis.

Halictus sp.

Sieversia turbinata:

Paragus bicolor.

Silene acaulis:

Exoprosopa volucris.

Silene halli:

Osmia hypoleuca.

Solidago missouriensis:

Anthrax halcyon.

Apis mellifica.

Bombus edwardsi.
Solidago missouriensis-Con. Bombus flavifrons. hunti. occidentalis. rufocinctus.

Colletes americanus. oromontis.

Epalpus bicolor.

Gnophaela vermiculata.

Halictus sp.

Mordella melaena.

Prosopis sp.

Psithyrus consultus.

Stanleya pinnatifida:

Agapostemon coloradensis.

sp.

Andrena vicina.

Apis mellifica.

Bombus bifarius. hunti.

morrisoni. rufocinctus.

Bracon vulgaris.

Ceratina sp.

Lithargus apicalis opuntiae.

Odynerus annulata.

Pompiloides sp.

Volucella satur.
Taraxacum officinale: Agapostemon coloradensis. splendens.

Apis mellifica.

Osmia propinqua.

Thermopsis montana:

Bombus americanorum. hunti.

juxtus.

Megachile wootoni.

Osmia sp.

Thalictrum fendleri:

Apis mellifica.

Halictus fendleri. sp.

Tradescantia virginiana:

Anthrax sinuosa.

Apis mellifica.

Halictus (Evylaeus) sp.

Panurginus sp.

Phormia regina.

Syrphus americanus.

Trifolium dasyphyllum:

Bombus hunti. kirbyellus.

Valeriana edulis:

Epalpus rufus.

Sphecodes sophiae. 


\section{BIBLIOGRAPHY.}

Aigner-Abafi, L. 1900. Gorka "Die Insekten und die Blumen." Ill. Zeits. Ent. 5:57. AlLARD, H. A. 1911. Some experimental observations concerning the behavior of various bees in their visits to cotton blossoms. I, Am. Nat. 45:607; II, Ib., 45:668. Jour. Anim. Behav. 2:383.

Andreae, E. 1903. Inwiefern werden Insekten durch Farbe und Duft der Blumen angezogen? Beih. Bot. Cent. 15:427.

Balbiani, E. G. 1866. Note sur les antennes servant aux insectes pour la recherche des sexes. Ann. Soc. Ent. France 6:xxxvirI.

Barrows, W. 1907. The reactions of the pomace fly, Drosophila ampelophila Loew, to odorous substances. Jour. Exp. Zool. 4:515.

Bedford, F. P. 1897. Pieris brassicae attracted by artificial flowers. Entomology 30:197. Rev. Scient. 8:56.

BEDEL, L. 1900. Sur la fécondation du jasmine. Rev. Scient. 14:727.

Belvorr, W. J. 1860 . The sagacity of the humble-bee. Gard. Chron. - 853.

Benary, H. 1900. Eine getäuschte Hummel. Ill. Zeits. Ent. 5:203.

BenNetT, A. W. 1881. On the constancy of insects in their visits to flowers. Rep. Brit. Assoc. 50:667; Nature 24:501. Proc. Linn. Soc. Zool. 17:176; Nature 27:498.

Bessey, C. E. 1897. The phylogeny and taxonomy of Angiosperms. Bot. Gaz. 24:145.

- 1907. A synopsis of plant phyla. Univ. Nebr. Stud. 7:285.

- 1909. The phyletic idea in taxonomy. Science 29:91.

Bethe, A. 1898. Dürfen wir den Ameisen und Bienen psychische Qualitäten zuschreiben? Arch. Ges. Physiol. 70:15.

-1 1902. Die Heimkehrfähigkeit der Ameisen und Bienen zum Theil nach neuen Versuchen. Biol. Cent. 7:193; 8:234.

Blanchard, R. 1891. Erreur des sens chez un lépidoptère. Bull. Soc. Zool. France $16: 23,205$.

Bonnier, G. 1878. Les nectaires. Etude critique, anatomique et physiologique. Ann. Sci. Nat. Bot. 6:8:5. Summary in Comp. Rend. 88:662, 1879.

Bouvier, E. L. 1900. Le retour au nid chez les hyménoptères prédateurs du genre Bembex. Comp. Rend. Soc. Biol. 52:874.

-1922. The psychic life of insects. Trans. by Howard.

Burton, F. M. 1878. Insects and artificial flowers. Nature 17:162.

Bulman, G. W. 1890. On the supposed selective action of bees on flowers. Zoologist $14: 424$.

1892. The constancy of the bee. Trans. Nat. Hist. Soc. Glasgow 5:85.

-1 1897. Bees and the development of flowers. Nat. Sci. 11:103.

- 1899. Bees and the origin of flowers. Ib. 14:128.

Buttel-Reepen, H. 1900. Sind die Bienen "Reflexmaschinen"? Experimentelle Beiträge zur Biologie der Honigbiene. Biol. Cent. 20:97.

\begin{tabular}{l} 
1905. Der Geruchssinn der Bienen. Bienenw. Cent. 41:95. \\
\hline 1907. Are bees reflex machines? Trans. by Geisler. \\
1907. Zur Psychobiologie der Hummeln. Biol. Cent. 27:579, 604. Psycho- \\
biologische und biologische Beobachtungen an Ameisen, Bienen und \\
Wespen. Naturw. Wochens.
\end{tabular}

\begin{tabular}{l} 
1905. Der Geruchssinn der Bienen. Bienenw. Cent. 41:95. \\
\hline 1907. Are bees reflex machines? Trans. by Geisler. \\
Bur Psychobiologie der Hummeln. Biol. Cent. 27:579, 604. Psycho- \\
biologische und biologische Beobachtungen an Ameisen, Bienen und \\
Wespen. Naturw. Wochens.
\end{tabular}

\begin{tabular}{l} 
1905. Der Geruchssinn der Bienen. Bienenw. Cent. 41:95. \\
\hline 1907. Are bees reflex machines? Trans. by Geisler. \\
Zur Psychobiologie der Hummeln. Biol. Cent. 27:579, 604. Psycho- \\
biologische und biologische Beobachtungen an Ameisen, Bienen und \\
Wespen. Naturw. Wochens.
\end{tabular}

\begin{tabular}{l} 
1905. Der Geruchssinn der Bienen. Bienenw. Cent. 41:95. \\
\hline 1907. Are bees reflex machines? Trans. by Geisler. \\
Zur Psychobiologie der Hummeln. Biol. Cent. 27:579, 604. Psycho- \\
biologische und biologische Beobachtungen an Ameisen, Bienen und \\
Wespen. Naturw. Wochens.
\end{tabular}

\begin{tabular}{l} 
1905. Der Geruchssinn der Bienen. Bienenw. Cent. 41:95. \\
\hline 1907. Are bees reflex machines? Trans. by Geisler. \\
bur Psychobiologie der Hummeln. Biol. Cent. 27:579, 604. Psycho- \\
biologische und biologische Beobachtungen an Ameisen, Bienen und \\
Wespen. Naturw. Wochens.
\end{tabular}

—. 1908. Der Geruchsvermögen der Bienen. Ib. $44: 352$.

- 1914. Dysteleologen in der Natur (Zur Psychobiologie der Hummeln II) Biol. Cent. 34:664.

- 1915. Leben und Wesen der Bienen.

Claparède, E. 1903. La faculté d'orientation lointaine. Arch. Psych. Geneve 2:132.

Clements, F. E., and Long, F. L. 1918-1923. Experimental pollination. Year Books 17 to 22, Carnegie Inst. Wash.

Chatin, J. 1880. Les organs des sens dans la série animale. 
Cornalia, E. 1856. Monografia del bombice del gelso. Mem. Real. Inst. Lomb. Sci. 6:1.

DAHL, F. 1889. Die Insekten können Formen unterscheiden. Zool. Anz. 12:243.

DARwin, C. 1876. The effects of cross and self fertilization in the vegetable kingdom.

Deupino, F. 1867. Sugli apparecchi della fecondazione nelle piante autocarpee.

Detro, C. 1905. Biologische Untersuchungen. II. Versuche über die Blütenorientierung und das Lernen der Honigbiene. Flora 94:424.

Doвkiewicz, L. 1912. Beitrag zur Biologie der Honigbiene. Biol. Cent. 32: 664 .

Dodel-Port, A. 1880. Ein direkter Beweis von der Konkurrenz der Blumen um die Gunst der sie besuchenden Insekten. Kosmos 7:294.

Dönhofr, E. 1861. Vom Geruchsorgan der Bienen. Bien. Zeit. 1:507.

Duвors, R. 1895. Sur le rôle de l'olfaction dans les phénomènes d'accouplement chez les papillons. Comp. Rend. Assoc. Fran. Avan. Sci. Bordeaux. 24: 1:293.

Dugés, A. 1838. Traité de physiologie comparée, 1:160.

Errera, L., and G. Gevaert. 1878. Sur la structure et les modes de fécondation des fleurs. Bull. Soc. Roy. Bot. Belg. 12:102.

Exner, S. 1875. Ueber das Sehen von Bewegungen und die Theorie des zusammengesetzten Auges. Sitzb. Akad. Wiss. Wien 72:156.

1881. Die Frage von der Functionsweise der Facettenaugen. Biol. Cent. 1:272.

- 1891. Die Physiologie der facettierten Augen der Krebsen und Insekten.

FABRE, J. H. 1879. Souvenirs entomologiques. Première série. XIX. Retour au nid. p. 261. XX. Les Chalicodomes. p. 275. XXI. Experiences. p. 293.

- 1882. Id. Deuxième série. VII. Nouvelles recherches sur les Chalicodomes. p. 99. Id. Septième série. VII. L'instinct botanique.

Ferton, C. 1894. Seconde note sur les mœurs de quelques Hyménoptères du genre Osmia. Act. Soc. Linn. Bordeaux 47:

-1901. Notes détachées sur l'instinct des hyménoptères mellifères et ravisse Ann. Soc. Ent. France 70:83. Sur le peu variabilité de l'instinct ches les hyménoptères, p. 88 . Fleurs et insectes, p. 95. Intelligence et instinct, p. 141.

Id. Ib. $71: 503$.

1902. Variation de l'instinct chez l'Osmia papaveris.

1905. Id. Ib. 74:56. Fleurs et insectes, p. 63. Le retour au nid, p. 89.

1908. Id. Ib. $77: 535$. Le retour au nid (Le sens musculaire et l'attention), p. 578 .

Fielde, A. M.

Id. Ib. 79:176. L'attention dans le retour au nid.

1901. A study of an ant. Proc. Acad. Nat. Sci. Phil. 53:425.

$1901^{2}$. Further study of an ant. Ib. 521.

1902. Notes on an ant. Ib. 54:599.

Focke, W. O. 1889. Blumen und Insekten. Abh. Naturw. Ver. Bremen 10:437.

Fores, A. 1874. Les fourmis de la Suisse. Nouv. Mem. Soc. Helv. Sci. Nat. 26:118.

1878. Beitrag zur Kenntniss der Sinnesempfindungen der Insekten. Mitt. Münch. Ent. Ver. 2:21.

1886. Expériences et remarques critiques sur les sensations des insectes. Première partie. Rec. Zool. Suisse 4:1. Deuxième partie. Ib. 30, 145.

1888. Appendices à mon mémoire sur les sensations des insectes. Ib. 515.

1901. Critiques des expériences faîtes des 1887. Riv. Biol. Gen. Como 3:

$1901^{2}$. Die psychischen Fähigkeiten der Ameisen und anderer Insekten: mit einem Anhang über die Eigenthümlichkeiten des Geruchsinnes bei jenen Tieren. Vortr. Inter. Zool.-Kong. Berlin 1901.

1904. Ants and some other insects. An inquiry into the psychic powers of these animals, with an appendix on the peculiarities of their olfactory sense. Trans. by Wheeler.

1903. Nochmals Herr Dr. Bethe und die Insekten Psychologie. Biol. Cent. 23:1.

1907. Mémoire du temps et association des souvenirs chez les abeilles. Comp.

Rend. Assoc. Fran. Avan. Sci. Lyon 1906. 2:459 (note only in 1:104).

1908. The sensations of insects. Trans. by Yeardsley.

Forbes, H. O. 1878. Selective discrimination of insects. Nature 17:62.

Frisch, K. 1913. Zur Frage nach dem Farbensinn der Tiere. Verh. Ges. Naturf. Aerzt., p. 1. 
Frisch, K. 19132. Ueber den Farbensinn der Bienen und die Blumenfarbe. Münch. Med. Wochens., p. 1.

1914. Demonstration von Versuchen zum Nachweis des Farbensinnes bei angeblich total farbenblinden Tiernen. Verh. Deut. Zool. Ges.

Der Farbensinn und Formensinn der Biene. Zool. Jahrb. 35:1.

1915. Ueber den Geruchsinn der Biene und seine Bedeutung für den Blumenbesuch. Verh. Zool. Bot. Ges. Wien. 65:

1918. Id. II. Ib. 68:

1919. Zur Streitfrage nach dem Farbensinn der Bienen. Biol. Cent. 39:122. Ueber den Geruchsinn der Biene und seine blütenbiologische Bedeutung. Zool. Jahrb. 37:1.

Gazagnaire, J. 1895. Au sujet de la communication de M. P. Lesne: Sur le rôle de la vision chez les diptères mélitophiles. Ann. Soc. Ent. France 64: ccxlır.

Grutax, E. 1900. L'enseignement botanique a l'École supérieure d'agriculture et forestière de Wageningen tel qu'il se trouve représenté à l'Exposition universelle de Paris de 1900, pp. 14-16. Cf. Plateau 1902:657.

- 1904. Ueber die Bedeutung der Krone bei den Blüthen und über das Farbenunterscheidungsvermögen der Insekten. I. Jahrb. Wiss. Bot. 40:368.

1906. Id. II. Ib. $43: 468$.

GorkA, A. 1898. Zwei biologische Erscheinungen. Rovart. Lapok. 4:197. Ill. Zeits. Ent. 3:270.

1900. Die Insekten und die Blumen. Rovart. Lapok. 5:139. Ill. Zeits. Ent. $5: 57$.

Graber, V. 1884. Grundlinien zur Erforschung des Helligskeits und Farbensinnes der Thiere.

1885. Vergleichende Grundversuche über die Wirkung und die Aufnahmestellen chemischer Reize bei den Tieren. Biol. Cent. 5:385.

—. 1887. Neue Versuche über die Function der Insektenfühler. Ib. 7:13.

Gratacap, L. P. 1883. Color preferences in nocturnal Lepidoptera. Am. Nat. 17:791.

Grenacher, H. 1874. Zur Morphologie und Physiologie des facettierten ArthropodenAuges. Nachr. Ges. Wiss. Göttingen, p. 645.

Hadser, G. 1880. Physiologische und histologische Untersuchungen über das Geruchsorgan der Insekten. Zeit. Wiss. Zool. 34:367.

Hess, C. 1913. Experimentelle Untersuchungen über den angeblichen Farbensinn der Bienen. Zool. Jahrb. 34:81.

—_. 1916. Messende Untersuchung des Lichtsinnes der Biene. Archiv. Ges. Physiol. 163:289.

—_ 1917. Der Farbensinn der Vögel und die Lehre von den Schmuckfarben. Ib. $166: 381$.

Ueber die Bedeutung bunter Farben bei Pflanzen und Tieren. Naturwissenschaften $5: 398$.

- 1918. Beiträge zur Frage nach einem Farbensinn bei Bienen. Archiv. Ges. Physiol. 170:337.

- 1919. Ueber Lichtreaktionen bei Raupen und die Lehre von den tierischen Tropismen. Ib. 177:108.

Hicks, J. B. 1857. On a new organ in insects. Jour. Linn. Soc. Zool. 1:136.

-1 1859. Further remarks on the organs found on the bases of the halteres and wings of insects. Trans. Linn. Soc. Zool. 22:141.

- 1860. On certain sensory organs in insects, hitherto undescribed. Ib. 23:139. Hildebrand, F. 1867. Die Geschlechts-Verteilung bei den Pflanzen.

Нттснсоск, A. S. 1893. Pollination of Oenothera missouriensis and Pentstemon cobaea. Bull. Torr. Club 20:362: cf. Bot. Gaz. 18:345.

Horfer, E. 1886. Wunderbares Erinnerungsvermögen der Hummeln. Kosmos 18:111. Holmes, S. J. 1911. The evolution of animal intelligence.

Hodzead, J. C. 1872. Études sur les facultés mentales des animaux comparées à celles de l'homme.

Jong, E. 1891. De l'existence d'un soi-disant sens de direction ou d'orientation chez l'homme et les animaux. Comp. Rend. Soc. Helv. Sci. Nat. p. 4.

Katheriner, L. 1903. Versuche über die Art der Orientierung bei der Honigbiene. Biol. Cent. 23:1903. 
Keller, I. A. 1892. The phenomenon of fertilization in the flowers of Monarda fistulosa. Proc. Acad. Sci. Phila. 44:452.

Kelloga, V. L. 1907. Some silkworm moth reflexes. Biol. Bull. 12:152.

Kerner, A. 1876. Die Schutzmittel der Blüten gegen unberufene Gäste.

. 1878. Flowers and their unbidden guests. Trans. by Ogle.

Kienitz-Gerloff, F. 1896-1898. Felix Plateau, Comment les fleurs attirent les insects. Recherches expérimentales. Bot. Zeit. 54:124, 55:84, 108, 56:138.

1898. Professor Plateau und die Blumentheorie. Biol. Cent. 18:417.

1899. Felix Plateau, Nouvelles recherches sur les rapports entre les insectes et les fleurs. Ib. 19:349.

1. 1903. Professor Plateau und die Blumentheorie. Ib. 23:557.

Krnyon, J. 1907. Color of hives. Glean. Bee Cult. 35:262. KNoLL, F. 1919. Gibt es eine Farbendressur der Insekten? Die Naturwissenschaften

- 1921. Insekten und Blumen. Experimentelle Arbeiten zur Vertiefung unserer Kenntnisse über die Wechselbeziehungen zwischen Pflanzen und Tieren. Heft 1:I. Zeitgemäsze Ziele und Methoden für das Studium der Oekologischen Wechselbeziehungen. II. Bombylius fuliginosus und die Farbe Der Blumen. Abh. Zool. Bot. Ges. Wien 12:3.

1922. Id Heft 2. Lichtsinn und Blumenbesuch des Falters von Macroglossa
stellatarum. Ib. 12:125. KNUTH, P. 1898. Blütenbiologie.

18982. Künstliche Blumen und Syrphus. Ill. Zeits. Ent. 3:71.

1906. Handbook of flower pollination. Trans. by Davis.
Koelreuter, J. G. 1761 . Vorläufige Nachricht von einigen das Geschlecht der Pflanzen
betreffenden Versuchen betreffenden Versuchen und Beobachtungen.

Kranichaeld, H. 1915. Zum Farbensinn der Bienen. Biol. Cent. 35:39.

Krapelin, K. 1883. Ueber die Geruchsorgane der Gliederthiere.

Kronfeld, M. 1888. Zur Blumenstetigkeit der Bienen und Hummeln. Verh. Zool. Bot. Ges. Wien 38:785.

KüHN, A. 1919. Die Orientierung der Tiere im Raum.

1921. Nachweis des simultanen Farbenkontrastes bei Insekten. Die Naturand R. PoHL. 1921. Dressurfähigkeit der Bienen auf Spektrallinien. Ib. 9:738.

KURR, J. G. 1833. Untersuchungen über die Bedeutung der Nektarien in den Blumen. Küster, H. C. 1844. Zoologische Notizen:Die Fühlhörner sind die Riechorgane der Ladd-Franklin, C. 1913. A non-chromatic region in the spectrum for bees. Science

LAYARD, C. 1878. Smell and hearing in insects. Nature 18:301.

Lefervre, A. 1838. Note sur le sentiment olfactif des antennes. Ann. Soc. Ent. France 7:395.

Lesne, P. 1895. Sur le rôle de la vision chez les diptères mélitophiles. Ann. Soc. Ent.
France $64:$ cCXX.

LOEw, E. 1884. Beobachtungen über den Blumenbesuch von Insekten an Freilandpflanzen des Botanischen Gartens zu Berlin. Jahrb. Bot. Gard. Berlin

LONGYEAR, B. O. 1909. Rocky Mountain wild flower studies.

Lossing, W. 1906. Painting hives. Glean. Bee Cult. 34:1428. Lovell, J. H. 1909 . The color sense of the honey-bee: is conspicuousness an advantage
to flowers? Am. Nat. $43: 338$.

1310. The color sense of the honey-bee: can hees distinguish colors? Ib. $44: 673$.
1912. The color sense of the honey-bee: the pollination of green flowers. Ib.
$46: 83$.

- 19122. Bees which visit only one species of flower. Pop. Sci. Mon. 81:198.

- 1914. Conspicuous flowers rarely visited by insects. Jour. Anim. Behav. 4:147.

-19142. The origin of oligotropism. Ent. News. 25:314.

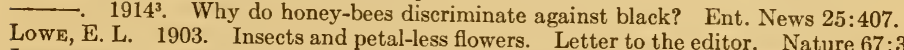

LUввоск, J. 1882 . Ants, bees, and wasps. Aners. Letter to the editor. Nature 67:368. the social Hymenoptera. 
Luввоск, J. 1882. Observations on ants, bees, and wasps. Colors of flowers as an attraction to bees: experiments and considerations thereon. Jour. Linn. Soc. Zool. 16:110.

1888. On the senses, instincts, and intelligence of animals, with special reference to insects.

LUdwig, F. 1885. Die biologische Bedeutung des Farbenwechsels mancher Blumen. Biol. Cent. 4:196.

—. 1887. Einige neue Fälle von Farbenwechsel in verblühenden Blüthenständen. Ib. $6: 1$.

MAcLeOD, J. 1894. Over de bevruchting der bloemen in het Kempisch gedeelte van Vlandered. Bot. Jaarb. Dodonaea 6:499.

Marchal, P. 1900. Le retour au nid chez Pompilus sericeus. Comp. Rend. Soc. Biol. $52: 1113$.

Marchand, E. 1900. Sur le retour au nid de Bembex rostrata Fabr. Bull. Soc. Sci. Nat. Ouest. 10:247.

Mayor, A. G. 1900. On the mating instinct in moths. Psyche 9:15; Ann. Mag. Nat. Hist. $7: 5: 183$.

McIndoo, N. E 1914. The olfactory sense of the honey-bee. Jour. Exp. Zool., 16:265.

- $1914^{2}$. The olfactory sense of the Hymenoptera. Proc. Acad. Nat. Sci. Phil. $66: 294$

—_ 1914 ${ }^{3}$. The olfactory sense of insects. Smithson. Misc. Coll. 63:9:1.

Meenan, T. 1876. Natural flowering of Mentzelia ornata. Self-fertilization in Mentzelia ornata. Proc. Acad. Nat. Sci. Phil. 18:173, 202.

-1 1892. Notes on Monarda fistulosa. Ib. 44:449.

Merritr, A. J. 1893. Notes on fertilization. Zoe 3:311.

1896. Notes on the pollination of some California mountain flowers. Erythrea $4: 101,147$

- 1897. Id. Ib. 5:1, 15, 56 .

Motelay, L. 1898. Note sur un papillon que la vue et non l'odeur des fleurs attirait. Act. Soc. Linn. Bordeaux 53: Lxiv.

MUEller, F. 1877. Flowers and insects. Nature 17:17.

Mueller, H. 1873. Die Befruchtung der Blumen durch Insekten und die gegenseitigen Anpassungen beider.

1880. Gaston Bonnier's angebliche Widerlegung der modernen Blumentheorie. Kosmos 7:219.

18802. Saxifraga umbrosa adorned with brilliant colors by the selection of the Syrphidae. Nature 22:219.

1881. Die Entwickelung der Blumenthätigkeit der Insekten. 4. Verschiedene Blumenthätigkeit der Männchen und Weibchen. Kosmos 9:415.

1883. Versuche über die Farbenliebhaberei der Honigbiene. Ib. 12:272.

18832. The fertilization of flowers. Trans. by Thompson.

1883 ${ }^{3}$. The effect of the change of colour in the flowers of Pulmonaria officinalis upon the fertilizers. Nature 28:81.

Mueller, J. 1826. Zur vergleichenden Physiologie des Gesichtsinnes.

NAEgELI, C. 1865. Entstehung und Begriff der naturhistorischen Art, p. 22.

OrD, G. W. 1897. The constancy of the bee. Trans. Nat. Hist. Soc. Glasgow 5:85.

PARKIN, J. 1897. A bee's movements in a room. Nature 57:8.

Peскнam, G. W. and E. G. 1887. Some observations on the special senses of wasps. Proc. Nat. Hist. Soc. Wis. 1:121.

- 1898. On the instincts and habits of the solitary wasps. Bull. Wis. Geol. Nat. Hist. Surv. 2:1.

PÉrez, J. 1889. Les abeilles.

1894. De l'attraction exercée par les odeurs et les couleurs sur les insectes. Act. Soc. Linn. Bordeaux 47:245.

- 1895. L'instinct des insectes et les observations de M. Fabre. Ib. 47:276.

- 1897. Sur les causes de l'attraction des fleurs sur les insectes. Ib. 52:Lxxxvr.

1903. De l'attraction exercée par les couleurs et les odeurs sur les insectes, deuxième mémoire. Mem. Soc. Phys. Nat. Bordeaux 6:3:1.

L'Labeille butineuse, est-elle fidèle à un espèce de plante déterminée. Ib. 24 .

Perris, E. 1850. Mémoire sur le siège de l'odorat dans les articulés. Ann. Sci. Nat. Zool. 3:14:149. 
Pieron, H. 1904. Du rôle du sense musculaire dans l'orientation des fourmis. Bull. Inst. Gen. Psych. $4: 168$. See also Ib. $6: 29$.

Plateau, F. 1877. L'instinct des insectes peut-il être mis en défaut par des fleurs artificielles? Expériences faítes à propos d'une observation de M. R. Vallete. Comp. Rend. Assoc. Fran. Avan. Sci., p. 535.

-1885. Recherches expérimentales sur la vision chez les insectes. Les insectes distinguent-ils la forme des objets? Bull. Acad. Roy. Belg. 3:10:231.

1887. Recherches expérimentales sur la vision chez les Arthropodes, première partie. $a$. Résumé des travaux effectués jusqu' in 1887 sur la structure et la fonctionnement des yeux simples. $b$. Vision chez les Myriopodes. Bull. Acad. Roy. Belg. 3:14:407. Id. Deuxième partie. Vision chez les Arachnides. Ib. 545 .

1886. Une expérience sur la fonction des antennes chez la blatte (Periplaneta orientalis). Bull. Comp. Rend. Ann. Soc. Ent. Belg. 30:118.

1888. Id. Troisième partie. a. Vision chez les chenilles. b. Rôle des ocelles frontaux chez les insects parfaits. Ib. 15:28. Id. Quatrième partie. Vision à l'aide des yeux composés. Résumé anatomo-physiologique et expériencessur les insectes. Mem. Acad. Roy. Belg. 43: Id. Cinquième partie. $a$. Perception des mouvements chez les insectes. $b$. Additions aux recherches sur le vol des insectes aveuglés. c. Résumé général. Bull. Acad. Roy. Belg. 3:16:395.

1895. Un filet empêche-t-il le passage des insectes ailés. Ib. 3:30:281.

1895. Comment les fleurs attirent les insectes. Recherches expérimentales. Première partie. Ib. 466 .

1896. Id. Deuxième partie. Ib. 32:505.

1897. Id. Troisième partie. Ib. 33:17. Id. Quatrième partie. Ib. 34:601. Id. Cinquième partie. Ib. 847 .

1898. Nouvelles recherches sur les rapports entre les insectes et les fleurs. Etude sur le rôle de quelque organs dits vexillaires. Mem. Soc. Zool. France 11:339.

1899. Id. Deuxième partie. Le choix des couleurs par les insectes. Ib. 12:336.

1900. Id. Troisième partie. Les syrphides admirent-ils les couleurs des fleurs? Ib. $13: 266$.

18992. La vision chez l'Anthidium manicatum. Ann. Soc. Ent. Belg. 43:452.

$1900^{2}$. Expériences sur l'attraction des insectes par les étoffes colorées et les objets brillants. Ib. 44:174.

1901. Observations sur le phénomène de la constance chez quelques hyménoptères. Ib. 45: 56 .

1902. Observations sur les erreurs commises par les hyménoptères visitant les fleurs. Ib. 46:113.

19022. L'ablation des antennes chez les bourdons, et les appreciations d'Auguste Forel. Ib. 414.

1906. Le macroglosse, observations et expériences. Mem. Soc. Ent. Belg. $12: 176$.

1906². Les fleurs artificielles et les insectes. Nouvelles experiénces et observations. Mem. Acad. Roy. Belg. 2:1:3.

1910. Recherches expérimentales sur les fleurs entomophiles peu visitées par les insectes rendues attractives au moyen de liquides sucrés odorants. Ib. $2: 2: 3$.

Porsch, O. 1904. Die Anlockungsmittel der Blumen im Lichte neuerer Forschung. Mitt. Nat. Ver. Univ. Wien $2: 25$.

—_. 1922. Methodik der Blütenbiologie, in Abderhalden's Handbuch der biologischen Arbeitsmethoden.

Porter, C. J. A. 1883. Experiments with the antennæ of insects. Am. Nat. 17:1238. Reeker, H. 1898. Wie ziehen die Blumen die Insekten an? Zool. Gart. 39:105, 137. Romanes, G. J. 1884. Mental evolution in animals.

- 1885. Homing faculties of Hymenoptera. Nature 32:630.

Robertson, C. 1889. Flowers and insects. I. Bot. Gaz. 14:120. III. Ib. 297.

—. 1892. Id. IX. Ib. 17:269.

- 1893. Id. XI. Ib. 18:272. 
RoBertson, C. 1895. Id. XIV. Ib. 20:139.

1914. Origin of oligotropy of bees. Ent. News 25:67.

-1. 1922. Flowers and insects. XXI. Data of anthecology. Bot. Gaz. 73:148.

SCHENK, O. 1903. Die antennalen Hautsinnesorgane einiger Lepidopteren und Hymenopteren mit besonderer Berücksichtigung der sexuellen Unterscheide. Zool. Jahrb. (Anat.) 17:573.

Schnabl, J. 1896. Macroglossa stellatarum stützt sich auf gemalte Blüten von Tropaeolum. Ill. Wochens. Ent. 1:147.

SCHRÖDER, C. 1901. Experimentelle Studien über den Blumenbesuch, besonders der Syritta pipiens L. Allg. Zeits. Ent. 6:181.

SLAter, J. W. 1848. The seat of the sense of smell in insects. Entomologist 11:233.

Smith, E. M. 1915. The investigation of mind in animals.

Sprengel, C. K. 1793. Das entdeckte Geheimnis der Natur im Bau und in der Befruch. tung der Blumen.

Theen, H. 1896. Ueber den Farbensinn der Bienen. Ill. Wochens. Ent. 1:101.

ThorNDike, E. L. 1911. Animal Intelligence.

ThorNley, A. 1897. Insects and color. Nature 57:30.

Trodvelot, L. 1877. The use of the antennæ in insects. Am. Nat. 11:193.

Turner, C. H. 1908. The homing of the mud-dauber. Biol. Bull. 15:215.

1910. Experiments on the color-vision of the honey-bee. Biol. Bull. 19:257. Jour. Anim. Behav. 1:403.

- 1911. Experiments on the pattern-vision of the honey-bee. Biol. Bull. 21:249. Jour. Anim. Behav. 2:383.

- 19112. Literature for 1910 on the behavior of spiders and insects other than ants. Jour. Anim. Behav. 1:401.

1912. Literature for 1911. Ib. $2: 380$.

1913. Literature for 1912. Ib. 3:401.

1914. Literature for 1913 . Ib. $4: 394$.

1915. Literature for 1914. Ib. 5:415.

1916. Literature for 1915 . Ib. $6: 383$.

VALLETE, R. 1875. Letter from M. R. Vallete on Macroglossa stellatarum. Ann. Soc.

Ent. Belg. 18:xxviII.
1879. Letter to M. de Borre on Macroglossa stellatarum Ib. 21:Lxvir.

Wagner, W. 1907. Psycho-biologische Untersuchungen an Hummeln. Zoologica 19:1. Wasmann, E. 1899. Die psychischen Fähigkeiten der Ameisen.

Weismann, A. 1902. Vorträge über Descendenztheorie, 1:219.

WEED, C. M. 1884. Bombus plundering different species of plants. Am. Nat. 18:936.

WERY, J. 1904. Quelques experiences sur l'attraction des abeilles par les fleurs. Bull. Acad. Roy. Belg., p. 1211.

Wheeler, W. M. 1910. Ants, their structure, development and behavior.

Wolf, O. J. B. 1875. Das Riechorgan der Biene. Nov. Act. Deut. Akad. Naturf. 38: 1.

ZANDER, E. 1913. Das Geruchsvermögen der Bienen. Biol. Cent. 33:711. 


\section{INDEX.}

Acer pseudoplatanus, 151

Achillea millefolium, 115

Acmaeops longicornis, 63

Aconitum, 18, 90, 91, 93, 241

columbianum, 15, 18, 111

lycoctonum, 16

napellus, 16

Agrostis, 150

Ajuga, 131

Allium recurvatum, 106, 137

Althea rosea, 137, 161, 188

Amarantus, 196, 241

Ammophila, 221

Ampelopsis, 146, 168

Anchusa, 162, 164, 193

Andrena, 101, 104, 134, 181

crataegi, $27,28,30,31,37,79,97,105,106$, 109

madronitens, $33,35,39,46,62,65,105$

vetula, 175

vicina, $29,33,65,69,70,71$

Anemone, 130

japonica, 149

Angelica, 165

Anoda triloba, 187

Anthidium, 131, 147, 151, 153, 154, 157, 181

manicatum, 155, 239

Anthophora acervorum, 176

pilipes, 243

simillima, 34, 40, 68, 74, 77, 106, 109, 136, 155,181

Anthoxanthum, 150

Antirrhinum, 131

majus, $147,148,170,184$

Apis mellifica, 27, 28, 30, 31, 32, 33, 39, 40, 46, $52,57,58,60,61,62,69,74,75,78,89$, $93,97,104,106,109,114,131,134,136$, $148,149,150,153,155,157,160,161,162$, $164,165,179,180,181,183,244$

Aporus fasciatus, 221

Aquilegia coerulea, 100, 101, 105, 106, 111

Arabis, 136

Argemone platyceras, 217

Argynnis atlantis, 46, 79, 80, 89, 91, 119, 181

Asparagus, 138

Asphodius, 226

Aster, 80, 109, 185

bigelovi, $85,106,115$

Aucuba, 137

Bembex labiatus, 221, 222

mori, 225

Bombus, 62

appositus, $88,89,91,119$

bifarius, $15,16,17,18,20,21,22,33,35,39$, $41,44,46,49,58,66,73,74,79,90,92$, $116,119,134$

californicus, 40

edwardsi, $19,22,23,24,25,33,62,76$

flavifrons, 33

hortorum, 158

hunti, 119

hypnorum, 158
Bombus-Continued.

juxtus, $15,16,17,19,20,21,22,23,24,25$, $26,29,30,34,36,37,38,39,41,43,44,45$, $46,48,49,51,52,53,58,59,61,62,63$, $66,70,73,75,76,77,78,79,88,89,90$, $91,92,93,101,105,110,116,119,134$, 241

lapidarius, 132,158

morrisoni, $23,29,76,77,80,91$

muscorum, 132, 147, 158

occidentalis, $30,57,91,105,119$

pennsylvanicus, 79

pratorum, 141

proximus, $24,25,26,31,33,35,36,37,39$, $46,76,77,79,80,134$

silvarum, 132

terrestris, 132, 141, 147, 149, 158

terricola, 194

Bombylius fimbriatus, 175, 182

fuliginosus, 205, 206

Borrago, 159, 175

officinalis, 175

Brachypodium, 150

Brassica, 173

Bromus, 150

Bryonia dioeca, 138, 187

Calceolaria, 131

Calliphora, 156

Callosamia promethea, 159

Calluna, 131

Calochortus gunnisoni, 115

Caltha, 131

Campanula, 61, 62, 92, 106, 115, 240

Camponotus, 229

Carabus, 230

Carex, 150

Castilleia, 64

affinis, 64

linarifolia, 64

miniata, 106, 109

Celerio lineata, 55

Centaurea, 130, 133, 169 cyanus, $148,162,170,171,184$

Cerceris, 221

Chalicodoma, 218, 219, 220

Chamaenerium, $46,48,54,57,58,78,81,85$, $89,93,98,99,101,105,110,111,114,115$, $116,119,239,241$

Chenopodium album, 150

Chrysanthemum, 176, 186 leucanthemum, 178

Cirsium oleraceum, 133 palustre, 133

Cistus, 176

Clematis jackmanni, 165, 196

Cleome serrulata, 95, 98, 99, 101, 104

Clisodon terminalis, $36,38,58,68,69,70,71$, $72,75,81,88,89,91,119,134$

Coelioxys, 40

Convolvulus, 136

sepium, 149, 165

Corylus avellana, 150 
Crataegus, 187

Crocus, 136, 161, 178, 179, 182

luteus, 161

sativus, 185

vernus, 161

Cucurbita maxima, 194

Cytisus, 131

Dahlia, 145, 147, 148, 149, 152, 157, 168, 172, $180,183,184,185,186$

variabilis, 161,181

Deiliphila, 159

elpenor, 175,192

Dejeania vexatrix, 62

Delphinium ajacis, 147, 164

consolida, 23, 147

elatum, 23

scopulorum, 22, 93, 111, 115

tricorne, 23

Deutzia, 187, 188

Dianthus barbatus, 153, 175, 192

carthusianorum, $132,151,164,175$

Digitalis purpurea, 147, 148, 151, 169, 194

Dodecatheon meadia, 112

Doronicum caucasicum, 180

Echinacea purpurea, 187

Elephantella groeplandica, 112, 114

Epilobium spicatum, 131, 184

Eranthis nivalis, 178

Erigeron macranthus, 115

Eristalis tenax, 130, 147, 156, 157, 181, 182, 183,191

Erynnis leonardus snowi, 79, 80, 89, 91

Eschscholtzia, 184, 185

Eupatorium, 131

Festuca, 150

Ficaria, 131

Fragaria, 62

Frasera carolinensis, 59 speciosa, $61,92,93,95,98,99,111,240$

Fritillaria, 136

Formica fusca, 225

rufa, 227, 229

Fumaria officinalis, 165

Galium, 206

Gentiana parryi, 115

Geum intermedium, 131

rivale, 131

urbanum, 131

Geranium, 28, 39, 41, 57, 58, 80, 82, 92, 95 $99,104,115,119$

caespitosum, $85,89,101,105,106,110,114$, 115,134

carolinianum, 40

maculatum, 40

richardsoni, $40,98,105,106,110,116,134$

Gerardia purpurea, 195

Gilia aggregata, 82, 85, 110, 115, 119

Glycine, 167

Halictus, 27, 28, 39, 41, 63, 113, 160, 165

(Evylaeus) sp., 62, 63

(Lasioglossum) sp., 46

pulzenus, $31,36,39,44,62,64,65,66,70$, $73,75,78,79,92$
Helianthus annuus, 162, 185

Heliopsis levis, 187, 188

Helix, 222

Heracleum lanatum, 106, 133, 148, 169

Hesperis, 186

Hieracium, 176, 240

Hyacinthus, 136

Hydrangea, 153

Hyloicus separatus, 55

Ipomoea purpurea, 147

Jamesia americana, 97

Laciniaria punctata, 217

Lamium album, 129, 132

Lantana, 243

Lathyrus, 133

latifolius, 151

Lavandula, 131

Leucanthemum vulgare, 162

Leycesteria, 131

Lilium candidum, 165

Linum perenne, 165

Linaria vulgaris, 207

Listera, 169

Lobelia erinus, 147, 169

Lucilia, 157, 161

caesar, 225, 226

Lycaena, 16

Macroglossa, 16, 153, 164, 165, 205, 206 stellatarum, 136, 164, 190, 191, 192, 193

Malva, 159, 175

silvestris, 184

Megachile pugnata, 46 wootoni, $34,105,106,109,145,146,148$, $149,151,154,155,156,161,165,239$

Melampyrum nemorosum, 132

Melandrium, 162

Melanostoma, 154

Melissodes fremonti, 71, 198

Melolontha, 230

Mentzelia, 57, 58, 92

Mercurialis, 131

Mertensia alpina, 100, 101, 105, 106 sibirica, 62, 63, 95, 98, 105

Monarda fistulosa, 79, 80, 81, 82, 85, 88, 89, $91,110,115,116,117,134,239$

Monumetha albifrons, $27,34,36,39,66$

Musca, 151, 156, 179

Muscari comosum, 175, 205

Myosotis alpestris, 151,161

Myrmica ruginodis, 225

Nicotiana, 148

Odynerus, 150,151

Oenothera biennis, 55, 131, 147, 210, 212, 217

fruticosa, 55

missouriensis, 55

pinnatifida, 55

speciosa, 165

Osmia, 28, 30, 31, 40, 92, 113, 161, 181

bruneri, $33,34,39,70,71,73,76$

californica, 48

coloradella, 65 
Osmia-Continued.

densa, 65, 68

ferruginea, 222

melanotricha, $65,69,70,71,72,73$

phacelia, 65, 68, 69, 70, 71, 73, 75, 76, 105

pentstemonis, $62,65,69,70,72,73,75,76$

rufohirta, 222

tricornis, 176

Opulaster opulifolius, 95, 97, 101, 104, 134

Oxybelus, 151

Paeonia, 181

Papaver orientalis, $159,160,161,174,180$ rhoeas, $160,171,172,184$

Papilio, 164

Passiflora, 165

Pedicularis canadensis, 129

Pelargonium zonale, 149, 165, 166, 174, 196

Pentstemon, 134

barbatus, 100, 101, 106, 109, 112, 113, 114, 115

barbatus labrosus, 68

bridgesi, 68

glaber, $78,89,111,112,113,114$

glaucus, $111,112,114$

gracilis, $78,111,112,113,114,115$

halli, $111,112,113,114$

palmeri, 68

secundiflorus, $78,100,101,106,109,113,115$ unilateralis, $112,113,114$

Perdita, 133

Petunia, 147, 176, 240

hybrida, 165

Phlox drummondi, 175

paniculata, 149, 159, 164, 175, 192

Pieris, 136, 137, 145, 146, 149, 153, 156, 161, $163,171,181$ brassicae, 154, 191

Pirus communis, 194

Pisum sativum, 165

Poa, 150

Polistes pallipes, 224 gallicus, 141, 225

Polygonum convolvulus, 165

Pompilus, 221

scelestus, 233

Portulaca grandiflora, 196, 242

Primula, 131, 136, 181

Prosopis, 28, 37, 41, 92, 101, 105, 106, 113 , $161,163,165,181$

elliptica, 34, 39, 73, 79

episcopalis, 32,33

varifrons, $41,66,75$

Protoparce quinquemaculata, 55

Prunus demissa, 28, 101, 134 pennsylvanica, 28

Pseudomasaris vespoides, $39,67,68,70,71$, $77,90,101,109$

Pulmonaria, 136, 243

Pyrethrum leucanthemum, 184

Ranunculus, 130, 136 acris, 171

Ratibida, 217

Reseda, 180

Rheum tataricum, 150

Rhodocera, 153

rhamni, 192
Rhododendron ciliatum, 179, 186

Ribes, 138

sanguineum, 150

rubrum, 151

Rosa, 18, 33, 34, 92, 95, 104, 105, 106, 109, 134 acicularis, 101, 102, 134

canina, 34

rubiginosa, 34

Rubus deliciosus, 24, 28, 32, 33, 81, 89, 92, $93,95,101,134,241$

strigosus, $32,33,62,95,97,99,101,102$. 106,134

Rudbeckia, 157, 188, 241

laciniata, 187, 217

Rumex obtusifolius, 150

Salix, 131, 138

Salvia horminum, $153,154,155,165,181,183$, 193

splendens, 166

Sarcophaga vivipara, 225

Saturnia carpini, 225

Saxifraga umbrosa, 151

Scabiosa, 130, 132, 149, 154

atropurpurea, 161

Scrophularia nodosa, 100, 101, 106, 109, 115

Secale, 150

Selasphorus platycercus, 63, 64, 74, 79

Silpha thoracica, 227, 230

Solanum rostratum, 217

Solidago, 217

Sphecodes sp., 64

Sphex vulgaris, 39

Sphinx convoluta, 189

Stelis, 163

Symphoricarpus racemosus, 151, 167

Symphytum officinale, 184

Syritta pipiens, 178, 238, 240

Systoechus vulgaris, 74, 77

Syrphus americanus, 35, 129, 130, 137, 154 . 156,191

opinator, 38

Tagetes, 147, 151

Teucrium chamaedrys, 137 scorodonia, 137

Thanaos martialis, $23,26,76$

Tilia, 131

Titusella pronitens, 66,74

Tragopogon, 130

Tremandra, 131

Trichius, 136

Trifolium, 132

Tropaeolum, 131

majus, 191

Vanessa, 136, 145, 146, 161, 181

Verbena, 192

Veronica, 141

Vespa germanica, 27, 46, 62, 65, 69, 70, 71, 72 , $73,76,77,141,149,150,164,165$

Vicia americana, 129 sepium, 132

Viola, 136 odorata, 161

Volucella, 182

Zinnia, 130, 154, 183 elegans, 161,181 


\section{Descriptions of Plates.}

Plate 1. Painted flowers of Aconitum and Delphinium, showing experimental method.

Plate 2. Life-history of flowers: Aconitum columbianum: (1) bud opening; (2) 4 anthers open; (3) 8 anthers open; (4) 16 anthers open; (5) 4 anthers whole; (6) all anthers shed, styles visible; (7) carpels enlarging, stamens shrunken; (8) petals falling. Delphinium scopulorum: (9) flower just open; (10) 4 anthers shed; (11) 8 anthers shed; (12) 16 anthers shed; (13) 4 anthers whole; (14) all anthers shed, styles visible; (15) carpels enlarging, stamens shrunken; (16) sepals falling.

Plate 3. Life-history of flowers: Rubus strigosus: (1) bud in section; (2) bud partly open; (3) flower open, upper anthers shedding; (4) sepals flat, petals converging, all erect anthers shedding; (5) petals erect, stamens mostly shed, converging; (6) petals flat, stamens brown; (7) petals falling; (8) sepals erect. Potentilla arguta: (9) bud cut, stamens converging; (10) flower half open, stamens erect, stigmas receptive; (11) petals flat, stamens spreading; (12) petals ascending, inner stamens erect; (13) all stamens shedding and converging; (14) petals fallen, sepals erect, anthers shrunken; (15) sepals closed.

Plate 4. Life-history of flowers: Heracleum lanatum, $\times 6$ : (1) bud; (2) 1 stamen out; (3) 2 stamens out; (4) 3 stamens out; (5) 4 stamens out; (6) all stamens out, erect, mostly shedding; (7) stamens deflexed, stigma tips visible; (8) stamens fallen, styles lengthened; (9) petals falling, styles and stylopodium full-grown. Sedum stenopetalum, $\times 6$ : (10) bud in section; (11) flower half open; (12) flower open, inner anthers shedding; (13) inner anthers shed, outer shedding: carpels separating; (14) all anthers shed, stigmas receptive; (15) stamens recurving, carpels converging; (16) anthers fallen, filaments ascending; (17) petals ascending, drying.

Plate 5. Life-history of flowers: Galium boreale, $\times 10$ : (1) bud in section; (2) flower open, stamens erect, shedding; (3) stamens spreading, anthers shed; (4) stamens flat, styles receptive, spreading; (5) stamens deflexed, stigmas enlarged; (6) corolla withering, style elongated. Saxifraga bronchialis, $\times 4$ : (7) bud hanging; (8) bud horizontal, enlarged; (9) flower open; (10) inner row of anthers shedding; (11) inner shed, outer shedding, style tips recurved, receptive; (12) petals and anthers fallen, carpels enlarging.

Plate 6. Life-history of flowers: Campanula rotundifolia, $\times 1.5$ : (1) bud in section, erect; (2) bud horizontal; (3) bud hanging; (4) flower half open, anthers shedding on style; (5) flower open, stamens curling downward, style dusted with pollen; (6) anthers separating, stigmas starting to recurve; (7) stigmas recurved, receptive; (8) corolla shriveling and drying. Erysimum asperum, $\times 2$ : (9) bud in section; (10) stigma protruding, receptive, petals incurled; (11) flower opening, 4 upper anthers shedding; (12) flower open, upper anthers recurving, 2 lower shedding; (13) upper anthers shrunken, lower shed; (14) lower anthers shrinking, petals falling.

Plate 7. Life-history of flowers: Geranium caespitosum, $\times 1.5$ : (1) bud horizontal, corolla tip appearing; (2) bud erect, petals separating; (3) flower open; (4) upper anthers shedding; (5) upper shed, lower shedding; (6) anthers mostly fallen; (7) styles spread, receptive; (8) petals fallen, pistil enlarged. Dodecatheon meadia, $\times 1.5$ : (9) bud upright; (10) bud hanging, in section; (11) flower half open, stigma receptive, anthers swollen; (12) flower fully open, petals reflexed, anthers shrinking; (13) flower horizontal, anthers separating; (14) flower erect, anthers spread; (15) petals shrunken and dried; (16) young pod with stigma still fresh. 
Plate 8. Life-history of flowers: Chamaenerium angustifolium, $\times 2$ : (1) bud hanging; (2) bud rising; (3) bud in section, horizontal, beginning to open; (4) flower open, style reflexed, stamens whole; (5) 2 longer stamens shedding; (6) 4 longer stamens shedding, style hanging; (7) 4 anthers shrunken and 4 shedding, stigma lobes spreading; (8) all anthers shrunken, hanging, stigma lobes recurved, receptive; $(9)$ petals closed, stigma projecting; $(10)$ flower withering.

Plste 9. Life-history of flowers: Pachylophus caespitosus, $\times 1$ : (1) bud in section, anthers shedding; (2) bud opening, stigma lobes protruding; (3) stigma lobes separating; (4) stigma lobes horizontal; (5) flower fully open, anthers shed; (6) petals erect, corolla closing; (7) petals withering, bringing anthers against stigma lobes; (8) corolla wilted.

Plate 10. Life-history of flowers: Pirola elliptica, $\times 2$ : (1) bud in section, pores directed inward; (2) flower opening, style appearing, straight, pores still closed but directed downward; (3) pores open, downward, style curved, bringing stigma under pores; (4) style full length, curved forward, carpels enlarged, petals fallen. Frasera speciosa, $\times 1.5$ : (5) bud in section; (6) flower half open, anthers vertical, introrse; (7) flower open, anthers horizontal; (8) anthers extrorse; (9) 1 anther shedding; (10) 2 opposite anthers shedding; (11) 3 anthers shedding; (12) 2 anthers shedding and 2 shed; (13) petals erect, flower half closed; (14) flower tightly closed, stamens projecting. Gentiana amarella, $\times 2$ : (15) bud in section, stamens introrse, short; (16) bud in section, anthers horizontal, level with style; (17) anthers extrorse, shedding: (18) anthers shed, stigmas recurved; (19) flower closed, stigmas closed, pistil enlarged, corolla withering.

Plate 11. Life-history of flowers: Gilia aggregata, $\times 1.5$ : (1) bud, anthers whole; (2) bud, anthers shedding; (3) corolla lobes erect, anthers mostly shed; (4) lobes spread, style elongated; (5) lobes reflexed, anthers all shed, style longer, stigmas opening; (6) stigma lobes fully spread, receptive; (7) corolla fallen, style still turgid. Gilia pinnatifida, $\times 3$ : (8) flower half open, 1 stamen out; (9) flower open, 2 stamens out; (10) 3 stamens out; (11) first anther shed; (12) 2 anthers shed, style one-half length; (13) 3 anthers shed, style two-thirds length; (14) all anthers shed, style full length; (15) stamens shrunken, stigmas turgid. Mertensia sibirica, $\times 2$ : (16) bud in section; (17) bud partly open, style protruding, receptive; (18) anthers shedding, style elongating; (19) style as long as corolla; (20) anthers shed; (21) corolla wilting and closing, style bent. Lithospermum multiflorum, $\times 2$ : (22) bud in section, about two-thirds grown; (23) flower just open, anthers shedding; (24) corolla lobes spreading; (25) anthers shed; (26) style lengthening, stigma lobes separating; (27) corolla fallen.

Plate 12. Life-history of flowers: Pentstemon glaber, $\times 2$ : (1) flower just open, anthers whole; (2) upper pair of anthers shedding; (3) upper pair shed, lower shedding; (4) anthers all shed, style elongated; (5) stigma curved downward; (6) corolla fallen, stigma turgid; (7) longisection of stage 2 ; (8) longisection of stage 5 .

Plate 13. Life-history of flowers: Castilleia miniata, $\times 2$ : (1) corolla in calyx, $7 \mathrm{~mm}$. long; (2) corolla $10 \mathrm{~mm}$. beginning to open; (3) corolla $15 \mathrm{~mm}$., stigma protruding, receptive; (4) outside view of full-grown calyx with stigma exserted; (5) section of preceding; (6) style $3 \mathrm{~mm}$. long, erect; (7) section of preceding, showing the pollen mass; (8) corolla full length, style $5 \mathrm{~mm}$. long; (9) style withering at tip; (10) style reflexed, corolla withering. Monarda fistulosa, $\times 2$ : (11) bud in section, anthers cracking; (12) flower open, anthers shedding; (13) stigma projecting; (14) stamens withering, style elongated, stigma lobes spread; (15) lower lip withering; (16) corolla and style withering. 
Plate 14. Life-history of flowers: Allium cernuum, $\times 3$ : (1) Bud hanging, cracking; (2) bud starting to ascend, 1 stamen out; (3) bud at 45 degrees, perianth lobes opening, 2 stamens out, 1 anther shedding; (4) 3 stamens out, 1 anther shedding, and 1 shed; (5) 5 stamens out, 2 shed and 1 shedding; (6) flower horizontal, 5 anthers shed; (7) flower ascending, style elongating; (8) anthers falling, style exserted, receptive; (9) anthers fallen, corolla withering; (10) style shrunken, corolla withered. Zygadenus elegans, $\times 2$ : (11) flower half open; (12) flower open, anthers contiguous; (13) outer row of anthers spread and shedding; (14) inner row of anthers spread and shedding; (15) anthers shed, converging, stigmas beginning to spread; (16) anthers fallen, stigmas separated, receptive; (17) petals ascending, pistil enlarged; (18) petals erect, keeled.

Plate 15. Mutilated and inverted flowers of Aconitum, $\times 1$.

Plate 16. Mutilated flowers: Aconitum columbianum, $\times 1.5$ : (1) lower sepals removed; (2) hood removed; (3) perianth removed; (4) hood split and spread; (5) hood and nectaries removed; (6) side petals removed. Delphinium scopulorum, $\times 1.5$ : (7) normal flower; (8) petals removed; (9) side sepals removed, (10) lower sepals removed; (11) spur cut off. Monarda fistulosa, $\times 2$ : (12) lower lip cut off; (13) upper lip cut off; (14) both lips cut off; (15) lower lip split; (16) corolla shortened; (17) upper lip, stamens and style cut away.

Plate 17. Mutilated flowers: Geranium caespitosum, $\times 1.5$ : (1) petals shortened half; (2) petals trifid; (3) petals removed. Chamaenerium angustifolium, $\times 2$ : (4) petals shortened half; (5) petals removed; (6) all parts removed except pistil and nectary; (7) petals and sepals removed; (8) flower reduced to ovary and nectary. Pentstemon glaber, $\times 2$ : (9) lower lip removed; (10) upper lip removed; (11) both lips removed; (12) corolla lobes split. 


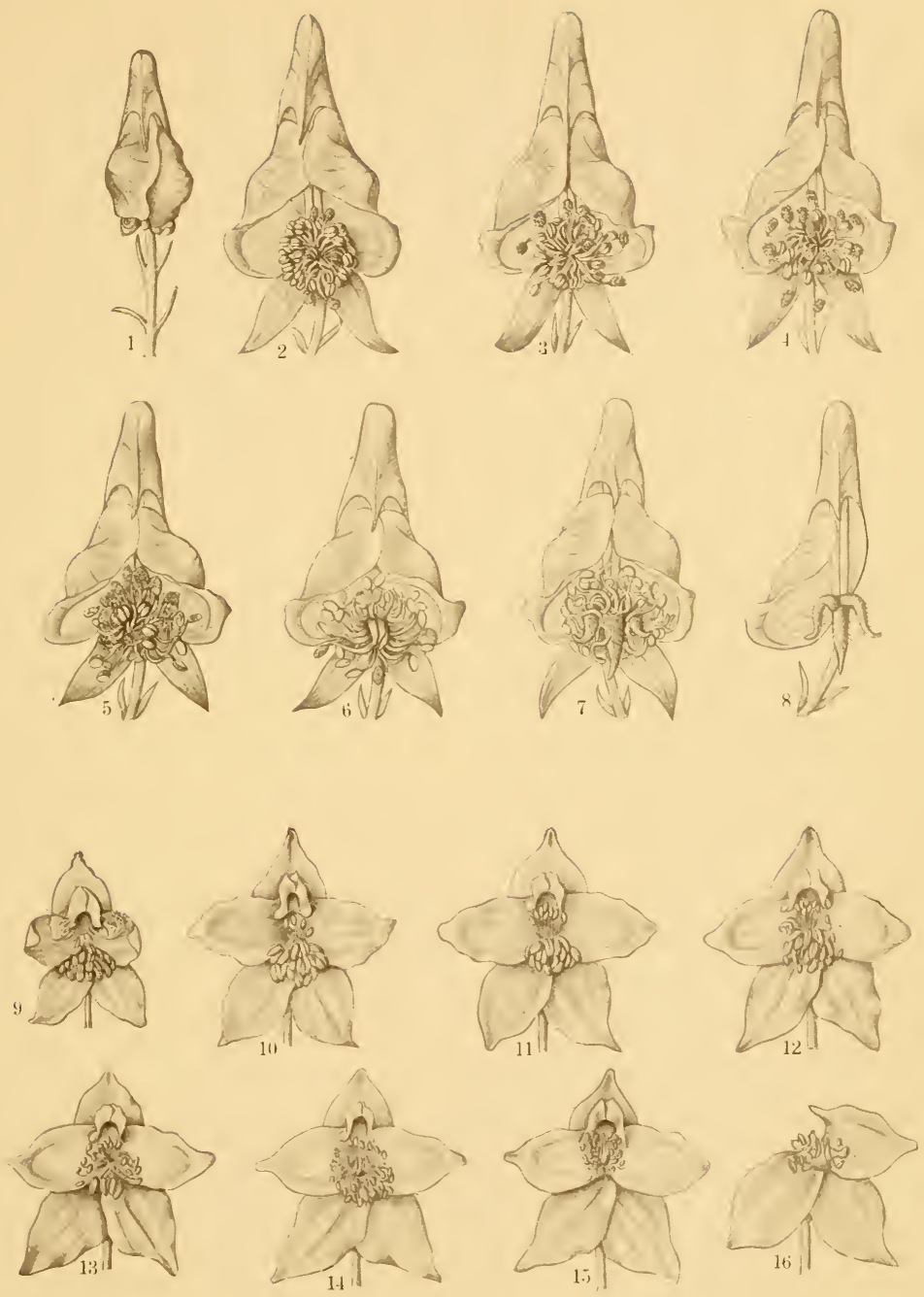

Edith s. Clements del.

Life-history of the flowers of Aconitum columbiamum and Delphinium. scopulorum. 


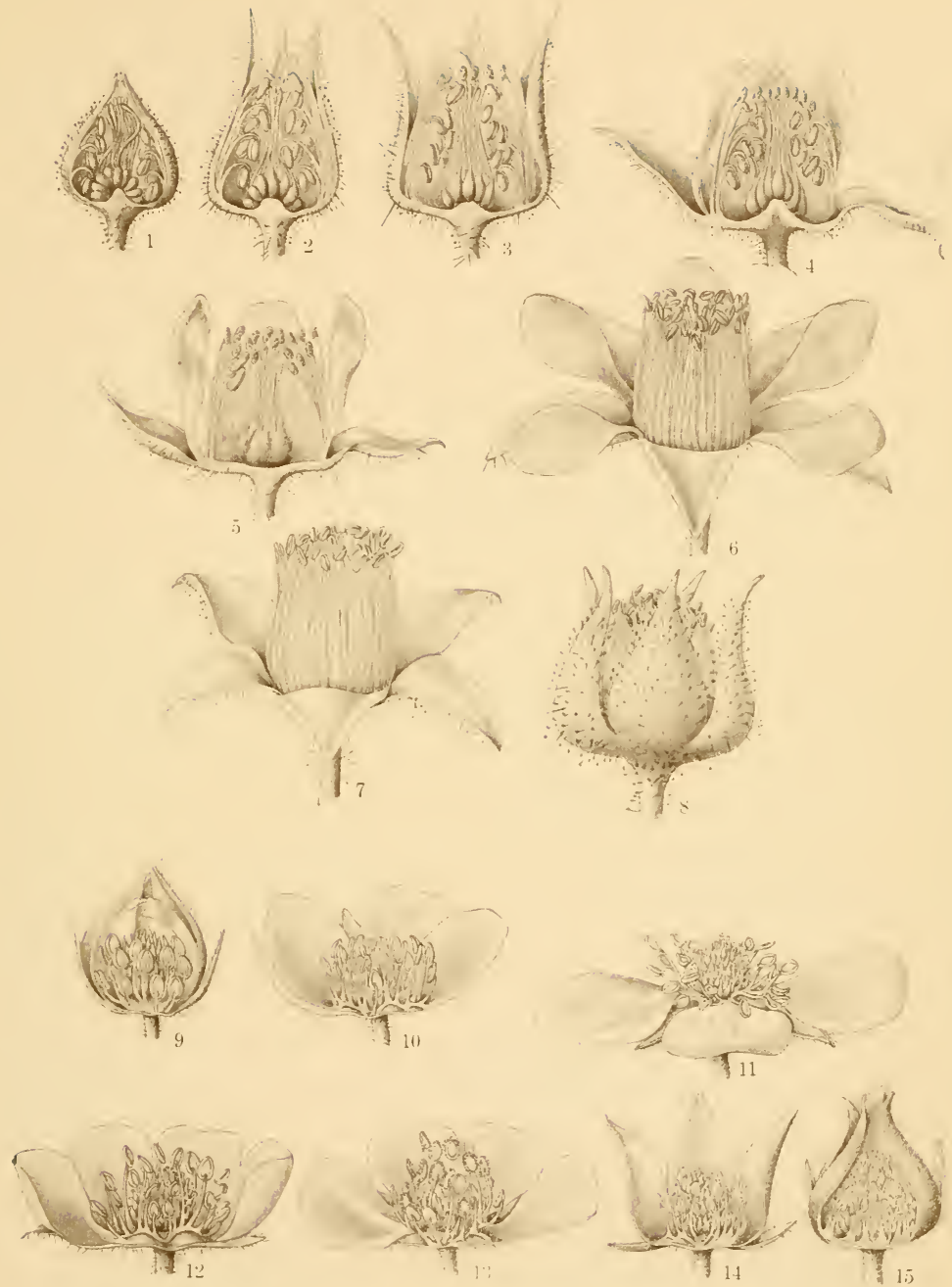

Erlith S. Clements del.

Life-history of the flowers of Rubus strigosus and Potentilla gracilis. 


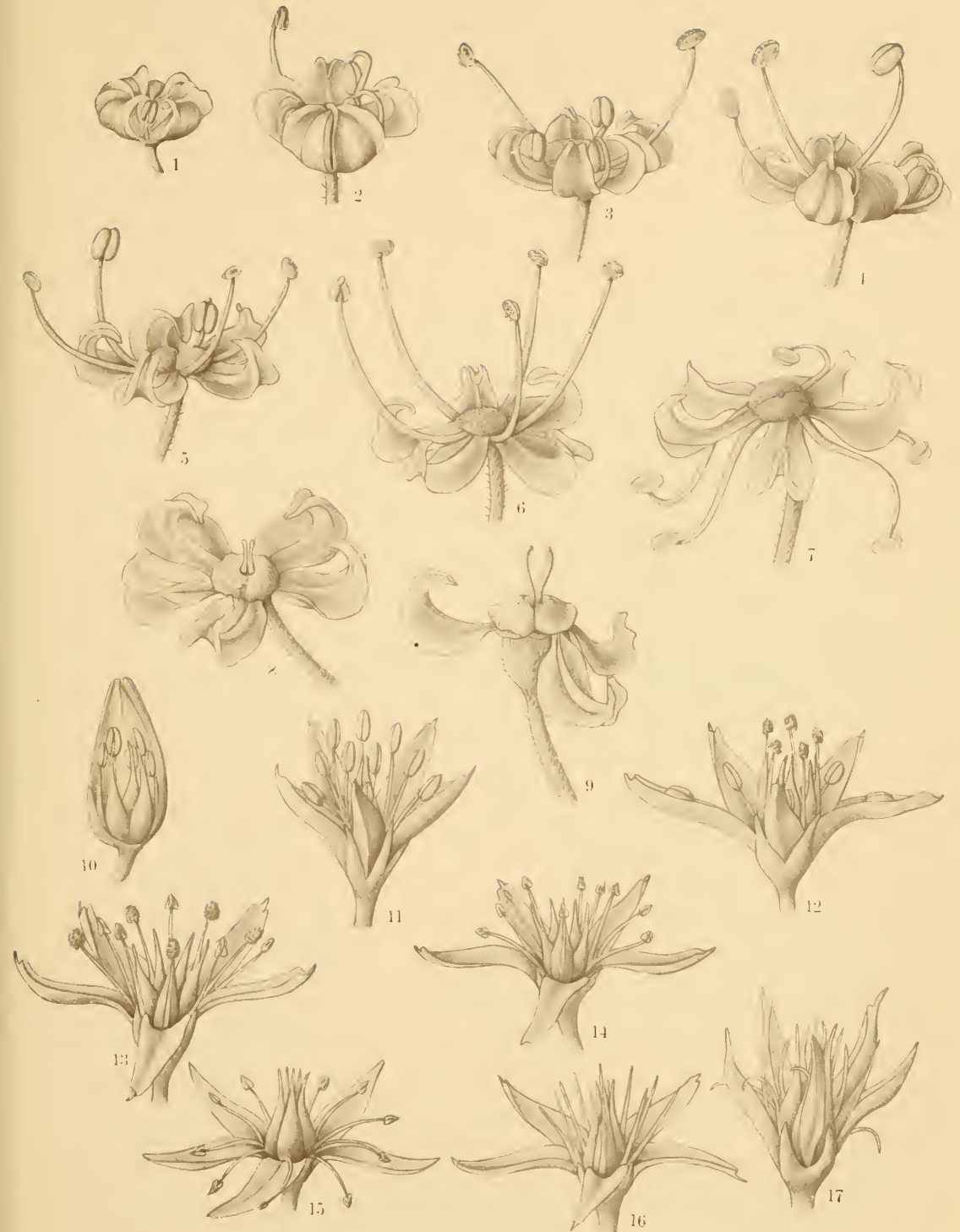


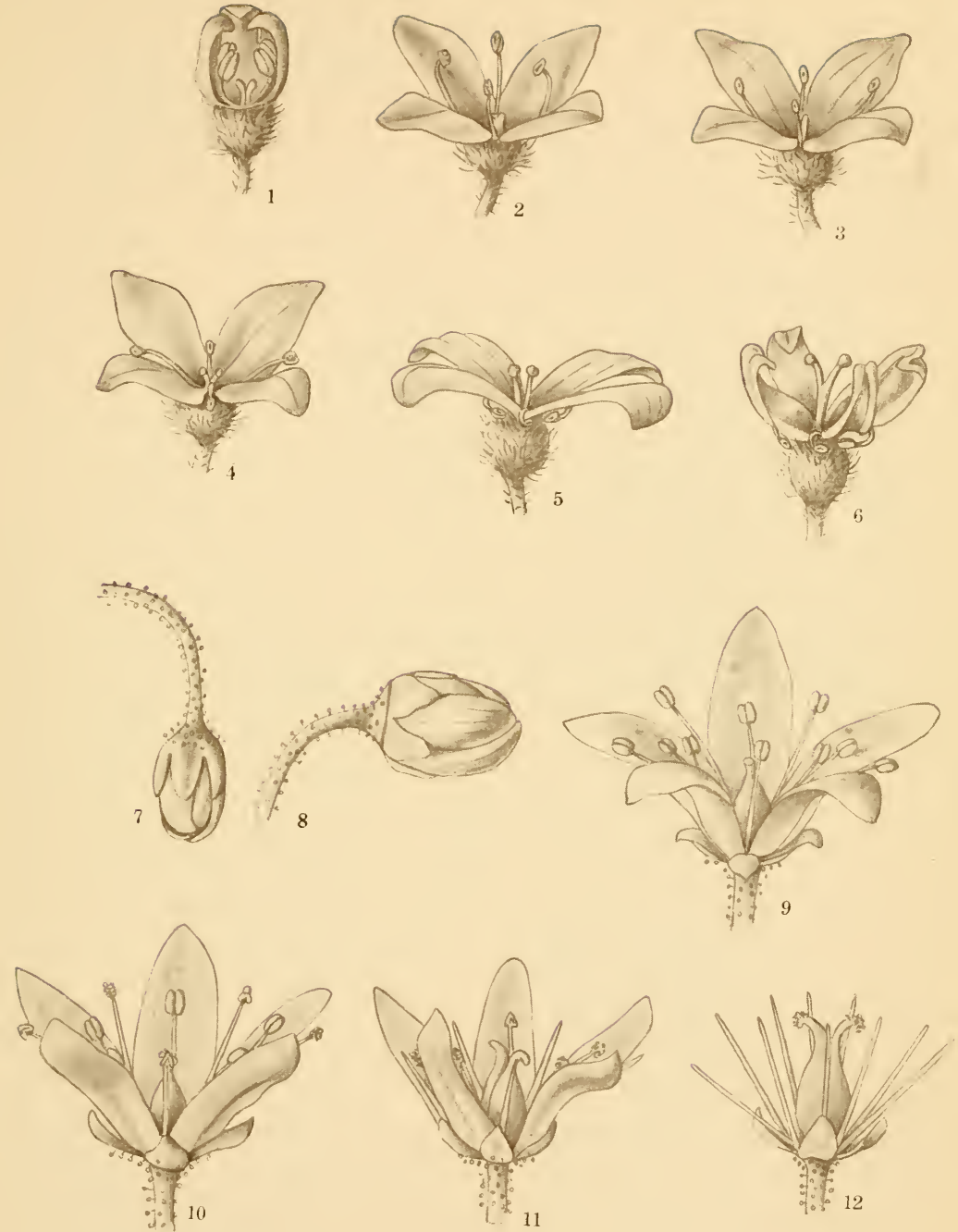

Edith S. Clements del.

Life-history of the flowers of Galium boreale and Saxifraga bronchialis. 


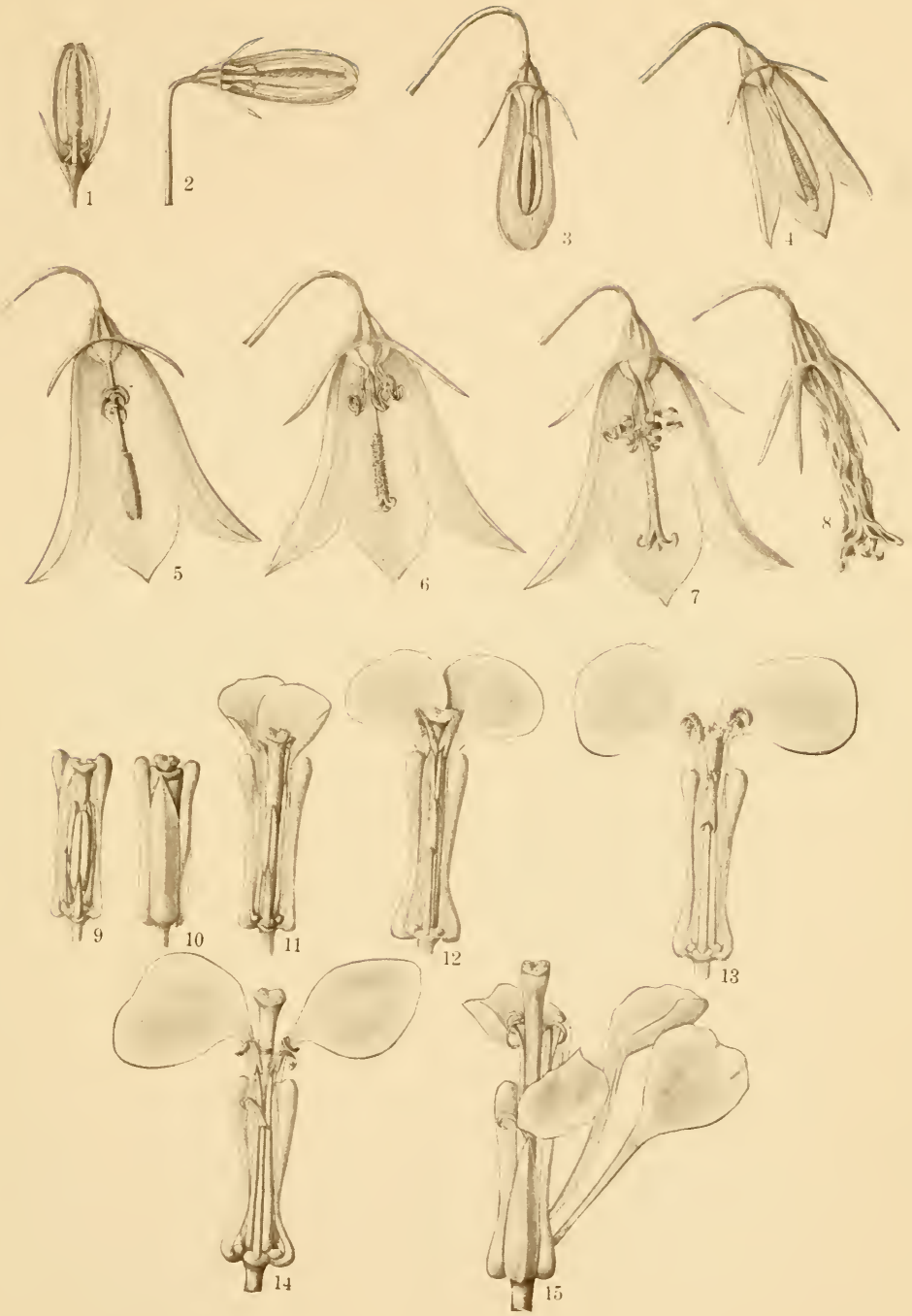

Edith S. Clements del.

Life-history of the flowers of Campanula rotundifolia and Erysimum asperum. 


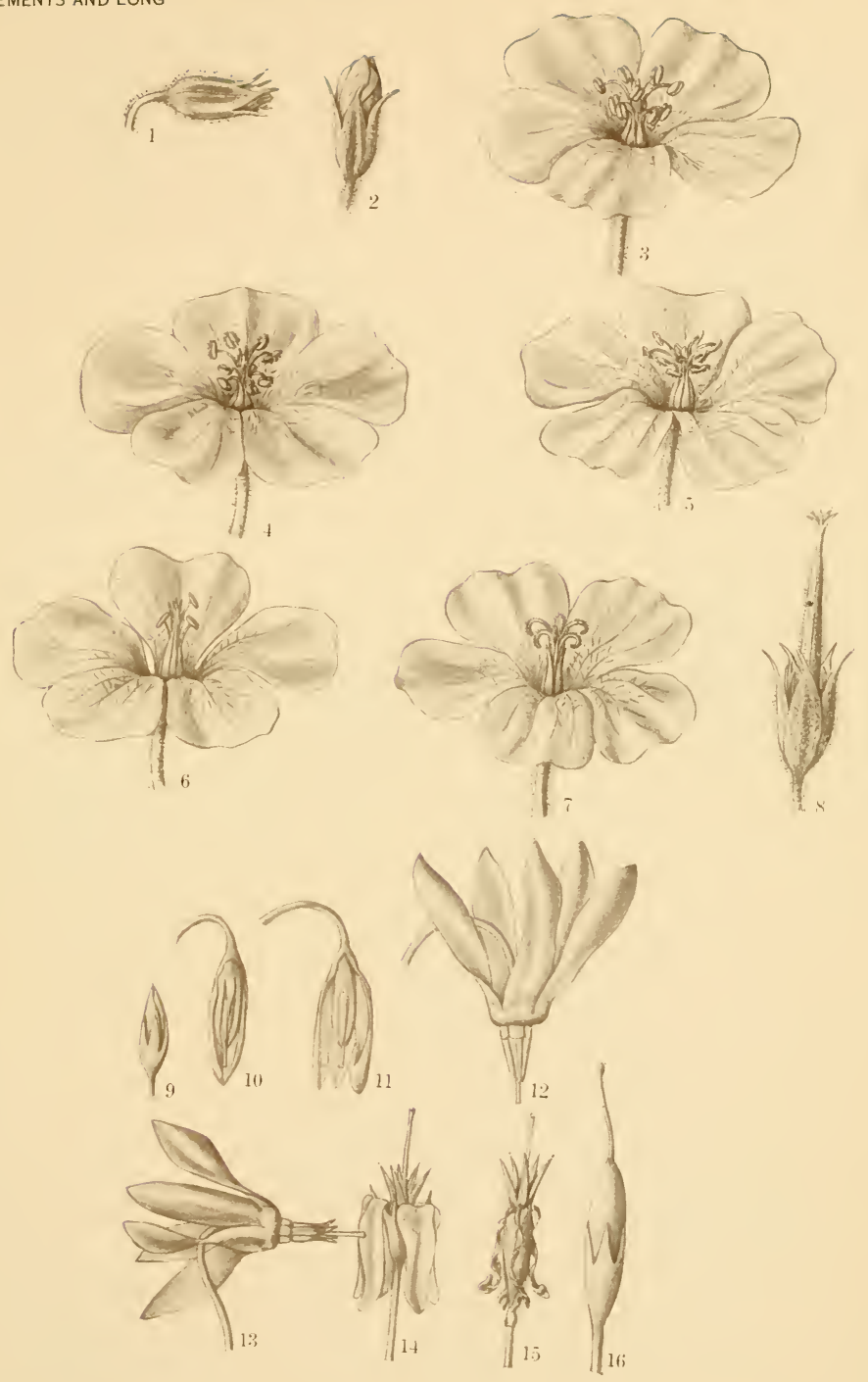

Edith s. Clements del.

Life-history of the flowers of Geranium caespitosum and Dodecatheon meadia. 


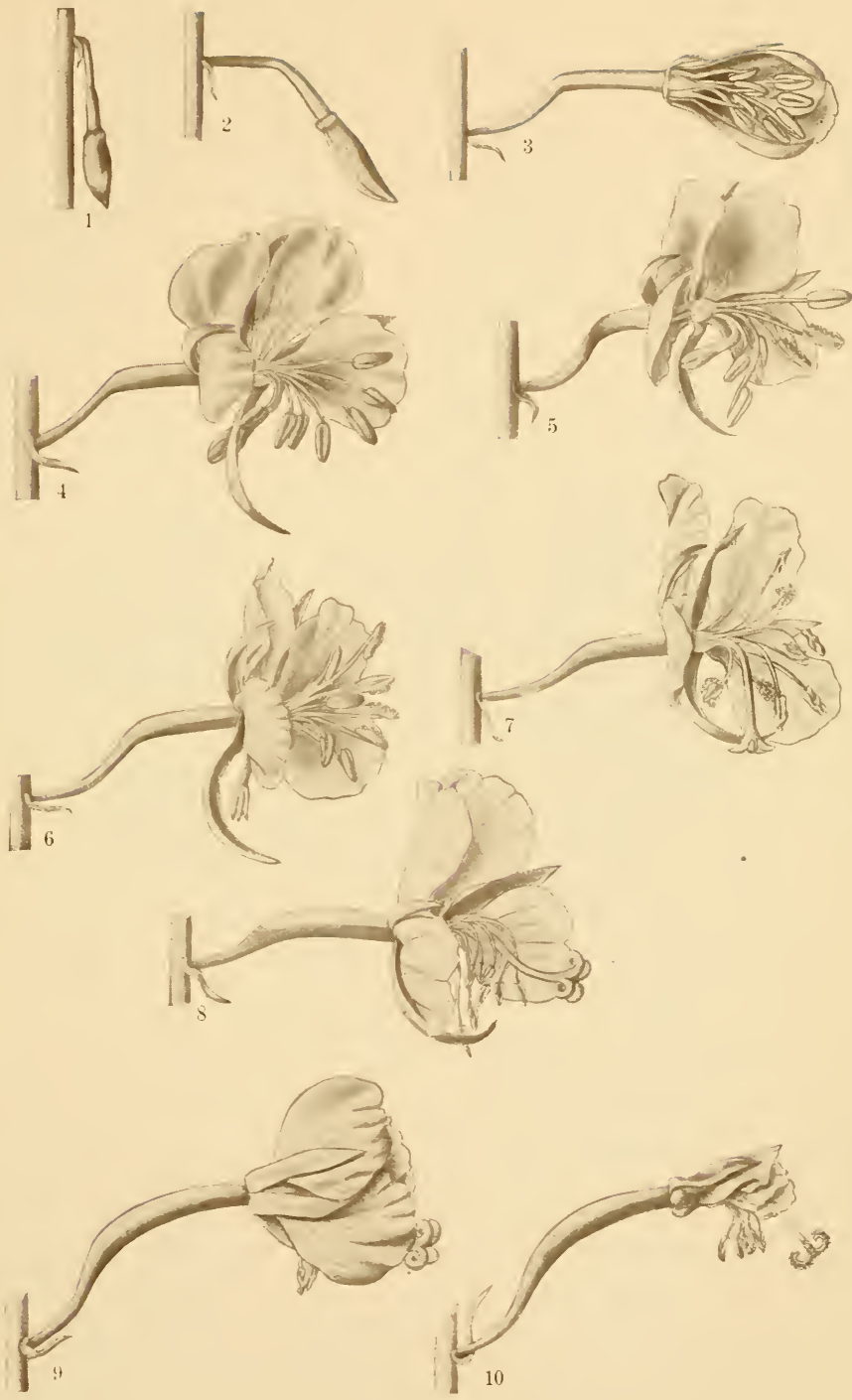

Edith S. Clements del.

Life-history of the flower of Chamaenerium angustifolium. 



$$
\begin{array}{lll}
011 \\
10
\end{array}
$$




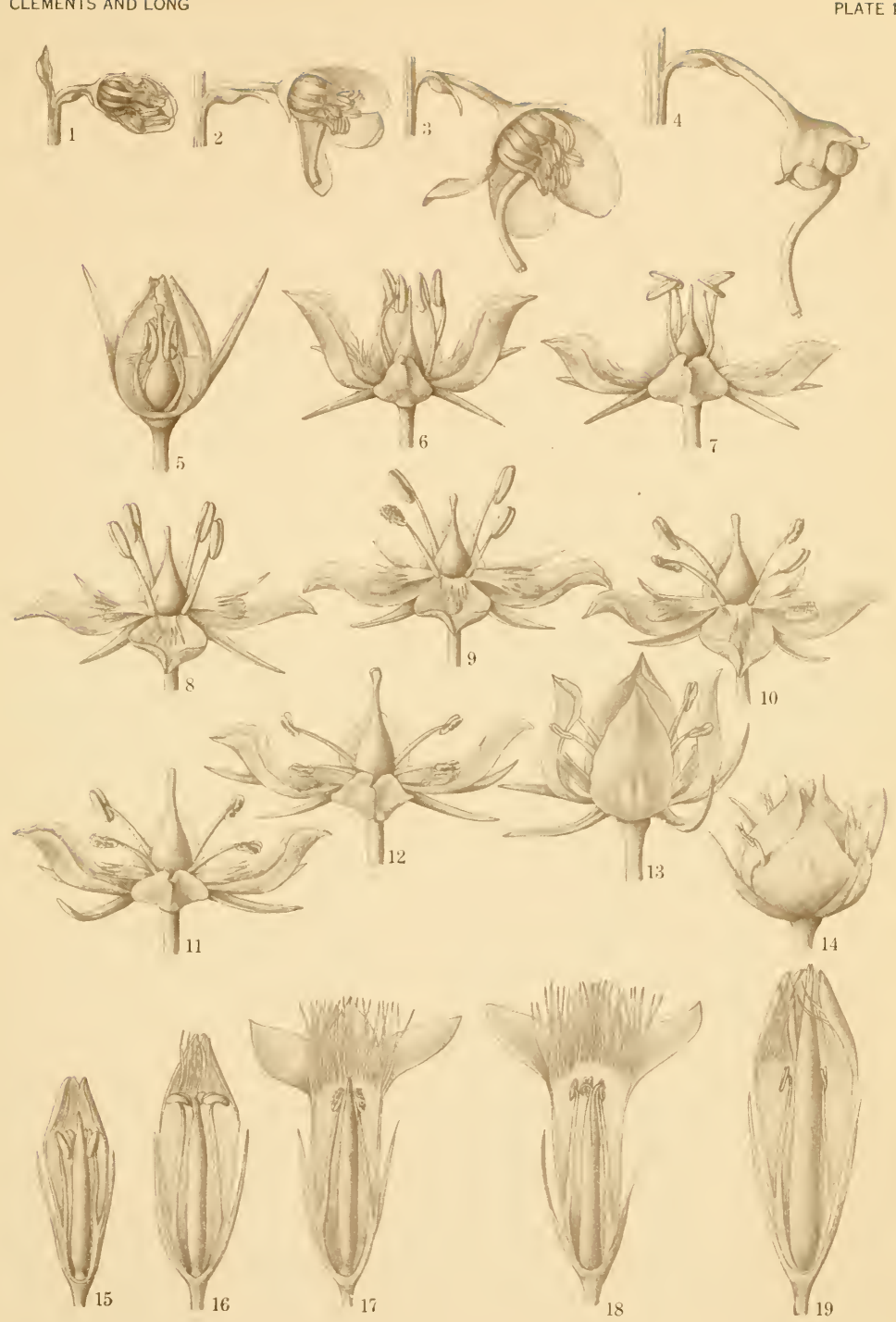

Erith S. Clements del.

Life-histery of the flowers of Pirola elliptica, Frasern speciosa, and Contiane amarelln. 


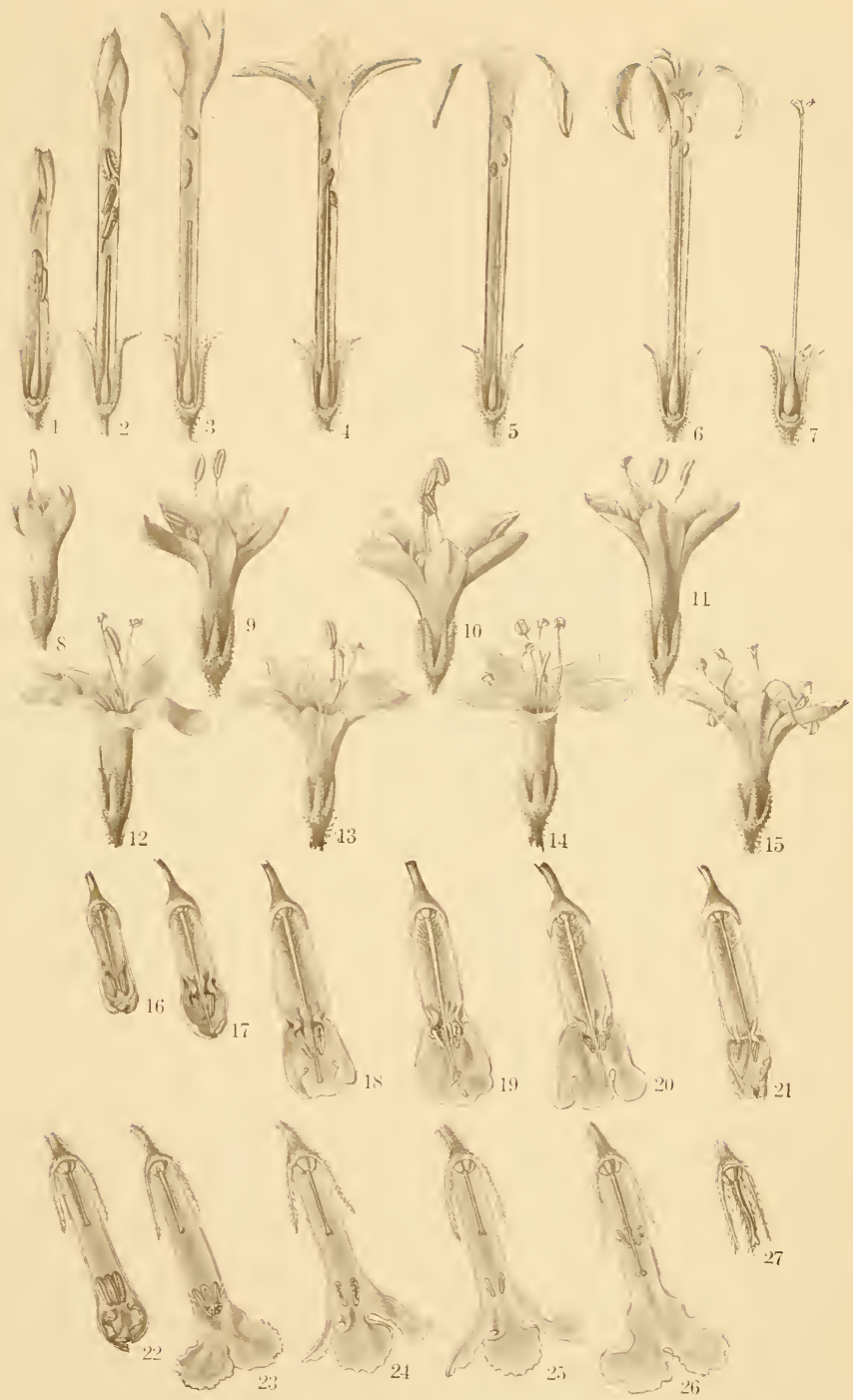

Edith S. Clements del.

Life-history of the flowers of Gilia aggreguta and pinmatifien, Mertensia sibiricu, and Lithospermum multiforum. 


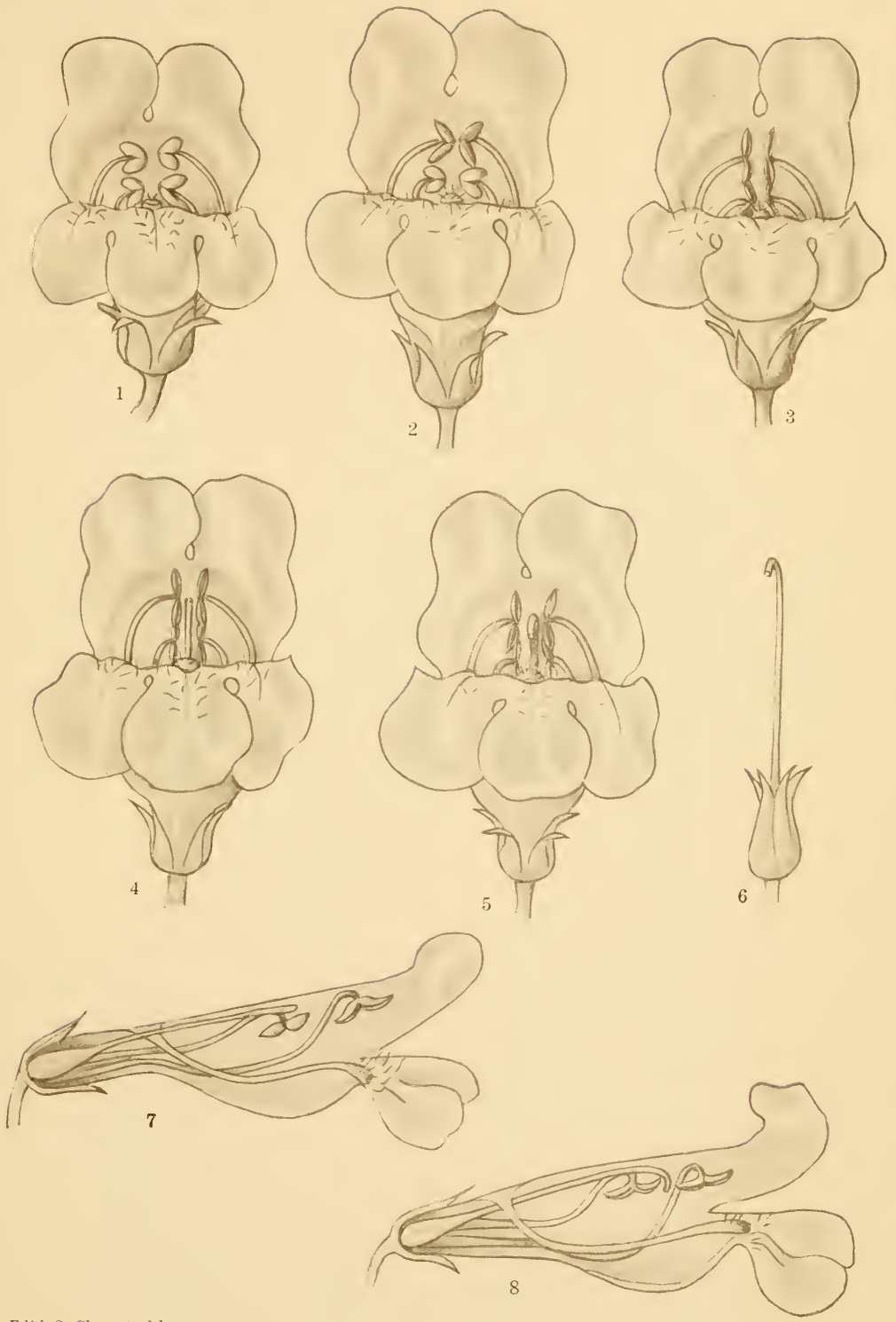

Edith S. Clements del.

Life-history of the flower of Pentstemon glaber. 



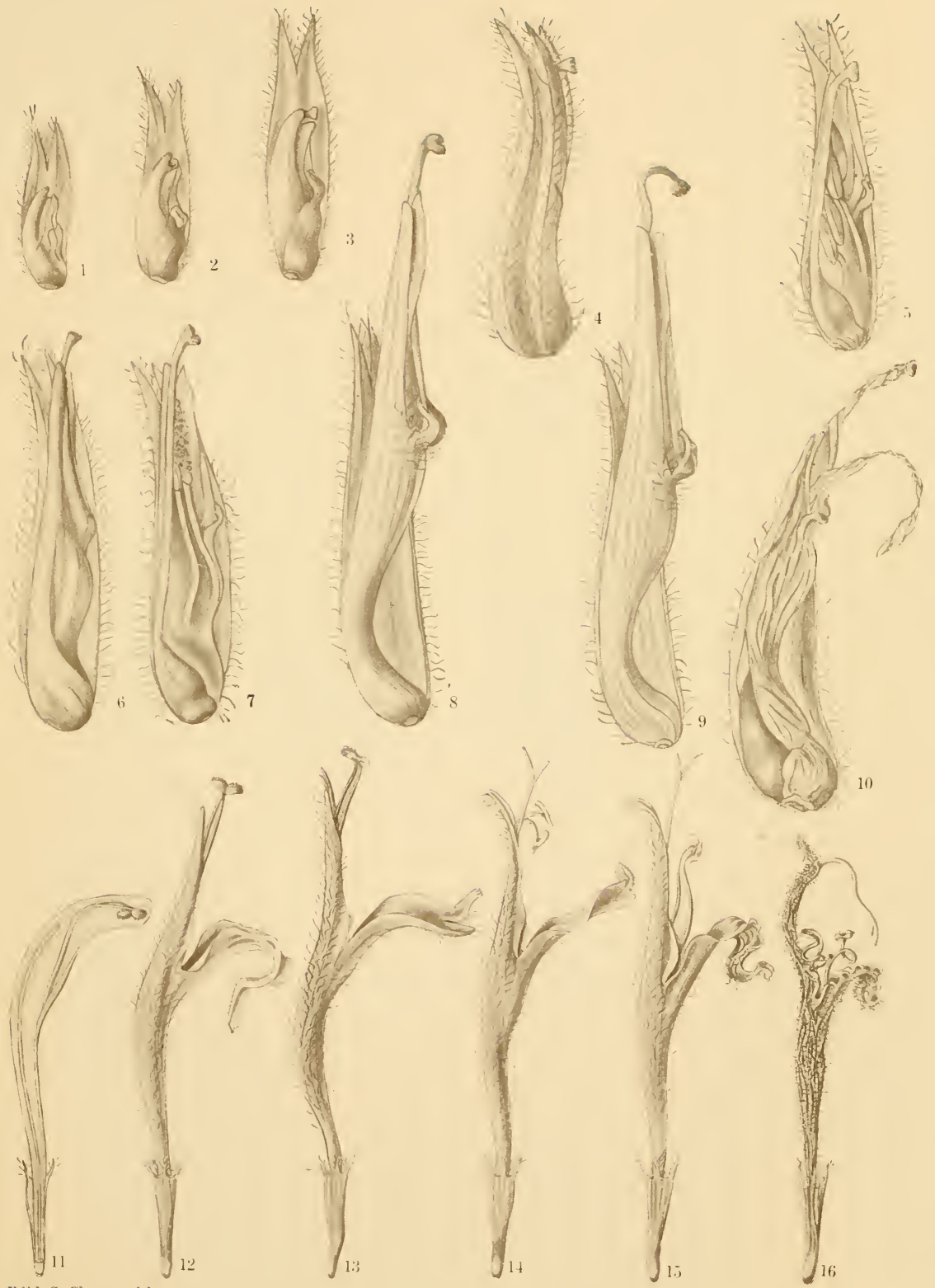

Edith S. Clements del. 


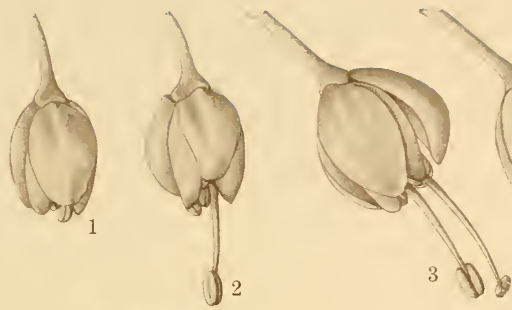

3 b
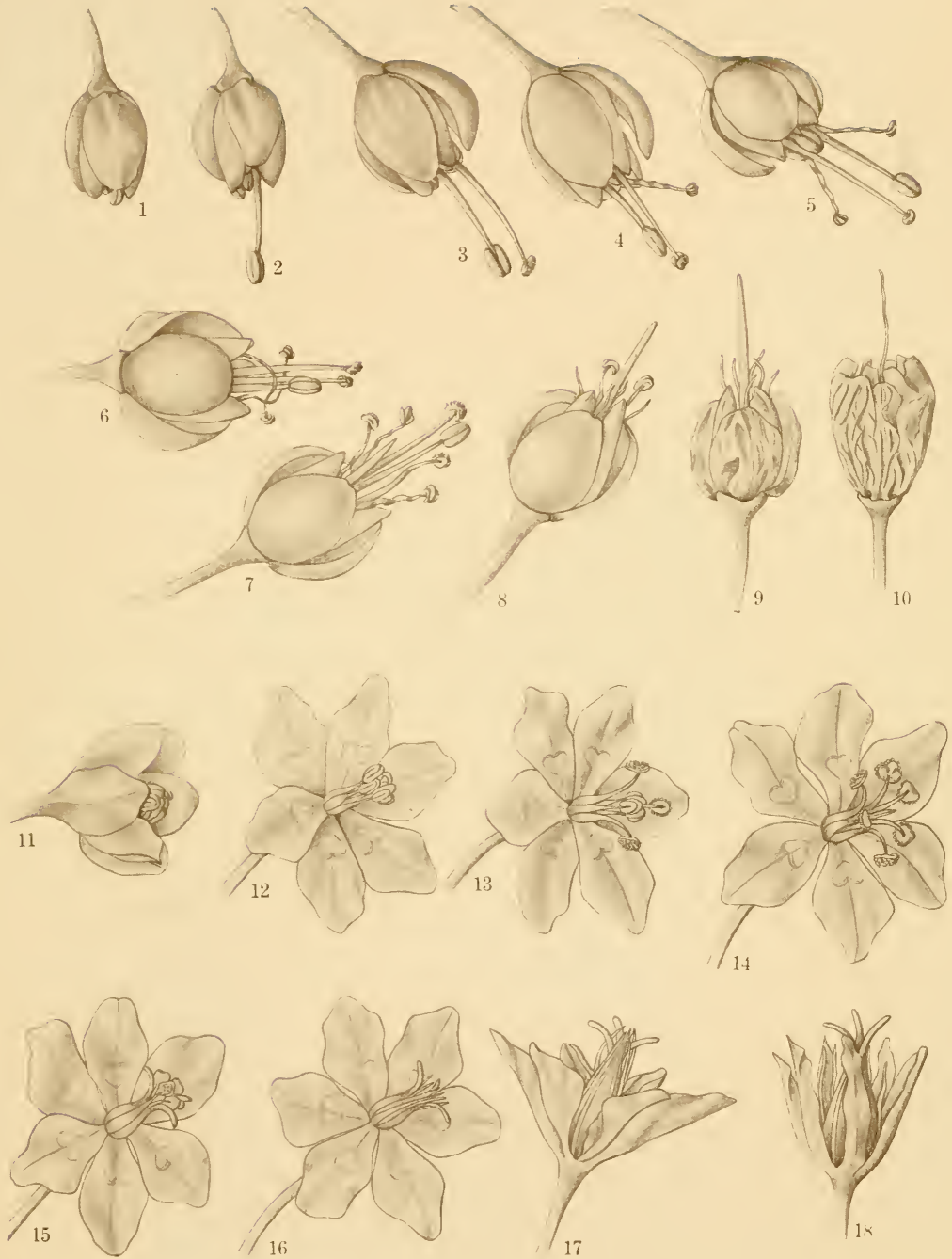

Edith S. Clements del.

Life-history of the flowers of . Allium cernum and Zygademus elegans. 



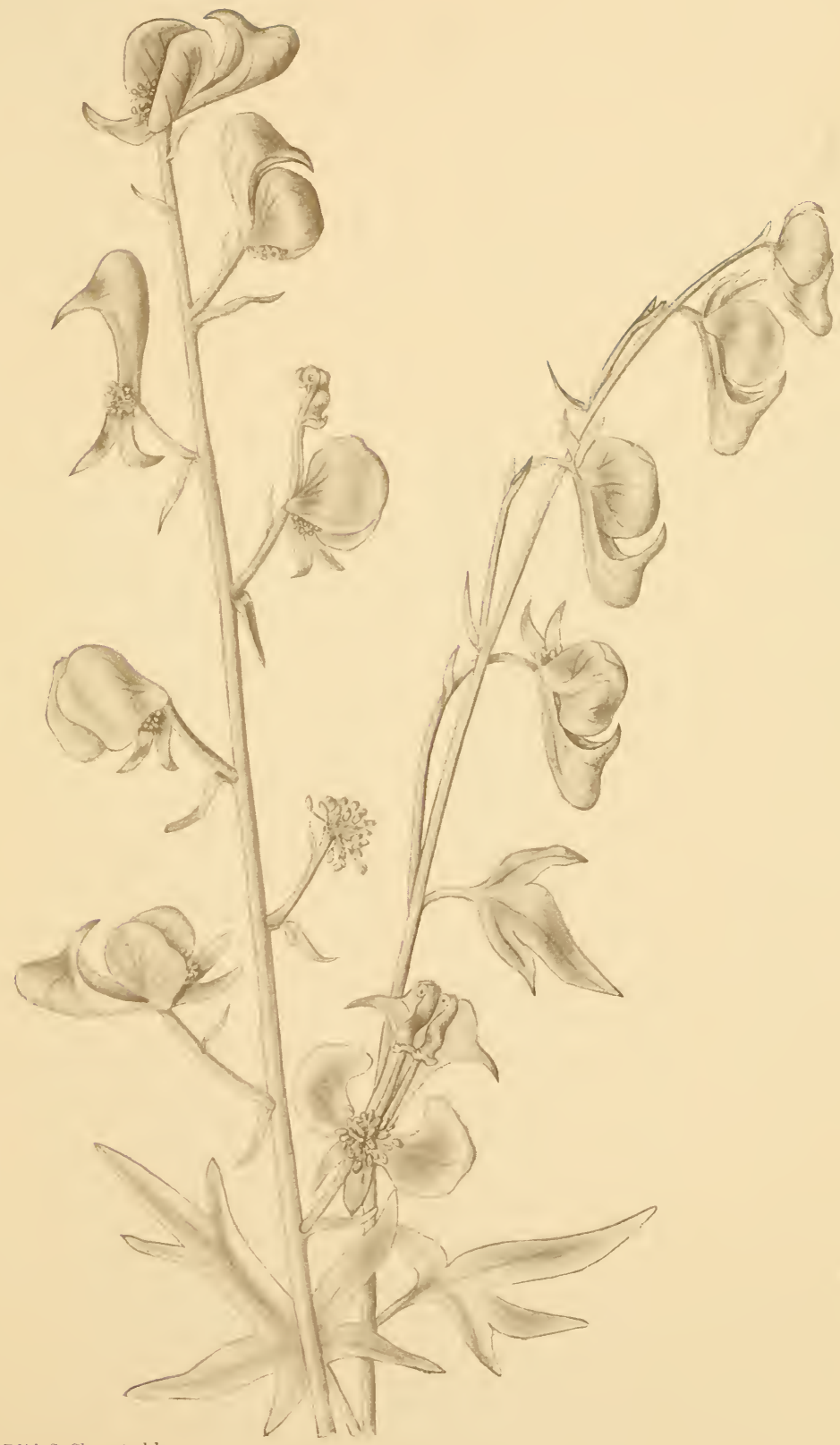




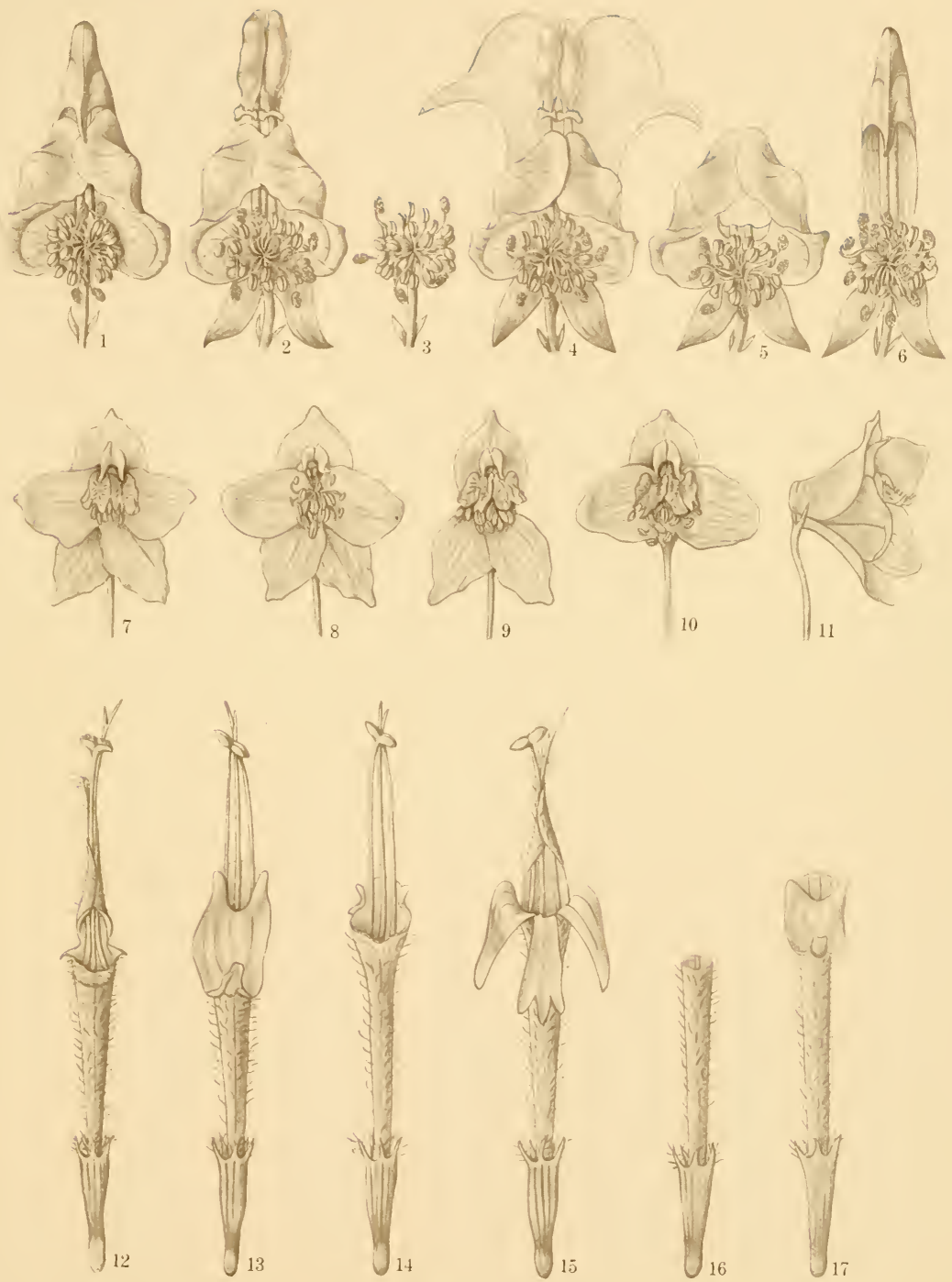

Edith s. Clements del.

Mutilated flowers of Aconitum, Delphinium, and Monarda. 


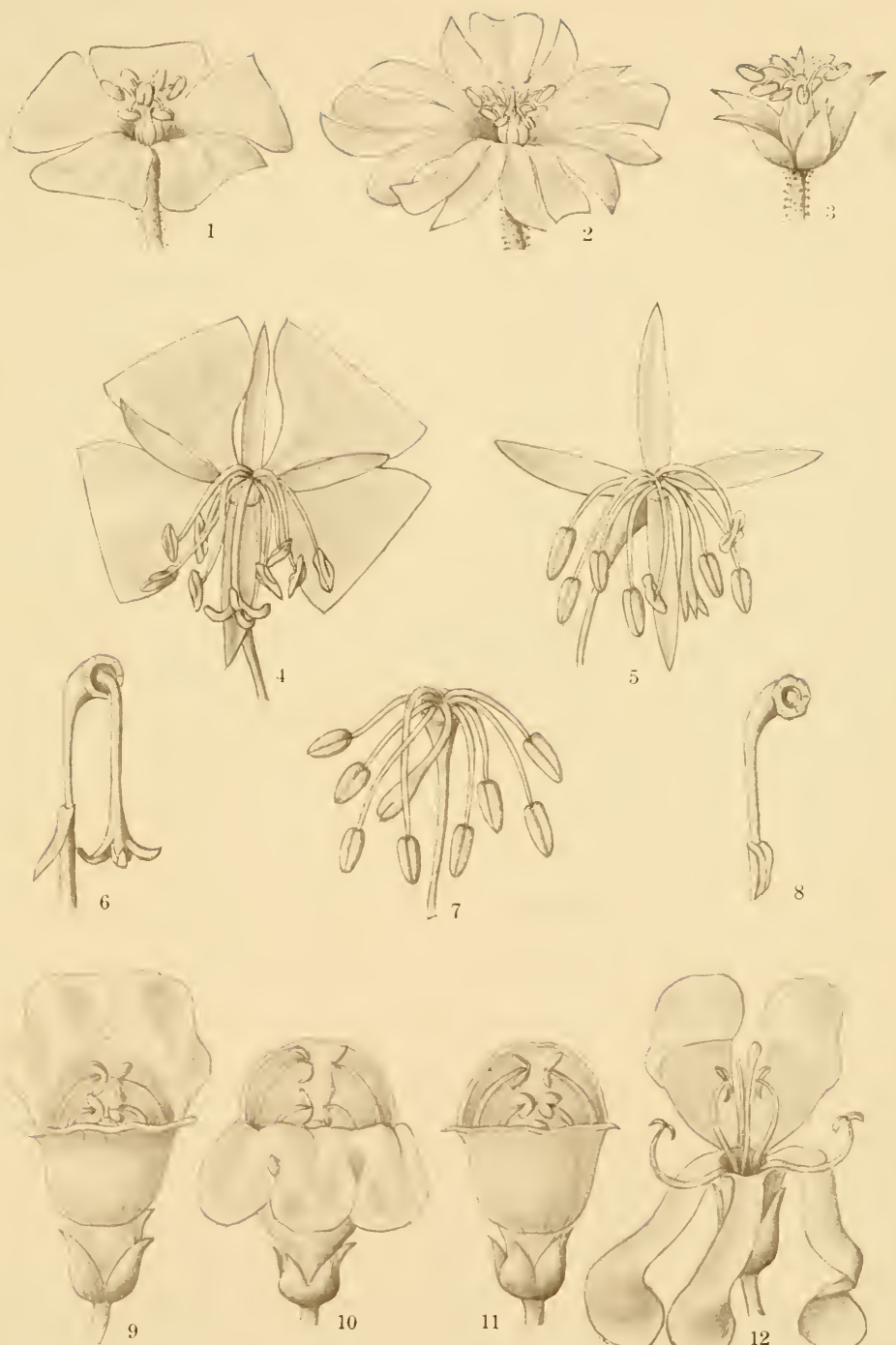

Edith S. Clements del.

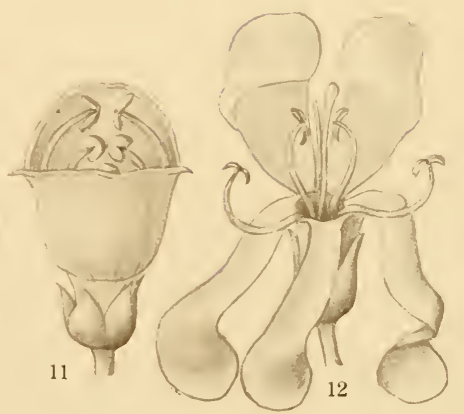

Mutilated flowers of Geranium. Chamaenerium, and Pentstemon glaber. North Carolina State Library

$$
\text { Raleigh }
$$

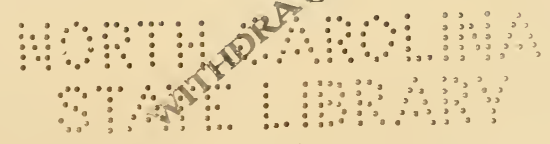




